\title{
Evaluated kinetic and photochemical data for atmospheric chemistry: Volume VI - heterogeneous reactions with liquid substrates
}

\author{
M. Ammann ${ }^{1}$, R. A. Cox ${ }^{2}$, J. N. Crowley ${ }^{3}$, M. E. Jenkin ${ }^{4}$, A. Mellouki ${ }^{5}$, M. J. Rossi ${ }^{6}$, J. Troe ${ }^{7}$, and T. J. Wallington ${ }^{8}$ \\ ${ }^{1}$ Laboratory of Radiochemistry and Environmental Chemistry, OFLB 103, Paul Scherrer Institut, 5232 Villigen, Switzerland \\ ${ }^{2}$ Centre for Atmospheric Science, Dept. of Chemistry, University of Cambridge, Lensfield Road, Cambridge CB2 1EP, UK \\ ${ }^{3}$ Max-Planck-Institut für Chemie, Division of Atmospheric Chemistry, Hahn-Meitner-Weg 1, 55128 Mainz, Germany \\ ${ }^{4}$ Atmospheric Chemistry Services, Okehampton, Devon EX20 1FB, UK \\ ${ }^{5}$ ICARE (Institut de Combustion, Aérothermique, Réactivité et Environnement)/OSUC, CNRS (Centre National de la \\ Recherche Scientifique) - UPR3021, 1C, Avenue de la recherche scientifique, 45071 Orléans cedex 02, France \\ ${ }^{6}$ Laboratory of Atmospheric Chemistry, OFLA 008, Paul Scherrer Institut, 5232 Villigen, Switzerland \\ ${ }^{7}$ Institute of Physical Chemistry, University of Göttingen, Tammannstr. 6, 37077 Göttingen, Germany \\ ${ }^{8}$ Ford Motor Company, Research and Advanced Engineering, Mail Drop RIC-2122, Dearborn, Michigan 48121-2053, USA \\ Correspondence to: M. Ammann (markus.ammann@psi.ch)
}

Received: 3 September 2012 - Published in Atmos. Chem. Phys. Discuss.: 17 December 2012

Revised: 29 May 2013 - Accepted: 2 June 2013 - Published: 21 August 2013

\begin{abstract}
This article, the sixth in the ACP journal series, presents data evaluated by the IUPAC Task Group on Atmospheric Chemical Kinetic Data Evaluation. It covers the heterogeneous processes involving liquid particles present in the atmosphere with an emphasis on those relevant for the upper troposphere/lower stratosphere and the marine boundary layer, for which uptake coefficients and adsorption parameters have been presented on the IUPAC website since 2009. The article consists of an introduction and guide to the evaluation, giving a unifying framework for parameterisation of atmospheric heterogeneous processes. We provide summary sheets containing the recommended uptake parameters for the evaluated processes. The experimental data on which the recommendations are based are provided in data sheets in separate appendices for the four surfaces considered: liquid water, deliquesced halide salts, other aqueous electrolytes and sulfuric acid.
\end{abstract}




\section{Introduction}

Since 2005 the IUPAC Task Group on Atmospheric Chemical Kinetic Data Evaluation has extended its evaluation work to produce recommendations for essential parameters, which can be used to calculate the rates of heterogeneous reactions of trace gases in the atmosphere. The results of this work have been added to the IUPAC website over the last 5 years, together with the updated kinetic data for gas phase reactions. Following our policy of publication of our updated evaluations in Atmospheric Chemistry and Physics, we first presented evaluations of heterogeneous processes involving solid particles in Volume V (Crowley et al., 2010). Volume VI of the series extends our work to cover heterogeneous processes involving liquid particles present in the atmosphere. This is done with a view to widening the dissemination and enhancing the accessibility of this evaluated material to the scientific community. The evaluation fosters usage of a unified terminology throughout the scientific community (Kolb et al., 2010) and identifies areas of large uncertainty thus motivating further studies. Last but not least, it will enable appropriate incorporation of kinetic parameters of heterogeneous processes into atmospheric models.

This volume covers substrates that are considered homogeneous liquids under atmospheric conditions. Given the importance of aqueous solutions for chemistry in clouds, in the upper troposphere/lower stratosphere and in the marine boundary layer, past studies of heterogeneous processes with liquid substrates placed the emphasis on these systems, which is also reflected in the present evaluation. This evaluation is also constrained to studies that have quantified gasliquid uptake kinetics rather than a complete evaluation of aqueous phase kinetics. Further systems will be evaluated in the future and published in future volumes if warranted.

The products of our evaluation published in this volume are preferred values of important kinetic parameters which reflect the present state of progress. The preferred values are based on consideration of suitability of experimental method, coverage of parameter space (temperature, partial pressure of gas phase species, humidity, concentrations in the condensed phase), within the atmospherically relevant range of variability. The general approach and methods used have been reviewed recently by Cox (2012). It is recognized that preferred values may change with publication of new data, and such changes are updated at the website.

The article consists of summary sheets containing the preferred values for the parameters describing adsorption, solvation and reaction, for which sufficient experimental information exists to allow a recommendation. The summary sheets also provide an overview of the individual processes considered in this evaluation. Uncertainties to the kinetic parameters and parameters describing equilibria and liquid phase diffusion are listed in the individual datasheets only. The summary tables are followed by a guide to the datasheets, which outlines the physico-chemical basis underlying the quantitative parameters describing atmospheric heterogeneous processes, and which provides definitions of terms employed. Finally, we present four appendices containing the data sheets for uptake of a range of $\mathrm{O}_{\mathrm{X}}, \mathrm{HO}_{\mathrm{X}}, \mathrm{NO}_{\mathrm{X}}, \mathrm{SO}_{\mathrm{X}}$, organic, and halogen-containing trace gases, on liquid surfaces of water (Appendix A1), deliquesced halide salts (Appendix A2), other aqueous electrolytes (Appendix A3) and sulfuric acid (Appendix A4). As adopted in Volume V, the data sheets follow a similar format to those used for gas phase reactions, providing details of published experimental information upon which the recommendations are based, a table of preferred values and their reliability, and comments on the state of knowledge leading to the preferred values. The data sheets include relevant references. 


\section{Summary sheets}

\section{Preferred values for uptake on water surfaces - Appendix A1}

\begin{tabular}{|c|c|c|c|c|c|c|}
\hline ID & Species/Reaction & $\gamma_{\mathrm{ss}}$ & $\alpha_{\mathrm{s}}$ & $\alpha_{\mathrm{b}}$ & $k_{\mathrm{b}} / \mathrm{M}^{-1} \mathrm{~s}^{-1}$ & $T / \mathrm{K}$ \\
\hline VI.A1.1 & $\mathrm{O}_{3}$ & & & $>10^{-3}$ & & 298 \\
\hline VI.A1.2 & $\mathrm{H}_{2} \mathrm{O}_{2}$ & & & $1.3 \times 10^{-6} \exp (3230 / T)$ & & $260-292$ \\
\hline VI.A1.3 & $2 \mathrm{NO}_{2}(\mathrm{~g})+\mathrm{H}_{2} \mathrm{O}(\mathrm{l}) \rightarrow \mathrm{HNO}_{2}(\mathrm{aq})+\mathrm{HNO}_{3}(\mathrm{aq})$ & & & $2 \times 10^{-2}$ & $8.1 \times 10^{9} \exp (-1630 / T) \mathrm{M}^{-1} \mathrm{~s}^{-1}$ & $276-293$ \\
\hline VI.A1.4 & $\mathrm{NO}_{3}$ & & & $1.3 \times 10^{-2}$ & $k^{\mathrm{I}}=23 \mathrm{~s}^{-1}$ & 273 \\
\hline VI.A1.5 & $\mathrm{N}_{2} \mathrm{O}_{5}$ & $2.7 \times 10^{-5} \exp (1800 / T)$ & & & & $265-300$ \\
\hline VI.A1.6 & $\mathrm{NH}_{3}$ & & & 0.1 & & $260-300$ \\
\hline VI.A1.7 & $\begin{array}{l}2 \mathrm{HNO}_{2}(\mathrm{~g})+\mathrm{H}_{2} \mathrm{O}(\mathrm{l}) \leftrightarrows \mathrm{NO}(\mathrm{g}) \\
+\mathrm{NO}_{2}(\mathrm{~g})+2 \mathrm{H}_{2} \mathrm{O}(\mathrm{l})\end{array}$ & & & 0.05 & $\begin{array}{l}k_{\rightarrow}=3.1 \times 10^{14} \exp (-9090 / T) \mathrm{M}^{-1} \mathrm{~s}^{-1} \\
k_{\leftarrow}=1.7 \times 10^{8} \mathrm{M}^{-1} \mathrm{~s}^{-1}\end{array}$ & $\begin{array}{l}273-300 \\
273-300\end{array}$ \\
\hline VI.A1.8 & $\mathrm{HNO}_{3}$ & & & $7.5 \times 10^{-5} \exp (2100 / T)$ & & $268-300$ \\
\hline VI.A1.9 & $\mathrm{CH}_{3} \mathrm{SO}_{3} \mathrm{H}$ & & & 1 & & $260-300$ \\
\hline VI.A1.10 & $\mathrm{SO}_{2}(\mathrm{~g})+\mathrm{H}_{2} \mathrm{O}(\mathrm{l}) \leftrightarrows \mathrm{SO}_{2}(\mathrm{aq})+\mathrm{H}_{2} \mathrm{O}(\mathrm{l})$ & & 1 & $0.18 \times(1-\theta)$ & $k^{\mathrm{I}}=3.4 \times 10^{-6} \mathrm{~s}^{-1}$ & $260-300$ \\
\hline VI.A1.11 & $\mathrm{HCl}$ & & & $4.4 \times 10^{-6} \exp (2898 / T)$ & & $272-294$ \\
\hline VI.A1.12 & $\mathrm{HBr}$ & & & $1.3 \times 10^{-8} \exp (4290 / T)$ & & $263-281$ \\
\hline VI.A1.13 & $\mathrm{HI}$ & & & $6.35 \times 10^{-9} \exp (4519 / T)$ & & $262-278$ \\
\hline VI.A1.14 & $\begin{array}{l}\mathrm{ClNO}(\mathrm{g})+\mathrm{H}_{2} \mathrm{O}(\mathrm{l}) \rightarrow \mathrm{HCl}(\mathrm{aq}) \\
+\mathrm{HNO}_{2}(\mathrm{aq})\end{array}$ & 0.01 & & & & $273-293$ \\
\hline VI.A1.15 & $\mathrm{ClNO}_{2}$ & $3 \times 10^{-6}$ & & $9 \times 10^{-3}$ & & $273-298$ \\
\hline VI.A1.16 & $\begin{array}{l}\mathrm{ClONO}_{2}(\mathrm{~g})+\mathrm{H}_{2} \mathrm{O}(\mathrm{l}) \rightarrow \mathrm{HOCl}(\mathrm{aq}) \\
+\mathrm{HONO}_{2}(\mathrm{aq})\end{array}$ & & & 0.11 & & $273-290$ \\
\hline VI.A1.17 & $\mathrm{OH}$ & & & $>0.1$ & & $275-310$ \\
\hline VI.A1.18 & $\mathrm{H}_{2} \mathrm{O}$ & & & $3.6 \times 10^{-5} \exp (2370 / T)$ & & $258-298$ \\
\hline VI.A1.19 & $\mathrm{SO}_{2}(\mathrm{~g})+\mathrm{H}_{2} \mathrm{O}_{2}(\mathrm{aq}) \leftrightarrows \mathrm{H}_{2} \mathrm{SO}_{4}(\mathrm{aq})$ & & & 0.11 & $2.1 \times 10^{6} /\left(0.1+\left[\mathrm{H}^{+}\right]\right) \mathrm{M}^{-2} \mathrm{~s}^{-1}$ & $268-298$ \\
\hline VI.A1.20 & $\mathrm{HO}_{2}$ & & & $>0.5$ & & $270-300$ \\
\hline
\end{tabular}

Preferred values of uptake coefficients on aqueous halide salt surfaces - Appendix A2

\begin{tabular}{|c|c|c|c|c|c|c|c|}
\hline ID & Species/Reaction & $\gamma_{\mathrm{ss}}$ & $\alpha_{\mathrm{s}}$ & $k_{\mathrm{s}}$ & $\alpha_{\mathrm{b}}$ & $k_{\mathrm{b}} / \mathrm{M}^{-1} \mathrm{~s}^{-1}$ & $T / \mathrm{K}$ \\
\hline VI.A2.0 & $\mathrm{O}_{3}(\mathrm{~g})+\mathrm{I}^{-}(\mathrm{aq}) \rightarrow$ products & & & & $>0.1$ & $(2.4 \pm 1.3) \times 10^{9}$ & 293 \\
\hline VI.A2.0 & $\mathrm{O}_{3}(\mathrm{~g})+\mathrm{Br}^{-}(\mathrm{aq}) \rightarrow$ products & & & see datasheet & & $6.3 \times 10^{8} \exp (-4450 / T)$ & $273-298$ \\
\hline VI.A2.1 & $\mathrm{OH}(\mathrm{g})+\mathrm{Cl}^{-}(\mathrm{aq}) \rightarrow$ products & $\gamma_{\mathrm{gs}}=0.04 \times\left(\left[\mathrm{Cl}^{-}\right] / \mathrm{M}\right)$ & & & $>0.1$ & & 298 \\
\hline VI.A2.2 & $\mathrm{HO}_{2}$ & 0.1 & & & $>0.5$ & & $290-300$ \\
\hline VI.A2.4 & $2 \mathrm{NO}_{2}(\mathrm{~g})+\mathrm{NaCl}(\mathrm{aq}) \rightarrow \mathrm{NOCl}(\mathrm{g})+\mathrm{NaNO}_{3}(\mathrm{aq})$ & & & & & 200 & 298 \\
\hline VI.A2.5 & $\mathrm{NO}_{3}(\mathrm{~g})+\mathrm{Cl}^{-}(\mathrm{aq}) \rightarrow \mathrm{NO}_{3}^{-}(\mathrm{aq})+\mathrm{Cl}(\mathrm{aq})$ & & & & $1.3 \times 10^{-2}$ & $2.76 \times 10^{6}$ & 273 \\
\hline VI.A2.5 & $\mathrm{NO}_{3}(\mathrm{~g})+\mathrm{Br}^{-}(\mathrm{aq}) \rightarrow \mathrm{NO}_{3}^{-}(\mathrm{aq})+\mathrm{Br}(\mathrm{aq})$ & & & & $1.3 \times 10^{-2}$ & $1.02 \times 10^{8}$ & 273 \\
\hline VI.A2.5 & $\mathrm{NO}_{3}(\mathrm{~g})+\mathrm{I}^{-}(\mathrm{aq}) \rightarrow \mathrm{NO}_{3}^{-}(\mathrm{aq})+\mathrm{I}(\mathrm{aq})$ & & & & $1.3 \times 10^{-2}$ & $4.6 \times 10^{9}$ & 273 \\
\hline VI.A2.6 & $\mathrm{N}_{2} \mathrm{O}_{5}$ & 0.02 & & & & & $260-300$ \\
\hline VI.A2.7 & $\mathrm{HNO}_{3}$ & & & & $>0.5$ & & 298 \\
\hline VI.A2.8 & $\mathrm{HOCl}$ & $<2 \times 10^{-4}$ & & & & & 296 \\
\hline VI.A2.9 & $\mathrm{ClNO}_{2}(\mathrm{~g})+\mathrm{Cl}^{-}(\mathrm{aq}) \rightarrow$ products & & & & 0.01 & $>10^{7}$ & 274 \\
\hline VI.A2.9 & $\mathrm{ClNO}_{2}(\mathrm{~g})+\mathrm{Br}^{-}(\mathrm{aq}) \rightarrow$ products & & & & 0.01 & & 274 \\
\hline VI.A2.10 & $\mathrm{ClONO}_{2}(\mathrm{~g})+\mathrm{Cl}^{-}(\mathrm{aq}) \rightarrow \mathrm{Cl}_{2}(\mathrm{~g})+\mathrm{HNO}_{3}(\mathrm{aq})$ & & & & 0.11 & & $273-290$ \\
\hline VI.A2.10 & $\mathrm{ClONO}_{2}(\mathrm{~g})+\mathrm{Br}^{-}(\mathrm{aq}) \rightarrow \mathrm{ClBr}(\mathrm{g})+\mathrm{HNO}_{3}(\mathrm{aq})$ & & & & 0.11 & & $273-290$ \\
\hline VI.A2.11 & $\mathrm{HOBr}(\mathrm{g})+\mathrm{Cl}^{-} / \mathrm{Br}^{-}(\mathrm{aq})+\mathrm{H}^{+}(\mathrm{aq}) \rightarrow$ products & & & & 0.6 & $k_{\mathrm{ter}}>5.6 \times 10^{9} \mathrm{M}^{-2} \mathrm{~s}^{-1}$ & 296 \\
\hline VI.A2.12 & $\mathrm{HOI}(\mathrm{g})+\mathrm{Cl}^{-} / \mathrm{Br}^{-}(\mathrm{aq}) \rightarrow \mathrm{IBr} / \mathrm{ICl}(\mathrm{g})+\mathrm{HO}^{-}(\mathrm{aq})$ & & & & $>0.1$ & & 298 \\
\hline VI.A2.13 & $\mathrm{BrCl}(\mathrm{g})+\mathrm{Br}^{-}(\mathrm{aq}) \rightarrow$ Products & & & & 0.33 & & $270-280$ \\
\hline VI.A2.14 & $\mathrm{ICl}(\mathrm{g})+\mathrm{Br}^{-}(\mathrm{aq}) \rightarrow \mathrm{IBr}(\mathrm{g})+\mathrm{Cl}^{-}(\mathrm{aq})$ & & & & 0.016 & $>10^{3}$ & 298 \\
\hline VI.A2.15 & $\mathrm{IBr}(\mathrm{g})+\mathrm{Cl}^{-} / \mathrm{Br}^{-}(\mathrm{aq}) \rightarrow$ products & & & & 0.016 & & 298 \\
\hline VI.A2.16 & $\mathrm{Cl}_{2}(\mathrm{~g})+\mathrm{Br}^{-}(\mathrm{aq}) \rightarrow \mathrm{BrCl}(\mathrm{g})+\mathrm{Cl}^{-}(\mathrm{aq})$ & & 1 & see datasheet & 1 & $4.58 \times 10^{14} \exp (-2866 / T)$ & $260-295$ \\
\hline
\end{tabular}

Preferred values for uptake on other aqueous electrolyte surfaces - Appendix A3

\begin{tabular}{llllll}
\hline ID & Species/Reaction & $\gamma_{\mathrm{ss}}$ & $\alpha_{\mathrm{s}}$ & $\alpha_{\mathrm{b}}$ & $k_{\mathrm{b}} / \mathrm{M}^{-1} \mathrm{~s}^{-1}$ \\
\hline VI.A3.5 & $\mathrm{N}_{2} \mathrm{O}_{5}(\mathrm{~g})+\mathrm{H}_{2} \mathrm{O}(\mathrm{l})\left(\left(\mathrm{NH}_{4}\right)_{2} \mathrm{SO}_{4}(\mathrm{aq})\right) \rightarrow$ products & $\gamma_{\mathrm{r}}=0.244-7.9 \times 10^{-4} T(\mathrm{~K})$ & 0.03 & $1.0 \times 10^{5}$ \\
VI.A3.6 & $\mathrm{N}_{2} \mathrm{O}_{5}(\mathrm{~g})+\mathrm{H}_{2} \mathrm{O}(\mathrm{l})\left(\mathrm{NH}_{4} \mathrm{HSO}_{4}(\mathrm{aq})\right) \rightarrow$ products & & 0.04 & $1.5 \times 10^{5}$ \\
VI.A3.7 & $\mathrm{N}_{2} \mathrm{O}_{5}(\mathrm{~g})+\mathrm{H}_{2} \mathrm{O}(\mathrm{l})\left(\mathrm{Na} / \mathrm{NH}_{4} \mathrm{NO}_{3}(\mathrm{aq})\right) \rightarrow$ products & & 0.04 & $1.5 \times 10^{5}\left\{1-\frac{k_{2}\left[\mathrm{NO}_{3}{ }^{-}\right]}{k_{2}\left[\mathrm{NO}_{3}{ }^{-}\right]+k_{3}\left[\mathrm{H}_{2} \mathrm{O}\right]}\right\}$ & 298 \\
VI.A3.8 & $\mathrm{N}_{2} \mathrm{O}_{5}(\mathrm{~g})+\mathrm{H}_{2} \mathrm{O}(\mathrm{l})(\mathrm{humic}$ acid$(\mathrm{aq})) \rightarrow$ products & $3.1 \times 10^{-5} \mathrm{exp}(0.046 \cdot \mathrm{RH}(\%))$ & & 298 \\
VI.A3.8 & $\mathrm{N}_{2} \mathrm{O}_{5}(\mathrm{~g})+\mathrm{H}_{2} \mathrm{O}(\mathrm{l})\left(\mathrm{CH}_{2}(\mathrm{COOH})_{2}(\mathrm{aq})\right) \rightarrow$ products & & 0.035 & $1.0 \times 10^{5}$ \\
VI.A3.8 & $\mathrm{N}_{2} \mathrm{O}_{5}(\mathrm{~g})+\mathrm{H}_{2} \mathrm{O}(\mathrm{l})\left(\left(\mathrm{CH}_{2}\right)_{2}(\mathrm{COOH})_{2}(\mathrm{aq})\right) \rightarrow$ products & & 0.035 & $3.0 \times 10^{4}$ \\
VI.A3.8 & $\mathrm{N}_{2} \mathrm{O}_{5}(\mathrm{~g})+\mathrm{H}_{2} \mathrm{O}(\mathrm{l})\left(\left(\mathrm{CH}_{2}\right)_{3}(\mathrm{COOH})_{2}(\mathrm{aq})\right) \rightarrow$ products & & 0.035 & $5.0 \times 10^{4}$ \\
VI.A3.9 & $\mathrm{HO}_{2}(\mathrm{~g})+\mathrm{NH}_{4} \mathrm{HSO}_{4}(\mathrm{aq}) \rightarrow$ products & $>0.5$ & see datasheet \\
VI.A3.10 & $\mathrm{HO}_{2}(\mathrm{~g})+\left(\mathrm{NH}_{4}\right)_{2} \mathrm{SO}_{4}(\mathrm{aq}) \rightarrow$ products & & $>0.5$ & see datasheet
\end{tabular}


Preferred values for uptake on sulfuric acid surfaces - Appendix A4

\begin{tabular}{|c|c|c|c|c|c|c|c|}
\hline ID & Species/Reaction & $\gamma_{\mathrm{ss}}$ & $\alpha_{\mathrm{s}}$ & $k_{\mathrm{s}}$ & $\alpha_{\mathrm{b}}$ & $k_{\mathrm{b}} / \mathrm{M}^{-1} \mathrm{~s}^{-1}$ & $T / \mathrm{K}$ \\
\hline VI.A4.0 & $\mathrm{O}_{3}$ & $<10^{-6}$ & & & & & $200-220$ \\
\hline VI.A4.1 & $\mathrm{OH}$ & & & & 1 & & $220-298$ \\
\hline VI.A4.2 & $\mathrm{HO}_{2}$ & & & & 0.8 & & $220-300$ \\
\hline VI.A4.3 & $\mathrm{H}_{2} \mathrm{O}_{2}$ & $7.8 \times 10^{-4}$ & & & & & $270-300$ \\
\hline VI.A4.4 & NO & $<5 \times 10^{-6}$ & & & & & $200-298$ \\
\hline VI.A4.5 & $\mathrm{NO}_{2}$ & $<10^{-6}$ & & & & & $200-298$ \\
\hline VI.A4.6 & $\mathrm{NO}_{3}$ & $<1 \times 10^{-3}$ & & & & & $200-270$ \\
\hline VI.A4.7 & $\mathrm{HNO}_{2}$ & $\gamma_{\mathrm{gs}}<10^{-5}$ & & & $>0.05$ & 320 & $220-300$ \\
\hline VI.A4.8 & $\mathrm{HNO}_{3}$ & & $>0.8$ & & $>0.8$ & & $188-223$ \\
\hline VI.A4.9 & $\mathrm{HO}_{2} \mathrm{NO}_{2}$ & & & & $>0.2$ & & $205-225$ \\
\hline VI.A4.10 & $\mathrm{NH}_{3}\left(>50 \mathrm{wt} \% \mathrm{H}_{2} \mathrm{SO}_{4}\right)$ & 1.0 & & & & & $265-300$ \\
\hline VI.A4.11 & $\mathrm{N}_{2} \mathrm{O}_{5}(\mathrm{~g})+\mathrm{H}_{2} \mathrm{O}(\mathrm{l})$ & $\gamma_{\mathrm{r}}=[(7353 / T)-24.83]^{-1}$ & & & $2.3 \times 10^{-5} \exp (2240 / T)$ & & $240-300$ \\
\hline VI.A4.12 & $\mathrm{H}_{2} \mathrm{CO}$ & $\Gamma_{\mathrm{b}, \text { poly }}=0.001$ & & & 0.04 & $\begin{array}{l}k_{\mathrm{H} 20}= \\
7800 \exp (-1910 / T)\left(1+870\left[\mathrm{H}^{+}\right]\right) \mathrm{M}^{-1} \mathrm{~s}^{-1}\end{array}$ & $200-300$ \\
\hline VI.A4.13 & $\mathrm{CH}_{3} \mathrm{C}(\mathrm{O}) \mathrm{OONO}_{2}(\mathrm{PAN})$ & & & & $>0.008$ & & \\
\hline VI.A4.14 & $\mathrm{HCl}$ & & $>0.9$ & & $\begin{array}{l}k_{\mathrm{sol}}=7.84 \times 10^{10} / \eta(\mathrm{cP}) \\
k_{\mathrm{des}}=8.0 \times 10^{17} \exp (-5000 / T)\end{array}$ & & $190-300$ \\
\hline VI.A4.15 & $\mathrm{ClO}\left(\mathrm{pH}_{2} \mathrm{O}=6.7 \times 10^{-4} \mathrm{mbar}\right)$ & $\begin{array}{l}\ln \gamma_{\mathrm{ss}}=-9.361+(3.22 \pm 1.34) \\
\times(1000 / T-3.840)\end{array}$ & & & & & $240-295$ \\
\hline VI.A4.16 & $\mathrm{HOBr}$ & & & & & & \\
\hline VI.A4.17 & $\mathrm{HBr}$ & & & & & & \\
\hline VI.A4.18 & HOI & & & & & & \\
\hline VI.A4.19 & $\left(\mathrm{CH}_{3}\right)_{2} \mathrm{CO}$ & & & & & & \\
\hline VI.A4.20 & $\mathrm{CHBr}_{3}$ & & & & & & \\
\hline VI.A4.21 & $\mathrm{H}_{2} \mathrm{SO}_{4}$ & & & & $>0.7$ & & $200-300$ \\
\hline VI.A4.22 & $\mathrm{HOCl}(\mathrm{g})+\mathrm{HCl}(\mathrm{g}) \rightarrow \mathrm{H}_{2} \mathrm{O}(\mathrm{l})+\mathrm{Cl}_{2}(\mathrm{~g})$ & & & & $\alpha_{\mathrm{b}}(\mathrm{HOCl})=1$ & $80\left[\mathrm{H}^{+}\right] \mathrm{T} / \eta$ & $190-273$ \\
\hline VI.A4.23 & $\mathrm{HOCl}(\mathrm{g})+\mathrm{HBr}(\mathrm{g}) \rightarrow \mathrm{BrCl}(\mathrm{g})+\mathrm{H}_{2} \mathrm{O}(\mathrm{l})$ & & & & $\alpha_{\mathrm{b}}(\mathrm{HOCl})=1$ & $1 \times 10^{7}$ & 228 \\
\hline VI.A4.24 & $\begin{array}{l}\mathrm{ClONO}_{2}(\mathrm{~g})+\mathrm{HCl}(\mathrm{g}) \rightarrow \mathrm{HONO}_{2}(\mathrm{aq}) \\
+\mathrm{Cl}_{2}(\mathrm{~g})\end{array}$ & $\begin{array}{l}\Gamma_{\mathrm{s}}=66.12 \exp (-1374 / T) \\
\times \mathrm{H}_{\mathrm{ClONO} 2} \times \mathrm{M}_{\mathrm{HCl}}\end{array}$ & 1.0 & & & see datasheet for $\Gamma_{\mathrm{b}}$ & $190-280$ \\
\hline VI.A4.25 & $\begin{array}{l}\mathrm{ClONO}_{2}(\mathrm{~g})+\mathrm{H}_{2} \mathrm{O}(\mathrm{l}) \rightarrow \mathrm{HONO}_{2}(\mathrm{aq}) \\
+\mathrm{HOCl}(\mathrm{g})\end{array}$ & & & & 1.0 & $\begin{array}{l}k_{\mathrm{H} 2 \mathrm{O}}=1.95 \times 10^{10} \exp (2800 / T) \mathrm{s}^{-1} \\
k_{\mathrm{H}+}=1.22 \times 10^{12} \exp (6200 / T) \mathrm{M}^{-1} \mathrm{~s}^{-1}\end{array}$ & $190-280$ \\
\hline VI.A4.26 & $\mathrm{HOBr}(\mathrm{g})+\mathrm{HCl}(\mathrm{g}) \rightarrow \mathrm{BrCl}(\mathrm{g})+\mathrm{H}_{2} \mathrm{O}(\mathrm{l})$ & & & & 1.0 & $\exp (154-1.63 W) \exp (-(38500-478 w t) / T)$ & $200-230$ \\
\hline VI.A4.27 & $\mathrm{HOBr}(\mathrm{g})+\mathrm{HBr}(\mathrm{g}) \rightarrow \mathrm{Br}_{2}(\mathrm{~g})+\mathrm{H}_{2} \mathrm{O}(\mathrm{l})$ & & & & 0.3 & $5 \times 10^{4}$ & 228 \\
\hline VI.A4.28 & $\mathrm{BrONO}_{2}(\mathrm{~g})+\mathrm{H}_{2} \mathrm{O}(\mathrm{l}) \rightarrow \mathrm{HOBr}(\mathrm{g})+\mathrm{HNO}_{3}(\mathrm{aq})$ & $\begin{array}{l}\Gamma_{\mathrm{b}}=0.11+\exp (29.2 \\
\left.-0.40 \mathrm{wt} \% \mathrm{H}_{2} \mathrm{SO}_{4}\right)\end{array}$ & & & 0.8 & & $210-300$ \\
\hline VI.A4.29 & $\mathrm{HONO}(\mathrm{g})+\mathrm{HCl}(\mathrm{g}) \rightarrow \mathrm{ClNO}(\mathrm{g})+\mathrm{H}_{2} \mathrm{O}(\mathrm{l})$ & & 1 & $\begin{array}{l}\text { see } \\
\text { datasheet }\end{array}$ & & $25\left[\mathrm{H}^{+}\right] T / \eta$ & $200-300$ \\
\hline VI.A4.30 & $\mathrm{HONO}(\mathrm{g})+\mathrm{HBr}(\mathrm{g}) \rightarrow \mathrm{BrNO}(\mathrm{g})+\mathrm{H}_{2} \mathrm{O}(\mathrm{l})$ & & & & 1.0 & 0.1 & $200-300$ \\
\hline VI.A4.31 & $\mathrm{HOCl}$ & & & & & & \\
\hline $\begin{array}{l}\text { VI.A4.32 } \\
\text { VI.A4.33 }\end{array}$ & $\begin{array}{l}\mathrm{CH}_{3} \mathrm{SO}_{3} \mathrm{H} \\
\mathrm{N}_{2} \mathrm{O}_{5}(\mathrm{~g})+\mathrm{HCl}(\mathrm{g}) \rightarrow \mathrm{HONO}_{2}(\mathrm{aq})+\mathrm{ClNO}_{2}(\mathrm{~g})\end{array}$ & & & & $\begin{array}{l}1.0 \\
0.11\end{array}$ & see datasheet & $\begin{array}{l}296 \\
200-220\end{array}$ \\
\hline
\end{tabular}




\section{Guide to the data sheets}

The heterogeneous processes considered in this evaluation involve chemical and/or physical interactions between trace gases and liquid atmospheric condensed phase material. Broadly, this material falls into 2 categories: (i) large water droplets (diameter, $\mathrm{d}>1 \mu \mathrm{m}$ ), and (ii) fine liquid submicron $(\mathrm{d}<1 \mu \mathrm{m})$ aerosol particles. The interaction can be reversible (physisorption at the surface or dissolution), reactive, catalytic or a combination of all or some of these operating in parallel or sequentially, and can depend strongly on ambient conditions such as temperature or relative humidity.

This publication covers interactions between gases and liquid surfaces including aqueous droplets, salt solutions (e.g., halide and sulphate) and sulphuric acid. This evaluation covers homogeneous liquid substrates, which commonly have viscosities that lead to well mixed solutions. We do not consider non-uniform semi-solids (Koop et al., 2011) in this evaluation.

The parameterisation of a heterogeneous process depends on the nature of the surface but here we present a general framework for reaction kinetics for both solid and liquid substrates.

A complete description of the interaction of a trace gas with a surface would include transport to and accommodation at the surface, followed by a number of competitive or parallel processes such as desorption back to the gas phase, reaction with the substrate surface or with other trace gases on the surface, and diffusion into and reaction in the particle bulk. The rates and efficiencies of these processes are controlled by surface and bulk-phase rate coefficients, local reactant concentrations, diffusion coefficients in the condensed phase, and solubilities. Each of these controlling factors may change with temperature and composition. This convolution of equilibrium and kinetic parameters for phase change and reaction renders the description of atmospheric heterogeneous processes highly complex.

Only rarely are all the individual steps controlling reaction rates of heterogeneous processes known. A quasi steady state resistance model has frequently been used to describe the uptake of gas species to surfaces, and to relate the experimentally observable net probability of uptake ( $\gamma$, see below) to fundamental physical parameters. In this model, a linear combination of flux resistances (decoupled and normalized fluxes) by analogy to resistances in electric circuits, is used to describe the uptake process (Ammann et al., 2003; Hanson, 1997; Jayne et al., 1990; Pöschl et al., 2007), and we will refer to these formulations below where appropriate. Models involving solution of coupled differential rate equations of mass transport and chemical reactions using continuum flow formulations (Winkler et al., 2004) and gas kinetic formulations (Behr et al., 2004; Flückiger and Rossi, 2003; Pöschl et al., 2007; Pfrang et al., 2010; Shiraiwa et al., 2009, 2010) have recently been described and circumvent steady state approximations that are not easy to assess.

\subsection{Description of heterogeneous kinetics}

\subsubsection{Definition of the uptake coefficient}

The most widely used approach to describe the kinetics of heterogeneous processes is to use the uptake coefficient, $\gamma$, which is the net probability that a molecule $\mathrm{X}$ undergoing a gas-kinetic collision with a surface is actually taken up at the surface. This approach links the processes at the interface and beyond with an apparent first order loss of $\mathrm{X}$ from the gas phase:

$\frac{d[\mathrm{X}]_{\mathrm{g}}}{d t}=-k_{\mathrm{r}}[\mathrm{X}]_{\mathrm{g}}=-\gamma \frac{\bar{c}}{4}[\mathrm{SS}]_{\mathrm{g}}[\mathrm{X}]_{\mathrm{g}}$

$[\mathrm{X}]_{\mathrm{g}}$ denotes the concentration of $\mathrm{X}$ in the gas phase (molecule $\mathrm{cm}^{-3}$ ), $[\mathrm{SS}]_{\mathrm{g}}$ is the specific surface area of the condensed phase $\left(\mathrm{cm}^{-1}\right)$ (i.e., surface area of condensed phase per unit volume of gas phase), $k_{\mathrm{r}}$ is the first order rate coefficient for loss, and $\bar{c}$ is the mean thermal velocity of $\mathrm{X}$ $\left(\mathrm{cm} \mathrm{s}^{-1}\right) . \gamma$ often depends on time, as uptake may be limited by adsorption equilibrium on the surface, by a limited number of reactant molecules on the surface, by solubility, or by a limited number of reactant molecules in the bulk of the particles. $\gamma$ may also depend on the gas phase concentration of $\mathrm{X}$. Therefore, $\gamma$ is not a constant, and $\gamma$ values reported from laboratory measurements often cannot be transferred directly to other conditions. This must be done through a proper parameterization of the processes at the interface and beyond, as outlined below. Only a systematic variation of conditions in laboratory studies enables deconvolution of measured uptake coefficients into these underlying processes.

\subsubsection{Gas phase diffusion}

If $\gamma$ is large, $[\mathrm{X}]_{\mathrm{g}}$ may become depleted near the particle surface. In this case, a correction factor is commonly applied, such that Eq. (1) can still be used to relate the net flux into the particle phase with the overall loss from the gas phase. $\gamma$ in Eq. (1) is then replaced by $\gamma_{\text {eff }}$, which is given by $\gamma_{\text {eff }}=C_{\text {diff }} \gamma$, where $C_{\text {diff }}$ is a correction factor. Under appropriate steady state assumptions, this relation can also be expressed in the form of a resistor formulation (FinlaysonPitts and Pitts, 2000; Hanson et al., 1994; Schwartz, 1986):

$$
\frac{1}{\gamma_{\mathrm{eff}}}=\frac{1}{\Gamma_{\mathrm{diff}}}+\frac{1}{\gamma}
$$

Approximate formulas for $C_{\text {diff }}$ or $\Gamma_{\text {diff }}$ have been derived in the literature (Brown, 1978; Fuchs and Sutugin, 1970; Pöschl et al., 2007; Seinfeld and Pandis, 1998) for various geometries, such as suspended aerosol particles, but also for cylindrical flow tubes. They are a function of the geometry (e.g., particle diameter, $d_{\mathrm{p}}$ ) and the diffusion coefficient of X, $D_{\mathrm{g}}$, and $\gamma$. Therefore, temperature and bath gas dependent diffusion coefficients for $\mathrm{X}$ are required. Diffusion may also limit 
uptake rates to particles in the atmosphere, requiring a similar treatment for uptake kinetics.

\subsubsection{Surface accommodation and kinetics of adsorp- tion}

A molecule colliding with the surface of a solid or liquid can undergo elastic or inelastic scattering processes that involve collisions with one or a few surface atoms or molecules on time scales of up to $10^{-12} \mathrm{~s}$. Elastic and inelastic scattering result in reflection back to the gas phase. The molecule can also undergo adsorption, in which case it accommodates into a weakly bound state, which may involve hydrogen bonds, charge transfer, or Van der Waals interactions. Adsorbed molecules may leave the surface through thermally activated desorption, which results in lifetimes on the surface of typically between nanoseconds and seconds at atmospheric temperatures. Thermally desorbing molecules can be distinguished from scattered molecules through molecular beam experiments (Morris et al., 2000; Nathanson et al., 1996). The adsorption state as defined above is usually referred to as physisorption in the surface science literature (Masel, 1996). Physisorption should be differentiated from chemisorption, which involves breaking of chemical bonds or significant distortion of electronic structure of adsorbate and substrate. As discussed below, chemisorption is considered to be a surface reaction. We recommend use of the term "surface accommodation coefficient", $\alpha_{\mathrm{s}}$, for the probability of adsorption on a clean surface. Note that the symbol S and terms such as sticking probability or adsorption coefficient are used in the literature (Ammann et al., 2003; Carslaw and Peter, 1997; Davidovits et al., 1995; Garrett et al., 2006; Hanson, 1997; Jayne et al., 1990; Pöschl et al., 2007; Tabazadeh and Turco, 1993; Vieceli et al., 2005), however these terms often lack an unequivocal definition. The term thermal accommodation coefficient, $\alpha_{\mathrm{t}}$, has been used to describe the probability that a molecule accommodates to the thermal energy of the substrate upon adsorption in a single collision model, when a molecule collides with the surface ( $\mathrm{Li}$ et al., 2001; Vieceli et al., 2005; Winkler et al., 2004; Worsnop et al., 2002). A more detailed discussion of the terminology issues has been given by Kolb et al. (2010).

In spite of the fact that Langmuir type adsorption is strictly only applicable to solid surfaces with fixed, periodically arranged surface sites, we also adopt this concept for liquid surfaces to represent the competition for limited surface area. The concept of Langmuir type adsorption assumes that molecules can only adsorb on free surface sites, so that the adsorption flux (molecule $\mathrm{cm}^{-2} \mathrm{~s}^{-1}$ ) is given by

$J_{\mathrm{ads}}=\frac{\alpha_{\mathrm{s}} \bar{c}}{4}(1-\theta)[\mathrm{X}]_{\mathrm{g}}$

Note that this equation has been corrected from the corresponding equation in Crowley et al. (2010) that contained a typo. $\theta$ denotes the fractional surface coverage, which is related to the surface concentration, $[\mathrm{X}]_{\mathrm{s}}$, via $[\mathrm{X}]_{\mathrm{S}}=\theta N_{\max }$, where $N_{\max }$ is the maximum number of molecules that can be adsorbed per $\mathrm{cm}^{2}$. For the reverse process, the thermally activated desorption flux is usually parameterised by a first order rate expression:

$J_{\mathrm{des}}=k_{\mathrm{des}}[\mathrm{X}]_{\mathrm{s}}$

$k_{\text {des }}$ denotes the desorption rate constant $\left(\mathrm{s}^{-1}\right)$. In the absence of surface reaction or transfer to the bulk, the uptake coefficient as a function of time is given by

$\gamma(t)=\alpha_{\mathrm{s}} e^{-B t}$

with

$B=\alpha_{\mathrm{s}} \frac{\bar{c}[\mathrm{X}]_{\mathrm{g}}}{4 N_{\max }}+k_{\mathrm{des}}$

Equation (5) indicates that for low coverages, where $k_{\text {des }}$ is much larger than $\alpha_{\mathrm{s}}\left(\bar{c}[\mathrm{X}]_{\mathrm{g}}\right) / 4 N_{\max }$ (applies for many atmospherically relevant adsorption processes), the characteristic time to reach equilibrium is given by $1 / k_{\mathrm{des}}$. Note that $k_{\mathrm{des}}$ and thus the equilibrium coverage may be strongly temperature dependent. After equilibrium has been established (see below), $\gamma$ drops to zero. Therefore, at all concentrations, sufficient time resolution is necessary to observe an uptake coefficient equal to $\alpha_{\mathrm{s}}$, and laboratory experiments have to be carefully evaluated to judge whether initial uptake coefficients (normally reported as $\gamma_{0}$ ) may correspond to $\alpha_{\mathrm{s}}$ or are lower limits to $\alpha_{\mathrm{s}}$. In the data sheets we tabulate reported values of $\gamma_{0}$ and provide a preferred value for $\alpha_{\mathrm{s}}$ if appropriate and as discussed in the associated comments. Equation (5) may also be used to parameterize the temperature dependence of the uptake coefficient observed at a given time or averaged over a given time interval.

\subsubsection{Adsorption equilibrium}

The kinetics of adsorption may be relevant for extracting $\alpha_{\mathrm{s}}$ from laboratory measurements, but only rarely represents a rate limiting step of loss of gas phase species under atmospheric conditions. Here, adsorption equilibrium is of wider importance as it may be used to estimate gas surface partitioning which defines the concentration of surface species available for surface reaction or for transfer to the bulk underneath (e.g., in liquid water clouds or aerosols). Thus adsorption of surface-active gases on aqueous solutions (Donaldson and Anderson, 1999) or of gases that form a relatively stable surface complex as intermediate to solvation (Jayne et al., 1990) or to a surface reaction (Donaldson and Valsaraj, 2010) has been described using this concept. Adsorption equilibrium is established when $J_{\text {ads }}=J_{\text {des }}$ and can be described by:

$\theta=\frac{N}{N_{\max }}=\frac{K_{\text {LangC }}[\mathrm{X}]_{\mathrm{g}}}{1+K_{\mathrm{LangC}}[\mathrm{X}]_{\mathrm{g}}}$ 
$K_{\text {LangC }}[\mathrm{X}]_{\mathrm{g}}=\frac{\alpha_{\mathrm{s}} \bar{c}}{4 k_{\mathrm{des}} N_{\max }}$

Equation (7) is an isotherm commonly referred to as the Langmuir isotherm, which allows derivation of the partition coefficient, $K_{\text {LangC }}$, from measurements of surface coverage (molecule $\mathrm{cm}^{-2}$ ) as a function of trace gas concentration or pressure. Equation (8) relates the partition coefficient to the kinetic parameters that determine the equilibrium on a molecular level. Therefore, measurement of $K_{\text {LangC }}$ also provides constraints on $\alpha_{\mathrm{s}} . k_{\mathrm{des}}$ is likely the main driver of the temperature dependence of the partition coefficient.

The Langmuir isotherm appears to be a reasonable approximation for adsorption characteristics on many model surfaces used in laboratory studies of adsorption of atmospheric trace gases onto both solid and liquid surfaces, in the latter case mainly for less soluble gases. We have adopted this formalism for representation of evaluated data, unless there is a gross departure from the simple picture. Note also that an expression similar to that of Eq. (7) can be used to express the equilibrium between the bulk of an aqueous solution and the surface for surface active solutes (Donaldson and Anderson, 1999). From a thermodynamic point of view, the equilibrium between the gas and the surface can also be expressed using a dimensionless partition coefficient, $K_{\mathrm{p}}^{0}$ :

$$
\left([\mathrm{X}]_{\mathrm{s}} /[\mathrm{X}]_{\mathrm{g}}\right)(A / V)=\exp \left(-\Delta G_{\mathrm{ads}}^{0} / R T\right) \equiv K_{\mathrm{p}}^{0}
$$

where $A / V$ is the area-to-volume ratio $\left(\mathrm{cm}^{-1}\right)$ of an ideal gas adsorbed at the surface $\left(\sim 1.7 \times 10^{7} \mathrm{~cm}^{-1}\right.$; Kemball, 1946; Kemball and Rideal, 1946; Donaldson et al., 2012) and $\Delta G_{\text {ads }}^{0}$ is the free energy of adsorption. $A / V$ defines the standard state for the adsorbed phase, which corresponds to a molar area of $A=3.74 \times 10^{7} \mathrm{~m}^{2} \mathrm{~mol}^{-1} . \Delta G_{\text {ads }}^{0}$ is related as usual via the Gibbs equation to the enthalpy and entropy of adsorption:

$-R T \ln K_{\mathrm{p}}^{0}=\Delta H_{\mathrm{ads}}^{0}-T \Delta S_{\mathrm{ads}}^{0}$

The relation between $K_{\mathrm{p}}^{0}$ and $K_{\mathrm{LangC}}$ (the "C" of LangC refers to the fact that units of concentration in molecules $\mathrm{cm}^{-3}$ are used) is equivalent to

$$
K_{\text {LangC }}=K_{\mathrm{p}}^{0} \frac{V}{A} \frac{1}{N_{\max }} \text { in units of } \mathrm{cm}^{3} \text { molecule }{ }^{-1}
$$

The use of gas pressures results in:

$$
K_{\text {LangP }}=K_{\mathrm{p}}^{0} \frac{V}{A} \frac{1}{k_{\mathrm{b}} T N_{\max }}
$$

in units of $\mathrm{Pa}^{-1}$ or $\mathrm{atm}^{-1}$ or $\mathrm{Torr}^{-1}$ or $\mathrm{mbar}^{-1}$. A modified analysis using only the linear regime of the adsorption isotherm is sometimes possible. The partition coefficient $\left(K_{\text {linC }}\right)$ once again has different units:

$$
K_{\text {linC }}=K_{\mathrm{p}}^{0} \cdot V / A
$$

$K_{\text {linC }}$ has units of molecule $\mathrm{cm}^{-2} /$ molecule $\mathrm{cm}^{-3}$ (or $\mathrm{cm}$ ) if concentrations (in molecule $\mathrm{cm}^{-3}$ ) are used, and units of molecule $\mathrm{cm}^{-2} \mathrm{~Pa}^{-1}$ or molecule $\mathrm{cm}^{-2} \mathrm{Torr}^{-1}$ if pressure is used, then denoted as $K_{\text {linP. }}$. Fractional surface coverages can be calculated from each different form of the partition coefficient via:

$$
\begin{aligned}
\Theta_{\mathrm{X}} & =K_{\mathrm{p}}^{0} \frac{V}{A} \frac{p_{\mathrm{x}}}{k_{\mathrm{b}} T N_{\max }}=K_{\mathrm{p}}^{0} \frac{V}{A} \frac{[\mathrm{X}]_{\mathrm{g}}}{N_{\max }}=K_{\mathrm{LinC}} \frac{[\mathrm{X}]_{\mathrm{g}}}{N_{\max }} \\
& =K_{\mathrm{LinP}} \frac{p_{\mathrm{x}}}{N_{\text {max }}}=K_{\mathrm{Lang}}[\mathrm{X}]_{\mathrm{g}}=K_{\mathrm{LangP}} p_{\mathrm{x}}
\end{aligned}
$$

For the purpose of comparing partition coefficients and deriving preferred expressions for calculating equilibrium surface coverages, a single form of the partition coefficient is required. In principle $K_{\mathrm{p}}^{0}$ would be the best choice; the disadvantage is that it is difficult to extract from the various studies if experimental surface to volume ratios $\left(S_{\exp } / V_{\exp }\right)$ are not known, or if $N_{\max }$ has to be chosen arbitrarily and not from the experiment itself. Therefore, for practical purposes (e.g., using the constants to calculate surface coverages) reporting consistently in the form of $K_{\text {linC }}$ has the advantage that no inherent assumption about $N_{\max }$ has to be made to derive partitioning from the experiments at low trace gas pressures. The tabulated values of partition coefficients are therefore presented as $K_{\text {linc. }}$. The accompanying notes in each data sheet provide the original expressions and the values of $N_{\max }$ and $V / A$ used to calculate $K_{\text {linC }}$.

If data are available from the low coverage (linear) part of the isotherm these are used preferably, as the influence of lateral interactions is reduced, and $N_{\max }$, which is often difficult to obtain experimentally due to adsorbate-adsorbate interactions (Jedlovsky et al., 2006), is not required. The Van't Hoff equation (i.e., the differential form of the Gibbs equation):

$$
\frac{d\left(\ln K_{\mathrm{p}}^{0}\right)}{d(1 / T)}=\frac{-\Delta H^{0}}{R}
$$

describes the temperature dependence of $K$, but the entropy and enthalpy of adsorption derived from this analysis can be coverage dependent and this needs to be considered when comparing results from different experiments.

\subsubsection{Surface reactions}

Parameterisation of uptake resulting from reaction of trace gases on a surface (reactive uptake) requires knowledge of the mechanism of the reaction. Generally there are two types of reaction. First, those in which the molecule arriving at the surface reacts with a constituent from the bulk phase to form either involatile products (e.g., stable hydrates) or volatile products which partition back to the gas phase. Second, those in which the molecule arriving at the surface reacts with a second species, which is present on the surface in the adsorbed state to form either involatile or volatile products. In both types the kinetics depend on the surface concentration of the second reactant, which must be included 
in any parameterisation of the reactive uptake coefficient. The two mechanisms, which are commonly used to describe the kinetics of surface reactions, are often referred to as Langmuir-Hinshelwood (LH) and Eley-Rideal mechanisms (ER). It should be noted that some reports in the literature use the term Langmuir-Rideal for the latter and that the reverse abbreviation RE has also been used (see also IUPAC Gold Book). They differ in that the LH mechanism involves adsorption of the arriving molecule at available surface sites prior to a bimolecular reaction. The ER mechanism involves direct collision induced reaction of the arriving gaseous molecule with a reactant molecule present on the surface. The LH mechanism thus may involve competition of both reactant molecules for available surface sites. Moreover on the surface of bulk liquids, the second reactant molecule may originate in the gas phase or the bulk liquid phase. For parameterisation of the uptake coefficients we adopt the approach presented by Ammann et al. (2003), which builds on earlier studies (Elliott et al., 1991; Mozurkewich, 1993; Tabazadeh and Turco, 1993; Carslaw and Peter, 1997).

\section{Bimolecular reaction between two surface species}

The parameterisation for the reactive uptake coefficient, $\gamma$, for gas phase species $\mathrm{X}$ reacting with surface species, Y, after adsorption on the surface (LH mechanism) is given by:

$$
\frac{1}{\gamma}=\frac{1}{\alpha_{\mathrm{s}}}+\frac{1}{\Gamma_{\mathrm{s}}} \quad \text { with } \quad \Gamma_{\mathrm{s}}=\frac{4 k_{\mathrm{s}}[\mathrm{Y}]_{\mathrm{s}} K_{\text {LangC }}(\mathrm{X}) N_{\mathrm{max}}}{\bar{c}\left(1+K_{\mathrm{LangC}}(\mathrm{X})[\mathrm{X}]_{\mathrm{g}}\right)}
$$

Here $[\mathrm{Y}]_{\mathrm{s}}$ is the surface concentration (molecule $\mathrm{cm}^{-2}$ ) of species $\mathrm{Y}$ and $k_{\mathrm{s}}$ is the surface reaction rate coefficient (units of $\mathrm{cm}^{2}$ molecule $\left.{ }^{-1} \mathrm{~s}^{-1}\right) .1 / \Gamma_{\mathrm{s}}$ can be considered the resistance for the surface reaction. Note that $\Gamma_{\mathrm{s}}$ represents a normalized rate and is therefore not restricted to values smaller than one. If $\mathrm{Y}$ is a volatile molecule also present in the gas phase, its equilibrium surface concentration, $[\mathrm{Y}]_{\mathrm{s}}$, can be calculated using an appropriate adsorption isotherm. Values of $k_{\mathrm{S}} K_{\mathrm{LangC}}(\mathrm{X})$ can be determined experimentally from measurements of $\gamma$ as a function of surface coverage $[\mathrm{Y}]_{\mathrm{s}}$. Equation (16) demonstrates that $\gamma$ depends on the gas phase concentration of $\mathrm{X}$, if $K_{\mathrm{LangC}}(\mathrm{X})[\mathrm{X}]_{\mathrm{g}}$ is similar to or larger than 1 (i.e., at high coverage). This is especially important when interpreting data from laboratory experiments performed using gas-phase reactant concentrations which lead to significant surface coverage. In the data sheets, we provide preferred values for $\alpha_{\mathrm{s}}$ and $k_{\mathrm{s}}$.

\section{Direct gas surface reaction}

Parameterisation for the reactive uptake coefficient, $\gamma$, for gas phase species $\mathrm{X}$ directly reacting with surface species, $\mathrm{Y}$, upon collision (ER mechanism) is given by:

$\gamma_{\mathrm{gs}}=\gamma_{\mathrm{gs}}^{\theta=1}(\mathrm{X}) \cdot \theta^{\mathrm{Y}}=\gamma_{\mathrm{gs}}^{\theta=1}(\mathrm{X}) \cdot \frac{[\mathrm{Y}]_{\mathrm{s}}}{N_{\mathrm{max}}^{\mathrm{Y}}}$

Here $\gamma_{\mathrm{gs}}$ is the elementary reaction probability that a gas phase molecule $\mathrm{X}$ colliding with surface component $\mathrm{Y}$ reacts with it. $N_{\max }(\mathrm{Y})$ denotes the maximum coverage of $\mathrm{Y}$ for a volatile species $\mathrm{Y}$ in equilibrium with the gas phase. $\gamma$ can be calculated for a given gas phase concentration of $\mathrm{Y}$ if values of $K_{\mathrm{LangC}}(\mathrm{Y})$ and $\gamma_{\mathrm{gs}}$ are available. In the absence of other rate limiting reactions, values of $\gamma_{\mathrm{gs}}$ can be determined experimentally from measurements of $\gamma$ as a function of surface coverage near saturation, or by extrapolation using an appropriate adsorption isotherm. In the ER mechanism, $\gamma$ does not depend on the gas phase concentration of $\mathrm{X}$, whereas in the LH type mechamism (at high $[\mathrm{X}]_{\mathrm{g}}$ ), it does. Also the temperature dependence, driven by the temperature dependence of $K_{\text {LangC }}(\mathrm{X})$ in the LH case, is substantially different (Pöschl et al., 2007; Ammann and Pöschl, 2007).

\subsubsection{Exchange with the bulk and bulk accommodation}

Previously, the process of transfer of a gas molecule from the gas phase into the bulk of a liquid has been considered a quasi-elementary process, and the mass accommodation coefficient has been defined as the probability that a molecule colliding with the surface is actually taken up into the bulk, mostly in relation with liquids. However, in many cases it is necessary to decouple this process into adsorption on the surface and surface to bulk transfer, i.e., dissolution (Davidovits et al., 1995; Hanson, 1997).

With the aim to clearly differentiate uptake into the bulk from surface accommodation, the term bulk accommodation is recommended, and the corresponding coefficient as bulk accommodation coefficient, $\alpha_{\mathrm{b}}$ (Kolb et al., 2010). In the absence of surface reactions,

$\alpha_{\mathrm{b}}=\alpha_{\mathrm{s}}\left(k_{\mathrm{sb}} /\left(k_{\mathrm{sb}}+k_{\mathrm{des}}\right)\right)$

In Eq. (18), $k_{\mathrm{sb}}$ denotes the surface to bulk transfer rate coefficient in units of $\mathrm{s}^{-1}$. If the adsorption equilibrium is established much faster than transfer to the bulk, the two processes can be expressed in the form of separated resistances:

$\frac{1}{\alpha_{\mathrm{b}}}=\frac{1}{\alpha_{\mathrm{s}}}+\frac{1}{\Gamma_{\mathrm{sb}}} \quad$ with $\quad \Gamma_{\mathrm{sb}}=\frac{\alpha_{\mathrm{s}} k_{\mathrm{sb}}}{k_{\mathrm{des}}}$

Equations (18) and (19) also allow parameterization of the temperature dependence of $\alpha_{\mathrm{b}}$, which has been used as a proof of the nature of bulk accommodation as a coupled process (Davidovits et al., 1995).

\subsubsection{Solubility equilibrium}

If the rates of transfer from the surface to the bulk and back are equal, solubility equilibrium is established:

$K_{\mathrm{cc}}=K_{\mathrm{cp}} R T=[\mathrm{X}]_{\mathrm{b}, \mathrm{eq}} /[\mathrm{X}]_{\mathrm{g}} \approx H$ 
$K_{\mathrm{cc}}$ denotes the solubility equilibrium constant in dimensionless units, $K_{\mathrm{cp}}$ in pressure/molarity based units (Sander, 1999). For infinitely dilute solutions, $K_{\mathrm{cc}}$ or $K_{\mathrm{cp}}$ becomes equivalent to the Henry's Law constant: $K_{\mathrm{cp}} \approx H$ in units of $\mathrm{Matm}^{-1}$. This equilibrium can be related to the kinetic parameters via (Hanson, 1997; Pöschl et al., 2007):

$K_{\mathrm{cc}}=\frac{k_{\mathrm{sb}}}{k_{\mathrm{bs}}} \frac{k_{\mathrm{ads}}}{k_{\mathrm{des}}}=\frac{k_{\mathrm{sb}}}{k_{\mathrm{bs}}} \frac{\alpha_{\mathrm{s}}(1-\theta) \bar{c}}{4 k_{\mathrm{des}}}$

$k_{\mathrm{bs}}$ denotes the rate coefficient associated with bulk to surface transfer, i.e., desolvation. As evident from this expression, solubility becomes linked to the surface coverage, adding the constraint that Henry's Law is only valid for sufficiently dilute conditions also at the surface. Examples of deviations have been shown for $\mathrm{SO}_{2}$ (Jayne et al., 1990) at high pressures or for surface active organics (Djikaev and Tabazadeh, 2003). A more detailed discussion of such cases has been given by Ammann and Pöschl (2007).

For the majority of cases in this evaluation, the link of solubility to adsorption is either not relevant or has not been considered in the experiments. The most direct measurement of $H$ is expressed in Eq. (20), i.e., through measurement of both liquid phase and gas phase concentrations at equilibrium. Values from such measurements are used when available to evaluate kinetic parameters. Note that we quote values of $H$ from the literature but do not evaluate $H$ measurements themselves.

\subsubsection{Solubility limited uptake into the bulk}

In the absence of surface or bulk reactions, uptake into the bulk of liquid particles proceeds until the solubility equilibrium is reached. Under quasi-steady state conditions, the uptake coefficient can be described by Eq. (22):

$$
\frac{1}{\gamma}=\frac{1}{\alpha_{\mathrm{b}}}+\frac{1}{\Gamma_{\mathrm{sol}}} \quad \text { with } \quad \Gamma_{\mathrm{sol}}=\frac{4 H R T}{\bar{c} \sqrt{\pi}} \sqrt{\frac{D_{1}}{t}}
$$

$H$ denotes the Henrys Law coefficient $\left(\mathrm{M} \mathrm{atm}^{-1}\right), R$ the gas constant $\left(1 \mathrm{~atm} \mathrm{~mol}{ }^{-1} \mathrm{~K}^{-1}\right)$ and $D_{1}$ the liquid phase diffusion coefficient $\left(\mathrm{cm}^{2} \mathrm{~s}^{-1}\right)$ (Schwartz, 1986). Solubility limited uptake can be used to measure the product $H\left(D_{1}\right)^{0.5}$, through the time dependence of the observed $\gamma$. If independent measurements of the solubility are available, a value for the diffusion coefficient can be obtained. Otherwise, the diffusion coefficient can be estimated from viscosity data to get an estimate for $H$ (see also Sect. 2.2).

\subsubsection{Reactive uptake into the bulk}

For atmospheric trace gas uptake to the bulk of liquid (usually aqueous) particles, in the absence of a surface reaction,

$\frac{1}{\gamma}=\frac{1}{\alpha_{\mathrm{b}}}+\frac{1}{\Gamma_{\mathrm{b}}} \quad$ with $\quad \Gamma_{\mathrm{b}}=\frac{4 H R T}{\bar{c}} \sqrt{D_{\mathrm{l}} k_{\mathrm{b}}^{\prime}}$ $k_{\mathrm{b}}^{\prime}$ is the pseudo first-order bulk reaction rate coeffcient. For small droplets the concept of the reacto-diffusive length is important. This is the characteristic distance beyond the surface of the particle in which the trace gas is lost by reaction and is given by:

$l=\sqrt{\frac{D_{1}}{k_{\mathrm{b}}^{\prime}}}$

For spherical particles, Eq. (23) can be modified to account for this with:

$\frac{1}{\gamma}=\frac{1}{\alpha_{\mathrm{b}}}+\frac{c}{4 H R T \sqrt{D_{\mathrm{l}} \cdot k_{\mathrm{b}}^{\prime}}[\operatorname{coth}(r / l)-(l / r)]}$

This is the basis of the "Framework" paper (Hanson et al., 1994) for modelling uptake rates to stratospheric aerosol. Note that for a molecule that can dissociate in the aqueous phase, an effective solubility, $H^{*}$, is used whereby:

$H^{*}=H \cdot\left(\frac{1+K_{\mathrm{a}}\left[\mathrm{H}^{+}\right]_{\mathrm{e}}}{K_{\mathrm{w}}}\right)$

$K_{\mathrm{w}}$ is the autoprotolysis constant of $\mathrm{H}_{2} \mathrm{O}, K_{\mathrm{a}}$ is the acid dissociation constant of the trace gas in water and $\left[\mathrm{H}^{+}\right]_{\mathrm{e}}$ is the equilibrium hydrogen ion concentration.

In the limiting case for small liquid particles or mixed phase particles when the volume of the liquid phase is such that $l>r$, the reactants fill the entire liquid phase and uptake rate becomes volume limited. In this case the diffusion restriction in the bulk term in Eq. (23) disappears. If $\alpha_{\mathrm{b}} \gg \Gamma_{\mathrm{b}}$ this leads to a linear dependence of the uptake coefficient on the volume/surface ratio of the liquid phase. For spherical geometry Eq. (25) simplifies to:

$\gamma=\frac{4 H R T k^{\prime}\left(\frac{V_{1}}{S_{\mathrm{a}}}\right)}{\bar{c}}$

where $V_{1}$ and $S_{\mathrm{a}}$ are the volume and surface area of the liquid phase, respectively.

\subsubsection{Coupled processes on the surface and in the bulk}

When processes occur on both the surface and in the bulk, adsorption and transfer to the bulk have to be separated. Following previous derivations (Ammann et al., 2003; Davidovits et al., 1995; Hanson, 1997; Jayne et al., 1990; Pöschl et al., 2007; Shi et al., 1999), coupling a Langmuir-Hinshelwood type surface reaction with a reaction in the bulk leads to:

$\frac{1}{\gamma}=\frac{1}{\alpha_{\mathrm{s}}}+\frac{1}{\Gamma_{\mathrm{s}}+\left(\frac{1}{\Gamma_{\mathrm{sb}}}+\frac{1}{\Gamma_{\mathrm{b}}}\right)^{-1}}$

In the case of an ER reaction which occurs without prior adsorption or surface to bulk transfer, the resistance acts in 
parallel to adsorption, leading to an expression proposed by Pöschl et al. (2007):

$$
\frac{1}{\gamma}=\frac{1}{\gamma_{\mathrm{gs}}+\left(\frac{1}{\alpha_{\mathrm{s}}}+\frac{1}{\Gamma_{\mathrm{sb}}}+\frac{1}{\Gamma_{\mathrm{b}}}\right)^{-1}}
$$

Note that while Eq. (29) is consistent with the resistor diagram of Hu et al. (1995), it is not consistent with their expression for $1 / \gamma$. In follow-up papers, e.g., Shi et al. (1999), Eq. (29) was used.

\subsection{Liquid surfaces considered}

\subsubsection{Sulphuric acid}

Stratospheric aerosols consist mainly of sub-micron size liquid particles containing aqueous concentrated $\mathrm{H}_{2} \mathrm{SO}_{4}$ (50 to $80 \mathrm{wt} \%)$ at low temperature $(185-260 \mathrm{~K})$. The water content depends in a predictable way on the relative humidity, which is defined by the temperature and the absolute water concentration. Substrates with well-characterised surface area and acid content are relatively straightforward to investigate experimentally, either as bulk substrates or as an aerosol of submicron particles of defined size distribution. The latter form minimises the limiting effects of gas-phase diffusion on the uptake rates, which can be a problem when bulk surfaces are used and $\gamma$ values are large.

In spite of the chemical simplicity of this substrate, parameterization of uptake and reaction of trace gases on and within sulfuric acid is fairly complex due to the strong dependence of physical and acidic properties of sulphuric acid on composition, which itself is a strong function of humidity and temperature. The thermodynamic basis for describing sulphuric acid composition for atmospheric conditions has been given in detail by Carslaw et al. (1995). $\mathrm{H}_{2} \mathrm{SO}_{4}$ content is mostly given in units of weight percent (wt \%), then referred to as $w t$, or mole fraction $X$, which can be interconverted using

$X=w t /(w t+(100-w t) 98 / 18)$

Shi et al. (2001) present a parameterization for the water activity:

$$
\begin{aligned}
a_{\mathrm{w}} & =\exp \left[\left(-69.775 X-18253.7 X^{2}+31072.2 X^{3}\right.\right. \\
& \left.\left.-25668.8 X^{4}\right)\left(1 / T-26.9033 / T^{2}\right)\right]
\end{aligned}
$$

Since many of the relevant reactions in sulphuric acid solutions are acid catalyzed Shi et al. also suggest a parameterization of acid activity in units of $\mathrm{M}$, which also extends the Carslaw et al. model to dilute solutions:

$$
\begin{aligned}
a_{\mathrm{H}^{+}} & =\exp \left[60.51-0.095 w t+0.0077 w t^{2}\right. \\
& -1.61 \times 10^{-5} w t^{3}-\left(1.76+2.52 \times 10^{-4} w t^{2}\right) T^{0.5} \\
& \left.+\left(-805.89+253.05 w t^{0.076}\right) / T^{0.5}\right]
\end{aligned}
$$

Knopf et al. (2003) have reported measurements of the protonation state of bisulfate ion, $\mathrm{HSO}_{4}^{-}$. Based on a Pfitzer ion interaction model they derived a new formulation of the acid dissociation constant. Based on that, they found significant deviations for several solution parameters as compared to the Carslaw et al. (1995) model. The follow up discussion (Clegg and Brimblecombe, 2005; Knopf et al., 2005) emphasized the need to further develop the thermodynamic models. Where appropriate, this is included in the datasheets in the discussion of the uncertainties of the corresponding rate parameters, such as parameterizations of reactions in terms of $\mathrm{H}^{+}$.

An inherent physical property influencing the rate of stratospheric heterogeneous processes is the viscosity, $\eta$, in units of cP. Williams and Long (1995) provide direct measurements of viscosity for a range of relevant sulphuric acid compositions and temperatures. Again, combining with data from dilute solutions, Shi et al. extended the fit of Williams and Long to an empirical equation originally derived by Eicher and Zwolinski (1971) to more dilute solutions:

$$
\begin{aligned}
& \eta=A T^{-1.43} \exp \left(448 \mathrm{~K} /\left(T-T_{0}\right)\right) \\
& A\left(\mathrm{Matm}^{-1} \mathrm{~K}^{1.43}\right) \\
& \quad=169.5+5.18 w t-0.0825 w t^{2}+3.27 \times 10^{-3} w t^{3}
\end{aligned}
$$

$T_{0}(K)=144.11+0.166 w t-0.015 w t^{2}+2.18 \times 10^{-4} w t^{3}$

The viscosity calculated from these parameterisations can be used to obtain an estimate for the diffusion coefficient using the Stokes-Einstein equation:

$D_{1}=c T / \eta$

The constant $c$ has been either determined from fits to experimentally measured diffusion coefficients or has been estimated. Values are given in the individual datasheets.

\subsubsection{Aqueous aerosols}

Aerosol particles in the troposphere frequently consist of water-soluble electrolyte salts. Over marine regions the aerosol is dominated by sea salt aerosol, with $\mathrm{NaCl}$ as the main constituent. In continental regions ammonium sulphate, ammonium bisulphate, and ammonium nitrate are major inorganic constituents of the aerosol. The phase of the particles depends on relative humidity. At low humidity, below efflorescence RH, the particles can contain solid crystals. At higher humidity $(\geq 40 \%)$ the particles exist as aqueous droplets and this is the predominant form in the troposphere. The dependence of the particle composition (e.g. water content) on relative humidity and concentrations of ionic constituents (and selected soluble organics) can be calculated using the Extended Aerosol Thermodynamics Model (AIM) (Wexler and Clegg, 2002) (http://www.aim.env.uea.ac.uk/ 
aim/aim.php). Aqueous tropospheric particles may also contain a large range of organic solutes. Smaller carboxylic acids lead to comparable solutions, and they have also been included in the AIM. As far as they have been used in trace gas uptake studies, they are dealt with in the category "other aqueous electrolytes" in the present evaluation. As noted in the introduction, we consider the aqueous substrates to be well mixed homogeneous solutions. Solutes may have a varying propensity for the surface, which is discussed in the context of surface reactions in the datasheets, where appropriate. For larger organic solutes, we note however that the physical state of the homogeneous solution is not always well defined as they may form highly viscous semi-solid phases or even glasses at low humidity or low temperature (Koop et al., 2011; Zobrist et al., 2008). These substrates are not covered by the present evaluation. We also note that organic coatings in the form of surfactant monolayers, multilayers or phase separated layers on aqueous substrates may affect trace gas uptake (Abbatt et al., 2012). In this evaluation, we do not provide a recommendation with respect to the quantitative effect of organic coatings on uptake.

Liquid substrate surfaces with well characterised surface area and electrolyte content are relatively straightforward to prepare, either as bulk substrates in wetted wall or droplet train configuration, or as an aerosol of sub-micron particles of defined size distribution. In the atmosphere mixed phase particles may occur. The rate parameters given in this evaluation can be used for uptake into particles which have predominantly liquid (aqueous) phase, at least near the surface. In this case the spherical geometry applies but the size threshold for volume limited uptake (see Eq. 27) may be affected. This may be the preferred paramerisation for small multicomponent aerosol particles in the troposphere. For particles of predominantly solid phase we refer to recommendations in ACP V (Crowley et al., 2010). Under most ambient conditions the aqueous phase diffusion coefficient for most trace gases for the substrates used in the present evaluation is close to $10^{-5} \mathrm{~cm}^{2} \mathrm{~s}^{-1}$. Individual values required for parameterisation of $\gamma$ are listed in the datasheets. Exceptions are sulphuric acid solutions at low temperature dealt with in the previous subsection or highly viscous solutions (Zobrist et al., 2008).

\subsection{Surface areas}

$\gamma$ is usually obtained from observed loss rates of gas-phase species and calculated collision rates with the surface. For the latter the surface area available for uptake/reaction $(A)$ is required. For liquid surfaces this generally poses no problems as the surface is "smooth" at the molecular level and the geometric surface area $\left(A_{\text {geom }}\right)$ is generally applicable and readily defined. The use of aerosol particles rather than bulk surfaces in principle provides a better mimic of atmospheric conditions for experimental surface area and may provide confirmation of particle size dependent uptake coefficients when reaction and diffusion compete.

\subsection{Methods used in the study of heterogeneous pro- cesses}

A number of experimental techniques have been developed for the study of heterogeneous processes. Most methods rely on the determination of loss rates or time dependent concentration changes of gas-phase species in contact with a surface. These include low pressure, coated surface laminar flow tube reactors and Knudsen cells for bulk surfaces and films, and droplet train reactors, aerosol flow tubes and static aerosol chambers for dispersed surfaces. Surface adsorbed reactants and products have frequently been observed using surface-sensitive techniques, such as reflectance infrared spectroscopy (DRIFTS, RAIRS), and these have in a few cases been applied to kinetics studies. Since each technique is specific in its suitability for an individual heterogeneous process or in the parameter space it may access, we refrain from providing a critical review of the methods in general. Methodological aspects are however discussed in the data sheets as far as they are relevant for the preferred values. A list of abbreviations for methods used in the data sheets is given in Table 2 below.

\subsection{Organisation of the datasheets}

The basic structure of the heterogeneous datasheets is similar to the well established datasheets on homogeneous gas-phase reactions. For each heterogenous interaction on a particular substrate we give a list of experimentally measured values of the uptake coefficients $(\gamma)$, accommodation coefficients $(\alpha)$, partition coefficients $\left(H, K_{\text {linC }}\right)$, and diffusion coefficients $\left(D_{1}\right)$, where appropriate for physical uptake. For reactive uptake reported values for rate coefficients for reaction in the liquid phase, including their temperature and composition dependence where known. The parameters are distinguished according to the definitions given above (e.g., $\alpha_{\mathrm{s}}, \alpha_{\mathrm{b}}, \gamma_{0}, \gamma_{\mathrm{ss}}$, $H^{*}, k_{\mathrm{r}}$, etc.). Also given are references and pertinent information about the technique, reactant concentration, substrate and other conditions in linked comments.

Preferred values for the uptake coefficient, $\gamma$ and/or for parameters needed for its calculation (e.g. $\alpha_{\mathrm{s}}, \alpha_{\mathrm{b}}, k_{\mathrm{r}}^{\prime}, H$, $K_{\text {linC }}, N_{\max }, D_{1}, \gamma_{\mathrm{gs}}$ etc.) using an expression specified in the text, are provided. Recommended temperature dependencies are given in Arrhenius form when appropriate, together with our estimate of the uncertainties in the parameters. Comments on the state of the data set and justification of the recommendations are then presented, followed by a list of references cited. A list of the symbols and description of the parameters used in the datasheets is given in Table 1 below. The datasheets available at the website http://www.iupac-kinetic.ch.cam.ac.uk also contain figures where appropriate to illustrate comparison between our recommendation and available experimental data.

In the usage of units, we follow the policy established in previous evaluations, in which and SI units are employed, 
where appropriate. We adopt the common usage of several parameters in the atmospheric science community, such as pressure in bar, and also follow the commonly used exceptions from SI, such as for the Henry' Law constant in $\mathrm{Matm}^{-1}$ or pressure dependent diffusion coefficients in $\operatorname{atm~cm} \mathrm{s}^{-1}$.

The ordering of reacting species within each surface category follows that adopted for gas phase reactions, i.e. $\mathrm{O}_{\mathrm{X}}$, $\mathrm{HO}_{\mathrm{X}}, \mathrm{NO}_{\mathrm{X}}, \mathrm{SO}_{\mathrm{X}}$, organics, and halogenated species. The website also offers search options to access individual datasheets.

\subsection{Citation}

The citation for recommendations in the data sheets and summary tables is: "Ammann, M., Cox, R. A., Crowley, J. N., Jenkin, M. E., Mellouki, A., Rossi, M. J., Troe, J., and Wallington, T. J.: Evaluated kinetic and photochemical data for atmospheric chemistry: Volume VI - heterogeneous reactions with liquid substrates, Atmos. Chem. Phys., 13, 80458228, 2013, IUPAC Task Group on Atmospheric Chemical Kinetic Data Evaluation, http://iupac.pole-ether.fr/index. html."

Acknowledgements. We thank I.U.P.A.C. for the financial help which facilitated the preparation of this evaluation. We also acknowledge financial support from the following organisations: EU Framework Program 6 and 7, ACCENT network of excellence; the European Science Foundation (INTROP program), the UK Natural Environmental Research Council; the Swiss National Science Foundation (Projects 200020_125204 and 200021_130175), and the Deutsche Forschungsgemeinschaft (SFB 357). We have appreciated valuable comments by H. Herrmann, D. Knopf and an anonymous reviewer.

Edited by: W. T. Sturges

\section{References}

Abbatt, J. P. D., Lee, A. K. Y., and Thornton, J. A.: Quantifying trace gas uptake to tropospheric aerosol: recent advances and remaining challenges, Chem. Soc. Rev., 41, 6555-6581, 2012.

Ammann, M., Pöschl, U., and Rudich, Y.: Effects of reversible adsorption and Langmuir-Hinshelwood surface reactions on gas uptake by atmospheric particles, Phys. Chem. Chem. Phys., 5, 351-356, 2003.

Ammann, M. and Pöschl, U.: Kinetic model framework for aerosol and cloud surface chemistry and gas-particle interactions - Part 2: Exemplary practical applications and numerical simulations, Atmos. Chem. Phys., 7, 6025-6045, doi:10.5194/acp-7-60252007, 2007.

Behr, P., Terziyski, A., and Zellner, R.: Reversible gas adsorption in coated wall flow tube reactors, model simulations for Langmuir kinetics, Z. Phys. Chem. Int. J. Res. Phys. Chem. Chem. Phys, 218, 1307-1327, 2004.

Brown, R. L.: Tubular flow reactor with first-order kinetics, J. Res. Natl. Bureau St., 83, 1-8, 1978.
Carslaw, K. S., Clegg, S. L., and Brimblecombe, P.: A thermodynamic model of the system $\mathrm{HCl}-\mathrm{HNO}_{3}-\mathrm{H}_{2} \mathrm{SO}_{4}-\mathrm{H}_{2} \mathrm{O}$, including solubilities of $\mathrm{HBr}$, from $<200$ to $328 \mathrm{~K}$, J. Phys. Chem., 99, 11557-11574, 1995.

Carslaw, K. S. and Peter, T.: Uncertainties in reactive uptake coefficients for solid stratospheric particles. 1. Surface chemistry, Geophys. Res. Lett., 24, 1743-1746, 1997.

Clegg, S. L. and Brimblecombe, P.: Comment on the "Thermodynamic dissociation constant of the bisulfate ion from Raman and ion interaction modeling studies of aqueous sulfuric acid at low temperatures", J. Phys. Chem. A, 109, 2703-2706, doi:10.1021/jp0401170, 2005.

Cox, R. A.: Evaluation of laboratory kinetics and photochemical data for atmospheric chemistry applications, Chem. Soc. Rev., 41, 6231-6246, 2012.

Crowley, J. N., Ammann, M., Cox, R. A., Hynes, R. G., Jenkin, M. E., Mellouki, A., Rossi, M. J., Troe, J., and Wallington, T. J.: Evaluated kinetic and photochemical data for atmospheric chemistry: Volume V - heterogeneous reactions on solid substrates, Atmos. Chem. Phys., 10, 9059-9223, doi:10.5194/acp-10-90592010, 2010.

Davidovits, P., Hu, J. H., Worsnop, D. R., Zahniser, M. S., and Kolb, C. E.: Entry of gas molecules into liquids, Faraday Discuss., 100, 65-81, 1995.

Djikaev, Y. S. and Tabazadeh, A.: Effect of adsorption on the uptake of organic trace gas by cloud droplets, J. Geophys. Res.-Atmos., 108, art. no. 4689, 2003.

Donaldson, D. J. and Anderson, D.: Adsorption of atmospheric gases at the air-water interface. $2 . \mathrm{C}_{1}-\mathrm{C}_{4}$ alcohols, acids, and acetone, J. Phys. Chem. A, 103, 871-876, 1999.

Donaldson, D. J. and Valsaraj, K. T.: Adsorption and reaction of trace gas-phase organic compounds on atmospheric water film surfaces: A Critical Review, Env. Sci. Technol., 44, 865-873, 2010.

Donaldson, D. J., Ammann, M., Bartels-Rausch, T., and Pöschl, U.: Standard states and thermochemical kinetics in heterogeneous atmospheric chemistry, J. Phys. Chem. A, 116, 6323-6316, 2012.

Eicher, L. D. and Zwolinski, B. J.: High-precision viscosity of supercooled water and analysis of extended range temperature coefficient, J. Phys. Chem., 75, 2016-2024, 1971.

Elliott, S., Turco, R. P., Toon, O. B., and Hamill, P.: Application of Physical adsorption thermodynamics to heterogeneous chemistry on polar stratospheric clouds, J. Atmos. Chem., 13, 211224, 1991.

Finlayson-Pitts, B. J. and Pitts, J. N., Jr.: Chemistry of the upper and lower atmosphere, Academic Press, San Diego, CA, 2000.

Flückiger, B. and Rossi, M. J.: Common precursor mechanism for the heterogeneous reaction of $\mathrm{D}_{2} \mathrm{O}, \mathrm{HCl}, \mathrm{HBr}$, and $\mathrm{HOBr}$ with water ice in the range 170-230 K: Mass accommodation coefficients on ice, J. Phys. Chem. A, 107, 4103-4115, 2003.

Fuchs, N. A. and Sutugin, A. G.: Highly dispersed aerosols, Ann Arbor Science Publishers, Inc., Ann Arbor, London, 1970.

Garrett, B. C., Schenter, G. K., and Morita, A.: Molecular simulations of the transport of molecules across the liquid/vapor interface of water, Chem. Rev., 106, 1355-1374, 2006.

Hanson, D. R., Ravishankara, A. R., and Solomon, S.: Heterogeneous reactions in sulfuric-acid aerosols - a framework for model-calculations, J. Geophys. Res.-Atmos., 99, 3615-3629, 1994. 
Hanson, D. R.: Surface specific reactions on liquids, J. Phys. Chem. B, 101, 4998-5001, 1997.

Hu, J. H., Shi, Q., Davidovits, P., Worsnop, D. R., Zahniser, M. S., and Kolb, C. E.: Reactive uptake of $\mathrm{Cl}_{2}(\mathrm{~g})$ and $\mathrm{Br}_{2}(\mathrm{~g})$ by aqueous surfaces as a function of $\mathrm{Br}$ - and I-ion concentration: the effect of chemical reaction at the interface, J. Phys. Chem., 99, 87688776, 1995.

Huff, A. K. and Abbatt, J. P. D.: Gas-Phase $\mathrm{Br}_{2}$ production in heterogeneous reactions of $\mathrm{Cl}_{2}, \mathrm{HOCl}$ and $\mathrm{BrCl}$ with halide-ice surfaces, J. Phys. Chem. A, 104, 7284-7293, 2000.

Jayne, J. T., Davidovits, P., Worsnop, D. R., Zahniser, M. S., and Kolb, C. E.: Uptake of $\mathrm{SO}_{2}(\mathrm{~g})$ by aqueous surfaces as a function of $\mathrm{pH}$ - the effect of chemical-reaction at the interface, J. Phys. Chem., 94, 6041-6048, 1990.

Jedlovszky, P., Partay, L., Hoang, P. N. M., Picaud, S., von Hessberg, P., and Crowley, J. N.: Determination of the adsorption isotherm of methanol on the surface of ice. An experimental and Grand Canonical Monte Carlo simulation study, J. Am. Chem. Soc., 128, 15300-15309, 2006.

Kemball, C.: The Adsorption of Vapours on Mercury .2. The Entropy and Heat of Adsorption of Non-Polar Substances, P. Roy. Soc. Lond. A Mat., 187, 73-87, 1946.

Kemball, C. and Rideal, E. K.: The Adsorption of Vapours on Mercury .1. Non-Polar Substances, P. Roy. Soc. Lond. A Mat., 187, 53-73, 1946.

Kolb, C. E., Cox, R. A., Abbatt, J. P. D., Ammann, M., Davis, E. J., Donaldson, D. J., Garrett, B. C., George, C., Griffiths, P. T., Hanson, D. R., Kulmala, M., McFiggans, G., Pöschl, U., Riipinen, I., Rossi, M. J., Rudich, Y., Wagner, P. E., Winkler, P. M., Worsnop, D. R., and O'Dowd, C. D.: An overview of current issues in the uptake of atmospheric trace gases by aerosols and clouds, Atmos. Chem. Phys., 10, 10561-10605, doi:10.5194/acp-1010561-2010, 2010.

Knopf, D. A., Luo, B. P., Krieger, U. K., and Koop, T.: Thermodynamic dissociation constant of the bisulfate ion from Raman and ion interaction modeling studies of aqueous sulfuric acid at low temperatures, J. Phys. Chem. A, 107, 4322-4332, doi:10.1021/jp027775, 2003.

Knopf, D. A., Luo, B. P., Krieger, U. K., and Koop, T.: Reply to "Comment on the 'Thermodynamic dissociation constant of the bisulfate ion from Raman and ion interaction modeling studies of aqueous sulfuric acid at low temperatures", J. Phys. Chem. A, 109, 2707-2709, doi:10.1021/jp040300t, 2005.

Koop, T., Bookhold, J., Shiraiwa, M., and Pöschl, U.: Glass transition and phase state of organic compounds: dependency on molecular properties and implications for secondary organic aerosols in the atmosphere, Phys. Chem. Chem. Phys., 13, 19238-19255, 2011.

Li, Y. Q., Davidovits, P., Shi, Q., Jayne, J. T., Kolb, C. E., and Worsnop, D. R.: Mass and thermal accommodation coefficients of $\mathrm{H}_{2} \mathrm{O}(\mathrm{g})$ on liquid water as a function of temperature, J. Phys. Chem. A, 105, 10627-10634, 2001.

Masel, R. I.: Principles of adsorption and reaction on solid surfaces, 1st ed., John Wiley \& Sons, New York, 804 pp., 1996.

Morris, J. R., Behr, P., Antman, M. D., Ringeisen, B. R., Splan, J., and Nathanson, G. M.: Molecular beam scattering from supercooled sulfuric acid: Collisions of $\mathrm{HCl}, \mathrm{HBr}$, and $\mathrm{HNO}_{3}$ with 70 wt \% $\mathrm{D}_{2} \mathrm{SO}_{4}$, J. Phys. Chem. A, 104, 6738-6751, 2000.
Mozurkewich, M.: Effect of competitive adsorption on polar stratospheric cloud reactions, Geophys. Res. Lett., 20, 355-358, 1993.

Nathanson, G. M., Davidovits, P., Worsnop, D. R., and Kolb, C. E.: Dynamics and kinetics at the gas-liquid interface, J. Phys. Chem., 100, 13007-13020, 1996.

Pfrang, C., Shiraiwa, M., and Pöschl, U.: Coupling aerosol surface and bulk chemistry with a kinetic double layer model (K2-SUB): oxidation of oleic acid by ozone, Atmos. Chem. Phys., 10, 45374557, doi:10.5194/acp-10-4537-2010, 2010.

Pöschl, U., Rudich, Y., and Ammann, M.: Kinetic model framework for aerosol and cloud surface chemistry and gas-particle interactions - Part 1: General equations, parameters, and terminology, Atmos. Chem. Phys., 7, 5989-6023, doi:10.5194/acp-75989-2007, 2007.

Sander, R.: Compilation of Henry's law constants for inorganic and organic species of potential importance in environmental chemistry (Version 3): http://www.henrys-law.org, 1999.

Santschi, C. and Rossi, M. J.: The heterogeneous interaction of $\mathrm{HOCl}$ with solid $\mathrm{KBr}$ substrates: The catalytic role of adsorbed halogens, Phys. Chem. Chem. Phys., 7, 2599-2609, 2005.

Schwartz, S. E.: Mass transport considerations pertinent to aqueous phase reactions of gases in liquid water clouds, in: NATO ASI Ser., edited by: Jaeschke, W., Springer-Verlag, New York, 415471, 1986.

Seinfeld, J. H. and Pandis, S. N.: Atmospheric chemistry and physics: From air pollution to climate change, John Wiley \& Sons, Inc., New York, Chichester, Weinheim, Brisbane, Singapore, Toronto, 1998.

Shi, Q., Davidovits, P., Jayne, J. T., Worsnop, D. R., and Kolb, C. E.: Uptake of gas-phase ammonia. 1. Uptake by aqueous surfaces as a function of pH, J. Phys. Chem. A, 103, 8812-8823, 1999.

Shi, Q., Jayne, J. T., Kolb, C. E., Worsnop, D. R., and Davidovits, P.: Kinetic model for reaction of $\mathrm{ClONO}_{2}$ with $\mathrm{H}_{2} \mathrm{O}$ and $\mathrm{HCl}$ and $\mathrm{HOCl}$ with $\mathrm{HCl}$ in sulfuric acid solutions, J. Geophys. Res.Atmos., 106, 24259-24274, 2001.

Shiraiwa, M., Garland, R. M., and Pöschl, U.: Kinetic double-layer model of aerosol surface chemistry and gas-particle interactions (K2-SURF): Degradation of polycyclic aromatic hydrocarbons exposed to $\mathrm{O}_{3}, \mathrm{NO}_{2}, \mathrm{H}_{2} \mathrm{O}, \mathrm{OH}$ and $\mathrm{NO}_{3}$, Atmos. Chem. Phys., 9, 9571-9586, doi:10.5194/acp-9-9571-2009, 2009.

Shiraiwa, M., Pfrang, C., and Pöschl, U.: Kinetic multi-layer model of aerosol surface and bulk chemistry (KM-SUB): the influence of interfacial transport and bulk diffusion on the oxidation of oleic acid by ozone, Atmos. Chem. Phys., 10, 3673-3691, doi:10.5194/acp-10-3673-2010, 2010.

Tabazadeh, A. and Turco, R. P.: A model for heterogeneous chemical processes on the surfaces of ice and nitric-acid trihydrate particles, J. Geophys. Res.-Atmos., 98, 12727-12740, 1993.

Vieceli, J., Roeselova, M., Potter, N., Dang, L. X., Garrett, B. C., and Tobias, D. J.: Molecular dynamics simulations of atmospheric oxidants at the air-water interface: solvation and accommodation of $\mathrm{OH}$ and $\mathrm{O}_{3}$, J. Phys. Chem. B, 109, 15876-15892, 2005.

Wexler, A. S. and Clegg, S. L.: Atmospheric aerosol models for systems including the ions $\mathrm{H}^{+}, \mathrm{NH}_{4}^{+}, \mathrm{Na}^{+}, \mathrm{SO}_{4}^{2-}, \mathrm{NO}_{3}^{-}, \mathrm{Cl}^{-}, \mathrm{Br}^{-}$, and $\mathrm{H}_{2} \mathrm{O}$, J. Geophys. Res.-Atmos., 107, art. no. 4207, 2002.

Williams, L. R. and Long, F. S.: Viscosity of supercooled sulfuricacid-solutions, J. Phys. Chem., 99, 3748-3751, 1995. 
Winkler, P. M., Vrtala, A., Wagner, P. E., Kulmala, M., Lehtinen, K. E. J., and Vesala, T.: Mass and thermal accommodation during gas-liquid condensation of water, Phys. Rev. Lett., 93, art. no. 075701, 2004.

Worsnop, D. R., Morris, J. W., Shi, Q., Davidovits, P., and Kolb, C. E.: A chemical kinetic model for reactive transformations of aerosol particles, Geophys. Res. Lett., 29, art. no. 1996, 2002.

Zobrist, B., Marcolli, C., Pedernera, D. A., and Koop, T.: Do atmospheric aerosols form glasses?, Atmos. Chem. Phys., 8, 52215244, doi:10.5194/acp-8-5221-2008, 2008. 
Table 1. Parameters used to describe heterogeneous reactions.

\begin{tabular}{|c|c|c|c|}
\hline Parameter & Description & Units & Notes \\
\hline$\gamma\left(\gamma_{\mathrm{ss}}, \gamma_{0}\right)$ & Net uptake coefficient & - & $\mathrm{a}$ \\
\hline$\Gamma_{\mathrm{b}}$ & Limiting uptake coefficient for bulk reaction (liquid) & & \\
\hline$\Gamma_{\mathrm{sol}}$ & Limiting uptake coefficient for dissolution (liquid) & & \\
\hline$\Gamma_{\text {diff }}$ & Limiting uptake coefficient for gas-phase diffusion & & \\
\hline$\Gamma_{\mathrm{sb}}$ & Limiting uptake coefficient for surface to bulk transfer & & \\
\hline$\alpha_{\mathrm{S}}$ & Surface accommodation coefficient & - & $\mathrm{b}$ \\
\hline$\alpha_{\mathrm{t}}$ & Thermal accommodation coefficient & & \\
\hline$\gamma_{\mathrm{gs}}$ & Elementary gas-surface reactive uptake coefficient (or $\gamma_{\mathrm{ER}}$ ) & - & \\
\hline$k_{\mathrm{s}}$ & Surface reaction rate coefficient & $\mathrm{cm}^{2}$ molecule ${ }^{-1} \mathrm{~s}^{-1}$ & \\
\hline$\alpha_{\mathrm{b}}$ & Bulk accommodation coefficient & & $\mathrm{c}$ \\
\hline$\varepsilon$ & Evaporation coefficient & & \\
\hline$K_{\operatorname{linC}}$ & Gas-Surface partition coefficient (liquid surfaces) & $\mathrm{cm}^{-2} / \mathrm{cm}^{-3}$ & $\mathrm{~d}$ \\
\hline$K_{\mathrm{V}}$ & Gas-Volume partition coefficient (liquid surfaces) & $\mathrm{cm}^{-3} / \mathrm{cm}^{-3}$ & $\mathrm{e}$ \\
\hline$k_{\mathrm{b}}^{\prime}$ & pseudo-first order bulk reaction rate coefficient & $\mathrm{s}^{-1}$ & \\
\hline$\stackrel{\mathrm{D}}{H}$ & Solubility (Henry) & $\mathrm{M} \mathrm{atm}^{-1}$ & \\
\hline$D_{1}$ & Liquid phase diffusion coefficient & $\mathrm{cm}^{2} \mathrm{~s}^{-1}$ & \\
\hline$l$ & reacto-diffusive length & & \\
\hline$D_{\mathrm{g}}$ & Gas phase diffusion coeffcient & $\mathrm{cm}^{2} \mathrm{~s}^{-1}$ & \\
\hline$N$ & Surface coverage & molecule $\mathrm{cm}^{-2}$ & \\
\hline$N_{\max }$ & Surface coverage at saturation & molecule $\mathrm{cm}^{-2}$ & \\
\hline
\end{tabular}

a: As $\gamma$ can be time dependent, subdivisions are necessary, whereby $\gamma_{0}$ is the experimentally observed, initial (frequently maximum) uptake coefficient; and $\gamma_{\mathrm{ss}}$ is the experimentally observed, steady state uptake coefficient. b: The probability (per collision) that a gas phase molecule impinging on the solid surface resides on the surface for a finite time $\left(\gg 10^{-12} \mathrm{~s}\right)$

c: The probability (per collision) that a gas phase molecule impinging on the liquid surface enters the liquid. $\mathrm{d}$ : The partition coefficient that describes the gas-surface partitioning at equilibrium. As described above, the Langmuir isotherm is most commonly used in various units. We report the partitioning coefficient in the limit of low coverage (linear dependence of coverage on gas concentration) where the units are as given above. e: The partition coefficient that describes the distribution of trace gas between the gas phase and condensed phase volumes. For a liquid particle this is the solubility in the volume of the particle.

Table 2. Techniques used to study heterogeneous reactions.

\begin{tabular}{ll}
\hline Methods & \\
\hline CWFT & Coated Wall Flow Tube \\
WWFT & Wetted Wall Flow Tube \\
RWFT & Rotating Wetted Wall Flow Tube \\
CRFT & Coated Rod Flow Tube \\
AFT & Aerosol Flow Tube \\
Knudsen & Knudsen Reactor \\
DT & Droplet Train \\
LJ & Liquid Jet \\
BC & Bubble Column \\
PBFT & Packed Bed Flow Tube \\
\hline Detection & \\
\hline AMS & Aerosol Mass Spectrometry \\
ATR & Attenuated Total Reflectance spectroscopy \\
APS & Aerosol Particle Sizer \\
DRIFTS & Diffuse Reflectance Infra-red Fourier Transform Spectroscopy \\
DMA & Differential Mobility Analyser \\
RF & Resonance Fluorescence \\
CL & Chemi-Luminescence \\
GC & Gas Chromatography \\
MS & Mass Spectrometry \\
MBMS & Molecular Beam Sampling MS \\
CIMS & Chemical Ionisation Mass Spectrometry \\
UV-Vis & Ultra-Violet-Visible Spectroscopy \\
SR & Static Reactor \\
SMPS & Scanning Mobility Particle Sizer \\
TDL & Tunable Diode Laser absorption spectroscopy \\
TIR & Transmission Infra Red spectroscopy \\
TEM & Transmission Electron Microsopy \\
RC & Counting of decays of radioactive isotopes \\
\hline & \\
\hline & \\
\hline
\end{tabular}




\section{Datasheets}

\section{Appendix A1}

\section{Uptake on liquid water surfaces}

\section{VI.A1.1}

$\mathrm{O}_{3}(\mathrm{~g})+\mathrm{H}_{2} \mathrm{O}(\mathbf{l}) \rightarrow$ products

\section{Experimental data}

\begin{tabular}{llll}
\hline Parameter & $T / \mathrm{K}$ & Reference & Technique/Comments \\
\hline Accommodation coefficients: $\alpha_{\mathrm{b}}$ & & & \\
$\alpha_{\mathrm{b}}>2 \times 10^{-3}( \pm 20 \%)$ & 276 & Utter et al. (1992) & WWFT-CLD (a) \\
$\alpha_{\mathrm{b}}>2 \times 10^{-3}\left(2.89 \mathrm{M}>\left[\mathrm{I}^{-}\right]>0.36 \mathrm{M}\right)$ & 282 & Magi et al. (1997) & DT-MS (b) \\
$>2.0 \times 10^{-2}$ & 298 & Schütze and Herrmann (2002) & (c) \\
\hline
\end{tabular}

\section{Comments}

(a) Wetted-wall flow reactor with flowing film of liquid water $(0.2 \mathrm{~mm}$ thick). The ozone concentration was $10^{11}$ molecule $\mathrm{cm}^{-3}$. No uptake of $\mathrm{O}_{3}$ was observed into pure deionized water, but $\gamma$ increased as a function of the concentration of the trapping agent (e.g., $\mathrm{Na}_{2} \mathrm{SO}_{3}$ ) to values in the $10^{-2}$ range. A conservative lower limit for the accommodation coefficient of $2 \times 10^{-3}$ was obtained.

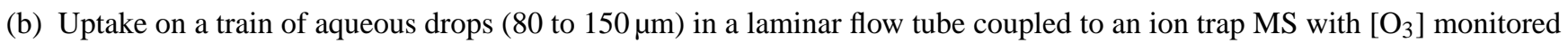
at $\mathrm{m} / \mathrm{e}=46\left(\mathrm{NO}_{2}^{+}\right)$after titration by $\mathrm{NO}$ to $\mathrm{NO}_{2}$. No measurable uptake of $\mathrm{O}_{3}$ on pure water. The lower limit for $\alpha_{\mathrm{b}}$ was found from the intercept of a plot of $1 / \gamma$ vs. $a\left(\mathrm{I}^{-}\right)^{-\frac{1}{2}}$ when NaI was used as scavenger.

(c) Uptake onto static single drop (2-3 mm in diameter) containing NaI as scavenger. The product $\mathrm{I}_{3}^{-}$was monitored by timeresolved UV/Vis absorption spectroscopy. Absorbance-time profiles at two different wavelengths $(288,353 \mathrm{~nm}) \mathrm{were}$ used to derive uptake coefficients. The tabulated value of $\alpha_{\mathrm{b}}$ results from the intercept of $1 / \gamma$ vs. $a\left(\mathrm{I}^{-}\right)^{-\frac{1}{2}}$ plots.

\section{Preferred values}

\begin{tabular}{lll}
\hline Parameter & Value & $T / \mathrm{K}$ \\
\hline$\alpha_{\mathrm{b}}$ & $>10^{-3}$ & 298 \\
$D_{\mathrm{l}}\left(\mathrm{cm}^{-2} \mathrm{~s}^{-1}\right)$ & $1.85 \times 10^{-5}$ & \\
$H\left(\mathrm{M} \mathrm{atm}^{-1}\right)$ & $1.15 \times 10^{-2} \exp (2560 / T-8.6)$ & 298 \\
Reliability & & \\
$\Delta \log \left(\alpha_{\mathrm{b}}\right)$ & \pm 0.3 & 298 \\
$\Delta \log \left(k^{\mathrm{II}}\right)$ & \pm 0.5 & \\
\hline
\end{tabular}

\section{Comments on preferred values}

In the absence of fast loss processes, the uptake of $\mathrm{O}_{3}$ on pure water is reversible (Staehelin and Hoigné, 1982). The low solubility of $\mathrm{O}_{3}$ means that uptake rapidly saturates and net $\mathrm{O}_{3}$ uptake is observable under conditions of the work of Utter et al. (1992). Therefore, the studies which derived an estimate for the bulk accommodation coefficient $\alpha_{\mathrm{b}}$ used a scavenger $\left(\mathrm{SO}_{3}^{2-}\right.$ or $\left.\mathrm{I}^{-}\right)$to obtain $\alpha_{\mathrm{b}}$ from the intercept of $1 / \gamma$ vs. $a\left(\mathrm{I}^{-}\right)^{-\frac{1}{2}}$ plots. We prefer the lower limit obtained by Magi et al. (1997) from a relatively large data set. The data of Schütze and Herrmann (2002) are more strongly affected by diffusion, and the model to take that into account required several simplifications; their lower limit to $\alpha_{\mathrm{b}}$ is however consistent with that obtained by Magi et al. In addition, Schütze and Herrmann found evidence for limitation of product formation via $\mathrm{HOI}+2 \mathrm{I}^{-} \rightarrow \mathrm{I}_{3}^{-}+\mathrm{OH}^{-}$, while Magi et al. directly determined the net loss of $\mathrm{O}_{3}$ from the gas phase. Note that for more concentrated iodide solutions, we prefer a value of $\alpha_{\mathrm{b}}>0.1$. Since halogenide ions may play a role in the bulk accommodation of ozone, we refrain from transferring the high bulk accommodation coefficient to dilute solutions. 
The preferred solubility is the expression compiled by Chameides (1984). The room temperature value of the diffusion coefficient is from Matrozov et al. (1976).

\section{References}

Chameides, W. L.: J. Geophys. Res., 89, 4739-4755, 1984.

Magi, L., Schweitzer, F., Pallares, C., Cherif, S., Mirabel, P., and George, C.: J. Phys. Chem. A, 101, 4943-4949, 1997.

Matrozov, V. I., Kashtanov, S. A., Stepanov, A. M., and Tregubov, B. A.: J. Appl. Chem.-USSR, 49, 1111-1114, 1976.

Staehelin, J. and Hoigné, J.: Environ. Sci. Technol., 16, 676-681, 1982.

Schütze, M. and Herrmann, H.: Phys. Chem. Chem. Phys., 4, 60-67, 2002.

Utter, R. G., Burkholder, J. B., Howard, C. J., and Ravishankara, A. R.: J. Phys. Chem., 96, 4973-4979, 1992. 
VI.A1.2

$\mathrm{H}_{2} \mathrm{O}_{2}(\mathrm{~g})+\mathrm{H}_{2} \mathrm{O}(\mathrm{l}) \rightarrow$ products

Experimental data

\begin{tabular}{lcll}
\hline Parameter & $T / \mathrm{K}$ & Reference & Technique/Comments \\
\hline Accommodation coefficients: $\alpha_{\mathrm{b}}$ & & & \\
$0.32 \pm 0.02$ & 260 & Worsnop et al. (1989) & DT-TDL (a) \\
$0.18 \pm 0.02$ & 273 & & \\
$0.08 \pm 0.02$ & 292 & & \\
\hline
\end{tabular}

\section{Comments}

(a) Droplets $(\mathrm{pH}=7)$ with interaction times from 0.7 to $14 \mathrm{~ms}$. Initial $\mathrm{H}_{2} \mathrm{O}_{2}$ densities were in the range 1.5 to $15 \times$ $10^{12}$ molecule $\mathrm{cm}^{-3}$.

\section{Preferred values}

\begin{tabular}{lll}
\hline Parameter & Value & $T / \mathrm{K}$ \\
\hline$\alpha_{\mathrm{b}}$ & $1.3 \times 10^{-6} \exp (3230 / T)$ & $260-292$ \\
$\begin{array}{l}\text { Reliability } \\
\Delta(E / R)\end{array}$ & $\pm 500 \mathrm{~K}$ & $260-292$ \\
\hline
\end{tabular}

\section{Comments on preferred values}

We adopt the single dataset of Worsnop et al. (1989) as the basis of our recommendation. The strong negative temperature dependence of $\alpha_{\mathrm{b}}$ was suggested to derive from an activation energy necessary to overcome a barrier between a precursor state and the solvated state of $\mathrm{H}_{2} \mathrm{O}_{2}$. The title reaction therefore represents a complex reaction involving a preequilibrium whose temperature dependence affects the overall T-dependence of the uptake.

\section{References}

Worsnop, D. R., Zahniser, M. S., Kolb, C. E., Gardner, J. A., Watson, L. R., Van Doren, J. M., Jayne, J. T., and Davidovits, P.: J. Phys. Chem., 93, 1159-1172, 1989. 
VI.A1.3

$2 \mathrm{NO}_{2}(\mathrm{~g})+\mathrm{H}_{2} \mathrm{O}(\mathrm{l}) \rightarrow \mathrm{HNO}_{2}(\mathrm{aq})+\mathrm{HNO}_{3}(\mathrm{aq})$

Experimental data

\begin{tabular}{|c|c|c|c|}
\hline Parameter & Temp./K & Reference & Technique/Comments \\
\hline \multicolumn{4}{|l|}{ Uptake coefficients: $\gamma$} \\
\hline $10^{-7}$ (pure water and $0.05 \mathrm{M} \mathrm{NaOH}$ ) & 273 & Lee and Tang (1988) & (a) \\
\hline$(1.5 \pm 0.6) \times 10^{-3}\left(9 \times 10^{14}\right.$ molecule $\left.\mathrm{cm}^{-3} \mathrm{NO}_{2}\right)$ & 298 & Ponche et al. (1993) & DT-IC (b) \\
\hline$(8.7 \pm 0.6) \times 10^{-5}$ & 298 & Msibi et al. (1993) & CWFT (c) \\
\hline$(2.4 \pm 1.4) \times 10^{-4}\left(9 \times 10^{14}\right.$ molecule $\left.\mathrm{cm}^{-3} \mathrm{NO}_{2}\right)$ & 298 & Mertes and Wahner (1995) & $\mathrm{LJ}(\mathrm{d})$ \\
\hline$(1.2 \pm 0.4) \times 10^{-3}\left(5 \times 10^{15}\right.$ molecule $\left.\mathrm{cm}^{-3} \mathrm{NO}_{2}\right)$ & 298 & & \\
\hline$(9.5 \pm 1.5) \times 10^{-7}\left(3-6 \times 10^{14}\right.$ molecule $\left.\mathrm{cm}^{-3} \mathrm{NO}_{2}\right)$ & 298 & Kleffmann et al. (1998) & Bubbler-IR/IC (e) \\
\hline$<5 \times 10^{-4}$ & 273 & Cheung et al. (2000) & DT-MS (f) \\
\hline \multirow{2}{*}{$\leq 10^{-7}(\mathrm{pH} 2-12)$} & 298 & Gutzwiller et al. (2002) & \\
\hline & & Ammann et al. (2005) & WWFT-CLD (g) \\
\hline$\approx 10^{-6}\left(6 \times 10^{14} \mathrm{~cm}^{-3} \mathrm{NO}_{2}, 0.01 \mathrm{M} \mathrm{NaOH}\right)$ & 288 & Komiyama and Inoue (1980) & Bubbler-UV (h) \\
\hline \multicolumn{4}{|l|}{ Accommodation coefficient: $\alpha_{\mathrm{b}}$} \\
\hline$(6.3 \pm 0.7) \times 10^{-4}\left(>10^{-2} \mathrm{M}\right.$ hydrochinone $)$ & 273 & Lee and Tang (1988) & (a) \\
\hline$(4.2 \pm 0.9) \times 10^{-4}\left(5 \times 10^{-2} \mathrm{M}\right.$ ascorbate $)$ & 298 & Msibi et al. (1993) & CWFT (c) \\
\hline$(2.4 \pm 1.8) \times 10^{-2}$ (deliquesced dihydroxyphenolates) & 296 & Sosedova et al. (2009) & AFT-RC (i) \\
\hline \multicolumn{4}{|l|}{$H k_{2}^{1 / 2}$} \\
\hline $70 \mathrm{M}^{-1 / 2} \mathrm{~atm}^{-1} \mathrm{~s}^{-1 / 2}$ & 295 & Lee and Schwartz (1981) & (j) \\
\hline $134 \mathrm{M}^{-1 / 2} \mathrm{~atm}^{-1} \mathrm{~s}^{-1 / 2}$ & 284 & Cape et al. (1993) & (k) \\
\hline $71 \pm 10 \mathrm{M}^{-1 / 2} \mathrm{~atm}^{-1} \mathrm{~s}^{-1 / 2}$ & 293 & Cheung et al. (2000) & (f) \\
\hline $92 \mathrm{M}^{-1 / 2} \mathrm{~atm}^{-1} \mathrm{~s}^{-1 / 2}$ & 295 & Park and Lee (1988) & (1) \\
\hline \multicolumn{4}{|l|}{ Solublity: $H$} \\
\hline $2.0 \times 10^{-2} \mathrm{M} \mathrm{atm}^{-1}$ & 298 & Andrew and Hanson (1960) & (m) \\
\hline $2.2 \times 10^{-2} \mathrm{M} \mathrm{atm}^{-1}$ & 288 & Komiyama and Inoue (1980) & (h) \\
\hline$(7.0 \pm 0.5) \times 10^{-3} \mathrm{M} \mathrm{atm}^{-1}$ & 295 & Lee and Schwartz (1981) & (i) \\
\hline$(5.5 \pm 0.6) \times 10^{-2} \mathrm{M} \mathrm{atm}^{-1}$ & 284 & Cape et al. (1993) & (k) \\
\hline$(1.4 \pm 0.2) \times 10^{-2} \mathrm{M} \mathrm{atm}^{-1}$ & 293 & Cheung et al. (2000) & (f) \\
\hline$\left(2.3_{-0.9}^{+0.3}\right) \times 10^{-2} \mathrm{M} \mathrm{atm}^{-1}$ & 276 & & \\
\hline \multicolumn{4}{|l|}{ Liquid phase rate constant } \\
\hline$(1.0 \pm 0.1) \times 10^{8} \mathrm{M}^{-1} \mathrm{~s}^{-1}$ & 295 & Lee and Schwartz (1981) & (j) \\
\hline$(8.4 \pm 1.5) \times 10^{7} \mathrm{M}^{-1} \mathrm{~s}^{-1}$ & 295 & Park and Lee (1988) & (m) \\
\hline$(6.0 \pm 2.0) \times 10^{6} \mathrm{M}^{-1} \mathrm{~s}^{-1}$ & 284 & Cape et al. (1993) & (k) \\
\hline$(3.0 \pm 0.9) \times 10^{7} \mathrm{M}^{-1} \mathrm{~s}^{-1}$ & 293 & Cheung et al. (2000) & (f) \\
\hline$(2.2 \pm 0.6) \times 10^{7} \mathrm{M}^{-1} \mathrm{~s}^{-1}$ & 276 & & \\
\hline
\end{tabular}

\section{Comments}

(a) Uptake experiment involving a stopped flow of $\mathrm{NO}_{2}$ (initial concentration $10^{15} \mathrm{~cm}^{-3}$ ) in humidified He carrier gas exposed to a circulating fluid sample of either pure water, water with $0.05 \mathrm{M} \mathrm{NaOH}$, or water containing $(1-7) \times 10^{-2} \mathrm{M}$ hydroquinone sodium salt. The uptake coefficients were corrected for gas phase diffusion.

(b) Gas uptake into a monodisperse ( $70 \mu \mathrm{m}$ to $110 \mu \mathrm{m}$ diameter) droplet train. The $\mathrm{pH}$ of water was adjusted to $4,5.6$ and 11 . Uptake was determined by detecting nitrate by ion chromatography in the collected aqueous phase after addition of $0.16 \mathrm{M}$ $\mathrm{H}_{2} \mathrm{O}_{2}$ to convert all nitrite to nitrate. The uptake coefficient corrected for gas phase diffusion was independent of $\mathrm{pH}$. The value for the diffusion coefficient used was $0.192 \mathrm{~cm}^{2} \mathrm{~s}^{-1}$ in the gas phase and $1 \times 10^{-5} \mathrm{~cm}^{2} \mathrm{~s}^{-1}$ in the liquid phase. The solubility was assumed to be $1.2 \times 10^{-2} \mathrm{M} \mathrm{atm}^{-1}$. The observed uptake coefficient $\gamma_{\mathrm{obs}}$ was larger than expected from 
solubility limited uptake, independent of $\mathrm{pH}$. Impurities might have been present as a liquid phase sink for $\mathrm{NO}_{2}$ to drive reaction limited uptake.

(c) A flow of 61 per min of air at $97 \%$ relative humidity containing about $0.5 \mathrm{ppm} \mathrm{NO}_{2}$ at atmospheric pressure passed an annular glass reactor, coated with either deionised water or a mixture of $0.05 \mathrm{M}$ ascorbic acid and $0.05 \mathrm{M} \mathrm{NaOH}(\mathrm{pH} 9.3)$. $\mathrm{NO}_{2}$ was measured using a luminol based $\mathrm{NO}_{2}$ analyzer.

(d) Liquid jet ( $50 \mu \mathrm{m}$ diameter) in a reactor at $298 \mathrm{~K}$. Experiments were done with pure water, with $0.01 \mathrm{M} \mathrm{NaOH}, 33.4 \mathrm{~g} / \mathrm{l}$ triethanolamine and $1 \mathrm{~g} / 1 \mathrm{NaAsO}_{2}$ to vary the liquid phase sink for $\mathrm{NO}_{2}$. Nitrite and nitrate were measured spectrophotometrically. $\mathrm{NO}_{2}$ uptake was independent of $\mathrm{pH}$ or added sink, but was much larger than solubility limited uptake. The authors therefore proposed a surface reaction proceeding with the uptake coefficients listed in the table.

(e) $\mathrm{NO}_{2}$ was circulated through a thermostated bubbler containing 125 to $500 \mathrm{ml}$ of water. $\mathrm{NO}_{2}$ and $\mathrm{HNO}_{2}$ were measured using tunable diode laser absorption spectrometry. Nitrate and nitrite in the liquid were measured using ion chromatography, showing that they were initially formed at equimolar amounts. The first order rate constant for $\mathrm{NO}_{2}$ decay did not depend on the $\mathrm{NO}_{2}$ concentration, indicating overall first-order behavior.

(f) Experiments were performed with both a droplet train and a bubble train apparatus. The droplet train was operated with $10^{13}-10^{16} \mathrm{NO}_{2}$ molecule $\mathrm{cm}^{-3}$. Uptake of $\mathrm{NO}_{2}$ was not detectable in the droplet train experiment, leading to an upper limit of $\gamma<5 \times 10^{-4}$ at $273 \mathrm{~K}$. In the bubble train flow reactor, the $\mathrm{NO}_{2}(\mathrm{~g})$ concentration was monitored by QMS. Loss of $\mathrm{NO}_{2}$ from the gas phase was fitted with a model of $\mathrm{NO}_{2}$ uptake considering both solubility limitation and reaction in the bulk. This led to both, independent values for $\mathrm{H}$ and the second order liquid phase rate constant.

(g) The wetted wall flow tube was operated at room temperature and with $80 \mathrm{ppb}$ of $\mathrm{NO}_{2}$ in $\mathrm{N}_{2}$. The uptake coefficient listed in the table was obtained as blank values for pure water and water with $\mathrm{pH}$ adjusted to between 2 and 12 as part of a study to explore the reactivity of $\mathrm{NO}_{2}$ with hydroxysubstituted aromatics.

(h) $\mathrm{NO}_{2}$ (10 to $2000 \mathrm{ppm}$ ) was passed either over a flat liquid surface (both gas and liquid stirred) or through a bubbler. $\mathrm{NO}_{2}$ concentration in the gas phase and nitrate and nitrite were measured using UV absorption. The mass transfer characteristics were determined with $\mathrm{CO}_{2}$. Nitrate and nitrite concentrations were equal over the whole $\mathrm{NO}_{2}$ pressure range. The $\mathrm{NO}_{2}$ absorption rate reported over the full range was proportional to the square of the $\mathrm{NO}_{2}$ pressure at high and proportional to $\mathrm{NO}_{2}$ at low $\mathrm{NO}_{2}$ pressures as expected for mass transport limitation. The absorption rate reported for about $6 \times 10^{14}$ molecule $\mathrm{cm}^{-3}$ is converted to an uptake coefficient and listed in the table.

(i) Aerosol particles were produced from nebulizing aqueous solutions of dihydroxybenzoic acid and hydrochinone sodium salts. ${ }^{13} \mathrm{~N}$ labeled $\mathrm{NO}_{2}$ was used as reactant, and uptake to particles was monitored by counting radioactive decays of ${ }^{13} \mathrm{~N}$ associated with particles after the flow reactor with residence times between 1 and $60 \mathrm{~s}$ at ambient pressure and $40 \%$ relative humidity. The observed uptake coefficients in the range of a few $10^{-3}$ could be well explained by bulk reaction limited uptake, which allowed derivation of the estimate for $\alpha_{\mathrm{b}}$ listed in the table.

(j) $\mathrm{NO}_{2}$ at partial pressures of $100 \mathrm{ppb}$ to $800 \mathrm{ppm}$ was passed through 10 to $70 \mathrm{ml}$ of water in a fritted bubbler in a thermostated vessel. $\mathrm{NO}_{2}$ was measured with a chemiluminescence detector. The ionic products in water were determined with a conductivity detector online. Nitrate and nitrite were measured offline with a colorimetric method. The mass transport characteristics were calibrated using $\mathrm{CO}_{2}$, leading to mass transfer times between 1.7 and $5.3 \mathrm{~s}$.

(k) $\mathrm{NO}_{2}$ at partial pressures of 10 to $100 \mathrm{ppb}$ was passed through 1.01 of water or aqueous solution in a fritted bubbler in a thermostated vessel. The loss of $\mathrm{NO}_{2}$ was measured with a chemiluminescence detector. The mixing time in the reactor was $60 \mathrm{~s}$ based on experiments with $\mathrm{CO}_{2}$. The authors caution that the distribution of $\mathrm{NO}_{2}$ in the reactor may have not been uniform, leading to an overestimate of the rate constants.

(1) Investigation of $\mathrm{HNO}_{2}$ decomposition kinetics in water in a bubbler type apparatus. The kinetics of the hydrolysis reaction was indirectly derived from the evolution of $\mathrm{NO}$ and $\mathrm{NO}_{2}$ measured with a chemiluminescence detector.

(m) $\mathrm{NO}_{2}(200 \mathrm{ppm}$ to $10 \%)$ was passed through water in a bubbler type reactor. The solubility listed in the table was derived from observations of $\mathrm{HNO}_{2}$ formation as a function of $\mathrm{NO}_{2}$ pressure. 


\section{Preferred values}

\begin{tabular}{lll}
\hline Parameter & Value & $T / \mathrm{K}$ \\
\hline$\alpha_{\mathrm{b}}$ & $2 \times 10^{-2}$ & $273-298$ \\
$k / \mathrm{M}^{-1} \mathrm{~s}^{-1}$ & $8.1 \times 10^{9} \exp (-1630 / T)$ & $276-293$ \\
$H / \mathrm{M} \mathrm{atm}^{-1}$ & $4.4 \times 10^{-6} \exp (-2350 / T)$ & $273-298$ \\
Reliability & & \\
$\Delta \log \left(\alpha_{\mathrm{b}}\right)$ & \pm 0.7 & $273-298$ \\
$\Delta \log (k)$ & \pm 0.08 & $273-298$ \\
$\Delta \log (H)$ & \pm 0.06 & $273-298$ \\
$\Delta \log (E / R)$ & \pm 50 & $273-298$ \\
\hline
\end{tabular}

\section{Comments on preferred values}

Uptake of $\mathrm{NO}_{2}$ to pure water is driven by the low solubility and slow second order hydrolysis in bulk water. The study by Cheung et al. (2000) has covered the $\mathrm{NO}_{2}$ concentration range down to atmospherically relevant levels and most carefully elaborated the associated mass transfer issues, allowing them to obtain an independent estimate for the solubility at $293 \mathrm{~K}$. They also estimate a value at $276 \mathrm{~K}$ using arguments about the expected solubility dependence presented by Schwartz and White (1981). The recommended expression for the temperature dependence is based on these two values.

Cheung et al. also show that their value for $H k^{1 / 2}$ is consistent with most earlier studies covering the lower concentration range, especially the one by Lee and Schwartz (1981). The disagreement with Cape et al. (1993) is likely due to inhomogeneous distribution of $\mathrm{NO}_{2}$ in their reactor, as cautioned by the authors. Due to strong coupling between the liquid phase rate constant and the solubility, we calculate an average value of $H k^{1 / 2}$ extracted from the Cheung et al. (2000), Lee and Schwartz (1981) and Park and Lee (1988) and use the solubility as recommended to arrive at the expression for the rate constant.

Bambauer et al. (1994) report an experiment in a cloud chamber, in which the cloud droplet seeds were $\mathrm{NaCl}$, which seemed to be inconsistent with the second-order reaction of $\mathrm{NO}_{2}$ in water. This and other evidence for apparent first order uptake with surprisingly high uptake coefficient can be discussed as due to reactions with impurities (Ponche et al., 1993; Msibi et al., 1993; Mertes and Wahner, 1995) rather than being representative of bulk accommodation limitation. Yabushita et al. (2009) suggest the formation of a surface complex with chloride ions to explain enhanced $\mathrm{NO}_{2}$ hydrolysis in $\mathrm{mM}$ chloride solutions (see also data sheet VI.A2.4). Due to the low solubility of $\mathrm{NO}_{2}$, a strong aqueous phase scavenger is required to get into a bulk accommodation limited kinetic regime. While the CWFT study by Msibi et al. (1993) was likely affected by evaporation, Lee and Tang (1988) show evidence for the transition from reaction limited to bulk accommodation limited kinetics. Sosedova et al. (2009) used an aerosol flow tube approach, which is practically free of gas phase diffusion effects, to obtain a bulk accommodation coefficient of 0.02 for deliquesced sodium salts of hydrochinone and dihydroxybenzoate, which is used as a basis for the recommendation for $\alpha_{\mathrm{b}}$.

The recommended values can be used to calculate uptake coefficients for the reaction of $\mathrm{NO}_{2}$ with dilute aqueous solutions in absence of significant aqueous phase scavengers. In this case, $1 / \alpha_{\mathrm{b}}$ is not rate limiting, and the uptake coefficients can be calculated using

$\gamma=\frac{4 H R T}{\bar{c}} \sqrt{D_{1} \cdot k^{\prime}}, \quad k^{\prime}=H_{\mathrm{NO} 2} p_{\mathrm{NO} 2} k$

This leads to uptake coefficients of e.g. $6 \times 10^{-9}$ at $10 \mathrm{ppb} \mathrm{NO}_{2}$ due to hydrolysis. Under many conditions, the reacto-diffusive length may be large compared to the diameter of the droplet, so that the geometry correction needs to be applied to this expression, which would lead to even lower values for the uptake coefficient. On shorter time scales and for large droplets, it needs to be carefully evaluated whether or not $1 / \Gamma_{\text {sol }}$ is rate limiting.

\section{References}

Ammann, M., Rössler, E., Strekowski, R., and George, C.: Phys. Chem. Chem. Phys., 7, 2513-2518, 2005.

Andrew, S. P. S. and Hanson, D.: Chem. Eng. Sci., 14, 105-114, 1961.

Bambauer, A., Brantner, B., Paige, M., and Novakov, T.: Atmos. Environ., 28, 3225-3232, 1994.

Cape, J. N., Storeton-West, R. L., Devine, S. F., Beatty, R. N., and Murdoch, A.: Atmos. Environ., 27A, 2613-2621, 1993. 
Cheung, J. L., Li, Y. Q., Boniface, J., Shi, Q., Davidovits, P., Worsnop, D. R., Jayne, J. T., and Kolb, C. E.: J. Phys. Chem. A, 104, 2655-2662, 2000.

Gutzwiller, L., George, C., Rössler, E., and Ammann, M.: J. Phys. Chem. A, 106, 12045-12050, 2002.

Kleffmann, J., Becker, K. H., and Wiesen, P.: Atmos. Environ., 32, 2721-2729, 1998.

Kleffmann, J., Becker, K. H., and Wiesen, P.: J. Chem. Soc. Faraday Trans., 94, 3289-3292, 1998.

Komiyama, H. and Inoue, H.: Chem. Eng. Sci., 35, 154-161, 1980.

Lee, Y.-N. and Schwartz, S. E.: J. Phys. Chem., 85, 840-848, 1981.

Lee, J. H. and Tang, I. N.: Atmos. Environ., 22, 1147-1151, 1988.

Mertes, S. and Wahner, A.: J. Phys. Chem., 99, 14000-14006, 1995.

Park, J.-Y. and Lee, Y.-N.: J. Phys. Chem., 92, 6294-6302, 1988.

Ponche, J. L., George, C., and Mirabel, P.: J. Atmos. Chem., 16, 1-21, 1993.

Shen, C. H. and Rochelle, G. T.: Environ. Sci. Technol., 32, 1994-2003, 1998.

Shen, C. H. and Rochelle, G. T.: J. Air Waste Man. Assoc., 49, 332-338, 1999.

Sosedova, Y., Rouvière, A. L., Gäggeler, H. W., and Ammann, M.: J. Phys. Chem. A, 113, 10979-10987, 2009.

Yabushita, A., Enami, S., Sakamoto, Y., Kawasaki, M., Hoffmann, M. R., and Colussi, A. J.: J. Phys. Chem. A, 113, 4844-4848, 2009. 
VI.A1.4

$\mathrm{NO}_{3}(\mathrm{~g})+\mathrm{H}_{2} \mathrm{O}(\mathrm{l}) \rightarrow$ products

\section{Experimental data}

\begin{tabular}{llll}
\hline Parameter & $T / \mathrm{K}$ & Reference & Technique/Comments \\
\hline$\alpha_{\mathrm{b}}$ & & & \\
$>4 \times 10^{-2}$ & $273 \pm 1$ & Rudich et al. (1996) & WWFT-AS (a) \\
$>2 \times 10^{-3}$ & 293 & Thomas et al. (1998) & (b) \\
$4.2_{-1.7}^{+2.2} \times 10^{-3}$ & $293 \pm 1$ & Schütze et al. (2005) & (c) \\
$H\left(\mathrm{M} \mathrm{atm}^{-1}\right)$ & & & \\
$0.6 \pm 0.3$ & $273 \pm 1$ & Rudich et al. (1996) & WWFT-AS (a) \\
1.8 & 293 & Thomas et al. (1998) & (b) \\
$0.2 \pm 0.1$ & $293 \pm 1$ & Schütze et al. (2005) & (c) \\
\hline
\end{tabular}

\section{Comments}

(a) Flow tube operated at $12-23$ mbar. $\mathrm{NO}_{3}\left(2-10 \times 10^{11}\right.$ molecule $\left.\mathrm{cm}^{-3}\right)$ was formed by the thermal dissociation of $\mathrm{N}_{2} \mathrm{O}_{5}$ and detected by diode laser absorption at $662 \mathrm{~nm}$ over a $12.6 \mathrm{~m}$ pathlength. A lower limit for $\alpha_{\mathrm{b}}$ was estimated from reactive uptake measurements (see datasheet VI.A2.05). The dependence of uptake coefficient, $\gamma$, on $\mathrm{Cl}^{-}$ concentrations was combined with a literature value (Exner et al., 1992) for the rate coefficient for $\mathrm{Cl}^{-}$with $\mathrm{NO}_{3}$ $\left(2.76 \times 10^{6} \mathrm{M}^{-1} \mathrm{~s}^{-1}\right.$ at $\left.273 \mathrm{~K}\right)$ to determine a value of $H D_{1}^{0.5}$ of $(1.9 \pm 0.4) \times 10^{-3} \mathrm{M} \mathrm{atm}^{-1} \mathrm{~cm} \mathrm{~s}^{-0.5}$. Assuming a value of $D_{1}$ of $(1.0 \pm 0.5) \times 10^{-5} \mathrm{~cm}^{2} \mathrm{~s}^{-1}$ enabled a solubility of $\mathrm{NO}_{3}$ in $\mathrm{H}_{2} \mathrm{O}$ to be derived.

(b) Uptake of $\mathrm{NO}_{3}$ (generated by mixing $\mathrm{NO}$ with $\mathrm{O}_{3}$ at $\approx 400^{\circ} \mathrm{C}$ ) to $0.1 \mathrm{M}$ chloride solution was monitored using three serial coiled glass denuders ( $2 \mathrm{~mm}$ id). Nitrate in solution was determined following reduction to $\mathrm{NO}_{2}^{-}$and photometric detection of $\mathrm{NO}_{2}^{-}$using nitrite as the diazotization reagent for the formation of an absorbing azocompound. Large diffusion limitations result in only a lower limit to $\gamma$.

(c) Single droplet $\left(\approx 7 \mathrm{~mm}^{3}\right)$ suspended from a pipette in a flow tube $(10 \mathrm{mbar} H \mathrm{He})$ with UV-Vis absorption spectroscopy for concentration measurement in both gas and aqueous phases $\left(\mathrm{NO}_{3}^{-}\right.$at $235 \mathrm{~nm}, \mathrm{NO}_{3}$ using the $662 \mathrm{~nm}$ feature). $\mathrm{NO}_{3}$ was generated by reacting $\mathrm{NO}_{2}$ with $\mathrm{O}_{3}$ at $393 \mathrm{~K}$ to keep the $\mathrm{N}_{2} \mathrm{O}_{5}$ level low $(\approx 5 \%)$. $\mathrm{HNO}_{3}$ was formed at approximately the same concentration as $\mathrm{NO}_{3}$. Uptake of $\mathrm{NO}_{3}$ to the droplet was monitored by nitrate anion absorption. A value of $H D_{1}^{0.5} k^{0.5}=(1.9 \pm 0.2) \mathrm{M} \mathrm{atm}^{-1} \mathrm{~cm} \mathrm{~s}^{-0.5}$ was derived.

\section{Preferred values}

\begin{tabular}{lll}
\hline Parameter & Value & $T / \mathrm{K}$ \\
\hline$\alpha_{\mathrm{b}}$ & $1.3 \times 10^{-2}$ & 273 \\
$k_{\mathrm{H} 2 \mathrm{O}}\left(\mathrm{M}^{-1} \mathrm{~s}^{-1}\right)$ & 23 & 273 \\
$H\left(\mathrm{M} \mathrm{atm}^{-1}\right)$ & 0.6 & 273 \\
Reliability & & \\
$\Delta \log \left(\alpha_{\mathrm{b}}\right)$ & \pm 0.5 & 273 \\
$\Delta \log \left(k_{\mathrm{H} 2 \mathrm{O}}\right)$ & \pm 0.5 & 273 \\
$\Delta \log (H)$ & \pm 0.5 & 273 \\
\hline
\end{tabular}

\section{Comments on preferred values}

The accommodation coefficient, $\alpha_{\mathrm{b}}$, was derived from uptake of $\mathrm{NO}_{3}$ to salt solutions as described in datasheet VI.A2.5.

The solubility, $H$, of $\mathrm{NO}_{3}$ has been determined on several occasions, the more recent results suggest that it is low, with numbers of $(0.6 \pm 0.3)$ and $(1.8 \pm 1.5) \mathrm{M}^{-1} \mathrm{~atm}^{-1}$ derived by Rudich et al. (1996) and Thomas et al. (2005) compared to e.g. $12 \mathrm{M}^{-1} \mathrm{~atm}^{-1}$ reported by Chameides (1986). We prefer the results of Rudich et al., in order to maintain an internally consistent set of parameters for modelling $\mathrm{NO}_{3}$ uptake to both pure water and halide solutions (see VI.A2.5). 
Rudich et al. (1996) observed reactive uptake of $\mathrm{NO}_{3}$ in the absence of halide ions (or other detectable impurities) and attributed this to the hydrolysis of $\mathrm{NO}_{3}$ :

$\mathrm{NO}_{3}(\mathrm{aq})+\mathrm{H}_{2} \mathrm{O}(\mathrm{l}) \rightarrow \mathrm{OH}(\mathrm{aq})+\mathrm{HNO}_{3}(\mathrm{aq}) \quad \mathrm{R}_{\text {forward }}$

$\mathrm{OH}(\mathrm{aq})+\mathrm{HNO}_{3}(\mathrm{aq}) \rightarrow \mathrm{NO}_{3}(\mathrm{aq})+\mathrm{H}_{2} \mathrm{O}(\mathrm{l}) \quad \mathrm{R}_{\text {back }}$

with a rate constant of $k_{\mathrm{H} 2 \mathrm{O}}=23_{-13}^{+30} \mathrm{M}^{-1} \mathrm{~s}^{-1}$ for the forward reaction. Similarly, Schütze et al. (2005) observed reactive uptake and formation of nitrate ions in the interaction of $\mathrm{NO}_{3}$ with a pure $\mathrm{H}_{2} \mathrm{O}$ droplet with an uptake coefficient of $\sim 10^{-4}$ implying a hydrolysis rate coefficient of $670_{-580}^{+2300} \mathrm{M}^{-1} \mathrm{~s}^{-1}$ if nitrate (i.e. aqueous phase $\mathrm{HNO}_{3}$ ) was formed only as shown above. Even the lower limits of these rate constants are incompatible (by orders of magnitude) with the observations of Thomas et al. (1998), who derive an upper limit of $0.5 \mathrm{M}^{-1} \mathrm{~s}^{-1}$ for $k_{\mathrm{H} 2 \mathrm{O}}$.

Whilst Rudich et al. made efforts to eliminate reaction with impurities in their water film and ruled out gas-phase reactions as being responsible for $\mathrm{NO}_{3}$ loss, Thomas et al. hypothesise that impurities, a surface (rather than bulk) reaction of $\mathrm{NO}_{3}$ or non-laminar flow in the liquid film of Rudich et al. could contribute to observation of an apparent, large hydrolysis rate constant. On the other hand, calculations of the equilibrium constant for reaction of $\mathrm{NO}_{3}$ with water by Rudich et al. combined with the measured rate constant for the back reaction (Katsamura et al., 1991) result in $k_{\mathrm{H} 2 \mathrm{O}}=6 \mathrm{M}^{-1} \mathrm{~s}^{-1}$ at $298 \mathrm{~K}$, roughly consistent with the observations.

Whilst recognising that there is very large uncertainty associated with values of each of $\alpha_{\mathrm{b}}, H$ and $k_{\mathrm{H} 2 \mathrm{O}}$, we adopt the results of Rudich et al. (1996) so that the following expression, when used to calculate an uptake coefficient for $\mathrm{NO}_{3}$ on pure water, returns a value of $\gamma \sim 2 \times 10^{-4}$, which is consistent with their experimental observations.

$\gamma=\left\{\frac{1}{\alpha_{\mathrm{b}}}+\frac{\bar{c}}{4 H R T\left(D_{1} k_{\mathrm{H} 2 \mathrm{O}}^{\prime}\right)^{0.5}}\right\}^{-1}$

with $D_{1} \sim 1 \times 10^{-5} \mathrm{~cm}^{2} \mathrm{~s}^{-1}$.

The aqueous phase products of $\mathrm{NO}_{3}$ hydrolysis are suggested to be $\mathrm{OH}$ and $\mathrm{HNO}_{3}$. Clearly, further work on the uptake and reaction of $\mathrm{NO}_{3}$ on water is required to reduce uncertainties associated with this process.

\section{References}

Chameides, W. L.: J. Geophys. Res. 91, 14571-14572, 1986.

Exner, M., Herrmann, H., and Zellner, R.: Ber. Bunsen. Ges. Phys. Chem. Chem. Phys 96, 470-477, 1992.

Rudich, Y., Talukdar, R. K., Ravishankara, A. R., and Fox, R. W.: J. Geophys. Res., 101, 21023-21031, 1996.

Schütze, M. and Herrmann, H.: J. Atmos. Chem. 52, 1-18, 2005.

Thomas, K., Volz-Thomas, A., Mihelcic, D., Smit, H. G. J., and Kley, D.: J. Atmos. Chem., 29, 17-43, 1998. 


\section{VI.A1.5}

$\mathrm{N}_{2} \mathrm{O}_{5}(\mathrm{~g})+\mathrm{H}_{2} \mathrm{O}(\mathrm{l}) \rightarrow$ products

\section{Experimental data}

\begin{tabular}{llll}
\hline Parameter & $T / \mathrm{K}$ & Reference & Technique/Comments \\
\hline $\begin{array}{l}\text { Uptake coefficients: } \gamma, \gamma_{\mathrm{ss}}, \gamma_{0} \\
\gamma=0.040 \pm 0.005\end{array}$ & 282 & Van Doren et al. (1990) & DT-TDLAS (a) \\
$\gamma=0.061 \pm 0.004$ & 271 & & \\
$>0.005$ & 293 & Kirchner et al. (1990) & LJ-IC (b) \\
$\gamma=0.030 \pm 0.002$ & 262 & George et al. (1994) & DT-FTIR/HPLC (c) \\
$\gamma=0.013 \pm 0.008$ & 277 & & \\
$\gamma=0.018 \pm 0.003$ & $262-278$ & Schweitzer et al. (1998) & DT-FTIR/MS (d) \\
$\gamma=0.011_{+0.012}^{-0.006}$ & 293 & Schütze and Herrmann (2002) & DT-UV/Vis (e) \\
\hline
\end{tabular}

\section{Comments}

(a) Fast train of monodisperse $200 \mu \mathrm{m} \mathrm{H}_{2} \mathrm{O}$ droplets traversing a flow tube with TDLAS detection. The temperature of the droplet was controlled by varying partial pressure of $\mathrm{H}_{2} \mathrm{O}$ in the carrier gas and hence evaporation rate. The temperature reported is the mean temperature in the vicinity of the droplet. Total pressures $=5.02$ Torr at $271 \mathrm{~K}$ and 9.26 Torr at $282 \mathrm{~K}$. $\left[\mathrm{N}_{2} \mathrm{O}_{5}\right] \sim 2 \times 10^{14}$ molecule $\mathrm{cm}^{-3} \cdot \gamma$ determined from measured fractional uptake with and without droplets present, with (small, $<10 \%$ ) correction for gas phase diffusion and distortion of molecular velocity distribution.

(b) Interaction of $\mathrm{N}_{2} \mathrm{O}_{5}(116 \mathrm{ppm}$ in 1 bar air, measured by UVA) with a $90 \mathrm{~mm}$ dia. liquid jet of pure water with contact time $0.03-1.0 \mathrm{~ms}$. Uptake coefficients were deduced by comparing $\mathrm{NO}_{3}^{-}$concentrations in the absorbing liquid, which are measured as a function of contact time, with numerical solutions of the convective diffusion equation. $\gamma$ is regarded as a lower limit due to its sensitivity to the value of $D_{\mathrm{g}}\left(\mathrm{N}_{2} \mathrm{O}_{5}\right)$ and uncertainties in the velocity distribution of the liquid jet.

(c) Fast train of water droplets $(80-150 \mu \mathrm{m}$ diameter) inside a flow tube at total pressures of $27-80$ mbar synthetic air with 4-16 ms contact time. The temperature of the droplet was controlled by varying partial pressure of $\mathrm{H}_{2} \mathrm{O}$ in the carrier gas and hence evaporation rate. $\mathrm{N}_{2} \mathrm{O}_{5}(20$ to $2000 \mathrm{ppm})$ monitored by FTIR and the extent of uptake was followed by measuring the $\mathrm{NO}_{3}^{-}$concentration in the collected droplets using HPLC.

(d) Experimental configuration (c). FTIR absorption and ion-trap mass spectrometry used for detection of changes in gas phase $\mathrm{N}_{2} \mathrm{O}_{5}$ on exposure to droplets. No products were detected. The uptake coefficients were independent of temperature in the stated range.

(e) Uptake onto static single drop monitored by time-resolved UV/Vis absorption spectroscopy in the range 240 to $800 \mathrm{~nm}$. Uptake coefficient determined from absorbance-time profiles of the product $\mathrm{NO}_{3}^{-}$at two different wavelengths (302, $345 \mathrm{~nm})$ after diffusion correction. $\left[\mathrm{N}_{2} \mathrm{O}_{5}\right]=(2.3$ to 4.6$) \times 10^{13}$ molecule $\mathrm{cm}^{-3}$ at a total pressure $(\mathrm{He})$ of $100 \mathrm{mbar}$.

\section{Preferred values}

\begin{tabular}{lll}
\hline Parameter & Value & $T / \mathrm{K}$ \\
\hline$\gamma$ & $2.7 \times 10^{-5} \exp (1800 / T)$ & $265-300$ \\
Reliability & & \\
$\Delta \log (\gamma)$ & \pm 0.3 & 298 \\
$\Delta(\mathrm{E} / \mathrm{R})$ & $\pm 1000 \mathrm{~K}$ & $265-300$ \\
\hline
\end{tabular}

\section{Comments on preferred values}

Except for the liquid jet experiment of Kirchner et al. (1990), the reported studies all used similar experimental configurations involving uptake onto large water droplets, but with different methods used for measurement of uptake rate, i.e. loss of $\mathrm{N}_{2} \mathrm{O}_{5}$ from gas phase (Van Doren et al., 1990; Schweitzer et al., 1998) and accumulation of hydrolysis product $\mathrm{NO}_{3}^{-}$in the droplets (George et al., 1992; Schütze and Herrmann, 2002). Corrections for effects of gas phase diffusion on uptake rates were necessary in all cases, and are a particular source of uncertainty in the liquid drop experiment. The values of $\gamma$ from the different studies are broadly consistent with each other, and show a negative temperature dependence, although the $\gamma$ values of Van 
Doren et al. (1990) are higher than in the other studies. There are potential sources of systematic error in these studies but there is no obvious explanation of the differences in the results. The recommended expression for $\gamma$ is a least squares fit to all the cited data from the droplet train experiments, plotted in Arrhenius form, with large error limits reflecting the possible systematic errors.

It has been suggested that the measured uptake coefficient represents the mass accommodation coefficient for $\mathrm{N}_{2} \mathrm{O}_{5}$ on an aqueous surface, which by definition gives the maximum rate of reactive uptake. Maximum uptake coefficients for $\mathrm{N}_{2} \mathrm{O}_{5}$ on aqueous electrolyte aerosols (e.g. $\mathrm{NaCl}$, malonic acid, $\mathrm{H}_{2} \mathrm{SO}_{4}$ ) at room temperature and high $\mathrm{RH}$ often exceed those measured on pure water by a factor of $\sim 2$ to 3 . The mass accommodation coefficient for $\mathrm{N}_{2} \mathrm{O}_{5}$ at $298 \mathrm{~K}$ is thus likely to be at least 0.03 .

\section{References}

George, C., Ponche, J. L., Mirabel, P., Behnke, W., Scheer, V., and Zetzsch, C.: J. Phys. Chem., 98, 8780-8784, 1994.

Kirchner, W., Welter, F., Bongartz, A., Kames, J., Schweighofer, S., and Schurath, U.: J. Atm. Chem., 19, 427-449, 1990.

Schütze, M. and Herrmann, H.: Phys. Chem. Chem. Phys., 4, 60-67, 2002.

Schweitzer, F., Mirabel, P., and George, C.: J. Phys. Chem. A, 102, 3942-3952, 1998.

Van Doren, J. M., Watson, L. R., Davidovits, P., Worsnop, D. R., Zahniser, M. S. and Kolb, C. E.: J. Phys. Chem., 94, 32653269, 1990. 
VI.A1.6

$\mathrm{NH}_{3}(\mathrm{~g})+\mathrm{H}_{2} \mathrm{O}(\mathrm{l}) \rightarrow$ Products

Experimental data

\begin{tabular}{lcll}
\hline Parameter & $T / \mathrm{K}$ & Reference & Technique/Comments \\
\hline Uptake coefficients: $\gamma, \gamma_{s s}, \gamma_{0}$ & & & \\
$0.040_{-0.005}^{+0.03}$ & 299 & Bongartz et al. (1995) & LJ-IC (a) \\
$0.097 \pm 0.009$ & 290 & Ponche et al. (1993) & DT-FTIR/HPLC (b) \\
$0.1(\mathrm{pH}=0.5-3.0)$ & 291 & Shi et al. (1999) & DT-FTIR/MS (c) \\
$0.06(\mathrm{pH}=8)$ & 291 & & \\
$0.006(\mathrm{pH}=10-13)$ & 291 & & \\
$0.35(\mathrm{pH}=0.5-3.0)$ & 260 & & \\
\hline
\end{tabular}

\section{Comments}

(a) Uptake of $\mathrm{NH}_{3}$ in a liquid jet of dilute $\mathrm{HCl}$ solution with continuous measurement of $\mathrm{NH}_{4}^{+}$in the collected jet waters. Contact time of $0.1 \mathrm{~ms}$ to $0.8 \mathrm{~ms}$ virtually free of saturation effects in the liquid phase. The $\gamma$ values for air $(+\mathrm{He})$ as carrier gas agreed very well with those measured in $\mathrm{He}\left(\gamma=3.5 \times 10^{-2}\right.$ in air vs. $4.0 \times 10^{-2}$ in $\left.\mathrm{He}\right)$.

(b) Gas interaction with monodisperse ( $70 \mu \mathrm{m}$ to $110 \mu \mathrm{m}$ diameter) droplet train propagating axially in a low pressure (46 mbar to $93 \mathrm{mbar}$ ) flow tube. Uptake determined by ion chromatographic analysis of collected aqueous phase was independent of $\mathrm{pH}$ in the range 4.2 to 11.5 but dependent on the contact time and pressure. The value listed in the table has been corrected for gas phase diffusion. The measured average uptake coefficient $\gamma_{\text {obs }}$ was $(2.4 \pm 1.0) \times 10^{-2}$ at $93 \mathrm{mbar}_{2}$ and $290 \mathrm{~K}$, obtained by extrapolation to zero interaction time.

(c) Uptake experiment of gas phase $\mathrm{NH}_{3}$ on train of droplets whose size was in the range 150-300 $\mu \mathrm{m}$ entrained in a flowing mixture of helium and water vapour (between 2.9 and $23.3 \mathrm{mbar}$ ). The reaction time was between 2 and $15 \mathrm{~ms}$, the ammonia concentration was in the range $10^{13}$ to $2 \times 10^{14}$ molecule $\mathrm{cm}^{-3}$ and was monitored using a VUV lamp emitting at $\lambda=121.6 \mathrm{~nm}$. The theoretical framework included gas phase diffusion of ammonia, mass accommodation, dissolution, bulk and surface reaction whose relative contributions changed with $\mathrm{pH}$. The effective Henry's law solubility was measured in the range 264 to $350 \mathrm{~K}: \log (\mathrm{H})=-3.221+1396 / T$. The uptake coefficient was dependent on $\mathrm{pH}$, falling rapidly from $\sim 0.08$ at $\mathrm{pH}=7$ to 0.006 at $\mathrm{pH}=10$. At low $\mathrm{pH}$ there is a negative temperature dependence of $\gamma$, which is attributed to accommodation controlled uptake. At high $\mathrm{pH}, \mathrm{NH}_{3}$ is less soluble and uptake controlled by a surface complex is suggested. Co-deposition with $\mathrm{SO}_{2}$ enhanced the ammonia uptake to values corresponding to acidic solutions.

\section{Preferred values}

\begin{tabular}{lll}
\hline Parameter & Value & $T / \mathrm{K}$ \\
\hline$\alpha_{\mathrm{b}}$ & 0.1 & $260-300$ \\
Reliability & & \\
$\Delta \log \left(\alpha_{\mathrm{b}}\right)$ & \pm 0.3 & $260-300$ \\
\hline
\end{tabular}

\section{Comments on preferred values}

The uptake coefficients on pure water, measured using the droplet train technique are somewhat larger than onto dilute $\mathrm{HCl}$ in a liquid jet. Both methods require correction for gas phase diffusion and for saturation effects. On balance, the DT experiment gives more reliable data and we therefore base the recommendation on the results of Ponche et al. (1993) and Shi et al. (1999), who also determined the temperature dependence at $\mathrm{pH}=1$. The value is higher than usually observed for the mass accommodation coefficient, $\alpha_{\mathrm{b}}$, for uptake on pure water, and the strong dependence of $\gamma$ on $\mathrm{pH}$ (Shi et al., 1999), indicates a direct chemical interaction of $\mathrm{NH}_{3}$ at the surface, e.g. by protonation. 


\section{References}

Bongartz, A., Schweighoefer, S., Roose, C., and Schurath, U.: J. Atmos. Chem., 20, 35-58, 1995.

Ponche, J. L., George, C., and Mirabel, P.: J. Atmos. Chem., 16, 1-21, 1993.

Shi, Q., Davidovits, P., Jayne, J. T., Worsnop, D. R., and Kolb, C. E.: J. Phys. Chem. A, 103, 8812-8823, 1999. 


\section{VI.A1.7}

$2 \mathrm{HNO}_{2}(\mathrm{~g})+\mathrm{H}_{2} \mathrm{O}(\mathrm{l}) \leftrightarrows \mathrm{NO}(\mathrm{g})+\mathrm{NO}_{2}(\mathrm{~g})+2 \mathrm{H}_{2} \mathrm{O}(\mathrm{l})$

\section{Experimental data}

\begin{tabular}{|c|c|c|c|}
\hline Parameter & $T / \mathrm{K}$ & Reference & Technique/Comments \\
\hline \multicolumn{4}{|l|}{ Bulk accommodation coefficients: $\alpha_{\mathrm{b}}$} \\
\hline$>5 \times 10^{-3}$ & 299 & Kirchner et al. (1990) & LJ-IC (a) \\
\hline $4.3 \times 10^{-3}\left(\right.$ wet $\left.\mathrm{Na}_{2} \mathrm{CO}_{3}\right)$ & 298 & Msibi et al. (1993) & CWFT (b) \\
\hline$\left(5_{-1}^{+2}\right) \times 10^{-2}$ & 297 & Bongartz et al. (1994) & LJ-IC (c) \\
\hline$\left(5_{-1}^{+14}\right) \times 10^{-2}$ & 245 & & DT-IC (c) \\
\hline $4 \times 10^{-3}<\alpha_{\mathrm{b}}<4 \times 10^{-2}$ & 278 & Mertes and Wahner (1995) & $\mathrm{LJ}(\mathrm{d})$ \\
\hline \multicolumn{4}{|l|}{ Solubility: $H$} \\
\hline $223 \pm 11$ & 273 & Park and Lee (1988) & Bubbler-CLD (e) \\
\hline \multicolumn{4}{|l|}{$121 \pm 6$} \\
\hline \multicolumn{4}{|l|}{$60 \pm 3$} \\
\hline \multicolumn{4}{|l|}{$38 \pm 2$} \\
\hline$H^{*}=194 \pm 25\left(8.7 \mathrm{wt} \% \mathrm{H}_{2} \mathrm{SO}_{4}\right)$ & 269 & Becker et al. (1996) & Static-TDLAS/IC (f) \\
\hline$H^{*}=117 \pm 20\left(8.7 \mathrm{wt} \% \mathrm{H}_{2} \mathrm{SO}_{4}\right)$ & 278 & & \\
\hline$H^{*}=73 \pm 10\left(8.7 \mathrm{wt} \% \mathrm{H}_{2} \mathrm{SO}_{4}\right)$ & 285 & & \\
\hline$H^{*}=50 \pm 8\left(8.7 \mathrm{wt} \% \mathrm{H}_{2} \mathrm{SO}_{4}\right)$ & 291 & & \\
\hline$H^{*}=34 \pm 5\left(8.7 \mathrm{wt} \% \mathrm{H}_{2} \mathrm{SO}_{4}\right)$ & 298 & & \\
\hline \multicolumn{4}{|l|}{ Rate constants, $k_{1}\left[\mathrm{M}^{-1} \mathrm{~s}^{-1}\right]$} \\
\hline 3.46 & 283 & Park and Lee (1988) & Bubbler-CLD (e) \\
\hline 13.4 & 295 & & \\
\hline 28.6 & 303 & & \\
\hline \multicolumn{4}{|l|}{ Rate constants, $k_{-1}\left[\mathrm{M}^{-1} \mathrm{~s}^{-1}\right]$} \\
\hline $1.98 \times 10^{8}$ & 283 & Park and Lee (1988) & Bubbler-CLD (e) \\
\hline $1.58 \times 10^{8}$ & 295 & & \\
\hline $1.67 \times 10^{8}$ & 303 & & \\
\hline
\end{tabular}

\section{Comments}

(a) Interaction of $\mathrm{HNO}_{2}(60 \mathrm{ppm})$ with a liquid jet of pure water. The kinetics were studied by ion chromatographic analysis of the liquid jet nitrite content. The gas phase diffusion coefficient value used was $0.13 \mathrm{~cm}^{2} \mathrm{~s}^{-1}$, the value used for the solubility of $\mathrm{HNO}_{2}$ in water was $60 \mathrm{M} \mathrm{atm}^{-1}$. A kinetic model taking into account diffusion in the gas phase as well as the radially resolved flow velocity within the jet was used to simulate the rate of appearance of nitrite in the aqueous phase. Agreement with the data was not very good likely due to uncertainties in the velocity distribution of the liquid jet. Taking into account dissociation of $\mathrm{HNO}_{2}$ in the aqueous phase did not improve the fits. Thus, the bulk accommodation coefficient is regarded as a lower limit.

(b) A flow of 61 per min of air at $97 \%$ relative humidity containing about $0.5 \mathrm{ppm} \mathrm{NO}_{2}$ at atmospheric pressure passed an annular glass reactor, coated with a mixture of $\mathrm{Na}_{2} \mathrm{CO}_{3}$ and glycerol. Uptake of nitrous acid detected by wet extraction of reactor segments.

(c) Two experimental flow techniques, an improved version of the liquid jet and the droplet train technique, were used. Both techniques involve the measurement of the concentration of $\mathrm{NO}_{2}^{-}$in the collected liquid droplets of $10 \mu \mathrm{m}$ to $100 \mu \mathrm{m}$ diameter at residence times of $3.7 \mathrm{~ms}$ to $16 \mathrm{~ms}$ at total pressures of $40 \mathrm{mbar}$ to $80 \mathrm{mbar}$. Temperature refers to droplet surface temperature of $(245 \pm 5) \mathrm{K}$. A $20 \%$ uncertainty in $D_{\mathrm{g}}$ leads to the stated error intervals.

(d) Liquid jet at $298 \mathrm{~K}$. Experiments were done with pure water, with $0.01 \mathrm{M} \mathrm{NaOH}, 33.4 \mathrm{gl}^{-1}$ triethanolamine and $1 \mathrm{~g} \mathrm{l}^{-1}$ $\mathrm{NaAsO}_{2}$ to vary the liquid phase sink. $\mathrm{HNO}_{2}$ was measured by DOAS in a White cell. $\mathrm{HNO}_{2}$ was produced indirectly by reaction of $\mathrm{NO}_{2}$ with the glass walls upstream of the jet leading to concentrations of $10^{13}$ to $10^{14}$ molecule $\mathrm{cm}^{-3}$ in presence of a factor of 50 more $\mathrm{NO}_{2}$. Nitrite and nitrate were measured spectrophotometrically. $\mathrm{HNO}_{2}$ uptake was independent of $\mathrm{pH}$ or added sink. Within the short residence time of the jet, the liquid phase remained far from equilibrium. A 
kinetic model was used to obtain the likely range for $\alpha_{\mathrm{b}}$ based on the observed loss of $\mathrm{HNO}_{2}$ from the gas phase (lower limit) and the appearance of nitrite in the aqueous phase (upper limit), respectively.

(e) A thermostated pyrex reactor with a fritted gas inlet. The solubility of $\mathrm{HNO}_{2}$ was measured by using low concentration $\mathrm{HNO}_{2}$ solutions $\left(10^{-6} \mathrm{M}\right)$ and observing the purge behavior with a chemiluminescence detector. $\mathrm{HNO}_{2}$ decomposition experiments were performed at higher solution concentrations $>10^{-5} \mathrm{M}$ to allow observation of $\mathrm{NO}$ and $\mathrm{NO}_{2}$ purging from the bubbler apparatus. The rate constants listed in the table for the forward (decomposition) $\left(k_{1}\right)$ and backward reaction $\left(k_{-1}\right)$ were obtained by fitting a kinetic model to the purge data. The mass transfer properties of the bubbler were calibrated using $\mathrm{CO}_{2}$.

(f) Solubility of $\mathrm{HNO}_{2}$ was measured in a 11-L Pyrex glass reactor directly by monitoring both gas phase composition by tunable diode laser spectrometry and liquid phase by ion chromatography. Formation of $\mathrm{NO}_{2}$ due to 2 $\mathrm{HNO}_{2}+\mathrm{H}_{2} \mathrm{O} \leftrightarrows \mathrm{NO}+\mathrm{NO}_{2}+2 \mathrm{H}_{2} \mathrm{O}$ was observed. Since the $\mathrm{NO}_{2}$ concentration equilibrated with time, this reaction was included into calculating the effective solubility.

\section{Preferred values}

\begin{tabular}{lll}
\hline Parameter & Value & $T / \mathrm{K}$ \\
\hline$\alpha_{\mathrm{b}}$ & 0.05 & $273-300$ \\
$H^{*}$ & $4.2 \times 10^{-6} \exp (4873 / T)$ & $273-300$ \\
& $\left(1+5.9 \times 10^{-4} \exp (-1760(1 / T-1 / 298)) /\left[\mathrm{H}^{+}\right]\right)$ & \\
$k_{1}\left(\mathrm{M}^{-1} \mathrm{~s}^{-1}\right)$ & $3.1 \times 10^{14} \exp (-9090 / T)$ & $273-300$ \\
$k_{-1}\left(\mathrm{M}^{-1} \mathrm{~s}^{-1}\right)$ & $1.7 \times 10^{8}$ & $273-300$ \\
$\operatorname{Reliability}$ & & \\
$\Delta \log \left(\alpha_{\mathrm{b}}\right)$ & \pm 0.7 & $273-300$ \\
$\Delta \log (k)$ & \pm 0.3 & $273-300$ \\
$\Delta \mathrm{E} / \mathrm{R}[\mathrm{K}]$ & \pm 50 & $273-300$ \\
\hline
\end{tabular}

\section{Comments on preferred values}

Most of the attempts to measure the bulk accommodation coefficient of $\mathrm{HNO}_{2}$ into water or dilute aqueous solutions were done with a liquid jet experiment at relatively high pressure. Uncertainties arise from not understanding precisely the radial flow velocity distribution within the jet, which critically determines whether or not uptake is limited by solubility. The other significant issue is that especially at atmospheric pressure, transfer of the gas into the liquid is strongly affected by gas phase diffusion. We therefore adopt the value from the Bongartz et al. (1994) study performed at lower pressure than the others.

The solubility of $\mathrm{HNO}_{2}$ in water has been directly measured by Park and Lee (1988). Their data are also in line with the extrapolated solubility from those by Becker et al. (1996), who measured the solubility as a function of sulphuric acid composition ( $0.3 \mathrm{wt} \%$ and above). The preferred expression is consistent with that presented in data sheet VI.A4.7 for $0 \mathrm{wt} \% \mathrm{H}_{2} \mathrm{SO}_{4}$ and agrees well with the temperature dependence measured by Park and Lee. The acid dissociation constant used in this expression is that determined by Park and Lee, which is identical to that calculated from the standard free energies of formation of $\mathrm{HNO}_{2}(\mathrm{~g})$ and $\mathrm{HNO}_{2}(\mathrm{aq})$ (Schwartz and White, 1981). We note that the acid dissociation constant determined by Riordan et al. (2005) was somewhat lower $\left(1.6 \times 10^{-3}(\mathrm{pK}=2.8)\right.$ at $\left.298 \mathrm{~K}\right)$.

The rate constants for the decomposition reaction of $\mathrm{HNO}_{2}\left(k_{1}\right)$ and the reverse process $\left(k_{-1}\right)$ have been adopted from Park and Lee (1988); for $k_{-1}$ the average of the available rate constants at three temperatures have been taken as preferred value. They are somewhat above those of earlier studies (Schwartz and White, 1981, and references therein), but better represent the low concentrations expected under atmospheric conditions. The preferred value for $k_{1}$ is much lower than that in $\mathrm{H}_{2} \mathrm{SO}_{4}$ at about $50 \mathrm{wt} \%\left(320 \mathrm{M}^{-1} \mathrm{~s}^{-1}\right.$, see data sheet VI.A4.7). Given that the back reaction is significant, an expression for $\gamma$ based on the resistance model is not appropriate.

\section{References}

Becker, K. H., Kleffmann, J., Kurtenbach, R., and Wiesen, P.: J. Phys. Chem., 100, 14984-14990, 1996.

Bongartz, A., Kames, J., Schurath, U., George, C., Mirabel, P., and Ponche, J. L.: J. Atmos. Chem., 18, 149-169, 1994.

Kirchner, W., Welter, F., Bongartz, A., Kames, J., Schweighofer, S., and Schurath, U.: J. Atmos. Chem., 10, 427-449, 1990. 
Mertes, S. and Wahner, A.: J. Phys. Chem., 99, 14000-14006, 1995.

Msibi, I. M., Shi, J. P., and Harrison, R. M.: J. Atmos. Chem., 17, 339-351, 1993.

Park, J.-Y. and Lee, Y.-N.: J. Phys. Chem., 92, 6294-6302, 1988.

Ponche, J. L., George, C., and Mirabel, P.: J. Atmos. Chem., 16, 1-21, 1993.

Riordan, E., Minogue, N., Healy, D., O’Driscol, P., and Sodeau, J. R.: J. Phys. Chem. A, 109, 779-786, 2005.

Schwartz, S. E. and White, W. H.: in: Advances in Environmental Science and Engineering, edited by: Pfafflin, J. R. and Ziegler, E. N., Gordon and Breach Science Publishers, NY, 1-45, 1981. 


\section{VI.A1.8}

$\mathrm{HNO}_{3}(\mathrm{~g})+\mathrm{H}_{2} \mathrm{O}(\mathrm{l}) \rightarrow \mathrm{HNO}_{3}(\mathrm{aq})+\mathrm{H}_{2} \mathrm{O}(\mathrm{l})$

\section{Experimental data}

\begin{tabular}{lcll}
\hline Parameter & $T / \mathrm{K}$ & Reference & Technique/Comments \\
\hline Uptake coefficients: $\gamma$ & & & \\
$0.19 \pm 0.02$ & 268 & Van Doren et al. (1990) & DT-IR (a) \\
$0.071 \pm 0.02$ & 293 & & \\
$>0.01$ & 298 & Kirchner et al. (1990) & LJ-IC (b) \\
$0.11 \pm 0.01$ & 298 & Ponche et al. (1993) & DT-IC (c) \\
0.03 & 298 & Schütze and Herrmann (2002) & (d) \\
\hline
\end{tabular}

\section{Comments}

(a) Experiments performed at room temperature flow with the water vapor pressure adjusted to the vapour pressure of water at the experimental temperature. $\mathrm{HNO}_{3}$ was detected downstream of the flow tube using IR absorption. The uptake coefficients were corrected for gas phase diffusion. The data show significant negative temperature dependence within the range indicated in the table. Given that under the experimental conditions the near surface region of the droplet does not saturate, it is argued that the uptake coefficients derived are actually bulk accommodation coefficients equivalent to the rate limiting step being solvation.

(b) Interaction of $\mathrm{HNO}_{3}(60 \mathrm{ppm})$ in 1 bar of synthetic air with a liquid jet of pure water. The kinetics were studied by ion chromatographic analysis of the liquid jet nitrate content. The uptake coefficient was attributed to a bulk accommodation coefficient and is regarded as a lower limit due to uncertainties in the velocity distribution of the liquid jet. The gas phase diffusion coefficient value used was $0.132 \mathrm{~cm}^{2} \mathrm{~s}^{-1}$, the value used for the effective solubility of $\mathrm{HNO}_{3}$ in water was $2.45 \times 10^{6} \mathrm{M}^{2} \mathrm{~atm}^{-1}$.

(c) Gas uptake into a monodisperse ( $70 \mu \mathrm{m}$ to $110 \mu \mathrm{m}$ diameter) droplet train. The $\mathrm{pH}$ of water was adjusted to 9.5 and 11.0. Uptake determined by chemical analysis (ion chromatography) of collected aqueous phase. The uptake coefficient corrected for gas phase diffusion was independent of $\mathrm{pH}$, of the contact time and of the $\mathrm{HNO}_{3}$ concentration in the range 10 to $100 \mathrm{ppm}$. The value for the diffusion coefficient used was $0.160 \mathrm{~cm}^{2} \mathrm{~s}^{-1}$ in the gas phase and $2.6 \times 10^{-5} \mathrm{~cm}^{2} \mathrm{~s}^{-1}$ in the liquid phase. The solubility was assumed to be $2.1 \times 10^{5} \mathrm{M} \mathrm{atm}^{-1}$. The measured average uptake coefficient $\gamma_{\text {obs }}$ was $(5.0 \pm 0.9) \times 10^{-2}$ at $67 \mathrm{mbar}_{2}$ and $298 \mathrm{~K}$.

(d) A drop of water (2-3 mm diameter) was exposed to $\mathrm{HNO}_{3}\left(3-5 \times 10^{13}\right.$ molecule $\left.\mathrm{cm}^{-3}\right)$ in a flow tube. The drop was probed by UV spectroscopy to monitor the appearance of nitrate in the aqueous phase. A model was used to determine the effect of gas phase diffusion on the measured uptake coefficient. The value for the gas phase diffusion coefficient was $0.124 \mathrm{~cm}^{2} \mathrm{~s}^{-1}$ in $\mathrm{H}_{2} \mathrm{O}$ at $298 \mathrm{~K}$ and $0.534 \mathrm{~atm} \mathrm{~cm}^{2} \mathrm{~s}^{-1}$ in $\mathrm{He}$ at 298. The value used for the effective solubility of $\mathrm{HNO}_{3}$ in water was $2.1 \times 10^{5} \mathrm{M} \mathrm{atm}^{-1}$. The measurements indicate that the uptake coefficient given in the table is a lower limit.

\section{Preferred values}

\begin{tabular}{lll}
\hline Parameter & Value & $T / \mathrm{K}$ \\
\hline$\alpha_{\mathrm{b}}$ & $7.5 \times 10^{-5} \exp (2100 / T)$ & $268-300$ \\
Reliability & & \\
$\Delta \log \left(\alpha_{\mathrm{b}}\right)$ & \pm 0.7 & \\
$\Delta \mathrm{E} / \mathrm{R}[\mathrm{K}]$ & \pm 1000 & \\
\hline
\end{tabular}

\section{Comments on preferred values}

The experiments on $\mathrm{HNO}_{3}$ uptake to pure water all resulted in large uptake coefficients, and all studies concluded that bulk accommodation rather than solubility or reaction in the liquid phase (dissociation) was rate limiting. They all carry a significant uncertainty due to gas phase diffusion, depending on geometry and pressure. The high pressure liquid jet experiment by 
Kirchner et al. (1990) was most sensitively affected by the magnitude of the diffusion coefficient and in addition contained an uncertainty with respect to the liquid flow regime. Schütze and Herrmann (2002) also used several simplifications and suggest that their uptake coefficient represents a lower limit to the bulk accommodation coefficient. Also, the diffusion correction commonly applied for high uptake coefficients to the droplet train experiments as reported by Van Doren et al. (1990) has recently been challenged (Morita et al., 2003; Hanson et al., 2004; Garrett et al., 2006; Davidovits et al., 2006). Van Doren's experiments at high temperature were measured at higher total pressure than those at lower temperature. The two droplet train studies, in spite of determining uptake via loss of gas phase $\mathrm{HNO}_{3}$ in one case (Van Doren et al., 1990) and the appearance of nitrate in the aqueous phase in the other (Ponche et al., 1993), but both using the same method to correct for diffusion, agree fairly well with each other. The recommended expression for $\alpha_{\mathrm{b}}$ is a least square fit to the data by Ponche et al. and Van Doren et al. in Arrhenius form, with large error limits to account for potential systematic errors.

\section{References}

Davidovits, P., Kolb, C. E., Williams, L. R., Jayne, J. T., and Worsnop, D. R.: Chem. Rev., 106, 1323-1354, 2006.

Garrett, B. C., Schenter, G. K., and Morita, A.: Chem. Rev., 106, 1355-1374, 2006.

Hanson, D. R., Sugiyama, M., and Morita, A.: J. Phys. Chem. A, 108, 3739-3744, 2004.

Kirchner, W., Welter, F., Bongartz, A., Kames, J., Schweighofer, S., and Schurath, U.: J. Atmos. Chem., 10, 427-449, 1990.

Morita, A., Sugiyama, M., and Koda, S.: J. Phys. Chem. A, 107, 1749-1759, 2003.

Ponche, J. L., George, C., and Mirabel, P.: J. Atmos. Chem., 16, 1-21, 1993.

Schütze, M. and Herrmann, H.: Phys. Chem. Chem. Phys., 4, 60-67, 2002.

Van Doren, J. M., Watson, L. R., Davidovits, P., Worsnop, D. R., Zahniser, M. S., and Kolb, C. E.: J. Phys. Chem., 94, 32653269, 1990. 
VI.A1.9

$\mathrm{CH}_{3} \mathrm{SO}_{3} \mathrm{H}(\mathrm{g})+\mathrm{H}_{2} \mathrm{O}(\mathrm{l}) \rightarrow \mathrm{CH}_{3} \mathrm{SO}_{3} \mathrm{H}(\mathrm{aq})+\mathrm{H}_{2} \mathrm{O}(\mathrm{l})$

\section{Experimental data}

\begin{tabular}{llll}
\hline Parameter & $T / \mathrm{K}$ & Reference & Technique/Comments \\
\hline Accommodation coefficient: $\alpha_{\mathrm{b}}$ & & & \\
$0.15 \pm 0.01$ & 264 & De Bruyn et al. (1994) & DT (a) \\
$0.11 \pm 0.02$ & 279 & & \\
$0.16 \pm 0.04$ & 261 & Schweitzer et al. (1998) & DT-MS (b) \\
$0.11 \pm 0.01$ & 283 & & \\
$0.89 \pm 0.04\left(7-15 \mathrm{wt} \% \mathrm{H}_{2} \mathrm{SO}_{4}\right)$ & 296 & Hanson (2005) & AFT-CIMS (c) \\
\hline
\end{tabular}

\section{Comments}

(a) Monodispersed droplets of 50 to $200 \mu \mathrm{m}$ in diameter Uptake coefficients were corrected for gas phase diffusion using $D_{\mathrm{g}}=0.066 \mathrm{~atm} \mathrm{~cm}^{2} \mathrm{~s}^{-1}$ in $\mathrm{H}_{2} \mathrm{O}$ and $0.299 \mathrm{~atm} \mathrm{~cm}^{2} \mathrm{~s}^{-1}$ in He. The measured uptake coefficients were independent of $\mathrm{pH}$ adjusted with $\mathrm{NaOH}$ or $\mathrm{HCl}$ and independent of $\mathrm{NaCl}$ content up to $3.5 \mathrm{M}$. Since the observed uptake coefficient were time-independent, uptake was considered limited by bulk accommodation.

(b) Monodispersed droplets of 80 to $150 \mu \mathrm{m}$ in diameter $\mathrm{CH}_{3} \mathrm{SO}_{3} \mathrm{H}$ was admitted to the reactor at $10^{13} \mathrm{~cm}^{-3}$; its concentration at the reactor exit was measured by an ion-trap mass spectrometer. Uptake coefficients were corrected for gas phase diffusion using $D_{\mathrm{g}}=0.13 \mathrm{~cm}^{2} \mathrm{~s}^{-1}$ in $\mathrm{H}_{2} \mathrm{O}$ and $0.37 \mathrm{~cm}^{2} \mathrm{~s}^{-1}$ in $\mathrm{He}$ and assuming the $T$ dependence following $T^{1.75}$. The corrected uptake coefficients were independent of time and $\mathrm{NaCl}$ content up to $2 \mathrm{M}$. It was considered limited by bulk accommodation in all cases.

(c) Uptake to sulphuric acid aerosol was studied in a laminar flow reactor coupled to CIMS detection using $\mathrm{HNO}_{3}$ as source of primary ions. Sulphuric acid particles were generated by homogeneous nucleation from supersaturated vapour leading to a lognormal particle size distribution within $50-120 \mathrm{~nm}$, with a few $10^{4}$ particles per $\mathrm{cm}^{3}$, characterised by a differential mobility analyzer. Concentrations of $\mathrm{CH}_{3} \mathrm{SO}_{3} \mathrm{H}$ were $3 \times 10^{10}$ molecule $\mathrm{cm}^{-3}$ in the flow tube. The measured uptake coefficients were corrected for gas phase diffusion using the Fuchs-Sutugin correction factor. The diffusion coefficient was directly measured based on the observed wall loss rates in absence of aerosol particles. It did not significantly depend on humidity. Its average value was $0.0786 \mathrm{~atm} \mathrm{~cm}^{2} \mathrm{~s}^{-1}$.

\section{Preferred values}

\begin{tabular}{lll}
\hline Parameter & Value & $T / \mathrm{K}$ \\
\hline$\alpha_{\mathrm{b}}$ & 1 & $260-300$ \\
$\begin{array}{l}\text { Reliability } \\
\Delta \log \left(\alpha_{\mathrm{b}}\right)\end{array}$ & \pm 0.3 & $260-290$ \\
\hline
\end{tabular}

\section{Comments on preferred values}

The two droplet train studies of $\mathrm{CH}_{3} \mathrm{SO}_{3} \mathrm{H}$ uptake to water and dilute aqueous solutions agree very well and report a bulk accommodation coefficient around 0.1. However, the aerosol flow tube study by Hanson (2005) found a value for $\alpha_{\mathrm{b}}$ not different from 1. Since this experiment was much less affected by gas phase diffusion, we adopt this result for our recommendation for $\alpha_{\mathrm{b}}$. Solubility of $\mathrm{CH}_{3} \mathrm{SO}_{3} \mathrm{H}$ is high enough to allow bulk accommodation limited uptake into the droplets over the experimental gas-particle interaction times of all studies. While $\alpha_{\mathrm{b}}$ was apparently independent of $\mathrm{pH}$ and $\mathrm{NaCl}$ concentration, Schweitzer et al. (1998) and De Bruyn et al. (1994) found a temperature dependence, which they interpreted in terms of nucleation of a critical cluster as rate limiting step for the solvation rate leading to an average cluster of $\mathrm{CH}_{3} \mathrm{SO}_{3} \mathrm{H} \times 0.5 \mathrm{H}_{2} \mathrm{O}$. This would, however, indicate a quite low ability of this very soluble species $\left(H=8.7 \times 10^{11} \mathrm{M} / \mathrm{atm}\right.$, Brimblecombe and Clegg, 1988) and strong acid $\left(p K_{\mathrm{a}}=-2\right.$, Serjeant and Dempsey, 1979) to hydrogen bond to water. 


\section{References}

Brimblecombe, P. and Clegg, S. L.: J. Atmos. Chem., 7, 1-18, 1988.

De Bruyn, W. J., Shorter, J. A., Davidovits, P., Worsnop, D. R., Zahniser, M. S., and Kolb, C. E.: J. Geophys. Res., 99, 1692716932, 1994.

Hanson, D. R.: J. Phys. Chem. A, 109, 6919-6927, 2005.

Schweitzer, F., Magi, L., Mirabel, P., and George, C.: J. Phys. Chem. A, 102, 593-600, 1998.

Serjeant, E. P. and Dempsey, B.: Ionization Constants of Organic Acids in Solution, IUPAC Chemical Data Series No. 23, Pergamon Press, Oxford, UK, 1979. 


\section{VI.A1.10}

$\mathrm{SO}_{2}(\mathrm{~g})+\mathrm{H}_{2} \mathrm{O}(\mathrm{l}) \leftrightarrows \mathrm{SO}_{2}(\mathrm{aq})+\mathrm{H}_{2} \mathrm{O}(\mathrm{l})$

\section{Experimental data}

\begin{tabular}{llll}
\hline Parameter & $T / \mathrm{K}$ & Reference & Technique/Comments \\
\hline $\begin{array}{l}\gamma, \gamma_{0} \\
0.054 \pm 0.006 \text { (init. droplet } \mathrm{pH}=11.5)\end{array}$ & 295 & Gardner et al. (1987, 1989) & DT-TDL (a) \\
$\gamma_{0}=0.12$ & & & \\
$\gamma_{0}=0.11 \pm 0.2$ (init. droplet $\left.\mathrm{pH}=11.5\right)$ & $260-292$ & Worsnop et al. (1989) & DT-TDL (b) \\
$\begin{array}{l}8.0 \times 10^{-3}(\text { droplet } \mathrm{pH}=0 \text { to } 2) \\
0.11(\text { droplet } \mathrm{pH}>6)\end{array}$ & 283 & Jayne et al. (1990) & DT-TDL (c) \\
$0.06(+0.14,-0.03)$ & 300 & Welter et al. (1990) & LJ-IC (d) \\
$\gamma_{\mathrm{o}}=0.13 \pm 0.01$ & 298 & Ponche et al. (1993) & DT-IC (e) \\
$0.028 \pm 0.010(\mathrm{pH}=13.2)$ & 293.5 & Shimono and Koda (1996) & (f) \\
\hline
\end{tabular}

\section{Comments}

(a) Uptake of $\mathrm{SO}_{2}$ into a fast moving train of water droplets propagated axially in a flow tube. The droplet diameter varied from 80 to $180 \mu \mathrm{m}$ and the residence time of the individual droplet ranged from 2.2 to $12.8 \mathrm{~ms}$. The total pressure was $28 \mathrm{mbar}\left(\sim 6 \mathrm{mbar} \mathrm{He}+\sim 22 \mathrm{mbar} \mathrm{H}_{2} \mathrm{O}\right)$. [ $\left[\mathrm{SO}_{2}\right]$ measured by diode-laser adsorption in a long path $(728 \mathrm{~cm})$ White cell; range: $(1.5-15.0) \times 10^{12}$ molecule $\mathrm{cm}^{-3}$. Surface saturation effects were shown to be absent at $\left[\mathrm{SO}_{2}\right]$ and initial $\mathrm{pH}$ used. Measurements of aqueous [S(IV)] in exposed droplets confirmed uptake coefficient values determined from $\mathrm{SO}_{2}$ loss. Correction for gas phase diffusion to a static drop gives the cited value of $\gamma_{0}$, which can be considered equal to the bulk accommodation coefficient.

(b) Experiment designed to determine the temperature-dependent bulk accommodation coefficients of $\mathrm{SO}_{2}$ and $\mathrm{H}_{2} \mathrm{O}_{2}$ on aqueous surfaces, using oxidation of $\mathrm{HSO}_{3}^{2-}$ to overcome solubility limitation of $\mathrm{S}(\mathrm{IV})$ uptake. A fast moving train of $200 \mathrm{~mm}$ diameter water droplets propagated in a flow tube either in axial or transverse direction with $\left[\mathrm{SO}_{2}\right]_{0}=$ $1 \times 10^{13}$ molecule $\mathrm{cm}^{-3}$. The interaction time ranged from 2 to $12 \mathrm{~ms}$ (axial) or from 0.5 to $2 \mathrm{~ms}$ (transverse), with a temperature range $260-292 \mathrm{~K}$ at pressures from 13.3 to $66.5 \mathrm{mbar}\left(\mathrm{He}+\mathrm{H}_{2} \mathrm{O}\right)$ for the axial configuration, and 3.1 to $13.3 \mathrm{mbar}$ for the transverse geometry. Uptake coefficients were corrected for gas diffusion. At low $\mathrm{pH}, \gamma$ decreased with droplet exposure time due to reduced solubilty of $\mathrm{S}(\mathrm{IV})$, and increased with $\mathrm{pH}$. Temperature dependence of the initial uptake coefficient $\gamma_{\mathrm{o}}$ was given by the expression: $\gamma_{\mathrm{o}} /\left(\gamma_{\mathrm{o}}-1\right)=A \exp (-\Delta \mathrm{E} / \mathrm{RT})$ with $A=4 \times 10^{-2}$ and $\Delta \mathrm{E}=-2 \pm 5 \mathrm{~kJ} \mathrm{~mol}^{-1}$. The value of $\gamma_{\mathrm{o}}$ equates to the bulk accommodation coeficient $\alpha_{\mathrm{b}}$.

(c) details as (b). Uptake measured for a range of initial $\mathrm{pH}$ in the bulk droplets from 0 to 12 and at $\left[\mathrm{SO}_{2}\right]_{0}$ between $10^{13}$ and $10^{15}$ molecule $\mathrm{cm}^{-3}$. Corrections for gas phase diffusion and additional acidification of the droplet due to $\mathrm{SO}_{2}$ adsorption were applied to the uptake kinetics. The $\gamma_{\mathrm{o}}$ values displayed in the table are corrected values obtained at minimal droplet-gas interaction time $(2 \mathrm{~ms})$ and minimum $\mathrm{SO}_{2}$ density $\left(10^{13}\right.$ molecule $\left.\mathrm{cm}^{-3}\right)$. The observed uptake rates over the $\mathrm{pH}$ range were significantly greater than predicted on the basis of the known rate of $\mathrm{SO}_{2}$ reaction in bulk liquid water at $\mathrm{pH}>5$ and known Henry's law solubility at low $\mathrm{pH}$. A mechanism involving formation of a surface complex $\mathrm{HSO}_{3}^{-}-\mathrm{H}^{+}$ was proposed. Jayne et al. (1990) derive kinetic and thermodynamic parameters governing these surface interactions.

(d) Liquid jet of water (100 $\mu$ m diameter); $\mathrm{H}_{2} \mathrm{O}_{2}$ was added in order to rapidly oxidize $\mathrm{SO}_{2}$ to sulfate. The uptake kinetics of typically $100 \mathrm{ppm} \mathrm{SO}_{2}$ in synthetic air were measured by analysis of the sulfate concentration in the collected jet waters using ion chromatography. Retrieval of $\gamma$ using a gas diffusion model to define the gas-surface collision rate. The uptake was found to be dependent on $\left[\mathrm{SO}_{2}\right]$ due to a change in surface $\mathrm{pH}$. Addition of $\mathrm{NH}_{3}$ to the $\mathrm{SO}_{2}$ /air mixture minimized the $\mathrm{pH}$ dependence.

(e) Uptake into droplet train of $\left[\mathrm{SO}_{2}\right]=2.8$ to $28 \mathrm{ppmv}$ at 50 mbar total pressure. Dilute aqueous $\mathrm{H}_{2} \mathrm{O}_{2}$ is added to the condensed phase to rapidly oxidize dissolved $\mathrm{SO}_{2}$ to $\mathrm{H}_{2} \mathrm{SO}_{4}$. Uptake monitored by chemical analysis of the collected aqueous sulphate by ion chromatography. The gas/liquid contact time varied between 3.7 and $45 \mathrm{~ms}$. The observed uptake coefficient $\gamma$ is strongly dependent on the initial $\mathrm{pH}$ of the droplet in the range 4 to 11 and, at $\mathrm{pH}<11$, on the interaction time. Cited value of $\gamma_{0}$ which is independent of $\mathrm{pH}$ is corrected for gas phase diffusion and represents the mass accommodation coefficient. (The uncorrected $\gamma_{0}$ at $t=0$ was $0.060 \pm 0.008$ ). 
(f) Uptake measurement of $\mathrm{SO}_{2}$ on counterflowing liquid $\mathrm{H}_{2} \mathrm{O}$ using LIF detection of $\mathrm{SO}_{2}$ excited at $224.34 \mathrm{~nm}$. The range of $\left[\mathrm{SO}_{2}\right]$ was between $3.3 \times 10^{11}$ and $1.7 \times 10^{14}$ molecule $\mathrm{cm}^{-3}$ in the temperature range $280-305 \mathrm{~K}$ at an average contact time of $37 \mathrm{~ms}$ and a total pressure range of 37-131 mbar. $\gamma$ was determined from the concentration dependence of $\mathrm{SO}_{2}$ in the impinging flow field and was found to strongly depend on the $\mathrm{pH}$ of the condensed phase.

\section{Preferred values}

\begin{tabular}{lll}
\hline Parameter & Value & $T / \mathrm{K}$ \\
\hline$\alpha_{\mathrm{s}}$ & 1 & $260-300$ \\
$k_{\mathrm{des}}\left(\mathrm{s}^{-1}\right)$ & $5.8 \times 10^{4}$ & $260-300$ \\
$k_{\mathrm{sb}}\left(\mathrm{s}^{-1}\right)$ & $1.3 \times 10^{4}$ & $260-300$ \\
$N_{\max }\left(\mathrm{cm}^{-2}\right)$ & $10^{14}$ & $260-300$ \\
$K_{\mathrm{LinC}}(\mathrm{cm})$ & 0.13 & $260-300$ \\
$k^{\mathrm{I}}\left(\mathrm{s}^{-1}\right)$ & $3.4 \times 10^{-6}$ & $260-300$ \\
Reliability & & \\
$\Delta \log \left(\alpha_{\mathrm{s}}\right)\left(\mathrm{s}^{-1}\right)$ & \pm 1 & $260-300$ \\
$\Delta \log \left(k_{\operatorname{des}}\right)\left(\mathrm{s}^{-1}\right)$ & \pm 1 & $260-300$ \\
$\Delta \log \left(k_{\mathrm{sb}}\right)\left(\mathrm{cm}^{-2}\right)$ & \pm 1 & $260-300$ \\
$\Delta \log \left(N_{\max }\right)(\mathrm{cm})$ & \pm 0.3 & $260-300$ \\
$\Delta \log \left(K_{\text {LinC }}\right)(\mathrm{cm})$ & \pm 0.3 & $260-300$ \\
\hline
\end{tabular}

\section{Comments on preferred values}

When $\mathrm{SO}_{2}$ is adsorbed at the surface and enters aqueous solution it reacts with water molecules and an equilibrium is set up between the forms of $\mathrm{S}(\mathrm{IV})$ : hydrated $\mathrm{SO}_{2}, \mathrm{HSO}_{3}^{-}$and $\mathrm{SO}_{3}^{2-}$ via the following equilibria:

$$
\begin{aligned}
& \mathrm{SO}_{2}(\mathrm{~g})+\mathrm{H}_{2} \mathrm{O} \rightleftarrows \mathrm{SO}_{2} \cdot \mathrm{H}_{2} \mathrm{O} \quad H \\
& \mathrm{SO}_{2} \cdot \mathrm{H}_{2} \mathrm{O} \rightleftarrows \mathrm{HSO}_{3-}+\mathrm{H}+\quad K_{1} \\
& \mathrm{HSO}_{3}^{-} \rightleftarrows \mathrm{SO}_{3}^{2-}+\mathrm{H}+\quad K_{2} \\
& \text { where } \quad H=\frac{\left[\mathrm{SO}_{2} \cdot \mathrm{H}_{2} \mathrm{O}\right]}{p\left(\mathrm{SO}_{2}\right)} \\
& K_{1}=\frac{\left[\mathrm{H}^{+}\right]\left[\mathrm{HSO}_{3}^{-}\right]}{\left[\mathrm{SO}_{2} \cdot \mathrm{H}_{2} \mathrm{O}\right]} \\
& \text { and } \quad K_{2}=\frac{\left[\mathrm{H}^{+}\right]\left[\mathrm{SO}_{3}^{2-}\right]}{\left[\mathrm{HSO}_{3}^{-}\right]}
\end{aligned}
$$

which gives in turn:

$$
\begin{aligned}
{[\mathrm{S}(\mathrm{IV})]_{\text {total }} } & =p\left(\mathrm{SO}_{2}\right) H \times\left\{1+\frac{K_{1}}{\left[\mathrm{H}^{+}\right]}+\frac{K_{1} K_{2}}{\left[\mathrm{H}^{+}\right]^{2}}\right\} \\
& =p\left(\mathrm{SO}_{2}\right) \cdot H^{*}
\end{aligned}
$$

This leads to the mole fractions and total dissolved S(IV) being a strong function of $\mathrm{pH}$. Thus the effective Henry's law solubilty constant, $H^{*}$, decreases with $\mathrm{pH}$. Over the $\mathrm{pH}$ range typical of atmospheric droplets ( $\mathrm{pH} 2$ to 6), most dissolved $\mathrm{SO}_{2}$ is in the form of $\mathrm{HSO}_{3}^{-}$.

From kinetic gas-uptake experiments to solutions with varying $\mathrm{pH}$, Jayne et al. (1990) suggest a rapid surface reaction to form an $\mathrm{HSO}_{3}^{-}-\mathrm{H}^{+}$surface complex, which is in equilibrium with gas-phase $\mathrm{SO}_{2}$. This complex allows a more rapid entry of $\mathrm{S}(\mathrm{IV})$ into the bulk as $\mathrm{HSO}_{3}^{-}$compared to transfer and reaction of $\mathrm{SO}_{2}$ molecules. We interpret the surface complex as suggested by Jayne et al. as the adsorbed species; see also Ammann and Pöschl (2007) for a complete time dependent modelling of this uptake process. The presence of a surface adsorbed, partially hydrated $\mathrm{SO}_{2}$ species is also in line with second harmonic generation (SHG) experiments reported by Donaldson et al. (1995). The equilibrium constant denoted by $A_{\text {eq }}^{*}$ by Jayne et al. is equal to $K_{\mathrm{LinC}}$ preferred here; similarly, the kinetic parameters $k_{\mathrm{i}-\mathrm{g}}=k_{\mathrm{des}}$ and $k_{\mathrm{i}-1}=k_{\mathrm{sb}}$. As discussed in detail by Jayne et al., it is difficult to constrain these parameters from the available data of the time dependence of the uptake coefficients. $K_{\text {LinC }}$ 
was obtained from the slope of the time dependent uptake coefficients. Because the surface accommodation coefficient is not directly accessible and

$K_{\mathrm{LinC}}=\frac{\alpha_{\mathrm{s}} \bar{c}}{4 k_{\mathrm{des}}}$

only the ratio of $\alpha_{\mathrm{s}}$ and $k_{\mathrm{des}}$ is constrained by the experiment at low $\mathrm{SO}_{2}$ pressures. The bulk accommodation coefficient is linked to these parameters via

$\alpha_{\mathrm{b}}=\alpha_{\mathrm{s}}(1-\theta) \frac{k_{\mathrm{sb}}}{k_{\mathrm{sb}}+k_{\mathrm{des}}}$

Where the surface coverage is given by $\theta=\frac{K_{\mathrm{Lang}}[\mathrm{X}]_{\mathrm{g}}}{1+K_{\mathrm{Lang}}[\mathrm{X}]_{\mathrm{g}}}$, with $K_{\mathrm{LangC}}=K_{\mathrm{LinC}} / N_{\max }$, which leads to the pressure dependence of $\alpha_{\mathrm{b}}$ as observed by Jayne et al. (1990).

In absence of an additional loss process of the surface complex at the surface itself, the uptake coefficient is given by:

$\frac{1}{\gamma} \approx \frac{1}{\alpha_{\mathrm{s}}}+\frac{1}{\Gamma_{\mathrm{sb}}}+\frac{1}{\Gamma_{\mathrm{sol}}+\Gamma_{\mathrm{b}}}=\frac{1}{\alpha_{\mathrm{b}}}+\frac{1}{\Gamma_{\mathrm{sol}}+\Gamma_{\mathrm{b}}}=\frac{1}{\alpha_{\mathrm{s}}}+\frac{\alpha_{\mathrm{s}} \bar{c}}{4 k_{\mathrm{des}} N_{\max }}[\mathrm{X}]_{\mathrm{g}}+\frac{1}{\Gamma_{\mathrm{sol}}+\Gamma_{\mathrm{b}}}$

$\Gamma_{\mathrm{sol}}=\frac{4 R T H^{*}}{c}\left(\frac{D_{1}}{t}\right)^{1 / 2}$

$\Gamma_{\mathrm{b}}=\frac{4 H^{*} R T\left(D_{1} k^{\mathrm{I}}\right)^{1 / 2}}{c}$

In laboratory experiments the effect of aqueous chemistry on $H^{*}$ was found to lead to a strong dependence of the uptake coefficient on $\mathrm{pH}$. In addition, acidity due to the $\mathrm{H}^{+}$from hydrolysis of $\mathrm{SO}_{2}$ taken up into the layer near the surface, leading to lower effective surface $\mathrm{pH}$, needs to be accounted for in the uptake kinetics. Assuming that gas-phase $\mathrm{SO}_{2}$ is in equilibrium with $\mathrm{SO}_{2}(\mathrm{aq})$ at the liquid surface and neglecting the second dissociation involving $K_{2}$, the actual $\left[\mathrm{H}^{+}\right]$at the surface is given by:

$\left[\mathrm{H}^{+}\right]=H^{\prime} \pm\left(H^{\prime 2}+K_{\mathrm{w}}+K_{1}\left[\mathrm{SO}_{2}\right]\right)^{1 / 2}$

where

$H^{\prime}=\frac{1}{2}\left(\left[\mathrm{H}^{+}\right]_{0}-\frac{K_{\mathrm{W}}}{\left[\mathrm{H}^{+}\right]_{0}}\right)$

Literature values for the Henry's constant, $H$, for $\mathrm{SO}_{2}$, and for the dissociation constants $K_{\mathrm{W}}\left(=10^{14} \mathrm{M}^{2}\right)$ for water, and $K_{1}$ and $K_{2}$, for bisulphite and sulphite ions respectively, are taken from Goldberg and Parker (1985):

\begin{tabular}{|c|c|c|}
\hline$H / \mathrm{M} \mathrm{atm}^{-1}$ & $3.42 \times 10^{-5} \exp (3133 / T)$ & $273-300$ \\
\hline$K_{1} / \mathrm{M}$ & $1.4 \times 10^{-2}$ & 298 \\
\hline$K_{2} / \mathrm{M}$ & $6.5 \times 10^{-8}$ & 298 \\
\hline$D_{1}\left(\mathrm{SO}_{2}\right) / \mathrm{cm}^{2} \mathrm{~s}^{-1}$ & $8 \times 10^{-6}$ & 283 \\
\hline
\end{tabular}

These are used to compute the effective solubility $H^{*}$ for a specified $\mathrm{pH}$, taking into account the effect of dissolved $\mathrm{SO}_{2}$ (as described in Worsnop et al., 1989, and Ponche et al., 1993).

We have adopted a value of $\alpha_{\mathrm{s}}=1$, with a large uncertainty. Reducing $\alpha_{\mathrm{s}}$ by a factor of 10 leads to adjustments of $k_{\mathrm{sb}}$ and $k_{\text {des }}$ of similar magnitude. These parameters lead to a value of $\alpha_{\mathrm{b}}$ of 0.11 at low $\mathrm{SO}_{2}$ pressure, consistent also with the other experiments. $k^{\mathrm{I}}$ is the pseudo first order rate constant for reaction of $\mathrm{SO}_{2}$ with $\mathrm{H}_{2} \mathrm{O}$. Taking into account the surface complex, the pressure dependent uptake kinetics over a range of $\mathrm{pH}$ can be described well with the above expression for $\gamma$ and with the value of $k^{\mathrm{I}}$ in bulk aqueous solution measured by Eigen et al. $(1961)\left(=3.4 \times 10^{6} \mathrm{~s}^{-1} ;\left(D_{1} / k^{\mathrm{I}}\right)^{0.5}=15 \mathrm{~nm}\right)$.

In alkaline droplets (e.g. $\mathrm{pH}=11$ ) surface saturation of $\mathrm{SO}_{2}$ is negligible and $\gamma$ is time independent. At lower $\mathrm{pH} \gamma$ decreases with time due to saturation of the surface layer. These effects demand careful attention to the design of experiments and the model used to interpret the results. Notwithstanding this, the results cited in the table from different experimental systems, are in reasonably good agreement, especially when the uncertainties and assumptions made are taken into account. Thus after correction for gas phase diffusion and exposure time, the values reported for the initial uptake coefficent at $\mathrm{pH}>6$, lie in the range 0.06 to 0.13 . 


\section{References}

Donaldson, D. J., Guest, J. A., and Goh, M. C.: J. Phys. Chem.-US, 99, 9313-9315, 1995.

Eigen, M., Kustin, K., and Maass, G.: Z. Phys. Chem. N. F., 30, 130-136, 1961.

Gardner, J. A., Watson, L. R., Adewuyi, Y. G., Davidovits, P., Zahniser, M. S., Worsonop, D., and Kolb, C. E.: J. Geophys. Res., 92, 10887-10895, 1987.

Gardner, J. A., Watson, L. R., Adewuyi, Y. G., Van Doren, J. M., Davidovits, P., Worsnop, D. R., Zahniser, M. S., and Kolb, C. E.: Biogenic Sulfur in the Environment, Am. Chem. Soc. Symp. Ser., vol. 393, edited by: Saltzman, E. S. and Cooper, W. J., 504, ACS Washington D.C., 1989.

Jayne, J. T., Davidovits, P., Worsnop, D. R., Zahniser, M. S., and Kolb, C. E.: J. Phys. Chem., 94, 6041-6048, 1990.

Jayne, J. T., Gardner, J. A., Davidovits, P., Worsnop, D. R., Zahniser, M. S., and Kolb, C. E.: J. Geophys. Res., 95, 2055920563, $1990 \mathrm{~b}$.

Li, L., Chen, M. Z., Zhang, Y. H., Zhu, T., Li, J. L., and Ding, J.: Atmos. Chem. Phys. 6, 2453-2464, doi:10.5194/acp-6-24532006, 2006.

Ponche, J. L., George, C., and Mirabel, P.: J. Atm. Chem., 16, 1-21, 1993.

Shimono, A. and Koda, S.: J. Phys. Chem., 100, 10269-10276, doi:10.1021/jp9537670, 1996.

Welter, F., Schweighoefer, S., and Schurath, U.: The Proceedings of Eurotrac Symposium 90', edited by: Borrell, P. et al., 335, SPB Academic Publishing, 1991.

Worsnop, D. R., Zahniser, M. S., Kolb, C. E., Gardner, J. A., Watson, L. R., Van Doren, J. M., Jayne, J. T., and Davidovits, P.: J. Phys. Chem., 93, 1159-1172, 1989. 


\section{VI.A1.11}

$\mathrm{HCl}(\mathrm{g})+\mathrm{H}_{2} \mathrm{O}(\mathrm{l}) \rightarrow \mathrm{HCl}(\mathrm{aq})+\mathrm{H}_{2} \mathrm{O}(\mathrm{l})$

\section{Experimental data}

\begin{tabular}{llll}
\hline Parameter & $T / \mathrm{K}$ & Reference & Technique/Comments \\
\hline Accommodation coefficients: $\alpha_{\mathrm{b}}$ & & & \\
$\left(1.77_{-1.7}^{+2.4}\right) \times 10^{-1}$ & 274 & Van Doren et al. (1990) & DT-LAS (a) \\
$\left(6.4_{-0.8}^{+1.2}\right) \times 10^{-2}$ & 294 & & \\
$0.01-0.02$ & 296.7 & Kirchner et al. (1990) & LJ-HPLC (b) \\
$0.24 \pm 0.02$ & 263 & Schweitzer et al. (2000) & DT-MS (c) \\
$0.13 \pm 0.01$ & 281 & & \\
$0.24 \pm 0.02$ & 273 & Li et al. (2002) & DT-MS (d) \\
$0.10 \pm 0.01$ & 293 & & \\
\hline
\end{tabular}

\section{Comments}

(a) Droplets (200 $\mu \mathrm{m}$ diameter) crossing a laminar flow tube in transverse geometry. Trace gas analysis is by IR diode laser absorption at total pressures of 6.7-26.6 mbar. $[\mathrm{HCl}]$ was typically $=7.3 \times 10^{12}$ molecule $\mathrm{cm}^{-3}$. Values listed are corrected for gas phase diffusion and distortion of velocity vector due to rapid uptake.

(b) The interaction of $\mathrm{HCl}$ (about $223 \mathrm{ppm}$ ) in synthetic air with a liquid jet of pure water. The uptake kinetics was studied by analyzing the liquid water content for $\mathrm{Cl}^{-}$using ion chromatography. The jet diameter was $90 \mu \mathrm{m}$, the jet length between 0.2 and $6 \mathrm{~mm}$ leading to contact times of 0.03 to $1.0 \mathrm{~ms}$. The uptake coefficient was interpreted as a bulk accommodation coefficient. The results are regarded as lower limits due to uncertainties in the velocity distribution of the liquid jet. The bulk accommodation coefficient showed a weak dependence on the mean speed of the jet $\left(10-750 \mathrm{~cm} \mathrm{~s}^{-1}\right)$ and was independent of the relative humidity ( 0 to $48 \%$ ) of the gas phase.

(c) Droplets of $80-150 \mu \mathrm{m}$ diameter with a gas-liquid interaction time of $0-20 \mathrm{~ms}$. The $\mathrm{HCl}$ concentrations were in the range $10^{12}-10^{14}$ molecule $\mathrm{cm}^{-3}$, with most experiments performed at $10^{13}$ molecule $\mathrm{cm}^{-3}$. Rate of uptake was time-independent as well as independent of $\mathrm{pH}$ in the range 7-14. Diffusion-corrected uptake coefficient is interpreted as a bulk accommodation coefficient $\alpha_{\mathrm{b}}$ having a significant negative temperature dependence.

(d) Droplet train experiment with ethylene glycol/water mixtures. Droplet size was in the range 70 to $300 \mu \mathrm{m}, 2.7-25.3 \mathrm{mbar}$ of (mostly) He in flow tube with trace gas species concentrations in the range $2 \times 10^{13}$ to $3 \times 10^{14}$ molecule $\mathrm{cm}^{-3}$. The value of $\alpha_{\mathrm{b}}$ was independent of the interaction time in the range 2.5 to $17 \mathrm{~ms}$ and had a significant negative temperature dependence. $\alpha_{\mathrm{b}}$ varies continuously with increasing mole fraction of $\mathrm{H}_{2} \mathrm{O}$ from a high (pure glycol) to a low (pure $\mathrm{H}_{2} \mathrm{O}$ ) value which has been successfully modelled using surface tension data for $\mathrm{glycol} / \mathrm{H}_{2} \mathrm{O}$ solutions of variable composition.

\section{Preferred values}

\begin{tabular}{lll}
\hline Parameter & Value & $T / \mathrm{K}$ \\
\hline$\alpha_{\mathrm{b}}$ & $7.4 \times 10^{-2}$ & 298 \\
$\alpha_{\mathrm{b}}$ & $4.4 \times 10^{-6} \exp (2898 / T)$ & $272-294$ \\
Reliability & & \\
$\Delta \log (\alpha)$ & \pm 0.2 & 298 \\
$\Delta(E / R)$ & $\pm 500 \mathrm{~K}$ & $272-294$ \\
\hline
\end{tabular}

\section{Comments on preferred values}

Van Doren et al. (1990) interpret their diffusion corrected uptake coefficients as mass accommodation coefficients. The effective Henry's law constant for aqueous dissolution of $\mathrm{HCl}$ is large enough to make the characteristic phase relaxation time significantly longer than the time scale for the droplet train uptake experiment, typically one to a few ms such that there is no surface saturation of the gas-water interface. A surprising result is that both the absolute values of $\alpha_{\mathrm{b}}$ as well as its strong negative temperature dependence were found for $\mathrm{HCl}, \mathrm{HNO}_{3}, \mathrm{~N}_{2} \mathrm{O}_{5}, \mathrm{H}_{2} \mathrm{O}_{2}$ and others that were investigated using the same 
experimental technique. This strongly points towards physical solvation as the rate-determining process whose absolute rate is not accessible as the bulk accommodation coefficient only describes the overall (complex) process and is therefore not an elementary reaction parameter.

The preferred values are taken from Van Doren et al. (1990), Schweitzer et al. (2000) and Li et al. (2002), despite the rather large uncertainty in the Van Doren et al. (1990) study. This fact is due in part to the use of the droplet train apparatus in transverse geometry which affords a restricted range of gas-liquid contact times and therefore a low dynamic range of the measurements. All three studies were performed using the same experimental technique, and the individual $\alpha_{\mathrm{b}}$ values are within the experimental uncertainties of the cited studies. The activation energy of $\alpha_{\mathrm{b}}$ is $E=-24.1 \mathrm{~kJ} \mathrm{~mol}^{-1}$.

The liquid jet technique used by Kirchner et al. (1990) that combines the measurement of the $\mathrm{HCl}$ uptake kinetics with the numerical simulation of the convective diffusion towards the thin $\mathrm{H}_{2} \mathrm{O}$ jet resulted in a best fit value $0.02 \geq \alpha_{\mathrm{b}} \geq 0.01$ of the bulk accommodation coefficient which is in agreement with the recommendation when regarded as a lower limiting value. The sensitivity of the experimental technique used on $\alpha_{\mathrm{b}}$ is low in the range $1 \geq \alpha_{\mathrm{b}} \geq 0.05$ and seems most suited for the measurement of values $\alpha_{\mathrm{b}} \leq 0.01$. Moreover, the careful study of the pressure dependence of $\gamma$ in the Li et al. (2002) study enabled an easy separation of $\alpha_{\mathrm{b}}$ from the measured uptake coefficients $\gamma_{\mathrm{obs}}$.

\section{References}

Kirchner, W., Welter, F., Bongartz, A., Kames, J., Schweighofer, S., and Schurath, U.: J. Atmos. Chem., 10, 427-449, 1990. Li, Y. Q., Zhang, H. Z., Davidovits, P., Jayne, J. T., Kolb, C. E., and Worsnop, D. R.: J. Phys. Chem. A, 106, 1220-1227, 2002. Schweitzer, F., Mirabel, P., and George, C.: J. Phys. Chem. A, 104, 72-76, 2000.

Van Doren, J. M., Watson, L. R., Davidovits, P., Worsnop, D. R., Zahniser, M., and Kolb, C. E.: J. Phys. Chem., 94, 3265-3269, 1990. 
VI.A1.12

$\mathrm{HBr}(\mathrm{g})+\mathrm{H}_{2} \mathrm{O}(\mathrm{l}) \rightarrow \mathrm{HBr}(\mathrm{aq})+\mathrm{H}_{2} \mathrm{O}(\mathrm{l})$

Experimental data

\begin{tabular}{lcll}
\hline Parameter & $T / \mathrm{K}$ & Reference & Technique/Comments \\
\hline Accommodation coefficients: $\alpha_{\mathrm{b}}$ & & & \\
0.16 & 263 & Schweitzer et al. (2000) & DT-MS (a) \\
$6.8 \times 10^{-2}$ & 281 & & \\
$0.26 \pm 0.02$ & 273 & Li et al. (2002) & DT-MS (b) \\
$0.14 \pm 0.02$ & 283 & & \\
\hline
\end{tabular}

\section{Comments}

(a) $80-150 \mu \mathrm{m}$ diameter droplets with a gas-liquid interaction time of $0-20 \mathrm{~ms}$. The $\mathrm{HBr}$ concentrations were in the range $10^{12}-10^{14}$ molecule $\mathrm{cm}^{-3}$, with most experiments performed at $10^{13}$ molecule $\mathrm{cm}^{-3}$. Rate of uptake was time-independent as well as independent on $\mathrm{pH}$ in the range 7-14. Diffusion-corrected uptake coefficient is interpreted as a bulk accommodation coefficient $\alpha_{\mathrm{b}}$ having a significant negative temperature dependence.

(b) Droplet train experiment with ethylene glycol/water mixtures. Droplet size was in the range 70 to $300 \mu \mathrm{m}, 2.6-25 \mathrm{mbar}$ of (mostly) He in flow tube with trace gas species concentrations in the range $2 \times 10^{13}$ to $3 \times 10^{14}$ molecule $\mathrm{cm}^{-3}$. The value of $\alpha_{\mathrm{b}}$ was found to be independent of the interaction time in the range 2.5 to $17 \mathrm{~ms}$, and temperature. $\alpha_{\mathrm{b}}$ varied continuously with increasing mole fraction of $\mathrm{H}_{2} \mathrm{O}$ from a high (pure glycol) to a low (pure $\mathrm{H}_{2} \mathrm{O}$ ) value which has been successfully modelled using surface tension data for glycol/ $\mathrm{H}_{2} \mathrm{O}$ solutions of variable composition.

\section{Preferred values}

\begin{tabular}{lll}
\hline Parameter & Value & $T / \mathrm{K}$ \\
\hline$\alpha_{\mathrm{b}}$ & $2.3 \times 10^{-2}$ & 298 \\
$\alpha_{\mathrm{b}}$ & $1.3 \times 10^{-8} \exp (4290 / T)$ & $263-281$ \\
Reliability & & \\
$\Delta \log \left(\alpha_{\mathrm{b}}\right)$ & \pm 0.3 & 298 \\
$\Delta(E / R)$ & $\pm 600 \mathrm{~K}$ & $263-281$ \\
\hline
\end{tabular}

\section{Comments on preferred values}

Although both Schweitzer et al. (2000) and Li et al. (2002) present bulk accommodation coefficients with a strong negative temperature dependence, there is disagreement of a factor of between 3 and 5 in the absolute values of $\alpha_{\mathrm{b}}$. We have taken the data of Schweitzer et al. (2000) as the basis of our recommended values owing in part to the larger number of data taken within a larger temperature range.

\section{References}

Li, Y. Q., Zhang, H. Z., Davidovits, P., Jayne, J. T., Kolb, C. E., and Worsnop, D. R.: J. Phys. Chem. A, 106, 1220-1227, 2002. Schweitzer, F., Mirabel, P., and George, C.: J. Phys. Chem. A, 104, 72-76, 2000. 
VI.A1.13

$\mathrm{HI}(\mathrm{g})+\mathrm{H}_{2} \mathrm{O}(\mathrm{l}) \rightarrow \mathrm{HI}(\mathbf{a q})+\mathrm{H}_{2} \mathrm{O}(\mathrm{l})$

Experimental data

\begin{tabular}{lcll}
\hline Parameter & $T / \mathrm{K}$ & Reference & Technique/Comments \\
\hline Accommodation coefficients: $\alpha_{\mathrm{b}}$ & & & \\
$8 \times 10^{-2}$ & 278 & Schweitzer et al. (2000) & DT-MS (a) \\
0.19 & 262 & & \\
\hline
\end{tabular}

\section{Comments}

(a) Uptake experiment on fast droplet train of 80-150 $\mu$ m diameter with a gas-liquid interaction time of 0-20 ms. The HI concentrations were in the range $10^{12}-10^{14}$ molecule $\mathrm{cm}^{-3}$, with most experiments performed at $10^{13}$ molecule $\mathrm{cm}^{-3}$. The rate of uptake was time-independent thus non-saturating as well as independent of $\mathrm{pH}$ in the range 7-14. The diffusioncorrected uptake coefficient is interpreted as a bulk accommodation coefficient $\alpha_{\mathrm{b}}$ with a significant negative temperature dependence.

\section{Preferred values}

\begin{tabular}{lll}
\hline Parameter & Value & $T / \mathrm{K}$ \\
\hline$\alpha_{\mathrm{b}}$ & $2.4 \times 10^{-2}$ & 298 \\
$\alpha_{\mathrm{b}}$ & $6.35 \times 10^{-9} \exp (4519 / T)$ & $262-278$ \\
Reliability & & \\
$\Delta \log \left(\alpha_{\mathrm{b}}\right)$ & \pm 0.3 & 298 \\
$\Delta(E / R)$ & $\pm 300 \mathrm{~K}$ & $262-278$ \\
\hline
\end{tabular}

\section{Comments on preferred values}

The uptake data were interpreted as bulk accommodation coefficients. Saturation effects of $\mathrm{HI}$ on the surface of the $\mathrm{H}_{2} \mathrm{O}$ drop were absent because the uptake kinetics on neutral water and $1 \mathrm{M} \mathrm{NaOH}$ aqueous solution were identical. The resulting activation energy is $E=-37.6 \mathrm{~kJ} \mathrm{~mol}^{-1}$, the Arrhenius plot had a correlation coefficient of 0.9697 .

\section{References}

Schweitzer, F., Mirabel, P., and George, C.: J. Phys. Chem. A, 104, 72-76, 2000. 
VI.A1.14

$\mathrm{CINO}(\mathrm{g})+\mathrm{H}_{2} \mathrm{O}(\mathrm{l}) \rightarrow \mathrm{HCl}(\mathrm{aq})+\mathrm{HNO}_{2}(\mathrm{aq})$

Experimental data

\begin{tabular}{lllll}
\hline Parameter & {$[\mathrm{X}] / \mathrm{M}$} & $T / \mathrm{K}$ & Reference & Technique/Comments \\
\hline$\gamma$ & & & & \\
$5.8 \times 10^{-3}$ & $\mathrm{H}_{2} \mathrm{O}$ film & $273-293$ & Scheer et al. (1997) & WWFT/DT-FTIR/IC (a) \\
$1.2 \times 10^{-2}$ & $\mathrm{H}_{2} \mathrm{O}$ droplets & & & \\
$1.2 \times 10^{-2}$ & $1 \mathrm{M} \mathrm{NaOH}(\mathrm{aq})$ & & & \\
\hline
\end{tabular}

\section{Comments}

(a) The uptake kinetics has been measured using the two complementary techniques of the wetted-wall flow-tube at atmospheric and reduced (89-90 mbar) pressure and the droplet train technique, with combined FTIR and HPLC detection. A slight negative temperature dependence of $\gamma$ in the range indicated was observed. The rate of uptake of CINO on aqueous $\mathrm{NaCl}$ (up to $1 \mathrm{M}$ ) and $\mathrm{HCl}$ (up to $1 \mathrm{M}$ ) was the same as on pure water. The hydrolysis products were $\mathrm{HNO}_{2}$ and $\mathrm{HCl}$, detected as $\mathrm{NO}_{2}^{-}$and $\mathrm{Cl}^{-}$in solution.

\section{Preferred values}

\begin{tabular}{lll}
\hline Parameter & Value & $T / \mathrm{K}$ \\
\hline$\gamma$ & 0.01 & $273-293$ \\
Reliability & & \\
$\Delta \log (\gamma)$ & \pm 0.5 & 298 \\
\hline
\end{tabular}

\section{Comments on preferred values}

The recommendation accepts the value of Scheer et al. (1997). The results show that ClNO is reactive towards liquid water surfaces. The products are $\mathrm{HCl}$ and $\mathrm{HNO}_{2} ; \mathrm{HNO}_{2}$ was released to the gas phase, but the efficiency of transfer to the gas-phase depended on the droplet acidity.

\section{References}

Scheer, V., Frenzel, A., Behnke, W., Zetzsch, C., Magi, L., George, C., and Mirabel, P.: J. Phys. Chem. A, 101, 9359, 1997. 


\section{VI.A1.15}

$\mathrm{ClNO}_{2}(\mathrm{~g})+\mathrm{H}_{2} \mathrm{O}(\mathrm{l}) \rightarrow$ products

\section{Experimental data}

\begin{tabular}{lllll}
\hline Parameter & {$[\mathrm{X}] / \mathrm{M}$} & $T / \mathrm{K}$ & Reference & Technique/Comments \\
\hline$\gamma, \gamma_{\mathrm{ss}}, \gamma_{0}$ & & & & \\
$\gamma<10^{-5}$ & $\mathrm{H}_{2} \mathrm{O}$ droplets & 280 & George et al. (1995) & DT-FTIR/IC (a) \\
$\gamma_{\mathrm{ss}}=4.8 \times 10^{-6}$ & $\mathrm{H}_{2} \mathrm{O}$ film & 291 & Behnke et al. (1997) & WWFT-FTIR (b) \\
$\gamma_{0}=3.4 \times 10^{-6}$ & $\mathrm{H}_{2} \mathrm{O}$ film & 278 & Frenzel et al. (1998) & WWFT-FTIR (c) \\
$\gamma_{0}=9.0 \times 10^{-6}$ & & 282 & & \\
$\gamma_{0}=4.5 \times 10^{-6}$ & & 287 & & \\
$\gamma_{0}=(4.8 \pm 0.1) \times 10^{-6}$ & & 291 & & \\
$\gamma_{\mathrm{ss}}=(2.6 \pm 1.8) \times 10^{-6}$ & $\mathrm{H}_{2} \mathrm{O}$ film & 274 & Fickert et al. (1998) & WWFT-MS (d) \\
accommodation coefficient: $\alpha_{\mathrm{b}}$ & & & & \\
$(9 \pm 4) \times 10^{-3}$ & & & & \\
\hline
\end{tabular}

\section{Comments}

(a) Uptake study using the droplet train technique at typically 13 to $40 \mathrm{mbar}$ total pressure. The trace gas density is monitored at the entry of the flow tube by FTIR. The amounts of $\mathrm{Cl}^{-}$and $\mathrm{NO}_{3}^{-}$in the droplets measured by ion chromatography was below the detection limit, therefore only an upper limit of $\gamma$ is given. The continuous flow of $\mathrm{ClNO}_{2}$ diluted in synthetic air at concentrations of up to $2500 \mathrm{ppm}$ was generated by passing $\mathrm{N}_{2} \mathrm{O}_{5}$ through a $30 \mathrm{~cm}$ long wetted wall flow tube interacting with a $3 \mathrm{M} \mathrm{NaCl}$ aqueous solution.

(b) Variable length $(10-80 \mathrm{~cm})$ wetted-wall flow tube at 1 bar of synthetic air. The liquid film thickness was between 0.8 and $1.2 \mathrm{~mm}$ at a surface speed of $2-10 \mathrm{~cm} \mathrm{~s}^{-1}$. The gas flow rate was in the range $200-400 \mathrm{~mL} \mathrm{~min}^{-1}$ at $291 \mathrm{~K}$ resulting in an average linear flow velocity of $15-30 \mathrm{~cm} \mathrm{~s}^{-1}$. The initial $\left[\mathrm{ClNO}_{2}\right]$ was measured upstream, the unreacted $\mathrm{ClNO}_{2}$ was measured downstream of the WWFT using FTIR. Between pure $\mathrm{H}_{2} \mathrm{O}$ and $1 \mathrm{M} \mathrm{NaCl} \gamma$ decreases by more than a factor of ten.

(c) Experimental details as (b). The uptake coefficients were obtained by fitting the initial measured time/position-dependent concentration profiles using a complex reaction mechanism including gas and liquid phase diffusion. The formation of $\mathrm{ClNO}_{2}$ was also observed when $\mathrm{Cl}_{2}$ interacted with the $\mathrm{H}_{2} \mathrm{O}$ film.

(d) Uptake study in a wetted-wall tubular flow reactor on a falling film of pure water and aqueous alkali halide salt solutions. The $\mathrm{ClNO}_{2}$ reactant and products was monitored using a differentially-pumped MS with electron impact ionization The value of $\gamma_{\mathrm{ss}}$ remains unchanged upon addition of $1 \mathrm{M} \mathrm{NaCl}$ whereas it increased upon addition of $0.1 \mathrm{M} \mathrm{OH}^{-}$. Analysis of uptake rates measured under gas-phase diffusion controlled conditions $(0.5 \mathrm{M} \mathrm{KOH}$ film) gave the cited value for the accommodation coefficient on aqueous surfaces, $\alpha_{\mathrm{b}}=(9 \pm 4) \times 10^{-3}$.

\section{Preferred values}

\begin{tabular}{lll}
\hline Parameter & Value & $T / \mathrm{K}$ \\
\hline$\alpha_{\mathrm{b}}$ & $9 \times 10^{-3}$ & $273-298$ \\
$\gamma_{\mathrm{ss}}$ & $3 \times 10^{-6}$ & $273-298$ \\
Reliability & & \\
$\Delta \log \left(\alpha_{\mathrm{b}}\right)$ & \pm 0.5 & $273-298$ \\
$\Delta \log (\gamma)$ & \pm 0.5 & $273-298$ \\
\hline
\end{tabular}




\section{Comments on preferred values}

The results show consistently that $\mathrm{ClNO}_{2}$ is non reactive towards liquid water surfaces. The recommended accommodation coefficient is based on the measurement of Fickert et al. (1998). The reactive uptake is controlled by hydrolysis which is very slow in pure water. The products have not been definitely identified.

\section{References}

Behnke, W., George, C., Scheer, V., and Zetzsch, C.: J. Geophys. Res., 102, 3795-3804, 1997.

Fickert, S., Helleis, F., Adams, J., Moortgat, G. K., and Crowley, J. N.: J. Phys. Chem. A, 102, 10689-10696, 1998.

Frenzel, A., Scheer, V., Sikorski, R., George, C., Behnke, W., and Zetzsch, C.: J. Phys. Chem. A, 102, 1329-1337, 1998.

George, C., Behnke, W., Scheer, V., Zetzsch, C., Magi, L., Ponche, J. L., and Mirabel, P.: Geophys. Res. Lett., 22, 1505-1508, 1995. 
VI.A1.16

$\mathrm{ClONO}_{2}(\mathrm{~g})+\mathrm{H}_{2} \mathrm{O}(\mathrm{l}) \rightarrow \mathrm{HOCl}(\mathrm{g})+\mathrm{HONO}_{2}(\mathrm{aq})$

Experimental data

\begin{tabular}{lllll}
\hline Parameter & {$[\mathrm{X}] / \mathrm{M}$} & $T / \mathrm{K}$ & Reference & Technique/Comments \\
\hline$\gamma$ & & & & \\
$0.027 \pm 0.0025$ & pure water & $275-285$ & Deiber et al. (2004) & DFT-MS (a) \\
\hline
\end{tabular}

Comments

(a) Uptake rates measured onto $200 \mu \mathrm{m}$ pure water droplets following loss of reactant in conventional droplet train apparatus. Droplet temperature controlled by evaporative cooling with adjustment of $p\left(\mathrm{H}_{2} \mathrm{O}\right)$. Uptake coefficient determined with a simple correction for diffusion effects. No products were detected in the gas phase by the MS.

\section{Preferred values}

\begin{tabular}{lll}
\hline Parameter & Value & $T / \mathrm{K}$ \\
\hline$\alpha_{\mathrm{b}}$ & 0.11 & $273-290$ \\
$H\left(k^{\mathrm{I}}\right)^{1 / 2}\left(\mathrm{M} \mathrm{atm}^{-1} \mathrm{~s}^{-1 / 2}\right)$ & $1.2 \times 10^{5}$ & $273-290$ \\
Reliability & \pm 0.15 & $273-290$ \\
$\Delta \log \left(\alpha_{\mathrm{b}}\right)$ & \\
\hline
\end{tabular}

\section{Comments on preferred values}

The cited work is the only study of reactive uptake of $\mathrm{ClONO}_{2}$ on liquid water substrates, all of the other reported studies used solid substrates (ice) or sulphuric acid solutions. These studies showed that uptake led to $\mathrm{HOCl}$ and $\mathrm{HNO}_{3}$ formation by hydrolysis. No gas phase products were observed from uptake on water droplets due to the high solubility of the products. The measured uptake coefficient was independent of temperature over the small range investigated, but increased significantly when $\mathrm{Br}^{-}$was present in solution (see data sheet VI.A2.10 for $\mathrm{ClONO}_{2}+\mathrm{Cl}^{-} / \mathrm{Br}^{-}$). This was interpreted in terms of decreasing chemical lifetime of $\mathrm{ClONO}_{2}$ (aq) due to reaction with $\mathrm{Br}^{-}$. This allowed evaluation of the accommodation coefficient by extrapolation of the uptake coefficients corrected for gas phase diffusion effects, to high $\left[\mathrm{Br}^{-}\right]$using the resistance model:

$$
\frac{1}{\gamma}-\frac{1}{\gamma_{\text {diff }}}=\left\{\frac{1}{\alpha_{\mathrm{b}}}+\frac{c}{4 H R T\left(D_{1} k^{1}\right)^{0.5}}\right\}^{-1} \text { where } k^{\mathrm{I}}=k^{\mathrm{II}}\left[\mathrm{Br}^{-}\right]
$$

This gave $\alpha_{\mathrm{b}}=(0.108 \pm 0.011)$ at $274.5 \mathrm{~K}$. The recommended accommodation coefficient is based on this analysis. The value of $H \sqrt{ } k^{\mathrm{I}}$ can also be derived using the resistance model, assuming that the reduction in uptake coefficient into water compared to the accommodation limited rate, is due to slow rate of hydrolysis in solution. A value of $D_{1}=5.0 \times 10^{-6} \mathrm{~cm}^{-2} \mathrm{~s}^{-1}$ was used for this analysis. There are no reported values of $H$ or $D_{1}$.

\section{References}

Deiber, G., George, C., Le Calvé, S., Schweitzer, F., and Mirabel, P.: Atmos. Chem. Phys., 4, 1291-1299, doi:10.5194/acp-41291-2004, 2004. 
VI.A1.17

$\mathrm{OH}(\mathrm{g})+\mathrm{H}_{2} \mathrm{O}(\mathrm{l}) \rightarrow$ products

Experimental data

\begin{tabular}{llll}
\hline Parameter & $T / \mathrm{K}$ & Reference & Technique/Comments \\
\hline Uptake coefficients: $\gamma$ & & & \\
$\gamma_{\mathrm{ss}}>3.5 \times 10^{-3}$ & 275 & Hanson et al. (1992) & WWFT-LIF (a) \\
$(4.2 \pm 2.8) \times 10^{-3} \mathrm{pH} \mathrm{5.6}$ & 293 & Takami et al. (1998) & $(\mathrm{b})$ \\
$(8.2 \pm 2.6) \times 10^{-3} \mathrm{pH} \mathrm{1}$ & & & \\
$(1.2 \pm 0.3) \times 10^{-2} \mathrm{pH} \mathrm{11}$ & & & \\
Accommodation coefficients: $\alpha_{b}$ & & & \\
1 & $281-312$ & Takami et al. (1998) & (b) \\
\hline
\end{tabular}

\section{Comments}

(a) $\mathrm{OH}$ concentrations of $(0.5-3) \times 10^{11}$ molecule $\mathrm{cm}^{-3}$ were generated through the reaction $\mathrm{H}+\mathrm{NO}_{2}$ and was monitored using LIF. Deionized water was flowed down the vertical flow tube at $274.5 \mathrm{~K}$ and $12 \mathrm{mbar}$ total pressure. The value listed in the table was corrected for gas phase diffusion. The diffusion coefficient for $\mathrm{OH}$ in $\mathrm{H}_{2} \mathrm{O}$ has been taken to be the value of the self-diffusion coefficient for $\mathrm{H}_{2} \mathrm{O}$.

(b) A carrier gas flow impinging on a flowing water surface at about $100 \mathrm{mbar}$ total pressure. The uptake coefficient was derived from the $\mathrm{OH}$ gradient above the liquid measured using laser-induced fluorescence and after correction for gas phase diffusion. The uptake coefficient was found to decrease during the first $300 \mathrm{~ms}$. The observed $\mathrm{pH}$ dependence was in agreement with bulk reaction limited uptake due to reaction with $\mathrm{HSO}_{4}^{-}, \mathrm{OH}^{-}, \mathrm{O}^{-}$and self reaction, simulated with a kinetic model of diffusion and reaction in the bulk liquid. For the highest uptake coefficients, best agreement between model simulation and data was obtained for $\alpha_{\mathrm{b}}=1$. A slight negative temperature dependence of the uptake coefficient was observed.

\section{Preferred values}

\begin{tabular}{lll}
\hline Parameter & Value & $T / \mathrm{K}$ \\
\hline$\alpha_{\mathrm{b}}$ & $>0.1$ & $275-310$ \\
$H^{*}$ & $\exp (1010 / T)\left(1+1.2 \times 10^{-12} \times 10^{\mathrm{pH}}\right)$ & $275-310$ \\
Reliability & & \\
$\Delta \log \left(\alpha_{\mathrm{b}}\right)$ & undetermined & \\
$\Delta \log \left(H^{*}\right)$ & \pm 0.7 & $275-310$ \\
\hline
\end{tabular}

\section{Comments on preferred values}

The available studies of the interaction of $\mathrm{OH}$ with liquid water agree that the bulk accommodation coefficient is large. In both experiments, gas phase diffusion affected the observed kinetics. Hanson et al. (1992) likely observed uptake driven by the self reaction of $\mathrm{OH}$ in the bulk, if the Henry's law coefficient is on the order of $100 \mathrm{M} \mathrm{atm}^{-1}$. Takami et al. (1998) come to a similar conclusion and explain their $\mathrm{pH}$ dependent data by applying a kinetic model for the bulk liquid using the following reactions (Buxton et al., 1988):

$\begin{array}{ll}\mathrm{OH}+\mathrm{HSO}_{4}^{-} \rightarrow \mathrm{SO}_{4}^{-}+\mathrm{H}_{2} \mathrm{O} & k_{\mathrm{HSO}}-=1.7 \times 10^{6} \mathrm{M}^{-1} \mathrm{~s}^{-1} \\ \mathrm{OH}+\mathrm{OH} \rightarrow \mathrm{H}_{2} \mathrm{O}_{2} & k_{\mathrm{OH}}=5.0 \times 10^{9} \mathrm{M}^{-1} \mathrm{~s}^{-1} \\ \mathrm{OH}+\mathrm{OH}^{-} \rightarrow \mathrm{O}^{-}+\mathrm{H}_{2} \mathrm{O} & k_{\mathrm{OH}}-=1.2 \times 10^{10} \mathrm{M}^{-1} \mathrm{~s}^{-1} \\ \mathrm{H}_{2} \mathrm{O}+\mathrm{O}^{-} \rightarrow \mathrm{OH}+\mathrm{OH}^{-} & k_{\mathrm{O}}-=1.8 \times 10^{6} \mathrm{M}^{-1} \mathrm{~s}^{-1}\end{array}$

The expression for the effective Henry's law constant given above is adopted from Takami et al. (1998), with the temperature dependence as suggested by Hanson et al. (1992). The temperature dependence of the rate constant of the OH self reaction in water above tropospheric temperatures has been investigated in detail by Elliot et al. (1990) and Janik et al. (2007).

At low $\mathrm{pH}$ (due to the fast reaction with $\mathrm{HSO}_{4}^{-}$) and high $\mathrm{pH}$ (self reaction and increase of effective Henry's law constant), the uptake coefficients were high enough to provide a constraint on the value of $\alpha_{\mathrm{b}}$. Given the degrees of freedom to adjust the 
simulations, a lower limit of $\alpha_{\mathrm{b}}$ of 0.1 is preferred, which lies a factor of 10 above the largest observed uptake coefficient. The negative temperature dependence of the observed uptake coefficient was likely due to the interplay of temperature dependencies of the effective Henry's law constant and the diffusion coefficient, rather than $\alpha_{\mathrm{b}}$. High values for $\alpha_{\mathrm{b}}$ were predicted by molecular dynamics simulations (Roeselova et al., 2003).

\section{References}

Buxton, G. V., Greenstock, C. L., Helman, W. P., and Ross, A. B.: J. Phys. Chem. Ref. Data, 17, 513-886, 1988.

Elliot, A. J., McCracken, D. R., Buxton, G. V., and Wood, N. D.: J. Chem. Soc. Faraday Trans., 86, 1539-1547, 1990.

Hanson, D. R., Burkholder, J. B., Howard, C. J., and Ravishankara, A. R.: J. Phys. Chem., 96, 4979-4985, 1992.

Janik, I., Bartels, D. M., and Jonah, C. D.: J. Phys. Chem. A, 111, 1835-1843, 2007.

Takami, A., Kato, S., Shimono, A., and Koda, S.: Chem. Phys., 231, 215-227, 1998.

Roeselova, M., Jungwirth, P., Tobias, D. J., and Gerber, R. B.: J. Phys. Chem. B, 107, 12690-12699, 2003. 
VI.A1.18

$\mathrm{H}_{2} \mathrm{O}(\mathrm{g})+\mathrm{H}_{2} \mathrm{O}(\mathrm{l}) \rightarrow 2 \mathrm{H}_{2} \mathrm{O}(\mathrm{l})$

\section{Experimental data}

\begin{tabular}{llll}
\hline Parameter & $T / \mathrm{K}$ & Reference & Technique/Comments \\
\hline Accommodation coefficients: $\alpha_{\mathrm{b}}, \alpha_{\mathrm{t}}$ & & & \\
$\alpha_{\mathrm{b}}>0.5$ & $263-298$ & Eames et al. (1997) & (a) \\
$\alpha_{\mathrm{b}}>0.1$ (dynamic conditions) & $255-372$ & Marek and Straub (2001) & (b) \\
$\alpha_{\mathrm{b}}<0.1$ (stagnant conditions) & & & \\
$\alpha_{\mathrm{b}}=0.17 \pm 0.03\left(\mathrm{H}_{2}^{17} \mathrm{O}\right.$ on liquid) & 280 & Li et al. (2001) & DT (c) \\
$\alpha_{\mathrm{b}}=0.32 \pm 0.04$ & 258 & & \\
$\alpha_{\mathrm{t}}=1.0 \pm 0.1\left(\mathrm{D}_{2} \mathrm{O} \mathrm{H} / \mathrm{D}\right.$ exchange) & $265-280$ & & \\
$\alpha_{\mathrm{b}}=1.0($ Ag-seeded $\mu \mathrm{m}$-size droplets) & $250-290$ & Winkler et al. (2004) & (d) \\
$\alpha_{\mathrm{b}}=0.3$ & 295 & Cappa et al. (2005) & LJ-MS (e) \\
$\alpha_{\mathrm{b}}=0.62 \pm 0.09$ & 295 & Smith et al. (2006) & (f) \\
$\alpha_{\mathrm{b}}=0.18 \pm 0.08$ & 273 & Zientara et al. (2008) & (g) \\
$\alpha_{\mathrm{b}}=0.13 \pm 0.02$ & 293 & & \\
$\alpha_{\mathrm{t}}=1.0 \pm 0.1$ & $273-293$ & & (h) \\
$\alpha_{\mathrm{b}}=0.57 \pm 0.06\left(\mathrm{D}_{2} \mathrm{O}\right)$ & 295 & Drisdell et al. (2008) & \\
\hline
\end{tabular}

\section{Comments}

(a) Literature review in which most of the early experimental results on the evaporation coefficient $(\varepsilon)$ of $\mathrm{H}_{2} \mathrm{O}$ from liquid water surfaces were evaluated.

(b) Review of literature for liquid $\mathrm{H}_{2} \mathrm{O}$ up until 2001.

(c) Droplet diameters 70-130 $\mu \mathrm{m}$ or 150-300 $\mu \mathrm{m}$. Experiments conducted at various carrier gas pressures and for different carrier gases.

(d) Cloud expansion chamber study. Experimental water droplet growth curves monitored by Mie scattering of laser light.

(e) Measurement of the evaporation rate from a $2.5 \mu \mathrm{m}$ radius $\mathrm{H}_{2} \mathrm{O}$ microjet. The conditions were chosen so as to avoid recondensation of water vapour.

(f) The change in volume-averaged temperature of an evaporating train of microdroplets of 6-8 $\mu \mathrm{m}$ radius was measured using Raman emission excited at $514.5 \mathrm{~nm}$ to obtain evaporation rates. The numerical fit used a model explicitly taking into account the temperature gradient of the droplet.

(g) The temporal droplet radius evolution of a levitated water droplet of around $8 \mu \mathrm{m}$ diameter was observed in an electrostatic balance using angle-resolved Mie scattering at atmospheric pressure of $\mathrm{N}_{2}$ or air on evaporation.

(h) Same as (f), but for $\mathrm{D}_{2} \mathrm{O}$.

\section{Preferred values}

\begin{tabular}{lll}
\hline Parameter & Value & $T / \mathrm{K}$ \\
\hline$\alpha_{\mathrm{b}}$ & $3.6 \times 10^{-5} \exp (2370 / T)$ & $258-298$ \\
Reliability & & \\
$\Delta \log \left(\alpha_{\mathrm{b}}\right)$ & \pm 0.3 & $258-298$ \\
\hline
\end{tabular}

\section{Comments on preferred values}

The uptake of gas phase water to liquid water has seen a long history of experiment, theory and debate due to its significance in cloud droplet and aerosol particle growth. The most recent evaluation of experimental and theoretical results within the atmospheric science community on this subject has been compiled by Davidovits et al. (2006), Garrett et al. (2006) and updated 
by Kolb et al. (2010) and Davidovits et al. (2011). This debate has been initiated by the conflicting results between $\mathrm{H}_{2} \mathrm{O}$ uptake experiments to a train of droplets (Li et al., 2001) and one cloud droplet growth experiment (Winkler et al., 2004) and involved consideration of mass transfer aspects in the gas phase but also questions around energy dissipation in the condensed phase. We are not reiterating a detailed discussion here.

The preferred values refer to pure water and to experimental conditions that only marginally depart from equilibrium and where the growth rates due to condensation of water vapour are accordingly low. H/D isotope exchange experiments on a train of liquid water droplets essentially yield $\alpha_{\mathrm{S}}=1.0$, when we do not differentiate between surface accommodation and thermal accommodation. The differing kinetic behaviour of oxygen isotope exchange vs. H/D exchange reported by Li et al. (2001) provides convincing evidence for precursor mediated bulk accommodation as proposed by Davidovits (1991) that is consistent with the negative temperature dependence of $\alpha_{\mathrm{b}}$ observed in the droplet train experiments. Davidovits et al. (2004) in their comparison between Li et al. (2001) and Winkler et al. (2004) point out the agreement on the measured value of the thermal accommodation coefficient $\left(0.85 \leq \alpha_{\mathrm{t}} \leq 1.0\right)$ but state the disagreement of the results on $\alpha_{\mathrm{b}}$. A potential reason may lie in the vastly differing growth rates applied in the two experiments. We allow for sufficient uncertainty in the absolute value of $\alpha_{\mathrm{b}}$ to take into account possible systematic errors in the analysis of the experiments discussed in the above mentioned reviews. Similar negative temperature dependence of $\alpha_{\mathrm{b}}$ and values between 0.1 and 1 have also been found for other highly soluble trace gases to liquid substrates as well as for the uptake of $\mathrm{H}_{2} \mathrm{O}$ on ice (see datasheet V.A1.6, Crowley et al., 2010).

Since condensation and evaporation rates are equal at equilibrium, information about $\alpha_{\mathrm{b}}$ can also be retrieved from evaporation rate measurements. These were therefore also considered a source of relevant data. Eames et al. (1997) propose that the most probable value of the evaporation coefficient $\varepsilon$ (numerically equal to $\alpha_{\mathrm{b}}$ ) is unity across all experimental conditions. In contrast, Marek and Straub (2001) conclude in their review that the condensation and evaporation coefficients are different from each other, and a decline of both coefficients with increasing temperature and pressure is derived, in disagreement with theoretical predictions and the principle of microscopic reversibility. The data of Zientara et al. (2008) obtained on a stationary droplet are consistent with a negative $T$ dependence of $\alpha_{\mathrm{b}}$ and $\alpha_{\mathrm{t}}=1$. Other evaporation rate measurements were inconclusive about the temperature dependence (Smith et al., 2006; Drisdell et al., 2008). Although the emphasis of the work of Cappa et al. (2005) was placed on obtaining (H/D) isotope fractionation ratios, the cooling of the microjet along the axis was used to derive $E_{\mathrm{a}}=55 \mathrm{~kJ} \mathrm{~mol}^{-1}$ for the evaporation rate of $\mathrm{H}_{2} \mathrm{O}$ which is approximately $10 \mathrm{~kJ} \mathrm{~mol}^{-1}$ larger than $\Delta \mathrm{H}_{\mathrm{vap}}$. Supporting TST (transition state) calculations by Cappa et al. (2007) were also consistent with a negative $T$ dependence of the evaporation coefficient but with a different slope than in the experiments. They noted a temperature dependence of the pre-exponential factor, though. Therefore, most evaporation rate measurements are also in reasonable agreement with our recommended uptake parameters.

\section{References}

Cappa, C. D., Drisdell, W. S., Smith, J. D., Saykally, R.J., and Cohen, R. C.: J. Phys. Chem. B, 109, 24391-24400, 2005. Cappa, C. D., Smith, J. D., Drisdell, W. S., Saykally, R. J., and Cohen, R. C.: J. Phys. Chem. C, 111, 7011-7020, 2007. Davidovits, P., Jayne, J. T., Duan, S. X., Worsnop, D. R., Zahniser, M. S., and Kolb, C. E.: J. Phys. Chem., 95, 6337-6340, 1991.

Davidovits, P., Worsnop, D. R., Jayne, J. T., Kolb, C. E., Winkler, P., Vrtala, A., Wagner, P. E., Kulmala, M., Lehtinen, K. E. J., Vesala, T., and Mozurkewich, M.: Geophys. Res. Lett., 31, L22111, doi:10.1029/2004GL020835, 2004.

Davidovits, P., Kolb, C. E., Williams, L. R., Jayne, J. T., and Worsnop, D. R.: Chem. Rev., 106, 1323-1354, 2006.

Davidovits, P., Kolb, C. E., Williams, L. R., Jayne, J. T., and Worsnop, D. R.: Chem. Rev., 111, doi:10.1021/cr100360b, 2011. Drisdell, W. S., Cappa, C. D., Smith, J. D., Saykally, R. J., and Cohen, R. C.: Atmos. Chem. Phys., 8, 6699-6706, doi:10.5194/acp-8-6699-2008, 2008.

Eames, I. W., Marr, N. J., and Sabir, H.: Int. J. Heat Mass Transfer, 40, 2963-2973, 1997.

Garrett, B. C., Schenter, G. K., and Morita, A.: Chem. Rev., 106, 1355-1374, 2006.

Li, Y. Q., Davidovits, P., Shi, Q., Jayne, J. T., Kolb, C. E., and Worsnop, D. R.: J. Phys. Chem. A, 105, 10627-10634, 2001.

Kolb, C. E., Cox, R. A., Abbatt, J. P. D., Ammann, M., Davis, E. J., Donaldson, D. J., Garrett, B. C., George, C., Griffiths, P. T., Hanson, D. R., Kulmala, M., McFiggans, G., Pöschl, U., Riipinen, I., Rossi, M. J., Rudich, Y., Wagner, P. E., Winkler, P. M., Worsnop, D. R., and O'Dowd, C. D.: Atmos. Chem. Phys., 10, 10561-10605, doi:10.5194/acp-10-10561-2010, 2010.

Marek, R. and Straub, J.: Int. J. Heat Mass Transfer, 44, 39-53, 2001.

Smith, J. D., Cappa, C. D., Drisdell, W. S., Cohen, R. C., and Saykally, R. J.: J. Amer. Chem. Soc., 128, 12892-12898, 2006. Winkler, P. M., Vrtala, A., Wagner, P. E., Kulmala, M., Lehtinen, K. E. J., and Vesala, T.: Phys. Rev. Lett., 93, 075701, doi:10.1103/PhysRevLett.93.075701, 2004.

Zientara, M., Jakubczyk, D., Kolwas, K., and Kolwas, M.: J. Phys. Chem. A, 112, 5152-5158, 2008. 
VI.A1.19

$\mathrm{SO}_{2}(\mathrm{~g})+\mathrm{H}_{2} \mathrm{O}_{2}(\mathrm{aq}) \rightleftarrows \mathrm{H}_{2} \mathrm{SO}_{4}(\mathrm{aq})$

\section{Experimental data}

\begin{tabular}{lcll}
\hline Parameter & $T / \mathrm{K}$ & Reference & Technique/Comments \\
\hline Uptake coefficients: $\gamma, \gamma_{0}\left(\mathrm{SO}_{2}\right), \gamma\left(\mathrm{H}_{2} \mathrm{O}_{2}\right)$ & & & \\
$0.054 \pm 0.005($ droplet $\mathrm{pH}=11.5)$ & 295 & Gardner et al. (1987, 1989) & DT-TDL (a) \\
$\gamma_{0}=(0.11 \pm 0.2)($ droplet $\mathrm{pH}=11.5)$ & 273 & Worsnop et al. (1989) & DT-TDL (b) \\
$\gamma\left(\mathrm{H}_{2} \mathrm{O}_{2}\right)=(0.18 \pm 0.2)$ & 273 & & \\
$(8.0 \pm 2.0) \times 10^{3} \mathrm{pH}=0.25,1 \mathrm{M} \mathrm{H}_{2} \mathrm{O}_{2}$ droplets & 283 & Jayne et al. (1990b) & DT-TDL (c) \\
$0.020 \pm 0.006 \mathrm{pH}=2,1 \mathrm{M} \mathrm{H}_{2} \mathrm{O}_{2}$ droplets & & & \\
$0.035 \pm 0.004 \mathrm{pH}=4,1 \mathrm{M} \mathrm{H}_{2} \mathrm{O}_{2}$ droplets & & & \\
$0.06+0.14-0.03$ & 300 & Welter et al. (1990) & LJ-IC (d) \\
$0.11 \pm 0.01$ & 298 & Ponche et al. (1993) & DT-IC (e) \\
\hline
\end{tabular}

\section{Comments}

(a) The droplet size varied from 80 to $180 \mu \mathrm{m}$ and the residence time of the individual droplet ranged from 2.2 to $12.8 \mathrm{~ms}$. $\left[\mathrm{SO}_{2}\right]$ ranged between 1.5 and $15 \times 10^{12}$ molecule $\mathrm{cm}^{-3}$ and the total pressure was $27.9 \mathrm{mbar}\left(\mathrm{He}+\mathrm{H}_{2} \mathrm{O}\right)$.

(b) Experiment to determine the temperature-dependent mass accommodation coefficients of $\mathrm{SO}_{2}$ and $\mathrm{H}_{2} \mathrm{O}_{2}$ on aqueous surfaces. A fast moving train of $200 \mu \mathrm{m}$ diameter water droplets propagated in a flow tube either in axial or transverse direction with $\left[\mathrm{SO}_{2}\right]_{0}=10^{13}$ molecule $\mathrm{cm}^{-3}$. The interaction time ranged from 2 to $12 \mathrm{~ms}$ (axial) or from 0.5 to $2 \mathrm{~ms}$

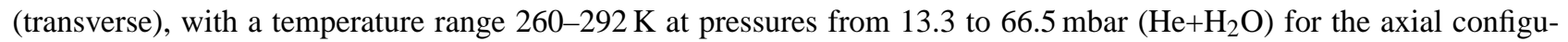
ration, and 3.1 to 13.3 mbar for the transverse geometry. Uptake coefficients were corrected for gas diffusion with gas diffusion coefficients measured for $\mathrm{SO}_{2}$ and $\mathrm{SO}_{2}$ in $\mathrm{H}_{2} \mathrm{O}$, Ar and $\mathrm{He}$ in the same study. For $\mathrm{SO}_{2}$ at low pH, $\gamma$ decreased with droplet exposure time due to saturation, and increased with $\mathrm{pH}$. No saturation effects were observed for $\mathrm{H}_{2} \mathrm{O}_{2}$ uptake on the timescale of the experiments. Variation of droplet temperature by changing the water vapour content of the experimental atmosphere was used to determine the effect of surface temperature on the uptake rate. Temperature dependence of the initial uptake coefficient for $\mathrm{SO}_{2}$ and $\mathrm{H}_{2} \mathrm{O}_{2}$ was given by the expression: $\gamma_{\mathrm{o}} /\left(\gamma_{\mathrm{o}}-1\right)=A \exp (-\Delta E / R T)$ with $A=4 \times 10^{-2}$ and $\Delta E=-2 \pm 5 \mathrm{~kJ} \mathrm{~mol}^{-1}$ for $\gamma_{\mathrm{o}}\left(\mathrm{SO}_{2}\right)$, and $A=3 \times 10^{-6}$ and $\Delta E=-26 \pm 7 \mathrm{~kJ} \mathrm{~mol}^{-1}$ for $\gamma_{\mathrm{o}}\left(\mathrm{H}_{2} \mathrm{O}_{2}\right)$ (see also data sheet VI.A1.1). The value of $\gamma_{\mathrm{o}}$ in both cases equates to the accommodation coefficient $\alpha_{\mathrm{b}}$.

(c) details as (b). Uptake of $\mathrm{SO}_{2}$ measured for a range of initial $\mathrm{pH}$ in the bulk droplets from 0 to 8 and with $\mathrm{H}_{2} \mathrm{O}_{2}$ content up to $1 \mathrm{M}$. The observed uptake coefficents over the $\mathrm{pH}$ and $\left[\mathrm{H}_{2} \mathrm{O}_{2}\right]$ range were consistent with the reaction rate of $\mathrm{H}_{2} \mathrm{O}_{2}$ with S(IV) measured in bulk solution.

(d) Liquid jet of water (100 $\mu$ m diameter); $\mathrm{H}_{2} \mathrm{O}_{2}$ was added in order to rapidly oxidize $\mathrm{SO}_{2}$ to sulfate. The uptake kinetics of typically $100 \mathrm{ppm} \mathrm{SO}_{2}$ in synthetic air was measured by analysis of the sulfate concentration in the collected jet waters using ion chromatography. $\gamma$ was retrieved by applying a gas diffusion model to correct the loss rate of $\mathrm{SO}_{2}$. The uptake was found to be dependent on $\left[\mathrm{SO}_{2}\right]$ due to a change in surface $\mathrm{pH}$. Addition of $\mathrm{NH}_{3}$ to the $\mathrm{SO}_{2}$ /air mixture minimized the $\mathrm{pH}$ dependence.

(e) Uptake monitored by chemical analysis of the collected aqueous phase by ion chromatography. The gas/liquid contact time varied between 3.7 and $45 \mathrm{~ms}$. Dilute aqueous $\mathrm{H}_{2} \mathrm{O}_{2}$ is added to the condensed phase in order to rapidly oxidize dissolved $\mathrm{SO}_{2}$ to $\mathrm{H}_{2} \mathrm{SO}_{4}$. The observed uptake coefficient is strongly dependent on the $\mathrm{pH}$ of the droplet in the range 4 to 11 and on the interaction time. 


\section{Preferred values}

\begin{tabular}{lll}
\hline Parameter & Value & $T / \mathrm{K}$ \\
\hline$\alpha_{\mathrm{b}}$ & 0.11 & $268-298$ \\
$k / \mathrm{M}^{-2} \mathrm{~s}^{-1}$ & $2.1 \times 10^{6} /\left(0.1+\left[\mathrm{H}^{+}\right]\right)$ & 283 \\
$k^{\mathrm{I}} / \mathrm{s}^{-1}$ & see Eq. (ii) & \\
$D_{\mathrm{l}}\left(\mathrm{SO}_{2} . \mathrm{aq}\right) / \mathrm{cm}^{2} \mathrm{~s}^{-1}$ & $8 \times 10^{-6}$ & 283 \\
Reliability & & \\
$\Delta\left(\log \alpha_{\mathrm{b}}\right)$ & \pm 0.1 & $268-298$ \\
$\Delta\left(\log k^{\mathrm{I}}\right)$ & \pm 0.3 & $268-298$ \\
\hline
\end{tabular}

\section{Comments on preferred values}

The oxidation of sulphur dioxide gas by hydrogen peroxide in aqueous droplets has been recognised as an important process for production of sulphates following studies of the reaction kinetics in the late 1970s (Hoffmann and Edwards, 1975; Penkett et al., 1979; Martin and Damschen, 1981). However direct measurements of $\mathrm{SO}_{2}$ gas uptake kinetics to determine $\gamma$ values were not achieved successfully until the improvements in experimental techniques for multiphase atmospheric processes in the late $1980 \mathrm{~s}$.

When $\mathrm{SO}_{2}$ enters aqueous solution droplets it reacts with water molecules and an equilibrium is set up between the forms of $\mathrm{S}(\mathrm{IV})$ : hydrated $\mathrm{SO}_{2}, \mathrm{HSO}_{3}^{-}$and $\mathrm{SO}_{3}^{2-}$ via the following equilibria:

$$
\begin{array}{ll}
\mathrm{SO}_{2}(\mathrm{~g})+\mathrm{H}_{2} \mathrm{O} \rightleftarrows \mathrm{SO}_{2} \cdot \mathrm{H}_{2} \mathrm{O} & H \\
\mathrm{SO}_{2} \cdot \mathrm{H}_{2} \mathrm{O} \rightleftarrows \mathrm{HSO}_{3}^{-}+\mathrm{H}^{+} & K_{1} \\
\mathrm{HSO}_{3}^{-} \rightleftarrows \mathrm{SO}_{3}^{2-}+\mathrm{H}^{+} & K_{2}
\end{array}
$$

where $\quad H=\frac{\left[\mathrm{SO}_{2} \cdot \mathrm{H}_{2} \mathrm{O}\right]}{p\left(\mathrm{SO}_{2}\right)}$

$K_{1}=\frac{\left[\mathrm{H}^{+}\right]\left[\mathrm{HSO}_{3}^{-}\right]}{\left[\mathrm{SO}_{2} \cdot \mathrm{H}_{2} \mathrm{O}\right]}$

and $\quad K_{2}=\frac{\left[\mathrm{H}^{+}\right]\left[\mathrm{SO}_{3}^{2-}\right]}{\left[\mathrm{HSO}_{3}^{-}\right]}$

which gives in turn:

$$
\begin{aligned}
{[\mathrm{S}(\mathrm{IV})]_{\text {total }} } & =p\left(\mathrm{SO}_{2}\right) \cdot H \cdot\left\{1+\frac{K_{1}}{\left[\mathrm{H}^{+}\right]}+\frac{K_{1} K_{2}}{\left[\mathrm{H}^{+}\right]^{2}}\right\} \\
& =p\left(\mathrm{SO}_{2}\right) \cdot H^{*}
\end{aligned}
$$

This leads to the equilibrium mole fractions and total dissolved S(IV) being a strong function of pH. Thus the effective Henry's solubility constant, $H^{*}$, decreases with $\mathrm{pH}$. Literature values for the Henry's constant, $H$, for $\mathrm{SO}_{2}$, and for the dissociation constants $K_{\mathrm{w}}\left(=10^{14} \mathrm{M}^{2}\right)$ for water, and $K_{1}$ and $K_{2}$, for bisulphite and sulphite ions respectively, are taken from Goldberg and Parker (1985):

$\begin{array}{lll}H / \mathrm{M} \mathrm{bar}^{-1} & 3.42 \times 10^{-5} \exp (3133 / T) & 273-300 \\ K_{1} / \mathrm{M} & 1.4 \times 10^{-2} & 298 \\ K_{2} / \mathrm{M} & 6.5 \times 10^{-8} & 298\end{array}$

These are used to compute the effective solubility $H^{*}$ for a specified pH, taking into account the effect of dissolved $\mathrm{SO}_{2}$ (as described in Worsnop et al., 1989, and Ponche et al., 1993).

Over the $\mathrm{pH}$ range typical of atmospheric droplets ( $\mathrm{pH} 2$ to 6), most dissolved $\mathrm{S}\left(\mathrm{IV}\right.$ ) is in the form of $\mathrm{HSO}_{3}^{-}$. In the presence of $\mathrm{H}_{2} \mathrm{O}_{2}$ the $\mathrm{HSO}_{3}^{-}$is oxidised to sulphuric acid by the following mechanism:

$$
\begin{array}{ll}
\mathrm{HSO}_{3}^{-}+\mathrm{H}_{2} \mathrm{O}_{2} \rightleftarrows \mathrm{HO}_{2} \mathrm{SOO}^{-}+\mathrm{H}_{2} \mathrm{O} & k_{1}, k_{-1} \\
\mathrm{HO}_{2} \mathrm{SOO}^{-}+\mathrm{H}^{+} \rightleftarrows \mathrm{H}_{2} \mathrm{SO}_{4} & k_{2}
\end{array}
$$

The rate law for this reaction in bulk solution has been given by Martin and Damschen (1981) as:

$-\frac{d[\mathrm{~S}(\mathrm{IV})]}{d t}=\frac{d[\mathrm{~S}(\mathrm{VI})]}{d t}=k\left[\mathrm{H}^{+}\right]\left[\mathrm{H}_{2} \mathrm{O}_{2}\right]\left[\mathrm{HSO}_{3}^{-}\right]$ 
where

$k\left(\mathrm{M}^{-2} \mathrm{~s}^{-1}\right)=\frac{2.1 \times 10^{6}}{0.1+\left[\mathrm{H}^{+}\right]} \quad$ at $283 \mathrm{~K}$

Taking account of the equilibria following entry of $\mathrm{SO}_{2}$ into solution the pseudo first order rate constant for aqueous reaction of $\mathrm{HSO}_{3}^{-}$with $\mathrm{H}_{2} \mathrm{O}_{2}, k^{\mathrm{I}}$, for a given $\mathrm{pH}$ is given by:

$k^{\mathrm{I}}\left(s^{-1}\right)=\frac{H}{H^{*}} k K_{1}\left[\mathrm{H}_{2} \mathrm{O}_{2}\right]$

and the reactive uptake coefficient for $\mathrm{SO}_{2}$ into aqueous droplets containing $\mathrm{H}_{2} \mathrm{O}_{2}$ is given by the expression:

$\Gamma_{\mathrm{b}}=\frac{4 H^{*} R T}{c}\left(D_{1} k^{\mathrm{I}}\right)^{1 / 2}$

The overall uptake of $\mathrm{SO}_{2}$ is a convolution of this reactive uptake, which is time independent, with the time-dependent $\mathrm{SO}_{2}$ uptake due to solubility without added $\mathrm{H}_{2} \mathrm{O}_{2}$, which is liquid diffusion controlled and also contains a term to represent the surface adsorption of $\mathrm{SO}_{2}$ molecules (see data sheet for $\mathrm{SO}_{2}+\mathrm{H}_{2} \mathrm{O}(\mathrm{aq})$ : VI.A1.10).

Jayne et al. demonstrated that at $\mathrm{pH}<3$ the measured uptake coefficient both in magnitude and $\mathrm{pH}$ dependence, at contact times of 2-10 ms, was in reasonable accord with the bulk $\mathrm{S}(\mathrm{IV})+\mathrm{H}_{2} \mathrm{O}_{2}$ reaction rate, given by the expressions above. Above $\mathrm{pH} 3$ the uptake of $\mathrm{SO}_{2}$ increases but in a complex manner due to interaction of rapidly varying diffusion controlled solubility and $\mathrm{S}(\mathrm{IV})+\mathrm{H}_{2} \mathrm{O}_{2}$ reaction kinetics. No evidence was found for a surface reaction and furthermore the solubility of $\mathrm{H}_{2} \mathrm{O}_{2}$ is high, and so equilibrium between gas phase and bulk phase is established rapidly. The maximum overall reactive uptake of $\mathrm{SO}_{2}$ is limited by the value of $\alpha_{\mathrm{b}}$ of 0.11 . The rate coefficient for oxidation, $k^{\mathrm{I}}$, reduces with increasing $\mathrm{pH}$ due to the rate determining reaction of the intermediate $\mathrm{HO}_{2} \mathrm{SOO}^{-}$ion with $\mathrm{H}^{+}$(as represented in Eq. i) but the overall reaction rate increases with $\mathrm{pH}$ since there is more $\mathrm{S}(\mathrm{IV}$ ) available for reaction (Eq. ii). Because the reactive uptake is liquid diffusion controlled the reaction rate enters as the square root in (Eq. iii).

The uptake coefficients can be calculated from:

$\gamma_{\mathrm{rxn}}=\left(\frac{1}{\alpha_{\mathrm{b}}}+\frac{1}{\Gamma_{\mathrm{b}}}\right)^{-1}$

The recommended value for $\alpha_{\mathrm{b}}$ is based on the measurements of Worsnop et al. (1989) and Ponche et al. (1993). Note that this value is only recommended for low $\mathrm{SO}_{2}$ pressures. For higher $\mathrm{SO}_{2}$ pressures, the parameterization explained on the data sheet VI.A1.10 for $\mathrm{SO}_{2}+\mathrm{H}_{2} \mathrm{O}$ (aq) should be used. The rate constant for bulk phase oxidation reaction of $\mathrm{S}(\mathrm{IV})$ by $\mathrm{H}_{2} \mathrm{O}_{2}$ (Eq. i) is taken from Martin and Damschen (1981). This parameterisation gives a good fit to the laboratory measurement of Jayne et al. (1990) at $\left[\mathrm{H}_{2} \mathrm{O}_{2}\right]=1 \mathrm{M}$ and Ponche et al. (1993) at $\left[\mathrm{H}_{2} \mathrm{O}_{2}\right]=0.16 \mathrm{M}$.

\section{References}

Gardner, J. A., Watson, L. R., Adewuyi, Y. G., Davidovits, P., Zahniser, M. S., Worsnop, D., and Kolb, C. E.: J. Geophys. Res., 92, 10887-10895, 1987.

Gardner, J. A., Watson, L. R., Adewuyi, Y. G., Van Doren, J. M., Davidovits, P., Worsnop, D. R., Zahniser, M. S., and Kolb, C. E.: Biogenic Sulfur in the Environment, Am. Chem. Soc. Symp. Ser., vol. 393, edited by: Saltzman, E. S. and Cooper, W. J., 504, ACS Washington D.C., 1989.

Goldberg, R. N. and Parker, V. B.: J. Res. Nat. Bur. Stand., 90, 341-358, 1985.

Hoffmann, M. R., and Edwards, J. O.: J. Phys. Chem., 79, 2096-2098, 10.1021/j100587a005, 1975.

Jayne, J. T., Davidovits, P., Worsnop, D. R., Zahniser, M. S., and Kolb, C. E.: J. Phys. Chem., 94, 6041-6048, 1990a.

Jayne, J. T., Gardner, J. A., Davidovits, P., Worsnop, D. R., Zahniser, M. S. and Kolb, C. E.: J. Geophys. Res., 95, 20559-20563, 1990b.

Martin, L. R. and Damschen, D. E.: Atmos. Environ., 15, 1615-1621, 1981.

Penkett, S. A., Jones, B. M. R., Brice, K. A., and Eggleton, A. E. J.: Atmos. Environ., 13, 123-137, 1979.

Ponche, J. L., George, C., and Mirabel, P.: J. Atm. Chem., 16, 1-21, 1993.

Welter, F., Schweighoefer, S., and Schurath, U.: The Proceedings of Eurotrac Symposium 90', edited by: Borrell, P. et al., 335, SPB Academic Publishing, 1991.

Worsnop, D. R., Zahniser, M. S., Kolb, C. E., Gardner, J. A., Watson, L. R., Van Doren, J. M., Jayne, J. T., and Davidovits, P.: J. Phys. Chem., 93, 1159-1172, 1989. 
VI.A1.20

$\mathrm{HO}_{2}(\mathrm{~g})+\mathrm{H}_{2} \mathrm{O}(\mathrm{l}) \rightarrow$ products

Experimental data

\begin{tabular}{llll}
\hline & $T / \mathrm{K}$ & Reference & Technique/Comments \\
\hline $\begin{array}{l}\text { Accomodation coefficients: } \alpha_{\mathrm{b}} \\
>0.01\end{array}$ & 275 & Hanson et al. (1992) & WWFT-LIF (a) \\
\hline
\end{tabular}

\section{Comments}

(a) Uptake of $\mathrm{HO}_{2}\left(5-30 \times 10^{10}\right.$ molecule $\left.\mathrm{cm}^{-3}\right)$ to a film $\left(0.2 \mathrm{~mm}\right.$ thick) of de-ionised water, or water containing $10^{-3} \mathrm{M}$ $\mathrm{CuSO}_{4} \cdot \mathrm{HO}_{2}$ was formed in the reaction of $\mathrm{F}$ with $\mathrm{H}_{2} \mathrm{O}_{2}$ and detected as $\mathrm{OH}$ after reaction with $\mathrm{NO} . \mathrm{HO}_{2}$ uptake was limited by diffusion through the 1.3 mbar of $\mathrm{He}$ bath gas. Levels of $\mathrm{HO}_{2}$ were sufficiently low to neglect loss due to gas-phase self reaction. Addition of $\mathrm{CuSO}_{4}$ had no effect on $\mathrm{HO}_{2}$ loss rates.

\section{Preferred values}

\begin{tabular}{lll}
\hline Parameter & Value & $T / \mathrm{K}$ \\
\hline$\alpha_{\mathrm{b}}$ & $>0.5$ & $270-300$ \\
Reliability & & \\
$\Delta\left(\log \alpha_{\mathrm{b}}\right)$ & undetermined & \\
\hline
\end{tabular}

\section{Comments on preferred values}

The sole experimental study of the uptake of $\mathrm{HO}_{2}$ to pure water returned a lower limit to the accommodation coefficient of $\alpha_{\mathrm{b}}>0.01$. This is consistent with molecular dynamics calculations of the $\mathrm{HO}_{2}$-water interaction (Morita et al., 2004) which suggest that the accomodation coefficient could be unity and also with more sensitive experiments on other aqueous surfaces such as $\left(\mathrm{NH}_{4}\right)_{2} \mathrm{SO}_{4}$ and $\mathrm{NH}_{4} \mathrm{HSO}_{4}$ (see datasheets VI.A3.09 and VI.A3.10). We thus prefer a value of $\alpha_{\mathrm{b}}$ of $>0.5$.

The uptake of $\mathrm{HO}_{2}$ in aqueous solution with $\mathrm{pH}>5$, is presently believed to be driven by self-reaction and acid-base dissociation of $\mathrm{HO}_{2}(\mathrm{pKa} \sim 4.7)$ with formation of $\mathrm{H}_{2} \mathrm{O}_{2}$ (Reactions $\left.\mathrm{R} 2, \mathrm{R} 3\right)$. In the presence of transition metal ions (TMI) the reaction of $\mathrm{HO}_{2}$ and especially $\mathrm{O}_{2}^{-}$(Reaction $\mathrm{R} 4$ ) can be important:

$\mathrm{HO}_{2}(\mathrm{~g}) \rightarrow \mathrm{O}_{2}^{-}(\mathrm{aq})+\mathrm{H}^{+}(\mathrm{aq})$

$\mathrm{HO}_{2}(\mathrm{aq})+\mathrm{HO}_{2}(\mathrm{aq}) \rightarrow \mathrm{H}_{2} \mathrm{O}_{2}(\mathrm{aq})+\mathrm{O}_{2}(\mathrm{aq})$

$\mathrm{O}_{2}^{-}(\mathrm{aq})+\mathrm{HO}_{2}(\mathrm{aq})\left(+\mathrm{H}_{2} \mathrm{O}(\mathrm{l})\right) \rightarrow \mathrm{H}_{2} \mathrm{O}_{2}(\mathrm{aq})+\mathrm{O}_{2}(\mathrm{aq})+\mathrm{OH}^{-}(\mathrm{aq})$

$\mathrm{O}_{2}^{-}(\mathrm{aq})+\mathrm{TMI}(\mathrm{aq}) \rightarrow$ products

If a first-order loss process for $\mathrm{HO}_{2}$ or $\mathrm{O}_{2}^{-}$in the aqueous phase dominates (e.g. reaction with $\mathrm{TMI}$ such as $\mathrm{Cu}(\mathrm{II})$ ), and assuming equal rates of reaction throughout the particle, the uptake coefficient can be calculated from the expression below:

$\frac{1}{\gamma}=\frac{1}{\alpha_{\mathrm{b}}}+\frac{\bar{c}}{4 H^{\mathrm{eff}} R T \sqrt{k_{\mathrm{TMI}}[\mathrm{TMI}] D_{1}}}$

$\mathrm{H}^{\mathrm{eff}}=\mathrm{H}^{\mathrm{HO} 2}\left(1+\mathrm{K}_{\mathrm{eq}} /\left[\mathrm{H}^{+}\right], \mathrm{K}_{\mathrm{eq}}=2.1 \times 10^{-5} \mathrm{M}\right.$ at $298 \mathrm{~K}(\mathrm{Jacob}, 2000), \mathrm{H}^{\mathrm{HO} 2}=9.5 \times 10^{-6} \exp (5910 / T)($ Hanson et al., 1992) and $D_{1}=\left[1 \times 10^{-5}(T / 298)\right] /\left(1.09 \times 10^{8} \exp (-0.068 T)+0.873\right) \mathrm{cm}^{2} \mathrm{~s}^{-1}$ (Schwartz, 1984; Thornton et al., 2008) where the denominator in the $D_{1}$ term was derived from a fit to the water viscosity data of Hallett (1963).

According to the reaction scheme above, in the absence of TMI, the rates of loss of aqueous-phase $\mathrm{HO}_{2}$ are quadratically dependent on $\left[\mathrm{HO}_{2}\right]_{\mathrm{aq}}$ and $\left[\mathrm{O}_{2}^{-}\right]_{\mathrm{aq}}$ and are thus strongly dependent on the gas-phase concentration of $\mathrm{HO}_{2}$. At low $\mathrm{HO}_{2}$ concentrations (e.g. as found in the atmosphere) the liquid phase reactions become rate limiting and $\gamma$ is expected to be much 
smaller as observed in dilute solutions by Mozurkewich et al. (1987) and the simple formalism above breaks down. Thornton and Abbatt (2005) suggest that the rate of loss of $\mathrm{HO}_{2}$ from the gas-phase (in molecule $\mathrm{cm}^{-3} \mathrm{~s}^{-1}$ ) is best described by a system in thermodynamic (Henry's law) equilibrium so that (Thornton et al., 2008):

$\frac{1}{\gamma}=\frac{1}{\alpha_{\mathrm{b}}}+\frac{3 \bar{c} N_{\mathrm{A}}}{8000\left(H^{\mathrm{eff}} R T\right)^{2} k_{\mathrm{aq}}\left[\mathrm{HO}_{2}\right] r}$

$k_{\text {aq }}$ can be calculated from the rate coefficients for Reaction (R2) $\left(k_{2}\right)$ and Reaction (R3) ( $\left.k_{3}\right)$ (Bielski et al., 1985) and the pH:

$k_{\mathrm{aq}}=\frac{k_{2}+\left(\frac{K_{\mathrm{eq}}}{\left[\mathrm{H}^{+}\right] \mathrm{aq}}\right) k_{3}}{\left(1+\frac{K_{\mathrm{eq}}}{\left[\mathrm{H}^{+}\right] \mathrm{aq}}\right)^{2}}$

This formalism predicts that the loss of $\mathrm{HO}_{2}$ to particles is favoured by high $\mathrm{HO}_{2}$ mixing ratios, low temperatures (higher solubility) and low $\mathrm{pH}$. At low concentrations of $\mathrm{HO}_{2}$ (whereby the self reaction and reaction with $\mathrm{O}_{2}^{-}$are inefficient), values of $\gamma$ of $<0.005$ are calculated, which are however much less than the uptake coefficients of Taketani et al. (2008) who investigated the uptake of low concentrations of $\mathrm{HO}_{2}$ to $\left(\mathrm{NH}_{4}\right)_{2} \mathrm{SO}_{4}$ particles. In addition, as discussed by Hanson et al. (1992) and Thornton and Abbatt (2005), there is considerable uncertainty (factor of 2.5) associated with the solubility of $\mathrm{HO}_{2}\left(\mathrm{H}^{\mathrm{HO} 2}\right)$ and its temperature dependence. The above schemes also do not account for the RH dependence of uptake observed for $\left(\mathrm{NH}_{4}\right)_{2} \mathrm{SO}_{4}$ particles (see datasheet VI.A3.10).

Until these apparent discrepancies have been resolved by further experiments, we make no recommendation for parameterising $\mathrm{HO}_{2}$ uptake to aqueous aerosol. We refer to recent publications for a more detailed description of the effect of different parameterisation schemes (Thornton et al., 2008; Mao et al., 2013).

\section{References}

Bielski, B. H. J., Cabelli, D. E., Arudi, R. L., and Ross, A. B.: J. Phys. Chem. Ref. Data, 14, 1041-1100, 1985.

Hanson, D. R., Burkholder, J. B., Howard, C. J., and Ravishankara, A. R.: J. Phys. Chem., 96, 4979-4985, 1992. Jacob, D. J.: Atmos. Env., 34, 2131-2159, 2000.

Mao, J., Fan, S., Jacob, D. J., and Travis, K. R.: Atmos. Chem. Phys., 13, 509-519, doi:10.5194/acp-13-509-2013, 2013.

Morita, A., Kanaya, Y., and Francisco, J. S.: J. Geophys. Res.-Atmos., 109, 2004.

Mozurkewich, M., McMurry, P. H., Gupta, A., and Calvert, J. G.: J. Geophys. Res.-Atmos., 92, 4163-4170, 1987.

Schwartz, S. E.: J. Geophys. Res.-Atmos., 89, 1589-1598, 1984.

Taketani, F., Kanaya, Y., and Akimoto, H.: J. Phys. Chem. A, 112, 2370-2377, doi:10.1021/jp0769936, 2008.

Thornton, J. and Abbatt, J. P. D.: J. Geophys. Res.-Atmos., 110, D08309, doi:10.1029/2004JD005402, 2005. 


\section{Appendix A2}

\section{Uptake on deliquesced halide salts}

\section{VI.A2.0}

$\mathrm{O}_{3}(\mathrm{~g})+\mathrm{Cl}^{-} / \mathrm{Br}^{-} / \mathrm{I}^{-}(\mathrm{aq}) \rightarrow$ products

\section{Experimental data}

\begin{tabular}{|c|c|c|c|}
\hline Parameter & $T / \mathrm{K}$ & Reference & Technique/Comments \\
\hline \multicolumn{4}{|l|}{ Uptake, Accommodation coefficients: $\gamma, \alpha$} \\
\hline$\gamma_{\mathrm{ss}}>2 \times 10^{-3}( \pm 20 \%)\left(\mathrm{SnCl}_{2}\right.$ solution $)$ & 276 & Utter et al. (1992) & WWFT (a) \\
\hline$\alpha_{\mathrm{b}}=0.10$ & 277 & Hu et al. (1995) & DT-MS (b) \\
\hline \multicolumn{4}{|l|}{$\begin{array}{l}1 / \gamma_{1}=\left(85_{-10}^{+20}\right) a\left(\mathrm{I}^{-}\right)^{-\frac{1}{2}}+(10 \pm 5) \text { with }\left[\mathrm{I}^{-}\right] \\
\text {between } 0.5 \text { and } 3.0 \mathrm{M}\end{array}$} \\
\hline$\gamma_{\mathrm{ss}}=3.7 \times 10^{-3}\left(a\left(\mathrm{I}^{-}\right)=0.36 \mathrm{M}\right)$ & 282 & Magi et al. (1997) & DT-MS (c) \\
\hline $\begin{array}{l}\gamma_{\mathrm{ss}}=1.16 \times 10^{-2}\left(a\left(\mathrm{I}^{-}\right)=2.89 \mathrm{M}\right) \\
\alpha_{\mathrm{b}}>0.1\end{array}$ & 282 & & \\
\hline $\begin{array}{l}\gamma_{\mathrm{ss}}<1.0 \times 10^{-4} \text { (unbuffered and buffered } \\
(\mathrm{pH}=7.2) \mathrm{NaCl} \text { aerosol })\end{array}$ & 300 & Abbatt and Waschewsky (1998) & AFT-CIMS (d) \\
\hline$\alpha_{\mathrm{b}}>2.0 \times 10^{-2}(\mathrm{NaI}$ solution $)$ & 298 & Schütze and Herrmann (2002) & (e) \\
\hline$\alpha_{\mathrm{b}}=0.6_{-0.5}^{+0.4}($ deliquesced KI aerosol, $\mathrm{rh}=72 \%)$ & 293 & Rouvière et al. (2010) & $\operatorname{AFT}(f)$ \\
\hline \multicolumn{4}{|l|}{$\gamma_{0}=(1.1 \pm 0.2) \times 10^{-2}\left(\right.$ excess I $\left.^{-}\right)$} \\
\hline & $\begin{array}{l}\gamma_{0}=4.4 \times 10^{-4} \\
\left(\text { mixed } \mathrm{KI} / \mathrm{NaCl} \text { aerosol with }\left[\mathrm{I}^{-}\right]=0.9 \mathrm{M},\left[\mathrm{Cl}^{-}\right]=6.1 \mathrm{M}\right)\end{array}$ \\
\hline $1 / \gamma_{\mathrm{s}}=(1.4 \pm 0.2) \times 10^{-7}\left[\mathrm{O}_{3}\right]+0.06 \times 10^{7}$ & 273 & Oldridge and Abbatt (2011) & CWFT (g) \\
\hline$\gamma_{1}=(7.7 \pm 1.8) \times 10^{-8}$ & 273 & & \\
\hline
\end{tabular}

\section{Comments}

(a) Uptake of $\mathrm{O}_{3}\left(10^{11}\right.$ molecule $\left.\mathrm{cm}^{-3}\right)$ to a liquid film ( $20 \mu \mathrm{m}$ thick). The total pressure was between 13.6 to $14.6 \mathrm{mbar}$ with half of it being $\mathrm{H}_{2} \mathrm{O}$ vapor. No uptake of $\mathrm{O}_{3}$ was observed into pure de-ionized water, but $\gamma$ increased as a function of the concentration of the trapping agent (e.g., $\mathrm{SnCl}_{2}$ ) to values in the $10^{-2}$ range. The measured loss rate was limited by the diffusion of $\mathrm{O}_{3}$ to the wetted wall when $\gamma$ was larger than 0.02 in the presence of solutions of scavengers $\mathrm{Na}_{2} \mathrm{SO}_{3}$, $\mathrm{Na}_{2} \mathrm{~S}_{2} \mathrm{O}_{3}$ and $\mathrm{SnCl}_{2}$.

(b) Droplet diameters in the range 120-250 $\mu \mathrm{m}$. The concentration of $\mathrm{O}_{3}$ varied from $5 \times 10^{12}$ to $1 \times 10^{14}$ molecule $\mathrm{cm}^{-3}$ at a gas residence time between 2 to $15 \mathrm{~ms}$. Detection of the reactant gas is by residual gas electron-impact quadrupole mass spectrometry. The partial pressure of $\mathrm{H}_{2} \mathrm{O}$ in the reacting zone is in the range 2.9 to $23.3 \mathrm{mbar}$ corresponding to temperatures -10 to $20^{\circ} \mathrm{C}$ using $\mathrm{Kr}$ as an internal standard. $\mathrm{H}_{2} \mathrm{O}$ vapor was mixed with variable amounts of He. The iodide ion concentration was in the range 0.5 to $3.0 \mathrm{M}$.

(c) Uptake on a train of aqueous $\mathrm{NaI}$ droplets $(80$ to $150 \mu \mathrm{m})$ in a laminar flow tube operated in the range $275-293 \mathrm{~K}$. The $\mathrm{O}_{3}$ concentration in the flow tube was measured at $\mathrm{m} / \mathrm{e} 46\left(\mathrm{NO}_{2}^{+}\right)$after titration by $\mathrm{NO}$ and conversion to $\mathrm{NO}_{2}$. No measurable uptake of $\mathrm{O}_{3}$ on pure water was observed. The uptake into aqueous $\mathrm{NaI}$ was limited by reaction of $\mathrm{O}_{3}$ with $\mathrm{I}^{-}$as shown by the dependence of $\gamma_{\mathrm{ss}}$ on the ionic strength of the solution. From the intercept and linearity of the plot of $1 / \gamma$ vs. $a\left(\mathrm{I}^{-}\right)^{-\frac{1}{2}}$ Magi et al. (1997) derive a lower limit of $\alpha_{\mathrm{b}}$ of 0.1 .

(d) The $\mathrm{NaCl}$ aerosol had a bimodal distribution (large average diameter: $2-4 \mu \mathrm{m}$, small average diameter: $<1 \mu \mathrm{m}$ ) with typical surface areas and particle number densities in the range of $(1-6) \times 10^{-3} \mathrm{~cm}^{2} \mathrm{~cm}^{-3}$ and $(1-4) \times 10^{4}$ particles cm $\mathrm{cm}^{-3}$, respectively. The value of $\gamma$ is an upper limit and is given for unbuffered and $\mathrm{NaCl}$ aerosol buffered at $\mathrm{pH}=7.2$ using $\mathrm{NaH}_{2} \mathrm{PO}_{4} / \mathrm{Na}_{2} \mathrm{HPO}_{4}$. A slow wall-catalyzed reaction occurred when working with $\mathrm{HCl}$-acidified $\mathrm{NaCl}$ aerosol at $\mathrm{pH}=0.3$ resulting in $\mathrm{Cl}_{2}$. This reaction presumably occurs on $\mathrm{NaCl}$ aerosol particles adhering to the walls of the flow tube. 
(e) Uptake onto a static single drop (2-3 mm in diameter) containing NaI $\left(2 \times 10^{-2}\right.$ to $\left.4 \mathrm{M}\right)$ was monitored by time-resolved UV/Vis absorption spectroscopy in the range 240 to $800 \mathrm{~nm}$. The time-dependent values of the optical density of $\mathrm{I}_{3}^{-}$were analyzed to derive uptake coefficients $\gamma$ in the range $2.0 \times 10^{-5}$ to $1.5 \times 10^{-2}$.

(f) Aerosol flow tube experiment at atmospheric pressure using deliquesced $\mathrm{KI}$ and $\mathrm{KI} / \mathrm{NaCl}$ aerosol. Aerosol mode ranged from 70 to $573 \mathrm{~nm}$ and $\mathrm{O}_{3}$ concentration detected by CLD from 70 to $300 \mathrm{ppb}$. Iodide excess for pseudo first-order conditions could not be maintained in all experiments such that numerical data analysis had to be applied in order to retrieve the bulk accommodation coefficient $\alpha_{\mathrm{b}}$ and the second-order rate constant $k^{\mathrm{II}}$ for the liquid phase reaction $\mathrm{O}_{3}+\mathrm{I}^{-}$. The remainder of the parameters for data retrieval is effectively identical to the work of Magi et al. (1997).

(g) CWFT study at 120 mbar of air coupled to $\mathrm{I}^{-}$-CIMS detection of $\mathrm{O}_{3}, \mathrm{H}_{2} \mathrm{O}$ and $\mathrm{Br}_{2} . \mathrm{O}_{3}$ was monitored at $254 \mathrm{~nm}$ and was in excess relative to bromide. The detection limit for most negative ions was in the range $10^{9}-10^{10}$ molecule $\mathrm{cm}^{-3}$. The liquid sample was positioned in a container lying on the bottom of the horizontal flow tube and consisted of an aqueous solution of $0.55 \mathrm{M} \mathrm{NaCl}$ and $8.5 \mathrm{mM} \mathrm{KBr}$ at $\mathrm{pH}=1.97$ exposed to $\mathrm{O}_{3}$ at $273 \mathrm{~K}$. Uptake coefficients were derived from the rate of appearance of $\mathrm{Br}_{2}$ as product assuming no other reactive losses other than the reaction $2 \mathrm{Br}^{-}(\mathrm{aq})+\mathrm{O}_{3}(\mathrm{~g})+2 \mathrm{H}^{+}(\mathrm{aq}) \rightarrow \mathrm{Br}_{2}(\mathrm{~g})+\mathrm{O}_{2}(\mathrm{~g})+\mathrm{H}_{2} \mathrm{O}(\mathrm{l})$

\section{Preferred values}

\begin{tabular}{lll}
\hline Parameter & Value for Iodide ion as a reactant & $T / \mathrm{K}$ \\
\hline$\alpha_{\mathrm{b}}$ & $>0.1$ & 298 \\
$k^{\mathrm{II}} / \mathrm{M}^{-1} \mathrm{~s}^{-1}$ & $(2.4 \pm 1.3) \times 10^{9}\left(\right.$ average $\left.\left[\mathrm{I}^{-}\right]\right)$ & 293 \\
& $(3.2 \pm 1.5) \times 10^{8}$ & 275 \\
$D_{\mathrm{l}} / \mathrm{cm}^{2} \mathrm{~s}^{-1}$ & $1.85 \times 10^{-5}$ & 293 \\
$H / \mathrm{M} \mathrm{atm}^{-1}$ & $1.15 \times 10^{-2} \exp (2560(1 / T-1 / 298))$ & $273-293$ \\
Reliability & & \\
$\Delta \log \left(\alpha_{\mathrm{b}}\right)$ & undetermined & 298 \\
$\Delta \log \left(k^{\mathrm{II}}\right)$ & \pm 0.2 & 298 \\
\hline Parameter & Value for Bromide ion as a reactant & $T / \mathrm{K}$ \\
\hline$K_{\mathrm{LangC}} / \mathrm{cm}^{3}$ molecule & \\
$k_{\mathrm{b}}^{\mathrm{II}} / \mathrm{M}^{-1} \mathrm{~s}^{-1}$ & $10^{-13}$ & $233-273$ \\
$D_{\mathrm{l}}$ & $6.3 \times 10^{8} \exp (-4450 / T)$ & $273-298$ \\
$H / \mathrm{M}$ atm & 273 \\
Reliability & $8.9 \times 10^{-6} \mathrm{~cm}^{2} \mathrm{~s}^{-1}$ & 273 \\
$\Delta \log \left(k^{\mathrm{II}}\right)$ & $1.15 \times 10^{-2} \exp (2560(1 / T-1 / 298))$ & \\
$\Delta \log K_{\text {LangC }}$ & \pm 0.3 & $273-298$ \\
& \pm 0.5 & $233-273$ \\
\hline
\end{tabular}

\section{Comments on preferred values}

Due to the very low reactivity of $\mathrm{O}_{3}$ with chloride, uptake of $\mathrm{O}_{3}$ to aqueous sea salt solutions is dominated by the reactions with bromide and iodide (Haag and Hoigné, 1983). We thus only provide kinetic parameters for the reactive processes with bromide and iodide, treated separately in this discussion. We assume that the solubility and the bulk accommodation coefficient for a pure $\mathrm{NaCl}$ solution would be the same as that preferred for the iodide solution.

$\mathrm{O}_{3}+\mathrm{I}^{-}$

The datasets of Hu et al. (1995), Magi et al. (1997), Rouvière et al. (2010) concur in that the reaction proceeds without a significant surface component and can be described by the following resistor expression:

$\frac{1}{\gamma}=\frac{1}{\alpha_{\mathrm{b}}}+\frac{\bar{c}}{4 H R T \sqrt{k^{\mathrm{II}} a\left(\mathrm{I}^{-}\right) D_{\mathrm{l}}}}$

These studies indicate that $\alpha_{\mathrm{b}}>0.1$. The absence of a surface component is not consistent with experimental and theoretical evidence that indicates a high surface propensity for the iodide ion (Jungwirth and Tobias, 2006, and references therein). Rouvière 
et al. (2010) argue that a surface reaction may be masked by the very strong reaction in the bulk solution that dominates the uptake.

There is excellent agreement in the retrieved parameters $\alpha_{\mathrm{b}}$ and $k^{\mathrm{II}}$ of Rouvière et al. (2010) and Magi et al. (1997) despite the different types of experiments. The liquid phase rate constant $k^{\mathrm{II}}$ obtained in both studies agreed with literature values (Garland et al. (1980) derive $2 \times 10^{9} \mathrm{M}^{-1} \mathrm{~s}^{-1}$ at $298 \mathrm{~K}$ ) and the values reported by Magi et al. (1997) are recommended. The value of $k^{\mathrm{II}}=4 \times 10^{9} \mathrm{M}^{-1} \mathrm{~s}^{-1}$ at $277 \mathrm{~K}$ derived by Hu et al. (1995) seems to be larger by at least a factor of two when compared to literature values for $\mathrm{O}_{3}+\mathrm{I}^{-}$.

The effects of salting out (decrease of $H$ with increasing scavenger concentration) on $k^{\mathrm{II}}$ is within the experimental uncertainty of the data and has been ignored in the data evaluation. The values for $k^{\mathrm{II}}$ displayed in the Table therefore correspond to an average iodide concentration.

$\mathrm{O}_{3}+\mathrm{Br}^{-}$

The experiments of Oldridge and Abbatt (2011), the only ones reported in the literature on the interaction of $\mathrm{O}_{3}$ with liquid aqueous bromide solutions at $273 \mathrm{~K}$, are interpreted in terms of both a surface as well as a bulk reactivity component of excess $\mathrm{O}_{3}$ reacting with a constant supply of surface bromide in terms of two limiting cases. The surface reaction is invoked, because at low $\mathrm{O}_{3}$ concentration, the uptake coefficient was about an order of magnitude higher than predicted by bulk reaction alone, and because $\gamma$ falls off with increasing $\mathrm{O}_{3}$ concentration similar to other surface reactions analyzed in terms of Langmuir-Hinshelwood kinetics. A concurrent bulk and surface reaction agrees, at least qualitatively, with the laboratory study of Clifford and Donaldson (2007) on the interaction of $\mathrm{O}_{3}$ with bromide at the air-aqueous interface in which the authors have studied the occurrence of a $\mathrm{pH}$ change at the interface using a surface-adsorbed $\mathrm{pH}$ indicator.

The reaction of $\mathrm{O}_{3}$ with aqueous bromide proceeds via:

$\mathrm{O}_{3}+\mathrm{Br}^{-} \rightarrow \mathrm{O}_{2}+\mathrm{OBr}^{-}$

We recommend using the bulk reaction rate constant measured by Haag and Hoigné (1983) over the temperature range of interest here. At low $\mathrm{pH}\left(\mathrm{pH}=2\right.$ in the experiments by Oldridge and Abbatt), the likely fate of $\mathrm{OBr}^{-}$is the reaction of $\mathrm{HOBr}$ with bromide or chloride in sea salt to form $\mathrm{Br}_{2}$ or $\mathrm{BrCl}$, respectively.

The full expression for the uptake coefficient of $\mathrm{O}_{3}$ to aqueous bromide solutions based on the resistor model including both surface and bulk reaction is:

$\frac{1}{\gamma}=\frac{1}{\alpha_{\mathrm{s}}}+\frac{1}{\Gamma_{\mathrm{s}}+\left(\frac{1}{\Gamma_{\mathrm{sb}}}+\frac{1}{\Gamma_{\mathrm{b}}}\right)^{-1}}$

Since the bulk accommodation coefficient is likely to be $>0.1$ and the observed steady state uptake coefficients are $10^{-6}$ at maximum, surface accommodation and surface to bulk transfer are not limiting $\left(\alpha_{\mathrm{s}} \gg \gamma ; \Gamma_{\mathrm{sb}} \gg \Gamma_{\mathrm{b}}\right)$ and the expression simplifies to:

$\gamma \approx \Gamma_{\mathrm{s}}+\Gamma_{\mathrm{b}}$

For the surface reaction, the expression for a Langmuir-Hinshelwood reaction is:

$\Gamma_{\mathrm{s}}=\frac{4 k_{\mathrm{s}}^{\mathrm{II}}\left[\mathrm{Br}^{-}\right]_{\mathrm{s}} K_{\mathrm{LangC}} N_{\max }}{\bar{c}\left(1+K_{\mathrm{LangC}}\left[\mathrm{O}_{3}\right]_{\mathrm{g}}\right)}$

The surface concentration of bromide ions can be estimated by normalizing the bulk mole fraction to the surface density of $\mathrm{H}_{2} \mathrm{O}$ molecules $\left(10^{15}\right.$ molecules $\left.\mathrm{cm}^{-2}\right)$, leading to $\left[\mathrm{Br}^{-}\right]_{\mathrm{s}} \approx 2.9 \times 10^{12}$ molecules $\mathrm{cm}^{-2}$ for the $8.5 \mathrm{mM}$ solution of Oldridge and Abbatt. Since the surface to volume ratio was not varied in these experiments, only the product $k_{\mathrm{s}}^{\mathrm{II}} \times N_{\text {max }}$ is constrained by the data for which a value of $0.03 \mathrm{~s}^{-1}$ is obtained for the best fit. Assuming that $N_{\max }$ is about $10^{15}$ molecules cm $\mathrm{cm}^{-2}, k_{\mathrm{s}}^{\mathrm{II}}$ would be a few $10^{-17} \mathrm{~cm}^{2}$ molecule ${ }^{-1}$. In turn, the value for $K_{\mathrm{LangC}}$ is well constrained by the inverse $\mathrm{O}_{3}$ concentration dependence, and the value found by Oldridge and Abbatt is adopted.

The contribution owing to uptake in the bulk reaction can be calculated by:

$\Gamma_{\mathrm{b}}=\frac{4 H R \mathrm{~T}}{\bar{c}} \sqrt{D_{\mathrm{l}} k_{\mathrm{b}}^{\mathrm{II}}}$

In the absence of independent measurements of the solubility of $\mathrm{O}_{3}$ in halide solutions, we recommend using the expression as compiled by Chameides (1984). The diffusion coefficient given in the table for $273 \mathrm{~K}$ has been extrapolated from its room temperature value via the Stokes-Einstein relation. The parameterization reproduces the experimental data by Oldridge and Abbatt 
fairly well, even though it overestimates $\gamma$ at high concentration, because the surface reaction does not fall off as quickly. Note that the reacto-diffusive length for deliquesced sea-salt is at least a few tens of $\mu \mathrm{m}$, making the correction necessary for small spherical particles. However, for the atmospherically relevant concentration range $\left(<10^{12} \mathrm{molecules}^{-3}\right)$, the shape independent surface reaction term would dominate.

$\mathrm{Br}_{2}$ has been observed as gas-phase product resulting from the interaction of $\mathrm{O}_{3}$ with frozen and aqueous bromide surfaces (Oum et al., 1998; Hunt et al., 2004).

\section{References}

Abbatt, J. P. D. and Waschewsky, G. C. G.: J. Phys. Chem. A, 102, 3719, 1998.

Chameides, W. L.: J. Geophys. Res., 89, 4739-4755, 1984.

Clifford, D. and Donaldson, D. J.: J. Phys. Chem. A, 111, 9809, 2007.

Garland, J. A., Elzermann, A. W., and Penkett, S. A.: J. Geophys. Res., 85, 7488, 1980.

Haag, W. R. and Hoigné, J.: Environ. Sci. Technol., 17, 261-267, doi:10.1021/es00111a004, 1983.

Hu, J., Shi, Q., Davidovits, P., Worsnop, D. R., Zahniser, M., and Kolb, C. E.: J. Phys. Chem., 95, 8768, 1995.

Hunt, S. W., Roeselova, M., Wang, W., Wingen, L. M., Knipping, E. M., Tobias, D. J., Dabdub, D., and Finlayson-Pitts, B. J.: J. Phys. Chem. A, 108, 11559, 2004.

Jungwirth, P. and Tobias, D. J.: Chem. Rev., 106, 1259-1281, 2006.

Magi, L., Schweitzer, F., Pallares, C., Cherif, S., Mirabel, P., and George, C.: J. Phys. Chem. A, 101, $4943,1997$.

Oldridge, N. W. and Abbatt, J. P. D.: J. Phys. Chem. A, 115, 2590, 2011.

Oum, K. W., Lakin, M. J., and Finlayson-Pitts, B. J.: Geophys. Res. Lett., 25, 3923-3926, 1998.

Rouvière, A., Sosedova, Y., and Ammann, M.: J. Phys. Chem. A, 114, 7085, 2010.

Rouvière, A. and Ammann, M.: Atmos. Chem. Phys., 10, 11489, doi:10.5194/acp-10-11489-2010, 2010.

Schütze, M. and Herrmann, H.: Phys. Chem. Chem. Phys., 4, 60, 2002.

Utter, R. G., Burkholder, J. B., Howard, C. J., and Ravishankara, A. R.: J. Phys. Chem., 96, 4973, 1992. 
VI.A2.1

$\mathrm{OH}(\mathrm{g})+\mathrm{Cl}^{-}(\mathbf{a q}) \rightarrow$ products

Experimental data

\begin{tabular}{lllll}
\hline Parameter & $\mathrm{RH} / \%$ & $T / \mathrm{K}$ & Reference & Technique/Comments \\
\hline Uptake coefficients: $\gamma$ & & & & \\
$\approx 0.2$ & 82 & 297 & Knipping et al. (2000) & (a) \\
$>0.1$ & $70-80$ & 298 & Laskin et al. (2006) & (b) \\
\hline
\end{tabular}

\section{Comments}

(a) $\mathrm{NaCl}$ aerosol was produced using a nebulizer and dispersed in a chamber. Formation of $\mathrm{Cl}_{2}$ was observed with atmospheric pressure chemical ionization MS in presence of $(0.63-3.4) \times 10^{14}$ molecule $\mathrm{cm}^{-3}$ of $\mathrm{O}_{3}$ and $254 \mathrm{~nm}$ light in the chamber. $\mathrm{Cl}_{2}$ formation was simulated with a kinetic model that was extended in the follow up study by Knipping and Dabdub (2002). The uptake coefficient given in the table is the result of fitting the simulation to experimental data based on a parameterization of a surface reaction between $\mathrm{OH}$ and $\mathrm{Cl}^{-}$. Parallel uptake of $\mathrm{OH}$ into the bulk of the particles (with $\left.\alpha_{\mathrm{b}}=0.1\right)$ and aqueous phase chemistry therein was considered as well.

(b) $\mathrm{NaCl}$ aerosol was produced using a nebulizer followed by drying, resulting in $0.9 \mu \mathrm{m}$ mean diameter particles that were deposited on 300 mesh gold grids. The grids were exposed to $\mathrm{OH}$ from $\mathrm{O}_{3}$ photolysis in an ambient temperature, atmospheric pressure flow cell. The humidity was first raised to $85 \% \mathrm{RH}$ to safely induce deliquescence and then kept between 70 and $80 \%$ for the experiments. OH concentrations were around a few $10^{9}$ molecule $\mathrm{cm}^{-3}$. Offline particle analysis using SEM/EDX was used to determine $\mathrm{Cl}$ loss as a function of time using $\mathrm{Na}$ as reference. Wet particle sizes were inferred from dry particle sizes. The uptake coefficient is considered a lower limit as gas phase diffusion limitations existed.

\section{Preferred values}

\begin{tabular}{lll}
\hline Parameter & Value & $T / \mathrm{K}$ \\
\hline$\alpha_{\mathrm{b}}$ & $>0.1$ & 298 \\
$\gamma_{\mathrm{gs}}$ & $0.04 \times\left(\left[\mathrm{Cl}^{-}\right] / \mathrm{M}\right)$ & 298 \\
Reliability & & \\
$\Delta \log \left(\alpha_{\mathrm{b}}\right)$ & undetermined & \\
$\Delta \log \left(\gamma_{\mathrm{ER}}\right)$ & \pm 1 & 298 \\
\hline
\end{tabular}

\section{Comments on preferred values}

The only direct experimental investigation of the reaction of $\mathrm{OH}$ with deliquesced $\mathrm{NaCl}$ provides a lower limit to the uptake coefficient (Laskin et al., 2006). The chamber experiment by Knipping et al. (2000) provided evidence for formation of $\mathrm{Cl}_{2}$ from the reaction of $\mathrm{OH}$ with deliquesced $\mathrm{NaCl}$ due to an overall reaction $(\mathrm{R} 1)$.

$\mathrm{OH}+\mathrm{Cl}^{-} \rightarrow 0.5 \mathrm{Cl}_{2}+\mathrm{OH}^{-}$

In the bulk aqueous phase, the initial reaction of $\mathrm{OH}$ is believed to be (Finlayson-Pitts, 2003)

$\mathrm{OH}+\mathrm{Cl}^{-} \rightarrow \mathrm{ClOH}^{-} \quad k_{2}=4.3 \times 10^{9} \mathrm{M}^{-1} \mathrm{~s}^{-1}$ at $\mathrm{pH} 2$

Known bulk aqueous phase kinetics was unable to explain $\mathrm{Cl}_{2}$ formation in the study by Knipping et al. (2000) and later by Knipping and Dabdub (2002). Therefore, an Eley-Rideal type surface reaction was proposed to bring experiment and simulation into agreement, which is recommended in parameterized form as a function of the chloride concentration. Note that in this case the surface process acts parallel to bulk accommodation and bulk reaction:

$\gamma=\gamma_{\mathrm{gs}}+\left(\frac{1}{\alpha_{\mathrm{b}}}+\frac{1}{\Gamma_{\mathrm{b}}}\right)^{-1} \quad$ with $\quad \Gamma_{\mathrm{b}}=\frac{4 H R \mathrm{~T}}{\bar{c}} \sqrt{D_{\mathrm{l}} k_{\mathrm{b}}^{\prime}}$ 
where $k_{\mathrm{b}}^{\mathrm{I}}$ is the first order rate coefficient in the bulk aqueous phase, e.g., due to Reaction (R2). However, in many cases multiple reactions may occur in parallel in the bulk. For the Henry's law constant it is suggested to use the value recommended for pure water (see data sheet VI.A1.17, this evaluation).

Evidence for the formation of $\mathrm{OH}^{-}$was provided by Laskin et al. (2003) and by Shaka et al. (2007), who demonstrated formation of $\mathrm{OH}^{-}$in deliquesced $\mathrm{MgCl}_{2}$. For $\alpha_{\mathrm{b}}$, we recommend the same lower limit as for dilute aqueous solutions.

We have assigned a substantial uncertainty to this process in view of the complexity of the chamber experiment and in consideration of a single existing study.

On dry sea salt, measured uptake coefficients are on the order of $10^{-2}$ as reviewed by Rossi (2003) and Finlayson-Pitts (2003). Recently, the humidity dependence of the uptake coefficient of OH with sea salt was observed to be consistent with the humidity dependent uptake of $\mathrm{OH}$ on $\mathrm{MgCl}_{2}$ and $\mathrm{CaCl}_{2}$, the low deliquescing components of sea salt (Park et al., 2008, 2009), consistent with a much higher $\mathrm{OH}$ loss at the surface of hydrated halides.

\section{References}

Finlayson-Pitts, B. J.: Chem. Rev., 103, 4801-4822, doi:10.1021/cr020653t, 2003.

Knipping, E. M. and Dabdub, D.: J. Geophys. Res., 107, art. no. 4360, 2002.

Knipping, E. M., Lakin, M. J., Foster, K. L., Jungwirth, P., Tobias, D. J., Gerber, R. B., Dabdub, D., and Finlayson-Pitts, B. J.: Science, 288, 301-306, 2000.

Laskin, A., Gaspar, D. J., Wang, W., Hunt, S. W., Cowin, J. P., Colson, S. D., and Finlayson-Pitts, B. J.: Science, 301, 340-344, doi:10.1126/science.1085374, 2003.

Laskin, A., Wang, H., Robertson, W. H., Cowin, J. P., Ezell, M. J., and Finlayson-Pitts, B. J.: J. Phys. Chem. A, 110, 1061910627, 2006.

Park, J. H., Ivanov, A. V., and Molina, M. J.: J. Phys. Chem. A, 112, 6968-6977, 2008.

Park, J.-H., Christov, C. I., Ivanov, A. V., and Molina, M. J.: Geophys. Res. Lett., 36, art. no. L02802, doi:10.1029/2008GL036160, 2009.

Rossi, M. J.: Chem. Rev., 103, 4823-4882, 2003.

Shaka, H., Robertson, W. H., and Finlayson-Pitts, B. J.: Phys. Chem. Chem. Phys., 9, 1980-1990, 2007. 
VI.A2.2

$\mathrm{HO}_{2}(\mathrm{~g})+\mathrm{Cl}^{-} / \mathrm{Br}^{-} / \mathrm{I}^{-}(\mathrm{aq}) \rightarrow$ products

Experimental data

\begin{tabular}{llll}
\hline & $T / \mathrm{K}$ & Reference & Technique/Comments \\
\hline Uptake coefficients: $\gamma$ & & & \\
$0.1 \pm 0.03(\mathrm{NaCl}$, RH 53-75 \%) & $296 \pm 2$ & Taketani et al. (2008) & AFT (a) \\
$0.1 \pm 0.04$ (SSS, RH 53-75\%) & $296 \pm 2$ & Taketani et al. (2009) & AFT (b) \\
$0.1 \pm 0.03(\mathrm{NS}, \mathrm{RH} 53-75 \%)$ & & & \\
$0.07 \pm 0.03(\mathrm{KCl}, \mathrm{RH} 75 \%)$ & & & \\
Accomodation coefficients: $\alpha_{\mathrm{b}}$ & & & \\
$0.65 \pm 0.17$ & $296 \pm 2$ & Taketani et al. (2008) & AFT (a) \\
$0.55 \pm 0.19$ & $296 \pm 2$ & Taketani et al. (2009) & AFT (b) \\
\hline
\end{tabular}

\section{Comments}

(a) Uptake of $\mathrm{HO}_{2}\left(\sim 10^{8}\right.$ molecule $\left.\mathrm{cm}^{-3}\right)$ to aqueous $\mathrm{NaCl}$ particles (mean surface area weighted diameter of $\left.80-110 \mathrm{~nm}\right)$ at $\mathrm{RH}$ between 45 and $75 \%$. $\mathrm{HO}_{2}$ was generated by the photolysis of $\mathrm{H}_{2} \mathrm{O}$ in air and detected as $\mathrm{OH}$ (by LIF) following conversion in reaction with NO. In experiments to determine $\alpha_{\mathrm{b}}$ the particles contained $\mathrm{CuSO}_{4}(\sim 0.5 \mathrm{M})$ to scavenge $\mathrm{HO}_{2}$. The authors originally reported: $\gamma(\mathrm{NaCl})=0.11 \pm 0.03,0.09 \pm 0.02$ and $0.10 \pm 0.02$ at $\mathrm{RH}=53,63$ and $75 \%$, respectively.

(b) Same experimental set up as (a). SSS = synthetic sea-salt, NS = natural seawater. The authors originally reported: $\gamma(\mathrm{SSS})=0.07 \pm 0.03,0.12 \pm 0.04$ and $0.13 \pm 0.04$ at $\mathrm{RH}=35,50$ and $75 \%$, respectively. $\gamma(\mathrm{NS})=0.10 \pm 0.03$, $0.11 \pm 0.02$ and $0.10 \pm 0.03$ at $\mathrm{RH}=35,50$ and $75 \%$, respectively. In experiments to determine $\alpha_{\mathrm{b}}$ aqueous $\mathrm{KCl}$ particles contained $\mathrm{CuSO}_{4}(\sim 0.5 \mathrm{M})$ to scavenge $\mathrm{HO}_{2}$.

\section{Preferred values}

\begin{tabular}{lll}
\hline Parameter & Value & $T / \mathrm{K}$ \\
\hline$\alpha_{\mathrm{b}}$ & $>0.5$ & $290-300$ \\
$\gamma$ & 0.1 & $290-300$ \\
Reliability & & \\
$\Delta \log \alpha$ & undetermined & \\
$\Delta \log \gamma$ & \pm 1 & $290-300$ \\
\hline
\end{tabular}

\section{Comments on preferred values}

Taketani et al. (2008) observed exponential $\mathrm{HO}_{2}$ decay to aqueous $\mathrm{NaCl}$ particles with $\gamma$ equal to $0.65 \pm 0.17$ when $\mathrm{CuSO}_{4}$ was present, defining the lower limit to $\alpha_{\mathrm{b}}$. In the absence of $\mathrm{CuSO}_{4} \gamma$ was independent of RH and close to 0.1. Taketani et al. (2009) used synthetic sea salt and natural sea salt to derive similar results. Our preferred values for uptake of $\mathrm{HO}_{2}$ to aqueous sea-salt particles are based on this data-set. As the mechanism for $\mathrm{HO}_{2}$ loss in the particle remains unknown (see below) we add substantial uncertainty to the preferred value of $\gamma$.

The uptake of $\mathrm{HO}_{2}$ in aqueous solution with $\mathrm{pH}>5$, is presently believed to be driven by self-reaction and acid-base dissociation of $\mathrm{HO}_{2}(\mathrm{pKa} \sim 4.7)$ with formation of $\mathrm{H}_{2} \mathrm{O}_{2}$ (Reactions $\mathrm{R} 2, \mathrm{R} 3$ ), since no direct reaction with the halide ions occurs. In the presence of transition metal ions (TMI) the reaction of $\mathrm{HO}_{2}$ and especially $\mathrm{O}_{2}^{-}$(Reaction $\mathrm{R} 4$ ) can be important:

$\mathrm{HO}_{2}(\mathrm{~g}) \rightarrow \mathrm{O}_{2}^{-}(\mathrm{aq})+\mathrm{H}^{+}(\mathrm{aq})$

$\mathrm{HO}_{2}(\mathrm{aq})+\mathrm{HO}_{2}(\mathrm{aq}) \rightarrow \mathrm{H}_{2} \mathrm{O}_{2}(\mathrm{aq})+\mathrm{O}_{2}(\mathrm{aq})$

$\mathrm{O}_{2}^{-}(\mathrm{aq})+\mathrm{HO}_{2}(\mathrm{aq})\left(+\mathrm{H}_{2} \mathrm{O}(\mathrm{l})\right) \rightarrow \mathrm{H}_{2} \mathrm{O}_{2}(\mathrm{aq})+\mathrm{O}_{2}(\mathrm{aq})+\mathrm{OH}^{-}(\mathrm{aq})$

$\mathrm{O}_{2}^{-}(\mathrm{aq})+\mathrm{TMI}(\mathrm{aq}) \rightarrow$ products 
If a first-order loss process for $\mathrm{HO}_{2}$ or $\mathrm{O}_{2}^{-}$in the aqueous phase dominates (e.g. reaction with TMI such as $\mathrm{Cu}(\mathrm{II})$ ), and assuming equal rates of reaction throughout the particle, the uptake coefficient can be calculated from the expression below:

$$
\frac{1}{\gamma}=\frac{1}{\alpha_{\mathrm{b}}}+\frac{\bar{c}}{4 H^{\mathrm{eff}} R T \sqrt{k_{\mathrm{TMI}}[\mathrm{TMI}] D_{1}}}
$$

$H^{\mathrm{eff}}=H^{\mathrm{HO} 2}\left(1+K_{\mathrm{eq}} /\left[\mathrm{H}^{+}\right], K_{\mathrm{eq}}=2.1 \times 10^{-5} \mathrm{M}\right.$ at $298 \mathrm{~K}(\mathrm{Jacob}, 2000), H^{\mathrm{HO} 2}=9.5 \times 10^{-6} \exp (5910 / T)$ (Hanson et al., 1992) and $D_{1}=\left(1 \times 10^{-5}(T / 298)\right) /\left(1.09 \times 10^{8} \exp (-0.068 T)+0.873\right) \mathrm{cm}^{2} \mathrm{~s}^{-1}$ (Schwartz, 1984; Thornton et al., 2008) where the denominator in the $D_{1}$ term was derived from a fit to the water viscosity data of Hallett (1963).

According to the reaction scheme above, the rates of loss of aqueous-phase $\mathrm{HO}_{2}$ are quadratically dependent on $\left[\mathrm{HO}_{2}\right]_{\mathrm{aq}}$ and $\left[\mathrm{O}_{2}^{-}\right]_{\mathrm{aq}}$ and are thus strongly dependent on the gas-phase concentration of $\mathrm{HO}_{2}$ in the absence of TMI. At low $\mathrm{HO}_{2}$ concentrations (e.g. as found in the atmosphere) the liquid phase reactions become rate limiting and $\gamma$ is expected to be much smaller as observed in dilute solutions by Mozurkewich et al. (1987) and the simple formalism above breaks down. Thornton and Abbatt (2005) suggest that the rate of loss of $\mathrm{HO}_{2}$ from the gas-phase (in molecule $\mathrm{cm}^{-3} \mathrm{~s}^{-1}$ ) is best described by a system in thermodynamic (Henry's law) equilibrium so that (Thornton et al., 2008):

$$
\frac{1}{\gamma}=\frac{1}{\alpha_{\mathrm{b}}}+\frac{3 \bar{c} N_{\mathrm{A}}}{8000\left(H^{\mathrm{eff}} R T\right)^{2} k_{\mathrm{aq}}\left[\mathrm{HO}_{2}\right] r}
$$

$k_{\mathrm{aq}}$ can be calculated from the rate coefficients for Reactions (R2) $\left(k_{2}\right)$ and (R3) $\left(k_{3}\right)$ (Bielski et al., 1985) and the pH:

$$
k_{\mathrm{aq}}=\frac{k_{2}+\left(\frac{K_{\mathrm{eq}}}{\left[\mathrm{H}^{+}\right]_{\mathrm{aq}}}\right) k_{3}}{\left(1+\frac{K_{\mathrm{eq}}}{\left[\mathrm{H}^{+}\right]_{\mathrm{aq}}}\right)^{2}}
$$

This formalism predicts that the loss of $\mathrm{HO}_{2}$ to particles is favoured by high $\mathrm{HO}_{2}$ mixing ratios, low temperatures (higher solubility) and low $\mathrm{pH}$. At low concentrations of $\mathrm{HO}_{2}$ (where the self reaction and reaction with $\mathrm{O}_{2}^{-}$are slow), values of $\gamma$ of $<0.005$ are calculated, which are however much less than the uptake coefficients of Taketani et al. $(2008,2009)$ who investigated the uptake of low concentrations of $\mathrm{HO}_{2}$ to aqueous salt particles. In addition, as discussed by Hanson et al. (1992) and Thornton and Abbatt (2005), there is considerable uncertainty (factor of 2.5) associated with the solubility of $\mathrm{HO}_{2}\left(H^{\mathrm{HO} 2}\right)$ and its temperature dependence. Until these apparent discrepancies and uncertainties have been resolved by further experiments, we make no recommendation for parameterising $\mathrm{HO}_{2}$ uptake to halide containing aqueous aerosol. The hypothesis of a fast disproportionation reaction $2 \mathrm{HO}_{2} \rightarrow \mathrm{H}_{2} \mathrm{O}_{2}+\mathrm{O}_{2}$ in aqueous solution advanced by Thornton and Abbatt (2005) is inconsistent with the measured value of $\gamma$ for $\mathrm{HO}_{2}$ loss on both $\mathrm{NaCl}$ and $\left(\mathrm{NH}_{4}\right)_{2} \mathrm{SO}_{4}$ aerosol when extrapolated to the $\mathrm{HO}_{2}$ concentrations lower by a factor of 500 used in the work of Taketani et al. (2008). We suggest that a value close to 0.1 is appropriate for marine environments where sea salt aerosols will be deliquescent. We refer to recent publications for a more detailed description of the effect of different parameterisation schemes (Thornton et al., 2008; Mao et al., 2013).

Experiments conducted using dry salt surfaces at room temperature reveal a much lower uptake coefficient than those reported for aqueous particles (Taketani et al., 2008, 2009) with values ranging from 1.8-2.3 $\times 10^{-3}$ (Loukhovitskaya et al., 2009,

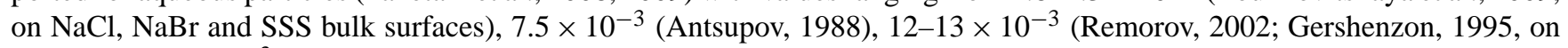
$\mathrm{NaCl}$ ) and $18 \times 10^{-3}$ (Gershenzon, 1995, on $\mathrm{KCl}$ ). Although disagreeing considerably on absolute values of the uptake coefficient (perhaps reflecting different modes of sample presentation and/or possible sample contamination) they all return strong, negative dependencies of $\gamma$ on the temperature and show that at most temperatures $\gamma$ is independent of the $\mathrm{HO}_{2}$ concentration, the exception being at the highest temperatures studied by Remorov (2002), where they observed that $\gamma$ decreased at lower $\left[\mathrm{HO}_{2}\right]$. Remorov et al. (2002) (bulk NaCl) and Loukhovitskaya et al. (2009) (bulk $\mathrm{MgCl}_{2} \cdot 6 \mathrm{H}_{2} \mathrm{O}$ ) both observed a decrease in $\mathrm{HO}_{2}$ uptake when the $\mathrm{RH}$ was increased. This is in stark contrast to the observation of Taketani et al. $(2008,2009)$ who observed that $\gamma$ increased when the RH was increased. In combination with the observation of $\mathrm{H}_{2} \mathrm{O}_{2}$ as sole product (at 0.5 yield, Loukhovitskaya et al., 2009), these observations indicate that, on solid particles, the uptake is driven by reversible surface accommodation of $\mathrm{HO}_{2}$ and subsequent self reaction independent of the presence of halide ions.

\section{References}

Antsupov, E.: Sov. J. Chem. Phys., 7, 1082, 1988.

Bielski, B. H. J., Cabelli, D. E., Arudi, R. L., and Ross, A. B.: J. Phys. Chem. Ref. Data, 14, 1041-1100, 1985.

Gershenzon, Y. M., Grigorieva, V. M., Ivanov, A. V., and Remorov, R. G.: Faraday Discuss., 100, 83-100, 1995. 
Hanson, D. R., Burkholder, J. B., Howard, C. J., and Ravishankara, A. R.: J. Phys. Chem., 96, 4979-4985, 1992. Jacob, D. J.: Atmos. Env., 34, 2131-2159, 2000.

Loukhovitskaya, E., Bedjanian, Y., Morozov, I., and Le Bras, G.: Phys. Chem. Chem. Phys., 11, 7896-7905, 2009

Mao, J., Fan, S., Jacob, D. J., and Travis, K. R.: Atmos. Chem. Phys., 13, 509-519, doi:10.5194/acp-13-509-2013, 2013.

Morita, A., Kanaya, Y., and Francisco, J. S.: J. Geophys. Res.-Atmos., 109, art. no. D09201, doi:10.1029/2003jd004240, 2004.

Mozurkewich, M., McMurry, P. H., Gupta, A., and Calvert, J. G.: J. Geophys. Res.-Atmos., 92, 4163-4170, 1987.

Remorov, R. G., Gershenzon, Y. M., Molina, L. T., and Molina, M. J.: J. Phys. Chem. A, 106, 4558-4565, 2002.

Schwartz, S. E.: J. Geophys. Res.-Atmos., 89, 1589-1598, 1984.

Taketani, F., Kanaya, Y., and Akimoto, H.: Atmospheric Environment, 43, 1660-1665, doi:10.1016/j.atmosenv.2008.12.010, 2009.

Taketani, F., Kanaya, Y., and Akimoto, H.: J. Phys. Chem. A, 112, 2370-2377, 2008.

Thornton, J. and Abbatt, J. P. D.: J. Geophys. Res.-Atmos., 110, D08309, doi:10.1029/2004JD005402, 2005. 
VI.A2.4

$\mathrm{NO}_{2}(\mathrm{~g})+\mathrm{NaCl}(\mathrm{aq})+\rightarrow \mathrm{NOCl}(\mathrm{g})+\mathrm{NaNO}_{3}(\mathrm{aq})$

\section{Experimental data}

\begin{tabular}{lllll}
\hline Parameter & $\mathrm{RH} / \%$ & $T / \mathrm{K}$ & Reference & Technique/Comments \\
\hline Uptake coefficients: $\gamma$ & & & & \\
$\gamma<10^{-4}$ & $50-80$ & 292 & Behnke et al. (1996) & (a) \\
$\gamma<10^{-4}$ & 75 & 298 & Abbatt and Waschewsky (1998) & AFT-CIMS (b) \\
$(3.7 \pm 0.5) \times 10^{-4}$ & 90 & 279 & Harrison and Collins (1998) & AFT-CLD (c) \\
$(2.8 \pm 0.5) \times 10^{-4}$ & 85 & 279 & & \\
$\approx 10^{-4}(1 \mathrm{~m} \mathrm{NaCl})$ & & 298 & Yabushita et al. (2009) & $(\mathrm{d})$ \\
Solublity, $\mathrm{H}\left(\mathrm{M} \mathrm{atm}^{-1}\right)$ & & & & \\
$(5.5 \pm 0.6) \times 10^{-2}$ & & 284 & Cape et al. (1993) & $(\mathrm{e})$ \\
Liquid phase rate constants & & & \\
$k_{\mathrm{R} 1}^{\mathrm{II}}=(1.8 \pm 0.7) \times 10^{6} \mathrm{M}^{-1} \mathrm{~s}^{-1}\left(30 \mathrm{~g}^{-1} \mathrm{NaCl}\right)$ & & 284 & Cape et al. (1993) & $(\mathrm{e})$ \\
$k_{\mathrm{R} 2}^{\mathrm{I}}=1.4 \times 10^{-6} \mathrm{M} \mathrm{s}^{-1}$ & 80 & 293 & Karlsson and Ljungström (1995) & AFT-IC (f) \\
$k_{\mathrm{R} 2}^{\mathrm{I}}=1.7 \times 10^{-6} \mathrm{M} \mathrm{s}^{-1}$ & & 283 & & \\
$k_{\mathrm{R} 2}^{\mathrm{I}}=4.4 \times 10^{-6} \mathrm{M} \mathrm{s}^{-1}$ & & 273 & & \\
\hline
\end{tabular}

\section{Comments}

(a) Deliquesced $\mathrm{NaCl}$ aerosol $\left(70 \mu \mathrm{g} \mathrm{m}^{-3}\right)$ was exposed to $58 \mathrm{ppb}$ of $\mathrm{NO}_{2}$ in a chamber, leading to about $10 \%$ of $\mathrm{NO}_{2}$ loss after about three hours in the dark, which was used to estimate the uptake coefficient listed in the table, based on the size distribution measured by SMPS. Switching on simulated sunlight did not result in $\mathrm{Cl}$ atoms expected from photolysis $\mathrm{NOCl}$, but rather in $\mathrm{OH}$ radicals presumably from photolysis of $\mathrm{HONO}$ formed via hydrolysis of NOCl.

(b) Uptake experiment on liquid $\mathrm{NaCl}$ in atmospheric pressure aerosol flow tube using CIMS detection. The $\mathrm{NaCl}$ aerosol produced with a nebulizer had a bimodal distribution (large average diameter: $2-4 \mu \mathrm{m}$, small: $<1 \mu \mathrm{m}$ ) with typical surface areas and particle number densities in the range of (1-6) $\times 10^{-3} \mathrm{~cm}^{2} \mathrm{~cm}^{-3}$ and (1-4) $\times 10^{4}$ particle $\mathrm{cm}^{-3}$, respectively. The solution nebulized was either unbuffered $\mathrm{NaCl}$ solution, or solution adjusted to $\mathrm{pH}=0.3$ with $\mathrm{HCl}$, or to $\mathrm{pH}=7.2$ with $\mathrm{NaH}_{2} \mathrm{PO}_{4} / \mathrm{Na}_{2} \mathrm{HPO}_{4}$. No NO loss could be detected between $3 \times 10^{12}$ and $2 \times 10^{14}$ molecule $\mathrm{cm}^{-3}$. The value of $\gamma$ is an upper limit based on the detection limit.

(c) Uptake experiment on dry and deliquesced $\mathrm{NaCl}$ aerosol in atmospheric pressure flow tube at $2 \mathrm{ppm}$ of $\mathrm{NO}_{2} . \mathrm{NO}_{2}$ loss was monitored using a chemiluminescence detector. A nylon filter and a filter impregnated with sodium carbonate was used to prevent $\mathrm{HNO}_{3}$ and $\mathrm{HONO}$, respectively, from being detected by the CLD. $\mathrm{NO}_{2}$ decay rates were determined as a function of the aerosol surface to volume ratio determined by SMPS, from which the uptake coefficient was derived. The values for the conditions of deliquesced $\mathrm{NaCl}$ aerosol are listed in the table. Surprisingly, the uptake coefficient for dry $\mathrm{NaCl}$ particles at $50 \%$ relative humidity was even higher, $10^{-3}$.

(d) Microdroplets were generated by nebulization of aqueous halogenide solutions into ppmv $\mathrm{NO}_{2}(\mathrm{~g}) / \mathrm{N}_{2} \quad((1-$ 5) $\times 10^{14}$ molecule $\mathrm{cm}^{-3}$ ) mixtures at atmospheric pressure, leading to interaction times of about $1 \mathrm{~ms}$. Droplets were then expanded into a mass spectrometer. The rate of appearance of nitrate, from which the uptake coefficient was estimated, had a maximum in the $10^{-3} \mathrm{M}$ range for chloride, bromide and iodide, which is listed in the table. The uptake coefficient for these solutions was 4 orders of magnitude larger than that on neat water.

(e) $\mathrm{NO}_{2}$ at partial pressures of 10 to $100 \mathrm{ppb}$ was passed through 1.01 of aqueous solution in a fritted bubbler in a thermostatted vessel. The loss of $\mathrm{NO}_{2}$ was measured with a chemiluminescence detector. Apart from pure water, the aqueous solutions used were $30 \mathrm{gl}^{-1} \mathrm{NaCl}$, two synthetic sea salt mixtures at comparable concentration, and authentic coastal sea-water. The solubility derived from the kinetic experiments was independent of the type of solution. However, the rate constants for the solutions were higher, up to a factor of 10 for sea-water (hydrolysis rate constant listed in the table, labelled with R1). The authors caution that the distribution of $\mathrm{NO}_{2}$ in the reactor may have not been uniform, leading to an overestimate of the rate constants. 
(f) The flow reactor consisted of six 101 halocarbon wax coated glass tubes connected in series. Sea salt aerosol was produced by nebulizing synthetic sea water and bringing to charge equilibrium with a ${ }^{85} \mathrm{Kr}$ source. The particle size distribution was measured with an electrostatic classifier coupled to an aerosol electrometer. The geometric mean number diameter was between 100 and $120 \mathrm{~nm}$. Nitrogen dioxide concentrations ranged from 50 to $500 \mathrm{ppbv}$ and were monitored with a chemiluminescence detector. Particles were collected on a filter after the flow reactor and after a $\mathrm{KMnO}_{4}$ coated denuder removing gas phase $\mathrm{NO}_{2}$. Experiments at humidities below the deliquescence of the particles indicated a lower limit for the uptake coefficient of $3 \times 10^{-4}$ with negative humidity dependence. The first order loss rate constants for chloride at $80 \%$ relative humidity listed in the table were derived from experiments at $190 \mathrm{ppb} \mathrm{NO}_{2}$. The authors ascribed this loss entirely to the reaction $2 \mathrm{NO}_{2}+\mathrm{Cl}^{-} \rightarrow \mathrm{NO}_{3}^{-}+\mathrm{NOCl}$ (labelled R2).

\section{Preferred values}

\begin{tabular}{lll}
\hline Parameter & Value & $T / \mathrm{K}$ \\
\hline$k_{\mathrm{R} 2}^{\mathrm{II}} / \mathrm{M}^{-1} \mathrm{~s}^{-1}$ & 200 & 298 \\
Reliability & & \\
$\Delta \log (k)$ & \pm 0.7 & \\
\hline
\end{tabular}

\section{Comments on preferred values}

While a significant number of studies have investigated the reaction of $\mathrm{NO}_{2}$ with solid $\mathrm{NaCl}$ and other sea salt proxies (Rossi, 2003) and references therein) and also the significant impact of humidity on these reactions, only a few studies have addressed the uptake to deliquesced sea salt particles representative of marine boundary layer conditions. The only aerosol flow tube study that covers relevant low $\mathrm{NO}_{2}$ concentrations is that by Abbatt and Waschewsky (1998), which reports an upper limit for $\gamma$ consistent with the results from the chamber experiment by Behnke et al. (1996). The high uptake coefficients obtained by Harrison and Collins (1998) are likely the result of an experimental artifact, e.g., due to the fact that particles were deposited on a filter before analysis of the gas phase, leading to additional residence time during which they were effectively exposed to $\mathrm{NO}_{2}$. These high uptake coefficients are not used to recommend a value for the bulk accommodation coefficient, $\alpha_{\mathrm{b}}$.

Apart from the hydrolysis reaction ( $\mathrm{R} 1)$, a possible fate of $\mathrm{NO}_{2}$ at low concentration is Reaction (R2):

$2 \mathrm{NO}_{2}+\mathrm{H}_{2} \mathrm{O} \rightarrow \mathrm{HNO}_{2}+\mathrm{HNO}_{3}$

$2 \mathrm{NO}_{2}+\mathrm{NaCl} \rightarrow \mathrm{NOCl}+\mathrm{NaNO}_{3}$

Karlsson and Ljungström (1995) determined removal rates of chloride in an aerosol flow tube experiment of $1.7 \times 10^{-6} \mathrm{M} \mathrm{s}^{-1}$ at $190 \mathrm{ppb} \mathrm{NO}$ at $293 \mathrm{~K}$, which increased with decreasing temperature. Taking the Henry's law constant for pure water of $1.4 \times 10^{-2} \mathrm{M} \mathrm{atm}^{-1}$ (Cheung et al., 2000) and a chloride concentration of $4.4 \mathrm{M}$, this would lead to a liquid phase rate constant for Reaction (R2) of $200 \mathrm{M}^{-1} \mathrm{~s}^{-1}$, which is the basis for the recommendation. Karlsson and Ljungström observed $\mathrm{NOCl}$ in a separate bubbler experiment with higher $\mathrm{NO}_{2}$ concentration. Behnke et al. (1996) hypothesised that $\mathrm{NOCl}$ hydrolysed to form $\mathrm{HONO}$ in their chamber experiment.

The $\mathrm{NO}_{2}$ loss rates measured by Cape et al. (1993) in a $0.5 \mathrm{M} \mathrm{NaCl}$ solution at $283 \mathrm{~K}$ between 10 and $100 \mathrm{ppb}$ of $\mathrm{NO}_{2}$ were not different from those in pure water and ascribed entirely to the hydrolysis reaction. Cape et al. observed $\mathrm{NO}_{2}$ removal rates enhanced by up to a factor of 10 in authentic sea water, which they ascribed either to catalysis of the hydrolysis reaction or to an unknown reaction with another species. The magnitude of the hydrolysis rate constant reported by Cape et al. was likely affected by non-uniform distribution of reactants in the reactor. We therefore do not provide a recommendation for Reaction (R1) here, but suggest using the rate constant recommended for pure water on data sheet VI.A1.3, $3.0 \times 10^{7} \mathrm{M}^{-1} \mathrm{~s}^{-1}$, also for deliquesced sea salt aerosol.

Bambauer et al. (1994) determined the rate of nitrate formation in cloud chamber experiments, in which the cloud droplets contained $\mathrm{mM}$ amounts of $\mathrm{NaCl}$. The reaction order was about 1, in disagreement with Cape et al. (1993). An uptake coefficient was not extracted, nor was the possibility explored that Reaction (R2) could have interfered with the hydrolysis of $\mathrm{NO}_{2}$. For droplets of similar composition, Yabushita et al. (2009) observed a very large uptake coefficient and suggest that $\mathrm{NO}_{2}$ hydrolysis is enhanced in presence of millimolar concentrations of halogenide ions through formation of a charge transfer complex $\mathrm{NO}_{2}-\mathrm{X}^{-}$at the solution - air interface, which could account for the discrepancy between the Bambauer et al. and Cape et al. studies that were otherwise discussed in terms of different mixing regimes. Given that the $\mathrm{NO}_{2}$ concentrations in the experiment by Yabushita et al. were three orders of magnitude above atmospheric, the extent of such a surface process for deliquesced sea salt particles remains uncertain, and no recommendation is given. 
The value reported for the solubility by Cape et al. (1993) is affected by the same issues as the rate constants mentioned above, as they are interconnected through $\mathrm{Hk}_{2}^{1 / 2}$, which is the parameter directly retrieved from their experiments. As Cape et al. did not see a difference in solubility between pure water and chloride solution, we recommend using the solubility for pure water reported by Cheung et al. (2000).

\section{References}

Abbatt, J. P. D. and Waschewsky, G. C. G.: J. Phys. Chem. A, 102, 3719-3725, 1998.

Bambauer, A., Brantner, B., Paige, M., and Novakov, T.: Atmos. Environ., 28, 3225-3232, 1994.

Behnke, W., Elend, M., George, C., Kruger, H.-U., Scheer, V., and Zetzsch, C.: in: Heterogeneous and Liquid-Phase Processes, edited by: Warneck, P., Springer-Verlag, Heidelberg, 153-162, 1996.

Cape, J. N., Storetonwest, R. L., Devine, S. F., Beatty, R. N., and Murdoch, A.: Atmos. Environ., 27a, $2613-2621,1993$.

Cheung, J. L., Li, Y. Q., Boniface, J., Shi, Q., Davidovits, P., Worsnop, D. R., Jayne, J. T., and Kolb, C. E.: J. Phys. Chem. A, 104, 2655-2662, 2000.

Harrison, R. M. and Collins, G. M.: J. Atmos. Chem., 30, 397-406, 1998.

Karlsson, R. and Ljungström, E.: J. Aerosol Sci., 26, 39-50, 1995.

Rossi, M. J.: Chem. Rev., 103, 4823-4882, 2003.

Yabushita, A., Enami, S., Sakamoto, Y., Kawasaki, M., Hoffmann, M. R., and Colussi, A. J.: J. Phys. Chem. A, 113, 4844-4848, 2009. 
VI.A2.5

$\mathrm{NO}_{3}(\mathrm{~g})+\mathrm{Cl}^{-} / \mathrm{Br}^{-} / \mathrm{I}^{-}(\mathrm{aq}) \rightarrow \mathrm{NO}_{3}^{-}(\mathrm{aq})+\mathrm{Cl} / \mathrm{Br} / \mathrm{I}(\mathrm{aq})$

Experimental data

\begin{tabular}{lllll}
\hline Parameter & Aqueous solution & $T / \mathrm{K}$ & Reference & Technique/Comments \\
\hline $\begin{array}{l}\text { Uptake coefficients, } \gamma \\
(0.9-3.5) \times 10^{-3}\end{array}$ & $\mathrm{I}^{-},\left(5 \times 10^{-6}-0.4\right) \mathrm{M}$ & $273 \pm 1$ & Rudich et al. (1996a) & WWFT-AS (a) \\
$(0.8-6.0) \times 10^{-3}$ & $\mathrm{Cl}^{-},(0.01-0.5) \mathrm{M}$ & $273 \pm 1$ & Rudich et al. (1996b) & WWFT-AS (b) \\
$(1.6-5.5) \times 10^{-3}$ & $\mathrm{Br}^{-},(0.1-0.01) \mathrm{M}$ & & & \\
$(1.1-2.0) \times 10^{-3}$ & $\mathrm{Cl}^{-},(0.125-1) \mathrm{M}$ & $293 \pm 1$ & Schütze et al. (2005) & (c) \\
$>2 \times 10^{-3}$ & $\mathrm{Cl}^{-}, 0.1 \mathrm{M}$ & 293 & Thomas et al. (1998) & (d) \\
Accommodation coefficient, $\alpha_{b}$ & & & & \\
$>4 \times 10^{-2}$ & $\mathrm{I}^{-},\left(5 \times 10^{-6}-0.4\right) \mathrm{M}$ & $273 \pm 1$ & Rudich et al. (1996a) & (a) \\
$>2 \times 10^{-3}$ & $\mathrm{Cl}^{-}, 0.1 \mathrm{M}$ & 293 & Thomas et al. (1998) & (d) \\
$4.2_{-1.7}^{+2.2} \times 10^{-3}$ & $\mathrm{Cl}^{-},(0.125-1) \mathrm{M}$ & $293 \pm 1$ & Schütze et al. (2005) & (c) \\
\hline
\end{tabular}

\section{Comments}

(a) Flow tube operated at 12-23 mbar. $\mathrm{NO}_{3}\left((2-10) \times 10^{11}\right.$ molecule $\left.\mathrm{cm}^{-3}\right)$ was formed by the thermal dissociation of $\mathrm{N}_{2} \mathrm{O}_{5}$ and detected by diode laser absorption at $662 \mathrm{~nm}$ over a $12.6 \mathrm{~m}$ pathlength. The salt solution had a $\mathrm{pH}$ of 5-6.5. The dependence of the experimental $\mathrm{NO}_{3}$ uptake coefficient on the $\mathrm{I}^{-}$concentration was used to derive a value of $H^{2} D_{1} k$ of $(1.75 \pm 0.5) \times 10^{4} \mathrm{M} \mathrm{atm}^{-2} \mathrm{~cm}^{2} \mathrm{~s}^{-2}$. Using a previously determined value for $H D_{1}^{0.5}$ (Rudich et al., 1996b, this datasheet) this leads to an aqueous-phase rate constant for $\mathrm{NO}_{3}+\mathrm{I}^{-}$of $(4.6 \pm 0.5) \times 10^{9} \mathrm{M}^{-1} \mathrm{~s}^{-1}$ at $273 \mathrm{~K}$. A lower limit for $\alpha_{\mathrm{b}}$ was estimated from the maximum values of the uptake coefficients.

(b) Same set-up as in comment (a). The dependence of $\gamma$ on salt concentrations was combined with a literature value (Exner et al., 1992) for the rate coefficient for $\mathrm{Cl}^{-}$with $\mathrm{NO}_{3}\left(2.76 \times 10^{6} \mathrm{M}^{-1} \mathrm{~s}^{-1}\right.$ at $\left.273 \mathrm{~K}\right)$ to determine (for chloride) a value of $H D_{1}^{0.5}$ of $(1.9 \pm 0.4) \times 10^{-3} \mathrm{Matm}^{-1} \mathrm{~cm} \mathrm{~s}^{-0.5}$. Assuming a value of $D_{1}$ enabled a solubility of $\mathrm{NO}_{3}$ in $\mathrm{H}_{2} \mathrm{O}$ of $(0.6 \pm 0.3) \mathrm{M}^{-1} \mathrm{~atm}^{-1}$ to be derived.

(c) Single droplet $\left(\approx 7 \mathrm{~mm}^{3}\right)$ suspended from a pipette in a flow tube $(10 \mathrm{mbar} H \mathrm{He})$ with UV-Vis absorption spectroscopy for concentration measurement in both gas and aqueous phases $\left(\mathrm{NO}_{3}^{-}\right.$at $235 \mathrm{~nm}, \mathrm{NO}_{3}$ using the $662 \mathrm{~nm}$ feature). $\mathrm{NO}_{3}$ was generated by reacting $\mathrm{NO}_{2}$ with $\mathrm{O}_{3}$ at $393 \mathrm{~K}$ to keep the $\mathrm{N}_{2} \mathrm{O}_{5}$ level low $(\approx 5 \%)$. $\mathrm{HNO}_{3}$ was formed at approximately the same concentration as $\mathrm{NO}_{3}$. Uptake of $\mathrm{NO}_{3}$ to the droplet was monitored by nitrate anion absorption. A value of $H D_{1}^{0.5} k^{0.5}=(1.9 \pm 0.2) \mathrm{M} \mathrm{atm}^{-1} \mathrm{~cm} \mathrm{~s}^{-0.5}$ was derived.

(d) Uptake of $\mathrm{NO}_{3}$ (generated by mixing $\mathrm{NO}$ with $\mathrm{O}_{3}$ at $\approx 400^{\circ} \mathrm{C}$ ) to $0.1 \mathrm{M}$ chloride solution was monitored using three serial coiled glass denuders ( $2 \mathrm{~mm}$ id). Nitrate in solution was determined following reduction to $\mathrm{NO}_{2}^{-}$and the Saltzman reaction. Large diffusion limitations result in only a lower limit to $\gamma$.

\section{Preferred values}

\begin{tabular}{lll}
\hline Parameter & Value & $T / \mathrm{K}$ \\
\hline$\alpha_{\mathrm{b}}$ & $1.3 \times 10^{-2}$ & 273 \\
$k_{\mathrm{Cl}}\left(\mathrm{M}^{-1} \mathrm{~s}^{-1}\right)$ & $2.76 \times 10^{6}$ & 273 \\
$k_{\mathrm{Br}}\left(\mathrm{M}^{-1} \mathrm{~s}^{-1}\right)$ & $1.02 \times 10^{8}$ & 273 \\
$k_{\mathrm{I}}\left(\mathrm{M}^{-1} \mathrm{~s}^{-1}\right)$ & $4.6 \times 10^{9}$ & 273 \\
Reliability & & \\
$\Delta \log (\gamma)$ & \pm 0.5 & 273 \\
\hline
\end{tabular}




\section{Comments on preferred values}

The detailed studies (Rudich et al., 1996b; Schütze et al., 2005) on the uptake of $\mathrm{NO}_{3}$ to aqueous chloride solutions of various ionic strength use very different methods and return values of the common observable $\left(H D_{1}^{0.5} k^{0.5}\right)$ which differ by $\approx 70 \%$, which can be considered to be in reasonable agreement. Some of the discrepancy can be attributed to different $\mathrm{NO}_{3}$ solubilities $(H)$ at 273 and $291 \mathrm{~K}$. The derivation of the accommodation coefficient is not exact in either Rudich et al. (1996a) nor in Schütze et al. (2005) and the results differ by at least a factor of 6 . The need to correct data due to aqueous nitrate formed from large impurity levels of $\mathrm{HNO}_{3}$ in the work of Schütze et al. (2005) leads us to prefer the results of Rudich et al. (1996). The accommodation coefficient chosen is slightly lower than the lower limit given by Rudich et al., as this better represents their dataset within the parameterisation listed below.

The rate coefficient for the aqueous phase reaction of $\mathrm{NO}_{3}$ with $\mathrm{Cl}^{-}$was taken from Exner et al. (1992), although there is some disagreement concerning this number (Herrmann, 2003). We adopt this rate coefficient and the solubility derived by Rudich et al. (1996b) as it allows us to present an internally consistent set of parameters based on observations of the composite $H D_{1}^{0.5} k^{0.5}$ term. The rate coefficient listed for the reaction of $\mathrm{NO}_{3}$ with $\mathrm{Br}^{-}$was taken from the ratio $k_{\mathrm{Cl}} / k_{\mathrm{Br}}=37 \pm 4$ as reported by Rudich et al. (1996b). The reliability of the parameters listed above cannot be given individually, but an assessment of the overall uncertainty in $\gamma$ (calculated as below) is given.

Parameterisation of the net uptake coefficient for interaction of $\mathrm{NO}_{3}$ with halide aerosol requires components for the hydrolysis term and the reaction with the halide ions (see expression below). There is large uncertainty association with the hydrolysis rate constant (VI.A1.4), though we note that for sea-salt aerosol $(5 \mathrm{M} \mathrm{NaCl})$, neither bromide, iodide nor hydrolysis contribute significantly to $\mathrm{NO}_{3}$ loss when compare to chloride. The net uptake coefficient can be calculated from:

$\gamma=\left\{\frac{1}{\alpha}+\frac{c}{4 H R T\left(D_{1} k^{\prime}\right)^{0.5}}\right\}^{-1}$ where $k^{\prime}=k_{\mathrm{Cl}}\left[\mathrm{Cl}^{-}\right]+k_{\mathrm{Br}}\left[\mathrm{Br}^{-}\right]+k_{\mathrm{Br}}\left[\mathrm{I}^{-}\right]+k_{\mathrm{H} 2 \mathrm{O}}^{\prime}$ and $\left[\mathrm{X}^{-}\right]$are the activities of the respective anions.

We recommend use of $D_{1}=1 \times 10^{-5} \mathrm{~cm}^{2} \mathrm{~s}^{-1}, H=0.6 \mathrm{M} \mathrm{atm}^{-1}$ and $k_{\mathrm{H} 2 \mathrm{O}}=23$ (see VI.A1.04).

There are some studies of the uptake of $\mathrm{NO}_{3}$ to solid salt surfaces (Seisel et al., 1997, 1999; Gratpanche et al., 1999; Gerschenzon et al., 1999). All suggest larger uptake coefficients to bromide surfaces compared to chloride, in line with the larger uptake coefficient listed above. There is also some indirect evidence of halogen atom release to the gas-phase (Seisel et al., 1997).

\section{References}

Chameides, W. L.: J. Geophys. Res., 91, 14571-14572, 1986.

Exner, M., Herrmann, H., and Zellner, R.: Ber. Bunsen. Ges. Phys. Chem. Chem. Phys., 96, 470-477, 1992.

Gershenzon, M. Y., Il'in, S., Fedotov, N. G., and Gershenzon, Y. M.: J. Atmos. Chem., 34, 119-135, 1999.

Gratpanche, F. and Sawerysyn, J. P.: J. Chim. Phys. Phys.-Chim. Biol., 96, 213-231, 1999.

Herrmann, H.: Chem. Rev., 103, 4691-4716, 2003.

Rudich, Y., Talukdar, R. K., Imamura, T., Fox, R. W., and Ravishankara, A. R.: Chem. Phys. Lett., 261, 467-473, 1996.

Rudich, Y., Talukdar, R. K., Ravishankara, A. R., and Fox, R. W.: J. Geophys. Res., 101, 21023-21031, 1996 b.

Schütze, M. and Herrmann, H.: J. Atmos. Chem., 52, 1-18, 2005.

Seisel, S., Caloz, F., Fenter, F. F., van den Bergh, H., and Rossi, M. J.: Geophys. Res. Lett., 24, 2757-2760, 1997.

Seisel, S., Fluckiger, B., Caloz, F., and Rossi, M. J.: Phys. Chem. Chem. Phys., 1, 2257-2266, 1999.

Thomas, K., Volz-Thomas, A., Mihelcic, D., Smit, H. G. J., and Kley, D.: J. Atmos. Chem., 29, 17-43, 1998. 


\section{VI.A2.6}

$\mathrm{N}_{2} \mathrm{O}_{5}(\mathrm{~g})+\mathrm{Cl}^{-} / \mathrm{Br}^{-}(\mathrm{aq}) \rightarrow$ products

\section{Experimental data}

\begin{tabular}{lllll}
\hline Parameter & Aqueous solution & $T / \mathrm{K}$ & Reference & Technique/ Comments \\
\hline Uptake coefficients, $\gamma$ & & & & \\
$(3.9 \pm 0.13) \times 10^{-2}$ & $\mathrm{NaCl}(1 \mathrm{M})$ & 263 & George et al. (1994) & DT-HPLC (a) \\
$(3.7 \pm 1.2) \times 10^{-2}$ & & 268 & & \\
$(1.4 \pm 0.3) \times 10^{-2}$ & & 273 & & \\
$(1.4 \pm 0.08) \times 10^{-2}$ & & 278 & & \\
$(3.2 \pm 0.2) \times 10^{-2}$ & $\mathrm{NaCl}(1.7-5.1 \mathrm{M})$ & 291 & Behnke et al. (1997) & Aerosol chamber (b) \\
$(1.8 \pm 0.3) \times 10^{-2}$ & $\mathrm{NaCl}(1 \mathrm{M}) \mathrm{NaBr}(0.1-1 \mathrm{M}) \mathrm{NaI}(0.1-1 \mathrm{M})$ & $262-278$ & Schweitzer et al. (1998) & DT-MS (c) \\
$0.64 \times 10^{-2}$ & $\mathrm{NaCl}(\mathrm{RH}=30 \%)$ & $295 \pm 2$ & Stewart et al. (2004) & AFT-CIMS (d) \\
$0.9 \times 10^{-2}$ & $\mathrm{NaCl}(\mathrm{RH}=50 \%)$ & & & \\
$1.04 \times 10^{-2}$ & $\mathrm{NaCl}(\mathrm{RH}=70 \%)$ & & & \\
$0.78 \times 10^{-3}$ & $\mathrm{NaCl}(\mathrm{RH}=80 \%)$ & & & \\
$1.6 \times 10^{-2}$ & natural sea-salt (RH=30\%) & & & \\
$2.8 \times 10^{-2}$ & natural sea-salt (RH=50\%) & & & \\
$1.3 \times 10^{-2}$ & natural sea-salt (RH=70\%) & & & \\
$3.1 \times 10^{-2}$ & natural sea-salt (RH=80\%) & & & \\
$(2.2 \pm 0.4) \times 10^{-2}$ & synthetic sea-salt (RH=50\%) & 295 & Thornton and Abbatt (2005) & AFT-CIMS (e) \\
$(3.0 \pm 0.8) \times 10^{-2}$ & synthetic sea-salt (RH=65\%) & & & \\
$(2.4 \pm 0.5) \times 10^{-2}$ & synthetic sea-salt (RH=70\%) & & & \\
\hline
\end{tabular}

\section{Comments}

(a) $\mathrm{N}_{2} \mathrm{O}_{5}$ made in-situ by reacting $\mathrm{NO}$ with $\mathrm{O}_{3}$. Droplet train flow tube operated at $27-80$ mbar He with $80-150 \mu \mathrm{m}$ droplets. Trace gas concentration measured by FTIR at entrance to flow tube, nitrate content of droplets analysed by HPLC to derive uptake coefficients. This required knowledge of the relative efficiency of nitrate and nitryl-chloride products.

(b) Teflon aerosol smog chamber at 1 atm. pressure. Initial concentration of $\mathrm{N}_{2} \mathrm{O}_{5}$ determined by FTIR. Subsequent to reaction of $\mathrm{N}_{2} \mathrm{O}_{5}$ with aerosol, $\mathrm{NO}_{3}$ (in equilibrium with gas-phase $\mathrm{N}_{2} \mathrm{O}_{5}$ ) was photolysed and $\mathrm{NO}_{\mathrm{x}}$ was analysed to indirectly derive total un-reacted $\mathrm{N}_{2} \mathrm{O}_{5} . \mathrm{N}_{2} \mathrm{O}_{5}$ taken up to the aerosol was calculated from the difference in initial and final concentrations. The amount of $\mathrm{ClNO}_{2}$ was determined by its photolytic conversion to $\mathrm{Cl}$ atoms (determined by hydrocarbon consumption). Aerosol number and size distribution (average diameter $\approx 150 \mathrm{~nm}$ ) were obtained using a DMA-CPC. Values for the uptake coefficient supersede those reported in short communications by Behnke et al. (1991, 1992, 1993).

(c) $\mathrm{N}_{2} \mathrm{O}_{5}$ made in-situ by reacting $\mathrm{NO}$ with $\mathrm{O}_{3} .80-150 \mu$ m droplets. Gas analysed by ion-trap MS and FTIR (for $\mathrm{ClNO}_{2}$ formation).

(d) Uptake of $\mathrm{N}_{2} \mathrm{O}_{5}$ (100-700 ppbv at atmospheric pressure) to particles of aqueous aerosol of pure $\mathrm{NaCl}$ or natural sea-salt with diameters of $\sim 60-250 \mathrm{~nm}$ at RH between 30 and $80 \% . \mathrm{N}_{2} \mathrm{O}_{5}$ was detected as the change in NO signal (monitored with ta CLD) following thermal dissociation to $\mathrm{NO}_{3}$ and titration with $\mathrm{NO}$. The measured uptake coeficients were strongly influenced by droplet size, indicating volume limited uptake. Once corrected for diffuso-reactive effects, the uptake coefficients (listed in the table) were independent of RH.

(e) Uptake of $\mathrm{N}_{2} \mathrm{O}_{5}$ (8-30 ppbv at atmospheric pressure) to particles of aqueous aerosol of synthetic sea-salt (containing $\mathrm{Na}^{+}$, $\mathrm{K}^{+}, \mathrm{Mg}^{2+}, \mathrm{Ca}^{2+}, \mathrm{Cl}^{-}$and $\mathrm{Br}^{-}$) with surface area weighted particle radii of 90 to $150 \mathrm{~nm} . \mathrm{N}_{2} \mathrm{O}_{5}$ was detected as $\mathrm{NO}_{3}^{-}$ using $\mathrm{I}^{-}$primary ions. No significant influence of particle size (varied e.g. for $\mathrm{RH}=50 \%$ from 85 to $134 \mathrm{~nm}$ ) on $\gamma$ was observed. 
Preferred values

\begin{tabular}{lll}
\hline Parameter & Value & $T / \mathrm{K}$ \\
\hline$\gamma$ & 0.02 & $260-300$ \\
$k_{3} / k_{2}$ & 450 & 298 \\
Reliability & & \\
$\Delta \log (\gamma)$ & \pm 0.3 & $260-300$ \\
$\Delta \log \left(k_{3} / k_{2}\right)$ & \pm 0.3 & 298 \\
\hline
\end{tabular}

\section{Comments on preferred values}

The preferred values of $\gamma$ are independent of RH and temperature and refer to the uptake of $\mathrm{N}_{2} \mathrm{O}_{5}$ to pure water-halide solutions. The presence of nitrate and/or organic components can reduce $\gamma$ (datasheets VI.A3.7 and VI.A3.8). Indeed, Thornton and Abbatt (2005) argue that the particle size dependence of $\gamma$ observed by Stewart et al. (2004) was not entirely due to reacto-diffusive length considerations but also to use of high gas-phase $\mathrm{N}_{2} \mathrm{O}_{5}$ resulting in high particle nitrate content, which suppresses the uptake of $\mathrm{N}_{2} \mathrm{O}_{5}$. Both Stewart et al. (2004) and Thornton and Abbatt (2005) showed that the uptake cofficient on sea-salt dried to below the crystallisation RH was much lower. For aqueous particles with $\mathrm{RH}>50 \%, \gamma$ is independent of chloride or bromide concentration or relative humidity. Within experimental scatter and the range covered there is also no dependence of $\gamma$ on the temperature, with datasets on synthetic salt surfaces at $295 \mathrm{~K}$ giving the same uptake coefficient as $\mathrm{NaCl}$ and $\mathrm{NaCl} / \mathrm{NaBr}$ containing aqueous solutions at $\sim 270 \mathrm{~K}$.

The observation that the uptake coefficient is insensitive to the aqueous composition (content of chloride, bromide or iodide) and that the yield of $\mathrm{ClNO}_{2}$ following uptake of $\mathrm{N}_{2} \mathrm{O}_{5}$ to chloride solutions of concentration $\geq 1 \mathrm{M}$ approaches unity (Behnke et al., 1997; Schweitzer et al., 1998; Roberts et al., 2009) has led to the following mechanism being proposed, with dissociation of $\mathrm{N}_{2} \mathrm{O}_{5}$ (Reaction R1) the rate limiting step.

$$
\begin{aligned}
& \mathrm{N}_{2} \mathrm{O}_{5}+\mathrm{H}_{2} \mathrm{O} \Leftrightarrow \mathrm{H}_{2} \mathrm{NO}_{3}^{+}+\mathrm{NO}_{3}^{-} \\
& \mathrm{H}_{2} \mathrm{NO}_{3}^{+}+\mathrm{H}_{2} \mathrm{O} \rightarrow \mathrm{H}_{3} \mathrm{O}^{+}+\mathrm{HNO}_{3} \\
& \mathrm{H}_{2} \mathrm{NO}_{3}^{+}+\mathrm{Cl}^{-} \rightarrow \mathrm{ClNO}_{2}+\mathrm{H}_{2} \mathrm{O}
\end{aligned}
$$

From the reaction scheme above, the yield of $\mathrm{ClNO}_{2}$ is defined by competition between hydrolysis (with rate coefficient $k_{2}$ ) and reaction with chloride anions (rate coefficient $k_{3}$ ) so that:

$$
\frac{\left[\mathrm{ClNO}_{2}\right]}{\Delta\left[\mathrm{N}_{2} \mathrm{O}_{5}\right]}=\left(\frac{k_{2}\left[\mathrm{H}_{2} \mathrm{O}\right]}{k_{3}\left[\mathrm{Cl}^{-}\right]}+1\right)^{-1}
$$

Schweitzer et al. (1999) reported unity (1.00 \pm 0.14$)$ yield of $\mathrm{ClNO}_{2}$ per $\mathrm{N}_{2} \mathrm{O}_{5}$ taken up to $1 \mathrm{M} \mathrm{Cl}^{-}$solution. Within the error bounds this is consistent with the results of Behnke et al. (1999) who used the WWFT method to derive yields of $\mathrm{ClNO}_{2}$ from 0.4 (at their lowest, non-zero chloride concentration) to $>0.9$ at $2 \mathrm{M}$ chloride and above. From their data they calculated $k_{3} / k_{2}$ $($ at $291 \mathrm{~K})=836 \pm 32$. On synthetic sea-salt $(50 \% \mathrm{RH})$ Thornton and Abbatt (2005) derived a lower limit to the $\mathrm{ClNO}_{2}$ yield of $50 \%$. Roberts et al. (2009), measured chloride molarity dependent yields of $\mathrm{ClNO}_{2}$ over the range 0.02 to $0.5 \mathrm{M} \mathrm{Cl}^{-}$. A number of chloride containing substrates were examined including $\left(\mathrm{NH}_{4}\right) \mathrm{HSO}_{4},\left(\mathrm{NH}_{4}\right)_{2} \mathrm{SO}_{4}$, water, oxalic acid, sea-salt. The yield of $\mathrm{ClNO}_{2}$ depended only on the chloride concentration, though there may have been evidence for a slightly enhanced yield at low $\mathrm{pH}$. They calculated $k_{3} / k_{2}$ (at $\left.297 \mathrm{~K}\right)=450 \pm 100$. Bertram and Thornton (2009) examined the effect of chloride and nitrate concentrations on the $\mathrm{ClNO}_{2}$ yield from the uptake of $\mathrm{N}_{2} \mathrm{O}_{5}$ to mixed nitrate/chloride particles and derived $k_{3} / k_{2}$ $($ at $298 \mathrm{~K})=483 \pm 175$.

Our preferred value for the value of $k_{3} / k_{2}$ (at $298 \mathrm{~K}$ ) is based on the most detailed study (Roberts et al., 2009). Roberts et al. (2009) suggest that $k_{2}$ (but not the ion recombination reaction, $k_{3}$ ) is likely to have a large barrier and thus be slower at lower temperatures, which would result in a larger $k_{3} / k_{2}$ and thus larger $\mathrm{ClNO}_{2}$ yield for a given $\mathrm{Cl}^{-}$concentration. The experimental datasets are however not precise enough to clarify if the larger $k_{3} / k_{2}$ value of Behnke et al. (1997) is due to use of slightly lower temperatures in their experiments or if it is related to use of various ionic strength solutions and thus $\mathrm{Cl}^{-}$ activities. We note also that, at low $\mathrm{pH}$ the yield of $\mathrm{ClNO}_{2}$ can be depleted due to conversion to $\mathrm{Cl}_{2}$ (Roberts et al., 2008). This is covered in datasheet VI.A2.9 dealing with $\mathrm{ClNO}_{2}$ uptake.

Schweitzer et al. (1999) report $\mathrm{BrNO}_{2}$ and $\mathrm{Br}_{2}$ formation when using $\mathrm{NaBr}$ solutions and $\mathrm{I}_{2}$ when using $\mathrm{NaI}$ solution. 
There have been a number of studies on the uptake of $\mathrm{N}_{2} \mathrm{O}_{5}$ to dry salt surfaces (Finlayson-Pitts, 1989; Leu et al., 1995; Fenter et al., 1996; Msibi et al., 1998; Koch et al., 1999; Hoffmann et al., 2003). These studies also report high yields of $\mathrm{ClNO}_{2}$ when $\mathrm{N}_{2} \mathrm{O}_{5}$ reacts with a chloride surface (Finlayson-Pitts et al., 1996; Fenter et al., 1996; Koch et al., 1999; Hoffmann et al., 2003). The reaction with bromide leads to $\mathrm{Br}_{2}$ formation, presumably via formation of $\mathrm{BrNO}_{2}$, which can further react with surface bromide (Fenter et al., 1996):

$\mathrm{N}_{2} \mathrm{O}_{5}+\mathrm{Br}^{-} \rightarrow \mathrm{BrNO}_{2}+\mathrm{NO}_{3}^{-}$

$\mathrm{BrNO}_{2}+\mathrm{Br}^{-} \rightarrow \mathrm{Br}_{2}+\mathrm{NO}_{2}^{-}$

\section{References}

Behnke, W., Krüger, H.-U., Scheer, V., and Zetzsch, C.: J. Aerosol Sci., 22, 609-612, 1991.

Behnke, W., Krüger, H.-U., Scheer, V., and Zetzsch, C.: J. Aerosol. Sci., 23, S933-S936, 1992.

Behnke, W., Scheer, V., and Zetzsch, C.: J. Aerosol Sci., 24, S115-S116, 1993.

Behnke, W., George, C., Scheer, V., and Zetzsch, C.: J. Geophys. Res., 102, 3795-3804, 1997.

Bertram, T. H. and Thornton, J. A.: Toward a general parameterization of $\mathrm{N}_{2} \mathrm{O}_{5}$ reactivity on aqueous particles: the competing effects of particle liquid water, nitrate and chloride, Atmos. Chem. Phys., 9, 8351-8363, doi:10.5194/acp-9-8351-2009, 2009.

Fenter, F. F., Caloz, F., and Rossi, M. J.: J. Phys. Chem., 100, 1008-1019, 1996.

Finlayson-Pitts, B. J., Ezell, M. J., and Pitts, J. N. J.: Nature, 337, 241-244, 1989.

George, C., Ponche, J. L., Mirabel, P., Behnke, W., Scheer, V., and Zetzsch, C.: J. Phys. Chem., 98, 8780-8784, 1994.

Hoffman, R. C., Gebel, M. E., Fox, B. S., and Finlayson-Pitts, B. J.: Phys. Chem. Chem. Phys., 5, 1780-1789, 2003.

Koch, T. G., Vandenbergh, H., and Rossi, M. J.: Phys. Chem. Chem. Phys., 1, 2687-2694, 1999.

Leu, M. T., Timonen, R. S., Keyser, L. F., and Yung, Y. L.: J. Phys. Chem., 99, 13203-13212, 1995.

Msibi, I. M., Li, Y., Shi, J. P., and Harrison, R. M.: J. Atmos. Chem., 18, 291-300, 1994.

Roberts, J. M., Osthoff, H. D., Brown, S. S., and Ravishankara, A. R.: Science, 321, 1059-1059, 2008.

Roberts, J. M., Osthoff, H. D., Brown, S. S., Ravishankara, A. R., Coffman, D., Quinn, P., and Bates, T.: Geophys. Res. Lett., 36, L20808, doi:10.1029/2009GL040448, 2009.

Schweitzer, F., Mirabel, P., and George, C.: J. Phys. Chem. A, 102, 3942-3952, 1998.

Stewart, D. J., Griffiths, P. T., and Cox, R. A.: Atmos. Chem. Phys., 4, 1381-1388, doi:10.5194/acp-4-1381-2004, 2004.

Thornton, J. A. and Abbatt, J. P. D.: J. Phys. Chem. A, 109, 10004-10012, 2005. 
VI.A2.7

$\mathrm{HNO}_{3}(\mathrm{~g})+\mathrm{Cl}^{-}(\mathrm{aq}) \rightarrow \mathrm{HCl}(\mathrm{g})+\mathrm{NO}_{3}^{-}(\mathrm{aq})$

\section{Experimental data}

\begin{tabular}{lllll}
\hline Parameter & $\mathrm{RH} / \%$ & $T / \mathrm{K}$ & Reference & Technique/Comments \\
\hline Uptake coefficients: $\gamma, \gamma_{s s}, \gamma_{0}$ & & & & \\
$\gamma>0.2$ (deliquesced NaCl) & 75 & 298 & Abbatt and Waschewsky (1998) & AFT-CIMS (a) \\
$\gamma=0.5 \pm 0.2($ deliquesced sea salt) & 55 & 300 & Guimbaud et al. (2002) & AFT-RC (b) \\
$\gamma_{0}=(4.9 \pm 2.7) \times 10^{-3}$ (deliquesced $\left.\mathrm{NaCl}\right)$ & 80 & 298 & Tolocka et al. (2004) & AFT-AMS (c) \\
$\gamma_{0}=0.15 \pm 0.05($ deliquesced $\mathrm{NaCl})$ & 60 & 298 & Saul et al. (2006) & AFT-AMS (d) \\
$\gamma_{0}=0.15 \pm 0.05\left(\right.$ deliquesced $\left.\mathrm{NaCl} / \mathrm{MgCl}_{2}\right)$ & 60 & 298 & & \\
$\gamma=0.21-0.11($ deliquesced $\mathrm{NaCl})$ & $55-80$ & 298 & Liu et al. (2007) & \\
$\gamma=0.25-0.12\left(\mathrm{NaCl} / \mathrm{MgCl}{ }_{2}\right)$ & $55-80$ & & & \\
$\gamma=0.27-0.12($ sea salt) & $55-80$ & & & AFT-RC/IC (f) \\
$\gamma=0.5_{-0.2}^{+0.5}$ (deliquesced $\left.\mathrm{NaCl}\right)$ & 60 & 296 & Stemmler et al. (2008) & \\
\hline
\end{tabular}

\section{Comments}

(a) $\mathrm{NaCl}$ aerosol was produced using a nebulizer. The particle sizes were measured using an optical particle counter and were in the range of 2 to $4 \mu \mathrm{m}$. The $\mathrm{HNO}_{3}$ concentration (about $10^{13}$ molecule $\mathrm{cm}^{-3}$ ) was measured downstream of the flowtube using chemical ionization mass spectrometry. The uptake coefficient was calculated from the measured apparent first order loss rate constant including correction for diffusion in the gas phase, leading to the lower limit given in the table.

(b) Sea salt aerosol was produced by nebulizing a sea salt solution. The particle size distribution (with a mode around $70 \mathrm{~nm}$ ) was monitored by SMPS. Experiments were performed at $55 \% \mathrm{RH}$. $\mathrm{HNO}_{3}$ (in the concentration range of $10^{11}$ to $10^{13}$ molecule $\mathrm{cm}^{-3}$ ) was labeled with the short-lived radioactive tracer ${ }^{13} \mathrm{~N}$. Both, the loss of $\mathrm{HNO}_{3}(\mathrm{~g})$ and appearance of aerosol phase product was monitored. The uptake coefficient (with only minor correction by diffusion) was independent of gas phase concentration up to $10^{12}$ molecule $\mathrm{cm}^{-3}$ and decreased at higher concentration due to depletion of chloride in the particulate phase. The Aerosol Inorganic Model (AIM) was used to confirm that the low concentration data were obtained under conditions far from equilibrium of the $\mathrm{HNO}_{3}$ (g,aq)- $\mathrm{HCl}(\mathrm{g}, \mathrm{aq})$ system.

(c) $\mathrm{NaCl}$ aerosol produced using a nebulizer, from which a monodisperse aerosol (100-220 nm diameter) was selected using a differential mobility analyzer. The size distribution was measured using SMPS. The product aerosol was sampled into a real-time laser ablation $(193 \mathrm{~nm})$ single particle time-of-flight mass spectrometer operating in negative-ion mode, from which the mole fraction of chloride and nitrate was obtained. Removal of chloride from the particulate phase was used to derive an uptake coefficient for $\mathrm{HNO}_{3}$. The reported uptake coefficient was independent of $\mathrm{HNO}_{3}$ concentration between $10^{12}$ and $10^{13}$ molecule $\mathrm{cm}^{-3}$. The small uptake coefficients were explained by slow formation of $\mathrm{HCl}$ in the aqueous phase that appeared to limit uptake of $\mathrm{HNO}_{3}$, the main argument being the observed size dependence that could not be due to gas phase diffusion or liquid phase diffusion.

(d) Same experimental approach as in (c). Additionally, mixtures of $\mathrm{NaCl}$ with 0.114 mole fraction of $\mathrm{MgCl}_{2}$ were used. The differences in the setup included changes to the flow reactor design that led to systematic errors in the quantification of the actual $\mathrm{HNO}_{3}$ concentration in the reactor of the previous study. With this revised setup, the observed chloride mole fractions as a function of exposure time at $2 \times 10^{12}$ molecule $\mathrm{cm}^{-3}$ of $\mathrm{HNO}_{3}$ was consistent with those in the previous study. However, the uptake coefficient derived using the correct $\mathrm{HNO}_{3}$ concentration led to uptake coefficients between 0.1 and 0.2 , still depending on size. Therefore, it is still suggested that formation of $\mathrm{HCl}$ in the aqueous phase is limiting uptake of $\mathrm{HNO}_{3}$.

(e) $\mathrm{NaCl}$ aerosol produced using a nebulizer and then deposited onto TEM grids (formvar on nickel grids) using an impactor. Experiments were performed by impinging a laminar jet of humidified $\mathrm{HNO}_{3}\left(10^{11}\right.$ molecule $\left.\mathrm{cm}^{-3}\right)$ in $\mathrm{N}_{2}$ onto the sample. The loss of $\mathrm{HNO}_{3}$ over the sample was measured by a chemiluminescence detector. Chemical processing of individual particles was monitored using offline scanning electron microscopy connected with energy dispersive X-ray analysis. The dry particle diameter was $0.9 \mu \mathrm{m}$, the wet particle size was estimated from the dry diameter measured in the SEM and hygroscopic growth curves in the literature. The dynamics of the trace gas - particle on the substrate interaction 
was accompanied by CFD to support the relationship between the measured loss rate, the particle density and the uptake coefficient on individual particles. It showed that the net uptake coefficient was largely controlled by gas phase diffusion and was therefore dependent on the (wet) particle diameter. The decrease of the uptake coefficient with increasing RH above the efflorescence point is explained by the decreasing chloride concentration in the particle, assuming that the formation of $\mathrm{HCl}$ is the rate limiting factor. A correction is not applied to account for gas phase diffusion and to report a true uptake coefficient at the particle surface.

(f) Same experimental approach as in (b) with only slight modifications. The main aim was to investigate the effects of surfactants on the $\mathrm{HNO}_{3}$ uptake. In the absence of surfactants, the uptake coefficients were consistent with those reported by Guimbaud et al. (2002). Offline, ion chromatographic analysis of filter samples confirmed the complete displacement of reacted chloride. The revised error analysis included a discussion of the mixing time in the flow tube and re-equilibration in the denuder system.

\section{Preferred values}

\begin{tabular}{lcc}
\hline Parameter & Value & $T / \mathrm{K}$ \\
\hline$\alpha_{\mathrm{b}}$ & $>0.5$ & 298 \\
Reliability & & \\
$\Delta \log \left(\alpha_{\mathrm{b}}\right)$ & \pm 0.3 & 298 \\
\hline
\end{tabular}

\section{Comments on preferred values}

The available studies agree that the acid displacement

$\mathrm{NaCl}(\mathrm{aq})+\mathrm{HNO}_{3}(\mathrm{~g}) \rightarrow \mathrm{NaNO}_{3}(\mathrm{aq})+\mathrm{HCl}(\mathrm{g})$

drives the uptake of $\mathrm{HNO}_{3}$ to sea salt solutions and their proxies, deliquesced $\mathrm{NaCl}$ or mixtures of $\mathrm{NaCl}$ with $\mathrm{MgCl}_{2}$, and that the uptake is fast. This is in line with many studies on solid halogenide salts, where the uptake coefficient of $\mathrm{HNO}_{3}$ showed a strong dependence on the amount of surface adsorbed water, providing evidence that chloride ion (partially or fully hydrated) is required to drive acid displacement (see Rossi, 2003, and references therein). The Abbatt and Waschewsky (1998) and the Liu et al. (2007) data were affected to a varying degree by gas phase diffusion, so that those reported uptake coefficients should be considered as lower limits. Regarding the absolute values of the uptake coefficient, the Saul et al. (2006) data based on an improved calibration of the $\mathrm{HNO}_{3}$ concentration are considered to supersede the Tolocka et al. (2004) data. Therefore, the available studies agree fairly well. From the very high solubility of $\mathrm{HNO}_{3}$, the very fast rates for its dissociation in the aqueous phase, and the very fast protonation of chloride, we conclude that solubility, reaction or diffusion cannot limit the rate of uptake of $\mathrm{HNO}_{3}$, which was suspected to be responsible for the size and humidity dependence by Saul et al., Liu et al. and also earlier by ten Brink (1998). We therefore recommend the bulk accommodation coefficient observed by Guimbaud et al. (2002) and Stemmler et al. (2008) as a lower limit. With $\mathrm{NaCl}$ solution in excess, $\mathrm{HNO}_{3}$ - protons are nearly completely displaced into the gas phase as $\mathrm{HCl}$ at equilibrium due to the divergent behaviour of the activity coefficients of chloride and nitrate at high ionic strength (Brimblecombe and Clegg, 1988).

\section{References}

Brimblecombe, P. and Clegg, S. L.: J. Atmos. Chem., 7, 1-18, 1988.

Guimbaud, C., Arens, F., Gutzwiller, L., Gäggeler, H. W., and Ammann, M.: Atmos. Chem. Phys., 2, 249-257, doi:10.5194/acp-2-249-2002, 2002.

Liu, Y., Cain, J. P., Wang, H., and Laskin, A.: J. Phys. Chem. A, 111, 10026-10043, 2007.

Rossi, M. J.: Chem. Rev., 103, 4823-4882, 2003.

Saul, T. D., Tolocka, M. P., and Johnston, M. V.: J. Phys. Chem. A, 110, 7614-7620, 2006.

Stemmler, K., Vlasenko, A., Guimbaud, C., and Ammann, M.: Atmos. Chem. Phys., 8, 5127-5141, doi:10.5194/acp-8-51272008, 2008.

ten Brink, H. M.: J. Aerosol Sci., 29, 57-64, 1998.

Tolocka, M. P., Saul, T. D., and Johnston, M. V.: J. Phys. Chem. A, 108, 2659-2665, 2004. 
VI.A2.8

$\mathrm{HOCl}(\mathrm{g})+\mathrm{Cl}^{-} / \mathrm{Br}^{-}(\mathrm{aq}) \rightarrow$ products

Experimental data

\begin{tabular}{lllll}
\hline Parameter & Aqueous solution & $T / \mathrm{K}$ & Reference & Technique/Comments \\
\hline $\begin{array}{llll}\text { Uptake coefficients, } \gamma \\
(0.39-1.79) \times 10^{-3}\end{array}$ & $\begin{array}{l}\text { Natural salt }(\mathrm{pH} \approx-0.7 \text { to }-1, \\
\mathrm{RH} 75 \%-85 \%)\end{array}$ & Pratte and Rossi (2006) & AFT-MS (a) \\
$<2 \times 10^{-4}$ & $\begin{array}{l}\mathrm{Cl}^{-} \text {and } \mathrm{RSS}(\mathrm{pH} \approx-0.7 \text { to }-1, \\
\mathrm{RH} 75 \%-85 \%)\end{array}$ & & \\
& & & \\
\hline
\end{tabular}

\section{Comments}

(a) Atmospheric pressure aerosol flow tube. Aerosols $\left(\approx 200-300 \mathrm{~nm}\right.$ diameter, $1.7-11 \times 10^{-4} \mathrm{~cm}^{2} \mathrm{~cm}^{-3}$ total surface area density) were made from acidified salt solutions $\left(0.034 \mathrm{M} \mathrm{Cl}^{-}\right)$at $\mathrm{pH}$ of 1 . The salts used were pure $\mathrm{NaCl}$, re-crystallised sea-salt (RSS) and natural sea-salt (NSS). The composition of the aerosol (3-3.8 $\left.\mathrm{M} \mathrm{Cl}^{-}, 2.5-6.4 \mathrm{M} \mathrm{H}_{2} \mathrm{SO}_{4}\right)$ was varied by adjusting the relative humidity. $\mathrm{No}$ uptake of $\mathrm{HOCl}$ was observed for $\mathrm{NaCl}$ and $\mathrm{RSS}$.

\section{Preferred values}

\begin{tabular}{lll}
\hline Parameter & Value & $T / \mathrm{K}$ \\
\hline$\gamma$ & $<2 \times 10^{-4}$ & 296 \\
reliability & & \\
$\Delta \log (\gamma)$ & undetermined & \\
\hline
\end{tabular}

\section{Comments on preferred values}

Pratte and Rossi (2006) observed a low uptake coefficient for $\mathrm{HOCl}$ to natural sea-salt solutions, with a negative dependence of $\gamma$ on relative humidity (i.e. with a positive dependence on ion concentrations). Uptake to pure chloride solution with the same composition was not observed.

The observation of Pratte and Rossi (2006), of measurable uptake onto aqueous NSS, but not to aqueous RSS (presumably with similar chloride/bromide composition) is difficult to understand. No products were observed in that study, so it is not possible to determine which reaction was driving the uptake. Pratte and Rossi also speculate that the high $\mathrm{H}_{2} \mathrm{SO}_{4}$ concentration may inhibit the uptake.

Inserting values for the termolecular rate constant for reaction of $\mathrm{HOCl}$ with $\mathrm{H}^{+} / \mathrm{Cl}^{-}\left(k_{\mathrm{ter}}=1.5 \times 10^{4} \mathrm{M}^{-2} \mathrm{~s}^{-1}\right.$, Wang and Margerum, 1994) the solubility of $\mathrm{HOCl}\left(H_{\mathrm{HOCl}}=6.6 \times 10^{2} \mathrm{M} \mathrm{atm}^{-1}\right.$. Huthwelker et al., 1995) a value for the liquid phase diffusion coefficient of $2 \times 10^{-5} \mathrm{~cm}^{2} \mathrm{~s}^{-1}$ and an accommodation coefficient $\left(\alpha_{\mathrm{b}}\right)$ of between 1 and 0.01 into the expression

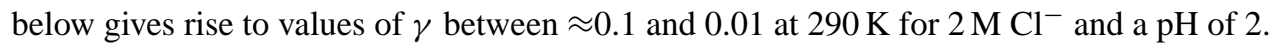

$\gamma=\left\{\frac{1}{\alpha}+\frac{\bar{c}}{4 H R T\left(D_{1} k_{\mathrm{ter}}\left[\mathrm{H}^{+}\right]\left[\mathrm{Cl}^{-}\right]\right)^{0.5}}\right\}^{-1}$

Uptake coefficients of this magnitude should have been observable. Note that the forward reaction forms $\mathrm{Cl}_{2}\left(\mathrm{HOCl}+\mathrm{H}^{+}\right.$ $+\mathrm{Cl}^{-} \rightarrow \mathrm{Cl}_{2}+\mathrm{H}_{2} \mathrm{O}$ ) which may hydrolyse back to $\mathrm{HOCl}$. The equilibrium constant $K=[\mathrm{HOCl}]\left[\mathrm{H}^{+}\right]\left[\mathrm{Cl}^{-}\right] /\left[\mathrm{Cl}_{2}\right]$ is circa $1 \times 10^{-3} \mathrm{M}^{2}$ at $25^{\circ} \mathrm{C}$, so that, a pH of 2 and $2 \mathrm{M} \mathrm{Cl}^{-}$result in an equilibrium ratio of $\mathrm{HOCl} / \mathrm{Cl}_{2} \approx 0.05$.

Experiments on solid salt surfaces (Santschi and Rossi, 2005; Huff and Abbatt, 2000) revealed no reactivity for $\mathrm{HOCl}$ on chloride surfaces, but high reactivity for pure bromide and mixed bromide/chloride surfaces. The uptake of $\mathrm{HOCl}$ to a frozen, mixed chloride/bromide surface at $248 \mathrm{~K}$ has been shown to result in formation of mainly $\mathrm{Br}_{2}$ (and little $\mathrm{BrCl}$ ) as gas-phase product. This presumably arises via conversion of $\mathrm{BrCl}$ (initially formed) with surface bromide.

$\mathrm{HOCl}+\mathrm{Br}^{-}+\mathrm{H}^{+} \rightarrow \mathrm{BrCl}+\mathrm{H}_{2} \mathrm{O}$ 
$\mathrm{BrCl}+\mathrm{Br}^{-} \rightarrow \mathrm{Br}_{2}+\mathrm{Cl}^{-}$

Until further data is available, we prefer to recommend an upper limit to $\gamma$ for reaction of $\mathrm{HOCl}$ with chloride/bromide containing aqueous particles.

\section{References}

Huff, A. K. and Abbatt, J. P. D.: J. Phys. Chem., 104, 7284-7293, 2000.

Huthwelker, T., Clegg, S. L., Peter, T., Carslaw, K., and Luo, B. P.: J. Atmos. Chem., 21, 81-95, 1995.

Pratte, P. and Rossi, M. J.: Phys. Chem. Chem. Phys., 8, 3988-4001, 2006.

Santschi, C. and Rossi, M. J.: Phys. Chem. Chem. Phys., 7, 2599-2609, 2005.

Wang, T. X. and Margerum, D. W.: Inorg. Chem., 33, 1050-1055, 1994. 
VI.A2.9

$\mathrm{ClNO}_{2}(\mathrm{~g})+\mathrm{Cl}^{-} / \mathrm{Br}^{-}(\mathrm{aq}) \rightarrow$ products

\section{Experimental data}

\begin{tabular}{lllll}
\hline Parameter & {$[\mathrm{X}] / \mathrm{M}$} & $T / \mathrm{K}$ & Reference & Technique/Comments \\
\hline Uptake coefficients: $\gamma, \gamma_{s s}, \gamma_{0}$ & & & & \\
$4.8 \times 10^{-6}$ & $4.6 \mathrm{M} \mathrm{NaCl}$ & 300 & Behnke et al. (1997) & WWFT-FTIR (a) \\
$(1.4 \pm 0.2) \times 10^{-5}$ & 0.5 and $1 \mathrm{mM} \mathrm{NaBr}, \mathrm{HBr}$ & 275,291 & Frenzel et al. (1998) & WWFT-FTIR (b) \\
$\gamma_{0}=9.0 \times 10^{-6}$ & 282 & & \\
$\gamma_{\mathrm{ss}}=(6.7 \pm 1.3) \times 10^{-6}$ & $10^{-4} \mathrm{M} \mathrm{NaBr}$ & $275-288$ & Schweitzer et al. (1998) & WWFT-FTIR/MS (c) \\
$\gamma_{\mathrm{ss}}=(8.2 \pm 1.0) \times 10^{-4}$ & $10^{-2} \mathrm{M} \mathrm{NaBr}$ & & & \\
$\gamma_{\mathrm{ss}}=(8.8 \pm 2.6) \times 10^{-4}$ & $1 \mathrm{M} \mathrm{NaBr}$ & & \\
$\gamma_{\mathrm{ss}}=(1-10) \times 10^{-4}$ & $10^{-4}$ to $1 \mathrm{M} \mathrm{NaBr}$ aqueous & 274 & Fickert et al. (1998) & WWFT-MS (d) \\
$(6 \pm 2) \times 10^{-3}$ & film & & & \\
& 0.05 to $6 \mathrm{M} \mathrm{NaCl}$ aqueous & 298 & Roberts et al. (2008) & WWFT-CRDS/CIMS (e) \\
\hline
\end{tabular}

\section{Comments}

(a) Variable length $(10-80 \mathrm{~cm})$ wetted-wall flow tube at 1 bar of synthetic air. The liquid film thickness was between 0.8 and $1.2 \mathrm{~mm}$ at a surface speed of $2-10 \mathrm{~cm} \mathrm{~s}^{-1}$. The gas flow rate was in the range $200-400 \mathrm{~mL} \mathrm{~min}^{-1}$ at $291 \mathrm{~K}$ resulting in an average linear flow velocity of $15-30 \mathrm{~cm} \mathrm{~s}^{-1}$. The initial $\left[\mathrm{ClNO}_{2}\right]$ was measured upstream, the unreacted $\mathrm{ClNO}_{2}$ was measured downstream of the WWFT using FTIR. Between pure $\mathrm{H}_{2} \mathrm{O}$ and $1 \mathrm{M} \mathrm{NaCl} \gamma$ decreases by more than a factor of ten.

(b) Uptake study in a variable length wetted-wall flow tube at $\mathrm{P}=1 \mathrm{~atm}$ of synthetic air. Experimental details are given in the data sheet VI.A1.15 for $\mathrm{ClNO}_{2}+\mathrm{H}_{2} \mathrm{O}$ under (b). The uptake coefficients were obtained by fitting the measured initial time/position-dependent concentration profiles in the range 0 to $7 \mathrm{~s}$ using a complex reaction mechanism including gas phase and liquid diffusion. Observed reaction products included $\mathrm{BrNO}_{2}, \mathrm{Br}_{2}, \mathrm{NO}_{2}$ in the gas phase and $\mathrm{Cl}^{-}, \mathrm{NO}_{2}^{-}$and $\mathrm{NO}_{3}^{-}$in the condensed phase

(c) Uptake experiment in a wetted-wall flow tube equipped with FTIR/long-path absorption and ion-trap mass spectrometry for gas phase detection of $\mathrm{ClNO}_{2}$ and products. The uptake coefficients were independent of temperature in the stated range and scaled linearly when plotted as $1 / \gamma$ vs. $[\mathrm{NaX}]^{-1}$ with $\mathrm{X}=\mathrm{I}^{-}$. The main gas phase product was $\mathrm{Br}_{2}$.

(d) Uptake study in a wetted-wall tubular flow reactor on a falling film of pure water and aqueous alkali halide salt solutions at 18 to 23 mbar of He as a carrier gas. The reactant was monitored using a differentially-pumped MS. The value of $\gamma_{\mathrm{ss}}$ remains unchanged upon addition of $1 \mathrm{M} \mathrm{NaCl}$ whereas it increased upon addition of $0.1 \mathrm{M} \mathrm{OH}^{-}$. Analysis of uptake rates measured under gas-phase diffusion controlled conditions $(0.5 \mathrm{M} \mathrm{KOH}$ film) gave the cited value for the accommodation coefficient on aqueous surfaces, $\alpha=(9 \pm 4) \times 10^{-3}$. Estimates of the diffusion coefficients $D^{\mathrm{ClNO} 2}$ in $\mathrm{He}, \mathrm{N}_{2}$ and $\mathrm{H}_{2} \mathrm{O}$ are reported as $275 \pm 26,75 \pm 6$ and $100 \pm 20 \mathrm{Torr}_{\mathrm{cm} \mathrm{s}}{ }^{-1}$ respectively. Parameters determining reactive uptake rates into $\mathrm{Br}^{-}$-solutions were determined interdependently as $H^{2} D_{1} k^{\mathrm{II}}=(0.101 \pm 0.015) \mathrm{M} \mathrm{cm}^{2} \mathrm{~s}^{-2}$. The gas phase products were found to be $\mathrm{Br}_{2}, \mathrm{BrNO}_{2}$ and minor amounts of $\mathrm{BrCl}$. $\mathrm{Br}_{2}$ was a secondary reaction product resulting from the condensed phase reaction of $\mathrm{BrNO}_{2}$ with $\mathrm{Br}^{-}$.

(e) Uptake study in a tubular flow reactor where $\mathrm{N}_{2} \mathrm{O}_{5}$ was converted to $\mathrm{ClNO}_{2}$ by reaction on aqueous slurry of $\mathrm{NaCl}$ and the resultant $\mathrm{ClNO}_{2}$ reacted with $\mathrm{NaCl} /$ oxalic acid solution at $\mathrm{pH}=1.8$. Relatively fast uptake of $\mathrm{ClNO}_{2}$ attributed to acid catalysed reaction producing $\mathrm{Cl}_{2}$ as the main product. The reactant $\mathrm{N}_{2} \mathrm{O}_{5}$ was monitored by CRDS after thermaldecomposition to $\mathrm{NO}_{3}$. Products were monitored by $\mathrm{I}^{-}$-CIMS. Analysis of uptake rates gave an estimate of $>10^{7} \mathrm{M}^{-1} \mathrm{~s}^{-1}$ for the rate constant for the reaction of $\mathrm{ClNO}_{2}$ with $\mathrm{Cl}^{-}$. 


\section{Preferred values}

\begin{tabular}{lll}
\hline Parameter & Value & $T / \mathrm{K}$ \\
\hline$\alpha_{\mathrm{b}}$ & 0.01 & 274 \\
$k^{\mathrm{II}}\left(\mathrm{M}^{-1} \mathrm{~s}^{-1}\right)(\mathrm{Cl} ; \mathrm{pH}<2)$ & $>10^{7}$ & \\
$H^{2} D_{\mathrm{l}} k^{\mathrm{II}}\left(\mathrm{M} \mathrm{cm}^{2} \mathrm{~s}^{-2}\right)(\mathrm{Br})$ & $0.101 \pm 0.015$ & 274 \\
Reliability & & \\
$\Delta \log \left(\alpha_{\mathrm{b}}\right)$ & \pm 0.3 & \\
\hline
\end{tabular}

\section{Comments on preferred values}

The results of the earlier studies are in broad agreement, and the recent work revealed an important change in mechanism at conditions of low $\mathrm{pH}$ leading to $\mathrm{Cl}_{2}$ production. The uptake of $\mathrm{ClNO}_{2}$ into the aqueous phase is slow into neutral solutions containing $\mathrm{Cl}^{-}$but is significantly enhanced in acid solutions $(\mathrm{pH}<2) . \mathrm{Cl}_{2}$ is not formed from neutral solutions but is produced with high yield at $\mathrm{pH}=1.8$ even at $\left[\mathrm{Cl}^{-}\right]=0.05 \mathrm{M}$ (Roberts et al., 2008), probably due to an acid catalysed reaction. Uptake is also significantly enhanced by introduction of $\mathrm{Br}^{-}$in the condensed phase, with formation of products $\mathrm{BrNO}_{2} / \mathrm{Br}_{2}$ which will partition rapidly to the gas phase. Reactive uptake is controlled by chemical reaction in the bulk, i.e. in terms of the resistance model:

$\gamma=\left\{\frac{1}{\alpha_{\mathrm{b}}}+\frac{\bar{c}}{4 H R T\left(D_{\mathrm{l}} k^{\mathrm{I}}\right)^{0.5}}\right\}^{-1} \quad$ where $\quad k^{\mathrm{I}}=k^{\mathrm{II}}\left[\mathrm{X}^{-}\right]_{\mathrm{aq}}\left(\mathrm{M}, \mathrm{X}=\mathrm{Cl}^{-}\right.$or $\left.\mathrm{Br}^{-}\right)$

The preferred value of $\alpha_{\mathrm{b}}$ is taken from the work of Fickert et al. (1998). The preferred values for uptake on $\mathrm{Cl}^{-}$are based on the work of Roberts et al. (2008), who used a value of $H=4 \times 10^{-2} \mathrm{M} \mathrm{atm}^{-1}$ in their analysis. The preferred values for uptake on $\mathrm{Br}^{-}$are based on the thorough analysis reported in the work of Fickert et al. (1998). The liquid phase diffusion coefficient has not been determined but a value of $\sim 1 \times 10^{-5} \mathrm{~cm}^{2} \mathrm{~s}^{-1}$ is normally used.

\section{References}

Behnke, W., George, C., Scheer, V., and Zetzsch, C.: J. Geophys. Res., 102, 3795-3804, 1997.

Fickert, S., Helleis, F., Adams, J., Moortgat, G. K., and Crowley, J. N.: J. Phys. Chem. A, 102, 10689-10696, 1998.

Frenzel, A., Scheer, V., Sikorski, R., George, C., Behnke, W., and Zetzsch, C.: J. Phys. Chem. A, 102, 1329-1337, 1998.

George, C., Behnke, W., Scheer, V., Zetzsch, C., Magi, L., Ponche, J. L., and Mirabel, P.: Geophys. Res. Lett., 22, 1505-1508, 1995.

Roberts, J. M., Osthoff, H. D., Brown, S. S., and Ravishankara, A. R.: Science, 321, 1059, 2008.

Schweitzer, F., Mirabel, P., and George, C.: J. Phys. Chem., 102, 3942-3952, 1998. 
VI.A2.10

$\mathrm{ClONO}_{2}(\mathrm{~g})+\mathrm{Cl}^{-} / \mathrm{Br}^{-}(\mathrm{aq}) \rightarrow \mathrm{Cl}_{2} / \mathrm{ClBr}(\mathrm{g})+\mathrm{HNO}_{3}(\mathrm{aq})$

\section{Experimental data}

\begin{tabular}{|c|c|c|c|c|}
\hline Parameter & {$[\mathrm{X}] / \mathrm{M}$} & $T / \mathrm{K}$ & Reference & Technique/Comments \\
\hline \multicolumn{5}{|c|}{ Uptake coefficients: $\gamma, \gamma_{s s}, \gamma_{0}$} \\
\hline$\gamma=0.0244 \pm 0.0023$ & $0.1 \mathrm{M} \mathrm{NaCl}$ & 274.6 & Deiber et al. (2004) & DFT-MS (a) \\
\hline$\gamma=0.041 \pm 0.0067$ & $0.01 \mathrm{M} \mathrm{NaBr}$ & 274.1 & & \\
\hline$\gamma=0.046 \pm 0.0019$ & & 277 & & \\
\hline$\gamma=0.047 \pm 0.0011$ & & 280.8 & & \\
\hline$\gamma=0.044 \pm 0.0027$ & $0.025 \mathrm{M} \mathrm{NaBr}$ & 274.3 & & \\
\hline$\gamma=0.041 \pm 0.0043$ & & 276.2 & & \\
\hline$\gamma=0.055 \pm 0.0060$ & $0.05 \mathrm{M} \mathrm{NaBr}$ & 274 & & \\
\hline$\gamma=0.054 \pm 0.0039$ & & 277 & & \\
\hline$\gamma=0.053 \pm 0.0028$ & & 281 & & \\
\hline$\gamma=0.057 \pm 0.0048$ & $0.10 \mathrm{M} \mathrm{NaBr}$ & 274.9 & & \\
\hline$\gamma=0.049 \pm 0.0024$ & & 276.2 & & \\
\hline$\gamma=0.056 \pm 0.0008$ & & 279.9 & & \\
\hline$\gamma=0.066 \pm 0.0015$ & $0.5 \mathrm{M} \mathrm{NaBr}$ & 274.4 & & \\
\hline$\gamma=0.066 \pm 0.0011$ & & 276.5 & & \\
\hline$\gamma=0.073 \pm 0.0106$ & $1.0 \mathrm{M} \mathrm{NaBr}$ & & & \\
\hline
\end{tabular}

\section{Comments}

(a) Uptake rates measured onto $200 \mu \mathrm{m}$ droplets following loss of reactant in conventional droplet train apparatus. Droplet temperature controlled by evaporative cooling with adjustment of $p\left(\mathrm{H}_{2} \mathrm{O}\right)$. Uptake coefficient determined with a simple correction for diffusion effects. $\gamma$ measured as function of $[\mathrm{NaCl}]$ and $[\mathrm{NaBr}]$. On $\mathrm{NaCl} \gamma$ was not significantly larger than on pure water, but $\mathrm{Cl}_{2}$ was observed as a unique gas-phase product. On $\mathrm{NaBr}$ droplets $\gamma$ increased with increasing $\left[\mathrm{Br}^{-}\right]$and was essentially independent of temperature over the small range investigated for all $\left[\mathrm{Br}^{-}\right]$. Both $\mathrm{BrCl}$ and $\mathrm{Br}_{2}$ were detected as gas phase products.

\section{Preferred values}

\begin{tabular}{lll}
\hline Parameter & Value & $T / \mathrm{K}$ \\
\hline$\alpha_{\mathrm{b}} \mathrm{III}\left(\mathrm{M}^{1 / 2} \mathrm{~atm}^{-1} \mathrm{~s}^{-1 / 2}\right)\left(\mathrm{Br}^{-}\right)$ & 0.11 & $273-290$ \\
$\mathrm{H} \sqrt{ } k^{\mathrm{II}}\left(0^{6}\right.$ & $273-290$ \\
Reliability & & \\
$\Delta \log \left(\alpha_{\mathrm{b}}\right)$ & \pm 0.2 & $273-290$ \\
$\Delta \log \left(H \sqrt{ } k^{\mathrm{II}}\right)$ & \pm 0.15 & $273-290$ \\
\hline
\end{tabular}

\section{Comments on preferred values}

The cited work is the only study of reactive uptake of $\mathrm{ClONO}_{2}$ on aqueous halide substrates $\mathrm{NaCl}$ and $\mathrm{NaBr}$; all the other reported studies used either solid substrates (ice) or sulphuric acid solutions. These studies showed that uptake led to $\mathrm{XCl}$ $\left(\mathrm{X}=\mathrm{Cl}\right.$ or $\mathrm{Br}$ ) and $\mathrm{HNO}_{3}$ formation. The dihalogens can partition to the gas phase, depending on their solubilty. No gas phase products were observed from uptake on water droplets due to the high solubilty of the products.

The measured uptake coefficient on $\mathrm{NaCl}$ was not significantly greater than on pure water droplets (see data sheet for $\mathrm{ClONO}_{2}+\mathrm{H}_{2} \mathrm{O}$, VI.A1.16). However it is expected that $\mathrm{Cl}_{2}$ rather than $\mathrm{HOCl}$ will be formed as products. When $\mathrm{Br}^{-}$was present in solution, $\gamma$ increased with increasing $\left[\mathrm{Br}^{-}\right]$and was independent of temperature over the small range investigated for all $\left[\mathrm{Br}^{-}\right]$. This was interpreted in terms of the resistance model with increasing liquid phase reaction rate of $\mathrm{ClONO}_{2}(\mathrm{aq})$ 
due to reaction with $\mathrm{Br}^{-}$allowing accommodation controlled uptake at high $\left[\mathrm{Br}^{-}\right]$;

$\gamma=\left\{\frac{1}{\alpha}+\frac{\bar{c}}{4 H R T\left(D_{1} k^{1}\right)^{0.5}}\right\}^{-1} \quad$ where $\quad k^{\mathrm{I}}\left(\mathrm{s}^{-1}\right)=k^{\mathrm{II}} \times\left[\mathrm{Br}^{-}\right]_{\mathrm{aq}}(\mathrm{M})$

This allowed evaluation of the reactive uptake parameters for uptake on $\mathrm{Br}^{-}$containing solutions at $274.5 \mathrm{~K}: \alpha_{\mathrm{b}}=(0.108 \pm$ 0.011 ) and the product $H \sqrt{ } k^{\mathrm{II}}=1.0 \times 10^{6} \mathrm{M}^{1 / 2} \mathrm{~atm}^{-1} \mathrm{~s}^{-1 / 2}$ from a plot of uptake coefficients corrected for gas phase diffusion effects $\left(1 / \gamma-\left(1 / \gamma_{\text {diff }}\right)\right.$, vs. $1 /[\mathrm{NaBr}]^{1 / 2}$, according to the resistance model with $D_{1}$ assumed to be $5 \times 10^{-6} \mathrm{~cm}^{2} \mathrm{~s}^{-1}$. The recommended uptake parameters are based on this analysis. There are no reported values of $H$ or $D_{1}$ for $\mathrm{ClONO}_{2}$.

\section{References}

Deiber, G., George, C., Le Calvé, S., Schweitzer, F., and Mirabel, P.: Atmos. Chem. Phys., 4, 1291-1299, doi:10.5194/acp-41291-2004, 2004. 
VI.A2.11

$\mathrm{HOBr}(\mathrm{g})+\mathrm{Cl}^{-} / \mathrm{Br}^{-}(\mathrm{aq}) \rightarrow$ products

Experimental data

\begin{tabular}{lllll}
\hline Parameter & Aqueous Solution & $T / \mathrm{K}$ & Reference & Technique/Comments \\
\hline Uptake coefficients, $\gamma$ & $\mathrm{NaCl}(\mathrm{pH} 0.3,75 \% \mathrm{RH})$ & 295 & Abbatt and Waschewsky (1998) & AFT-CIMS (a) \\
$>0.2$ & $\mathrm{NaCl}(\mathrm{pH} 7.2,75 \% \mathrm{RH})$ & & & \\
$>0.2$ & $\mathrm{NaCl}($ unbuffered, $75 \% \mathrm{RH})$ & & & \\
$<1.5 \times 10^{-3}$ & $\mathrm{NaCl}$ and natural salt & 296 & Pratte and Rossi (2006) & AFT-MS (b) \\
$8 \times 10^{-3}$ & $(\mathrm{pH} \approx-1$ to $-0.7, \mathrm{RH}>75 \%)$ & & & \\
& & & & \\
Accommodation coefficient, $\alpha_{\mathrm{b}}$ & $\mathrm{NaCl} / \mathrm{NaBr}(\mathrm{pH} 2-5)$ & 274 & Fickert et al. (1999) & WWFT-MS (c) \\
$>0.01$ & $\mathrm{NaBr}$ & $296 \pm 2$ & Wachsmuth et al. (2002) & AFT (d) \\
$0.6 \pm 0.2$ & & & \\
\hline
\end{tabular}

\section{Comments}

(a) Flow tube at 933-1013 mbar $\mathrm{N}_{2}$. Particle number density $\left((1-4) \times 10^{4}\right.$ particle $\left.\mathrm{cm}^{-3}\right)$ and diameter $(2-4 \mu \mathrm{m})$ of the $\mathrm{NaCl}$ particles were measured using an optical particle counter. $\operatorname{HOBr}\left((2-10) \times 10^{12}\right.$ molecule $\left.^{-3}\right)$, was made by passing damp $\mathrm{N}_{2}$ with traces of $\mathrm{Br}_{2}$ over $\mathrm{HgO}$ and was detected as $\mathrm{SF}_{5} \mathrm{O}^{-}$using $\mathrm{SF}_{6}^{-}$chemi-ions. No uptake observed to unbuffered and non-acidified chloride solutions. Uptake coefficient to acidified and buffered solutions is a lower limit, owing to diffusion limitations.

(b) Atmospheric pressure flow tube. Aerosols $\left(\approx 200-300 \mathrm{~nm}\right.$ diameter, $1.7-11 \times 10^{-4} \mathrm{~cm}^{2} \mathrm{~cm}^{-3}$ total surface area density) were made from acidified salt solutions $\left(0.034 \mathrm{M} \mathrm{Cl}^{-}\right)$at $\mathrm{pH}$ of 1 . The salts used were pure $\mathrm{NaCl}$, re-crystallised sea-salt (RSS) and natural sea-salt (NSS). The composition of the aerosol (1.7-4.4 $\mathrm{M} \mathrm{Cl}^{-}, 2.5-6.4 \mathrm{M} \mathrm{H}_{2} \mathrm{SO}_{4}$ ) was varied by varying the relative humidity. Measured uptake coefficients were found to suddenly increase from $\approx 2 \times 10^{-3}$ to $8 \times 10^{-3}$ at $\mathrm{RH} \approx 75-80 \%$ for $\mathrm{NaCl}$ and RSS and remain high. For NSS a different behaviour was observed with a peak in $\gamma$ (also $\approx 8 \times 10^{-3}$ ) at $\mathrm{RH}=75 \%$ and lower values (factor of 4 or more) at both higher and lower RH.

(c) Slow flowing aqueous film (50-100 $\mu$ m thick) on the internal surface of a flow tube operated at $\approx 13-35$ mbar He or $\mathrm{N}_{2}$. $\mathrm{HOBr}, \mathrm{Br}_{2}$ and $\mathrm{BrCl}$ were detected as positive ions using electron impact ionisation. $\mathrm{HOBr}\left(\approx 10^{12}\right.$ molecule $\left.\mathrm{cm}^{-3}\right)$ was eluted into the flow tube from an aqueous solution. The lower limit for $\alpha_{\mathrm{b}}$ was obtained from the pressure dependence of the uptake coefficient to an acidified film and assuming a value for the diffusion coefficient of $\mathrm{HOBr}$ in $\mathrm{H}_{2} \mathrm{O}$.

(d) Very low concentrations $\left(\approx 300\right.$ molecule $\mathrm{cm}^{-3}$ ) of $\mathrm{HOBr}$ detected using radioactive labelling. Uptake to $0.2 \mathrm{M} \mathrm{NaBr}$ aerosol particles (diameter 50-60 nm) at $\mathrm{RH}=37 \%$ and $\mathrm{pH}<6$. A small correction (4\%) for gas phase diffusion was applied.

\section{Preferred values}

\begin{tabular}{lll}
\hline Parameter & Value & $T / \mathrm{K}$ \\
\hline$\alpha_{\mathrm{b}}$ & 0.6 & 296 \\
$k_{\text {ter }}\left(\mathrm{M}^{-2} \mathrm{~s}^{-1}\right)$ & $>5.6 \times 10^{9}$ & 296 \\
$H\left(\mathrm{M} \mathrm{atm}^{-1}\right)$ & $6.1 \times 10^{3}$ & 296 \\
$D_{1}\left(\mathrm{~cm}^{2} \mathrm{~s}^{-1}\right)$ & $1.4 \times 10^{-5}$ & 296 \\
Reliability & & \\
$\Delta \log \left(\alpha_{\mathrm{b}}\right)$ & \pm 0.3 & 296 \\
\hline
\end{tabular}

\section{Comments on preferred values}

The large uptake coefficients reported for $\mathrm{HOBr}$ reacting with acidified aqueous bromide and chloride indicate that the accommodation coefficient is large (Abbatt and Waschewsky, 1998; Wachsmuth et al., 2002) and possibly unity. In terms of the 
resistance model, the uptake coefficient for $\mathrm{HOBr}$ reacting with sea-salt is given by:

$\gamma=\left\{\frac{1}{\alpha}+\frac{\bar{c}}{4 H R T\left(D_{1} k^{\prime}\right)^{0.5}}\right\}^{-1}$,

where $k^{\prime}=k_{\mathrm{ter}}\left[\mathrm{H}^{+}\right]\left[\mathrm{Cl}^{-}\right]$and the ionic concentrations are in $\mathrm{M}$. The termolecular rate constant, $k_{\mathrm{ter}}$, was taken from Vogt et al. (1996), the solubility and diffusion coefficient for $\mathrm{HOBr}$ were taken from Frenzel et al. (1998).

This expression predicts uptake coefficients that are close to the accommodation coefficient for $\mathrm{pH}<7$ when applied to fresh sea-salt with $\left[\mathrm{Cl}^{-}\right] \approx 5.3 \mathrm{M}$. This is in accord with the large lower limit to the uptake coefficient measured by Abbatt and Waschewski, but is higher than the uptake coefficients (factor 20) determined by Rossi and Pratte (2006). The observation of much lower uptake coefficients when the droplets are not acidified and/or buffered (Abbatt and Waschewsky, 1998) is related to rapid depletion of available $\left[\mathrm{H}^{+}\right]$when using large concentrations of $\mathrm{HOBr}$.

The important aqueous phase reactions in sea-salt aerosol containing chloride and bromide ions may be briefly summarised as follows:

$$
\begin{aligned}
& \mathrm{HOBr}+\mathrm{Cl}^{-}+\mathrm{H}^{+} \rightleftarrows \mathrm{BrCl}+\mathrm{H}_{2} \mathrm{O} \\
& \mathrm{BrCl}+\mathrm{Br}^{-} \rightleftarrows \mathrm{Br}_{2} \mathrm{Cl}^{-} \\
& \mathrm{Br}_{2} \mathrm{Cl}^{-} \rightleftarrows \mathrm{Br}_{2}+\mathrm{Cl}^{-}
\end{aligned}
$$

The relative efficiency of $\mathrm{Br}_{2}$ and $\mathrm{BrCl}$ release from acidified halide solutions ( $\mathrm{pH}<3$ or buffered to $<5.6$ ) with varying bromide/chloride ratios was found (Fickert et al., 1999) to be consistent with aqueous phase equilibrium constants for Reactions (R2) and (R3) (Wang et al., 1994). Following bulk accommodation to salt solutions with the approximate composition of sea-water $\left(\left[\mathrm{Cl}^{-}\right] /\left[\mathrm{Br}^{-}\right] \approx 700\right), \mathrm{HOBr}$ reacts almost exclusively with $\mathrm{H}^{+} / \mathrm{Cl}^{-}$to release mainly $\mathrm{Br}_{2}$. Only at reduced $\left[\mathrm{Br}^{-}\right]$are

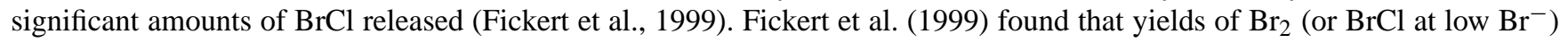
were close to $100 \%$ of the $\mathrm{HOBr}$ taken into solution as long as the $\mathrm{pH}$ was lower than $\approx 7$.

Several experimental investigations of the uptake of $\mathrm{HOBr}$ to dry and frozen halide surfaces (both pure chloride or bromide or mixed) have revealed a similar chemistry to that outlined above (Kirchner et al., 1997; Mochida et al., 1998; Chu et al., 2002; Huff and Abbatt, 2002; Adams et al., 2002). On pure chloride samples, $\mathrm{BrCl}$ is released at high yield and on pure bromide samples, $\mathrm{Br}_{2}$ is the sole product. On mixed chloride/bromide samples both $\mathrm{Br}_{2}$ and $\mathrm{BrCl}$ are observed, with a dependence on initial composition and temperature of the surface.

\section{References}

Abbatt, J. P. D. and Waschewsky, G. C. G.: J. Phys. Chem., 102, 3719-3725, 1998.

Adams, J. W., Holmes, N. S., and Crowley, J. N.: Atmos. Chem. Phys., 2, 79-91, doi:10.5194/acp-2-79-2002, 2002.

Chu, L. and Chu, L. T.: J. Phys. Chem. A, 103, 8640-8649, 1999.

Fickert, S., Adams, J. W., and Crowley, J. N.: J. Geophys. Res., 104, 23719-23727, 1999.

Frenzel, A., Scheer, V., Sikorski, R., George, C., Behnke, W., and Zetzsch, C.: J. Phys. Chem. A, 102, 1329-1337, 1998.

Huff, A. K. and Abbatt, J. P. D.: J. Phys. Chem. A, 106, 5279-5287, 2002.

Kirchner, U., Benter, T., and Schindler, R. N.: Ber. Bunsen Ges. Phys. Chem., 101, 975-977, 1997.

Mochida, M., Akimoto, H., van den Bergh, H., and Rossi, M. J.: J. Phys. Chem., 102, 4819-4828, 1998.

Pratte, P. and Rossi, M. J.: Phys. Chem. Chem. Phys., 8, 3988-4001, 2006.

Vogt, R., Crutzen, P. J., and Sander, R.: Nature, 383, 327-330, 1996.

Wachsmuth, M., Gäggeler, H. W., von Glasow, R., and Ammann, M.: Atmos. Chem. Phys., 2, 121-131, doi:10.5194/acp-2121-2002, 2002.

Wang, T. X., Kelley, M. D., Cooper, J. N., Beckwith, C., and Margerum, D. W.: Inorg. Chem., 33, 5872-5878, 1994. 
VI.A2.12

$\mathrm{HOI}(\mathrm{g})+\mathrm{Cl}^{-} / \mathrm{Br}^{-}(\mathrm{aq}) \rightarrow \mathrm{IBr} / \mathrm{ICl}(\mathrm{g})+\mathrm{HO}^{-}(\mathrm{aq})$

Experimental data

\begin{tabular}{lllll}
\hline Parameter & {$[\mathrm{X}] / \mathrm{M}$} & $T / \mathrm{K}$ & Reference & Technique/Comments \\
\hline $\begin{array}{l}\text { Uptake coefficients: } \gamma, \gamma_{s s}, \gamma_{0} \\
\gamma=2.2 \times 10^{-3}\end{array}$ & $\begin{array}{l}2\left(\mathrm{Cl}^{-}\right) \\
\text {pure water }\end{array}$ & 274 & Braban et al. (2007) & WWFT-EIMS (a) \\
$\gamma=2.0 \times 10^{-3}$ & Wur & \\
\hline
\end{tabular}

\section{Comments}

(a) The uptake of HOI $\left((5-50) \times 10^{10}\right.$ molecule $\left.\mathrm{cm}^{-3}\right)$ to aqueous surfaces was studied in the wetted-wall flow tube with MS detection at $\mathrm{m} / \mathrm{z}=144$. Several combinations of dissolved concentrations of $\mathrm{Cl}^{-}$and $\mathrm{Br}^{-}$in solutions of different $\mathrm{pH}$ were used. Uptake on pure water films was also measured. Experiments were all conducted at $274 \mathrm{~K}$ and at flow tube total pressures of 17 and 26 mbar. HOI was prepared in situ via the reaction of $\mathrm{O}$ atoms (generated in a microwave discharge) with $\mathrm{C}_{2} \mathrm{H}_{5} \mathrm{I}$ or $\mathrm{C}_{3} \mathrm{H}_{7} \mathrm{I}$ in a flow of $\mathrm{He}$ at reduced pressure. The uptake coefficient values were independent of composition or $\mathrm{pH}$ of the solution, except for pure water or very low electrolyte concentration. Calculations using HOI diffusion coefficients of $D_{\mathrm{H} 2 \mathrm{O}}^{\mathrm{HOI}}=36.8 \mathrm{~cm}^{2} \mathrm{~s}^{-1} \mathrm{Torr}^{-1}$, and $D_{\mathrm{He}}^{\mathrm{HOI}}=318.2 \mathrm{~cm}^{2} \mathrm{~s}^{-1} \mathrm{Torr}^{-1}$ at $274 \mathrm{~K}$, obtained by extrapolation from the data of Holmes et al. (2000), showed that uptake is gas phase diffusion limited in all cases. Uptake of HOI produced dihalogens $\mathrm{ICl}$ and $\mathrm{IBr}$ which were partially released to the gas phase; $\mathrm{IBr}$ was preferentially released whenever $\mathrm{Br}^{-}$was present with $\mathrm{Cl}^{-}$.

\section{Preferred values}

\begin{tabular}{lll}
\hline Parameter & Value & $T / \mathrm{K}$ \\
\hline$\alpha_{\mathrm{b}}$ & $>0.1$ & 298 \\
Reliability & & \\
$\Delta \log \left(\alpha_{\mathrm{b}}\right)$ & Not determined & \\
\hline
\end{tabular}

\section{Comments on preferred values}

Uptake and reaction of HOI in aqueous films evidently occur rapidly. However, the results do not allow determination of the accommodation coefficient for HOI on aqueous surfaces as the uptake was diffusion limited, based on the diffusion coefficients reported by Holmes et al. (2001); only a lower limit of $\alpha_{\mathrm{b}}>2.2 \times 10^{-3}$ can be deduced. Other studies using different surfaces suggest that $\alpha_{\mathrm{b}}$ is substantially higher. A lower limit of $\alpha_{\mathrm{b}}=0.3$ was given by Holmes et al. (2001) for HOI on aqueous sulphuric acid surfaces, and $\alpha_{\mathrm{b}}>0.12$ on dry salt particles at $253 \mathrm{~K}$. Mössinger and Cox (2001) observed a reactive uptake coefficient of $\gamma=0.06$ on solid sea salt aerosol at $23 \% \mathrm{RH}$, which leads to formation of IBr and ICl products. Thus it is highly likely that the accommodation coefficient of $\mathrm{HOI}$ on aqueous surfaces is at least 0.1 at ambient temperatures.

Rate coefficients for $\mathrm{HOI}+\mathrm{X}^{-}$in solution have not been reported. For $\mathrm{HOBr}$ the reaction is fast and uptake is accommodation limited under atmospheric conditions, and the same is likely for reactive uptake of HOI into salt droplets. The dihalogen products $\mathrm{ICl}$ and $\mathrm{IBr}$ formed by reaction with $\mathrm{Cl}^{-}$or $\mathrm{Br}^{-}$will partition rapidly to the gas phase. In mixed halide solutions $\mathrm{IBr}$ is preferentially released whenever $\mathrm{Br}^{-}$is present with $\mathrm{Cl}^{-}$, and $\mathrm{ICl}$ is only released when $\mathrm{Br}^{-}$has been chemically depleted.

\section{References}

Braban, C. F., Adams, J. W., Rodriguez, D., Cox, R. A., Crowley, J. N., and Schuster, G.: Phys. Chem. Chem. Phys., 9, 3136-3148, 2007.

Holmes, N. S., Adams, J. W., and Crowley, J. N.: Phys. Chem. Chem. Phys., 3, 1679-1687, 2001.

Mössinger, J. A. and Cox, R. A.: J. Phys. Chem. A, 105, 5165-5177, 2001.

Wachsmuth, M., Gaeggeler, H. W., Von Glasow, R., and Ammann, M.: Atmos. Chem. Phys., 2, 121-131, doi:10.5194/acp-2121-2002, 2002. 
VI.A2.13

$\mathrm{BrCl}(\mathrm{g})+\mathrm{Br}^{-}(\mathbf{a q}) \rightarrow$ Products

Experimental data

\begin{tabular}{lllll}
\hline Parameter & Aqueous Solution & $T / \mathrm{K}$ & Reference & Technique/Comments \\
\hline $\begin{array}{l}\text { Accomodation coefficient, } \alpha \\
0.33 \pm 0.18\end{array}$ & $270-285$ & Katrib et al. (2001) & DT-MS (a) \\
\hline
\end{tabular}

\section{Comments}

(a) $\mathrm{BrCl}$ was eluted into the gas phase from an aqueous solution and detected by mass spectrometer at $\mathrm{m} / \mathrm{z}=116 . \mathrm{Br}_{2}$ and $\mathrm{Cl}_{2}$ were present as impurities. Droplet size was $\approx 150 \mu \mathrm{m}$. The uptake of $\mathrm{BrCl}$ to bromide solutions did not follow firstorder kinetics and no values of $\gamma$ were reported. The accommodation coefficient was obtained from experiments using a different aqueous phase scavenger of $\mathrm{BrCl}$. No uptake was observed for pure $\mathrm{H}_{2} \mathrm{O}$ at $\mathrm{pH}=5.6\left(\gamma<10^{-3}\right)$.

\section{Preferred values}

\begin{tabular}{lll}
\hline Parameter & Value & $T / \mathrm{K}$ \\
\hline$\alpha_{\mathrm{b}}$ & 0.33 & $270-280$ \\
Reliability & & \\
$\Delta \log \left(\alpha_{\mathrm{b}}\right)$ & \pm 0.5 & $270-280$ \\
\hline
\end{tabular}

\section{Comments on preferred values}

The only experimental study of the uptake of $\mathrm{BrCl}$ to bromide containing aqueous solutions $\left(5 \times 10^{-2} \mathrm{M}\right)$ (Katrib et al., 2001) did not return values of $\gamma$. This was reported as being due to complications involving reaction of $\mathrm{Cl}_{2}$ impurity with the surface resulting in non first-order kinetics. $\mathrm{BrCl}$ is known to react in aqueous solutions with $\mathrm{Br}^{-}$to form $\mathrm{Br}_{2} \mathrm{Cl}$, which is in equilibrium with $\mathrm{Br}_{2}$ and $\mathrm{Cl}^{-}$. The net reaction can be written as:

$\mathrm{BrCl}+\mathrm{Br}^{-} \rightarrow \mathrm{Br}_{2}+\mathrm{Cl}^{-}$

Using the expression below and literature values for the aqueous-phase solubility of $\mathrm{BrCl}$ at $275 \mathrm{~K}\left(H=4.6 \mathrm{M} \mathrm{atm}^{-1}\right.$, Bartlett and Margerum, 1999), the rate constant for reaction of $\mathrm{BrCl}_{\text {with }} \mathrm{Br}^{-}\left(k_{\mathrm{Br}}>10^{8} \mathrm{M} \mathrm{s}^{-1}\right.$, Wang et al., 1994) an aqueous-phase diffusion coefficient of $10^{-5} \mathrm{~cm}^{2} \mathrm{~s}^{-1}$ and the value of $\alpha$ reported above results in uptake coefficients between 0.02 and 0.2 when $\left[\mathrm{Br}^{-}\right]$is varied between $10^{-3}$ and $1 \mathrm{M}$. The rate of uptake is thus accommodation controlled at high $\left[\mathrm{Br}^{-}\right]\left(\gamma \rightarrow \alpha_{\mathrm{b}}\right)$ and chemically controlled at low $\left[\mathrm{Br}^{-}\right]$. The calculated value for $\gamma$ obtained at $5 \times 10^{-2} \mathrm{M}$ bromide $\left(\gamma \approx 9 \times 10^{-2}\right)$ appears to be consistent with the raw data presented in Fig. 2 of Katrib et al. (2001), from which (by comparison with uptake to NaI) $\gamma$ is less than 0.1 .

$\gamma_{\mathrm{b}}=\left\{\frac{1}{\alpha_{\mathrm{b}}}+\frac{\bar{c}}{4 H R T\left(D_{\mathrm{l}} k^{\prime}\right)^{0.5}}\right\}^{-1}$ and $k^{\prime}=k_{\mathrm{Br}}\left[\mathrm{Br}^{-}\right] \quad$ where $\quad\left[\mathrm{Br}^{-}\right] \quad$ is the bromide activity.

This is however a simplification of the chemical interactions of molecular halogens in halide solutions, which are characterised by rapid equilibria involving several di- and tri-halogen species (Wang et al., 1999) and it is not obvious that a first-order analysis to obtain $\gamma$ is appropriate. This may in part explain the observations of unusual kinetics of Katrib et al. (2001). Accurate modelling of the uptake and release of halogens from sea-water requires a more detailed treatment of the aqueous phase processes than possible here.

Studies of the uptake of $\mathrm{BrCl}$ to dry and frozen bromide containing surfaces indicate conversion to $\mathrm{Br}_{2}$, as written above (Huff and Abbatt, 2000).

\section{References}

Bartlett, W. P. and Margerum, D. W.: Env. Sci. Tech., 33, 3410, 1999. 
Huff, A. K. and Abbatt, J. P. D.: J. Phys. Chem., 104, 7284-7293, 2000.

Katrib, Y., Deiber, G., Schweitzer, F., Mirabel, P., and George, C.: J. Aerosol Sci., 32, 893-911, 2001.

Wang, T. X., Kelley, M. D., Cooper J. N., and Margerum, D. W.: Inorg. Chem., 33, 5872-5878, 1994. 
VI.A2.14

$\mathrm{ICl}(\mathrm{g})+\mathrm{Br}^{-}(\mathrm{aq}) \rightarrow \mathrm{IBr}(\mathrm{g})+\mathrm{Cl}^{-}(\mathrm{aq})$

Experimental data

\begin{tabular}{|c|c|c|c|c|}
\hline Parameter & {$[\mathrm{X}] / \mathrm{M}$} & $T / \mathrm{K}$ & Reference & Technique/Comments \\
\hline \multicolumn{5}{|c|}{ Uptake coefficients: $\gamma, \gamma_{s s}, \gamma_{0}$} \\
\hline$\gamma=2.6 \times 10^{-3}$ & $2\left(\mathrm{Cl}^{-}\right)$ & 274 & Braban et al. (2007) & WWFT-EIMS (a) \\
\hline$\gamma=2.5 \times 10^{-3}$ & $2\left(\mathrm{Br}^{-}\right)$ & & & \\
\hline$\gamma=3 \times 10^{-3}$ & pure water & & & \\
\hline & $2\left(\mathrm{Br}^{-}\right)$ & & & \\
\hline $\begin{array}{l}\gamma=(0.6-1.6) \times 10^{-3} \\
\alpha_{\mathrm{b}}=0.01-1.0\end{array}$ & 20-272 mbar & 278 & & \\
\hline$\gamma=0.018 \pm 0.004$ & aq. $\mathrm{NaBr}$ aerosol & 274 & Braban et al. (2007) & AFT-CIMS (b) \\
\hline$\gamma=(0.1-1) \times 10^{-3}$ & $\begin{array}{l}\text { Sea salt aerosol } \\
(5-87 \% \mathrm{RH})\end{array}$ & 274 & & \\
\hline
\end{tabular}

\section{Comments}

(a) The uptake of ICl $\left((4-70) \times 10^{10}\right.$ molecule $\left.\mathrm{cm}^{-3}\right)$ to aqueous surfaces was studied in the wetted-wall flow tube with MS detection at $\mathrm{m} / \mathrm{z}=144$. Several combinations of dissolved concentrations of $\mathrm{Cl}^{-}$and $\mathrm{Br}^{-}$in solutions of different $\mathrm{pH}$ were used. Experiments were conducted at 274 and $293 \mathrm{~K}$ and at a range of flow tube pressures between 17 and $26 \mathrm{mbar}$, and at $278 \mathrm{~K}$ in a different system (see Holmes et al., 2001) over the pressure range 20-272 mbar. The uptake coefficient values were independent of composition or $\mathrm{pH}$ of the solution, but increased with deceasing pressure in the flow tube. Uptake is thus gas phase diffusion limited in all cases. Gas phase diffusion coefficients for ICl of $D_{\mathrm{H} 2 \mathrm{O}}^{\mathrm{ICl}}=(57 \pm 6) \mathrm{cm}^{2} \mathrm{~s}^{-1} \mathrm{Torr}^{-1}$, and $D_{\mathrm{He}}^{\mathrm{ICl}}=(289 \pm 19) \mathrm{cm}^{2} \mathrm{~s}^{-1} \mathrm{Torr}^{-1}$ at $278 \mathrm{~K}$, were obtained from the pressure dependence of $\gamma$. Uptake of ICl into $\mathrm{Br}^{-}$solutions produced $\mathrm{IBr}$ which was partially released to the gas phase.

(b) Atmospheric pressure aerosol flow tube with $\mathrm{ICl}\left(\approx 10^{13}\right.$ molecule $\left.\mathrm{cm}^{-3}\right)$ measured by CIMS, together with products $\mathrm{Br}_{2}$ or IBr. Aerosols were generated from salt solutions in a constant output atomiser (TSI 3076), dried, and then equilibrated at controlled humidity by addition of "wet" carrier gas before entry into the flow tube. The size distribution was measured with a differential mobility analyser (DMA). The area weighted radius and surface area of the aerosol in the flow tube was $100-1000 \mathrm{~nm}$, and $(1-80) \times 10^{-3} \mathrm{~cm}^{2} \mathrm{~cm}^{-3}$ respectively. Uptake coefficients were determined from the first order rate constants for ICl decay, corrected for wall loss, which were linearly dependent on surface area. Diffusion limitation was negligible for the size range used. Uptake of $\mathrm{ICl}$ onto $\mathrm{NaBr}$ aerosol $(\mathrm{pH}<8)$ led to $\mathrm{IBr}$ release with a yield of $0.6 \pm 0.3$. Lower uptake on sea salt attributed to depletion of $\mathrm{Br}^{-}$. The uptake coefficient on $\mathrm{NaBr}$ aerosol was independent of $\mathrm{RH}$ in the range $10-70 \%$ (and hence on $\left[\mathrm{Br}^{-}\right]$) and was independent of particle size. This indicates an accommodation controlled uptake process.

\section{Preferred values}

\begin{tabular}{lll}
\hline Parameter & Value & $T / \mathrm{K}$ \\
\hline$\alpha_{\mathrm{b}}$ & 0.016 & 298 \\
$k^{\mathrm{II}}\left(\mathrm{M}^{-1} \mathrm{~s}^{-1}\right)(\mathrm{Br})$ & $>10^{3}$ & 298 \\
$H / \mathrm{M} \mathrm{atm}^{-1}$ & 110 & 298 \\
$D_{\mathrm{l}} / \mathrm{cm}^{2} \mathrm{~s}^{-1}$ & $5.0 \times 10^{-6}$ & 298 \\
Reliability & & \\
$\Delta \log \left(\alpha_{\mathrm{b}}\right)$ & \pm 0.3 & 298 \\
\hline
\end{tabular}




\section{Comments on preferred values}

The recommended value of $\alpha_{\mathrm{b}}$ is based on the uptake coefficient into $\mathrm{NaBr}$ aerosol; the reaction of $\mathrm{ICl}$ with $\mathrm{Br}^{-}$is fast and it is likely that reactive uptake of ICl into salt droplets is accommodation limited under atmospheric conditions. The dihalogen product $\mathrm{IBr}$ will partition rapidly to the gas phase. The uptake coefficient at lower $\left[\mathrm{Br}^{-}\right]$is given in terms of the resistance model:

$\gamma=\left\{\frac{1}{\alpha_{\mathrm{b}}}+\frac{\bar{c}}{4 H R T\left(D_{\mathrm{l}} k^{\mathrm{I}}\right)^{0.5}}\right\}^{-1} \quad$ where $\quad k^{\mathrm{I}}\left(\mathrm{s}^{-1}\right)=k^{\mathrm{II}}\left[\mathrm{Br}^{-}\right]_{\mathrm{aq}}(\mathrm{M})$

At $298 \mathrm{~K}$, a value of $k^{\mathrm{II}}=5.0 \times 10^{4} \mathrm{M}^{-1} \mathrm{~s}^{-1}$ can be used to estimate $\gamma$.

\section{References}

Braban, C. F., Adams, J. W., Rodriguez, D., Cox, R. A., Crowley, J. N., and Schuster, G.: Phys. Chem. Chem. Phys., 9, 3136-3148, 2007.

Holmes, N. S., Adams, J. W., and Crowley, J. N.: Phys. Chem. Chem. Phys., 3, 1679-1687, 2001. 
VI.A2.15

$\mathrm{IBr}(\mathrm{g})+\mathrm{Cl}^{-} / \mathrm{Br}^{-}(\mathrm{aq}) \rightarrow$ products

Experimental data

\begin{tabular}{lllll}
\hline Parameter & {$[\mathrm{X}] / \mathrm{M}$} & $T / \mathrm{K}$ & Reference & Technique/Comments \\
\hline Uptake coefficients: $\gamma, \gamma_{s s}, \gamma_{0}$ & & & & \\
$\gamma=(2.0 \pm 0.3) \times 10^{-3}$ & $2\left(\mathrm{Cl}^{-}\right)$ & 274 & Braban et al. (2007) & WWFT-EIMS (a) \\
& $0.003\left(\mathrm{Br}^{-}\right)$ & & & \\
$\gamma_{0}=(1.8 \pm 0.2) \times 10^{-3}$ & pure water & 274 & & \\
\hline
\end{tabular}

\section{Comments}

(a) The uptake of IBr at concentrations of $(0.2-1) \times 10^{12}$ molecules $\mathrm{cm}^{-3}$ to aqueous surfaces was studied in the wetted-wall flow tube with MS detection at $\mathrm{m} / \mathrm{z}=144$. Uptake was measured on pure water and with dissolved concentrations of $\mathrm{Cl}^{-}$ $(2 \mathrm{M})$ and $\mathrm{Br}^{-}(0.003 \mathrm{M})$ to mimic sea water. Uptake was rapid and was gas phase diffusion limited in both cases, but on pure water the uptake coefficient reduced with increasing exposure length, indicating surface saturation. No gas phase products were observed.

\section{Preferred values}

\begin{tabular}{lll}
\hline Parameter & Value & $T / \mathrm{K}$ \\
\hline$\alpha_{\mathrm{b}}$ & 0.016 & 298 \\
$H / \mathrm{M} \mathrm{atm}^{-1}$ & 24 & 298 \\
$D_{\mathrm{l}} / \mathrm{cm}^{2} \mathrm{~s}^{-1}$ & $5.0 \times 10^{-6}$ & 298 \\
Reliability & & \\
$\Delta \log \left(\alpha_{\mathrm{b}}\right)$ & \pm 0.3 & 298 \\
\hline
\end{tabular}

\section{Comments on preferred values}

The uptake of IBr into aqueous halide is the same as into pure water, and is solubility limited, with no detectable reaction products in the gas phase. The recommendation is based on an analogy with ICl uptake on the same surfaces. The time dependent uptake coefficient is given by:

$\gamma=\left\{\frac{1}{\alpha}+\frac{\bar{c} \sqrt{\pi}}{8 H R T} \sqrt{\frac{t}{D_{1}}}\right\}^{-1}$

\section{References}

Braban, C. F., Adams, J. W., Rodriguez, D., Cox, R. A., Crowley, J. N., and Schuster, G.: Phys. Chem. Chem. Phys., 9, 3136-3148, 2007. 
VI.A2.16

$\mathrm{Cl}_{2}(\mathrm{~g})+\mathrm{Br}^{-}(\mathrm{aq}) \rightarrow \mathrm{BrCl}(\mathrm{aq})+\mathrm{Cl}^{-}(\mathrm{aq})$

Experimental data

\begin{tabular}{lllll}
\hline Parameter & Aqueous Solution & $T / \mathrm{K}$ & Reference & Technique/Comments \\
\hline $\begin{array}{l}\text { Uptake coefficients, } \gamma \\
\approx 4 \times 10^{-3}-0.16\end{array}$ & $\mathrm{Br}^{-},\left(1.25 \times 10^{-3}-0.5\right) \mathrm{M}$ & $263-293$ & Hu et al. (1995) & DT-MS (a) \\
\hline
\end{tabular}

\section{Comments}

(a) Flow tube at $8-27$ mbar $\mathrm{He}\left(+\mathrm{H}_{2} \mathrm{O}\right)$ with $120-250 \mu$ m droplets. $\mathrm{Cl}_{2}\left((5-100) \times 10^{12}\right.$ molecule $\left.\mathrm{cm}^{-3}\right)$ was detected by mass spectrometer. The magnitude of the uptake coefficient and its dependence on the bromide concentration could not be explained if only a bulk reaction was considered.

\section{Preferred values}

\begin{tabular}{lll}
\hline Parameter & Value & $T / \mathrm{K}$ \\
\hline$\alpha_{\mathrm{b}}$ & 1 & $260-295$ \\
$\alpha_{\mathrm{s}}$ & 1 & $260-295$ \\
$k_{\left(\mathrm{Br}^{-}\right)}\left(\mathrm{M}^{-1} \mathrm{~s}^{-1}\right)$ & $4.58 \times 10^{14} \exp (-2866 / T)$ & $260-295$ \\
$H\left(\mathrm{M} \mathrm{atm}^{-1}\right)$ & $1.44 \times 10^{-6} \exp (3181 / T)$ & $260-295$ \\
$D_{\mathrm{l}}\left(\mathrm{cm}^{2} \mathrm{~s}^{-1}\right)$ & $0.127 \exp (-2645 / T)$ & $260-295$ \\
$R\left(\mathrm{~L} \mathrm{~atm} \mathrm{~mol}^{-1} \mathrm{~K}^{-1}\right)$ & $8.2057 \times 10^{-2}$ & \\
$k_{\mathrm{s}} \cdot \mathrm{K}_{\mathrm{LangC}} \cdot \mathrm{N}_{\max }\left(\mathrm{L} \mathrm{mol}^{-1} \mathrm{~cm}^{-1} \mathrm{~s}^{-1}\right)$ & $4.92 \times 10^{-4} \exp (4134 / T)$ & $260-295$ \\
Reliability & & \\
$\Delta \log (\gamma)$ & \pm 0.3 & $260-295$ \\
\hline
\end{tabular}

\section{Comments on preferred values}

The only data available for the uptake of $\mathrm{Cl}_{2}$ to bromide containing, aqueous solutions is that of $\mathrm{Hu}$ et al. (1995). They showed that the uptake of $\mathrm{Cl}_{2}$ could not be explained by bulk phase reaction alone (high values of measured $\gamma$ and non-linear plot of inverse $\gamma$ versus $\left[\mathrm{Br}^{-}\right]^{-0.5}$ ) and proposed that reaction within a surface-near volume was responsible. In this case, the measured uptake coefficient $(\gamma)$ is given by:

$\frac{1}{\gamma}=\frac{1}{\alpha_{\mathrm{s}}}+\frac{1}{\Gamma_{\mathrm{s}}+\left(\frac{1}{\Gamma_{\mathrm{sb}}}+\frac{1}{\Gamma_{\mathrm{b}}}\right)^{-1}}$

where:

$\Gamma_{\mathrm{s}}=\frac{4 k_{\mathrm{s}} a_{(\mathrm{Br}-)} K_{\mathrm{LangC}} N_{\max }}{\bar{c}\left(1+K_{\text {LangC }}\left[\mathrm{Cl}_{2}\right]\right)}$ and

$\Gamma_{\mathrm{b}}=\frac{4 H R T}{\bar{c}} \sqrt{D_{\mathrm{l}} k_{(\mathrm{Br}-)} a_{(\mathrm{Br}-)}}$

and $a_{(\mathrm{Br}-)}$ is the activity $\left(\mathrm{mol} \mathrm{L}^{-1}\right)$ of the dissolved bromide ion.

For efficient interfacial mass transport, $\alpha_{\mathrm{s}}=\alpha_{\mathrm{b}}=1$ the first equation simplifies to:

$\frac{1}{\gamma}=1+\frac{1}{\Gamma_{\mathrm{s}}+\Gamma_{\mathrm{b}}}$

When far from surface saturation (low $K_{\text {LangC }}$ or low $\left[\mathrm{Cl}_{2}\right]$ ) the second expression also reduces to:

$\Gamma_{\mathrm{s}}=\frac{4 k_{\mathrm{s}} a_{(\mathrm{Br}-)} K_{\text {LangC }} N_{\max }}{\bar{c}}$ 
The units of the composite term $k_{\mathrm{S}} \cdot K_{\mathrm{LangC}} \cdot N_{\max }$ are $\mathrm{L} \mathrm{mol}^{-1} \mathrm{~cm}^{-1} \mathrm{~s}^{-1}$ if the surface concentration of bromide ions is considered (as in this case) to be proportional to the bulk activity $\left(\mathrm{mol} \mathrm{L}^{-1}\right)$. The depth through which the surface reaction is considered to take place is integrated in the values of $k_{\mathrm{S}} \cdot K_{\mathrm{LangC}} \cdot N_{\mathrm{max}}$, which were derived by fitting to experimental data.

The temperature dependence of $\Gamma_{\mathrm{s}}$ can arise from both the partition coefficient of $\mathrm{Cl}_{2}$ to the surface $\left(K_{\mathrm{LangC}}\right)$ or via the surface rate coefficient $\left(k_{\mathrm{s}}\right)$, though the former is expected to dominate. The parameterisation gives values of $\gamma$ that are consistent with those presented by Hu et al. (1995) at all temperatures and bromide activities covered in their experiments. Diffusive effects were also taken into account when fitting to the experimental datasets by using

$$
\frac{1}{\gamma}=1+\frac{1}{\Gamma_{\text {diff }}}+\frac{1}{\Gamma_{\mathrm{s}}+\Gamma_{\mathrm{b}}}
$$

and effective gas-phase diffusion coefficients for $\mathrm{Cl}_{2}$ reported by Hu et al. (1995).

The tabulated, temperature dependent expressions for aqueous phase rate coefficients, solubilities and aqueous phase diffusion coefficients listed for calculation of $\Gamma_{\mathrm{b}}$ were calculated from values given by $\mathrm{Hu}$ et al. (1995) at single temperatures. These values were taken in preference to other reports (e.g. of $k_{(\mathrm{Br}-)}$ by Wang et al., 1994) in order to maintain an internally consistent set of parameters. Note that $\gamma$ has almost no sensitivity to $\alpha_{\mathrm{s}}$ or $\alpha_{\mathrm{b}}$ as at high values of the uptake coefficient (when $\alpha_{\mathrm{s}}$ or $\alpha_{\mathrm{b}}$ may be rate limiting) the surface reaction dominates. At low uptake rates, the bulk-phase chemical reaction dominates and the effect of $\alpha$ is diminished.

Studies of the uptake of $\mathrm{Cl}_{2}$ to dry and frozen bromide containing salts surfaces have identified $\mathrm{Br}_{2}$ and $\mathrm{BrCl}$ as the main products released to the gas-phase (Berko et al., 1991; Mochida et al., 1998; Huff and Abbatt, 2000; Adams et al., 2002; Santschi and Rossi, 2004). $\mathrm{BrCl}$ is formed initially and is converted to $\mathrm{Br}_{2}$ by reaction with $\mathrm{Br}^{-}$. The same products are expected for the reaction on an aqueous surface, with the ratio of $\mathrm{BrCl}$ to $\mathrm{Br}_{2}$ defined by aqueous phase equilibria:

$$
\begin{aligned}
& \mathrm{Cl}_{2}+\mathrm{Br}^{-} \rightarrow \mathrm{BrCl}+\mathrm{Cl}^{-} \\
& \mathrm{BrCl}+\mathrm{Br}^{-} \Leftrightarrow \mathrm{Br}_{2} \mathrm{Cl}^{-} \\
& \mathrm{Br}_{2} \mathrm{Cl}^{-} \Leftrightarrow \mathrm{Br}_{2}+\mathrm{Cl}^{-}
\end{aligned}
$$

\section{References}

Adams, J. W., Holmes, N. S., and Crowley, J. N.: Atmos. Chem. Phys., 2, 79-91, doi:10.5194/acp-2-79-2002, 2002.

Berko, H. N., McCaslin, P. C., and Finlayson-Pitts, B. J.: J. Phys. Chem., 95, 6951-6958, 1991.

Hu, J. H., Shi, Q., Davidovits, P., Worsnop, D. R., Zahniser, M. S., and Kolb, C. E.: J. Phys. Chem., 99, 8768-8776, 1995.

Huff, A. K. and Abbatt, J. P. D.: J. Phys. Chem., 104, 7284-7293, 2000.

Mochida, M., Hirokawa, J., Kajii, Y., and Akimoto, H.: Geophys. Res. Lett., 25, 3927-3930, 1998.

Santschi, C. and Rossi, M. J.: Phys. Chem. Chem. Phys., 6, 3447-3460, 2004.

Wang, T. X., Kelley, M. D., Cooper J. N., and Margerum, D. W.: Inorg. Chem., 33, 5872, 1994. 


\section{Appendix A3}

Uptake on other aqueous electrolytes

\section{VI.A3.5}

$\mathrm{N}_{2} \mathrm{O}_{5}(\mathrm{~g})+\mathrm{H}_{2} \mathrm{O}(\mathrm{l})\left(\left(\mathrm{NH}_{4}\right)_{2} \mathrm{SO}_{4}(\mathrm{aq})\right) \rightarrow$ products

\section{Experimental data}

\begin{tabular}{|c|c|c|c|c|}
\hline Parameter & $\mathrm{RH} / \%$ & $T / \mathrm{K}$ & Reference & Technique/Comments \\
\hline \multicolumn{5}{|l|}{ Uptake coefficients: $\gamma, \gamma_{s s}, \gamma_{0}$} \\
\hline $0.043 \pm 0.005$ & 60 & 293 & Mozurkewitch and Calvert (1988) & AFT-CL (a) \\
\hline $0.017 \pm 0.002$ & 93.5 & 297 & Hu and Abbatt (1997) & AFT-CIMS/OPC \\
\hline $0.023 \pm 0.004$ & 83.0 & & & (b) \\
\hline $0.053 \pm 0.006$ & 68.5 & & & \\
\hline $0.044 \pm 0.008$ & 50.0 & & & \\
\hline $0.00094 \pm 0.00059$ & 8 & $295 \pm 1$ & Kane et al. (2001) & AFT- \\
\hline $0.0038 \pm 0.0008$ & 37 & & & CIMS/SMPS \\
\hline $0.012 \pm 0.001$ & 55 & & & (c) \\
\hline $0.020 \pm 0.002$ & 72 & & & \\
\hline $0.033 \pm 0.001$ & 86 & & & \\
\hline $0.042 \pm 0.002$ & 92 & & & \\
\hline $0.0182 \pm 0.0034$ & 62.1 & $295 \pm 2$ & Folkers et al. (2003) & FTIR/SMPS/APC (d) \\
\hline $0.0025-0.0063$ (+ natural organic) & $55-83$ & & & \\
\hline $0.0024 \pm 0.0006$ & 20 & 298 & Hallquist et al. (2003) & AFT-CL/SMPS (e) \\
\hline $0.0047 \pm 0.0013$ & 35 & & & \\
\hline $0.0141 \pm 0.0040$ & 50 & & & \\
\hline $0.0149 \pm 0.0052$ & 70 & & & \\
\hline $0.0164 \pm 0.0048$ & 80 & & & \\
\hline $0.025 \pm 0.0013$ & 50 & 288 & & \\
\hline $0.0141 \pm 0.0040$ & 50 & 298 & & \\
\hline $0.0040 \pm 0.008$ & 50 & 308 & & \\
\hline $0.0057 \pm 0.0013$ & 25 & & Badger et al. (2006) & AFT-CL/SMPS (f) \\
\hline $0.0150 \pm 0.0040$ & 50 & & & \\
\hline $0.0160 \pm 0.0052$ & 60 & & & \\
\hline $0.0190 \pm 0.0048$ & 70 & & & \\
\hline $0.00063 \pm 0.00004(6 \%$ humic acid $)$ & 25 & & & \\
\hline $0.0040 \pm 0.0010(6 \%$ humic acid $)$ & 50 & & & \\
\hline $0.0083 \pm 0.0006(6 \%$ humic acid $)$ & 70 & & & \\
\hline $0.035 \pm 0.002$ & 50 & 263 & Griffiths and Cox (2009) & AFT-CL/SMPS (g) \\
\hline $0.028 \pm 0.002$ & 50 & 275 & & \\
\hline $0.020 \pm 0.005$ & 50 & 283 & & \\
\hline $0.010 \pm 0.002$ & 50 & 293 & & \\
\hline $0.005 \pm 0.002$ & 50 & 303 & & \\
\hline
\end{tabular}

\section{Comments}

(a) Atmospheric pressure aerosol flow tube with $\mathrm{N}_{2} \mathrm{O}_{5}\left(\approx 10^{13}\right.$ molecule $\left.\mathrm{cm}^{-3}\right)$ measured by a modified chemiluminescence method, via thermal dissociation to $\mathrm{NO}_{3}$ and titration with $\mathrm{NO}$, which was detected. Aerosols generated in a constant output atomiser, dried, and size selected with a differential mobility analyser (DMA) coupled to a condensation particle counter (CPC), to count the particles. The monodisperse aerosol was then equilibrated at controlled humidity before entry into the flow tube. The size and surface area of the aerosol in the flow tube was calculated from the deliquescence properties of the aerosol, determined in separate tandem DMA experiments. The typical diameter, $d_{\text {mean }}$ was $0.08-0.2 \mu \mathrm{m}$, with surface area density of $(1-5) \times 10^{-5} \mathrm{~cm}^{2} \mathrm{~cm}^{-3}$. Uptake coefficients were determined from the first order rate constants for 
$\mathrm{N}_{2} \mathrm{O}_{5}$ decay, corrected for wall loss, which were linearly dependent on surface area. Diffusion limitation was negligible for the size range used.

(b) Atmospheric pressure aerosol flow tube with detection of $\mathrm{N}_{2} \mathrm{O}_{5}\left(7 \times 10^{12}\right.$ molecule $\left.\mathrm{cm}^{-3}\right)$ by CIMS using $\mathrm{I}^{-}$reagent ion. The aerosols were generated in an ultrasonic nebuliser and were equilibrated with the ambient humidity before entry into the flow tube. The size distribution, measured with an optical particle counter (OPC), was used to calculate the surface area of the aerosol in the flow tube. The mode diameter in the surface area weighted size distribution, $d_{\max }$, was between 2 and $4 \mu \mathrm{m}$. The counter was calibrated by collection of aerosol of known composition in a aqueous trap (assumed $100 \%$ efficient) and measurement of the electrical conductivity of the trapped electrolyte. Uptake coefficients were determined from the first order rate constants for $\mathrm{N}_{2} \mathrm{O}_{5}$ decay, corrected for wall loss (Brown correction), and for diffusion limitation to the particle surface assuming an average diameter, $d_{\max }$, of the polydisperse aerosol. Cited errors on $\gamma$ are $\pm 1 \sigma$ precision; the estimated potential systematic error arising mainly from measurement of the SA was $\pm 25 \%$.

(c) Atmospheric pressure aerosol flow tube with detection of $\mathrm{N}_{2} \mathrm{O}_{5}$ ((5 to 200) $\times 10^{12}$ molecule $\left.\mathrm{cm}^{-3}\right)$ by CIMS using $\mathrm{I}^{-}$ as reagent ion. Aerosols generated in a constant output atomiser and were dried and equilibrated at controlled humidity before entry into the flow tube. The size distribution was measured with a scanning mobility particle sizer (SMPS) coupled to a condensation particle counter (CPC). The surface area of the aerosol in the flow tube was calculated from the observed size distribution assuming the particles are spherical. The mean diameter, $d_{\text {mean }}$, was $0.12 \mu \mathrm{m}$, with surface area density of $0.0016 \mathrm{~cm}^{2} \mathrm{~cm}^{-3}$. Uptake coefficients were determined from the first order rate constants for $\mathrm{N}_{2} \mathrm{O}_{5}$ decay, corrected for wall loss, and for diffusion limitation to the particle surface using the size resolved Knudsen number for the non-monodisperse aerosol. Although the values of $\gamma$ showed some scatter (ony selected values from the 17 data points reported are cited), a large increase with RH throughout the RH range of 8-92\% was observed, which was fitted by the expression: $=2.79 \times 10^{-4}+1.3 \times 10^{-4} \times(\mathrm{RH})-3.43 \times 10^{-6} \times(\mathrm{RH})^{2}+7.52 \times 10^{-8} \times(\mathrm{RH})^{3}$. No dependence on the uptake coefficient on $\left[\mathrm{N}_{2} \mathrm{O}_{5}\right]$ was observed.

(d) Static aerosol chamber with inert Teflon walls at ambient pressure and temperature. $\mathrm{N}_{2} \mathrm{O}_{5}\left(\approx 10^{13}\right.$ molecule $\left.\mathrm{cm}^{-3}\right)$ produced in situ by reaction of $\mathrm{NO}_{2}$ with ozone. Gas phase species measured by FTIR and UV spectroscopy. Polydisperse aerosol (diameter of $20 \mathrm{~nm}$ to $5 \mu \mathrm{m}$ ) generated by spraying dilute ammonium sulphate solutions, with size distribution measured by SMPS and an aerodynamic particle sizer for particle diameters $>700 \mathrm{~nm}$. Uptake coefficients determined by fitting experimental time dependence of species with a numerical model of chemistry and integrated aerosol surface area.

(e) Atmospheric pressure aerosol flow tube with $\mathrm{N}_{2} \mathrm{O}_{5}\left((7.5-125) \times 10^{13}\right.$ molecule $\left.\mathrm{cm}^{-3}\right)$ measured via thermal dissociation to $\mathrm{NO}_{3}$ and titration with $\mathrm{NO}$, which was detected by chemiluminescence. Deliquesced aerosols were generated in a constant output atomiser, and conditioned by equilibration with an additional excess flow of controlled RH. Size distribution determined with a differential mobility analyser (DMA) coupled to Faraday cup electrometer to count the particles. The typical peak diameter, $d_{\max }$, was $200 \mathrm{~nm}$, with surface area density of (7 to 37$) \times 10^{-5} \mathrm{~cm}^{2} \mathrm{~cm}^{-3}$. Uptake coefficients were determined from the first order rate constants for $\mathrm{N}_{2} \mathrm{O}_{5}$ decay, after correction for wall loss and diffusion effects. The measured uptake coefficients were independent of $\left[\mathrm{N}_{2} \mathrm{O}_{5}\right]$ or on $\mathrm{RH}$ above $50 \%$, but $\gamma$ declined with decreasing $\mathrm{RH}$ below $50 \%$. This falloff was attributed to decreased liquid water amounts in the aerosol at low RH, supported by even lower $\gamma$ values for "dry" aerosols below the efflorescence RH.

(f) Same experimental details as (e); study focussed on effect of mixed AS-humic acid aerosols on $\gamma$, the aerosol surface area in range $0.12-0.50 \mathrm{~m}^{2} \mathrm{~m}^{-3}$ with an area weighted particle diameter of $\sim 300 \mathrm{~nm}$.

(g) Same experimental method as in (e), except that the halocarbon-wax-coated flow tube and the DMA were contained in a modified low temperature chamber so that the aerosol surface area, $S_{\mathrm{a}}$, could be measured at the same temperature as the gas uptake region, leading to improved accuracy of the uptake measurements. $\mathrm{N}_{2} \mathrm{O}_{5}$ mixing ratios were around $300 \mathrm{ppbv}$ and aerosol surface area density varied in the range 0.02 to $0.5 \mathrm{~cm}^{2} \mathrm{~cm}^{-3}$. The particle volume to surface ratio varied between 3 and $4 \times 10^{-9} \mathrm{~m}$. 


\section{Preferred values}

\begin{tabular}{lll}
\hline Parameter & Value & $T / \mathrm{K}$ \\
\hline$\alpha_{\mathrm{b}}$ & 0.03 & 298 \\
$\gamma$ & $0.244-7.9 \times 10^{-4} \mathrm{~T}(\mathrm{~K})$ & $260-305$ \\
$k^{\mathrm{I}}\left(\mathrm{s}^{-1}\right)$ & $k^{\mathrm{II}}\left[\mathrm{H}_{2} \mathrm{O}\right]_{\mathrm{aq}}(\mathrm{M})$ & \\
$k^{\mathrm{II}}\left(\mathrm{M}^{-1} \mathrm{~s}^{-1}\right)$ & $1.0 \times 10^{5}$ & 298 \\
Reliability & & \\
$\Delta \log (\alpha)$ & \pm 0.3 & 298 \\
$\Delta \log (\gamma)$ & \pm 0.3 at $50 \% \mathrm{RH}$ & $260-305$ \\
\hline
\end{tabular}

\section{Comments on preferred values}

Uptake studies conducted on aqueous $\left(\mathrm{NH}_{4}\right)_{2} \mathrm{SO}_{4}$ aerosols as a function of relative humidity show broad agreement in uptake coefficient values, but there are differences in detail. Only data for deliquesced aerosols are presented; at RH below the efflorescence $\mathrm{RH}$ for $\left(\mathrm{NH}_{4}\right)_{2} \mathrm{SO}_{4}$ aerosol $(\sim 37 \%)$ the particles may crystallise and under these conditions the uptake coefficient reduces dramatically to $\gamma<0.001$ due to reduced liquid volume. In most studies $\gamma$ shows little dependence on humidity above $\sim 50 \% \mathrm{RH}$ with $\gamma=0.015-0.02$ at $298 \mathrm{~K}$, but below $50 \% \mathrm{RH} \gamma$ declines significantly as RH reduces. Exceptions are the study of $\mathrm{Hu}$ and Abbatt (1997) in which $\gamma$ increased as RH reduces below $95 \%$ and Kane et al. (2001) in which $\gamma$ continued to increase monotonically above $50 \% \mathrm{RH}$. These opposite trends have not been reproduced in any of the other studies and suggest some source of systematic error. $\mathrm{Hu}$ and Abbatt used larger particles and for size calibration a trapping method was used, which could have underestimated the aerosol surface area of smaller particles at lower RH. Kane et al. give insufficient experimental detail of the sizing method using SMPS to evaluate the reliability of the surface area measurements at high RH. We therefore recommend an expression giving an approximately constant value of $\gamma$ above $50 \% \mathrm{RH}$ at $298 \mathrm{~K}$.

The value of $\gamma$ above $50 \% \mathrm{RH}$ is close to that on pure water drops $(\sim 0.015$ at $298 \mathrm{~K})$, and only slightly lower than that on $\mathrm{H}_{2} \mathrm{SO}_{4}$ droplets $\left(\gamma=0.036 \pm 0.008\right.$, Hallquist et al., 2000). The uptake leads to hydrolysis of $\mathrm{N}_{2} \mathrm{O}_{5}$ and formation of $\mathrm{HNO}_{3}$ which partially transfers to the gas phase. The lack of a dependence on the water content of deliquesced droplets at relative humidity $>50 \%$, suggests that uptake is controlled by a surface process, either mass accommodation or surface reaction. At lower RH, $\gamma$ declines, but the data show large scatter, which may be due to the presence of a mixed size population of solid and liquid particles, as a result of efflorescence. These data suggest that uptake at lower RH is limited by the rate of hydrolysis of $\mathrm{N}_{2} \mathrm{O}_{5}$ in bulk liquid phase, hence depends on $\left[\mathrm{H}_{2} \mathrm{O}\right]_{\mathrm{aq}}$ and, for small particles, on particle volume.

The recommended expression for $\mathrm{RH}$ dependence uses a size dependent resistance-model formulation:

$\gamma=\left\{\frac{1}{\alpha_{\mathrm{b}}}+\frac{\bar{c}}{4 H R T\left(D_{1} k^{\mathrm{I}}\right)^{0.5}}\left[\operatorname{coth}\left(\frac{r}{l}\right)-\left(\frac{l}{r}\right)\right]\right\}^{-1}$

The recommended value of $\alpha_{\mathrm{b}}=0.03$ is based on $\gamma$ observed for uptake on water, malonic acid (Thornton et al., 2004) and $\mathrm{H}_{2} \mathrm{SO}_{4}$ droplets. The recommended liquid phase rate constant $k^{\mathrm{I}}\left(=k^{\mathrm{II}} \times\left[\mathrm{H}_{2} \mathrm{O}\right]_{\mathrm{aq}}\right)$, calculated using $k^{\mathrm{II}}=1 \times 10^{5} \mathrm{M}^{-1} \mathrm{~s}^{-1}$, which is intermediate between the values derived by Thornton et al. (2003) from uptake of $\mathrm{N}_{2} \mathrm{O}_{5}$ on malonic acid aerosol $\left(2.5 \times 10^{4} \mathrm{M}^{-1} \mathrm{~s}^{-1}\right)$ and by Mentel et al. (1999) from uptake on $\mathrm{NaNO}_{3}$ aerosols $\left(1.5 \times 10^{5} \mathrm{M}^{-1} \mathrm{~s}^{-1}\right)$. The RH dependence of $\gamma$ can be calculated using water mass fractions taken from the AIM database and using $D_{1}=1 \times 10^{-5} \mathrm{~cm}^{2} \mathrm{~s}^{-1}$ and $2 \mathrm{M} \mathrm{atm}^{-1}$, values used in the analyses for $k^{\mathrm{II}}$. The expression fits the $>50 \% \mathrm{RH}$ data well but overestimates uptake rates at low RH. The reacto-diffusive parameter $\left(l=\left[D_{1} / k^{\mathrm{II}}\left[\mathrm{H}_{2} \mathrm{O}\right]\right]^{0.5}\right)$ predicts a significant size dependence of $\gamma$ for $r<100 \mathrm{~nm}$.

The temperature dependence of $\mathrm{N}_{2} \mathrm{O}_{5}$ uptake reported earlier by Hallquist et al. (2003) has recently been confirmed by Griffiths and Cox (2009), using improved determination of aerosol size and $S_{\mathrm{a}}$. There is a substantial negative temperature dependence of $\gamma$ at constant $\mathrm{RH}$ of $50 \%$. This is consistent with accommodation controlled uptake but the effect is much larger than the $T$ dependence of $\alpha$ deduced from the results obtained for $\mathrm{H}_{2} \mathrm{SO}_{4}$ droplets at $50 \% \mathrm{RH}$. The recommended expression is an empirical linear fit to the data over the stated temperature range and should be used with caution outside this range.

\section{References}

Badger, C. L., Griffiths, P. T., George, I., Abbatt, J. P. D., and Cox, R. A.: J. Phys. Chem. A, 110, $6986,2006$.

Griffiths, P. T. and Cox, R. A.: Temperature dependence of heterogeneous uptake of $\mathrm{N}_{2} \mathrm{O}_{5}$ by ammonium sulfate aerosol, Atmos. Sci. Lett., 10, 159-163, 2009.

Hallquist, M., Stewart, D. J., Baker, J., and Cox, R. A.: J. Phys. Chem., 104A, 3984, 2000.

Hallquist, M., Stewart, D. J., Stephenson, S. K., and Cox, R. A.: Phys. Chem. Chem. Phys., 5, $3453,2003$. 
Folkers, M., Mentel, Th. F., and Wahner, A.: Geophys. Res. Lett., 30, art. no. 1644, doi:10.1029/2003GL017168, 2003. Hu, J. H. and Abbatt, J. P. D.: J. Phys. Chem., A101, 871, 1997.

Kane, S. M., Caloz, F., and Leu, M.-T.: J. Phys. Chem., 105A, 6465, 2001.

Mentel, T. F., Sohn, M., and Wahner, A.: Phys. Chem. Chem. Phys., 1, 5451, 1999.

Mozurkewich, M. and Calvert, J. G.: J. Geophys. Res., 93, 15889, 1988.

Thornton, J. A., Braban, C. F. and Abbatt, J. P. D.: Phys. Chem. Chem. Phys., 5, 4593-4603, 2003. 
VI.A3.6

$\mathrm{N}_{2} \mathrm{O}_{5}(\mathrm{~g})+\mathrm{H}_{2} \mathrm{O}(\mathrm{l})\left(\mathrm{NH}_{4} \mathrm{HSO}_{4}(\mathrm{aq})\right) \rightarrow$ products

\section{Experimental data}

\begin{tabular}{|c|c|c|c|c|}
\hline Parameter & $\mathrm{RH} / \%$ & $T / \mathrm{K}$ & Reference & Technique/Comments \\
\hline \multicolumn{5}{|l|}{ Uptake coefficients: $\gamma, \gamma_{s s}, \gamma_{0}$} \\
\hline $0.020 \pm 0.0036$ & 13 & 293 & Mozurkewitch and Calvert (1988) & AFT-CL (a) \\
\hline $0.0218 \pm 0.0055$ & 35 & & & \\
\hline $0.050 \pm 0.0055$ & 45 & & & \\
\hline $0.0482 \pm 0.0055$ & 62.5 & & & \\
\hline $0.0382 \pm 0.0055$ & 77.5 & & & \\
\hline $0.0015 \pm 0.00042$ & 13 & $295 \pm 1$ & Kane et al. (2001) & AFT-CIMS (b) \\
\hline $0.0031 \pm 0.0023$ & 32 & & & \\
\hline $0.012 \pm 0.0032$ & 38 & & & \\
\hline $0.018 \pm 0.0027$ & 48 & & & \\
\hline $0.022 \pm 0.0019$ & 63 & & & \\
\hline $0.035 \pm 0.011$ & 74 & & & \\
\hline $0.046 \pm 0.012$ & 89 & & & \\
\hline $0.069 \pm 0.0095$ & 99 & & & \\
\hline $0.020 \pm 0.0020$ & 60 & $295 \pm 2$ & Folkers et al. (2003) & FTIR (c) \\
\hline $0.0190 \pm 0.0040$ & 67 & & & \\
\hline $0.0187 \pm 0.0043$ & 79.7 & & & \\
\hline $0.0025-0.0063$ (+ natural organic) & $55-83$ & & & \\
\hline $0.0031 \pm 0.0017$ & 20 & 298 & Hallquist et al. (2003) & AFT-CL (d) \\
\hline $0.0041 \pm 0.0020$ & 35 & & & \\
\hline $0.018 \pm 0.008$ & 50 & & & \\
\hline $0.023 \pm 0.0013$ & 70 & & & \\
\hline $0.015 \pm 0.006$ & 80 & & & \\
\hline $0.030 \pm 0.0022$ & 50 & 263 & & \\
\hline $0.0140 \pm 0.0062$ & 50 & 268 & & \\
\hline $0.0129 \pm 0.0045$ & 50 & 273 & & \\
\hline $0.036 \pm 0.0018$ & 50 & 283 & & \\
\hline $0.0037 \pm 0.008$ & 50 & 308 & & \\
\hline $0.0133 \pm 0.0009$ & 30 & 298 & Badger (2006) & AFT-CL (e) \\
\hline $0.015 \pm 0.002$ & 50 & & & \\
\hline $0.0196 \pm 0.0009$ & 60 & & & \\
\hline $0.024 \pm 0.001$ & 70 & & & \\
\hline $0.036 \pm 0.009$ & 50 & 263 & Griffiths and Cox (2009) & AFT-CL (f) \\
\hline $0.005 \pm 0.002$ & 50 & 268 & & \\
\hline $0.014 \pm 0.006$ & 50 & 278 & & \\
\hline $0.012 \pm 0.001$ & 50 & 283 & & \\
\hline $0.011 \pm 0.001$ & 50 & 288 & & \\
\hline $0.016 \pm 0.003$ & 50 & 293 & & \\
\hline $0.003 \pm 0.001$ & 50 & 303 & & \\
\hline $0.028 \pm 0.006$ & 60 & 298 & Bertram and Thornton (2009) & AFT-CIMS (g) \\
\hline $0.005 \pm 0.001$ & 5 & & & \\
\hline $0.013 \pm 0.002$ & 10 & & & \\
\hline $0.016 \pm 0.003$ & 15 & & & \\
\hline $0.024 \pm 0.004$ & 25 & & & \\
\hline $0.028 \pm 0.005$ & 40 & & & \\
\hline $0.025 \pm 0.004$ & 50 & & & \\
\hline $0.026 \pm 0.005$ & 50 & & & \\
\hline $0.033 \pm 0.007$ & 65 & & & \\
\hline $0.029 \pm 0.007$ & 75 & & & \\
\hline
\end{tabular}




\section{Comments}

(a) Atmospheric pressure aerosol flow tube with $\mathrm{N}_{2} \mathrm{O}_{5}\left(\approx 10^{13}\right.$ molecule $\left.\mathrm{cm}^{-3}\right)$ measured by a modified chemiluminescence method, via thermal dissociation to $\mathrm{NO}_{3}$ and titration with $\mathrm{NO}$, which was detected. Aerosols generated in a constant output atomiser, dried, and size selected with a differential mobility analyser (DMA) coupled to a condensation particle counter (CPC), to count the particles. The monodisperse aerosol was then equilibrated at controlled humidity before entry into the flow tube. The size and surface area of the aerosol in the flow tube was calculated from the deliquescence properties of the aerosol, determined in separate tandem DMA experiments. The typical mean diameter, $d_{\text {mean }}$, was $0.08-0.2 \mu \mathrm{m}$, with surface area density of $(1-5) \times 10^{-5} \mathrm{~cm}^{2} \mathrm{~cm}^{-3}$. Uptake coefficients were determined from the first order rate constants for $\mathrm{N}_{2} \mathrm{O}_{5}$ decay, corrected for wall loss, which were linearly dependent on surface area. Diffusion limitation was negligible for the size range used.

(b) Atmospheric pressure aerosol flow tube with detection of $\mathrm{N}_{2} \mathrm{O}_{5}\left((5-200) \times 10^{12}\right.$ molecule $\left.\mathrm{cm}^{-3}\right)$ by CIMS using I reagent ion. Aerosols generated in a constant output atomiser and were dried and equilibrated at controlled humidity before entry into the flow tube. The size distribution was measured with a scanning mobility particle sizer (SMPS) coupled to a condensation particle counter (CPC). The surface area of the aerosol in the flow tube was calculated from the observed size distribution assuming the particles are spherical. The mean diameter, $d_{\text {mean }}$, was $0.12 \mu \mathrm{m}$, with surface area density of $0.0016 \mathrm{~cm}^{2} \mathrm{~cm}^{-3}$. Uptake coefficients were determined from the first order rate constants for $\mathrm{N}_{2} \mathrm{O}_{5}$ decay, corrected for wall loss, and for diffusion limitation to the particle surface using the size resolved Knudsen number for the non-monodisperse aerosol. Although the values of $\gamma$ showed some scatter (ony selected values from the 17 data points reported are cited), a large increase with RH throughout the range 13-99\% was observed, which was fitted by the expression: $=2.79 \times 10^{-4}+1.3 \times 10^{-4} \times(\mathrm{RH})-3.43 \times 10^{-6} \times(\mathrm{RH})^{2}+7.52 \times 10^{-8} \times(\mathrm{RH})^{3}$. No dependence on the uptake coefficient on $\left[\mathrm{N}_{2} \mathrm{O}_{5}\right]$ was observed.

(c) Static aerosol chamber with inert teflon walls at ambient pressure and temperature. $\mathrm{N}_{2} \mathrm{O}_{5}\left(\approx 10^{13}\right.$ molecule $\left.\mathrm{cm}^{-3}\right)$ produced in situ by reaction of $\mathrm{NO}_{2}$ with ozone. Gas phase species measured by FTIR and UV spectroscopy. Polydisperse aerosol (diameters from $20 \mathrm{~nm}$ to $5 \mu \mathrm{m}$ ) generated by spraying dilute ammonium bisulphate solutions, with size distribution measured by SMPS for particle diameters $<700 \mathrm{~nm}$ and for larger diameters by aerodynamic particle sizer. Uptake coefficients determined by fitting experimental time dependence of species with a numerical model of chemistry and integrated aerosol surface area.

(d) Atmospheric pressure aerosol flow tube with $\mathrm{N}_{2} \mathrm{O}_{5}\left((7.5-125) \times 10^{13}\right.$ molecule $\left.\mathrm{cm}^{-3}\right)$ measured by thermal dissociation to $\mathrm{NO}_{3}$ and titration with $\mathrm{NO}$, which was detected by $\mathrm{O}_{3}$-chemiluminescence. Deliquesced aerosols were generated in a constant output atomiser, and conditioned by equilibration with an additional excess flow of controlled RH. Size distribution determined with a differential mobility analyser (DMA) coupled to Faraday cup electrometer to count the particles. The typical mode diameter, $d_{\max }$, was $200 \mathrm{~nm}$, with surface area density of (7-37) $\times 10^{-5} \mathrm{~cm}^{2} \mathrm{~cm}^{-3}$. Uptake coefficients were determined from the first order rate constants for $\mathrm{N}_{2} \mathrm{O}_{5}$ decay, after correction for wall loss and diffusion effects. The measured uptake coefficients were independent of $\left[\mathrm{N}_{2} \mathrm{O}_{5}\right]$ or on $\mathrm{RH}$ above $50 \%$, but $\gamma$ declined with decreasing $\mathrm{RH}$ below $50 \%$. This falloff was attributed to decreased liquid water amounts in the deliquesced aerosol at low RH.

(e) Same experimental details as (d); the aerosol surface area in range 0.06-0.27 $\mathrm{m}^{2} \mathrm{~m}^{-3}$ with an area weighted particle diameter of $260 \mathrm{~nm}$.

(f) Same experimental method as in (d), except that the halocarbon-wax-coated flow tube and the DMA were contained in a modified low temperature chamber so that aerosol $S_{\mathrm{a}}$ could be measured at the same temeperature as the gas uptake region, leading to improved accuracy of uptake measurements. $\mathrm{N}_{2} \mathrm{O}_{5}$ mixing ratios were around $300 \mathrm{ppbv}$ and aerosol surface area density varied in the range 0.02 to $0.5 \mathrm{~cm}^{2} \mathrm{~cm}^{-3}$. The aerosol volume to surface ratio varied between 3 and $4 \times 10^{-9} \mathrm{~m}$.

(g) Measurements of the reactive uptake coefficient for $\mathrm{N}_{2} \mathrm{O}_{5}$ on $\mathrm{NH}_{4} \mathrm{HSO}_{4}$ aerosols in an aerosol flow tube at 1 bar and at room temperature, using both time dependence and surface area dependence (at fixed time) of $\left[\mathrm{N}_{2} \mathrm{O}_{5}\right]$ decay. $\gamma$ was determined as a function of relative humidity (RH 5 to $75 \%$ ), and aerosol $\left[\mathrm{NO}_{3}^{-}\right]$. The low detection threshold for $\mathrm{N}_{2} \mathrm{O}_{5}$ $(<5 \mathrm{ppt})$ afforded by CIMS minimised the impact of accumulated $\left[\mathrm{NO}_{3}^{-}\right]$which can reduce uptake rates. A strong increase in $\gamma$ with RH up to $50 \%$ was observed, above which it remained constant. 


\section{Preferred values}

\begin{tabular}{lll}
\hline Parameter & Value & $T / \mathrm{K}$ \\
\hline$\alpha_{\mathrm{b}}$ & 0.04 & 298 \\
$k^{\mathrm{I}}\left(\mathrm{s}^{-1}\right)$ & $k^{\mathrm{II}}\left[\mathrm{H}_{2} \mathrm{O}\right]_{\mathrm{aq}}(\mathrm{M})$ & \\
$k^{\mathrm{II}}\left(\mathrm{M}^{-1} \mathrm{~s}^{-1}\right)$ & $1.5 \times 10^{5}$ & 298 \\
$D_{1} / \mathrm{cm}^{2} \mathrm{~s}^{-1}$ & $1 \times 10^{-5}$ & 298 \\
$H / \mathrm{M} \mathrm{atm}^{-1}$ & 2 & 298 \\
$\operatorname{Reliability}$ & & \\
$\Delta \log (\alpha)$ & \pm 0.3 & 298 \\
$\Delta \log (\gamma)$ at $50 \% \mathrm{RH}$ & \pm 0.3 & \\
\hline
\end{tabular}

\section{Comments on preferred values}

All studies used deliquesced or supersaturated aqueous $\mathrm{NH}_{4} \mathrm{HSO}_{4}$ aerosols, with uptake coefficients measured as a function of RH. $\gamma$ was generally seen to increase with RH over the range 5-90\% but there is poor agreement between the different studies. The early study of Mozurkewitch and Calvert (1988) reported much larger uptake coefficients than from more recent work even after the $15 \%$ downward revision of their reported $\gamma$ values suggested by Fried et al. (1995). The results of Kane et al. (2001) are very scattered at $\mathrm{RH}<50 \%$ and show a large increase in $\gamma$ above $70 \%$ RH which has not been reproduced in any of the other studies. The former authors suggest that evaporation of $\mathrm{NH}_{3}$ could lead to acidification of the particles, forming $\mathrm{H}_{2} \mathrm{SO}_{4}$ which is more reactive. Kane et al. give insufficient experimental detail of the sizing method using SMPS to evaluate the reliability of SA measurements at high $\mathrm{RH}$. The uptake leads to hydrolysis of $\mathrm{N}_{2} \mathrm{O}_{5}$ and formation of $\mathrm{HNO}_{3}$ which partitions between the gas phase and the $\mathrm{NH}_{4} \mathrm{HSO}_{4}$ aerosols as aqueous nitrate.

All other studies show little dependence of $\gamma$ on RH above $\sim 50 \%$ RH. Most of the studies give a value of $\gamma \approx 0.02$, but the results of Bertram and Thornton (2009) are distinctly higher throughout the range. These authors used much lower [ $\left.\mathrm{N}_{2} \mathrm{O}_{5}\right]$ than all other studies and, based on their quantitative analysis of their data for uptake in the presence of $\mathrm{NaNO}_{3}$, they believe their uptake coefficients to be free of nitrate suppression.

The $\gamma$ value at high $\mathrm{RH}$ and $\sim 295 \mathrm{~K}$ is similar to that on pure water drops $(\sim 0.015$ at $298 \mathrm{~K})$, and only slightly lower than that on $\mathrm{H}_{2} \mathrm{SO}_{4}$ droplets $(\gamma=0.036 \pm 0.008$, Hallquist et al., 2000). The lack of a dependence on the water content of deliquesced droplets at $\mathrm{RH}>50 \%$, suggests that uptake is controlled by a surface process, either mass accommodation or surface reaction. At lower RH, $\gamma$ declines. Since $\mathrm{NH}_{4} \mathrm{HSO}_{4}$ aerosols do not effloresce easily this result suggests that uptake at lower RH is limited by the rate of hydrolysis of $\mathrm{N}_{2} \mathrm{O}_{5}$ in the bulk liquid phase, and hence on $\left[\mathrm{H}_{2} \mathrm{O}\right]_{\mathrm{aq}}$. At low RH the hydrolysis rate slows and in addition the size of the particles is smaller, leading to volume-limited uptake coefficients. Bertram and Thornton favour this model over the whole $\mathrm{RH}$ range, and attribute the constancy of $\gamma$ above $\sim 50 \% \mathrm{RH}$ to a reduction in $\left[\mathrm{H}_{2} \mathrm{O}\right]_{\mathrm{aq}}$ dependence of the dissociation of $\left[\mathrm{N}_{2} \mathrm{O}_{5}\right]_{\mathrm{aq}}$. It is probable that the inhibition by nitrate is responsible for the large mismatch of the data of Bertram and Thornton at low $\left[\mathrm{N}_{2} \mathrm{O}_{5}\right]$ and the other studies at $\mathrm{RH}<40 \%$. The differences above $50 \% \mathrm{RH}$ are less and may still be accounted for by estimates which have been made for the accumulated $\left[\mathrm{NO}_{3}^{-}\right]$under the experimental conditions, and volume-limited uptake assumed by Bertram and Thornton is not indicated over the whole range of studies (see Griffiths et al., 2009).

We prefer to recommend an expression for the uptake on pure $\mathrm{NH}_{4} \mathrm{HSO}_{4}$ aerosols using a resistance-model formulation which gives an approximately constant value of $\gamma$ above $70 \% \mathrm{RH}$ at $298 \mathrm{~K}$.

$\gamma=\left\{\frac{1}{\alpha_{\mathrm{b}}}+\frac{\bar{c}}{4 H R T\left(D_{1} k^{1}\right)^{0.5}}\right\}^{-1}$

The recommended value of $\alpha_{\mathrm{b}}=0.04$ at $298 \mathrm{~K}$ is based on $\gamma$ observed for uptake on malonic acid (Thornton et al., 2004) and $\mathrm{H}_{2} \mathrm{SO}_{4}$ droplets (Hallquist et al., 2003). $k^{\mathrm{I}}$ is calculated using the recommended liquid phase rate constant for $\mathrm{N}_{2} \mathrm{O}_{5}+\left[\mathrm{H}_{2} \mathrm{O}\right]_{\mathrm{aq}}: k^{\mathrm{II}}=1.5 \times 10^{5} \mathrm{M}^{-1} \mathrm{~s}^{-1}$, which is based on the values derived by Mentel et al. (1999) from uptake on $\mathrm{NaNO}_{3}$ aerosols $\left(1.5 \times 10^{5} \mathrm{M}^{-1} \mathrm{~s}^{-1}\right)$, and on mixed $\mathrm{NH}_{4} \mathrm{HSO}_{4} /$ dicarboxylic acid aerosols by Griffiths et al. (2009). The RH dependence of $\gamma$ can be calculated using water mass fractions taken from the AIM database. At $>50 \%$ RH this expression provides a good compromise between the Bertram and Thornton data and the main body of the experimental data. Observed uptake rates at low $\mathrm{RH}$ are underestimated with this formula, due to the nitrate effect and volume limited uptake, as discussed above. The size dependence of $\gamma$ can be evaluated by Eq. (24) in the guide to the datasheets using the reacto-diffusive length, $l=\left(D_{1} / k^{\mathrm{II}}\left[\mathrm{H}_{2} \mathrm{O}\right]_{\mathrm{aq}}\right)^{0.5}$; the recommended values predict a significant size dependence of $\gamma$ for $r \leq 100 \mathrm{~nm}$.

Hallquist et al. (2003) reported a temperature dependence of $\mathrm{N}_{2} \mathrm{O}_{5}$ uptake on $\mathrm{NH}_{4} \mathrm{HSO}_{4}$ aerosols at constant $\mathrm{RH}$ of $50 \%$. Their data showed considerable scatter but generally $\gamma$ increased as $T$ decreased in the range $263-308 \mathrm{~K}$, but with a region 
of apparantly zero temperature dependence between $270-290 \mathrm{~K}$. The recent results of Griffiths and Cox (2009), which had reduced uncertainties in determination of the actual $S_{\mathrm{a}}$ of the aerosol, confirm this complex trend. However the origin of this behaviour is not consistent with our general parameterisation for uptake on aqueous liquids and we do not offer a recommendation at this stage.

\section{References}

Badger, C. L.: PhD thesis, University of Cambridge, 2006.

Bertram, T. H. and Thornton, J. A.: Atmos. Chem. Phys., 9, 8351-8363, doi:10.5194/acp-9-8351-2009, 2009.

Hallquist, M., Stewart, D. J., Baker, J., and Cox, R. A.: J. Phys. Chem., 104A, 3984, 2000.

Hallquist, M., Stewart, D. J., Stephenson, S. K., and Cox, R. A.: Phys. Chem. Chem. Phys., 5, 3453, 2003.

Fried, A., Henry, B. E., Calvert, J. G., and Mozurkewich, M.: J. Geophys. Res., 99, 3517, 1994.

Folkers, M., Mentel, Th. F., and Wahner, A.: Geophys. Res. Lett., 30, art. no. 1644, doi:10.1029/2003GL017168, 2003.

Griffiths, P. T. and Cox, R. A.: Atmos. Sci. Lett., 10, 159-163, 2009.

Griffiths, P. T., Badger, C. L., Cox, R. A., Folkers, M., Henk, H. H., and Mentel, T. F.: J. Phys. Chem. A, 113, 5082-5090, 2009.

Kane, S. M., Caloz, F., and Leu, M.-T.: J. Phys. Chem., 105A, 6465, 2001.

Mentel, T. F., Sohn, M., and Wahner, A.: Phys. Chem. Chem. Phys., 1, 5451, 1999.

Mozurkewich, M. and Calvert, J. G.: J. Geophys. Res., 93, 15889-15896, 1988.

Thornton, J. A., Braban, C. F., and Abbatt, J. P. D.: Phys. Chem. Chem. Phys., 5, 4593-4603, 2003. 
VI.A3.7

$\mathrm{N}_{2} \mathrm{O}_{5}(\mathrm{~g})+\mathrm{H}_{2} \mathrm{O}(\mathrm{l})\left(\mathrm{Na} / \mathrm{NH}_{4} \mathrm{NO}_{3}(\mathrm{aq})\right) \rightarrow$ products

\section{Experimental data}

\begin{tabular}{|c|c|c|c|c|c|}
\hline Parameter & $\begin{array}{l}{\left[\mathrm{NO}_{3}\right] /\left[\mathrm{NH}_{4} \mathrm{HSO}_{4}\right]} \\
\mathrm{M} / \mathrm{wt} \%\end{array}$ & $\mathrm{RH} / \%$ & $T / \mathrm{K}$ & Reference & Technique/Comments \\
\hline \multicolumn{6}{|c|}{ Uptake coefficients: $\gamma, \gamma_{s s}, \gamma_{0}$} \\
\hline $0.0018 \pm 0.0020$ & & 48 & $295 \pm 2$ & Wahner et al. (1999) & FTIR/SMPS/APC (a) \\
\hline $0.0032 \pm 0.0006$ & & 62 & & & \\
\hline $0.023 \pm 0.012$ & & 88 & & & \\
\hline $0.0040\left(\mathrm{NH}_{4} \mathrm{NO}_{3}\right)$ & & 54 & & & \\
\hline $0.0065\left(\mathrm{NH}_{4} \mathrm{NO}_{3}\right)$ & & 60 & & & \\
\hline $0.0090\left(\mathrm{NH}_{4} \mathrm{NO}_{3}\right)$ & & 70 & & & \\
\hline $0.016\left(\mathrm{NH}_{4} \mathrm{NO}_{3}\right)$ & & 79 & & & \\
\hline $0.00048 \pm 0.00011$ & & 20 & 298 & Hallquist et al. (2003) & AFT-CL/SMPS (b) \\
\hline $0.00049 \pm 0.00023$ & & 30 & & & \\
\hline $0.00065 \pm 0.00025$ & & 50 & & & \\
\hline $0.0010 \pm 0.00022$ & & 70 & & & \\
\hline $0.00063 \pm 0.00064$ & & 50 & 263 & & \\
\hline $0.00151 \pm 0.00096$ & & 50 & 278 & & \\
\hline $0.00031 \pm 0.00096$ & & 50 & 288 & & \\
\hline $0.025 \pm 0.005$ & $1.1(0.075)$ & 60 & 298 & Bertram and Thornton (2009) & AFT-CIMS/SMPS (c) \\
\hline $0.018 \pm 0.004$ & $2.0(0.065)$ & 60 & & & \\
\hline $0.012 \pm 0.003$ & $3.3(0.051)$ & 60 & & & \\
\hline $0.009 \pm 0.003$ & $4.4(0.041)$ & 60 & & & \\
\hline $0.006 \pm 0.003$ & $6.6(0.028)$ & 60 & & & \\
\hline $0.001 \pm 0.003$ & $9.2(0.0)$ & 55 & & & \\
\hline
\end{tabular}

\section{Comments}

(a) Static aerosol chamber with inert teflon walls at ambient pressure and temperature. $\mathrm{N}_{2} \mathrm{O}_{5}\left(\approx 10^{13}\right.$ molecule $\left.\mathrm{cm}^{-3}\right)$ produced in situ by reaction of $\mathrm{NO}_{2}$ with ozone. Gas phase species measured by FTIR and UV spectroscopy. Polydisperse aerosol (diameter from $20 \mathrm{~nm}$ to $5 \mu \mathrm{m}$ ) generated by spraying dilute ammonium bisulphate solutions, with size distribution measured by SMPS for particle diameters $<700 \mathrm{~nm}$ and aerodynamic particle sizer for larger diameters. The mean volume/surface ratio of the aerosol $\left(=r_{\mathrm{av}} / 3\right)$ was typically $1.1 \times 10^{-5} \mathrm{~cm}^{3} \mathrm{~cm}^{-2}$. Uptake coefficients determined by fitting experimental time dependence of species with a numerical model of chemistry and integrated aerosol surface area. At high RH $\gamma$ for uptake on $\mathrm{NaNO}_{3}$ aerosols was similar to that observed for sulphates and $\mathrm{NaCl}$, but as $\mathrm{RH}$ declined $\gamma$ declined to values a factor of 10 lower at $\sim 50 \% \mathrm{RH}$. A similar trend was observed for uptake on deliqueseced $\mathrm{NH}_{4} \mathrm{NO}_{3}$ aerosols.

(b) Atmospheric pressure aerosol flow tube with $\mathrm{N}_{2} \mathrm{O}_{5}\left((7.5-125) \times 10^{13}\right.$ molecule $\left.\mathrm{cm}^{-3}\right)$ measured by thermal dissociation to $\mathrm{NO}_{3}$ and titration with $\mathrm{NO}$, which was detected by $\mathrm{O}_{3}$-chemiluminescence. Deliquesced aerosols were generated in a constant output atomiser, and conditioned by equilibration with an additional excess flow of controlled RH. Size distribution determined with a differential mobility analyser (DMA) coupled to Faraday cup electrometer to count the particles. The typical mode diameter, $d_{\max }$, was $200 \mathrm{~nm}$, with surface area density of $(1.9-7.01) \times 10^{-3} \mathrm{~cm}^{2} \mathrm{~cm}^{-3}$. Uptake coefficients were determined from the first order rate constants for $\mathrm{N}_{2} \mathrm{O}_{5}$ decay, after correction for wall loss and diffusion effects. The measured uptake coefficients were approximately a factor of 10-20 lower than on sulphate aerosols at comparable RH and showed a weak increase with RH over the range 20-80\%. No significant temperature dependence of $\gamma$ was observed over the range $263-298 \mathrm{~K}$.

(c) Measurements of the reactive uptake coefficient for $\mathrm{N}_{2} \mathrm{O}_{5}$ on $\mathrm{NH}_{4} \mathrm{HSO}_{4}$ aerosols containing nitrate in an aerosol flow tube at 1 bar and at room temperature, using both time dependence and surface area dependence (at fixed time) of $\left[\mathrm{N}_{2} \mathrm{O}_{5}\right.$ ] decay. $\gamma$ was determined as a function of $\left[\mathrm{NaNO}_{3}\right]$ at relative humidity of $60 \%$ and aerosol containing $\left[\mathrm{NH}_{4} \mathrm{HSO}_{4}\right]$ of (0.028 to 0.086$) \mathrm{wt} \%$. At $55 \% \mathrm{RH}$ result for aerosol containing zero $\mathrm{NH}_{4} \mathrm{HSO}_{4}$. The low initial $\left[\mathrm{N}_{2} \mathrm{O}_{5}\right](<5 \mathrm{ppt})$ afforded 
by CIMS minimised the impact of $\left[\mathrm{NO}_{3}^{-}\right]$accumulated as a result of hydrolysis. A strong decrease in $\gamma$ with increasing $\left[\mathrm{NO}_{3}^{-}\right]$was observed.

\section{Preferred values}

\begin{tabular}{lll}
\hline Parameter & Value & $T / \mathrm{K}$ \\
\hline$\alpha_{\mathrm{b}}$ & 0.04 & 298 \\
$k^{\mathrm{I}}\left(\mathrm{s}^{-1}\right)$ & $k^{\mathrm{II}}\left[\mathrm{H}_{2} \mathrm{O}\right]_{\mathrm{aq}}(\mathrm{M})$ & \\
$k^{\mathrm{II}}\left(\mathrm{M}^{-1} \mathrm{~s}^{-1}\right)$ & $1.5 \times 10^{5}\left\{1-\frac{k_{2}\left[\mathrm{NO}_{3}^{-}\right]}{k_{2}\left[\mathrm{NO}_{3}{ }^{-}\right]+k_{3}\left[\mathrm{H}_{2} \mathrm{O}\right]}\right\}$ & 298 \\
$k_{2} / k_{3}$ & 0.054 & 298 \\
$\operatorname{Reliability}$ & & \\
$\Delta \log \left(\alpha_{\mathrm{b}}\right)$ & \pm 0.3 & 298 \\
$\Delta \log (\gamma)$ & \pm 0.3 at 50\% RH \\
\hline
\end{tabular}

\section{Comments on preferred values}

All studies show that the uptake of $\mathrm{N}_{2} \mathrm{O}_{5}$ on aerosols containing nitrate is much reduced except at $\mathrm{RH}$ near $100 \%$. The so called "nitrate effect" was first described by Wahner et al. (1996) and was accounted for by a liquid phase hydrolysis mechanism involving reversible dissociation of solvated $\mathrm{N}_{2} \mathrm{O}_{5}$, according to the reaction mechanism:

$\mathrm{N}_{2} \mathrm{O}_{5}(\mathrm{~g}) \rightarrow \mathrm{N}_{2} \mathrm{O}_{5}(\mathrm{aq})$ accommodation, $\alpha_{\mathrm{b}}$

$\mathrm{N}_{2} \mathrm{O}_{5}(\mathrm{aq}) \leftrightarrows \mathrm{NO}_{2}^{+}(\mathrm{aq})+\mathrm{NO}_{3}^{-}(\mathrm{aq}) \quad k_{1}, k_{2}^{-}$

$\mathrm{NO}_{2}^{+}(\mathrm{aq})+\mathrm{H}_{2} \mathrm{O}(\mathrm{l}) \rightarrow \mathrm{H}^{+}(\mathrm{aq})+\mathrm{HNO}_{3}(\mathrm{aq}) \quad k_{3}$

Thus the hydrolysis rate in solution was inhibited by the presence of nitrate ions which reduced uptake rate, making it chemically controlled as opposed to accommodation controlled. The inhibiting effect on $\gamma\left(\mathrm{N}_{2} \mathrm{O}_{5}\right)$ of $\mathrm{NO}_{3}^{-}$in aerosols containing sulphates and organics has also been investigated by Bertram and Thornton (2009) and by Griffiths et al. (2009). These studies gave values of $(6.0 \pm 1.0) \times 10^{-2}$ and $3.3 \times 10^{-2}$ for the ratio $k_{2} / k_{3}$, compared to a value of $\sim 0.10$ reported by Wahner et al. (1998).

The $\gamma$ values observed by Hallquist et al. (2003) were substantially smaller than observed by Mentel et al. (1999), who used aerosols with particles of larger mean size. This difference can be qualitatively accounted for by the effect of increased reacto-diffusive length as a result of the slower liquid phase hydrolysis, leading to volume-controlled uptake in small particles.

The recommended expression for RH dependence uses a size dependent resistance-model formulation:

$\gamma=\left\{\frac{1}{\alpha_{\mathrm{b}}}+\frac{\bar{c}}{4 H R T\left(D_{1} k^{1}\right)^{0.5}}\left[\operatorname{coth}\left(\frac{r}{l}\right)-\left(\frac{l}{r}\right)\right]\right\}^{-1}$

The recommended value of $\alpha_{\mathrm{b}}=0.04$ is based on $\gamma$ observed for uptake on malonic acid (Thornton et al., 2004) and $\mathrm{H}_{2} \mathrm{SO}_{4}$ droplets and $k^{\mathrm{I}}\left(=k^{\mathrm{II}}\left[\mathrm{H}_{2} \mathrm{O}\right]_{\mathrm{aq}}\right)$. The rate first order rate coefficient $k^{\mathrm{I}}$ is calculated using an expression for $k^{\mathrm{II}}$ modified for the presence of $\mathrm{NO}_{3}^{-}$based on a hydrolysis mechanism steady-state treatment of the $\mathrm{H}_{2} \mathrm{ONO}_{2}^{+}$reactive intermediate:

$k^{\mathrm{I}}=k^{\mathrm{II}} \times\left[\mathrm{H}_{2} \mathrm{O}\right] \quad$ where $\quad k^{\mathrm{II}}=k_{0}^{\mathrm{II}}\left\{1-\frac{k_{2}\left[\mathrm{NO}_{3}^{-}\right]}{k_{2}\left[\mathrm{NO}_{3}^{-}\right]+k_{3}\left[\mathrm{H}_{2} \mathrm{O}\right]}\right\}$

$k_{0}^{\mathrm{II}}$, the value in the absence of $\mathrm{NO}_{3}^{-}$, was set at $1.5 \times 10^{5} \mathrm{M}^{-1} \mathrm{~s}^{-1}$, which is the same as recommended for $\mathrm{N}_{2} \mathrm{O}_{5}$ hydrolysis in other aqueous aerosols. The ratio $k_{2} / k_{3}=0.053$ is the mean of the values deduced in the studies of Bertram and Thornton (2009), Griffiths et al. (2009) and Wahner et al. (1998). The RH dependence of $\gamma$ can be described using water and nitrate concentrations taken from the AIM database, and with $H\left(D_{1}\right)^{0.5}\left(\mathrm{M} \mathrm{atm}^{-1} \mathrm{~cm} \mathrm{~s}^{-0.5}\right)=2.0 \times 10^{-5}$.

The reacto-diffusive parameter $\left(D_{1} / k^{\mathrm{I}}\right)^{0.5}$ predicts a significant size dependence of $\gamma$ for $r<100 \mathrm{~nm}$. The expression for $100 \mathrm{~nm}$ particles fits the Mentel data quite well but overestimates uptake rates observed by Hallquist et al. (2003) at higher RH.

Hallquist et al. (2003) offer the only reported temperature dependence of $\mathrm{N}_{2} \mathrm{O}_{5}$ uptake. They observed no significant temperature dependence of $\gamma$ at constant RH of $50 \%$. This is consistent with aqueous chemistry control of uptake rate. 


\section{References}

Hallquist, M., Stewart, D. J., Stephenson, S. K., and Cox, R. A.: Phys. Chem. Chem. Phys., 5, 3453-3463, 2003. Mentel, T. F, Sohn, M., and Wahner, A.: Phys. Chem. Chem. Phys., 1, 5451-5457, 1999.

Thornton, J. A., Braban, C. F., and Abbatt, J. P. D.: Phys. Chem. Chem. Phys, 5, 4593-4603, 2003.

Wahner, A., Mentel, T. F., Sohn, M., and Stier, J.: J. Geophys. Res., 103 (D23), 31103-31112, 1998. 
VI.A3.8

$\mathrm{N}_{2} \mathrm{O}_{5}(\mathrm{~g})+\mathrm{H}_{2} \mathrm{O}(\mathrm{l})\left(\mathrm{R}(\mathrm{COOH})_{x}(\mathrm{aq})\right) \rightarrow$ products

\section{Experimental data}

\begin{tabular}{|c|c|c|c|c|}
\hline Parameter & $\mathrm{RH} / \%$ & $T / \mathrm{K}$ & Reference & Technique/Comments \\
\hline \multicolumn{5}{|c|}{ Uptake coefficients: $\gamma, \gamma_{s s}, \gamma_{0}$} \\
\hline \multicolumn{5}{|c|}{ Malonic Acid } \\
\hline $0.0020 \pm 0.0005$ & 10 & 298 & Thornton et al. (2003) & AFT-CIMS (a) \\
\hline $0.009 \pm 0.001$ & 20 & & & \\
\hline $0.0165 \pm 0.002$ & 30 & & & \\
\hline $0.022 \pm 0.0035$ & 40 & & & \\
\hline $0.025 \pm 0.003$ & 50 & & & \\
\hline $0.031 \pm 0.004$ & 70 & & & \\
\hline \multicolumn{5}{|l|}{ Humic acid } \\
\hline $0.0001 \pm 0.0001$ & 25 & 298 & Badger (2006) & AFT- \\
\hline $0.0003 \pm 0.0001$ & 50 & & & CL/SMPS (b) \\
\hline $0.0010 \pm 0.0004$ & 75 & & & \\
\hline \multicolumn{5}{|c|}{ Oxalic Acid (solid) } \\
\hline $0.0031 \pm 0.001$ & 74 & $295 \pm 2$ & Griffiths et al. (2008) & FTIR/SMPS/ \\
\hline Malonic Acid & & & & AFT/CL (c) \\
\hline $0.008 \pm 0.003$ & 30 & & & \\
\hline $0.012 \pm 0.002$ & 50 & & & \\
\hline $0.0169 \pm 0.0042$ & 64 & & & \\
\hline $0.016 \pm 0.003$ & 65 & & & \\
\hline \multicolumn{5}{|l|}{ Succinic Acid } \\
\hline$<0.0006$ & 30 & & & \\
\hline$<0.0003$ & 50 & & & \\
\hline $0.0052 \pm 0.0003$ & 55 & & & \\
\hline $0.0051 \pm 0.0008$ & 64 & & & \\
\hline $0.006 \pm 0.001$ & 65 & & & \\
\hline $0.009 \pm 0.003$ & 70 & & & \\
\hline \multicolumn{5}{|l|}{ Glutaric acid } \\
\hline $0.0006 \pm 0.0003$ & 30 & & & \\
\hline $0.0040 \pm 0.0009$ & 50 & & & \\
\hline $0.0081 \pm 0.0004$ & 65 & & & \\
\hline $0.0113 \pm 0.0029$ & 67 & & & \\
\hline $0.008 \pm 0.002$ & 75 & & & \\
\hline
\end{tabular}

\section{Comments}

(a) Measurements of the reactive uptake coefficient for $\mathrm{N}_{2} \mathrm{O}_{5}$ hydrolysis, $\gamma$, on sub-micron organic aerosols in an aerosol flow tube at 1 bar and at room temperature, as a function of relative humidity $(\mathrm{RH})$, aerosol phase, $\mathrm{N}_{2} \mathrm{O}_{5}$ partial pressure, and mean aerosol size. Aerosol phase and relative humidity were determined simultaneously, and chemical ionization mass spectrometry was used to detect the decay rate of $\mathrm{N}_{2} \mathrm{O}_{5}$ in the presence of malonic acid or azelaic acid aerosol. The $\gamma$ on solid malonic acid was determined to be less than $0.001(\mathrm{RH}=10-50 \%)$, and on solid azelaic acid, $\gamma$ was $0.0005 \pm 0.0003$. The values cited are for aqueous malonic acid aerosol. Evidence presented for an inverse dependence of $\gamma$ on the initial concentration of $\mathrm{N}_{2} \mathrm{O}_{5}$ in the range $(1.5-7) \times 10^{11}$ molecule $\mathrm{cm}^{-3}$, and a dependence on particle size for aerosol with surface area-weighted radii less than $100 \mathrm{~nm}$ at $50 \% \mathrm{RH}$. Super-saturated malonic acid aerosol results are consistent with $\mathrm{N}_{2} \mathrm{O}_{5}$ hydrolysis being both aerosol volume-limited where, for $\mathrm{RH}<50 \%$, water is the limiting reagent, and also with a surface-specific process. The rate coefficient for reaction of $\mathrm{N}_{2} \mathrm{O}_{5}$ with $\mathrm{H}_{2} \mathrm{O}$ in solution retrieved for from the volume-limited regime was $2.4 \times 10^{4} \mathrm{M}^{-1} \mathrm{~s}^{-1}$. 
(b) Atmospheric pressure aerosol flow tube with $\mathrm{N}_{2} \mathrm{O}_{5}\left(\sim 5 \times 10^{12}\right.$ molecule $\left.\mathrm{cm}^{-3}\right)$ measured via thermal dissociation to $\mathrm{NO}_{3}$ and titration with $\mathrm{NO}$, which was detected by $\mathrm{O}_{3}$-chemiluminescence. Aqueous humic acid aerosols were generated from filtered solutions of its $\mathrm{Na}$ salt in a constant output atomiser, and conditioned by equilibration with an additional excess flow of controlled RH. Size distribution determined with a differential mobility analyser (DMA). The typical peak diameter, $d_{\max }$, was $170 \mathrm{~nm}$, with surface area density of 1.2 to $5.0 \times 10^{-2} \mathrm{~cm}^{2} \mathrm{~cm}^{-3}$. Uptake coefficients were determined from the first order rate constants for $\mathrm{N}_{2} \mathrm{O}_{5}$ decay, after correction for wall loss and diffusion effects. The measured $\gamma$ on humic acid aerosol increased linearly with RH in the range $25-75 \% \mathrm{RH}$ and was typically a factor of 50 lower that on sulphate. Uptake on aerosols of a range of internally mixed composition of humic acid and $\left(\mathrm{NH}_{4}\right)_{2} \mathrm{SO}_{4}$ were also measured. Even $6 \mathrm{wt} \%$ of humic acid caused a factor of $>2$ reduction in uptake coefficient on $\left(\mathrm{NH}_{4}\right)_{2} \mathrm{SO}_{4}$ at $70 \% \mathrm{RH}$. This falloff was attributed to a decrease in bulk accommodation coefficient of $\mathrm{N}_{2} \mathrm{O}_{5}$ at the surface due to surfactant properties of humic acid.

(c) Uptake measurements on aqueous dicarboxylic acids (malonic, succinic, glutaric, oxalic) made using two different systems at 1 bar pressure: an aerosol flow tube system as described in comment (b); and a large static aerosol chamber, with $\mathrm{N}_{2} \mathrm{O}_{5}\left(\approx 10^{13}\right.$ molecule $\left.\mathrm{cm}^{-3}\right)$ produced in situ by reaction of $\mathrm{NO}_{2}$ with ozone, and gas phase species measured by FTIR and UV spectroscopy. Polydisperse aerosol (diameters from $20 \mathrm{~nm}$ to $5 \mu \mathrm{m}$ ) generated by spraying dilute solutions of carboxylic acids, with size distribution measured by SMPS for particle diameters $<700 \mathrm{~nm}$ and for larger diameters by aerodynamic particle sizer. Uptake coefficients determined by fitting experimental time dependence of species with a numerical model of chemistry and integrated aerosol surface area. The results for uptake on dicarboxylic acid aerosols at different humidities and phase were in good agreement using the two methods. The $\gamma$ values all increased linearly with $\mathrm{RH}$ up to $70 \%$ and for succinic and glutaric acid were distinctly lower than for malonic acid. For the latter, $\gamma$ values were lower than observed by Thornton et al. (2003), and were not observed to level off above $50 \%$ RH. This was attributed to a nitrate effect caused by accumulation of $\mathrm{HNO}_{3}$ product in the aqueous particles. Rate constants for liquid phase reaction of $\mathrm{N}_{2} \mathrm{O}_{5}+\mathrm{H}_{2} \mathrm{O}$ were obtained in this study for malonic acid :1.8 $\times 10^{4} \mathrm{M}^{-1} \mathrm{~s}^{-1}$; for succinic acid: $0.79 \times 10^{4} \mathrm{M}^{-1} \mathrm{~s}^{-1}$; for glutaric acid: $1.2 \times 10^{4} \mathrm{M}^{-1} \mathrm{~s}^{-}$from analysis of the volume limited uptake data.

\section{Preferred values}

\begin{tabular}{lll}
\hline Parameter & Value & $T / \mathrm{K}$ \\
\hline$\alpha_{\mathrm{b}}$ (dicarboxylic acids) & 0.035 & 298 \\
$\gamma($ humic acid) & $3.1 \times 10^{-5} \exp (0.046 \times \mathrm{RH}(\%))$ & 298 \\
$k^{\mathrm{I}}\left(\mathrm{s}^{-1}\right)$ & $k^{\mathrm{II}}\left[\mathrm{H}_{2} \mathrm{O}\right]_{\mathrm{aq}}(\mathrm{M})$ & \\
$k^{\mathrm{II}}\left(\mathrm{M}^{-1} \mathrm{~s}^{-1}\right)$ malonic acid & $1.0 \times 10^{5}$ & 298 \\
$k^{\mathrm{II}}\left(\mathrm{M}^{-1} \mathrm{~s}^{-1}\right)$ succinic acid & $3.0 \times 10^{4}$ & 298 \\
$k^{\mathrm{II}}\left(\mathrm{M}^{-1} \mathrm{~s}^{-1}\right)$ glutaric acid & $5.0 \times 10^{4}$ & 298 \\
Reliability & & \\
$\Delta \log \left(\alpha_{\mathrm{b}}\right)$ & \pm 0.3 & 298 \\
$\Delta \log (\gamma)$ humic acid & \pm 0.3 at $50 \% \mathrm{RH}$ & 298 \\
\hline
\end{tabular}

\section{Comments on preferred values}

All studies used deliquesced or supersaturated aqueous aerosols, with uptake coefficients measured as a function of RH. $\gamma$ was generally seen to increase with RH over the range 20-90\%, although for malonic acid the $\gamma$ value at RH $>50 \%$ Thornton et al. (2004) is constant and close to that on $\mathrm{H}_{2} \mathrm{SO}_{4}$ droplets $(\gamma=0.036 \pm 0.008)$. The lack of a dependence on the water content of deliquesced droplets at $\mathrm{RH}>50 \%$, suggests that uptake is controlled by surface accommodation. At lower RH for malonic and for the $\mathrm{C} 4$ and $\mathrm{C} 5$ acids, $\gamma$ declines, which suggests that uptake is limited by the rate of hydrolysis of $\mathrm{N}_{2} \mathrm{O}_{5}$ in the bulk liquid phase, and hence on $\left[\mathrm{H}_{2} \mathrm{O}\right]_{\text {aq }}$. For very small particles at low $\mathrm{RH}$, the uptake rate can become dependent on particle volume. The uptake rates observed by Griffiths et al. (2009) are lower than observed by Thornton et al. (2003). This was attributed to a nitrate effect caused by accumulation of $\mathrm{HNO}_{3}$ product in the aqueous particles, also indicated in the decline of $\gamma$ with $\left[\mathrm{N}_{2} \mathrm{O}_{5}\right]$ observed by Thornton et al. (2003). A numerical model was developed by Griffiths et al. involving explicit treatment of the coupled processes involved in uptake, including the nitrate effect. The rate coefficient for reaction of $\mathrm{N}_{2} \mathrm{O}_{5}$ with $\mathrm{H}_{2} \mathrm{O}$ in solution obtained using this model to analyse malonic acid data for $70 \% \mathrm{RH}\left(\left[\mathrm{H}_{2} \mathrm{O}\right]=23 \mathrm{M}\right)$ was $k^{\mathrm{II}}=2.1 \times 10^{5} \mathrm{M}^{-1} \mathrm{~s}^{-1} \mathrm{This}$ is larger than that deduced by Thornton et al. (2003), $k^{\mathrm{II}}=2.5 \times 10^{4} \mathrm{M}^{-1} \mathrm{~s}^{-1}$, leading to the conclusion that rate constants derived assuming volume limited uptake are too low. Thus the rate constants derived in their study from analysis of the linear 
region; for succinic acid: $0.79 \times 10^{4} \mathrm{M}^{-1} \mathrm{~s}^{-1}$; for malonic acid: $1.8 \times 10^{4} \mathrm{M}^{-1} \mathrm{~s}^{-1}$; and for glutaric acid: $1.2 \times 10^{4} \mathrm{M}^{-1} \mathrm{~s}^{-1}$ are also likely to be underestimated.

The recommended expression for RH dependence uses a size dependent resistance-model formulation:

$\gamma=\left\{\frac{1}{\alpha_{\mathrm{b}}}+\frac{\bar{c}}{4 H R T\left(D_{\mathrm{l}} k^{\mathrm{I}}\right)^{0.5}}\left[\operatorname{coth}\left(\frac{r}{l}\right)-\left(\frac{l}{r}\right)\right]\right\}^{-1}$

The recommended value of $\alpha_{\mathrm{b}}=0.035$ is based on $\gamma$ observed for uptake on malonic acid. $k^{\mathrm{I}}$ is calculated using the recommended liquid phase rate constant for $\mathrm{N}_{2} \mathrm{O}_{5}+\left[\mathrm{H}_{2} \mathrm{O}\right]_{\mathrm{aq}}: k^{\mathrm{II}}=1 \times 10^{5} \mathrm{M}^{-1} \mathrm{~s}^{-1}$, which is intermediate between the values derived by Thornton et al. (2003) from hydrolysis of $\mathrm{N}_{2} \mathrm{O}_{5}$ on malonic acid aerosol $\left(2.5 \times 10^{4} \mathrm{M}^{-1} \mathrm{~s}^{-1}\right)$ and by Mentel et al. (1999) from uptake on $\mathrm{NaNO}_{3}$ aerosols $\left(1.5 \times 10^{5} \mathrm{M}^{-1} \mathrm{~s}^{-1}\right)$. The RH dependence of $\gamma$ can be calculated using water mass fractions taken from the AIM database, and using $H\left(D_{1}\right)^{0.5}\left(\mathrm{M} \mathrm{atm}^{-1} \mathrm{~cm} \mathrm{~s}^{-0.5}\right)=6.3 \times 10^{-3}$. The expression fits the average values reported for malonic acid in the range $30-60 \%$ RH reasonably well, but the RH dependence is weaker than observed over the range. The reacto-diffusive parameter $\left(\left\{D_{1} / k^{\mathrm{II}}\left[\mathrm{H}_{2} \mathrm{O}\right]\right\}^{0.5}\right)$ predicts a significant size dependence of $\gamma$ for $r<100 \mathrm{~nm}$.

The lower uptake rates observed on succinic and glutaric acid particles cannot be entirely rationalised by reduced water mass fractions or acidity/nitrate effects (Badger, 2006), suggesting that the effective liquid phase rate constants $\left(k^{\mathrm{II}}\right)$ is lower for these acids by $\sim 70 \%$ and $50 \%$ compared to the recommended value for malonic acid.

The recommended uptake coefficient for $\mathrm{N}_{2} \mathrm{O}_{5}$ on humic acid as a function of RH is based on the results of Badger et al. (2006).

\section{References}

Badger, C. L., Griffiths, P. T., George, I., Abbatt, J. P. D., and Cox, R. A.: J. Phys. Chem., 110, 6986-6994, 2006.

Badger, C. L.: PhD thesis, University of Cambridge, 2006.

Griffiths, P. T., Badger, C. L., Cox, R. A., Folkers, M., Henk, H. H., and Mentel, T. F.: J. Phys. Chem. A, 113, 5082-5090, doi:10.1021/jp8096814, 2009.

Thornton, J. A., Braban, C. F., and Abbatt, J. P. D.: Phys. Chem. Chem. Phys., 5, 4593-4603, 2003. 
VI.A3.9

$\mathrm{HO}_{2}(\mathrm{~g})+\mathrm{NH}_{4} \mathrm{HSO}_{4}(\mathrm{aq}) \rightarrow$ products

Experimental data

\begin{tabular}{lcll}
\hline Parameter & $T / \mathrm{K}$ & Reference & Technique/Comments \\
\hline $\begin{array}{l}\text { Accomodation coefficients: } \alpha_{\mathrm{b}} \\
>0.2\end{array}$ & 293 & Mozurkewich et al. (1987) & AFT (a) \\
\hline
\end{tabular}

\section{Comments}

(a) Uptake experiments of $\mathrm{HO}_{2}\left(10^{8}-10^{9}\right.$ molecule $\left.\mathrm{cm}^{-3}\right)$ to deliquescent particles (diameters from 0.05 to $0.1 \mu \mathrm{m}$ ) containing $\mathrm{CuSO}_{4} \cdot \mathrm{HO}_{2}$ was formed by passing a mixture of $\mathrm{H}_{2}$ and $\mathrm{H}_{2} \mathrm{O}$ over a hot Nichrome wire and detected by chemically amplified conversion to $\mathrm{NO}_{2}$. Levels of $\mathrm{HO}_{2}$ were sufficiently low to neglect loss due to gas-phase self reaction. The average experimental uptake coefficient was $\gamma=0.4 \pm 0.08$ with no measurable dependence on the $\mathrm{CuSO}_{4}$ molality between 0.006-0.07 M. The uptake coefficient dropped sharply when the $\mathrm{CuSO}_{4}$ solution was less than $\sim 10^{-3} \mathrm{M}$ and was zero when less than $10^{-4} \mathrm{M}$. The authors make a conservative estimate of 0.2 for the lower limit to the accommodation coefficient, $\alpha_{\mathrm{b}}$.

\section{Preferred values}

\begin{tabular}{lll}
\hline Parameter & Value & $T / \mathrm{K}$ \\
\hline$\alpha_{\mathrm{b}}$ & $>0.5$ & $293 \mathrm{~K}$ \\
Reliability & & \\
$\Delta\left(\log \alpha_{\mathrm{b}}\right)$ & undetermined & \\
\hline
\end{tabular}

\section{Comments on preferred values}

The single experimental investigation of $\mathrm{HO}_{2}$ uptake to $\mathrm{NH}_{4} \mathrm{HSO}_{4}$ derived a lower limit to the accommodation coefficient of 0.2 , which is consistent with results on other aqueous surfaces where uptake coefficients as large as 0.5 have been measured (e.g. VI.A3.10).

The uptake of $\mathrm{HO}_{2}$ in aqueous solution with $\mathrm{pH}>5$, is presently believed to be driven by self-reaction and acid-base dissociation of $\mathrm{HO}_{2}(\mathrm{pKa} \sim 4.7)$ with formation of $\mathrm{H}_{2} \mathrm{O}_{2}$ (Reactions $\mathrm{R} 2, \mathrm{R} 3$ ). In the presense of transition metal ions (TMI) the reaction of $\mathrm{HO}_{2}$ and especially $\mathrm{O}_{2}^{-}$(Reaction $\mathrm{R} 4$ ) can be important:

$$
\begin{aligned}
& \mathrm{HO}_{2}(\mathrm{~g}) \rightarrow \mathrm{O}_{2}^{-}(\mathrm{aq})+\mathrm{H}^{+}(\mathrm{aq}) \\
& \mathrm{HO}_{2}(\mathrm{aq})+\mathrm{HO}_{2}(\mathrm{aq}) \rightarrow \mathrm{H}_{2} \mathrm{O}_{2}(\mathrm{aq})+\mathrm{O}_{2}(\mathrm{aq}) \\
& \mathrm{O}_{2}^{-}(\mathrm{aq})+\mathrm{HO}_{2}(\mathrm{aq})\left(+\mathrm{H}_{2} \mathrm{O}(\mathrm{l})\right) \rightarrow \mathrm{H}_{2} \mathrm{O}_{2}(\mathrm{aq})+\mathrm{O}_{2}(\mathrm{aq})+\mathrm{OH}^{-}(\mathrm{aq}) \\
& \mathrm{O}_{2}^{-}(\mathrm{aq})+\mathrm{TMI}(\mathrm{aq}) \rightarrow \text { products }
\end{aligned}
$$

If a first-order loss process for $\mathrm{HO}_{2}$ or $\mathrm{O}_{2}^{-}$in the aqueous phase dominates (e.g. reaction with TMI such as $\mathrm{Cu}(\mathrm{II})$ ), and assuming equal rates of reaction throughout the particle, the uptake coefficient can be calculated from the expression below:

$$
\frac{1}{\gamma}=\frac{1}{\alpha_{\mathrm{b}}}+\frac{\bar{c}}{4 H^{\mathrm{eff}} R T \sqrt{k_{\mathrm{TMI}}[\mathrm{TMI}] D_{1}}}
$$

$H^{\text {eff }}=H^{\mathrm{HO} 2}\left(1+K_{\mathrm{eq}} /\left[\mathrm{H}^{+}\right], K_{\mathrm{eq}}=2.1 \times 10^{-5} \mathrm{M}\right.$ at $298 \mathrm{~K}(\mathrm{Jacob}, 2000), H^{\mathrm{HO} 2}=9.5 \times 10^{-6} \exp (5910 / T)($ Hanson et al., 1992) and $D_{1}=\left[1 \times 10^{-5}(T / 298)\right] /\left(1.09 \times 10^{8} \exp (-0.068 T)+0.873\right) \mathrm{cm}^{2} \mathrm{~s}^{-1}$ (Schwartz, 1984; Thornton et al., 2008) where the denominator in the $D_{1}$ term was derived from a fit to the water viscosity data of Hallett (1963).

According to the reaction scheme above, in the absence of TMI, the rates of loss of aqueous-phase $\mathrm{HO}_{2}$ are quadratically dependent on $\left[\mathrm{HO}_{2}\right]_{\mathrm{aq}}$ and $\left[\mathrm{O}_{2}^{-}\right]_{\mathrm{aq}}$ and are thus strongly dependent on the gas-phase concentration of $\mathrm{HO}_{2}$. At low $\mathrm{HO}_{2}$ concentrations (e.g. as found in the atmosphere) the liquid phase reactions become rate limiting and $\gamma$ is expected to be much smaller as observed in dilute solutions by Mozurkewich et al. (1987) and the simple formalism above breaks down. Thornton 
and Abbatt (2005) suggest that the rate of loss of $\mathrm{HO}_{2}$ from the gas-phase (in molecule $\mathrm{cm}^{-3} \mathrm{~s}^{-1}$ ) is best described by a system in thermodynamic (Henry's law) equilibrium so that (Thornton et al., 2008):

$\frac{1}{\gamma}=\frac{1}{\alpha_{\mathrm{b}}}+\frac{3 \bar{c} N_{\mathrm{A}}}{8000\left(H^{\mathrm{eff}} R T\right)^{2} k_{\mathrm{aq}}\left[\mathrm{HO}_{2}\right] r}$

$k_{\text {aq }}$ can be calculated from the rate coefficients for Reaction (R2) $\left(k_{2}\right)$ and (R3) $\left(k_{3}\right)$ (Bielski et al., 1985) and the pH:

$k_{\mathrm{aq}}=\frac{k_{2}+\left(\frac{K_{\mathrm{eq}}}{\left[\mathrm{H}^{+}\right] \mathrm{aq}}\right) k_{3}}{\left(1+\frac{K_{\mathrm{eq}}}{\left[\mathrm{H}^{+}\right] \mathrm{aq}}\right)^{2}}$

This formalism predicts that the loss of $\mathrm{HO}_{2}$ to particles is favoured by high $\mathrm{HO}_{2}$ mixing ratios, low temperatures (higher solubility) and low $\mathrm{pH}$. At low concentrations of $\mathrm{HO}_{2}$ (whereby the self reaction and reaction with $\mathrm{O}_{2}^{-}$are inefficient), values of $\gamma$ of $<0.005$ are calculated, which are however much less than the uptake coefficients of Taketani et al. (2008) who investigated the uptake of low concentrations of $\mathrm{HO}_{2}$ to $\left(\mathrm{NH}_{4}\right)_{2} \mathrm{SO}_{4}$ particles. In addition, as discussed by Hanson et al. (1992) and Thornton and Abbatt (2005), there is considerable uncertainty (factor of 2.5) associated with the solubility of $\mathrm{HO}_{2}\left(\mathrm{H}^{\mathrm{HO} 2}\right)$ and its temperature dependence. The above schemes also do not account for the RH dependence of uptake observed for $\left(\mathrm{NH}_{4}\right)_{2} \mathrm{SO}_{4}$ particles (see datasheet VI.A3.10).

Until these apparent discrepancies have been resolved by further experiments, we make no recommendation for parameterising $\mathrm{HO}_{2}$ uptake to aqueous aerosol. We refer to recent publications for a more detailed description of the effect of different parameterisation schemes (Thornton et al., 2008; Mao et al., 2013).

\section{References}

Bielski, B. H. J., Cabelli, D. E., Arudi, R. L., and Ross, A. B.: J. Phys. Chem. Ref. Data, 14, 1041-1100, 1985.

Hanson, D. R., Burkholder, J. B., Howard, C. J., and Ravishankara, A. R.: J. Phys. Chem., 96, 4979-4985, 1992.

Jacob, D. J.: Atmos. Env., 34, 2131-2159, 2000.

Mao, J., Fan, S., Jacob, D. J., and Travis, K. R.: Atmos. Chem. Phys., 13, 509-519, doi:10.5194/acp-13-509-2013, 2013.

Morita, A., Kanaya, Y., and Francisco, J. S.: J. Geophys. Res.-Atmos., 109, art. no. D09201, doi:10.1029/2003JD004240, 2004.

Mozurkewich, M., McMurry, P. H., Gupta, A., and Calvert, J. G.: J. Geophys. Res.-Atmos., 92, 4163-4170, 1987.

Schwartz, S. E.: J. Geophys. Res.-Atmos., 89, 1589-1598, 1984.

Thornton, J. and Abbatt, J. P. D.: J. Geophys. Res.-Atmos., 110, D08309, doi:10.1029/2004JD005402, 2005. 
VI.A3.10

$\mathrm{HO}_{2}(\mathrm{~g})+\left(\mathrm{NH}_{4}\right)_{2} \mathrm{SO}_{4}(\mathrm{aq}) \rightarrow$ products

Experimental data

\begin{tabular}{llll}
\hline Parameter & $T / \mathrm{K}$ & Reference & Technique/Comments \\
\hline $\begin{array}{l}\text { Accomodation coefficients: } \alpha_{\mathrm{b}} \\
>0.5\end{array}$ & 298 & & \\
$>0.5$ & $296 \pm 2$ & Thornton and Abbatt (2005) & AFT (a) \\
\hline
\end{tabular}

\section{Comments}

(a) Uptake of $\mathrm{HO}_{2}\left((2.5-5.0) \times 10^{10}\right.$ molecule $\left.\mathrm{cm}^{-3}\right)$ to deliquescent particles (mean, surface area weighted radius of $\left.125 \mathrm{~nm}\right)$ at $\mathrm{RH}=40-45 \%$ containing $0.01-0.1 \mathrm{M} \mathrm{CuSO}_{4}$, and buffered to a $\mathrm{pH}$ of 5.1. $\mathrm{HO}_{2}$ was formed in the reaction of $\mathrm{H}$ atoms with $\mathrm{O}_{2}$ (the former made in a microwave discharge of $\mathrm{H}_{2}$ ). Detection of $\mathrm{HO}_{2}$ was by CIMS as $\mathrm{O}_{2}^{-}$using $\mathrm{F}^{-}$reagent ions, or conversion of $\mathrm{HO}_{2}$ to $\mathrm{H}_{2} \mathrm{SO}_{4}$ and detection of the product (as $\mathrm{HSO}_{4}^{-}$) using $\mathrm{I}^{-}$ions.

(b) Uptake of $\mathrm{HO}_{2}\left(\sim 10^{8}\right.$ molecule $\left.\mathrm{cm}^{-3}\right)$ to $\left(\mathrm{NH}_{4}\right)_{2} \mathrm{SO}_{4}$ particles (mean surface area weighted diameter of $80-110 \mathrm{~nm}$ ) at RH between 45 and $75 \%$. $\mathrm{HO}_{2}$ was generated by the photolysis of $\mathrm{H}_{2} \mathrm{O}$ in air and detected as $\mathrm{OH}$ (by LIF) following conversion in reaction with NO. The particles contained $\mathrm{CuSO}_{4}(\sim 0.5 \mathrm{M})$ to scavenge $\mathrm{HO}_{2}$ in order to determine $\alpha_{\mathrm{b}}$.

\section{Preferred values}

\begin{tabular}{lll}
\hline Parameter & Value & $T / \mathrm{K}$ \\
\hline$\alpha$ & $>0.5$ & $290-300$ \\
Reliability & & \\
$\Delta\left(\log \alpha_{\mathrm{b}}\right)$ & undetermined & \\
\hline
\end{tabular}

\section{Comments on preferred values}

Thornton and Abbatt (2005) derived an average experimental uptake coefficient of $\gamma=0.5 \pm 0.1$ on particles containing $\mathrm{CuSO}_{4}$ and suggest that this is a lower limit to the accommodation coefficient. In the absence of $\mathrm{CuSO}_{4}$ non-exponential loss of $\mathrm{HO}_{2}$ was observed, which the authors attributed to the aqueous phase self reaction of $\mathrm{HO}_{2}$ and derived an aqueous-phase rate coefficient of $(1 \pm 0.25) \times 10^{7} \mathrm{M}^{-1} \mathrm{~s}^{-1}$ for this process, consistent with kinetic data on the reaction of $\mathrm{HO}_{2}$ with itself and with $\mathrm{O}_{2}^{-}$. Using significantly lower $\mathrm{HO}_{2}$ concentrations, Taketani et al. (2008) observed exponential $\mathrm{HO}_{2}$ decays with $\gamma$ equal to $\sim 0.5$ when $\mathrm{CuSO}_{4}$ was present, defining the lower limit to $\alpha_{\mathrm{b}}$. In the absence of $\mathrm{CuSO}_{4} \gamma$ increased with $\mathrm{RH}$ with values of 0.11 (45\%), $0.15(55 \%), 0.17(65 \%)$ and $0.19(75 \%)$. Taketani et al. speculate that the RH dependence stems from the effect of particle size changes with RH and the reaction occurring in the transition regime between surface and volume limited uptake. Lower uptake coefficients have been reported for $\mathrm{HO}_{2}$ interaction with dry $\left(\mathrm{NH}_{4}\right)_{2} \mathrm{SO}_{4}$ particles with Taketani et al. (2008) reporting values of 0.04-0.05 and Gershenzon et al. (1995) reporting 0.011.

The uptake of $\mathrm{HO}_{2}$ in aqueous solution with $\mathrm{pH}>5$, is presently believed to be driven by self-reaction and acid-base dissociation of $\mathrm{HO}_{2}(\mathrm{pKa} \sim 4.7)$ with formation of $\mathrm{H}_{2} \mathrm{O}_{2}$ (Reactions $\mathrm{R} 2, \mathrm{R} 3$ ). In the presense of transition metal ions (TMI) the reaction of $\mathrm{HO}_{2}$ and especially $\mathrm{O}_{2}^{-}$(Reaction $\mathrm{R} 4$ ) can be important:

$$
\begin{aligned}
& \mathrm{HO}_{2}(\mathrm{~g}) \rightarrow \mathrm{O}_{2}^{-}(\mathrm{aq})+\mathrm{H}^{+}(\mathrm{aq}) \\
& \mathrm{HO}_{2}(\mathrm{aq})+\mathrm{HO}_{2}(\mathrm{aq}) \rightarrow \mathrm{H}_{2} \mathrm{O}_{2}(\mathrm{aq})+\mathrm{O}_{2}(\mathrm{aq}) \\
& \mathrm{O}_{2}^{-}(\mathrm{aq})+\mathrm{HO}_{2}(\mathrm{aq})\left(+\mathrm{H}_{2} \mathrm{O}(\mathrm{l})\right) \rightarrow \mathrm{H}_{2} \mathrm{O}_{2}(\mathrm{aq})+\mathrm{O}_{2}(\mathrm{aq})+\mathrm{OH}^{-}(\mathrm{aq}) \\
& \mathrm{O}_{2}^{-}(\mathrm{aq})+\mathrm{TMI}(\mathrm{aq}) \rightarrow \text { products }
\end{aligned}
$$

If a first-order loss process for $\mathrm{HO}_{2}$ or $\mathrm{O}_{2}^{-}$in the aqueous phase dominates (e.g. reaction with TMI such as $\mathrm{Cu}(\mathrm{II})$ ), and assuming equal rates of reaction throughout the particle, the uptake coefficient can be calculated from the expression below:

$\frac{1}{\gamma}=\frac{1}{\alpha_{\mathrm{b}}}+\frac{\bar{c}}{4 H^{\mathrm{eff}} R T \sqrt{k_{\mathrm{TMI}}[\mathrm{TMI}] D_{\mathrm{l}}}}$ 
$H^{\text {eff }}=H^{\mathrm{HO} 2}\left(1+K_{\text {eq }} /\left[\mathrm{H}^{+}\right]\right), K_{\mathrm{eq}}=2.1 \times 10^{-5} \mathrm{M}$ at $298 \mathrm{~K}(\mathrm{Jacob}, 2000), H^{\mathrm{HO} 2}=9.5 \times 10^{-6} \exp (5910 / T)$ (Hanson et al., 1992) and $D_{1}=\left[1 \times 10^{-5}(T / 298)\right] /\left(1.09 \times 10^{8} \exp (-0.068 T)+0.873\right) \mathrm{cm}^{2} \mathrm{~s}^{-1}$ (Schwartz, 1984; Thornton et al., 2008) where the denominator in the $D_{1}$ term was derived from a fit to the water viscosity data of Hallett (1963).

According to the reaction scheme above, in the absence of TMI, the rates of loss of aqueous-phase $\mathrm{HO}_{2}$ are quadratically dependent on $\left[\mathrm{HO}_{2}\right]_{\mathrm{aq}}$ and $\left[\mathrm{O}_{2}^{-}\right]_{\mathrm{aq}}$ and are thus strongly dependent on the gas-phase concentration of $\mathrm{HO}_{2}$. At low $\mathrm{HO}_{2}$ concentrations (e.g. as found in the atmosphere) the liquid phase reactions become rate limiting and $\gamma$ is expected to be much smaller as observed in dilute solutions by Mozurkewich et al. (1987) and the simple formalism above breaks down. Thornton and Abbatt (2005) suggest that the rate of loss of $\mathrm{HO}_{2}$ from the gas-phase (in molecule $\mathrm{cm}^{-3} \mathrm{~s}^{-1}$ ) is best described by a system in thermodynamic (Henry's law) equilibrium so that (Thornton et al., 2008):

$$
\frac{1}{\gamma}=\frac{1}{\alpha_{\mathrm{b}}}+\frac{3 \bar{c} N_{\mathrm{A}}}{8000\left(H^{\mathrm{eff}} R T\right)^{2} k_{\mathrm{aq}}\left[\mathrm{HO}_{2}\right] r}
$$

$k_{\mathrm{aq}}$ can be calculated from the rate coefficients for Reactions (R2) $\left(k_{2}\right)$ and (R3) $\left(k_{3}\right)$ (Bielski et al., 1985) and the pH:

$k_{\mathrm{aq}}=\frac{k_{2}+\left(\frac{K_{\mathrm{eq}}}{\left[\mathrm{H}^{+}\right] \mathrm{aq}}\right) k_{3}}{\left(1+\frac{K_{\mathrm{eq}}}{\left[\mathrm{H}^{+}\right] \mathrm{aq}}\right)^{2}}$

This formalism predicts that the loss of $\mathrm{HO}_{2}$ to particles is favoured by high $\mathrm{HO}_{2}$ mixing ratios, low temperatures (higher solubility) and low $\mathrm{pH}$. At low concentrations of $\mathrm{HO}_{2}$ (whereby the self reaction and reaction with $\mathrm{O}_{2}^{-}$are inefficient), values of $\gamma$ of $<0.005$ are calculated, which are however much less than the uptake coefficients of Taketani et al. (2008) who investigated the uptake of low concentrations of $\mathrm{HO}_{2}$ to $\left(\mathrm{NH}_{4}\right)_{2} \mathrm{SO}_{4}$ particles. In addition, as discussed by Hanson et al. (1992) and Thornton and Abbatt (2005), there is considerable uncertainty (factor of 2.5) associated with the solubility of $\mathrm{HO}_{2}\left(H^{\mathrm{HO} 2}\right)$ and its temperature dependence. The above schemes also do not account for the RH dependence of uptake observed by Taketani et al. (2008).

Until these apparent discrepancies have been resolved by further experiments, we make no recommendation for parameterising $\mathrm{HO}_{2}$ uptake to aqueous aerosol. The hypothesis of a fast disproportionation reaction $2 \mathrm{HO}_{2} \rightarrow \mathrm{H}_{2} \mathrm{O}_{2}+\mathrm{O}_{2}$ in aqueous solution advanced by Thornton and Abbatt (2005) is inconsistent with the measured value of $\gamma$ for $\mathrm{HO}_{2}$ loss on both $\mathrm{NaCl}$ and $\left(\mathrm{NH}_{4}\right)_{2} \mathrm{SO}_{4}$ aerosol when extrapolated to the $\mathrm{HO}_{2}$ concentrations lower by a factor of 500 used in the work of Taketani et al. (2008). We refer to recent publications for a more detailed description of the effect of different parameterisation schemes (Thornton et al., 2008; Mao et al., 2013).

\section{References}

Bielski, B. H. J., Cabelli, D. E., Arudi, R. L., and Ross, A. B.: J. Phys. Chem. Ref. Data, 14, 1041-1100, 1985.

Gershenzon, Y. M., Grigorieva, V. M., Ivanov, A. V., and Remorov, R. G.: Faraday Discuss., 100, 83-100, 1995.

Hanson, D. R., Burkholder, J. B., Howard, C. J., and Ravishankara, A. R.: J. Phys. Chem., 96, 4979-4985, 1992. Jacob, D. J.: Atmos. Env., 34, 2131-2159, 2000.

Mao, J., Fan, S., Jacob, D. J., and Travis, K. R.: Atmos. Chem. Phys., 13, 509-519, doi:10.5194/acp-13-509-2013, 2013.

Morita, A., Kanaya, Y., and Francisco, J. S.: J. Geophys. Res.-Atmos., 109, 2004.

Mozurkewich, M., McMurry, P. H., Gupta, A., and Calvert, J. G.: J. Geophys. Res.-Atmos., 92, 4163-4170, 1987.

Schwartz, S. E.: J. Geophys. Res.-Atmos., 89, 1589-1598, 1984.

Taketani, F., Kanaya, Y., and Akimoto, H.: J. Phys. Chem. A, 112, 2370-2377, 2008.

Thornton, J. and Abbatt, J. P. D.: J. Geophys. Res.-Atmos., 110, D08309, doi:10.1029/2004JD005402, 2005. 


\section{Appendix A4}

\section{Uptake on liquid sulphuric acid}

\section{VI.A4.0}

$\mathrm{O}_{3}(\mathrm{~g})+\mathrm{H}_{2} \mathrm{SO}_{4}(\mathrm{aq}) \rightarrow$ products

\section{Experimental data}

\begin{tabular}{llll}
\hline Parameter & $T / \mathrm{K}$ & Reference & Technique/Comments \\
\hline Uptake coefficients: $\gamma$ & & & \\
$<1 \times 10^{-6}$ & $300-270$ & Baldwin and Golden (1979) & Knudsen-MS (a) \\
$(4.79 \pm 1.38) \times 10^{-11}\left(75 \mathrm{wt} \% \mathrm{H}_{2} \mathrm{SO}_{4}\right)$ & 223 & Olszyna et al. (1979) & (b) \\
$<1 \times 10^{-6}$ & 195 & Dlugokencky and Ravishankara (1992) & $\mathrm{CWFT-CLD} \mathrm{(c)}$ \\
$(1.2 \pm 0.08) \times 10^{-6}\left(98 \mathrm{wt} \% \mathrm{H}_{2} \mathrm{SO}_{4}\right)$ & 239 & Il'in et al. (1992) & UV (d) \\
$(1.6 \pm 0.08) \times 10^{-6}\left(98 \mathrm{wt} \% \mathrm{H}_{2} \mathrm{SO}_{4}\right)$ & 258 & & \\
$(1.75 \pm 0.07) \times 10^{-6}\left(98 \mathrm{wt} \% \mathrm{H}_{2} \mathrm{SO}_{4}\right)$ & 273 & & \\
\hline
\end{tabular}

\section{Comments}

(a) No evidence for uptake of $\mathrm{O}_{3}$ to $\mathrm{H}_{2} \mathrm{SO}_{4}$ surface which contained less than $5 \%$ water.

(b) Static experiment with $\mathrm{H}_{2} \mathrm{SO}_{4}$ coated on glass beads in a round bottom flask. $\mathrm{O}_{3}$ analysed ex-situ. Slow loss of $\mathrm{O}_{3}$ was observed over several hours to derive the values of $\gamma$ listed.

(c) $\approx 2 \mathrm{~mm}$ thick (frozen) $\mathrm{H}_{2} \mathrm{SO}_{4}$ films were prepared from a bulk solution of 50 or $97 \mathrm{wt} \%$. $\left[\mathrm{O}_{3}\right]$ was either $5 \times 10^{8}$ or $2 \times 10^{9}$ molecule $\mathrm{cm}^{-3}$. The geometric surface area was used to calculate $\gamma$.

(d) Static reactor with $\mathrm{O}_{3}$ measured using optical absorption at $254 \mathrm{~nm}$. Initial $\left[\mathrm{O}_{3}\right]$ was $(1-6) \times 10^{15}$ molecule $\mathrm{cm}^{-3}$.

\section{Preferred values}

\begin{tabular}{lll}
\hline Parameter & Value & $T / \mathrm{K}$ \\
\hline$\gamma$ & $<10^{-6}$ & $200-220 \mathrm{~K}$ \\
Reliability & & \\
$\Delta \log (\gamma)$ & undetermined & \\
\hline
\end{tabular}

\section{Comments on preferred value}

The studies of the uptake of $\mathrm{O}_{3}$ to various $\mathrm{H}_{2} \mathrm{SO}_{4}$ surfaces confirm that the interaction is very weak with uptake coefficients lower than $10^{-6}$. Olszyna et al. (1979) measured comparable uptake coefficients on pure $\mathrm{H}_{2} \mathrm{SO}_{4}$ and $\mathrm{H}_{2} \mathrm{SO}_{4}$ doped with various cations $\left(\mathrm{Ni}^{2+}, \mathrm{Cu}^{2+}, \mathrm{Cr}^{3+}, \mathrm{Al}^{3+}, \mathrm{Fe}^{3+} \mathrm{NH}_{4}^{+}\right.$and $\left.\mathrm{Mn}^{2+}\right)$. Doping with $\mathrm{Fe}^{2+}$ resulted in $\gamma$ values close to $10^{-9}$. Uptake coefficients of the order of $10^{-8}$ to $10^{-9}$ were obtained on frozen $\mathrm{H}_{2} \mathrm{SO}_{4}$ surfaces at 217-263 (Harker and Ho, 1979). The preferred value is based on the uptake coefficients obtained in the flow tube experiments of Dlugokencky and Ravishankara (1992) which were carried out at stratospheric temperatures and using low $\left[\mathrm{O}_{3}\right]$.

\section{References}

Baldwin, A. C. and Golden, D. M.: Science, 206, 562-563, 1979.

Dlugokencky, E. J. and Ravishankara, A. R.: Geophys. Res. Lett., 19, 41-44, 1992.

Harker, A. B. and Ho, W. W.: Atmos. Environ., 13, 1005-1010, 1979.

Il'in, S. D., Selikhanovich, V. V., Gershenzon, Y. M., and Rozenshtein, V. B.: Sov. J. Chem. Phys., 8, 1858-1880, 1991. Olszyna, K., Cadle, R. D., and Depena, R. G.: J. Geophys. Res., 84, 1771-1775, 1979. 


\section{VI.A4.1}

$\mathrm{OH}(\mathrm{g})+\mathrm{H}_{2} \mathrm{SO}_{4}(\mathrm{aq}) \rightarrow$ products

Experimental data

\begin{tabular}{lllll}
\hline Parameter & {$\left[\mathrm{H}_{2} \mathrm{SO}_{4}\right] /$} & $T / \mathrm{K}$ & Reference & Technique/Comments \\
& wt $\%$ & & & \\
\hline $\begin{array}{l}\text { Uptake coefficients: } \gamma \\
\gamma_{\mathrm{ss}}=(4.5 \pm 0.5) \times 10^{-4}\end{array}$ & $>96$ & 298 & Baldwin and Golden (1980) & Kn-MS (a) \\
1 & 96 & 298 & Gershenzon et al. (1986) & (b) \\
$\gamma_{\mathrm{ss}}>8 \times 10^{-2}$ & 28 & 249 & Hanson et al. (1992) & WWFT-LIF(c) \\
$\begin{array}{l}\text { Accommodation coefficients: } \alpha_{\mathrm{b}} \\
>0.2\end{array}$ & $45-96$ & $220-298$ & Cooper and Abbatt (1996) & CWFT-RF (d) \\
\hline
\end{tabular}

\section{Comments}

(a) Hydroxyl radicals were generated by reaction of hydrogen atoms from microwave discharge of hydrogen with excess $\mathrm{NO}_{2}$. The uptake coefficient as listed in the table was not found to depend on $\mathrm{OH}$ pressure. The sulphuric acid solution was $>95 \mathrm{wt} \%$.

(b) Hydroxyl radicals were generated by reaction of hydrogen atoms from microwave discharge of hydrogen with $\mathrm{NO}_{2}$, leading to $\mathrm{OH}$ concentrations of $2 \times 10^{12}$ molecule $\mathrm{cm}^{-3}$ and lower. $\mathrm{OH}$ was detected by $\mathrm{EPR}^{\mathrm{H}} \mathrm{H}_{2} \mathrm{SO}_{4}$ was coated onto a quartz rod that was inserted into a Teflon coated quartz flow tube at about 6 mbar. No error is given to account for uncertainty due to the effects of gas phase diffusion.

(c) $\mathrm{OH}\left[(0.5-3) \times 10^{11}\right.$ molecule $\left.\mathrm{cm}^{-3}\right]$ was generated through the reaction $\mathrm{H}+\mathrm{NO}_{2}$ and was monitored using LIF. A fluid $28 \mathrm{wt} \% \mathrm{H}_{2} \mathrm{SO}_{4}-\mathrm{H}_{2} \mathrm{O}$ mixture was used at $249.5 \mathrm{~K}$ ( $2.1 \mathrm{mbar}$ total pressure). The value listed in the table was corrected for gas phase diffusion. The diffusion coefficient for $\mathrm{OH}$ in $\mathrm{H}_{2} \mathrm{O}$ vapor was taken to be the value of the self-diffusion coefficient for $\mathrm{H}_{2} \mathrm{O}, 116 \pm 20$ Torr $\mathrm{cm}^{2} \mathrm{~s}^{-1}$.

(d) Coated-wall flow tube with resonance fluorescence detection of $\mathrm{OH}$. First-order loss rate of $\mathrm{OH}$ measured in the presence of various types of surfaces. $\mathrm{OH}\left(<5 \times 10^{10}\right.$ molecule $\left.\mathrm{cm}^{-3}\right)$ was generated using both $\mathrm{F}+\mathrm{H}_{2} \mathrm{O}$ and $\mathrm{H}+\mathrm{NO}_{2}$. Total pressure in the flow tube was 1.33 mbar. Measured uptake was corrected for gas phase diffusion; the following binary diffusion coefficients were used: $0.035 T^{1.75} \mathrm{Torr} \mathrm{cm}^{2} \mathrm{~s}^{-1}$ for $\mathrm{OH}$ in $\mathrm{He}, 0.0063 T^{1.75} \mathrm{Torr} \mathrm{cm}^{2} \mathrm{~s}^{-1}$ for $\mathrm{OH}$ in $\mathrm{H}_{2} \mathrm{O}$.

\section{Preferred values}

\begin{tabular}{lll}
\hline Parameter & Value & $T / \mathrm{K}$ \\
\hline$\alpha_{\mathrm{b}}$ & 1 & $220-298$ \\
$\begin{array}{l}\text { Reliability } \\
\Delta \log \left(\alpha_{\mathrm{b}}\right)\end{array}$ & \pm 0.7 & $220-298$ \\
\hline
\end{tabular}

\section{Comments on preferred values}

The experiment by Hanson et al. (1992) was close to the diffusion limit, and the corrected uptake coefficient was still roughly consistent with bulk reaction limited uptake due to $\mathrm{OH}$ reacting with $\mathrm{HSO}_{4}^{-}$(Buxton et al., 1988), indicating that the bulk accommodation coefficient is significantly larger than this. The very high $\mathrm{H}_{2} \mathrm{SO}_{4}$ concentration (due to pumping on it) and thus lower $\mathrm{HSO}_{4}^{-}$concentration may have led to the lower uptake coefficient reported by Baldwin and Golden (1980). Gershenzon et al. (1986) estimated the uptake coefficient to be 1, also at room temperature, for $96 \%$ sulphuric acid not further concentrated. The experiment by Cooper and Abbatt (1996) was performed at a lower total pressure in the flow tube to reduce gas phase diffusion limitation and at high enough $\mathrm{H}_{2} \mathrm{SO}_{4}$ concentration to provide a strong enough bulk liquid sink for $\mathrm{OH}$, leading to 0.2 as lower limit, without indication of temperature dependence. We provide relatively large error limits to the recommended value for $\alpha_{\mathrm{b}}$ to take into account the uncertainty associated with diffusion limitations in Gershenzon's et al. (1986) experiment. 


\section{References}

Baldwin, A. C. and Golden, D. M.: J. Geophys. Res., 85, 2888-2889, 1980.

Buxton, G. V., Greenstock, C. L., Helman, W. P., and Ross, A. B.: J. Phys. Chem. Ref. Data, 17, 513-886, 1988.

Cooper, P. L. and Abbatt, J. P. D.: J. Phys. Chem., 100, 2249-2254, 1996.

Gershenzon, Y. M., Ivanov, A. V., Kucheryavyi, S. I., and Rozenshtein, V. B.: Kin. Catal., 27, 923-927, 1986.

Hanson, D. R., Burkholder, J. B., Howard, C. J., and Ravishankara, A. R.: J. Phys. Chem., 96, 4979-4985, 1992. 


\section{VI.A4.2}

$\mathrm{HO}_{2}(\mathrm{~g})+\mathrm{H}_{2} \mathrm{SO}_{4}(\mathrm{aq}) \rightarrow$ products

Experimental data

\begin{tabular}{llll}
\hline Parameter & $T / \mathrm{K}$ & Reference & Technique/Comments \\
\hline $\begin{array}{l}\text { Uptake coefficients: } \gamma \\
>0.05\end{array}$ & 249.5 & Hanson et al. (1992) & WWFT-LIF (a) \\
$>0.1$ & 243 & Gershenzon et al. (1995) & CRFT-EPR (b) \\
$0.055 \pm 0.02$ & 223 & Cooper and Abbatt (1996) & CWFT-RF (c) \\
$<0.01$ & 295 & Thornton et al. (2005) & AFT-CIMS (d) \\
$\begin{array}{l}\text { Accommodation coefficients: } \alpha_{\mathrm{b}} \\
>0.2\end{array}$ & 223 & Cooper and Abbatt (1996) & CWFT-RF (c) \\
$0.8 \pm 0.3$ & 295 & Thornton et al. (2005) & AFT-CIMS (d) \\
\hline
\end{tabular}

\section{Comments}

(a) Uptake of $\mathrm{HO}_{2}\left((5-30) \times 10^{10}\right.$ molecule $\left.\mathrm{cm}^{-3}\right)$ to $28 \mathrm{wt} \% \mathrm{H}_{2} \mathrm{SO}_{4}$ films $\approx 0.3 \mathrm{~mm}$ thick. $\mathrm{HO}_{2}$ was formed in the reaction of $\mathrm{F}$ with $\mathrm{H}_{2} \mathrm{O}_{2}$ and detected as $\mathrm{OH}$ after reaction with $\mathrm{NO}$. $\mathrm{HO}_{2}$ uptake was limited by diffusion through the 1 Torr of $\mathrm{He}$ bath gas.

(b) $\mathrm{HO}_{2}$ was detected either directly $\left(\left[\mathrm{HO}_{2}\right]=(3-5) \times 10^{9}\right.$ molecule $\left.\mathrm{cm}^{-3}\right)$ or as OH following reaction with $\mathrm{NO}\left(\left[\mathrm{HO}_{2}\right]=(1-\right.$ 3) $\times 10^{11}$ molecule $\left.\mathrm{cm}^{-3}\right) . \mathrm{H}_{2} \mathrm{SO}_{4}$ films were either 80 or $96 \mathrm{wt} \%$.

(c) Uptake of $\mathrm{HO}_{2}$ to $55 \mathrm{wt} \% \mathrm{H}_{2} \mathrm{SO}_{4}$ to determine $\gamma$. $\alpha$ was determined by doping the $\mathrm{H}_{2} \mathrm{SO}_{4}$ with with $0.1 \mathrm{M} \mathrm{CuSO}_{4}$. $\mathrm{HO}_{2}$ was formed in the reaction of $\mathrm{F}$ with $\mathrm{H}_{2} \mathrm{O}_{2}$ and detected as $\mathrm{OH}$ after reaction with $\mathrm{NO}$.

(d) $\mathrm{H}_{2} \mathrm{SO}_{4}$ aerosol (diameter $\approx 100 \mathrm{~nm}$ ) at $35-40 \%$ RH. $\alpha$ was determined by doping the $\mathrm{H}_{2} \mathrm{SO}_{4}$ aerosol (made from $0.0005-$ $0.005 \mathrm{M}$ aqueous solutions) with $0.1 \mathrm{M} \mathrm{CuSO}_{4}$. No dependence on $\mathrm{RH}$ was observed over the small range covered. $\mathrm{HO}_{2}$ (at concentrations of $\approx 4 \times 10^{10}$ molecule $\mathrm{cm}^{-3}$ ) was formed in the reaction of $\mathrm{H}$ with $\mathrm{O}_{2}$ and detected as $\mathrm{O}_{2}^{-}$using $\mathrm{F}^{-}$as chemi-ion or as $\mathrm{HSO}_{4}^{-}$following conversion to $\mathrm{H}_{2} \mathrm{SO}_{4}$ (addition of $\mathrm{NO}$ and $\mathrm{SO}_{2}$ ) and ionisation with $\mathrm{I}^{-}$. Loss of $\mathrm{HO}_{2}$ to $55 \mathrm{wt} \% \mathrm{H}_{2} \mathrm{SO}_{4}$ was indistinguishable from loss due to the reactor walls, hence the upper limit to $\gamma$.

\section{Preferred values}

\begin{tabular}{lll}
\hline Parameter & Value & $T / \mathrm{K}$ \\
\hline$\alpha_{\mathrm{b}}$ & 0.8 & $220-300$ \\
Reliability & & \\
$\Delta \alpha_{\mathrm{b}}$ & ${ }_{-0.4}$ & $220-300$ \\
\hline
\end{tabular}

\section{Comments on preferred value}

Two studies (Cooper and Abbatt, 1996; Thornton and Abbatt, 2005) show that bulk accomodation of $\mathrm{HO}_{2}$ to sulphate aerosol is very efficient with values of $\alpha_{\mathrm{b}}$ consistent with unity. The results from the four studies of the net uptake coefficient are however rather divergent, with values of $\gamma$ obtained that vary from $>0.1$ to $<0.01$. A probable explanation is related to the different experimental temperatures, with low temperatures favouring large uptake coefficients. Thornton and Abbatt (2005) suggest that the results from these studies are internally consistent and the increase in uptake coefficient at low tempertaure is due to enhanced solubility of $\mathrm{HO}_{2}$. Moreover, Thornton and Abbatt (2005) suggest that the net uptake depends on the gas-phase $\mathrm{HO}_{2}$ concentration which impacts strongly on aqueous phase loss rates (due to self-reaction) of $\mathrm{HO}_{2}$. As all experiments were carried out using $\mathrm{HO}_{2}$ concentations orders of magnitude greater than found in the atmosphere, no expression for $\gamma$ is given. 


\section{References}

Cooper, P. L. and Abbatt, J. P. D.: J. Phys. Chem., 100, 2249-2254, 1996.

Gershenzon, Y. M., Grigorieva, V. M., Ivanov, A. V., and Remorov, R. G.: Faraday Discuss., 83-100, 1995.

Hanson, D. R., Burkholder, J. B., Howard, C. J., and Ravishankara, A. R.: J. Phys. Chem., 96, 4979-4985, 1992.

Thornton, J. and Abbatt, J. P. D.: J. Geophys. Res., 110, art. no. D08309, doi:10.1029/2004jd005402, 2005. 
VI.A4.3

$\mathrm{H}_{2} \mathrm{O}_{2}(\mathrm{~g})+\mathrm{H}_{2} \mathrm{SO}_{4}(\mathrm{aq}) \rightarrow$ products

Experimental data

\begin{tabular}{llll}
\hline Parameter & $T / \mathrm{K}$ & Reference & Technique/Comments \\
\hline $\begin{array}{l}\text { Uptake coefficients: } \gamma \\
7.8 \times 10^{-4}\end{array}$ & $270-300$ & Baldwin and Golden (1979) & Knudsen-MS (a) \\
\hline
\end{tabular}

\section{Comments}

(a) After evacuating the Knudsen reactor containing the concentrated $\mathrm{H}_{2} \mathrm{SO}_{4}$ sample, the remaining substrate was suggested to contain less than $5 \%$ water.

\section{Preferred values}

\begin{tabular}{lll}
\hline Parameter & Value & $T / \mathrm{K}$ \\
\hline$\gamma$ & $7.8 \times 10^{-4}$ & $270-300$ \\
Reliability & & \\
$\Delta \log (\gamma)$ & 0.5 & \\
\hline
\end{tabular}

\section{Comments on preferred value}

The single published study of the uptake of $\mathrm{H}_{2} \mathrm{O}_{2}$ to sulphuric acid agrees with unpublished data (obtained using a Knudsen reactor) carried out using $60 \mathrm{wt} \% \mathrm{H}_{2} \mathrm{SO}_{4}$ at 203-223 K (Myhre and Nielsen, 1998) who derived values of $\gamma$ in the range $(0.69-3.8) \times 10^{-4}$ with the lower values obtained at the lowest temperature. There appears to be no information regarding the products of the interaction. We therefore recommend the uptake coefficient of Baldwin and Golden (1979) with expanded error limits.

\section{References}

Baldwin, A. C. and Golden, D. M.: Science, 206, 562-563, 1979.

Myhre, C. E. L. and Nielsen, C. J.: Polar Stratospheric Ozone 1997, Proceedings of the Fourth European Ozone Symposium, Schliersee, Bavaria, Germany, edited by: Harris, N. R. P., Kilbane-Dawe, T., and Amantidis, G. T., p. 589, European Communities, 1998. 
VI.A4.4

$\mathrm{NO}(\mathrm{g})+\mathrm{H}_{2} \mathrm{SO}_{4}(\mathrm{aq}) \rightarrow$ products

Experimental data

\begin{tabular}{lllll}
\hline Parameter & {$\left[\mathrm{H}_{2} \mathrm{SO}_{4}\right] / \mathrm{wt} \%$} & $T / \mathrm{K}$ & Reference & Technique/Comments \\
\hline $\begin{array}{l}\text { Uptake coefficients: } \gamma \\
\gamma<5.0 \times 10^{-6}\end{array}$ & 70 & $193-243$ & Saastad et al. (1993) & static (a) \\
\hline
\end{tabular}

\section{Comments}

(a) Measurement of the total pressure drop in a static system over $70 \% \mathrm{H}_{2} \mathrm{SO}_{4}-\mathrm{H}_{2} \mathrm{O}$ monitored by MS. The solution was believed to be a supercooled solution from its visual appearance. Total pressure was about $10^{-2} \mathrm{mbar}$, NO pressures $10^{-5}-10^{-2}$ mbar.

\section{Preferred values}

\begin{tabular}{lll}
\hline Parameter & Value & $T / \mathrm{K}$ \\
\hline$\gamma$ & $<5 \times 10^{-6}\left(70 \% \mathrm{H}_{2} \mathrm{SO}_{4}\right)$ & $200-298$ \\
Reliability & & \\
$\Delta \log (\gamma)$ & undetermined & \\
\hline
\end{tabular}

\section{Comments on preferred values}

The upper limit to $\gamma$ from the single study of Saastad et al. (1993) was adopted for the recommendation.

\section{References}

Saastad, O. W., Ellermann, T., and Nielsen, C. J.: Geophys. Res. Lett., 20, 1191-1193, 1993. 


\section{VI.A4.5}

$\mathrm{NO}_{2}(\mathrm{~g})+\mathrm{H}_{2} \mathrm{SO}_{4}(\mathrm{aq}) \rightarrow$ products

\section{Experimental data}

\begin{tabular}{lllll}
\hline Parameter & {$\left[\mathrm{H}_{2} \mathrm{SO}_{4}\right] / \mathrm{wt} \%$} & $T / \mathrm{K}$ & Reference & Technique/Comments \\
\hline $\begin{array}{l}\text { Uptake coefficients: } \gamma \\
\gamma<5.0 \times 10^{-6}\end{array}$ & & & & \\
$(4.1 \pm 1.5) \times 10^{-7}$ & 45 & $193-243$ & Saastad et al. (1993) & (a) \\
$(2.5 \pm 0.5) \times 10^{-7}$ & 70 & 298 & Kleffmann et al. (1998) & Bubbler-IC/IR (b) \\
$(5.2 \pm 0.5) \times 10^{-7}$ & 96 & & & \\
$\gamma<7.0 \times 10^{-7}$ & $39-68$ & $203-243$ & Langenberg et al. (1998) & (c) \\
Solubility: $H$ & 39 & 243 & Langenberg et al. (1998) & (c) \\
$0.5 \pm 0.1$ & 59 & & & \\
$1.4 \pm 0.5$ & 68 & & & \\
$0.5 \pm 0.2$ & 39 & 203 & & \\
$50 \pm 7$ & 59 & & & \\
$65 \pm 4$ & 68 & & & \\
$37 \pm 6$ & 59 & & & \\
$3.45 \times 10^{-9} \exp (4800 / T)$ & 68 & & & \\
$4.39 \times 10^{-9} \exp (4600 / T)$ & 68 & & & \\
\hline
\end{tabular}

\section{Comments}

(a) Measurement of the total pressure drop in a static system over $70 \% \mathrm{H}_{2} \mathrm{SO}_{4}-\mathrm{H}_{2} \mathrm{O}$ monitored by MS. From its appearance, the solution was believed to be supercooled. $\mathrm{NO}_{2}$ pressures were $10^{-5}-10^{-2} \mathrm{mbar}$.

(b) $\mathrm{NO}_{2}\left(10^{14}\right.$ molecule $\left.\mathrm{cm}^{-3}\right)$ in 962 mbar of $\mathrm{N}_{2}$ was circulated through a thermostated bubbler containing 125 to $500 \mathrm{ml}$ of water. $\mathrm{NO}_{2}$ and $\mathrm{HNO}_{2}$ were measured using tunable diode laser absorption spectrometry. Nitrate and nitrite in the liquid was measured using ion chromatography, showing that they were initially formed at equimolar amounts. The first order rate constant for $\mathrm{NO}_{2}$ decay did not depend on the $\mathrm{NO}_{2}$ concentration, indicating overall first-order behaviour, and was proportional to the estimated bubble surface area. This led the authors to conclude that $\mathrm{NO}_{2}$ uptake would be limited by a surface process. The increasing reactivity with increasing $\mathrm{H}_{2} \mathrm{SO}_{4}$ concentration was explained by formation of $\mathrm{HNO}_{2}^{+}$as intermediate.

(c) Measurement of chromatographic retention of $\mathrm{NO}_{2}$ in a $\mathrm{H}_{2} \mathrm{SO}_{4}$ coated, thermostated quartz capillary using a chemiluminescence detector. Equilibrium with $\mathrm{N}_{2} \mathrm{O}_{4}$ was accounted for in the analysis. This experiment showed reactive loss of $\mathrm{NO}_{2}$ of up to $40 \%$.

\section{Preferred values}

\begin{tabular}{lll}
\hline Parameter & Value & $T / \mathrm{K}$ \\
\hline$\gamma$ & $<10^{-6}\left(>45 \% \mathrm{H}_{2} \mathrm{SO}_{4}\right)$ & $200-298$ \\
$H$ & $3.45 \times 10^{-9} \exp (4800 / T)\left(59 \% \mathrm{H}_{2} \mathrm{SO}_{4}\right)$ & $200-250$ \\
& $4.39 \times 10^{-9} \exp (4600 / T)\left(68 \% \mathrm{H}_{2} \mathrm{SO}_{4}\right)$ & \\
Reliability & & \\
$\Delta \log (\gamma)$ & undetermined & $200-250$ \\
$\Delta \log (H)$ & \pm 0.5 & \\
\hline
\end{tabular}

\section{Comments on preferred values}

In view of the uncertainties related to the mass transfer characteristics pertinent to bubbler experiments (Lee and Schwartz, 1981; Cheung et al., 2000) it is not clear to what degree the experiment by Kleffmann et al. (1998) was solubility limited. 
Langenberg et al. (1998) provide an upper bound of the reactive uptake coefficient consistent with these values. We therefore used these to recommend an upper limit to the uptake coefficient and to extend the temperature range over that provided by Saastad et al. (1993).

No recommendation for the bulk accommodation coefficient is given. We adopt the temperature dependent solubility reported by Langenberg et al. for the two higher acid concentrations. The temperature dependence corresponds to an enthalpy of solvation of -39.9 and $-38.5 \mathrm{~kJ} \mathrm{~mol}^{-1}$ for the 59 and $68 \mathrm{wt} \%$ solutions, respectively.

\section{References}

Cheung, J. L., Li, Y. Q., Boniface, J., Shi, Q., Davidovits, P., Worsnop, D. R., Jayne, J. T., and Kolb, C. E.: J. Phys. Chem. A, 104, 2655-2662, 2000.

Kleffmann, J., Becker, K. H., and Wiesen, P.: Atmos. Environ., 32, 2721-2729, 1998.

Lee, Y.-N. and Schwartz, S. E.: J. Phys. Chem., 85, 840-848, 1981.

Langenberg, S., Proksch, V., and Schurath, U.: Atmos. Environ., 32, 3129-3137, 1998.

Saastad, O. W., Ellermann, T., and Nielsen, C. J.: Geophys. Res. Lett., 20, 1191-1193, 1993. 
VI.A4.6

$\mathrm{NO}_{3}(\mathrm{~g})+\mathrm{H}_{2} \mathrm{SO}_{4}(\mathrm{aq}) \rightarrow$ products

Experimental data

\begin{tabular}{llll}
\hline Parameter & $T / \mathrm{K}$ & Reference & Technique/Comments \\
\hline $\begin{array}{l}\text { Uptake coefficients: } \gamma \\
<1 \times 10^{-3}\left(60-95 \mathrm{wt} \% \mathrm{H}_{2} \mathrm{SO}_{4}\right)\end{array}$ & $170-200$ & Fenter and Rossi (1997) & Knudsen-LIF (a) \\
\hline
\end{tabular}

\section{Comments}

(a) Uptake of $\mathrm{NO}_{3}\left(10^{10}-10^{13}\right.$ molecule $\left.\mathrm{cm}^{-3}\right)$ to $0-95 \mathrm{wt} \% \mathrm{H}_{2} \mathrm{SO}_{4}$. A flow of $\mathrm{H}_{2} \mathrm{O}$ was added to maintain the $\mathrm{H}_{2} \mathrm{SO}_{4}$ composition over the course of an experiment. $\mathrm{NO}_{3}$ was formed in the thermal decomposition of $\mathrm{N}_{2} \mathrm{O}_{5} . \mathrm{NO}_{3}$ losses in the Knudsen reactor were attributed to reaction with a Halocarbon wax coating, so that a value of $\gamma<(6.0 \pm 6.8) \times 10^{-4}$ was derived for interaction with $\mathrm{H}_{2} \mathrm{SO}_{4}$. The authors quote a final upper limit of $1 \times 10^{-3}$.

\section{Preferred values}

\begin{tabular}{lll}
\hline Parameter & Value & $T / \mathrm{K}$ \\
\hline$\gamma$ & $<1 \times 10^{-3}\left(60-95 \mathrm{wt} \% \mathrm{H}_{2} \mathrm{SO}_{4}\right)$ & $200-270$ \\
Reliability & & \\
$\Delta \log (\gamma)$ & undetermined & \\
\hline
\end{tabular}

\section{Comments on preferred value}

The single study (Fenter and Rossi, 1997) of the interaction of $\mathrm{NO}_{3}$ with $\mathrm{H}_{2} \mathrm{SO}_{4}$ at various concentrations and temperatures derived an upper limit to the uptake coefficient, which we adopt as the preferred value.

\section{References}

Fenter, F. F. and Rossi, M. J.: J. Phys. Chem., 101, 4110-4117, 1997. 
VI.A4.7

$\mathrm{HNO}_{2}(\mathrm{~g})+\mathrm{H}_{2} \mathrm{SO}_{4}(\mathrm{aq}) \rightarrow$ products

\section{Experimental data}

\begin{tabular}{|c|c|c|c|c|}
\hline Parameter & {$\left[\mathrm{H}_{2} \mathrm{SO}_{4}\right] / \mathrm{wt} \%$} & $T / \mathrm{K}$ & Reference & Technique/Comments \\
\hline \multicolumn{5}{|l|}{ Uptake coefficients: $\gamma$} \\
\hline$\gamma_{\mathrm{ss}}=(1.60 \pm 0.09) \times 10^{-2}$ & 65.3 & 213.5 & Zhang et al. (1996) & CWFT-CIMS (a) \\
\hline$\gamma_{\mathrm{ss}}=(3.2 \pm 0.5) \times 10^{-2}$ & 68.8 & 218.6 & & \\
\hline$\gamma_{\mathrm{ss}}=(6.6 \pm 0.6) \times 10^{-2}$ & 71.3 & 222.6 & & \\
\hline$\gamma_{\mathrm{ss}}=(9.1 \pm 1.6) \times 10^{-2}$ & 73.0 & 226.1 & & \\
\hline$\gamma_{\mathrm{ss}}=(2.0 \pm 0.5) \times 10^{-4}$ & 55 & 220 & Fenter and Rossi (1996) & Kn-MS (b) \\
\hline$\gamma_{\mathrm{ss}}=(2.0 \pm 0.5) \times 10^{-3}$ & 60 & $215-235$ & & \\
\hline$\gamma_{\mathrm{ss}}=(5.5 \pm 1.0) \times 10^{-2}$ & 80 & $250-265$ & & \\
\hline$\gamma_{\mathrm{ss}}=0.31 \pm 0.02$ & 95 & $220-273$ & & \\
\hline$\gamma=(2.8 \pm 1.4) \times 10^{-6}$ & 60 & 298 & Baker et al. (1999) & AFT-CLD (c) \\
\hline$\gamma=(8.1 \pm 2.7) \times 10^{-6}$ & 60 & & & \\
\hline \multicolumn{5}{|l|}{ Solubility: $H^{*}\left(\mathrm{M} \mathrm{atm}^{-1}\right)$} \\
\hline$(4.2 \pm 0.5) \times 10^{2}$ & 31.5 & 250 & Becker et al. (1996) & Static-TDLAS/IC (d) \\
\hline$(1.1 \pm 0.2) \times 10^{2}$ & 31.5 & 267 & & \\
\hline$(3.1 \pm 0.5) \times 10^{1}$ & 31.5 & 283 & & \\
\hline$(2.0 \pm 0.2) \times 10^{1}$ & 31.5 & 298 & & \\
\hline$(3.1 \pm 0.5) \times 10^{2}$ & 51.2 & 249 & & \\
\hline$(6.4 \pm 0.7) \times 10^{1}$ & 51.2 & 267 & & \\
\hline$(1.7 \pm 0.3) \times 10^{1}$ & 51.2 & 283 & & \\
\hline $7.3 \pm 0.1$ & 51.2 & 298 & & \\
\hline$(4.3 \pm 0.2) \times 10^{4}$ & 67.3 & 251 & & \\
\hline$(1.2 \pm 0.5) \times 10^{4}$ & 67.3 & 268 & & \\
\hline$(4.1 \pm 1.0) \times 10^{3}$ & 67.3 & 283 & & \\
\hline$(1.6 \pm 0.2) \times 10^{3}$ & 67.3 & 298 & & \\
\hline $1.3 \times 10^{7}$ & 83 & 295 & Longfellow et al. (1998) & RWFT-CIMS (e) \\
\hline $9.8 \times 10^{3}$ & 71 & 295 & & \\
\hline $1.2 \times 10^{3}$ & 66 & 296 & & \\
\hline $1.5 \times 10^{6}$ & 79 & 295 & & \\
\hline $2.8 \times 10^{8}$ & 79 & 250 & & \\
\hline $4.6 \times 10^{9}$ & 79 & 230 & & \\
\hline $2.6 \times 10^{3}$ & 65 & 270 & & \\
\hline $9.0 \times 10^{3}$ & 65 & 249 & & \\
\hline $1.6 \times 10^{5}$ & 65 & 220 & & \\
\hline $6.1 \pm 1.1$ & 50.5 & 300.5 & Baker et al. (1999) & Bubbler-CLD (c) \\
\hline $10.2 \pm 1.1$ & 57.2 & 302 & & \\
\hline $14 \pm 2$ & 58.2 & 303 & & \\
\hline $15 \pm 3$ & 59.1 & 299 & & \\
\hline $25 \pm 4$ & 59.3 & 300 & & \\
\hline $38 \pm 6$ & 61.0 & 300 & & \\
\hline \multicolumn{5}{|l|}{ rate constants $k_{\mathrm{II}}\left(\mathrm{M}^{-1} \mathrm{~s}^{-1}\right)$} \\
\hline $300 \pm 40$ & 50.5 & 300.5 & Baker et al. (1999) & Bubbler-CLD (c) \\
\hline $185 \pm 40$ & 56.5 & 301.5 & & \\
\hline $122 \pm 15$ & 57.2 & 302 & & \\
\hline $81 \pm 10$ & 58.2 & 303 & & \\
\hline $39 \pm 5$ & 59.1 & 299 & & \\
\hline $32 \pm 4$ & 59.3 & 300 & & \\
\hline $7.8 \pm 0.8$ & 61.0 & 300 & & \\
\hline $4.5 \pm 0.5$ & 61.4 & 298.5 & & \\
\hline $0.13 \pm 0.01$ & 65.4 & 300 & & \\
\hline
\end{tabular}




\section{Comments}

(a) CIMS detection of $\mathrm{HNO}_{2}$ after reaction with $\mathrm{SF}_{6}^{-} \cdot 0.1 \mathrm{~mm}$ thick liquid $\mathrm{H}_{2} \mathrm{SO}_{4}$. The partial pressure of $\mathrm{HNO}_{2}$ was around $6 \times 10^{-7}$ mbar. The sulphuric acid composition was controlled by maintaining a fixed temperature and $\mathrm{H}_{2} \mathrm{O}$ partial pressure of $6 \times 10^{-4}$ mbar in the gas flows. Persistant uptake over more than $1 \mathrm{~h}$ was interpreted as formation of $\mathrm{NO}^{+} \mathrm{HSO}_{4}^{-}$ in the film. Its precipitation as a solid was not observed.

(b) $\mathrm{H}_{2} \mathrm{SO}_{4}$ solutions prepared by dilution of $95 \mathrm{wt} \% \mathrm{H}_{2} \mathrm{SO}_{4} . \mathrm{HNO}_{2}$ was produced by displacement from a $0.2 \mathrm{M} \mathrm{NaNO}_{2}$ solution by addition of $50 \mathrm{wt} \% \mathrm{H}_{2} \mathrm{SO}_{4}$.

(c) Typically $10^{7}$ particles $\mathrm{cm}^{-3}$ of $120 \mathrm{~nm}$ diameter were entrained in an aerosol laminar flow tube and interacted with $\mathrm{HNO}_{2}$ in the concentration range 305 to $610 \mathrm{ppb}$. Aerosol diagnostics included a counter and an optical extinction measurement in the 200 to $390 \mathrm{~nm}$ range whereas the gas phase was monitored using a $\mathrm{NO}_{\mathrm{x}}$ chemiluminescence analyzer. The observed uptake coefficient was found to be roughly proportional to the partial pressure of $\mathrm{HNO}_{2}$ in these experiments. Separate bubbler experiments were performed to measure the bimolecular rate constant for the reaction $2 \mathrm{HNO}_{2} \Rightarrow \mathrm{NO}_{+} \mathrm{NO}_{2}+\mathrm{H}_{2} \mathrm{O}$. The rate constant was found to fall off sharply beyond $56 \mathrm{wt} \%$ sulphuric acid. The rate constant was not sufficient to explain the observed uptake of $\mathrm{HNO}_{2}$ to aerosol particles by reaction in the bulk, so that a surface reaction mechanism was invoked.

(d) Solubility of $\mathrm{HNO}_{2}$ in a 11-L Pyrex glass reactor was measured directly by monitoring both gas phase composition by tunable diode laser spectrometry and liquid phase by ion chromatography. Formation of $\mathrm{NO}_{2}$ due to 2 $\mathrm{HNO}_{2}=\mathrm{NO}+\mathrm{NO}_{2}+\mathrm{H}_{2} \mathrm{O}$ was observed. Since the $\mathrm{NO}_{2}$ concentration equilibrated with time, this reaction was included into calculating the effective solubility. A further, very slow overall loss of $\mathrm{HNO}_{2}$ and concomitant formation of $\mathrm{N}_{2} \mathrm{O}$ with time was also observed.

(e) Determination of solubility was performed in a $2.2 \mathrm{~cm}$ i.d. coated wall flow tube and a $1.84 \mathrm{~cm}$ i.d. rotating wetted wall flow tube with CIMS detection of $\mathrm{HNO}_{2}$. Depending on the sulphuric acid concentration range, solubility could be determined in relative or absolute modes. No kinetics of uptake of $\mathrm{HNO}_{2}$ alone were reported.

\section{Preferred values}

\begin{tabular}{lll}
\hline Parameter & Value & $T / \mathrm{K}$ \\
\hline$\alpha_{\mathrm{b}}$ & $>0.05$ & $220-300$ \\
$A\left(\mathrm{M} \mathrm{atm}^{-1}\right)$ & $4.2 \times 10^{-6} \exp (4873 / T)$ & \\
$B\left((\mathrm{wt} \%)^{-1}\right)$ & $13.16 / T-0.0856$ & \\
$C\left(\mathrm{M} \mathrm{atm}^{-1}\right)$ & $2.0 \times 10^{8} \exp (-14000 / T)$ & \\
$D\left(\left(\mathrm{wt}^{-1}\right)\right.$ & $297.3 / T-0.474$ & \\
$k_{\mathrm{b}}\left(\mathrm{M}^{-1} \mathrm{~s}^{-1}\right)$ & 320 & 298 \\
$\gamma_{\mathrm{gs}}$ & $<10^{-5}$ & 298 \\
Reliability & & \\
$\Delta \log \left(\alpha_{\mathrm{b}}\right)$ & undetermined & \\
$\Delta \log \left(H^{*}\right)$ & \pm 0.3 & $220-300$ \\
$\Delta \log \left(k_{\mathrm{b}}\right)$ & \pm 0.1 & 298 \\
$\Delta \log \left(\gamma_{\mathrm{gs}}\right)$ & undetermined & \\
\hline
\end{tabular}

\section{Comments on preferred values}

Solubility of $\mathrm{HNO}_{2}$ in $\mathrm{H}_{2} \mathrm{SO}_{4}$ solutions depends strongly on composition. The exponential decrease with sulphuric acid content up to about $50 \mathrm{wt} \%$ is due to a salting out effect at decreased water activity (Becker et al., 1996). Dissociation of $\mathrm{HNO}_{2}$ into $\mathrm{H}^{+}$and $\mathrm{NO}_{2}^{-}$is only important below $1 \mathrm{wt} \%$ (see datasheet V.A1.7; Park and Lee, 1988). Above about 55 wt \%, solubility of $\mathrm{HNO}_{2}$ increases strongly due to the formation of either of $\mathrm{NO}^{+}, \mathrm{H}_{2} \mathrm{ONO}^{+}, \mathrm{NO}^{+} \mathrm{HSO}_{4}^{-}$, or a combination thereof (Burley and Johnston, 1992, and references therein; Riordan et al., 2005). The available studies determining the effective solubility of $\mathrm{HNO}_{2}$ directly by Becker et al. (1996), Longfellow et al. (1998) and Baker et al. (1999) agree very well as far as they overlap in composition and temperature. We recommend using an expression based on a parameterisation proposed by Becker et al. (1996):

$H^{*}\left(\mathrm{Matm}^{-1}\right)=A \exp (B(w t))+C \exp (D(w t))$ 
The preferred constants $A, B, C$ and $D$ listed in the table were determined by further taking into account the data at lower temperature and higher wt \% by Longfellow et al. (1998). While the low wt \% part represented by the first term in the expression for $H^{*}$ can be traced back to the salting coefficient based on the Setschenow equation (see Becker et al. 1996 for details), the other parameters were adjusted to broadly fit the available data without explicitly accounting for equilibria with $\mathrm{NO}^{+}$, $\mathrm{H}_{2} \mathrm{ONO}^{+}$and $\mathrm{NO}^{+} \mathrm{HSO}_{4}^{-}$.

Uptake of $\mathrm{HNO}_{2}$ into sulphuric acid solutions can be driven by the effective solubility encompassing dissociation, protonation and the disproportionation into $\mathrm{NO}_{2}$ and $\mathrm{NO}$, assuming that the time scale for equilibration is given by diffusion in the liquid phase:

$\frac{1}{\gamma}=\frac{1}{\alpha_{\mathrm{b}}}+\frac{1}{\Gamma_{\mathrm{sol}}} \quad$ with $\quad \Gamma_{\mathrm{sol}}=\frac{4 H_{\mathrm{HNO}_{2}}^{*} R T}{\bar{c}_{\mathrm{HNO}_{2}} \cdot \sqrt{\pi}} \cdot \sqrt{\frac{D_{1, \mathrm{HNO}_{2}}}{t}}$

The diffusion coefficient for $\mathrm{HNO}_{2}$ is parameterized by $D_{1, \mathrm{HNO} 2}=c_{\mathrm{HNO} 2} T / \eta$; with $c_{\mathrm{HNO} 2}=6.90 \times 10^{-8} \mathrm{~cm}^{2} \mathrm{cP} \mathrm{K}^{-1} \mathrm{~s}^{-1}$, estimated as suggested by Klassen et al. (1998) using a molar volume of $36 \mathrm{~cm}^{3} \mathrm{~mol}^{-1}$ (da Silva et al., 2006). For the viscosity, we suggest using the parameterization presented by Shi et al. (2001), which fits well to data by Williams and Long (1995) but extends into tropospherically more relevant dilute solutions at high $T$ :

$\eta=a T^{-1.43} \exp \left(448 \mathrm{~K} /\left(T-T_{0}\right)\right)$,

with $a=169.5+5.18 w t-0.0825 w t^{2}+3.27 \times 10^{-3} w t^{3}$,

and $T_{0}=144.11+0.166 w t-0.015 w t^{2}+2.18 \times 10^{-4} w t^{3}$

The kinetic experiments by Zhang et al. (1996) and Fenter and Rossi (1996) were likely limited by solubility and bulk accommodation. With $\alpha_{\mathrm{b}}>0.05$ and the recommended values for the effective solubility, the above equation yields uptake coefficients consistent with those reported for times between 10 and $100 \mathrm{~s}$.

The bulk reaction rate constant $k_{\mathrm{b}}$ for the disproportionation reaction was adopted from Baker et al. (1999) by assuming that the reduction of the effective bimolecular rate constant was due to the decreasing concentration of unprotonated $\mathrm{HNO}_{2}$ in solution. For the calculation of the concentration of unprotonated $\mathrm{HNO}_{2}$, the first term of the recommended expression for the effective solubility can be used:

$\left[\mathrm{HNO}_{2}\right]=p_{\mathrm{HONO}} A \exp (B w t)$

This leads to effective rates consistent with those measured by Baker et al. (1999). This rate constant is far too small to affect uptake of $\mathrm{HNO}_{2}$ to sulphuric acid appreciably over the short time scales of the kinetic experiments. The reaction of $\mathrm{HNO}_{2}$ with $\mathrm{NO}^{+} \mathrm{HSO}_{4}^{-}$to yield $\mathrm{N}_{2} \mathrm{O}$ was not quantified in the study by Wiesen et al. (1995) in a way that would allow extracting a rate constant.

For the conditions of the aerosol flow tube experiments by Baker et al. (1999), gas phase $\mathrm{HNO}_{2}$ rapidly equilibrates with the solution of the submicron particles, so that the uptake coefficient was due to an irreversible loss process in the particle phase. Since the bulk reaction rate constant $k_{\mathrm{b}}$ was several orders of magnitude too low to explain the measured uptake coefficients, uptake was attributed to a surface process. Baker et al. suggest an Eley-Rideal type reaction, which was adopted here for a recommendation of an upper limit for $\gamma_{\mathrm{gs}}$ in the atmospherically relevant $\mathrm{HNO}_{2}$ concentration range.

\section{References}

Baker, J., Ashbourn, S. F. M., and Cox, R. A.: Phys. Chem. Chem. Phys., 1, 683-690, 1999.

Becker, K. H., Kleffmann, J., Kurtenbach, R., and Wiesen, P.: J. Phys. Chem., 100, 14984-14990, 1996.

da Silva, G., Dlugogorski, B. Z., and Kennedy, E. M.: AIChE Journal, 52, 1558-1565, 2006.

Fenter, F. F. and Rossi, M. J.: J. Phys. Chem., 100, 13765-13775, 1996.

Klassen, J. K., Hu, Z., and Williams, L. R.: J. Geophys. Res., 103, 16197-16202, 1998.

Longfellow, C. A., Imamura, T., Ravishankara, A. R., and Hanson, D. R.: J. Phys. Chem. A, 102, 3323-3332, 1998.

Shi, Q., Jayne, J. T., Kolb, C. E., Worsnop, D. R., and Davidovits, P.: J. Geophys. Res., 106, 24259-24274, 2001.

Wiesen, P., Kleffmann, J., Kurtenbach, R., and Becker, K. H.: Faraday Discuss., 100, 121-127, 1995.

Williams, L. R. and Long, F. S.: J. Phys. Chem., 99, 3748-3751, 1995.

Zhang, R., Leu, M.-T., and Keyser, L. F.: J. Phys. Chem., 100, 339-345, 1996. 


\section{VI.A4.8}

$\mathrm{HNO}_{3}(\mathrm{~g})+\mathrm{H}_{2} \mathrm{SO}_{4}(\mathrm{aq}) \rightarrow$ products

\section{Experimental data}

\begin{tabular}{|c|c|c|c|c|}
\hline Parameter & {$\left[\mathrm{H}_{2} \mathrm{SO}_{4}\right] / \mathrm{wt} \%$} & $T / \mathrm{K}$ & Reference & Technique/Comments \\
\hline \multicolumn{5}{|l|}{ Uptake coefficients: $\gamma$} \\
\hline$\gamma_{\mathrm{ss}}=2.0 \times 10^{-3}$ & 75 & 230 & Tolbert et al. (1988) & Kn-MS (a) \\
\hline$\gamma_{\mathrm{ss}}=4.0 \times 10^{-3}$ & 96.5 & 295 & & \\
\hline$\gamma=0.28$ & 5 & 188 & Reihs et al. (1990) & Kn-MS (b) \\
\hline$\gamma=0.25$ & 40 & 188 & & \\
\hline$\gamma=0.12$ & 58 & 188 & & \\
\hline$\gamma=0.07$ & 74 & 188 & & \\
\hline$\gamma=0.05$ & 83 & 188 & & \\
\hline$\gamma=0.001$ & 96 & 188 & & \\
\hline$\gamma=0.07 \pm 0.01$ & $15-66$ & 223 & & \\
\hline$\gamma=0.015$ & 74 & 223 & & \\
\hline$\gamma=0.003$ & 87 & 223 & & \\
\hline$\gamma=0.11 \pm 0.01$ & 73 & 283 & Van Doren et al. (1991) & DT-IR (c) \\
\hline \multicolumn{5}{|l|}{ Accommodation coefficients: $\alpha$} \\
\hline$\alpha_{\mathrm{s}}>0.8\left(70 \mathrm{wt} \% \mathrm{D}_{2} \mathrm{SO}_{4}\right)$ & & 213 & Morris et al. (2000) & $\mathrm{MB}(\mathrm{d})$ \\
\hline \multicolumn{5}{|l|}{$\alpha_{\mathrm{b}}>0.8\left(70 \mathrm{wt} \% \mathrm{D}_{2} \mathrm{SO}_{4}\right)$} \\
\hline \multicolumn{5}{|l|}{ Solubility: $H$} \\
\hline$H^{*}=3.56 \times 10^{-3} \exp (3320 / T)$ & 87 & $188-240$ & Reihs et al. (1990) & (b) \\
\hline$H^{*}=8.54 \times 10^{-3} \exp (3550 / T)$ & 74 & & & \\
\hline$H^{*}=2.02 \times 10^{-1} \exp (3190 / T)$ & 66 & & & \\
\hline$H^{*}=7.47 \times 10^{-8} \exp (7160 / T)$ & 58 & & & \\
\hline$(4 \pm 1) \times 10^{3} \mathrm{M} \mathrm{atm}^{-1}$ & 73 & 283 & Van Doren et al. (1991) & (c) \\
\hline$H^{*}=9.03 \times 10^{-8} \exp (7750 / T)$ & 40 & $190-230$ & Zhang et al. (1993) & (e) \\
\hline$H^{*}=4.85 \times 10^{-8} \exp (7470 / T)$ & 50 & & & \\
\hline$H^{*}=2.44 \times 10^{-8} \exp (7300 / T)$ & 60 & & & \\
\hline$H^{*}=6.32 \times 10^{-9} \exp (7240 / T)$ & 70 & & & \\
\hline$H^{*}=6.13 \times 10^{-9} \exp (7030 / T)$ & 75 & & & \\
\hline
\end{tabular}

\section{Comments}

(a) The bulk substrate was cooled slowly to temperatures of $210 \mathrm{~K}$ to $230 \mathrm{~K}$. The recovery yield of $\mathrm{HNO}_{3}$ that was condensed at $230 \mathrm{~K}$ on $75 \% \mathrm{H}_{2} \mathrm{SO}_{4}$ was approximately $20 \%$ in contrast to $100 \%$ for pure ice.

(b) The sulphuric acid substrate was prepared from bulk solutions and cooled to the temperature range $188 \mathrm{~K}$ to $240 \mathrm{~K}$. $\gamma$ was time dependent, the uptake coefficients given in the table are those measured after $100 \mathrm{~s}$ (the experiments spanning a total time of $2000 \mathrm{~s}$ ). The time dependence was used to estimate the effective solubility assuming solubility limited uptake. The diffusion coefficient in the liquid phase was extrapolated from a room temperature value of $10^{-5} \mathrm{~cm}^{2} \mathrm{~s}^{-1}$ in $60 \%$ $\mathrm{H}_{2} \mathrm{SO}_{4}$ using temperature dependent viscosity data from the literature. The error in $H^{*}$ is estimated to be a factor of 3 . The expressions given in the table were obtained from fits to a Van't Hoff plot.

(c) Fast droplet train $\left(73 \% \mathrm{H}_{2} \mathrm{SO}_{4}-\mathrm{H}_{2} \mathrm{O}\right.$ droplets) traversing a flow tube. $\mathrm{HNO}_{3}$ was detected by TDLAS. The $\gamma$ values were corrected for gas-phase diffusion. The solubility was obtained by assuming that the measured uptake coefficient is due to solubility limited uptake. The bulk accommodation coefficient was assumed to be independent of $\mathrm{H}_{2} \mathrm{SO}_{4}$ concentration and similar to that of water (0.17). The liquid phase diffusion coefficient was estimated to be $9 \times 10^{-7} \mathrm{~cm}^{2} \mathrm{~s}^{-1}$ at $283 \mathrm{~K}$ based on the estimated temperature dependence of viscosity data.

(d) Molecular beam experiment with $\mathrm{HNO}_{3}$ beam produced from the expansion of a $1 \% \mathrm{HNO}_{3}$ in $\mathrm{H}_{2}$ mixture, leading to an incident $\mathrm{HNO}_{3}$ energy $150 \mathrm{~kJ} \mathrm{~mol}^{-1}$, hitting the $70.5 \% \mathrm{D}_{2} \mathrm{SO}_{4}$ at $213 \mathrm{~K}$. Fluxes were estimated to be below 
$10^{15} \mathrm{~cm}^{-2} \mathrm{~s}^{-1}$. Scattered or desorbing molecules were detected with a mass spectrometer at an exit angle of $45^{\circ}$. A large fraction of incident $\mathrm{HNO}_{3}$ molecules transfers their kinetic energy to the substrate; the inelastically scattered $\mathrm{HNO}_{3}$ molecules lost $85 \%$ of their original energy on average. We use this as a lower bound to $\alpha_{\mathrm{s}}$ reported in the table, even though the authors do not report the trapping probability for $\mathrm{HNO}_{3}$. They argue that it is close to 1 at low, atmospherically relevant incident energies. $95 \%$ of those molecules trapped on the surface undergo proton exchange in the bulk of $\mathrm{D}_{2} \mathrm{SO}_{4}$. Therefore $\alpha_{\mathrm{b}}$ is listed in the table with the same lower bounds.

(e) Static vapour pressure measurement of $\mathrm{HNO}_{3}\left(\mathrm{MS}\right.$ ) over a stirred $\mathrm{H}_{2} \mathrm{SO}_{4} / \mathrm{HNO}_{3} / \mathrm{H}_{2} \mathrm{O}$ solution.

\section{Preferred values}

\begin{tabular}{lll}
\hline Parameter & Value & $T / \mathrm{K}$ \\
\hline$\alpha_{\mathrm{s}}$ & $>0.8$ & $188-223$ \\
$\alpha_{\mathrm{b}}$ & $>0.8$ & $188-223$ \\
$m_{1}\left(\mathrm{wt} \%^{-2} \mathrm{~K}\right)$ & 0.14 & $190-300$ \\
$m_{2}\left(\mathrm{wt} \%^{-1} \mathrm{~K}\right)$ & -36 & $190-300$ \\
$m_{3}(\mathrm{~K})$ & 8980 & $190-300$ \\
$b_{1}\left(\mathrm{wt} \%^{-2}\right)$ & 0.00063 & $190-300$ \\
$b_{2}\left(\mathrm{wt} \%^{-1}\right)$ & 0.012 & $190-300$ \\
$b_{3}$ & 14.7 & $190-300$ \\
Reliability & & \\
$\Delta \log \left(\alpha_{\mathrm{b}}\right)$ & undetermined \\
$\Delta \log \left(\alpha_{\mathrm{s}}\right)$ & undetermined \\
$\Delta \log \left(H^{*}\right)$ & \pm 0.5 & $190-300$ \\
\hline
\end{tabular}

\section{Comments on preferred values}

The molecular beam experiment by Morris et al. (2000) provides the most direct picture of $\mathrm{HNO}_{3}$ interacting with the surface of sulphuric acid. Most of the $\mathrm{HNO}_{3}$ molecules colliding with the surface are trapped, and nearly all of these undergo rapid proton exchange due to efficient solvation in the bulk. $\mathrm{HNO}_{3}$ forms very stable complexes with $\mathrm{H}_{2} \mathrm{O}$ and $\mathrm{H}_{2} \mathrm{SO}_{4}$ that may also be important for the stabilization of $\mathrm{HNO}_{3}$ in the interfacial region (Yang and Finlayson-Pitts, 2001; Fairbrother and Somorjai, 2000). We therefore follow Morris et al. (2000) for recommending a lower limit to $\alpha_{\mathrm{s}}$ and $\alpha_{\mathrm{b}}$.

In Knudsen cell and droplet train experiments, uptake of $\mathrm{HNO}_{3}$ into $\mathrm{H}_{2} \mathrm{SO}_{4}$ solutions was time dependent and followed the behaviour expected for solubility limited uptake in the studies by Reihs et al. (1990) and Van Doren et al. (1991). The slow evaporation observed by Tolbert et al. (1988) with thermal desorption spectrometry appears to be consistent with this. Bulk accommodation was therefore not rate limiting the uptake. The decreasing trend with increasing sulphuric acid concentration reflects the increasing degree of solubility limitation at short interaction times. Initial uptake coefficients extracted from the time dependent traces are not reported that could be compared to the Morris et al. (2000) study.

Estimating Henry's law constants from the time dependent uptake data carries a large uncertainty, as high experimental stability is required to allow reliable $t^{1 / 2}$ fits to the data and also due to the uncertainty associated with estimating the temperature dependent diffusion coefficients. The solubility data extracted from the kinetic experiments by Reihs et al. (1990) and extrapolated to higher temperatures are consistent with vapour pressure measurements for the ternary $\mathrm{HNO}_{3}-\mathrm{H}_{2} \mathrm{SO}_{4}-\mathrm{H}_{2} \mathrm{O}$ system reported by Vandoni (1944) at $273 \mathrm{~K}$. We use the Zhang et al. (1993) solubility data based on $\mathrm{HNO}_{3}$ vapour pressure measurements, which covered the temperature range from 230 to $190 \mathrm{~K}$. We adopt a parameterization of their data in our table of preferred values in which:

$\log H^{*}=m / T-b \quad$ where

$m=m_{1}\left[\mathrm{H}_{2} \mathrm{SO}_{4}\right]^{2}+m_{2}\left[\mathrm{H}_{2} \mathrm{SO}_{4}\right]+m_{3} \quad$ and $\quad b=b_{1}\left[\mathrm{H}_{2} \mathrm{SO}_{4}\right]^{2}+b_{2}\left[\mathrm{H}_{2} \mathrm{SO}_{4}\right]+b_{3}$

and the $\mathrm{H}_{2} \mathrm{SO}_{4}$ concentration $\left[\mathrm{H}_{2} \mathrm{SO}_{4}\right]$ is in wt \%

As pointed out by Taleb et al. (1996), at high temperature, Zhang's data are consistent with Vandoni's data. Taleb et al. (1996) also provide a more comprehensive model to predict vapour pressure and activity of $\mathrm{H}_{2} \mathrm{O}, \mathrm{HNO}_{3}$ and $\mathrm{H}_{2} \mathrm{SO}_{4}$, which reproduces nicely the maximum in the $\mathrm{HNO}_{3}$ vapor pressure of about $1: 1$ (mole fraction) $\mathrm{HNO}_{3}-\mathrm{H}_{2} \mathrm{SO}_{4}$ mixtures reported by Vandoni (1944) and which is in closer agreement with Zhang's data than the work of Luo et al. (1995). 


\section{References}

Carslaw, K. S., Clegg, S. L., and Brimblecombe, P.: J. Phys. Chem., 99, 11557-11574, 1995.

Fairbrother, D. H. and Somorjai, G. A.: J. Phys. Chem. B, 104, 4649-4652, 2000.

Luo, B. P., Carslaw, K. S., Peter, T., and Clegg, S. L.: Geophys. Res. Lett., 22, 247-250, 1995.

Morris, J. R., Behr, P., Antman, M. D., Ringeisen, B. R., Splan, J., and Nathanson, G. M.: J. Phys. Chem. A, 104, 6738-6751, 2000.

Reihs, C. M., Golden, D. M., and Tolbert, M. A.: J. Geophys. Res., 95, 16545-16550, 1990.

Taleb, D. E., Ponche, J. L., and Mirabel, P.: J. Geophys. Res., 101, 25967-25977, 1996.

Tolbert, M. A., Rossi, M. J., and Golden, D. M.: Geophys. Res. Lett., 15, 847-850, 1988.

Van Doren, J. M., Watson, L. R., Davidovits, P., Worsnop, D. R., Zahniser, M. S., and Kolb, C. E.: J. Phys. Chem., 95, 16841689, 1991.

Vandoni, R.: Mem. Serv. Chim. Etat, 31, 87-111, 1944.

Yang, H. S. and Finlayson-Pitts, B. J.: J. Phys. Chem. A, 105, 1890-1896, 2001.

Zhang, R. Y., Wooldridge, P. J., and Molina, M. J.: J. Phys. Chem., 97, 8541-8548, 1993. 
VI.A4.9

$\mathrm{HO}_{2} \mathrm{NO}_{2}(\mathrm{~g})+\mathrm{H}_{2} \mathrm{SO}_{4}(\mathrm{aq}) \rightarrow$ products

\section{Experimental data}

\begin{tabular}{lllll}
\hline Parameter & {$\left[\mathrm{H}_{2} \mathrm{SO}_{4}\right] / \mathrm{wt} \%$} & $T / \mathrm{K}$ & Reference & Technique/Comments \\
\hline Uptake coefficient: $\gamma_{0}$ & & & & \\
0.23 & 58.3 & 207.9 & Zhang et al. (1997) & CWFT-CIMS (a) \\
0.20 & 58.3 & 213.5 & & \\
0.13 & 58.3 & 218.9 & & \\
0.07 & 58.3 & 226.8 & & \\
$H^{*}\left(D_{1}\right)^{0.5}$ & & & & \\
$2.95 \times 10^{-10} \exp (5940 / T)$ & 52.9 & $209-229$ & Zhang et al. (1997) & CWFT-CIMS (a) \\
$1.37 \times 10^{-8} \exp (4980 / T)$ & 58.3 & $208-227$ & & \\
$1.31 \times 10^{-5} \exp (3320 / T)$ & 66.4 & $201-215$ & & \\
$1.75 \times 10^{-3} \exp (2030 / T)$ & 73.8 & $204-224$ & & \\
\hline
\end{tabular}

\section{Comments}

(a) Coated-wall laminar flow reactor using CIMS detection of $\mathrm{HO}_{2} \mathrm{NO}_{2}$ (Pernitric acid, PNA) using both $\mathrm{SF}_{6}^{-}$and $\mathrm{I}^{-}$as source ions. PNA is either detected as $\mathrm{HO}_{2} \mathrm{NO}_{2} \mathrm{~F}^{-}$or $\mathrm{HO}_{2} \mathrm{NO}_{2}^{-}$. The first-order rate coefficient measured at a typical PNA concentration of $5 \times 10^{7}$ molecule $\mathrm{cm}^{-3}$ was corrected for gas phase diffusion (10\% for the smallest and a factor of four for the largest $\gamma$ values) using a gas phase diffusion constant of PNA in He of $D_{\mathrm{g}}=319 \mathrm{mbarcm}^{2} \mathrm{~s}^{-1}$. Liquid sulphuric acid films were approximately $0.1 \mathrm{~mm}$ thick. The uptake of PNA was reversible when the flow was halted. The time dependence of $\gamma$ was interpreted as solubility limited uptake and used to extract $H^{*}\left(D_{1}\right)^{0.5}$ values. Representative expressions for these are listed in the table.

\section{Preferred values}

\begin{tabular}{lll}
\hline Parameter & Value & $T / \mathrm{K}$ \\
\hline$\alpha_{\mathrm{b}}$ & $>0.2$ & $205-225$ \\
$H^{*}\left(\mathrm{M} \mathrm{atm}^{-1}\right)$ & $5.5 \times 10^{-23} \exp \left(w t\left(0.52-1.05 \times 10^{-4}(w t-53)^{2}\right) \times\right.$ & $205-225$ \\
& $\exp \left(\left(20683-346.29 w t+2.044 w t^{2}\right) / T\right)$ & \\
$c\left(\mathrm{~cm}^{2} \mathrm{cP} \mathrm{K}^{-1} \mathrm{~s}^{-1}\right)$ & $6.02 \times 10^{-8}$ & $205-225$ \\
$\Delta H_{\text {soln }}^{0}\left(\mathrm{~kJ} \mathrm{Mol}^{-1}\right)$ & -58.6 & \\
$S_{\text {soln }}^{0}\left(\mathrm{~J} \mathrm{Mol}^{-1} \mathrm{~K}^{-1}\right)$ & -159.0 & \\
Reliability & & \\
$\Delta \log \left(\alpha_{\mathrm{b}}\right)$ & undetermined & \\
$\Delta \log (H)$ & \pm 0.15 & \\
$\Delta \Delta H_{\text {soln }}^{0} \mathrm{~kJ} \mathrm{Mol}^{-1}$ & \pm 4.5 & \\
$\Delta S_{\text {soln }}^{0}\left(\mathrm{~J} \mathrm{Mol}^{-1} \mathrm{~K}^{-1}\right)$ & \pm 15 & \\
\hline
\end{tabular}

\section{Comments on preferred values}

The only study available presents a careful analysis of time dependent uptake of PNA into liquid sulphuric acid films. The largest initial uptake coefficient reported forms the basis for a lower limit to $\alpha_{\mathrm{b}}$. To obtain the recommended values for $H^{*}$ from the $H^{*}\left(D_{1}\right)^{0.5}$ values reported by Zhang et al. (1997), we estimate the diffusion coefficient based on the Wilke and Chang (1955) method, as suggested by Klassen et al. (1998) for a range of other species:

$c=\frac{7.4 \times 10^{-8} \sqrt{\kappa_{\text {solvent }}}}{V_{A}^{0.6}}$

For the solvent dependent empirical factor $\kappa_{\text {solvent }}$ Klassen et al. (1998) found a value of 64 to well represent $\mathrm{H}_{2} \mathrm{SO}_{4}$ solutions in this concentration range. With the partial molar volume $V_{\mathrm{A}}$ of $45.183 \mathrm{~cm}^{3} \mathrm{~mol}^{-1}$, we obtain the value for $c$ listed above that 
can be used to calculate the diffusion coefficient via $D_{1, \mathrm{HO} 2 \mathrm{NO} 2}=c T / \eta$. For the viscosity, we suggest to use the parameterization presented by Shi et al. (2001), which fits well to data by Williams and Long (1995) but extends into tropospherically more relevant dilute solutions at high $T$ :

$\eta=a T^{-1.43} \exp \left(448 \mathrm{~K} /\left(T-T_{0}\right)\right)$,

with $a=169.5+5.18 w t-0.0825 w t^{2}+3.27 \times 10^{-3} w t^{3}$,

and $T_{0}=144.11+0.166 w t-0.015 w t^{2}+2.18 \times 10^{-4} w t^{3}$

The $c$ values (and thus also the diffusion coefficients) are about a factor of 2 higher than those estimated by Zhang et al. (1997) based on another approach.

The effective solubilities of PNA in $\mathrm{H}_{2} \mathrm{SO}_{4}$ are strongly $T$-dependent but only slightly dependent upon $\mathrm{H}_{2} \mathrm{SO}_{4}$ concentration owing to the fact that PNA is a weak acid whose degree of dissociation is vanishingly small at relevant $\left[\mathrm{H}_{2} \mathrm{SO}_{4}\right]$.

The resulting $T$-dependence of $H^{*}$ allowed the evaluation of the dissolution parameters of PNA according to the following reaction: (1) $\mathrm{HO}_{2} \mathrm{NO}_{2}(\mathrm{~g}) \leftrightarrows \mathrm{HO}_{2} \mathrm{NO}_{2}(\mathrm{aq})$; (2) $\mathrm{HO}_{2} \mathrm{NO}_{2}(\mathrm{aq}) \leftrightarrows \mathrm{O}_{2} \mathrm{NO}_{2}^{-}+\mathrm{H}^{+}$. The values of $\Delta H_{\text {soln }}^{0}$ and $S_{\text {soln }}^{0}$ varied from -62.8 to $-54.4 \mathrm{~kJ} \mathrm{~mol}^{-1}$ and -174 to $-143.9 \mathrm{~J} \mathrm{~mol}^{-1} \mathrm{~K}^{-1}$ in the given $\mathrm{H}_{2} \mathrm{SO}_{4}$ concentration range.

No reaction products were detected in agreement with the identical shape of the uptake and desorption trace of PNA.

\section{References}

Klassen, J. K., Hu, Z., and Williams, L. R.: J. Geophys. Res., 103, 16197-16202, 1998.

Shi, Q., Jayne, J. T., Kolb, C. E., Worsnop, D. R., and Davidovits, P.: J. Geophys. Res., 106, 24259-24274, 2001.

Wilke, C. R. and Chang, P.: Aiche Journal, 1, 264-270, doi:10.1002/aic.690010222, 1955.

Williams, L. R. and Long, F. S.: J. Phys. Chem., 99, 3748-3751, 1995.

Zhang, R., Leu, M.-T., and Keyser, L. F.: J. Phys. Chem. A, 101, 3324-3330, 1997. 


\section{VI.A4.10}

$\mathrm{NH}_{3}(\mathrm{~g})+\mathrm{H}_{2} \mathrm{SO}_{4}(\mathrm{aq}) \rightarrow$ products

\section{Experimental data}

\begin{tabular}{llll}
\hline Parameter & $T / \mathrm{K}$ & Reference & Technique/Comments \\
\hline Uptake coefficients: $\gamma, \gamma_{s s}, \gamma_{0}$ & & & \\
$0.3\left(20 \% \mathrm{H}_{2} \mathrm{SO}_{4}\right)$ & $248-288$ & Swartz et al. (1999) & DT-UV/Vis (a) \\
$0.8\left(40 \% \mathrm{H}_{2} \mathrm{SO}_{4}\right)$ & & & \\
$1.0\left(55 \% \mathrm{H}_{2} \mathrm{SO}_{4}\right)$ & & & \\
$1.0\left(75 \% \mathrm{H}_{2} \mathrm{SO}_{4}\right)$ & & & \\
$0.98 \pm 0.15\left(40-65 \% \mathrm{H}_{2} \mathrm{SO}_{4}\right)$ & $293-297$ & Hanson and Kosciuch (2003) & AFT-CIMS (b) \\
$1.04 \pm 0.14\left(15-40 \% \mathrm{H}_{2} \mathrm{SO}_{4}\right)$ & $287-292$ & & \\
\hline
\end{tabular}

\section{Comments}

(a) Uptake experiment of gas phase $\mathrm{NH}_{3}$ on train of droplets whose size was in the range 150-300 $\mu \mathrm{m}$ entrained in a flowing mixture of helium and water vapour (between 2.9 and $23.3 \mathrm{mbar}$ ). The reaction time was between 2 and $15 \mathrm{~ms}$, the ammonia concentration was in the range $10^{13}$ to $2 \times 10^{14} \mathrm{~cm}^{-3}$ and was monitored using a VUV lamp emitting at $\lambda=121.6 \mathrm{~nm}$. The cited uptake coefficients were corrected for gas diffusion effects. The uptake coefficient increases as a function of acid concentration and reaches unity at about $55 \mathrm{wt} \% \mathrm{H}_{2} \mathrm{SO}_{4}$. The distinct negative temperature dependence of $\gamma$ observed in aqueous solutions (Shi et al., 1999) decreases with increasing concentration in the range 20-70\% $\mathrm{H}_{2} \mathrm{SO}_{4}$. The increased $\mathrm{NH}_{3}$ uptake in acid solution is apparently due to reaction between $\mathrm{NH}_{3}^{+}$and $\mathrm{H}^{+}$at the gas-liquid interface. The results yielded parameters required to model the reaction of $\mathrm{NH}_{3}$ with $\mathrm{H}^{+}$at the gas-liquid interface. These uptake experiments were expanded to include a detailed study of gas transport to a moving train of droplets.

(b) Uptake of 1-12 $\mathrm{ppb} \mathrm{NH}_{3}$ in $\mathrm{N}_{2}$ on $15-65 \% \mathrm{H}_{2} \mathrm{SO}_{4}$ aerosol flowing in an atmospheric pressure flow tube (810 mbar) which was characterised using a DMA/CNC combination. The particle size distribution peaked close to $100 \mathrm{~nm}$ at a particle number concentration in the range $4 \times 10^{4}$ to $1.5 \times 10^{5}$ particle $\mathrm{cm}^{-3}$ to afford a $\mathrm{NH}_{3}-\mathrm{H}_{2} \mathrm{SO}_{4}$ ratio of typically $0.10 . \mathrm{NH}_{3}$ was monitored using CIMS of protonated water clusters of the type $\mathrm{NH}_{4}^{+}\left(\mathrm{H}_{2} \mathrm{O}\right)_{\mathrm{m}}$ with m between 1 and 5. Corrections to the data have been made owing to an important $\mathrm{NH}_{4}^{+}$and a smaller $\mathrm{NH}_{3}$ background signal.

\section{Preferred values}

\begin{tabular}{lll}
\hline Parameter & Value & $T / \mathrm{K}$ \\
\hline$\gamma\left(\geq 50 \% \mathrm{H}_{2} \mathrm{SO}_{4}\right)$ & 1.0 & $265-300$ \\
Reliability & & \\
$\Delta \log (\gamma)$ & \pm 0.3 & $265-300$ \\
\hline
\end{tabular}

\section{Comments on preferred values}

Uptake of ammonia on sulphuric acid surfaces results in reaction to form $\mathrm{NH}_{4}^{+}$and $\mathrm{HSO}_{4}^{-}$. The available data for $\left[\mathrm{H}_{2} \mathrm{SO}_{4}\right]$ above $50 \mathrm{wt} \%$ are in agreement, showing an uptake coefficient close to unity. However for more dilute solutions, the results of uptake studies on fine aerosols (Hanson and Kosciuch, 2003) disagree with those from the droplet train experiments, which show a decline in $\gamma$ with increasing water content below $45 \mathrm{wt} \%$. In view of these apparent inconsistencies we confine our recommendation to concentrated acid $(\geq 50 \mathrm{wt} \%)$. The possible causes for this discrepancy at lower acid concentrations have been the subject of literature debate (Worsnop et al., 2004; Hanson and Kosciuch, 2004; Hanson et al., 2004; Morita et al., 2004a). One possible cause lies in the use of an inadequate gas resistance model in the interpretation of results from the droplet train experiments, which is discussed by Morita et al. (2004b) in their study of the uptake of $\mathrm{H}_{2} \mathrm{O}$ on water surfaces. A clear resolution will require further investigation.

The uptake coefficients all exceed the bulk accommodation coefficient, $\alpha_{\mathrm{b}}$, for uptake on pure water, and may indicate a direct chemical interaction of $\mathrm{NH}_{3}$ at the surface, e.g. by protonation. 


\section{References}

Hanson, D. R. and Kosciuch, E.: J. Phys. Chem. A, 107, 2199-2208, 2003.

Hanson, D. R. and Kosciuch, E.: J. Phys. Chem. A, 108, 8549-8551, 2004.

Hanson, D. R., Sugiyama, M., and Morita, A.: J. Phys. Chem. A, 108, 3739-3744, 2004.

Morita, A., Sugiyama, M., Kameda, H., Koda, S., and Hanson, D. R.: J. Phys. Chem. B, 108, 9111-9120, 2004a.

Morita, A., Sugiyama, M., and Koda, S.: J. Phys. Chem. A, 108, 8544-8545, 2004b.

Shi, Q., Davidovits, P., Jayne, J. T., Worsnop, D. R., and Kolb, C. E.: J. Phys. Chem. A, 103, 8812-8823, 1999.

Swartz, E., Shi, Q., Davidovits, P., Jayne, J. T., Worsnop, D. R., and Kolb, C. E.: J. Phys. Chem. A, 103, 8824-8833, 1999.

Worsnop, D. R., Williams, L. R., Kolb, C. E., Mozurkewich, M., Gershenzon, M., and Davidovits, P.: J. Phys. Chem. A, 108, 8546-8548, 2004. 
VI.A4.11

$\mathrm{N}_{2} \mathrm{O}_{5}(\mathrm{~g})+\mathrm{H}_{2} \mathrm{O}(\mathrm{l}) \rightarrow$ products

\section{Experimental data}

\begin{tabular}{|c|c|c|c|c|c|}
\hline Parameter & $\mathrm{RH} / \%$ & $\mathrm{H}_{2} \mathrm{SO}_{4} / \mathrm{wt} \%$ & $T / \mathrm{K}$ & Reference & Technique/Comments \\
\hline \multicolumn{6}{|c|}{ Uptake coefficients: $\gamma, \gamma_{s s}, \gamma_{0}$} \\
\hline $0.10 \pm 0.01$ & $1-10$ & & 293 & Mozurkewitch and Calvert (1988) & AFT-CL (a) \\
\hline $0.139 \pm 0.009$ & $1-10$ & & 274 & & \\
\hline $0.12 \pm 0.03$ & & 40 & 226 & Hanson and Ravishankara (1991a) & WWFT-CIMS (b) \\
\hline $0.14 \pm 0.03$ & & 60 & & & \\
\hline $0.10 \pm 0.02$ & & 70 & & & \\
\hline $0.10 \pm 0.02$ & & 75 & & & \\
\hline $0.058 \pm 0.006$ & & 73 & 283 & Van Doren et al. (1991) & DT-TDLAS (c) \\
\hline $0.055 \pm 0.010$ & & $74-96$ & $220 \pm 5$ & Williams et al. (1994) & Kn-MS (d) \\
\hline $0.06 \pm 0.04$ & & $79-84$ & 293 & Fried et al. (1994) & AFT-CL (e) \\
\hline $0.103 \pm 0.006$ & & $64-81$ & 273 & & \\
\hline $0.12 \pm 0.016$ & & $57-76$ & 260 & & \\
\hline $0.148 \pm 0.011$ & & $63-76$ & 247 & & \\
\hline $0.086 \pm 0.009$ & & $61-63$ & 247 & & \\
\hline $0.146 \pm 0.036$ & & $69-71$ & $230-234$ & & \\
\hline $0.102 \pm 0.011$ & & $65-69$ & $231-234$ & & \\
\hline $0.077 \pm 0.019$ & & $54-64$ & $225-231$ & & \\
\hline $0.076 \pm 0.018$ & 60 & & 270 & Hanson and Lovejoy (1994) & AFT-CIMS (f) \\
\hline $0.081 \pm 0.032$ & 60 & & 230 & & \\
\hline $0.061 \pm 0.013$ & 70 & & 296 & & \\
\hline $0.109 \pm 0.024$ & 70 & & 230 & & \\
\hline $0.077 \pm 0.016$ & 80 & & 270 & & \\
\hline $0.090 \pm 0.020$ & 80 & & 230 & & \\
\hline 0.11 & & 53 & 200 & Zhang et al. (1995) & WWFT-CIMS (g) \\
\hline 0.034 & & $29,16.4 \% \mathrm{HNO}_{3}$ & 195 & & \\
\hline 0.021 & & $5,41 \% \mathrm{HNO}_{3}$ & 200 & & \\
\hline 0.045 & & $40,10 \% \mathrm{HNO}_{3}$ & 200 & & \\
\hline 0.10 & & $5,41 \% \mathrm{HNO}_{3}$ & 220 & & \\
\hline $0.075 \pm 0.047$ & & 65 & $210-230$ & Beichert and Finlayson-Pitts (1996) & Kn-MS (h) \\
\hline $0.023 \pm 0.004$ & 90 & 17 & 297 & Hu and Abbatt (1997) & AFT-CIMS/OPC (i) \\
\hline $0.038 \pm 0.012$ & 58.5 & 40 & & & \\
\hline $0.060 \pm 0.020$ & 19.5 & 59 & & & \\
\hline $0.050 \pm 0.008$ & 8.5 & 66 & & & \\
\hline $0.187 \pm 0.028$ & & 69 & 240 & Robinson et al. (1997) & DT-TDLAS (j) \\
\hline $0.154 \pm 0.023$ & & 69 & 260 & & \\
\hline $0.159 \pm 0.024$ & & 39 & 231 & & \\
\hline $0.086 \pm 0.0129$ & & 39 & 255 & & \\
\hline $0.11 \pm 0.02$ & & 60 & $210-230$ & Hanson (1997) & WWFT and AFT-CIMS (k) \\
\hline 0.092 & & $55,5 \% \mathrm{HNO}_{3}$ & 202 & & \\
\hline 0.021 & & $45,15 \% \mathrm{HNO}_{3}$ & 230 & & \\
\hline 0.045 & & $59,0.08 \% \mathrm{HNO}_{3}$ & & & \\
\hline 0.10 & & $58,1-2 \% \mathrm{HNO}_{3}$ & & & \\
\hline $0.033 \pm 0.004$ & $8-80$ & $26.3-55$ & 298 & Hallquist et al. (2000) & AFT-CL/SMPS (1) \\
\hline $0.028 \pm 0.008$ & 40 & 49 & 298 & & \\
\hline $0.036 \pm 0.004$ & 40 & 48 & 288 & & \\
\hline $0.049 \pm 0.009$ & 40 & 44 & 278 & & \\
\hline $0.091 \pm 0.019$ & 40 & 42 & 268 & & \\
\hline $0.092 \pm 0.013$ & 40 & 42 & 263 & & \\
\hline 0.045 & 0.7 & 81 & $295 \pm 1$ & Kane et al. (2001) & AFT-CIMS/SMPS (m) \\
\hline $0.045 \pm 0.013$ & 2.9 & 76 & & & \\
\hline 0.030 & 7.7 & 70 & & & \\
\hline 0.075 & 16 & 63 & & & \\
\hline 0.061 & 28.4 & 55 & & & \\
\hline 0.050 & & $38 \pm 2$ & 193.6 & Wagner et al. (2005) & SR-FTIR (n) \\
\hline 0.044 & & $32,10 \% \mathrm{HNO}_{3}$ & & & \\
\hline 0.033 & & $17,34 \% \mathrm{HNO}_{3}$ & & & \\
\hline 0.016 & & $\begin{array}{l}9,48 \% \mathrm{HNO}_{3} \\
58,1-2 \% \mathrm{HNO}_{3}\end{array}$ & & & \\
\hline 0.049 & & $60 \pm 1$ & 298 & Knopf et al. (2007) & FR/CIMS (o) \\
\hline 0.050 & & $80 \pm 1$ & & & \\
\hline $0.10 \pm 0.01$ & & 50 & 210 & Talukdar et al. (2012) & WWFT,AFT/ \\
\hline $0.10 \pm 0.01$ & & 50 & 220 & & CIMS (p) \\
\hline $0.09 \pm 0.01$ & & 60 & 210 & & \\
\hline $0.11 \pm 0.01$ & & 60 & 220 & & \\
\hline
\end{tabular}




\section{Comments}

(a) Atmospheric pressure aerosol flow tube with $\mathrm{N}_{2} \mathrm{O}_{5}\left(\approx 10^{13}\right.$ molecule $\left.\mathrm{cm}^{-3}\right)$ measured by a modified chemiluminescence method, via thermal dissociation to $\mathrm{NO}_{3}$ and titration with $\mathrm{NO}$, which was detected. Aerosols generated in a constant output atomiser, dried, and size selected with a differential mobility analyser (DMA) coupled to a condensation particle counter (CPC). The monodisperse aerosol was then equilibrated at controlled humidity before entry into the flow tube. The typical diameter, $d_{\text {mean }}$, was $0.08-0.2 \mu \mathrm{m}$, with a surface area density of $(1-5) \times 10^{-5} \mathrm{~cm}^{2} \mathrm{~cm}^{-3}$. Uptake coefficients were determined from the first order rate constants for $\mathrm{N}_{2} \mathrm{O}_{5}$ decay, corrected for wall loss, which were linearly dependent on surface area. Diffusion limitation was negligible for the size range used. The uptake of $\mathrm{N}_{2} \mathrm{O}_{5}$ on $\mathrm{H}_{2} \mathrm{SO}_{4} / \mathrm{H}_{2} \mathrm{O}$ was independent of $\mathrm{RH}$ in the range $1-10 \%$.

(b) Wetted wall flow tube coupled to CIMS detection. Aqueous $\mathrm{H}_{2} \mathrm{SO}_{4}$ film residence time of 20-30s. $p\left(\mathrm{H}_{2} \mathrm{O}\right)$ was $\sim 1.3 \times 10^{-3}$ mbar. The temperature dependence of $\gamma$ as measured for the $60 \%$ and 70 solution: none was found within the reported error limits.

(c) Fast train of $200 \mu \mathrm{m} 73 \% / \mathrm{H}_{2} \mathrm{O}$ droplets traversing a flow tube with TDLAS detection. Pressures $=13.3 \mathrm{mbar}$ and dropletgas interaction times of $1-2 \mathrm{~ms}$.

(d) Knudsen cell technique using MS detection. $p\left(\mathrm{~N}_{2} \mathrm{O}_{5}\right)$ was 0.4 to $10 \times 10^{11}$ molecule $\mathrm{cm}^{-3} \cdot \gamma$ value of $0.02-0.03-$ independent of temperature, concentration (74 to $96 \mathrm{wt} \%) \cdot \gamma$ value corrected for saturation effects.

(e) High pressure (0.3 to $0.8 \mathrm{~atm}$ ) flow tube using slow flow conditions and submicron $\mathrm{H}_{2} \mathrm{SO}_{4}$ aerosol generated by homogeneous nucleation from the reaction of $\mathrm{SO}_{3}+\mathrm{H}_{2} \mathrm{O}$. Particle size 60-250 nm diameter at 225 to $293 \mathrm{~K}$, with $\mathrm{H}_{2} \mathrm{SO}_{4} 54$ to $82 \mathrm{wt} \%$ in concentration. $\mathrm{N}_{2} \mathrm{O}_{5}$ (30 to $200 \mathrm{ppb}$ ) detected by titrating with $\mathrm{NO}$ in a heated quartz tube, using TDLAS to monitor $\mathrm{NO}$ and also $\mathrm{H}_{2} \mathrm{O}$ vapor.

(f) Kinetics of $\mathrm{N}_{2} \mathrm{O}_{5}$ hydrolysis on sulphuric acid aerosol measured in laminar flow reactor at 825 mbar of $\mathrm{N}_{2}$, using CIMS detection. The aerosol surface area was determined by UV extinction using Mie theory. The $\mathrm{H}_{2} \mathrm{SO}_{4}$ particle concentration were in the range $(5-100) \times 10^{4}$ particles $\mathrm{cm}^{-3}$ with diameters between 0.2 to $0.4 \mu \mathrm{m}$. Initial $\mathrm{N}_{2} \mathrm{O}_{5}$ concentration was of the order of 1 to $5 \times 10^{13}$ molecule $\mathrm{cm}^{-3}$. The uptake measurements on $60 \% \mathrm{H}_{2} \mathrm{SO}_{4}$ at $230 \mathrm{~K}$ may have been influenced to some extent by $\mathrm{HNO}_{3}$ uptake and hence partial saturation.

(g) Wetted wall flow reactor - CIMS. Liquid sulphuric acid films were applied to the cooled wall of a horizontally mounted tube. Total pressure $=0.53$ mbar of $\mathrm{He}$ with partial pressure of $\mathrm{N}_{2} \mathrm{O}_{5}$ of $6.7 \times 10^{-7}$ mbar. The $\gamma$ values decrease with increasing $\mathrm{HNO}_{3}$ content hence decreasing temperature at constant $\mathrm{H}_{2} \mathrm{O}$ and $\mathrm{HNO}_{3}$ partial pressure. On the binary $\mathrm{H}_{2} \mathrm{SO}_{4} / \mathrm{H}_{2} \mathrm{O}$ surface $\gamma=0.1$ independent of temperature. In the temperature range 195 to $220 \mathrm{~K} \gamma$ may be expressed as $\gamma=-0.379+0.00213 T$ at $p_{\mathrm{H} 2 \mathrm{O}}=5 \times 10^{-7} \mathrm{mbar}$ and $p_{\mathrm{HNO} 3}=6.7 \times 10^{-7} \mathrm{mbar}$.

(h) Knudsen flow reactor using MS detection. $\mathrm{N}_{2} \mathrm{O}_{5}$ concentration was in the range 3 to $90 \times 10^{11}$ molecule $\mathrm{cm}^{-3}$.

(i) Atmospheric pressure aerosol flow tube with detection of $\mathrm{N}_{2} \mathrm{O}_{5}\left(7 \times 10^{12}\right.$ molecule $\left.\mathrm{cm}^{-3}\right)$ by CIMS using $\mathrm{I}^{-}$reagent ion. The aerosols were generated in an ultrasonic nebuliser and were equilibrated with the ambient humidity before entry into the flow tube. The size distribution, measured with an optical particle counter (OPC), was used to calculate the surface area of the aerosol in the flow tube. The peak in the surface area weighted size distribution, $d_{\max }$, was between 2 and $4 \mu \mathrm{m}$. The counter was calibrated by collection of aerosol of known composition in an aqueous trap (assumed $100 \%$ efficient) and measurement of the electrical conductivity of the trapped electrolyte. Uptake coefficients were determined from the first order rate constants for $\mathrm{N}_{2} \mathrm{O}_{5}$ decay, corrected for wall loss (Brown correction), and for diffusion limitation to the particle surface assuming $d_{\max }$ as the average diameter of the polydisperse aerosol. The first order rate constant for the title reaction scaled linearly with the aerosol surface area. Cited errors on $\gamma$ is $\pm 1 \sigma$ precision; the estimated potential systematic error arising mainly from measurement of the $\mathrm{SA}$ was $\pm 25 \% . \mathrm{HNO}_{3}$ accumulation in the aerosol was insignificant.

(j) Fast train of $200 \mu \mathrm{m} \mathrm{H}_{2} \mathrm{SO}_{4} / \mathrm{H}_{2} \mathrm{O}$ droplets traversing a flow tube with TDLAS detection. Pressures $=13.3 \mathrm{mbar}$ and droplet-gas interaction times of 2 to $20 \mathrm{~ms}$. The temperature of the droplets was inferred from the water partial pressure measured by TDL absorption. A negative temperature dependence of $\gamma_{\mathrm{ss}}$ was observed for $T \geq 230 \mathrm{~K}$ and $\gamma_{\mathrm{ss}}$ slightly increased with increasing concentration of $\mathrm{H}_{2} \mathrm{SO}_{4}$ measured at 39, 54 and $69 \mathrm{wt} \%$. Model involving neutral and acid catalysed mechanism for $\mathrm{N}_{2} \mathrm{O}_{5}$ hydrolysis fitted data from several laboratories.

(k) Flow reactors with sulphuric acid wall film $(0.2 \mathrm{~mm}$ thickness) and sub-micron aerosol (particle size $0.1 \mu \mathrm{m})-\mathrm{CIMS}$ detection. The pressure was $0.5 \mathrm{mbar} \mathrm{He}$ in the wall coated tube and $240 \mathrm{mbar}$ of $\mathrm{N}_{2}$ in the aerosol flow tube. Initial $\left[\mathrm{N}_{2} \mathrm{O}_{5}\right]$ was $5 \times 10^{11}$ molecule $\mathrm{cm}^{-3}$ for the aerosol and $5 \times 10^{11}$ molecule $\mathrm{cm}^{-3}$ for the bulk liquid experiment. 
(l) $\mathrm{N}_{2} \mathrm{O}_{5}$ uptake experiment in an aerosol flow tube at characteristic $\mathrm{N}_{2} \mathrm{O}_{5}$ concentrations of $500 \mathrm{ppb}$ coupled to $\mathrm{NO}_{2}$ detection using a chemiluminescence detector after thermal decomposition of $\mathrm{N}_{2} \mathrm{O}_{5}$ and following $\mathrm{NO}_{3}$ titration with $\mathrm{NO}$. Typical aerosol number densities were $(6-10) \times 10^{5}$ particles $\mathrm{cm}^{-3}$. The $\gamma$ values were independent of $\mathrm{RH}$ in the range 8-80\%, and hence on aerosol $\mathrm{H}_{2} \mathrm{O}$ content in the range 24.3-64.5 wt $\% \mathrm{H}_{2} \mathrm{SO}_{4} \cdot \gamma$ showed a negative temperature dependence at $\mathrm{RH}=40 \%$.

(m) Atmospheric pressure flow tube with contact times between 1.5 and $7 \mathrm{~s}$ once the $100 \mathrm{~nm}$ diameter aerosol was well mixed with $\mathrm{N}_{2} \mathrm{O}_{5}$ that was detected using CIMS. The reaction probability for $\mathrm{N}_{2} \mathrm{O}_{5}$ on $\mathrm{H}_{2} \mathrm{SO}_{4}$ aerosols shows only a weak dependence upon the relative humidity over the range $1-90 \%$. The $\gamma$ value over this range obtained from a fit to all available data is given by the following expression: $\gamma\left[\mathrm{H}_{2} \mathrm{SO}_{4}\right]=0.052-2.79 \times 10^{-4} \times(\mathrm{RH})$.

(n) Uptake of $\mathrm{N}_{2} \mathrm{O}_{5}$ prepared in situ in a large aerosol chamber (AIDA) equipped with aerosol metrology instrumentation, gasand particular phase $\mathrm{H}_{2} \mathrm{O}$ detection using hygrometers and FTIR extinction measurement capabilities. Saturated ternary solutions (STS) consisting of $\mathrm{H}_{2} \mathrm{SO}_{4} / \mathrm{HNO}_{3} / \mathrm{H}_{2} \mathrm{O}$ were formed by the interaction of $\mathrm{N}_{2} \mathrm{O}_{5}$ between the initial $38 \mathrm{wt} \%$ $\mathrm{H}_{2} \mathrm{SO}_{4} / \mathrm{H}_{2} \mathrm{O}$ background aerosol with $\mathrm{H}_{2} \mathrm{O}$ vapour from ice-coated chamber walls. The decrease of $\gamma$ with increasing mixing ratio of $\mathrm{HNO}_{3}$ is attributed to the nitrate effect at low temperatures.

(o) Measurement of $\gamma$ using a rectangular channel flow reactor designed for uptake on monolayer-coated liquid substrates. Total pressure up to 21 mbar required substantial corrections $(\sim 300 \%)$ for diffusion limitation. Cited values of $\gamma$ are corrected values for $\mathrm{H}_{2} \mathrm{SO}_{4} / \mathrm{H}_{2} \mathrm{O}$ substrates, which are consistent with values from earlier studies.

(p) Uptake coefficients of $\mathrm{N}_{2} \mathrm{O}_{5}$ in the interaction on neat and $\mathrm{HCl}$-doped aqueous $\mathrm{H}_{2} \mathrm{SO}_{4}(50 \%$ and $60 \%$ ) were measured at $210-220 \mathrm{~K}$. All gaseous species were measured using calibrated CIMS with $\mathrm{I}^{-}$as reagent ion. The acids were applied as a cold liquid to a rotating inner wall of the flow tube.

\section{Preferred values}

\begin{tabular}{lll}
\hline Parameter & Value & $T / \mathrm{K}$ \\
\hline$\alpha_{\mathrm{b}}$ & 0.042 & 298 \\
$\alpha_{\mathrm{b}}$ & $2.3 \times 10^{-5} \exp (2240 / T)$ & $240-300$ \\
$\gamma_{\mathrm{r}}$ & {$[(7353 / T)-24.83]^{-1}$} & $210-300$ \\
$\Delta \log (\alpha)$ & \pm 0.1 & 298 \\
$\Delta \log (\gamma)$ & \pm 0.3 at $50 \% \mathrm{RH}$ & $260-305$ \\
\hline
\end{tabular}

\section{Comments on preferred values}

There is a large body of experimental data on the uptake of $\mathrm{N}_{2} \mathrm{O}_{5}$ on $\mathrm{H}_{2} \mathrm{SO}_{4} / \mathrm{H}_{2} \mathrm{O}$ surfaces covering the wide range of temperature and humidity relevant for the atmosphere between the surface and the lower stratosphere. The results are generally consistent between the different studies which used both bulk and dispersed (aerosol) surfaces. At room temperature $\gamma$ shows little dependence on $\mathrm{RH}$ in the range 8-80\%, and hence on aerosol $\mathrm{H}_{2} \mathrm{O}$ content in the corresponding range 20-70 wt \% $\mathrm{H}_{2} \mathrm{SO}_{4}$. However at low temperatures there is a fall off in $\gamma$ with decreasing water content. $\gamma$ shows a distinct negative temperature dependence at $T>230 \mathrm{~K}$, but at lower temperature the temperature dependence becomes positive. The uptake leads to hydrolysis of $\mathrm{N}_{2} \mathrm{O}_{5}$ and formation of $\mathrm{HNO}_{3}$ which transfers to the gas phase. However at low temperatures the increased solubilty of $\mathrm{HNO}_{3}$ in the $\mathrm{H}_{2} \mathrm{SO}_{4} / \mathrm{H}_{2} \mathrm{O}$ particles leads to a reduction in the uptake rate.

The lack of a dependence on the water content of $\mathrm{H}_{2} \mathrm{SO}_{4} / \mathrm{H}_{2} \mathrm{O}$ surfaces and the negative temperature dependence at $T>230 \mathrm{~K}$ suggests that uptake is controlled by a surface process, either mass accommodation or surface reaction. It is suggested by Robinson et al. (1997) that the change in behaviour at low temperature is due to uptake under these conditions becoming limited by the rate of hydrolysis of $\mathrm{N}_{2} \mathrm{O}_{5}$ in bulk liquid phase. They presented a phenomenological model which accounts for the observed dependence of the uptake coefficients on concentration and temperature. Two hydrolysis pathways are proposed, a direct reaction with $\mathrm{H}_{2} \mathrm{O}$ and an acid-catalysed reaction involving dissociation of $\mathrm{N}_{2} \mathrm{O}_{5}$ promoted by $\mathrm{H}^{+}$ions.

The recommended expression for $\gamma$ uses a resistance-model formulation but with an empirical representation of the temperature dependent liquid phase resistance due to chemical reaction, $\gamma_{\mathrm{r}}$ :

$\gamma=\left\{\frac{1}{\alpha_{\mathrm{b}}}+\frac{1}{\gamma_{\mathrm{r}}}\right\}^{-1}$ 
The recommended value of $\alpha_{\mathrm{b}}$ is based on a linear least squares fit to all data at $T>240 \mathrm{~K}$, plotted in the form $\ln [\alpha /(1-\alpha)]$ vs. $1 / T$. The temperature dependence of the $\gamma_{\mathrm{r}}$ term was determined by plotting the difference term $\left(1 / \gamma_{\mathrm{obs}}-1 / \alpha\right)$ against $1 / T$ and using linear regression to evaluate the empirical relationship between $1 / \gamma_{\mathrm{r}}$ and temperature.

\section{References}

Badger, C. L., Griffiths, P. T., George, I., Abbatt, J. P. D., and Cox, R. A.: J. Phys. Chem. A, 110, 6986-6994, 2006.

Beichert, P. and Finlayson-Pitts, B. J.: J. Phys. Chem., 100, 15218-15228, 1996.

Griffiths, P. T. and Cox, R. A.: Atmos. Sci. Lett., 10, 159-163, 2009.

Hallquist, M., Stewart, D. J., Baker, J., and Cox, R. A.: J. Phys. Chem. A, 104, 3984-3990, 2000.

Hallquist, M., Stewart, D. J., Stephenson, S. K., and Cox, R. A.: Phys. Chem. Chem. Phys., 5, 3453-3463, 2003.

Fried, A., Henry, B. E., Calvert, J. G., and Mozurkewich, M.: J. Geophys. Res., 99, 3517-3532, 1994.

Folkers, M., Mentel, T. F., and Wahner, A.: Geophys. Res. Lett., 30, art. no. 1644, doi:10.1029/2003GL017168, 2003.

Golden, D. M., Manion, J. A., Reihs, C. M., and Tolbert, M. A.: in: CHEMRAWN VII: Chemistry of the Atmosphere: The Impact of Global Change, edited by: Calvert, J. G., Oxford University Press, 1992.

Hanson, D. R.: Geophys. Res. Lett., 24, 1087-1090, 1997.

Hanson, D. R. and Ravishankara, A. R.: J. Geophys. Res., 96, 17307-17314, 1991a.

Hu, J. H. and Abbatt, J. P. D.: J. Phys. Chem. A, 101, 871-878, 1997.

Kane, S. M., Caloz, F., and Leu, M.-T.: J. Phys. Chem. A, 105, 6465-6470, 2001.

Knopf, D. A., Cosman L. M., Mousavi, P., Mokamati, S. and Bertram, A. K., J. Phys. Chem. A 111, 11021, 2007.

Mentel, T. F., Sohn, M., and Wahner, A.: Phys. Chem. Chem. Phys., 1, 5451-5454, 1999.

Mozurkewich, M. and Calvert, J. G.: J. Geophys. Res., 93, 15889-15896, 1988.

Robinson, G. N., Worsnop, D. R., Kolb, C. E., and Davidovits, P.: J. Geophys. Res., 102, 3583-3601, 1997.

Talukdar, R. K., Burkholder, J. B., Roberts, J. M., Portmann, R. W., and Ravishankara, A. R.: J. Phys. Chem. A, 116, 6003, 2012.

Thornton, J. A., Braban, C. F., and Abbatt, J. P. D.: Phys. Chem. Chem. Phys., 5, 4593-4603, 2003.

Van Doren, J. M., Watson, L. R., Davidovits, P., Worsnop, D. R., Zahniser, M. S., and Kolb, C. E.: J. Phys. Chem., 95, 1684$1689,1991$.

Wagner, R., Naumann, K.-H., Mangold, A., Möhler, O., Saathoff, H., and Schurath, U.: J. Phys. Chem. A, 109, 8140-8148, 2005.

Williams, L. R., Manion, J. A., Golden, D. M., and Tolbert, M. A.: J. Appl. Meteorol., 33, 785-790, 1994.

Zhang, R., Leu, M.-T., and Keyser, L. F.: Geophys. Res. Lett., 22, 1493-1496, 1995.

Zhang, R., Leu, M.-T., and Keyser, L. F.: J. Geophys. Res., 100, 18845-18854, 1995a. 
VI.A4.12

$\mathrm{H}_{2} \mathrm{CO}(\mathrm{g})+\mathrm{H}_{2} \mathrm{SO}_{4}(\mathrm{aq}) \rightarrow$ products

Experimental data

\begin{tabular}{lllll}
\hline Parameter & {$\left[\mathrm{H}_{2} \mathrm{SO}_{4}\right] / \mathrm{wt} \%$} & $T / \mathrm{K}$ & Reference & Technique/Comments \\
\hline Uptake coefficients: $\gamma$ & & & & \\
0.01 & 67 & 223 & Tolbert et al. (1993) & Kn-MS (a) \\
0.08 & 75 & & & \\
$(2.7 \pm 0.4) \times 10^{-3}$ & 10 & 267 & Jayne et al. (1996) & DT-TDL (b) \\
$(6.7 \pm 0.9) \times 10^{-3}$ & 55 & 241 & & \\
$(1.14 \pm 0.09) \times 10^{-2}$ & 85 & 300 & & \\
$2 \times 10^{-3}$ & $48-95$ & $197-215$ & Iraci and Tolbert (1997) & SF-MS (c) \\
Solubility, $H^{*}\left(\mathrm{M} \mathrm{atm}^{-1}\right)$ & & & & \\
$2.0 \times 10^{6}$ & 48 & 206 & Iraci and Tolbert (1997) & SF-MS (c) \\
$4.0 \times 10^{6}$ & 64 & 207 & & \\
$4.0 \times 10^{6}$ & 76 & 201 & & \\
$6.3 \times 10^{6}$ & 86 & 209 & & \\
$1.7 \times 10^{6}$ & 95 & 207 & & \\
\hline
\end{tabular}

\section{Comments}

(a) Uptake experiments of $\mathrm{CH}_{2} \mathrm{O}$ on quiescent and stirred sulphuric acid solutions were performed in the range 60 to $75 \%$ wt $\mathrm{H}_{2} \mathrm{SO}_{4}$ at low temperature. The concentration of $\mathrm{CH}_{2} \mathrm{O}$ ranged from $2 \times 10^{10}$ to $2 \times 10^{11}$ molecule $\mathrm{cm}^{-3}$ and no new gas phase products were detected during uptake. Gentle stirring of the sulphuric acid solution increased the rate of uptake by $\mathrm{CH}_{2} \mathrm{O}$ on the order of a factor of four or so owing to surface saturation at low temperatures, slow diffusion in the liquid and large gas concentrations.

(b) Uptake to 10-85 wt \% droplets at temperatures between 241 and $300 \mathrm{~K}$. Time-dependent (reactive) uptake of $\mathrm{CH}_{2} \mathrm{O}$ was observed and interpreted in terms of formation of $\mathrm{CH}_{2}(\mathrm{OH})_{2}$ and protonated formaldehyde, $\mathrm{CH}_{3} \mathrm{O}^{+}$, at high acidities. The formation of a chemisorbed surface complex of $\mathrm{CH}_{2} \mathrm{O}$ at the gas-liquid interface has been invoked under mildly acidic conditions $(<20 \%$ acid $)$.

(c) Stirred flow reactor with $\mathrm{H}_{2} \mathrm{CO}$ partial pressures of $4 \times 10^{-6}$ to $2.7 \times 10^{-3}$ mbar. Thin $\mathrm{H}_{2} \mathrm{SO}_{4}$ films were made from the reaction of $\mathrm{SO}_{3}$ with $\mathrm{H}_{2} \mathrm{O}$ and supported on an optical window monitored by transmission FTIR spectroscopy.

\section{Preferred values}

\begin{tabular}{lll}
\hline Parameter & Value & $T / \mathrm{K}$ \\
\hline$\alpha_{\mathrm{b}}$ & 0.04 & $200-300$ \\
$c$ & $8 \times 10^{-8} \exp (-0.0272 \mathrm{wt})$ & $200-300$ \\
$H_{\mathrm{CH} 2 \mathrm{O}}\left(\mathrm{M} \mathrm{atm}^{-1}\right)$ & $\exp \left(-(-0.0456+55.5 / T) \times 0.46 m_{\mathrm{H} 2 \mathrm{SO} 4}\right)$ & $200-300$ \\
$H_{\mathrm{CH} 2(\mathrm{OH}) 2}^{*}\left(\mathrm{M} \mathrm{atm}^{-1}\right)$ & $H_{\mathrm{CH} 2 \mathrm{O}}\left(1+K_{2} a_{\mathrm{H} 2 \mathrm{O}}\right)$ & $200-300$ \\
$H_{\mathrm{CH} 3 \mathrm{O}+}^{*}\left(\mathrm{M} \mathrm{atm}^{-1}\right)$ & $H_{\mathrm{CH} 2 \mathrm{O}\left(1+K_{3}\left[\mathrm{H}^{+}\right]\right)}$ & $200-300$ \\
$K_{2}\left(\mathrm{M}^{-1}\right)$ & $\exp (4020 / T-5.83)$ & $200-300$ \\
$K_{3}\left(\mathrm{M}^{-1}\right)$ & $0.56 \exp (8.84(T-260) / T)$ & $200-300$ \\
$k_{\mathrm{H} 2 \mathrm{O}}\left(\mathrm{M}^{-1} \mathrm{~s}^{-1}\right)$ & $7800 \exp (-1910 / T)\left(1+870\left[\mathrm{H}^{+}\right]\right)$ & $200-300$ \\
$\Gamma_{\mathrm{b}, \operatorname{poly}}$ & 0.001 & $197-215$ \\
$R_{\operatorname{Reliability}}$ & & \\
$\Delta \log (\alpha)$ & \pm 0.3 & $200-300$ \\
$\Delta \log (H)$ & \pm 0.3 & $200-300$ \\
$\Delta \log (K)$ & \pm 0.3 & $200-300$ \\
$\Delta \log (\gamma)$ & \pm 0.7 & $200-300$ \\
\hline
\end{tabular}




\section{Comments on preferred values}

By analogy to known condensed phase kinetics $\mathrm{CH}_{2} \mathrm{O}$ is both solvated to methylene-glycol $\left(\mathrm{CH}_{2}(\mathrm{OH})_{2}\right)$ and present in protonated form $\left(\mathrm{CH}_{3} \mathrm{O}^{+}\right)$in $\mathrm{H}_{2} \mathrm{SO}_{4}$. The uptake of $\mathrm{HCHO}$ to $\mathrm{H}_{2} \mathrm{SO}_{4}$ shows a negative temperature dependence at constant $\left[\mathrm{H}_{2} \mathrm{SO}_{4}\right]$ and a pronounced $\mathrm{H}_{2} \mathrm{SO}_{4}$ concentration dependence: $\gamma$ increases with increasing concentration starting from a concentration where formaldehyde protonation is thought to be the dominant solvation mechanism. Jayne et al. (1996) present a set of parameters that reproduced the time dependent uptake of $\mathrm{CH}_{2} \mathrm{O}$ for the short time scale $(20 \mathrm{~ms})$ of their experiment, from which we adopt the value for $\alpha_{\mathrm{b}}$. In absence of static measurements we adopt their parameters relevant for the calculation of the solubility as a recommendation, since they appropriately link to more dilute solution as well as known hydrolysis rate constants (Jayne et al., 1992).

$H_{\mathrm{CH} 2 \mathrm{O}}$ describes the physical Henry's law for formaldehyde:

$\mathrm{CH}_{2} \mathrm{O}(\mathrm{g}) \leftrightarrows \mathrm{CH}_{2} \mathrm{O}(\mathrm{aq})$

It includes a Setchenow coefficient referenced to that for $\mathrm{HOCl}$.

$H_{\mathrm{CH} 2(\mathrm{OH}) 2}^{*}$ includes the hydration to the more soluble gem-diol form under equilibrium:

$\mathrm{CH}_{2} \mathrm{O}(\mathrm{aq})+\mathrm{H}_{2} \mathrm{O} \leftrightarrows \mathrm{CH}_{2}(\mathrm{OH})_{2}$ with the associated equilibrium constant $K_{2}$.

$H_{\mathrm{CH} 3 \mathrm{O}+}\left(\mathrm{M} \mathrm{atm}^{-1}\right)$ can be used to describe the partitioning into the protonated form of formaldehyde:

$\mathrm{CH}_{2} \mathrm{O}(\mathrm{aq})+\mathrm{H}^{+} \leftrightarrows \mathrm{CH}_{3} \mathrm{O}^{+}$with the associated equilibrium constant $K_{3}$.

We suggest using the parameterisation of Shi et al. (2001) for the proton concentration and the water activity:

$$
\begin{aligned}
\left(\mathrm{H}^{+}\right)=\exp \left(60.51-0.095 w t+0.0077 w t^{2}-1.61 \times 10^{-5} w t^{3}\right. \\
\left.-\left(1.76+2.52 \times 10^{-4} w t^{2}\right) T^{0.5}+\left(-805.89+253.05 w t^{0.076}\right) / T^{0.5}\right) \\
a_{\mathrm{w}}=\exp \left[\left(-69.775 X-18253.7 X^{2}+31072.2 X^{3}-25668.8 X^{4}\right)\left(1 / T-26.9033 / T^{2}\right)\right]
\end{aligned}
$$

where the mole fractions can be calculated from weight percent concentration by: $X=w t /(w t+(100-w t) 98 / 18)$

The three Henry's law constants can be used to calculate the overall equilibrium uptake and partitioning into $\mathrm{CH}_{2} \mathrm{O}(\mathrm{aq})$, $\mathrm{CH}_{2}(\mathrm{OH})_{2}$, and $\mathrm{CH}_{3} \mathrm{O}^{+}$. Jayne et al. (1996) also invoked a surface process, parameterized by a time dependent direct gassurface reaction probability to fully explain the observed uptake coefficient at short gas-droplet interaction times. Since the surface density of the corresponding surface complex remains low it does not affect the overall equilibrium of the other species. Iraci and Tolbert (1997) did not see evidence for the presence of $\mathrm{CH}_{2}(\mathrm{OH})_{2}$ in IR spectra taken after long exposure time at $210 \mathrm{~K}$ and $80 \% \mathrm{H}_{2} \mathrm{SO}_{4}$, but rather suspected formation of a polymer, e.g., through dehydration of $\mathrm{CH}_{2}(\mathrm{OH})_{2}$, which would lead to an apparently higher effective solubility than predicted from the equilibria above alone. The absence of $\mathrm{CH}_{2}(\mathrm{OH})_{2}$ may have been due to the fall off of $K_{2}$ at high $\mathrm{H}_{2} \mathrm{SO}_{4}$ concentration. Since the long term kinetics has not been measured at higher $T$ and lower $\left[\mathrm{H}_{2} \mathrm{SO}_{4}\right]$, where $\mathrm{CH}_{2}(\mathrm{OH})_{2}$ concentrations would be higher, we refrain from giving detailed kinetic parameters for this potential sink of formaldehyde, but simply recommend a constant value of $10^{-3}$ for $\Gamma_{\mathrm{b}}$,poly with large error limits, so that the overall $\gamma$ becomes consistent with the steady state uptake observed by Iraci and Tolbert after long exposure times.

The overall uptake coefficient is given by the expression:

$$
\frac{1}{\gamma}=\frac{1}{\alpha_{\mathrm{b}}}+\frac{1}{\Gamma_{\mathrm{sol}, \mathrm{HCHO}}+\frac{1}{\frac{1}{\Gamma_{\mathrm{sol}, \mathrm{CH} 2(\mathrm{OH}) 2}}+\frac{1}{\Gamma_{\mathrm{b}, \mathrm{CH} 2(\mathrm{OH}) 2}}}+\Gamma_{\mathrm{sol}, \mathrm{CH} 3 \mathrm{O}+}+\Gamma_{\mathrm{b}, \text { poly }}}
$$

The time dependent solubility limited uptake terms are given by:

$\Gamma_{\mathrm{sol}, \mathrm{X}}=\frac{4 H_{\mathrm{X}} R T \sqrt{\frac{4 D_{1}}{\pi t}}}{\bar{c}_{\mathrm{HCHO}}}$

The hydration reaction is parameterized by:

$\frac{1}{\Gamma_{\mathrm{b}, \mathrm{CH} 2(\mathrm{OH}) 2}}=\frac{4 H_{\mathrm{HCHO}} R T \sqrt{D_{1} a_{\mathrm{w}} k_{\mathrm{H} 2 \mathrm{O}}}}{\bar{c}_{\mathrm{HCHO}}}$ 
For the hydration rate constant $k_{\mathrm{H} 2 \mathrm{O}}$ we adopt the expression provided by Jayne et al. (1996) that is consistent with more dilute aqueous solutions.

For the diffusion coefficient, we suggest using the expression for the $c$ parameter given above, based on Jayne et al. (1996), via $D_{1}=c T / \eta$. For the viscosity, we suggest using the parameterization presented by Shi et al. (2001), which fits well to data by Williams and Long (1995) but extends into the tropospherically more relevant dilute solutions at high $T$ :

$\eta=a T^{-1.43} \exp \left(448 K /\left(T-T_{0}\right)\right)$

with $a=169.5+5.18 w t-0.0825 w t^{2}+3.27 \times 10^{-3} w t^{3}$,

and $T_{0}=144.11+0.166 w t-0.015 w t^{2}+2.18 \times 10^{-4} w t^{3}$

The combination of all three experiments shows that the rate of uptake of $\mathrm{CH}_{2} \mathrm{O}$ by $\mathrm{H}_{2} \mathrm{SO}_{4}$ solutions increases with acidity of $\mathrm{H}_{2} \mathrm{SO}_{4}$ at $228 \mathrm{~K}$ for $\left[\mathrm{H}_{2} \mathrm{SO}_{4}\right] \geq 70 \mathrm{wt} \%$ to values close to $\gamma=0.10$. At higher temperatures in the range of $241-300 \mathrm{~K}$ the solubility of dissolved $\mathrm{CH}_{2} \mathrm{O}$ and methyleneglycol $\left(\mathrm{CH}_{2}(\mathrm{OH})_{2}\right)$ increases with increasing temperature and decreases with increasing acid activity. For protonated formaldehyde $\left(\mathrm{CH}_{3} \mathrm{O}^{+}\right)$the solubility increases with increasing acid activity as well as decreasing temperature.

\section{References}

Iraci, L. T. and Tolbert, M. A.: J. Geophys. Res., 102, 16099-16107, 1997.

Jayne, J. T., Duan, S. X., Davidovits, P., Worsnop, D. R., Zahniser, M. S., and Kolb, C. E.: J. Phys. Chem., 96, 5452-5460, 1992.

Jayne, J. T., Worsnop, D. R., Kolb, C. E., Swartz, E., and Davidovits, P.: J. Phys. Chem., 100, 8015-8022, 1996.

Shi, Q., Jayne, J. T., Kolb, C. E., Worsnop, D. R., and Davidovits, P.: J. Geophys. Res., 106, 24259-24274, 2001.

Tolbert, M. A., Pfaff, J., Jayaweera, I., and Prather, M. J.: J. Geophys. Res., 98, 2957-2962, 1993.

Williams, L. R. and Long, F. S.: J. Phys. Chem., 99, 3748-3751, 1995. 
VI.A4.13

$\mathrm{CH}_{3} \mathrm{C}(\mathrm{O}) \mathrm{OONO}_{2}(\mathrm{~g})+\mathrm{H}_{2} \mathrm{SO}_{4}(\mathrm{aq}) \rightarrow$ products

\section{Experimental data}

\begin{tabular}{lllll}
\hline Parameter & $\mathrm{H}_{2} \mathrm{SO}_{4} \mathrm{wt} \%$ & $T / \mathrm{K}$ & Reference & Technique/Comments \\
\hline Uptake coefficients: $\gamma$ & & & & \\
$\gamma_{0}=0.008\left(85 \mathrm{wt}^{2} \mathrm{H}_{2} \mathrm{SO}_{4}\right)$ & & 200 & Zhang and Leu (1997) & WWFT-CIMS (a) \\
Solubility: $H^{*}\left(\mathrm{M} \mathrm{atm}^{-1}\right)$ & & & & \\
$6.47 \times 10^{4}$ & 46 & 199 & Zhang and Leu (1997) & WWFT-CIMS (a) \\
$5.54 \times$ & 46 & 216 & & \\
$2.0 \times 10^{4}$ & 54 & 208 & & \\
$8.75 \times 10^{2}$ & 54 & 226 & & \\
$2.42 \times 10^{4}$ & 59 & 208 & & \\
$4.01 \times 10^{3}$ & 59 & 216 & & \\
$5.58 \times 10^{4}$ & 72 & 208 & & \\
$3.31 \times 10^{3}$ & 72 & 222 & & \\
\hline
\end{tabular}

\section{Comments}

(a) PAN was observed to be reversibly taken up into sulphuric acid owing to its solubility. The quantity $H^{*}\left(D_{1}\right)^{0.5}$ was determined from the time-dependent uptake of PAN on sulphuric acid. The solubility constant $H^{*}$ was extracted using calculated diffusion coefficients based on the model developed by Luo et al. (1994) using the measured viscosities of $\mathrm{H}_{2} \mathrm{SO}_{4} / \mathrm{H}_{2} \mathrm{O}$ solution from Williams and Long (1995). The $H^{*}$ values were found to depend strongly on temperature and less strongly on acid composition (46-72 wt \%). For example, the effective $H^{*}$ at 208-222 $\mathrm{K}$ on $72 \mathrm{wt} \% \mathrm{H}_{2} \mathrm{SO}_{4}$ was approximately a factor of 2-3 higher than extrapolated from measurements at higher temperatures for more dilute solutions.

\section{Preferred values}

\begin{tabular}{lll}
\hline Parameter & Value & $T / \mathrm{K}$ \\
\hline$\alpha_{\mathrm{b}}$ & $>0.008$ & $190-230$ \\
$\Delta H / \mathrm{kJ} \mathrm{mol}^{-1}\left(46 \mathrm{wt} \mathrm{H}_{2} \mathrm{SO}_{4} \%\right)$ & 50.2 & $195-220$ \\
$\Delta / \mathrm{kJ} \mathrm{mol}^{-1}\left(72 \mathrm{wt} \% \mathrm{H}_{2} \mathrm{SO}_{4}\right)$ & 78.2 & $208-220$ \\
$\Delta S / \mathrm{J} \mathrm{mol}^{-1} \mathrm{~K}^{-1}\left(46 \mathrm{wt} \% \mathrm{H}_{2} \mathrm{SO}_{4}\right)$ & 160 & $195-220$ \\
$\Delta S / \mathrm{J} \mathrm{mol}^{-1} \mathrm{~K}^{-1}\left(72 \mathrm{wt} \% \mathrm{H}_{2} \mathrm{SO}_{4}\right)$ & 284 & $195-220$ \\
Reliability & & \\
$\Delta \log \alpha_{\mathrm{b}}$ & undetermined & \\
$\Delta \log H^{*}$ & \pm 0.3 & $15-220$ \\
\hline
\end{tabular}

\section{Comments on preferred values}

At $\mathrm{H}_{2} \mathrm{SO}_{4}$ concentrations lower than $72 \mathrm{wt} \%$ PAN uptake is reversible and solubility controls the amount taken up to the solution. The preferred values for the effective Henry's law solubility, $H^{*}$, are taken from the study by Zhang and Leu (1997), which are consistent with studies on water surfaces at higher temperatures (Kames and Schurath, 1995). The temperature dependence of $H^{*}$ for a given acid composition can be expressed as: $\ln H^{*}=-\Delta H / R T+\Delta S / R$. The values of the PAN solvation enthalpy and entropy $\Delta H$ and $\Delta S$ vary with acid composition in the range 46-72 wt \%. The values given in the table are for the lower and upper end of composition range and cover the range 200-222 K.

Measurement of accommodation coefficients in the time dependent regime leading to saturation is difficult as adsorption and desorption are not separated in time. The recommendation is based on the initial uptake coefficient reported by Zhang and Leu (1997) and is given a large uncertainty. 


\section{References}

Kames, J. and Schurath, U.: J. Atmos. Chem., 21, 151-164, 1995.

Luo, B. P., Clegg, S. L., Peter, T., Muller, R., and Crutzen, P. J.: Geophys. Res. Lett., 21, 49-52, doi:10.1029/93g102956, 1994. Williams, L. R. and Long, F. S.: J. Phys. Chem., 99, 3748-3751, 1995.

Zhang, R. and Leu, M. T.: J. Geophys. Res., 102, 8837-8843, 1997. 


\section{VI.A4.14}

$\mathrm{HCl}(\mathrm{g})+\mathrm{H}_{2} \mathrm{SO}_{4}(\mathrm{aq}) \rightarrow$ products

\section{Experimental data}

\begin{tabular}{|c|c|c|c|c|}
\hline Parameter & {$\left[\mathrm{H}_{2} \mathrm{SO}_{4}\right] / \mathrm{wt} \%$} & $T / \mathrm{K}$ & Reference & Technique/Comments \\
\hline \multicolumn{5}{|l|}{ Uptake coefficients: $\gamma$} \\
\hline$\gamma_{\mathrm{ss}}=1.5 \times 10^{-3}$ & 65 & 210 & Tolbert et al. (1988) & Kn-MS (a) \\
\hline$\gamma_{\mathrm{ss}}=2.6 \times 10^{-4}$ & 70 & 220 & & \\
\hline$\gamma_{\mathrm{ss}}>8.5 \times 10^{-5}$ & 70 & 230 & & \\
\hline$\gamma=(1.5 \pm 0.2) \times 10^{-1}$ & 20 & 283 & Watson et al. (1990) & DT-TDLAS (b) \\
\hline$\gamma=(1.6 \pm 0.3) \times 10^{-1}$ & 35 & & & \\
\hline$\gamma=(1.5 \pm 0.2) \times 10^{-1}$ & 40 & & & \\
\hline$\gamma=(1.0 \pm 0.1) \times 10^{-1}$ & 47 & & & \\
\hline$\gamma=(7.9 \pm 0.6) \times 10^{-2}$ & 52 & & & \\
\hline$\gamma=(4 \pm 6) \times 10^{-3}$ & 58 & & & \\
\hline$\gamma=(0 \pm 4) \times 10^{-3}$ & 73 & & & \\
\hline \multicolumn{5}{|l|}{ Accommodation coefficients: $\alpha_{\mathrm{b}}$} \\
\hline $0.8 \pm 0.2(\mathrm{HOCl}$ doped $)$ & 34 & 274 & Hanson and Lovejoy (1996) & RWFT-CIMS (c) \\
\hline $1.1 \pm 0.1$ & 39 & 230 & Robinson et al. (1998) & DT-TDLAS (d) \\
\hline $0.93 \pm 0.07$ & 39 & 240 & & \\
\hline $0.75 \pm 0.06$ & 39 & 252 & & \\
\hline $0.65 \pm 0.06$ & 39 & 261 & & \\
\hline $0.95 \pm 0.08$ & 49 & 233 & & \\
\hline $0.90 \pm 0.08$ & 49 & 244 & & \\
\hline $0.80 \pm 0.11$ & 49 & 254 & & \\
\hline $0.53 \pm 0.07$ & 49 & 261 & & \\
\hline $10^{-2}$ & $30-40$ & $185-207$ & Schwell et al. (2000) & EDB (e) \\
\hline$\alpha_{\mathrm{s}}>0.9$ & 70 & 213 & Morris et al. (2000) & $\mathrm{MB}(\mathrm{f})$ \\
\hline$\alpha_{\mathrm{b}} \approx 0.1$ & 70 & & & \\
\hline 0.75 & 53 & 213 & Behr et al. (2001) & $\mathrm{MB}(\mathrm{g})$ \\
\hline 0.52 & 60 & & & \\
\hline 0.27 & 65 & & & \\
\hline 0.12 & 69 & & & \\
\hline 0.1 & 70.5 & & & \\
\hline 0.66 & 58 & 213 & Behr et al. (2009) & MB (h) \\
\hline 0.50 & 63 & & & \\
\hline 0.28 & 67 & & & \\
\hline 0.25 & 74 & & & \\
\hline 0.33 & 72 & 213 & & \\
\hline 0.38 & 72 & 218 & & \\
\hline 0.42 & 72 & 223 & & \\
\hline 0.44 & 72 & 233 & & \\
\hline 0.47 & 72 & 238 & & \\
\hline \multicolumn{5}{|c|}{ Solubility: $\mathrm{H}\left(\mathrm{M} \mathrm{atm}^{-1}\right)$; Diffusion: $D_{1}\left(\mathrm{~cm}^{2} \mathrm{~s}^{-1}\right)$} \\
\hline$H^{*}=9.9 \times 10^{-13} \exp (9030 / T)$ & 50 & $220-230$ & Williams and Golden (1993) & Kn-MS (i) \\
\hline$H^{*}=3.0 \times 10^{-4} \exp (4150 / T)$ & 55 & $215-230$ & & \\
\hline$H^{*}=1.3 \times 10^{-5} \exp (4640 / T)$ & 60 & $200-230$ & & \\
\hline$H D_{1}^{l / 2}=3.6 \times 10^{-4} \exp (2060 / T)$ & 59.6 & $200-220$ & Hanson and Ravishankara (1993) & CWFT-CIMS (j) \\
\hline$H D_{1}^{l / 2}=1.1 \times 10^{-3} \exp (2070 / T)$ & 55.6 & $205-225$ & & \\
\hline$H D_{1}^{l / 2}=9.2 \times 10^{-4} \exp (2440 / T)$ & 50.5 & $200-230$ & & \\
\hline$H^{*}=2.7 \times 10^{-4} \exp (4910 / T)$ & 45 & $195-220$ & & \\
\hline$H^{*}=1.0 \times 10^{-4} \exp (5110 / T)$ & 45.3 & $195-220$ & & \\
\hline$H^{*}=2.6 \times 10^{-4} \exp (4650 / T)$ & 50 & $200-220$ & & \\
\hline$H^{*}=6.8 \times 10^{-6} \exp (5310 / T)$ & 51.1 & $200-220$ & & \\
\hline$H^{*}=1.2 \times 10^{-5} \exp (6100 / T)$ & 35 & $210-230$ & Zhang et al. (1993) & Static $(\mathrm{k})$ \\
\hline$H^{*}=6.5 \times 10^{-6} \exp (5880 / T)$ & 40 & $200-230$ & & \\
\hline$H^{*}=1.0 \times 10^{-6} \exp (5530 / T)$ & 50 & $195-230$ & & \\
\hline$H^{*}=4.2 \times 10^{-7} \exp (4920 / T)$ & 60 & $195-210$ & & \\
\hline$H^{*}=5.0 \times 10^{-4} \exp (5060 / T)$ & 43 & $205-225$ & Elrod et al. (1995) & Static (l) \\
\hline$H^{*}=1.2 \times 10^{-4} \exp (4940 / T)$ & 50 & $205-225$ & & \\
\hline$H^{*}=1.0 \times 10^{3}$ & 59.5 & 251 & Hanson and Lovejoy (1996) & RWFT-CIMS (c) \\
\hline$H^{*}=3.3 \times 10^{-5} \exp (5460 / T)$ & 45 & $205-225$ & Hanson (1998) & RWFT-CIMS (m) \\
\hline$H^{*}=6.9 \times 10^{-6} \exp (5450 / T)$ & 50 & & & \\
\hline$H D_{1}^{l / 2}=1.4 \times 10^{-6} \exp (4230 / T)$ & 49 & $230-260$ & Robinson et al. (1998) & DT-TDLAS (d) \\
\hline$H D_{1}^{i / 2}=9.8 \times 10^{-7} \exp (3900 / T)$ & 54 & $230-260$ & & \\
\hline$H D_{1}^{l / 2}=4.8 \times 10^{-5} \exp (2500 / T)$ & 59 & $235-265$ & & \\
\hline$H D_{1}^{l / 2}=7.9 \times 10^{-2}$ & 69 & 240 & & \\
\hline
\end{tabular}




\section{Comments}

(a) The bulk substrate $(1 \mathrm{~mL}$ to $5 \mathrm{~mL})$ was cooled slowly to temperatures of $210 \mathrm{~K}$ to $230 \mathrm{~K}$. The water vapour pressure was $5.3 \times 10^{-4}$ mbar. Measured uptake coefficients did not depend on the visible appearance of the sample (glassy or crystalline). At $230 \mathrm{~K}$, the measured uptake coefficient was diffusion limited; the larger value is therefore listed as lower limit. The recovery yield of $\mathrm{HCl}$ was at maximum $5 \%$ when the solution was warmed to $253 \mathrm{~K}$.

(b) Droplet diameters were between 110 and $280 \mu \mathrm{m}$. The $\mathrm{HCl}$ concentration (circa $10^{12}$ molecule $\mathrm{cm}^{-3}$ ) was measured downstream of the flow tube by tunable diode laser absorption. The uptake coefficients listed in the table were corrected by gas phase diffusion using $D_{\mathrm{HCl}-\mathrm{He}}=515$ torr $\mathrm{cm}^{2} \mathrm{~s}^{-1}$ and $D_{\mathrm{HCl}-\mathrm{H} 2 \mathrm{O}}=120$ torr $\mathrm{cm}^{2} \mathrm{~s}^{-1}$. The time dependent uptake coefficient was evaluated in terms of solubility driven uptake. $H^{*}$ was estimated by $H^{*}=H_{\mathrm{a}} /\left[\mathrm{H}^{+}\right]$at low $\mathrm{H}_{2} \mathrm{SO}_{4}$ concentrations and using the Hammett acidity concept to estimate the degree of dissociation of $\mathrm{HCl}^{\text {in }} \mathrm{high}$ wt $\% \mathrm{H}_{2} \mathrm{SO}_{4}$ solution. For the liquid phase diffusion coefficient, $10^{-5} \mathrm{~cm}^{2} \mathrm{~s}^{-1}$ was used.

(c) Uptake into a known amount of $\mathrm{H}_{2} \mathrm{SO}_{4}$ solution (around $1 \mathrm{~cm}^{3}$ ).

(d) Time dependent uptake coefficients were measured using droplet diameters between 120 and $250 \mu \mathrm{m}$. The $\mathrm{HCl}$ concentration of about $10^{12}$ molecule $\mathrm{cm}^{-3}$ was measured downstream of the flow tube by tunable diode laser absorption. The time dependent uptake coefficients were corrected for gas phase diffusion using $D_{\mathrm{HCl}-\mathrm{He}}=0.701 \mathrm{~atm} \mathrm{~cm}^{2} \mathrm{~s}^{-1}$, $D_{\mathrm{HCl}-\mathrm{Ar}}=0.157 \mathrm{~atm} \mathrm{~cm}^{2} \mathrm{~s}^{-1}$ and $D_{\mathrm{HCl}-\mathrm{H} 2 \mathrm{O}}=0.166 \mathrm{~atm} \mathrm{~cm}^{2} \mathrm{~s}^{-1}$. By varying the droplet size, the Knudsen number could be raised to 1 allowing determination of uptake coefficients in the range of 0.01 to 1 . The corrected uptake coefficients were evaluated in terms of solubility driven uptake to determine $H^{*} D_{1}^{1 / 2}$ and $\alpha_{\mathrm{b}}$.

(e) Uptake of $\mathrm{HCl}$ was monitored through the size changes of 30-70 $\mu \mathrm{m}$ diameter droplets held in an electrodynamic trap with $\mathrm{HCl}$ pressures at 0.01 to $0.1 \mathrm{mbar}$. The time dependent uptake was evaluated to obtain an independent measurement of the diffusion coefficient. For data in the phase transfer limited regime, $\alpha_{b}$ was estimated from the slope of a plot of the rate of uptake versus the $\mathrm{HCl}$ partial pressure. The authors indicated that the $\mathrm{HCl}$ pressure was not homogeneous throughout the chamber, so that the $\alpha_{\mathrm{b}}$ value reported is probably too low.

(f) Molecular beams produced from the expansion of $2 \% \mathrm{HCl}$ in $\mathrm{H}_{2}, 5 \% \mathrm{HCl}$ in $\mathrm{He}$ or $10 \% \mathrm{HCl}$ in $\mathrm{N}_{2}$. The substrate was $70 \% \mathrm{D}_{2} \mathrm{SO}_{4}$ at $213 \mathrm{~K}$. Scattered or desorbing molecules were detected with a mass spectrometer at an exit angle of $45^{\circ}$. At the lowest energy, the fraction of in-elastically scattered molecules was less than $10 \%$, from which we provide a lower bound to $\alpha_{\mathrm{s}}$ reported in the table. Only $11 \%$ of those molecules trapped on the surface undergo proton exchange in the bulk of $\mathrm{D}_{2} \mathrm{SO}_{4}$ leading to the value of $\alpha_{\mathrm{b}}$ listed in the table, if the proton exchange rate is limited by the solvation rate.

(g) Molecular beam experiment using the same setup as in Morris et al. (2000), but covering a broader range of $\mathrm{D}_{2} \mathrm{SO}_{4}$ concentration. Again, the measured fraction of $\mathrm{HCl}$ undergoing proton exchange to $\mathrm{DCl}$ is interpreted as $\alpha_{\mathrm{b}}$ assuming that $\alpha_{\mathrm{s}}$ is close to 1 , since inelastically scattered $\mathrm{HCl}$ molecules were not observed at low incident beam energies. The values given in the table were interpolated from the data provided as a plot only. A few experiments were also presented with DCl on $\mathrm{H}_{2} \mathrm{SO}_{4}$, showing about $20 \%$ higher values, tentatively interpreted as isotopic effects. Behr et al. (2001) also provide values for the solubility based on $\mathrm{HCl}$ residence time measurement that are in line with Carslaw et al. (1995) at low acid concentration but are higher above $65 \mathrm{wt} \%$.

(h) Molecular beam experiment comparable to the setup used by Morris et al. (2000).

(i) Time dependent $\mathrm{HCl}$ uptake coefficients measured in a Knudsen cell to derive values of $H^{*} D_{1}^{1 / 2}$. Values of $H^{*}$ were obtained by estimating the temperature dependent diffusion coefficient from the measured temperature dependence of the viscosity. Initial uptake coefficients were not reported. The expressions given in the table were obtained by fitting to the reported data.

(j) Time dependent $\mathrm{HCl}$ uptake coefficients measured in a cylindrical flow tube with $\mathrm{H}_{2} \mathrm{SO}_{4}$ contained in a boat were analysed to derive values of $H^{*} D_{1}^{1 / 2}$. Direct measurements of $H^{*}$ were done by static vapour pressure measurements. The parameters listed in the table were obtained by fitting to the tabulated datasets given by Hanson and Ravishankara (1993). Initial uptake coefficients were not reported.

(k) Static vapour pressure measurement using a mass spectrometer over a stirred $\mathrm{H}_{2} \mathrm{SO}_{4} / \mathrm{HCl} / \mathrm{H}_{2} \mathrm{O}$ solution $(0.01-5 \mathrm{wt} \%$ $\mathrm{HCl}$ ). The expression given in the table was obtained by fitting to the reported data.

(1) Vapour pressure measurement over ternary and quaternary solutions in a wetted wall flow tube. The expression given in the table was obtained by fitting to the reported data. 
(m) Vapour pressure measurement over $\mathrm{H}_{2} \mathrm{SO}_{4}$ solutions in a rotating wetted wall flow tube coupled to a CIMS. $\mathrm{HCl}$ was added to the solution at $10^{-2}$ to $10^{-3} \mathrm{M}$. Linearity between $\mathrm{HCl}$ concentration and flow rate was checked to assure equilibrated conditions. The expression in the table is obtained from a fit to the data as reported. The value of $H^{*}$ reported in Table 1 of Hanson (1998) for the $50 \mathrm{wt} \%$ solution $\left(1.36 \times 10^{7}\right)$ was corrected to $1.36 \times 10^{6}$ to be consistent with the value plotted in the figure. Hanson (1998) also reanalysed data from Hanson and Ravishankara (1993) to take into account proper handling of the $\mathrm{SF}_{6}^{-}$signal during CIMS calibration and a $\mathrm{HCl}$ background signal from memory effects on tubing downstream of the flow tube, which resulted in fair agreement with the newer measurements.

\section{Preferred values}

\begin{tabular}{lll}
\hline Parameter & Value & $T / \mathrm{K}$ \\
\hline$\alpha_{\mathrm{s}}$ & $>0.9$ & $213-238$ \\
$k_{\mathrm{sol}}\left(\mathrm{s}^{-1}\right)$ & $7.84 \times 10^{10} / \eta(\mathrm{cP})$ & $190-300$ \\
$k_{\mathrm{des}}\left(\mathrm{s}^{-1}\right)$ & $8.0 \times 10^{17} \mathrm{exp}(-5000 / T)$ & $190-300$ \\
$H^{*}\left(\mathrm{M} \mathrm{atm}^{-1}\right)$ & $\left(0.094-0.61 \mathrm{X}+1.2 \mathrm{X}^{2}\right) \exp \left(-8.68+\left(8515-10718 \mathrm{X}^{0.7}\right) / T\right)$ & $190-300$ \\
$c\left(\mathrm{~cm}^{2} \mathrm{cP} \mathrm{K}^{-1} \mathrm{~s}^{-1}\right)$ & $7.8 \times 10^{-8}$ & $190-300$ \\
$A\left(\mathrm{M} \mathrm{atm}^{-1} \mathrm{~K}^{1.43}\right)$ & $169.5+5.18(\mathrm{wt} \%)-0.0825(\mathrm{wt} \%)^{2}+3.27 \times 10^{-3}(\mathrm{wt} \%)^{3}$ & $190-300$ \\
$T_{0}(\mathrm{~K})$ & $144.11+0.166(\mathrm{wt} \%)-0.015(\mathrm{wt} \%)^{2}+2.18 \times 10^{-4}(\mathrm{wt} \%)^{3}$ & $190-300$ \\
Reliability & & \\
$\Delta \log \left(\alpha_{\mathrm{s}}\right)$ & \pm 0.3 & $213-238$ \\
$\Delta \log \left(k_{\mathrm{sol}}\right)$ & \pm 0.3 & $190-300$ \\
$\Delta \log \left(k_{\mathrm{des}}\right)$ & \pm 0.3 & $190-300$ \\
$\Delta \log \left(H^{*}\right)$ & \pm 0.3 & $190-300$ \\
\hline
\end{tabular}

\section{Comments on preferred values}

Uptake of $\mathrm{HCl}$ into $\mathrm{H}_{2} \mathrm{SO}_{4}$ solutions is fast. The molecular beam experiments provide the most direct measurement of the initial steps of $\mathrm{HCl}$ uptake. At low (close to thermal) incident beam energies, nearly all $\mathrm{HCl}$ molecules are thermally accommodated on the surface, evident from the absence of inelastically scattered molecules, leading to the recommended high value for $\alpha_{\mathrm{s}}$. The fraction of $\mathrm{HCl}$ molecules that actually undergo exchange with the bulk liquid phase can be tracked by observing proton exchanged $\mathrm{DCl}$ molecules desorbing from the surface. Assuming that solvation of $\mathrm{HCl}$ is the rate limiting step, this fraction is used to obtain the bulk accommodation coefficient $\alpha_{\mathrm{b}}$ (Behr et al., 2009).

The kinetic data by Watson et al. (1990) did not allow to clearly differentiate the contributions by bulk accommodation and solubility. Robinson et al. (1998) provided a more reliable data set at lower temperature using the droplet train technique that involved sufficiently high Knudsen number conditions to extract large bulk accommodation coefficients. The Robinson et al. and Behr et al. data sets agree in that $\alpha_{\mathrm{b}}$ is large $(>0.6)$ up to moderate sulphuric acid contents. However, the temperature dependence observed is negative for the 39 and $48 \mathrm{wt} \%$ solutions above $230 \mathrm{~K}$ for the Robinson et al. data and positive for the $72 \mathrm{wt} \%$ solution below $240 \mathrm{~K}$ as obtained by Behr et al. Robinson et al. interpret their negative $T$ dependence as driven by the Gibbs free energy of the transition state at the surface. This would be inconsistent with the high single value measured by Hanson and Lovejoy (1996) at $274 \mathrm{~K}$ on a $34 \mathrm{wt} \%$ solution. Behr et al. (2009) use capillary wave theory to explain the strong negative correlation of $\alpha_{\mathrm{b}}$ with viscosity (determining $k_{\mathrm{sol}}$ ). Our recommendation follows the suggestion by Behr et al. (2009) for $k_{\text {sol }}$. We use an Arrhenius expression for $k_{\text {des }}$ with an activation energy in between that of Behr et al. and Robinson et al. Using

$\alpha_{\mathrm{b}}=k_{\mathrm{sol}} /\left(k_{\mathrm{des}}+k_{\mathrm{sol}}\right)$

this leads to reasonable agreement with the data sets considered. It follows the strong negative dependence on sulphuric acid content at low $T$, whereby we prefer the newer Behr et al. (2009) data with respect to the absolute value while still aligning it parallel to the concentration dependence of the earlier data. The recommended parameterization resolves the apparent inconsistency of positive temperature dependence at low temperature and high sulphuric acid concentration and negative temperature dependence for the more dilute solutions.

In the absence of a reactive sink in the aqueous phase, uptake is driven by solubility, characterized by the effective Henry's law constant $H^{*}$ and the diffusion coefficient, $D_{1}$.

The more reliable solubility values are derived from experiments, in which the solubility was directly measured: Elrod et al. (1995), Hanson (1998) and the one data point by Hanson and Lovejoy (1996). The Zhang et al. (1993) data are likely too 
low due to $\mathrm{HCl}$ calibration issues as noted by Elrod et al. Many kinetic experiments were analysed in terms of solubility limited uptake to obtain $H^{*} D^{1 / 2}$. This requires estimating diffusion coefficients to obtain $H^{*}$, which in turn are parameterized in terms of the viscosity. We recommend using the parameterization presented by Shi et al. (2001), which fits well to data by Williams and Long (1995) but extends into tropospherically more relevant dilute solutions at high $T$ :

$\eta=A T^{-1.43} \exp \left(448 K /\left(T-T_{0}\right)\right)$

The temperature and concentration dependent diffusion coefficient can then be obtained by the Stokes-Einstein equation

$D_{1}=c T / \eta$

The diffusion coefficients of $\mathrm{HCl}$ thus obtained are in reasonable agreement with data obtained by Klassen et al. (1998), but in some disagreement with measurements at $T<190 \mathrm{~K}$ by Schwell et al. (2000), though at only two acid concentrations. Schwell et al. argue that the Stokes Einstein approach used by Klassen et al. may understimate the diffusion coefficient at temperatures below $200 \mathrm{~K}$.

This procedure to obtain $H^{*}$ from the measured $H D^{1 / 2}$ values leads to fair agreement with the directly measured $H^{*}$ values and aligns the higher temperature droplet train experiments by Robinson et al. (1998) to those at lower $T$.

We recommend the mole fraction based expression by Shi et al. (2001) for $H^{*}$ over $190-300 \mathrm{~K}$ for up to $70 \mathrm{wt} \%$ solutions $(X=w t /(w t+(100-w t) 98 / 18))$ noting the potential formation of $\mathrm{HSO}_{3} \mathrm{Cl}$ as suggested by Robinson et al. (1998) to explain the higher $H^{*}$ at $>70 \mathrm{wt} \%$ solution. Shi's parameterization builds upon the thermodynamic models of Carslaw et al. (1995) and Luo et al. (1995) and uses an expression modified from that used by Hanson (1998).

\section{References}

Behr, P., Morris, J. R., Antman, M. D., Ringeisen, B. R., Splan, J. R., and Nathanson, G. M.: Geophys. Res. Lett., 28, 19611964, 2001.

Behr, P., Scharfenort, U., Ataya, K., and Zellner, R.: Phys. Chem. Chem. Phys., 11, 8048-8055, doi:10.1039/b904629a, 2009.

Carslaw, K. S., Clegg, S. L., and Brimblecombe, P.: J. Phys. Chem., 99, 11557-11574, 1995.

Eicher, L. D. and Zwolinski, B. J.: J. Phys. Chem., 75, 2016-2024, 1971.

Elrod, M. J., Koch, R. E., Kim, J. E., and Molina, M. J.: Faraday Discuss., 100, 269-278, 1995.

Hanson, D. R. and Lovejoy, E. R.: J. Phys. Chem., 100, 6397-6405, 1996.

Hanson, D. R. and Ravishankara, A. R.: J. Phys. Chem., 97, 12309-12319, 1993.

Hanson, D. R.: J. Phys. Chem. A, 102, 4794-4807, 1998.

Hayduk, W. and Minhas, B. S.: Can. J. Chem. Eng., 60, 295-299, 1982.

Klassen, J. K., Hu, Z., and Williams, L. R.: J. Geophys. Res., 103, 16197-16202, 1998.

Luo, B. P., Carslaw, K. S., Peter, T., and Clegg, S. L.: Geophys. Res. Lett., 22, 247-250, 1995.

Morris, J. R., Behr, P., Antman, M. D., Ringeisen, B. R., Splan, J., and Nathanson, G. M.: J. Phys. Chem. A, 104, 6738-6751, 2000.

Robinson, G. N., Worsnop, D. R., Jayne, J. T., Kolb, C. E., Swartz, E., and Davidovits, P.: J. Geophys. Res., 103, 25371-25381, 1998.

Schwell, M., Baumgärtel, H., Weidinger, I., Kramer, B., Vortisch, H., Wöste, L., Leisner, T., and Rühl, E.: J. Phys. Chem. A, 104, 6726-6732, 2000.

Shi, Q., Jayne, J. T., Kolb, C. E., Worsnop, D. R., and Davidovits, P.: J. Geophys. Res., 106, 24259-24274, 2001.

Tolbert, M. A., Rossi, M. J., and Golden, D. M.: Geophys. Res. Lett., 15, 847-850, 1988.

Watson, L. R., Vandoren, J. M., Davidovits, P., Worsnop, D. R., Zahniser, M. S., and Kolb, C. E.: J. Geophys. Res., 95, 56315638, 1990.

Williams, L. R. and Golden, D. M.: Geophys. Res. Lett., 20, 2227-2230, 1993.

Williams, L. R. and Long, F. S.: J. Phys. Chem., 99, 3748-3751, 1995.

Zhang, R. Y., Wooldridge, P. J., and Molina, M. J.: J. Phys. Chem., 97, 8541-8548, 1993. 
VI.A4.15

$\mathrm{ClO}(\mathrm{g})+\mathrm{H}_{2} \mathrm{SO}_{4}(\mathrm{aq}) \rightarrow$ products

Experimental data

\begin{tabular}{lllll}
\hline Parameter & {$\left[\mathrm{H}_{2} \mathrm{SO}_{4}\right] / \mathrm{wt} \%$} & $T / \mathrm{K}$ & Reference & Technique/Comments \\
\hline Uptake coefficients: $\gamma$ & & & & \\
$(2.0 \pm 1) \times 10^{-5}$ & 90 & 295 & Martin et al. (1980) & CWFT-EPR (a) \\
$(1.5 \pm 1) \times 10^{-4}$ & 85 & 260 & & \\
$(2.2 \pm 1) \times 10^{-4}$ & 80 & 240 & & \\
$<1.0 \times 10^{-4}$ & $60-70$ & 213 & Abbatt (1996) & CWFT-RF (b) \\
\hline
\end{tabular}

\section{Comments}

(a) Measurement of the uptake kinetics in a fast flow tube with EPR detection of $\mathrm{ClO}$. Pure $\mathrm{Cl}_{2}$ at 0.67 mbar was discharged in a $\mu$-wave cavity and combined downstream with an excess of $\mathrm{O}_{3}$ in order to generate $\mathrm{ClO}$. The quartz flow tube was coated with halocarbon wax and the discharge tube with solid $\mathrm{B}_{2} \mathrm{O}_{3}$ in order to minimize wall losses of $\mathrm{ClO}$. The inside of the flow tube was coated with $\mathrm{H}_{2} \mathrm{SO}_{4}$ and the $\mathrm{H}_{2} \mathrm{O}$ vapor pressure was held constant throughout the temperature range at $6.7 \times 10^{-4}$ mbar leading to a changing composition of the $\mathrm{H}_{2} \mathrm{SO}_{4} / \mathrm{H}_{2} \mathrm{O}$ mixture as the temperature was changed $(96 \%$ at $300 \mathrm{~K}, 80 \%$ at $240 \mathrm{~K}$.

(b) Uptake rates in a coated wall flow tube at 1.3 mbar total pressure of He coupled to a resonance fluorescence (RF) detector after chemical conversion. $\mathrm{ClO}$ was generated from the reaction $\mathrm{Cl}+\mathrm{O}_{3} \rightarrow \mathrm{ClO}+\mathrm{O}_{2}$ by discharging $\mathrm{Cl}_{2} / \mathrm{He}$ in a microwave cavity and adding $\mathrm{O}_{3}$ downstream at typical $\left[\mathrm{O}_{3}\right]$ in the range from 1 to $3 \times 10^{13}$ molecule cm${ }^{-3}$. After $\mathrm{ClO}$ interacted with the active surface it was converted to $\mathrm{Cl}$ in the reaction $\mathrm{ClO}+\mathrm{NO} \rightarrow \mathrm{Cl}+\mathrm{NO}_{2}$ which was detected using a RF-excited $\mathrm{Cl}_{2} / \mathrm{He}$ lamp emitting in the VUV at $119 \mathrm{~nm}$ in conjunction with a flowing $\mathrm{O}_{2}$ filter. The sensitivity of the $\mathrm{RF}$ lamp was measured using the reaction $\mathrm{H}+\mathrm{Cl}_{2} \rightarrow \mathrm{HCl}+\mathrm{Cl}$. The $\mathrm{ClO}$ concentrations used in this work were on the order of 1 to $2 \times 10^{11}$ molecule $\mathrm{cm}^{-3}$.

\section{Preferred values}

No recommendation.

\section{Comments on preferred values}

In the work of Martin et al. (1980) no separation between the effects of changing composition of the $\mathrm{H}_{2} \mathrm{SO}_{4}$ solution (considered to be negligible) and the temperature dependence of $\gamma$ was performed. All kinetic results were obtained from the full numerical integration of the parabolic flow system including axial diffusion and resulted in a pronounced negative temperature dependence of the uptake coefficient $\gamma_{\mathrm{ss}}$. Martin et al. observed $\mathrm{HCl}$ as product of the heterogeneous reaction. No effect of irradiation by simulated sunlight on $\gamma$ was found within a $\pm 20 \%$ variation of $\gamma$. Martin et al. (1980) report a higher sensitivity for ClO-detection compared to Abbatt (1996). In the light of the disagreement between the two datasets we make no recommendations, but note that uptake of $\mathrm{ClO}$ to $\mathrm{H}_{2} \mathrm{SO}_{4}$ at stratospheric temperatures and composition is inefficient.

\section{References}

Martin, L. R., Judeikis, H. S., and Wun, M.: J. Geophys. Res., 85, 5511-5518, 1980.

Abbatt, J. P. D.: Geophys. Res. Lett., 23, 1681-1684, 1996. 
VI.A4.16

$\mathrm{HOBr}(\mathrm{g})+\mathrm{H}_{2} \mathrm{SO}_{4}(\mathrm{aq}) \rightarrow$ products

Experimental data

\begin{tabular}{llll}
\hline Parameter & $T / \mathrm{K}$ & Reference & Technique/Comments \\
\hline $\begin{array}{l}\text { Uptake coefficients: } \gamma \\
>0.06\left(60 \mathrm{wt} \% \mathrm{H}_{2} \mathrm{SO}_{4}\right)\end{array}$ & 228 & Abbatt (1994) & CWFT-MS (a) \\
$\begin{array}{l}\text { Solubility: } \mathrm{H}\left(\mathrm{M} \mathrm{atm}^{-1}\right) \\
3.8 \times 10^{5}(69.8 \mathrm{wt} \%)\end{array}$ & 212 & Abbatt (1995) & CWFT-MS (b) \\
$9.0 \times 10^{4}(69.8 \mathrm{wt} \%)$ & 228 & & \\
$\approx 1 \times 10^{6}\left(60 \mathrm{wt} \% \mathrm{H}_{2} \mathrm{SO}_{4}\right)$ & 210 & Hanson and Ravishankara (1995) & CWFT-CIMS (c) \\
$4.6 \times 10^{-4} \mathrm{exp}[(4500 \pm 480) / T]$ & $213-238$ & Waschewsky and Abbatt (1999) & CWFT-MS (d) \\
$1.4 \times 10^{5}(58-69 \mathrm{wt} \%)$ & 250 & Hanson (2003) & CWFT-CIMS (e) \\
$\approx 4 \times 10^{4}$ & 260 & & \\
$\approx 2.5 \times 10^{4}$ & 270 & & \\
\hline
\end{tabular}

\section{Comments}

(a) $\mathrm{HOBr}\left((0.5-5) \times 10^{12}\right.$ molecule $\left.\mathrm{cm}^{-3}\right)$ was generated by the reaction sequence: $\mathrm{H}+\mathrm{NO}_{2} \rightarrow \mathrm{OH}+\mathrm{NO}$ and $\mathrm{OH}+\mathrm{Br}_{2} \rightarrow \mathrm{HOBr}$, ionised by electron impact and detected as $\mathrm{HOBr}^{+}$. The carrier gas flow was humidified to maintain the $\mathrm{H}_{2} \mathrm{SO}_{4}$ concentration.

(b) $\mathrm{HOBr}\left(<1 \times 10^{12}\right.$ molecule $\left.\mathrm{cm}^{-3}\right)$ was generated by the reaction sequence: $\mathrm{H}+\mathrm{NO}_{2} \rightarrow \mathrm{OH}+\mathrm{NO}$ and $\mathrm{OH}+\mathrm{Br} 2 \rightarrow \mathrm{HOBr}$, ionised by electron impact and detected as $\mathrm{HOBr}^{+}$. The carrier gas flow was humidified to maintain the $\mathrm{H}_{2} \mathrm{SO}_{4}$ concentration $(69.8 \mathrm{wt} \%)$. Some evidence was found for a second-order component of $\mathrm{HOBr}$ loss due to self reaction. Values of $H D_{1}^{1 / 2}=(30 \pm 15)$ and $(20 \pm 10) \mathrm{M} \mathrm{atm}^{-1} \mathrm{~cm} \mathrm{~s}^{-1 / 2}$ were obtained at 212 and 228, respectively and converted to the values listed in the table using diffusion coefficients calculated as described by Klassen et al. (1998).

(c) $\mathrm{HOBr}$ detected using $\mathrm{SF}_{6}^{-}$chemi-ions. The evolution of the $\mathrm{HOBr}$ signal following uptake of $\mathrm{BrONO}_{2}((1-$ 4) $\times 10^{-7}$ mbar) to the $\mathrm{H}_{2} \mathrm{SO}_{4}$ surface was analysed to derive time dependent uptake coefficients and solubility. A value of $H D_{1}^{1 / 2}$ of $110( \pm 40) \mathrm{M} \mathrm{atm}^{-1} \mathrm{~cm} \mathrm{~s}^{-1 / 2}$ was converted to the solubility listed in the table using $D_{1} \approx 10^{-8} \mathrm{~cm}^{2} \mathrm{~s}^{-1}$.

(d) $\operatorname{HOBr}\left(\approx 5 \times 10^{-10} \mathrm{~atm}\right.$, measured by UV absorption at $\left.254 \mathrm{~nm}\right)$ was generated ex-situ by passing a humidified flow of $\mathrm{Br}_{2}$ in $\mathrm{He}$ over $\mathrm{HgO}$, ionised by electron impact and detected as $\mathrm{HOBr}^{+}$. The carrier gas flow was humidified to maintain the $\mathrm{H}_{2} \mathrm{SO}_{4}$ concentration. The time dependent $\mathrm{HOBr}$ signal was used to derive values of $H D_{1}^{1 / 2}$ at different temperatures and $\mathrm{H}_{2} \mathrm{SO}_{4}$ concentrations (59.7-70.1 wt \%). The uptake to fresh $\mathrm{H}_{2} \mathrm{SO}_{4}$ surfaces was found to be as much as a factor of two larger than to surfaces previously exposed to $\mathrm{HOBr}$. Only data from fresh surfaces is reported. Values of $H D_{1}^{1 / 2}$ were converted to $H_{\mathrm{HOBr}}$ using diffusion coefficients calculated as described by Klassen et al. (1998). The temperature dependence of the solubility yields a heat of dissolution of $-38( \pm 4) \mathrm{kJ} \mathrm{mol}^{-1}$.

(e) Rotating CWFT with stirring of the $\mathrm{H}_{2} \mathrm{SO}_{4}$ film (58-70 wt \%). $\mathrm{HOBr}$ (typically $10^{-10} \mathrm{~atm}$ ) was generated by reacting $\mathrm{BrONO}_{2}$ with water and detected using $\mathrm{SF}_{6}^{-}$chemi-ions. $H_{\mathrm{HOBr}}$ was determined by measuring the equibrium amount of $\mathrm{HOBr}$ taken up to a known volume of $\mathrm{H}_{2} \mathrm{SO}_{4}$. Correction was applied to take into account the uptake of e.g. $\mathrm{Br}_{2} \mathrm{O}$ with the total error assigned as $50 \%$. The temperature dependence of the solubility yields a heat of dissolution of $-52( \pm 15) \mathrm{kJ} \mathrm{mol}^{-1}$. Values of $H_{\mathrm{HOBr}}$ at tempertaures other than $250 \mathrm{~K}$ were not listed and no parameterisation was given, hence the values in the table at 260 and $270 \mathrm{~K}$ were taken from a plot and are approximate.

\section{Preferred values}

\begin{tabular}{lll}
\hline Parameter & Value & $T / \mathrm{K}$ \\
\hline$H_{\mathrm{HOBr}}$ & $5.22 \times 10^{-5} \exp (5427 / T)$ & $210-270$ \\
Reliability & & $210-270$ \\
$\Delta \log H_{\mathrm{HOBr}}$ & \pm 0.5 & 20 \\
\hline
\end{tabular}




\section{Comments on preferred value}

At low HOBr concentrations its uptake is time dependent and reversible (Waschewsky and Abbatt, 1999; Hanson, 2003) so that a net uptake coefficient is insufficient to describe the interaction, which is driven by solubility and liquid phase diffusion. Waschewsky and Abbatt (1999) suggest that the previous observation (Abbatt, 1995) of irreversible loss of $\mathrm{HOBr}$ to a $\mathrm{H}_{2} \mathrm{SO}_{4}$ surface was due to self-reaction caused by high [HOBr]. Waschewsky and Abbatt (1999) and Hanson (2003) found no significant variation of $\mathrm{H}_{\mathrm{HOBr}}$ with $\mathrm{H}_{2} \mathrm{SO}_{4}$ concentration at any given temperature, potentially a result of protonation which may increase the effective solubility at high $\mathrm{H}_{2} \mathrm{SO}_{4} \mathrm{wt} \%$ and compensate the expected decrease in physical solubility.

The data of Waschewsky and Abbatt (1999) and Hanson (2003) were obtained in different temperature regimes and extrapolated data are in poor agreement with much larger values (at some temperatures by a factor of $>10$ ) obtained by Hanson (2003). Hanson (2003) presents arguments that larger values of $H_{\mathrm{HOBr}}$ are more compatible with measurements of the rate coefficient for reaction of $\mathrm{HOBr}$ with $\mathrm{HCl}$ in $\mathrm{H}_{2} \mathrm{SO}_{4}$, which otherwise would exceed the diffusion limit. In addition, he argues that the use of time dependent uptake coefficients to derive $H_{\mathrm{HOBr}}$ is more prone to systematic error than measurements in an equilibrated solution that also do not require estimates of $D_{1}$. Following Hanson (2003), our preferred value for $H_{\mathrm{HOBr}}$ uses an average heat of solvation from Waschewsky and Abbatt (1999) and Hanson (2003), and the value of $H_{\mathrm{HOBr}}$ at $250 \mathrm{~K}$ derived by Hanson (2003).

\section{References}

Abbatt, J. P. D.: Geophys. Res. Lett., 21, 665-668, 1994.

Abbatt, J. P. D.: J. Geophys. Res., 100, 14009-14017, 1995.

Hanson, D. R.: J. Geophys. Res., 108, art. no. 4239, doi:10.1029/2002JD002519, 2003.

Hanson, D. R. and Ravishankara, A. R.: Geophys. Res. Lett., 22, 385-388, 1995.

Klassen, J. K., Hu, Z., and Williams, L. R.: J. Geophys. Res., 103, 16197-16202, 1998.

Waschewsky, G. C. G. and Abbatt, J. P. D.: J. Phys. Chem. A, 103, 5312-5320, 1999. 


\section{VI.A4.17}

$\mathrm{HBr}(\mathrm{g})+\mathrm{H}_{2} \mathrm{SO}_{4}(\mathrm{aq}) \rightarrow$ products

\section{Experimental data}

\begin{tabular}{lllll}
\hline Parameter & {$\left[\mathrm{H}_{2} \mathrm{SO}_{4}\right] / \mathrm{wt} \%$} & $T / \mathrm{K}$ & Reference & Technique/Comments \\
\hline Solubility: $H^{*}\left(\mathrm{M} \mathrm{atm}^{-1}\right)$ & & & & \\
$\log \left(H^{*}\right)=2680 / T-5.00$ & 54 & $200-240$ & Williams et al. (1995) & Knudsen-MS (a) \\
$\log \left(H^{*}\right)=2480 / T-4.93$ & 60 & & & \\
$\log \left(H^{*}\right)=2680 / T-4.87$ & 66 & & & \\
$\log \left(H^{*}\right)=2680 / T-4.80$ & 72 & 210 & Abbatt (1995) & CWFT-MS (b) \\
$5.95 \times 10^{6}$ & 59.6 & $218-298$ & Abbatt and Nowak (1997) & CWFT-MS (c) \\
$\log \left(H^{*}\right)=2900 / T-3.8$ & 40.3 & & & \\
$\log \left(H^{*}\right)=2800 / T-4.9$ & 48.8 & & & \\
$\log \left(H^{*}\right)=2400 / T-4.5$ & 59.6 & & & \\
$\log \left(H^{*}\right)=2400 / T-4.9$ & 50.5 & & & \\
$\log \left(H^{*}\right)=2500 / T-5.8$ & 64.4 & $195-250$ & Kleffmann et al. (2000) & (d) \\
$\log \left(H^{*}\right)=2200 / T-5.8$ & 69.8 & & & \\
$\operatorname{see}$ comment and preferred values & & $220-300$ & Klassen et al. (1998) & (e) \\
Diffusion coefficient: $D_{1}\left(\mathrm{~cm}^{2} \mathrm{~s}^{-1}\right)$ & & & & \\
$7.9 \times 10^{-8} T / \eta$ & $30-72$ & & &
\end{tabular}

\section{Comments}

(a) Values of $H D^{0.5}$ were extracted from time dependent $\mathrm{HBr}$ uptake to $\mathrm{H}_{2} \mathrm{SO}_{4}$ films of 59.8, 66.1 and $71.9 \mathrm{wt} \%$ and at temperatures between 200 and $240 \mathrm{~K}$. Values of $H D^{0.5}$ were converted to solubilities using diffusion coefficients calculated using $D=c T / \eta$ where $\eta$ is the viscosity of $\mathrm{H}_{2} \mathrm{SO}_{4}$ (taken from Williams and Long, 1995) and $c$ was estimated to be $1 \times 10^{-7} \mathrm{~cm}^{2} \mathrm{cP} \mathrm{s}^{-1} \mathrm{~K}^{-1}$. This value of $c$ compared well to later measured values (Klassen et al., 1998). Experiments were also conducted by measuring the vapour pressure of $\mathrm{HBr}$ above its solution (at known concentration) in $\mathrm{H}_{2} \mathrm{SO}_{4}$ at 54, 60 and $66 \mathrm{wt} \%$ in concentration.

(b) Values of $H D^{0.5}$ were extracted from time dependent $\mathrm{HBr}$ uptake to $\mathrm{H}_{2} \mathrm{SO}_{4}$ films of 59.6, 64.4 and 69.8 wt \% and at temperatures between 233 and $200 \mathrm{~K}$. $H$ was extracted using diffusion coefficients for $\mathrm{HBr}$ in $\mathrm{H}_{2} \mathrm{SO}_{4}$ as described by Williams et al. (1995) (see comment (a)). Only the result for $H D^{0.5}$ at $210 \mathrm{~K}(59.6 \mathrm{wt} \%)$ was listed though data were obtained over the temperature and concentration range indicated. The solubility listed was calculated using temperate and concentration dependent diffusion coefficients of Klassen et al. (1998).

(c) Equilibrium concentrations of $\mathrm{HBr}$ were measured above cold, $\mathrm{HBr}$-containing $\mathrm{H}_{2} \mathrm{SO}_{4}$ samples of known $\mathrm{HBr}$ concentration composition and wt \% (40.3-60.5\%). Solubility data at room temperature were obtained by bubbling $\mathrm{N}_{2}$ through a $\mathrm{HBr} / \mathrm{H}_{2} \mathrm{SO}_{4}$ solution of known composition and analysing the $\mathrm{HBr}$ mole fraction in the gas by re-dissolution in $\mathrm{H}_{2} \mathrm{O}$ with electrical conductivity measurement of ion concentrations. The data listed also contain a parameterisation of measurements (at 59.6, 64.4 and 69.8 wt \%) reported in Abbatt (1995), and described in comment (b).

(d) Head space above stirred, bulk solutions of known composition was analysed by tuneable diode laser absorption spectroscopy of $\mathrm{HBr}$. $\mathrm{H}_{2} \mathrm{SO}_{4}$ solutions of $53-75 \mathrm{wt} \%$ were used.

(e) Modified diaphragm cell method. The value of the parameter $c$ in the Stokes-Einstein expression for the diffusion coefficient, $D=c T / \eta$, was independent of the $\mathrm{H}_{2} \mathrm{SO}_{4}$ concentration and agrees well (within 5\%) with calculations using the Wilke and Chang (1955) expression. 


\section{Preferred values}

\begin{tabular}{lll}
\hline Parameter & Value & $T / \mathrm{K}$ \\
\hline$m_{1}\left(\mathrm{wt} \%^{-2} \mathrm{~K}\right)$ & $-1.977 \times 10^{-4}$ & \\
$m_{2}\left(\mathrm{wt} \%^{-1} \mathrm{~K}\right)$ & $-2.096 \times 10^{-2}$ & \\
$m_{3}(\mathrm{~K})$ & 4.445 & \\
$b_{1}\left(\mathrm{wt} \%^{-2}\right)$ & $-8.979 \times 10^{-5}$ & \\
$b_{2}\left(\mathrm{wt} \%^{-1}\right)$ & $2.141 \times 10^{-2}$ & \\
$b_{3}$ & -6.067 & \\
$c\left(\mathrm{~cm}^{2} \mathrm{cP} \mathrm{K}^{-1} \mathrm{~s}^{-1}\right)$ & $7.9 \times 10^{-8}$ & \\
$A$ & $169.5+5.18 w t-0.0825 w t^{2}$ & \\
& $+3.27 \times 10^{-3} w t^{3}$ & \\
$T_{0}$ & $144.11+0.166 w t-0.015 w t^{2}$ & \\
& $+2.18 \times 10^{-4} w t^{3}$ & \\
Reliability & & \\
$\Delta \log H^{*}$ & \pm 0.3 \\
\hline
\end{tabular}

\section{Comments on preferred value}

The available data on the interaction of $\mathrm{HBr}$ with $\mathrm{H}_{2} \mathrm{SO}_{4}$ solutions indicates very high solubility, especially in dilute solutions and at low temperatures. Efficient dissociation of $\mathrm{HBr}$ in $\mathrm{H}_{2} \mathrm{SO}_{4}$ implies that the solubilities are effective $\left(H^{*}\right)$. Data have been obtained using static or stirred samples with head-space analysis or using time dependent uptake coefficients in combination with diffusion coefficients of $\mathrm{HBr}$ in $\mathrm{H}_{2} \mathrm{SO}_{4}$. Most authors estimate the overall uncertainty as being better than a factor of two, which is borne out by the reasonable agreement from group to group. Kleffmann et al. (2000) have analysed the experimental datasets to produce a $\mathrm{H}_{2} \mathrm{SO}_{4}$ concentration and temperature dependent parameterisation of $\mathrm{HBr}$ effective solubility. This is adopted in our table of preferred values in which:

$\log _{10} H^{*}=1000 \mathrm{~m} / T+b$ where

$m=m_{1}\left[\mathrm{H}_{2} \mathrm{SO}_{4}\right]^{2}+m_{2}\left[\mathrm{H}_{2} \mathrm{SO}_{4}\right]+m_{3}$ and $b=b_{1}\left[\mathrm{H}_{2} \mathrm{SO}_{4}\right]^{2}+b_{2}\left[\mathrm{H}_{2} \mathrm{SO}_{4}\right]+b_{3}$

and the $\mathrm{H}_{2} \mathrm{SO}_{4}$ concentration $\left[\mathrm{H}_{2} \mathrm{SO}_{4}\right]$ is in wt \%

Note that the experimentally derived solubilities are factors of 2-6 lower than those calculated using activity coefficients (Luo et al., 1995).

Klassen et al. (1998) have parameterised the diffusion coefficient for $\mathrm{HBr}$ in $\mathrm{H}_{2} \mathrm{SO}_{4}$ as:

$D_{1}=c T / \eta$

where $c$ is a constant $\left(\mathrm{cm}^{2} \mathrm{cP} \mathrm{K}^{-1} \mathrm{~s}^{-1}\right)$ and $\eta$ is the viscosity of $\mathrm{H}_{2} \mathrm{SO}_{4}$ at a given wt $\%$ and temperature. Shi et al. (2001), have taken viscosity data from Williams and Long (1995) and for pure water to derive an extended formulation to cover $\mathrm{H}_{2} \mathrm{SO}_{4}$ viscosities from 0 to $80 \mathrm{wt} \%$, which can be used with the $c$ constant above to derive $D_{1}$ over the same concentration range using:

$\eta=A T^{-1.43} \exp \left(448 /\left(T-T_{0}\right)\right)$

This parameterisation results in values of $\eta$ which agree to better than $10 \%$ (for $40-70 \mathrm{wt} \% \mathrm{H}_{2} \mathrm{SO}_{4}$ solutions) with those of Klassen et al. (1998).

\section{References}

Abbatt, J. P. D.: J. Geophys. Res.-Atmos., 100, 14009-14017, 1995.

Abbatt, J. P. D. and Nowak, J. B.: J. Phys. Chem. A, 101, 2131-2137, 1997.

Klassen, J. K., Hu, Z. J., and Williams, L. R.: J. Geophys. Res.-Atmos., 103, 16197-16202, 1998.

Kleffmann, J., Becker, K. H., Broske, R., Rothe, D., and Wiesen, P.: J. Phys. Chem. A, 104, 8489-8495, 2000. (Erratum published in vol. 105, page 11593).

Luo, B., Carslaw, K. S., Peter, T., and Clegg, S.: Geophys. Res. Lett., 22, 247-250, 1995.

Shi, Q., Jayne, J. T., Kolb, C. E., Worsnop, D. R., and Davidovits, P.: J. Geophys. Res.-Atmos., 106, 24259-24274, 2001. 
Wilke, C. R. and Chang, P.: AIChE J., 1, 264-270, 1955.

Williams, L. R., Golden, D. M., and Huestis, D. L.: J. Geophys. Res.-Atmos., 100, 7329-7335, 1995.

Williams, L. R. and Long, F. S.: J. Phys. Chem., 99, 3748-3751, 1995. 
VI.A4.18

$\mathrm{HOI}(\mathrm{g})+\mathrm{H}_{2} \mathrm{SO}_{4}(\mathrm{aq}) \rightarrow$ products

Experimental data

\begin{tabular}{llll}
\hline Parameter & $T / \mathrm{K}$ & Reference & Technique/Comments \\
\hline $\begin{array}{l}\text { Accomodation coefficients: } \alpha_{\mathrm{b}} \\
>0.3\left(>58 \mathrm{wt} \% \mathrm{H}_{2} \mathrm{SO}_{4}\right)\end{array}$ & 253 & Holmes et al. (2001) & CWFT-MS (a) \\
$\begin{array}{l}\text { Uptake coefficients: } \gamma \\
1 \times 10^{-5} \exp \{(1700 \pm 200) / T\}\end{array}$ & $195-252$ & Allanic and Rossi (1999) & Knudsen-MS (b) \\
$>4 \times 10^{-2}\left(>58 \mathrm{wt} \% \mathrm{H}_{2} \mathrm{SO}_{4}\right)$ & 253 & Holmes et al. (2001) & CWFT-MS (a) \\
\hline
\end{tabular}

Comments

(a) $\mathrm{HOI}$ (at concentrations $<10^{10}$ molecule $\mathrm{cm}^{-3}$ ) was formed in the reaction of $\mathrm{O}\left({ }^{3} \mathrm{P}\right.$ ) with $\mathrm{C}_{3} \mathrm{H}_{7} \mathrm{I}$. The uptake to $>58 \mathrm{wt} \%$ $\mathrm{H}_{2} \mathrm{SO}_{4}$ was continuous and its size independent of the HOI concentration. No evidence for formation of iodine containing products was observed. The surface concentration of $\mathrm{H}_{2} \mathrm{SO}_{4}$ could have been much greater than the initial value of $58 \mathrm{wt} \%$ as the bulk gas-flow was not humidified.

(b) HOI (at approximate concentrations of $\sim 10^{10}$ molecule $\mathrm{cm}^{-3}$ ) was formed in the reaction of $\mathrm{O}\left({ }^{3} \mathrm{P}\right)$ with $\mathrm{C}_{2} \mathrm{H}_{5} \mathrm{I}$. 40 $70 \mathrm{wt} \% \mathrm{H}_{2} \mathrm{SO}_{4}$ solutions were kept at temperaures between 195 and $252 \mathrm{~K}$. The gas-phase $\mathrm{H}_{2} \mathrm{O}$ flow was adjusted to prevent surface concentration changes. The uptake coefficients displayed a negative temperature dependence, wih the parameters in the Table derived from an unweighted fit to the datapoints reported at each temperature.

\section{Preferred values}

None

\section{Comments on preferred values}

Both Allanic and Rossi (1999) and Holmes et al. (2001) found the uptake of $\mathrm{HOI}$ to $\mathrm{H}_{2} \mathrm{SO}_{4}$ solutions to be continuous (i.e. nonsaturating), suggestive of very high solubility, possibly enhanced by protonation to form $\mathrm{H}_{2} \mathrm{OI}^{+}$. The continuous uptake could also be caused by the presence of impurities in the HOI source reacting with $\mathrm{HOI}$ in/on $\mathrm{H}_{2} \mathrm{SO}_{4}$.

Allanic and Rossi observed the immediate formation of $\mathrm{I}_{2}$ as gas-phase product, albeit at a yield which was estimated to account for less than $50 \%$ of the HOI taken up. In contrast, Holmes et al. report no gas-phase iodine containing products. It is conceivable that the products observed by Allanic and Rossi were formed on surfaces other than $\mathrm{H}_{2} \mathrm{SO}_{4}$ in their Knudsen reactor. The single data point of Holmes et al. at $253 \mathrm{~K}$ does not fit with the trend in $\gamma$ with temperature observed by Allanic and Rossi, but is too high. This may reflect enhanced uptake to very concentrated $\mathrm{H}_{2} \mathrm{SO}_{4}$ surfaces which may have been present in the Holmes et al. experiments. On the other hand, Allanic and Rossi (1999) did not observe a change in HOI uptake coefficient when the $\mathrm{H}_{2} \mathrm{O}$ partial pressure above an initially $70 \mathrm{wt} \% \mathrm{H}_{2} \mathrm{SO}_{4}$ solution was increased by a factor of 4 .

Upon adding $\mathrm{NaCl}$ to the $\mathrm{H}_{2} \mathrm{SO}_{4}$ solution, Holmes et al. (2001) observed $\mathrm{ICl}$ formation with $100 \%$ yield, suggesting that dissolved $\mathrm{HOI}$ ( or $\mathrm{H}_{2} \mathrm{OI}^{+}$) reacts efficiently with halide ions.

The accomodation coefficient presented by Holmes et al. (2001) was derived from observation of pressure dependent values of $\gamma$ on $\mathrm{H}_{2} \mathrm{SO}_{4}$ solutions of largely unknown composition and thus no recommendation is made.

\section{References}

Allanic, A. and Rossi, M. J.: J. Geophys. Res., 104, 18689-18696, 1999.

Holmes, N. S., Adams, J. W., and Crowley, J. N.: Phys. Chem. Chem. Phys., 3, 1679-1786, 2001. 
VI.A4.19

Acetone $(\mathrm{g})+\mathrm{H}_{2} \mathrm{SO}_{4}(\mathrm{aq}) \rightarrow$ products

Experimental data

\begin{tabular}{lllll}
\hline Parameter & {$\left[\mathrm{H}_{2} \mathrm{SO}_{4}\right] / \mathrm{wt} \%$} & $T / \mathrm{K}$ & Reference & Technique/Comments \\
\hline Uptake coefficients: $\gamma$ & & & & \\
$\gamma_{0}=0.7$ & 85 & 200 & Duncan et al. (1998) & (a) \\
$\gamma_{\mathrm{ss}}=0.4$ & 85 & 200 & & \\
$\gamma_{\mathrm{ss}}=0.25$ & 75 & 201 & Duncan et al. (1999) & (a) \\
$\gamma_{\mathrm{ss}}=0.48$ & 85 & 221 & & \\
$\gamma_{\mathrm{ss}}=0.57$ & 85 & 221 & & Esteve and Noziere (2005) \\
$\gamma_{\mathrm{ss}}=5.2 \times 10^{-5}$ & 89.4 & 298 & & \\
$\gamma_{\mathrm{ss}}=5.6 \times 10^{-6}$ & 85.0 & & & \\
$\gamma_{\mathrm{ss}}=4.7 \times 10^{-6}$ & 80.8 & & & \\
$\gamma_{\mathrm{ss}}=1.6 \times 10^{-6}$ & 73.9 & & & Knud-MS (c) \\
Solubility: $H^{*}\left(\mathrm{Matm}^{-1}\right)$ & & & & \\
$H^{*}=7.1 \times 10^{7}$ & 70 & 180 & Duncan et al. (1999) & \\
$H^{*}=1.2 \times 10^{7}$ & 70 & 187 & & \\
$H^{*}=2.4 \times 10^{6}$ & 70 & 195 & & WWFT-MS (d) \\
$\log H^{*}=-7.50+2920 / T$ & 67.7 & $220-239$ & Klassen et al. (1999) \\
$\log H^{*}=-7.43+2750 / T$ & 60.7 & $223-234$ & & \\
$\log H^{*}=-7.39+2650 / T$ & 54.4 & $213-226$ & & WWFT-PIMS (e) \\
$\log H^{*}=-7.35+2580 / T$ & 48.3 & $212-222$ & & \\
$\ln H^{*}=3.0-\left[\mathrm{H}_{2} \mathrm{SO}_{4}\right] f-4850$ & $40-75$ & $198-292$ & Kane et al. (1999) \\
$(1 / 298.15-1 / T)$ & & & & \\
$H^{*}=2.1 \times 10^{4}$ & 50 & 230 & Imamura and Akiyoshi (2000) & \\
$H^{*}=1.3 \times 10^{3}$ & 50 & 250 & & \\
$H^{*}=8.2 \times 10^{4}$ & 60 & 230 & & \\
$H^{*}=4.4 \times 10^{3}$ & 60 & 250 & & \\
$H^{*}=2.5 \times 10^{4}$ & 69 & 250 & & \\
$H^{*}=2.2 \times 10^{5}$ & 76 & 250 & & \\
$H^{*}=2.2 \times 10^{4}$ & 79 & 270 & & \\
$H^{*}=9.5 \times 10^{4}$ & & & \\
\hline
\end{tabular}

\section{Comments}

(a) Low pressure, molecular flow reactor with FTIR and MS. Reflection-Absorption infrared spectroscopic analysis of $\mathrm{H}_{2} \mathrm{SO}_{4}$ films $\left(0.05-0.1 \mu \mathrm{m}\right.$ thick, $\left.180-260 \mathrm{~K}, 35-96 \mathrm{wt} \% \mathrm{H}_{2} \mathrm{SO}_{4}\right)$ exposed to acetone $\left(10^{-7}-10^{-4} \mathrm{mbar}\right)$ reveal presence of mesityl oxide and trimethylbenzene. The reaction proceeds via formation of protonated acetone, which, in $\mathrm{H}_{2} \mathrm{SO}_{4}$ solutions of $>70 \mathrm{wt} \%$, can undergo self-dehydration to form mesityl oxide. Trimethylbenzene is formed from mesityl oxide in solutions of $>85 \mathrm{wt} \%$. At concentrations lower than $70 \mathrm{wt} \%$ acetone uptake is reversible and the effective solubility, $H^{*}$, was determined by integrating the uptake until the thin film was saturated. Errors on $H^{*}$ are estimated as $25 \%$. Uptake coefficients obtained by gas-analysis using MS. The enthalpy and entropy of solution were determined as $-66 \mathrm{~kJ} \mathrm{~mol}^{-1}$ and $-249 \mathrm{~J} \mathrm{~mol}^{-1} \mathrm{~K}^{-1}$, respectively. The solubility data (180-195 K) can be described by: $\left.H^{*}=\exp \{(T * 216.7-66000) / 8.314 * T)\right\}$ for $70 \mathrm{wt} \% \mathrm{H}_{2} \mathrm{SO}_{4}$.

(b) Rotating WWFT generally at $\approx 100$ mbar with MS detection of acetone at high concentrations $\left((1-5) \times 10^{-5} \mathrm{~atm}\right)$. The experimental uptake coefficient, $\gamma_{\mathrm{ss}}$, was observed to increase with [acetone]. Reactive uptake observed at $\left[\mathrm{H}_{2} \mathrm{SO}_{4}\right]>70 \mathrm{wt} \%$ and reversible uptake at lower concentrations. Uptake coefficients were corrected for gas diffusion.

(c) Knudsen reactor using 48-68 wt $\% \mathrm{H}_{2} \mathrm{SO}_{4}$ at $210-240 \mathrm{~K}$. Solubility determined by measuring the time dependence of the acetone uptake and using liquid-phase diffusion coefficients calculated from viscosity data. Uncertainty estimated as $\pm 33 \%$. Addition of ammonium sulphate reduced the solubility slightly. 
(d) WWFT reactor using 40-87 wt $\% \mathrm{H}_{2} \mathrm{SO}_{4}$ at $198-300 \mathrm{~K}$. Uptake in dilute solutions ( $<75 \mathrm{wt} \%$ ) was found to be reversible. Solubility determined by measuring the time dependence of the acetone uptake and using liquid-phase diffusion coefficients calculated from viscosity data. The dependence of the solubility on the $\mathrm{H}_{2} \mathrm{SO}_{4}$ concentration and temperature is given by the equation in the table where $f=0.23+5 / T$ and $\left[\mathrm{H}_{2} \mathrm{SO}_{4}\right]$ is the molality of the $\mathrm{H}_{2} \mathrm{SO}_{4}$ solution. Note that the original expression given by the authors contains a typographical error, which has been subsequently corrected (Leu, 2003). The error limits on $H^{*}$ are reported to be $50 \%$. $\mathrm{In}_{2} \mathrm{SO}_{4}$ solutions of greater than $80 \mathrm{wt} \%$, both mesityl oxide and trimethylbenzene were observed my MS when liquid acetone was mixed with $\mathrm{H}_{2} \mathrm{SO}_{4}$.

(e) WWFT with PIMS detection of reversible acetone uptake to thin $\mathrm{H}_{2} \mathrm{SO}_{4}$ films (50-79 wt \%) at 230-270 K. Solubility determined by integrating the acetone uptake until the film was saturated. Uncertainties in $H^{*}$ reported to be $\pm 30 \%$.

\section{Preferred values}

\begin{tabular}{lll}
\hline Parameter & Value & $T / \mathrm{K}$ \\
\hline $\ln H^{*}$ & $3.0-\left[\mathrm{H}_{2} \mathrm{SO}_{4}\right] f-4850(1 / 298.15-1 / T)\left(40-75 \mathrm{wt} \% \mathrm{H}_{2} \mathrm{SO}_{4}\right)$ & $195-295 \mathrm{~K}$ \\
Reliability & & \\
$\Delta \log H$ & \pm 0.5 & \\
\hline
\end{tabular}

\section{Comments on preferred values}

The experimental data show that acetone is protonated to some extent in $\mathrm{H}_{2} \mathrm{SO}_{4}$ solutions and, at $\mathrm{H}_{2} \mathrm{SO}_{4}$ concentrations greater than $75 \mathrm{wt} \%$, dehydration reactions result in the formation of mesityl oxide and trimethylbenzene. At concentrations lower than $70 \mathrm{wt} \%$ acetone uptake is reversible and solubility controls the amount taken up to the solution. The preferred values for the effective Henry's law solubility are taken from the most extensive study by Kane et al. (1999), which covered the largest temperature and $\mathrm{H}_{2} \mathrm{SO}_{4}$ concentration range. $f=0.23+5 / T$ and $\left[\mathrm{H}_{2} \mathrm{SO}_{4}\right]$ is the molality of the $\mathrm{H}_{2} \mathrm{SO}_{4}$ solution. Where comparison is possible (overlap in $T$ and $\mathrm{H}_{2} \mathrm{SO}_{4}$ wt \%) the agreement between the studies is generally within a factor of 2-4. For this reason we present errors limits significantly greater than the $25-50 \%$ uncertainties reported by the various authors. The uptake coefficients presented by Duncan et al. $(1998,1999)$ and Esteve and Nozière (2005) diverge by several orders of magnitude, most likely due to the different temperature regimes investigated, and no recommendation is given.

\section{References}

Duncan, J. L., Schindler, L. R., and Roberts, J. T.: Geophys. Res. Lett., 25, 631-634, 1998.

Duncan, J. L., Schindler, L. R., and Roberts, J. T.: J. Phys. Chem. B, 103, 7247-7259, 1999.

Esteve, W. and Nozière, B.: J. Phys. Chem. A, 109, 10920-10928, 2005.

Imamura, T. and Akiyoshi, H.: Geophys. Res. Lett., 27, 1419-1422, 2000.

Kane, S. M., Timonen, R. S., and Leu, M. T.: J. Phys. Chem. A, 103, 9259-9265, 1999.

Klassen, J. K., Lynton, J., Golden, D. M., and Williams, L. R.: J. Geophys. Res., 104, 26355-26361, 1999.

Leu, M. T.: Int. Rev. Phys. Chem., 22, 341-376, 2003. 
VI.A4.20

$\mathrm{CHBr}_{3}(\mathrm{~g})+\mathrm{H}_{2} \mathrm{SO}_{4}(\mathrm{aq}) \rightarrow$ products

Experimental data

\begin{tabular}{llll}
\hline Parameter & T/K & Reference & Technique/Comments \\
\hline $\begin{array}{l}\text { Uptake coefficients: } \gamma \\
3 \times 10^{-3}\end{array}$ & 200 & Hanson and Ravishankara (1993) & CWFT-CIMS (a) \\
\hline
\end{tabular}

\section{Comments}

(a) Uptake study using a coated wall laminar flow tube coupled to CIMS detection. On liquid $58 \% \mathrm{H}_{2} \mathrm{SO}_{4}$ a reversible physical adsorption was observed with an initial uptake coefficient $\gamma_{0}=3 \times 10^{-3}$ (displayed) and $0.5 \mathrm{~s}$ exposure time within the wall-coated laminar flow tube. For longer exposure times $(\sim 20 \mathrm{~s}) \gamma$ decreases to $2 \times 10^{-4}$, most likely owing to partial saturation of the uptake and a rate-limiting acid-catalyzed hydrolysis.

\section{Preferred values}

No recommendation.

\section{Comments on preferred values}

In view of the single determination with very few experimental data at one temperature and one $\mathrm{H}_{2} \mathrm{SO}_{4}$ concentration no recommendation is given.

\section{References}

Hanson, D. R. and Ravishankara, A. R.: NATO ASI Series (17), 281, in: The Tropospheric Chemistry of Ozone in the Polar Regions, edited by: Niki, H. and Becker, K. H., Springer Verlag, 1993. 


\section{VI.A4.21}

$\mathrm{H}_{2} \mathrm{SO}_{4}(\mathrm{~g})+\mathrm{H}_{2} \mathrm{SO}_{4}(\mathrm{aq}) \rightarrow 2 \mathrm{H}_{2} \mathrm{SO}_{4}(\mathrm{aq})$

\section{Experimental data}

\begin{tabular}{lllll}
\hline Parameter & $\begin{array}{l}{\left[\mathrm{H}_{2} \mathrm{SO}_{4}\right] /} \\
\text { wt } \%\end{array}$ & $T / \mathrm{K}$ & Reference & Technique/Comments \\
\hline Accommodation coefficient: $\alpha_{\mathrm{b}}$ & & & & \\
$0.02-0.09$ & 43 & 298 & Van Dingenen and Raes (1991) & (a) \\
$>0.4$ & $73-98$ & 303 & Pöschl et al. (1998) & CWFT-CIMS (b) \\
$0.96 \pm 0.14$ & $7-40$ & 295 & Hanson (2005) & AFT-CIMS (c) \\
$0.76 \pm 0.05$ & $47-65$ & & & \\
\hline
\end{tabular}

\section{Comments}

(a) Uptake of $\mathrm{H}_{2} \mathrm{SO}_{4}$ was derived from particle growth measurements in a $230 \mathrm{~L}$ spherical batch reactor. Particle size distributions were measured with a differential mobility analyser. Seed $\mathrm{H}_{2} \mathrm{SO}_{4}$ particles were first produced by reaction of $\mathrm{SO}_{2}$ with $\mathrm{OH}$. $\mathrm{OH}$ was produced by photolysis of a $\mathrm{NO}_{\mathrm{x}}$ mixture, thus likely from photolysis of $\mathrm{HNO}_{2}$ formed on the chamber walls. Loss of these particles within the reactor was then measured under dark conditions. Growth of the particles was observed in a third stage by again inducing $\mathrm{H}_{2} \mathrm{SO}_{4}$ formation as before, but with higher light intensity, resulting in growth of $\mathrm{H}_{2} \mathrm{SO}_{4}$ particles due to condensation of $\mathrm{H}_{2} \mathrm{SO}_{4}$. OH concentrations were estimated from the decay of the ratio of the concentrations of propene and propane also added to the reactor. The estimated $\mathrm{OH}$ level was used to infer the $\mathrm{H}_{2} \mathrm{SO}_{4}$ concentrations. When deriving the bulk accommodation coefficient from the growth rates, the Fuchs-Sutugin correction factor was used to account for gas phase diffusion.

(b) Coated wall flow tube operated at 0.7-13 mbar with CIMS detection of $\mathrm{H}_{2} \mathrm{SO}_{4}$ after reaction with $\mathrm{SF}_{6}^{-} \cdot \mathrm{H}_{2} \mathrm{SO}_{4}$ was delivered from a thermostated reservoir kept at $348 \mathrm{~K}$. The reactor wall was coated by a thin $\mathrm{H}_{2} \mathrm{SO}_{4}$ film, the composition of which was determined by the $\mathrm{H}_{2} \mathrm{O}$ pressure. The uptake coefficient (interpreted as bulk accommodation coefficient) was determined by fitting the first order loss rates taking into account gas phase diffusion. The best fit was obtained for a value of 0.65 . Taking into account the uncertainties led to the lower limit listed in the table.

(c) Uptake to sulphuric acid aerosol was studied in a laminar flow reactor coupled to CIMS detection using $\mathrm{HNO}_{3}$ as source of primary ions. Sulphuric acid particles were generated by homogeneous nucleation from supersaturated vapour leading to a lognormal particle size distribution within $50-120 \mathrm{~nm}$, with a few $10^{4}$ particles per $\mathrm{cm}^{3}$, characterised by a differential mobility analyzer. Gas-phase sulphuric acid was generated by reaction of $\mathrm{OH}$ with $\mathrm{SO}_{2}$ leading to concentrations of $3 \times 10^{9} \mathrm{~cm}^{-3}$ in the flow tube. This concentration is at least two orders of magnitude above the vapour pressure of sulphuric acid. Uptake to the particles did not lead to significant growth. The measured uptake coefficients were corrected for gas phase diffusion using the Fuchs-Sutugin correction factor. The diffusion coefficient was directly measured based on the observed wall loss rates in absence of aerosol particles. Its negative humidity dependence was in line with previous measurements by Hanson and Eisele (2000).

\section{Preferred values}

\begin{tabular}{lll}
\hline Parameter & Value & $T / \mathrm{K}$ \\
\hline$\alpha_{\mathrm{b}},\left[\mathrm{H}_{2} \mathrm{SO}_{4}\right]<50 \mathrm{wt} \%$ & 1 & $200-300$ \\
$\alpha_{\mathrm{b}},\left[\mathrm{H}_{2} \mathrm{SO}_{4}\right]>50 \mathrm{wt} \%$ & $>0.7$ & $200-300$ \\
Reliability & \pm 0.3 & $200-300$ \\
$\Delta \log \left(\alpha_{\mathrm{b}}\right)$ & \pm \\
\hline
\end{tabular}

\section{Comments on preferred values}

Of the two more recent studies, the aerosol flow tube study by Hanson (2005) is much less affected by gas phase diffusion and can thus more reliably return high uptake coefficients. The slight trend for a lower bulk accommodation coefficient apparent in Hanson's data is not significant enough to provide a parameterized expression for the composition dependence. It is thus reflected by providing a lower limit of 0.7 for solutions $>50 \mathrm{wt} \%$. The coated wall flow tube study by Pöschl et al. (1998) is in 
agreement with these high values for $\alpha_{\mathrm{b}}$, keeping in mind that the wall loss rates were practically in the diffusion limit of that experiment. The earlier estimate of $\alpha_{\mathrm{b}}$ based on particle growth measurements certainly suffered from the fact that neither the concentration of $\mathrm{H}_{2} \mathrm{SO}_{4}$ nor that of its precursor $\mathrm{SO}_{2}$ was directly measured. In addition, the condensation rate derived was very sensitive to the wall loss rate of particles, which had to be determined in a separate experiment.

\section{References}

Hanson, D. R.: J. Phys. Chem. A, 109, 6919-6927, 2005.

Pöschl, U., Canagaratna, M., Jayne, J. T., Molina, L. T., Worsnop, D. R., Kolb, C. E., and Molina, M. J.: J. Phys. Chem. A, 102, 10082-10089, 1998.

Van Dingenen, R. and Raes, F.: Aerosol Sci. Technol., 15, 93-106, 1991.

Hanson, D. R. and Eisele, F.: J. Phys. Chem. A, 104, 1715-1719, 2000. 


\section{VI.A4.22}

$\mathrm{HOCl}(\mathrm{g})+\mathrm{HCl}(\mathrm{aq}) \rightarrow \mathrm{H}_{2} \mathrm{O}(\mathrm{l})+\mathrm{Cl}_{2}(\mathrm{~g})$

\section{Experimental data}

\begin{tabular}{|c|c|c|c|c|c|c|}
\hline Parameter & $\begin{array}{l}\mathrm{p}_{\mathrm{HOCl}} / \\
\text { mbar }\end{array}$ & $\begin{array}{l}\text { pHCl } / \\
\text { mbar }\end{array}$ & $\begin{array}{l}{\left[\mathrm{H}_{2} \mathrm{SO}_{4}\right] /} \\
\text { wt } \%\end{array}$ & $\begin{array}{l}\text { Temp./ } \\
\mathrm{K}\end{array}$ & Reference & Technique/Comments \\
\hline \multicolumn{7}{|l|}{ Uptake coefficients: $\gamma$} \\
\hline$\gamma_{\mathrm{HOCl}}=1 \times 10^{-3}$ & & $7 \times 10^{-6}$ & 60 & 263 & Hanson and Ravishankara (1991) & WWFT-CIMS (a) \\
\hline$\gamma_{\mathrm{HCl}}=6 \times 10^{-3}$ & $1.5 \times 10^{-5}$ & $9 \times 10^{-6}$ & 60 & 215 & & \\
\hline$\gamma_{\mathrm{HOCl}}=0.02-0.15$ & & $10^{-8}-10^{-6}$ & 59.6 & $200-205$ & Hanson and Ravishankara (1993) & WWFT-CIMS (b) \\
\hline$\gamma_{\mathrm{HOCl}}=0.45$ & & $4 \times 10^{-7}$ & 50 & 198 & Zhang et al. (1994) & WWFT-MS (c) \\
\hline$\gamma_{\mathrm{HOCl}}=7 \times 10^{-2}$ & & $4 \times 10^{-7}$ & 60 & 205 & & \\
\hline$\gamma_{\mathrm{HOCl}}=4 \times 10^{-3}$ & & $4 \times 10^{-7}$ & 68 & 214 & & \\
\hline$\gamma_{\mathrm{HOCl}}=0.1$ & & $4 \times 10^{-7}$ & 57 & 202 & & \\
\hline$\gamma_{\mathrm{HOCl}}=0.2$ & & $8 \times 10^{-7}$ & 50 & 198 & & \\
\hline$\gamma_{\mathrm{HOCl}}=0.5$ & & $2 \times 10^{-6}$ & 60 & 205 & & \\
\hline$\gamma_{\mathrm{HOCl}}=4.5 \times 10^{-3}$ & & $2 \times 10^{-6}$ & 59.6 & 251 & Hanson and Lovejoy (1996) & RWFT-CIMS (d) \\
\hline$\gamma_{\mathrm{HOCl}}=1.3 \times 10^{-2}$ & & $2 \times 10^{-5}$ & & & & \\
\hline$\gamma_{\mathrm{HOCl}}=2.7 \times 10^{-2}$ & & $7 \times 10^{-5}$ & & & & \\
\hline$\gamma_{\mathrm{HOCl}}=2.5 \times 10^{-2}(70 \mathrm{~nm})$ & & $3 \times 10^{-3}$ & 59.5 & 251 & Hanson and Lovejoy (1996) & AFT-CIMS (d) \\
\hline$\gamma_{\mathrm{HOCl}}=7.5 \times 10^{-2}(200 \mathrm{~nm})$ & & $3 \times 10^{-3}$ & & 251 & & \\
\hline$\gamma_{\mathrm{HOCl}}=1.0 \times 10^{-1}(400 \mathrm{~nm})$ & & $3 \times 10^{-3}$ & & & & \\
\hline$\gamma_{\mathrm{HOCl}}=0.07\left(a_{\mathrm{H} 2 \mathrm{O}}=0.10\right)$ & & $3 \times 10^{-3}$ & & & & \\
\hline$\gamma_{\mathrm{HOCl}}=0.4\left(a_{\mathrm{H} 2 \mathrm{O}}=0.28\right)$ & & $3 \times 10^{-3}$ & & & & \\
\hline$\gamma_{\mathrm{HOCl}}=0.86\left(a_{\mathrm{H} 2 \mathrm{O}}=0.56\right)$ & & $3 \times 10^{-3}$ & & & & \\
\hline$\gamma_{\mathrm{HCl}}=0.1(38 \mathrm{~nm})$ & $1.5 \times 10^{-3}$ & & 34 & 274 & & \\
\hline$\gamma_{\mathrm{HCl}}=0.32(160 \mathrm{~nm})$ & $1.5 \times 10^{-3}$ & & 34 & & & \\
\hline$\gamma_{\mathrm{HCl}}=0.58(420 \mathrm{~nm})$ & $1.5 \times 10^{-3}$ & & 34 & & & \\
\hline$\gamma_{\mathrm{HCl}}=0.08\left(a_{\mathrm{H} 2 \mathrm{O}}=0.58\right)$ & $1.5 \times 10^{-3}$ & & & $272-276$ & & \\
\hline$\gamma_{\mathrm{HCl}}=0.44\left(a_{\mathrm{H} 2 \mathrm{O}}=0.69\right)$ & $1.5 \times 10^{-3}$ & & & & & \\
\hline$\gamma_{\mathrm{HCl}}=0.75\left(a_{\mathrm{H} 2 \mathrm{O}}=0.79\right)$ & $1.5 \times 10^{-3}$ & & & & & \\
\hline$\gamma_{\mathrm{HOCl}}=0.013$ & & $5 \times 10^{-7}$ & 52 & 250 & Donaldson et al. (1997) & RWFT-CIMS (e) \\
\hline$\gamma_{\mathrm{HOCl}}=0.09$ & & $2 \times 10^{-5}$ & 52 & & & \\
\hline$\gamma_{\mathrm{HOCl}}=0.011$ & & $2 \times 10^{-5}$ & 62.5 & 250 & & \\
\hline$\gamma_{\mathrm{HOCl}}=0.045$ & & $2 \times 10^{-4}$ & 62.5 & & & \\
\hline$\gamma_{\mathrm{HOCl}}=0.0048$ & & $4 \times 10^{-5}$ & 67 & 250 & & \\
\hline$\gamma_{\mathrm{HOCl}}=0.018$ & & $1 \times 10^{-3}$ & 67 & & & \\
\hline$\gamma_{\mathrm{HOCl}}=0.043$ & & $5 \times 10^{-7}$ & 58 & 220 & & \\
\hline$\gamma_{\mathrm{HOCl}}=0.15$ & & $1 \times 10^{-5}$ & 58 & & & \\
\hline$\gamma_{\mathrm{HOCl}}=0.05$ & & $2 \times 10^{-6}$ & 60 & 220 & & \\
\hline$\gamma_{\mathrm{HOCl}}=0.12$ & & $4 \times 10^{-5}$ & 60 & & & \\
\hline$\gamma_{\mathrm{HOCl}}=0.023$ & & $1 \times 10^{-6}$ & 63 & 220 & & \\
\hline$\gamma_{\mathrm{HOCl}}=0.070$ & & $2 \times 10^{-5}$ & 63 & & & \\
\hline$\gamma_{\mathrm{HOCl}}=2.0 \times 10^{-3}(70 \mathrm{~nm})$ & & $10^{-3}$ & 67 & 250 & & AFT-CIMS (e) \\
\hline$\gamma_{\mathrm{HOCl}}=5.5 \times 10^{-3}(180 \mathrm{~nm})$ & & $10^{-3}$ & & & & \\
\hline$\gamma_{\mathrm{HOCl}}=1.3 \times 10^{-2}(400 \mathrm{~nm})$ & & $10^{-3}$ & & & & \\
\hline$\gamma_{\mathrm{HOCl}}=1.3 \times 10^{-2}(680 \mathrm{~nm})$ & & $10^{-3}$ & & & & \\
\hline Reacto-diffusive parameters & & & & & & \\
\hline $\begin{array}{l}H_{\mathrm{HOCl}}\left(D_{1} k_{\mathrm{b}} H_{\mathrm{HCl}}^{*}\right)^{l / 2} \\
=4.0 \times 10^{4} \mathrm{M} \mathrm{cm} \mathrm{s}^{-1} \mathrm{~atm}^{-3 / 2}\end{array}$ & & & 59.6 & 251 & Hanson and Lovejoy (1996) & RWFT-CIMS (d) \\
\hline$l_{\mathrm{HOCl}}=1.2 \times 10^{-5} \mathrm{~cm}$ & & & 59.5 & 251 & Hanson and Lovejoy (1996) & AFT-CIMS (d) \\
\hline$l_{\mathrm{HCl}}=1.2 \times 10^{-4} \mathrm{~cm}$ & & & 34 & 274 & & \\
\hline$\left(k_{\mathrm{b}} H_{\mathrm{HOCl}}\right)^{l / 2}=1.1 \times 10^{4} \mathrm{~atm}^{-1 / 2} \mathrm{~s}^{-1 / 2}$ & & & 34 & 274 & & \\
\hline
\end{tabular}

\section{Comments}

(a) The cold aqueous solution of $\mathrm{H}_{2} \mathrm{SO}_{4}$ flowed down the walls of the vertical flow tube. $p\left(\mathrm{H}_{2} \mathrm{O}\right)$ was generally around $1.3 \times 10^{-3} \mathrm{mbar},[\mathrm{HCl}]$ for the experiments on the $40 \mathrm{wt} \%$ solution was $2 \times 10^{11}$, for the 60 to $75 \mathrm{wt} \%$ solution it was in the range 1 to $3 \times 10^{11}$ molecule $\mathrm{cm}^{-3}$. 
(b) First order loss of $\mathrm{HOCl}$ was observed in a cylindrical flow tube with $\mathrm{H}_{2} \mathrm{SO}_{4}$ applied as a coating for the 200-205 K measurements or contained in a boat for the measurement at $219 \mathrm{~K}$. $\mathrm{HOCl}$ was generated by reacting $\mathrm{HF}$ with $\mathrm{Ca}(\mathrm{OCl})_{2}$ powder. $\mathrm{HCl}$ was added via uptake from the gas phase at pressures $>3 \times 10^{-7}$ mbar, leading to $\left[\mathrm{Cl}^{-}\right]>10^{-5} \mathrm{M}$, in excess of $\mathrm{HOCl}$. The value for $k_{\mathrm{b}}$ reported and listed in the table was obtained by estimates of the diffusion coefficients and solubilities as reported from the same study.

(c) WWFT with water vapour pressure maintained constant at $2.0 \times 10^{-3} \mathrm{mbar}$, to give $45-70 \mathrm{wt} \% \mathrm{H}_{2} \mathrm{SO}_{4}$ solutions for $195 \mathrm{~K}<\mathrm{T}<220 \mathrm{~K}$. Detection limits were $6.5 \times 10^{-8} \mathrm{mbar}$ for $\mathrm{HOCl}$ and $6.5 \times 10^{-7} \mathrm{mbar}$ for $\mathrm{HCl}$. Production of $\mathrm{Cl}_{2}$ matched the loss of $\mathrm{HOCl}$ or $\mathrm{HCl}$. Experiments with both excess of $\mathrm{HCl}$ and $\mathrm{HOCl}$ were performed. Uptake coefficients were consistent between analysis of reactant loss and $\mathrm{Cl}_{2}$ formation. Kinetics were not affected by the presence of $\mathrm{HNO}_{3}$ at $6.5 \times 10^{-7}$ mbar.

(d) Bulk measurements of first-order loss of either $\mathrm{HOCl}$ or $\mathrm{HCl}$ under conditions of mutual excess of the other, respectively. $\mathrm{HOCl}, \mathrm{HCl}$ and $\mathrm{Cl}_{2}$ were detected using $\mathrm{SF}_{6}^{-}$reactant ion. The parameter listed in the table is the slope of a plot of $1 / \gamma$ vs. the square root of the $\mathrm{HCl}$ pressure.

Aerosol flow tube experiment operated at $234 \mathrm{mbar}$ of $\mathrm{N}_{2}, 10 \mathrm{~cm}^{3} \mathrm{~s}^{-1} \mathrm{STP}$ (standard temperature and pressure) and 251$276 \mathrm{~K}$. The aerosol mode diameter was $200 \mathrm{~nm}$ with a geometric standard deviation of 1.2. Under the conditions of the experiment, for both $\mathrm{HOCl}$ and $\mathrm{HCl}$ diffusion controlled loss to the flow tube walls occurred.

(e) RWFT and AFT experiments identical to those done by Hanson and Lovejoy (1996). The total pressure in the WWFT was at maximum a few mbar (mostly $\mathrm{He}$ ), with a flow rate of $3-4 \mathrm{STP} \mathrm{cm}^{3} \mathrm{~s}^{-1}$.

\section{Preferred values}

\begin{tabular}{lll}
\hline Parameter & Value & $T / \mathrm{K}$ \\
\hline$\alpha_{\mathrm{b}, \mathrm{HCl}}$ & see datasheet VI.A4.14 & \\
$\alpha_{\mathrm{b}, \mathrm{HOCl}}$ & 1 & \\
$k_{\mathrm{b}}\left(\mathrm{M}^{-1} \mathrm{~s}^{-1}\right)$ & $80\left[\mathrm{H}^{+}\right] T / \eta$ & $190-273$ \\
Reliability & & \\
$\Delta \log \left(k_{\mathrm{b}}\right)$ & \pm 0.3 & \\
\hline
\end{tabular}

\section{Comments on preferred values}

$\mathrm{HOCl}$ reacts efficiently with $\mathrm{HCl}$ under acidic conditions (Eigen and Kustin, 1962). Most of the kinetic data covering tropospheric and lower stratospheric conditions were obtained by one group using coated wall and aerosol flow tubes. The measured uptake coefficients clearly established that kinetics is driven by reaction in the bulk (Lovejoy and Hanson, 1996). Donaldson et al. (1997) suggested protonated $\mathrm{HOCl}, \mathrm{H}_{2} \mathrm{OCl}^{+}$, being the reactive species, based on the strong sensitivity of the first order loss rate constant in the bulk on acidity and on theoretical evidence (Koch et al., 1997; Francisco and Sander, 1995; and references therein). Shi et al. (2001) suggested the expression adopted here for the second order rate constant to explicitly include the proton molarity and assumed that the rate constant is limited by diffusion of $\mathrm{HOCl}$ (leading to a dependence of the apparent rate constant on viscosity). As already pointed out by Shi et al., taking the revised parameterizations for $H_{\mathrm{HOCl}}$ (datasheet VI.A4.13) and $H_{\mathrm{HCl}}^{*}$ (datasheet VI.A4.14), this leads to good agreement with all available data of $\gamma_{\mathrm{HOCl}}$ for a wide range of conditions, including those by Zhang et al. (1994), another flow tube experiment at low temperature.

The recommended parameterisation reproduces the available data of $\gamma_{\mathrm{HCl}}$ and $\gamma_{\mathrm{HCl}}$ reasonably well and notably also the size dependence for both, as measured by Hanson and Lovejoy (1996) and Donaldson et al. (1997). The reacto-diffusive length is in the range of 0.1 to $1 \mu \mathrm{m}$. The parameterization also reproduces the dependence of the uptake as a function of water activity.

The uptake coefficients of $\mathrm{HOCl}$ and $\mathrm{HCl}$ on sulphuric acid in presence of $\mathrm{HCl}$ or $\mathrm{HOCl}$, respectively, can be obtained from:

$$
\begin{aligned}
& \frac{1}{\gamma_{\mathrm{HOCl}}}=\frac{1}{\alpha_{\mathrm{b}, \mathrm{HOCl}}}+\frac{\bar{c}_{\mathrm{HOCl}}}{4 H_{\mathrm{HOCl}} R T \sqrt{D_{\mathrm{l}, \mathrm{HOCl}} \cdot k_{\mathrm{b}} p_{\mathrm{HCl}} H_{\mathrm{HCl}}^{*}}\left[\operatorname{coth}\left(\frac{r_{\mathrm{p}}}{l_{\mathrm{HOCl}}}\right)-\left(\frac{l_{\mathrm{HOCl}}}{r_{\mathrm{p}}}\right)\right]} \\
& \frac{1}{\gamma_{\mathrm{HCl}}}=\frac{1}{\alpha_{\mathrm{b}, \mathrm{HCl}}}+\frac{\bar{c}_{\mathrm{HCl}}}{4 H_{\mathrm{HCl}}^{*} R T \sqrt{D_{\mathrm{l}, \mathrm{HCl}} \cdot k_{\mathrm{b}} p_{\mathrm{HOCl}} H_{\mathrm{HOCl}}}\left[\operatorname{coth}\left(\frac{r_{\mathrm{p}}}{l_{\mathrm{HCl}}}\right)-\left(\frac{l_{\mathrm{HCl}}}{r_{\mathrm{p}}}\right)\right]}
\end{aligned}
$$


$\alpha_{\mathrm{b}, \mathrm{HOCl}}$ is assumed to be one (see datasheet VI.A4.13). For $\alpha_{\mathrm{b}, \mathrm{HCl}}$ we recommend the parameterization given on datasheet VI.A4.14, which leads to slightly better agreement with data than assuming $\alpha_{\mathrm{b}, \mathrm{HCl}}=1: \alpha_{\mathrm{b}, \mathrm{HCl}}=k_{\mathrm{sol}} /\left(k_{\mathrm{des}}+k_{\mathrm{sol}}\right)$ with $k_{\mathrm{sol}}=7.84 \times 10^{10} / \eta$ and $k_{\mathrm{des}}=8.0 \times 10^{17} \exp (-5000 / T)$.

We suggest using the parameterisation of Shi et al. for the proton concentration:

$$
\begin{aligned}
{\left[\mathrm{H}^{+}\right] } & =\exp \left[60.51-0.095 w t+0.0077 w t^{2}-1.61 \times 10^{-5} w t^{3}\right. \\
& \left.-\left(1.76+2.52 \times 10^{-4} w t^{2}\right) T^{0.5}+\left(-805.89+253.05 w t^{0.076}\right) / T^{0.5}\right]
\end{aligned}
$$

The uncertainty of the proton activity in view of explicit measurements of the protonation state of $\mathrm{HSO}_{4}^{-}$by Knopf et al. (2003) is included in the uncertainty of the expression for $\mathrm{k}_{\mathrm{b}}$ given in the table. We take the preferred expression for the solubility of $\mathrm{HOCl}$ from datasheet VI.A4.13,

$H_{\mathrm{HOCl}}=1.91 \times 10^{-6} \exp (5862.4 / T) \exp \left(-(0.0776+59.18 / T)\left[\mathrm{H}_{2} \mathrm{SO}_{4}\right]\right)$

and that for $\mathrm{HCl}$ from datasheet VI.A4.14:

$H_{\mathrm{HCl}}^{*}=\left(0.094-0.61 X+1.2 X^{2}\right) \exp \left(-8.68+\left(8515-10718 X^{0.7}\right) / T\right)$

The mole fraction, $X$, of sulphuric acid is given by $X=w t /(w t+(100-w t) 98 / 18)$ and $\left[\mathrm{H}_{2} \mathrm{SO}_{4}\right]$ in $\mathrm{mol} \mathrm{L}^{-1}$ can be calculated from the sulphuric acid content using density data provided by Shi et al.

The diffusion coefficients for $\mathrm{HOCl}$ and $\mathrm{HCl}$ are parameterized by $D_{1, \mathrm{X}}=c_{\mathrm{X}} \times 10^{-8} T / \eta$; with $c_{\mathrm{HOCl}}=\mathrm{cm}^{2} \mathrm{cP} \mathrm{K}^{-1} \mathrm{~s}^{-1}$ (see datasheet VI.A4.13) and $c_{\mathrm{HCl}}=7.8 \times 10^{-8} \mathrm{~cm}^{2} \mathrm{cP} \mathrm{K}^{-1} \mathrm{~s}^{-1}$ (see datasheet VI.A4.14). For the viscosity, we suggest using the parameterization presented by Shi et al. (2001), which fits well to data by Williams and Long (1995) but extends into tropospherically more relevant dilute solutions at high $T$ :

$\eta=A T^{-1.43} \exp \left(448 \mathrm{~K} /\left(T-T_{0}\right)\right)$,

with $A=169.5+5.18 w t-0.0825 w t^{2}+3.27 \times 10^{-3} w t^{3}$,

and $T_{0}=144.11+0.166 w t-0.015 w t^{2}+2.18 \times 10^{-4} w t^{3}$

The reacto-diffusive lengths needed to account for finite particle sizes are given by:

$l_{\mathrm{HOCl}}=\left(D_{1, \mathrm{HOCl}} /\left(k_{\mathrm{b}} p_{\mathrm{HCl}} H_{\mathrm{HCl}}^{*}\right)\right)^{0.5}$

$l_{\mathrm{HCl}}=\left(D_{1, \mathrm{HCl}} /\left(k_{\mathrm{b}} p_{\mathrm{HOCl}} H_{\mathrm{HOCl}}\right)\right)^{0.5}$

\section{References}

Donaldson, D. J., Ravishankara, A. R., and Hanson, D. R.: J. Phys. Chem. A, 101, 4717-4725, 1997.

Eigen, M. and Kustin, K. J.: J. Am. Chem. Soc., 84, 1355-1361, 1962.

Francisco, J. S. and Sander, S. P.: J. Chem. Phys., 102, 9615-9618, 1995.

Hanson, D. R. and Lovejoy, E. R.: J. Phys. Chem., 100, 6397-6405, 1996.

Hanson, D. R. and Ravishankara, A. R.: J. Geophys. Res., 96, 17307-17314, 1991.

Hanson, D. R. and Ravishankara, A. R.: J. Phys. Chem., 97, 12309-12319, 1993.

Knopf, D. A., Luo, B. P., Krieger, U. K., and Koop, T.: J. Phys. Chem. A, 107, 4322-4332, 2003.

Koch, T. G., Banham, S. F., Sodeau, J. R., Horn, A. B., McCoustra, M. R. S., and Chesters, M. A.: J. Geophys. Res., 102, 1513-1522, 1997.

Shi, Q., Jayne, J. T., Kolb, C. E. Worsnop, D. R., and Davidovits, P.: J. Geophys. Res., 106, 24259-24274, 2001.

Williams, L. R. and Long, F. S.: J. Phys. Chem., 99, 3748-3751, 1995.

Zhang, R. Y., Leu, M. T., and Keyser, L. F.: J. Phys. Chem., 98, 13563-13574, 1994. 
VI.A4.23

$\mathrm{HOCl}(\mathrm{g})+\mathrm{HBr}(\mathrm{aq}) \rightarrow \mathrm{BrCl}(\mathrm{g})+\mathrm{H}_{2} \mathrm{O}(\mathrm{l})$

Experimental data

\begin{tabular}{llll}
\hline Parameter & $T / \mathrm{K}$ & Reference & Technique/Comments \\
\hline $\begin{array}{l}\text { Uptake coefficient, } \gamma \\
0.02-0.235\left(\mathrm{HBr}=(2-96) \times 10^{-9} \mathrm{~atm}\right)\end{array}$ & 228 & Abbatt and Nowak (1997) & CWFT-MS (a) \\
\hline
\end{tabular}

\section{Comments}

(a) (5-20) $\times 10^{10}$ molecule $\mathrm{cm}^{-3} \mathrm{HOCl}$ admitted into the flow tube via a movable injector. Experimental uptake coeffcients for $\mathrm{HOCl}$ were obtained at $228 \mathrm{~K}$ and $69.3 \mathrm{wt} \% \mathrm{H}_{2} \mathrm{SO}_{4}$ with various amounts of gas-phase $\mathrm{HBr}$ providing an excess concentration in the $\mathrm{H}_{2} \mathrm{SO}_{4}$ film.

\section{Preferred values}

\begin{tabular}{lll}
\hline Parameter & Value & $T / \mathrm{K}$ \\
\hline$k_{\mathrm{HOCl}+\mathrm{HBr}}\left(\mathrm{M}^{-1} \mathrm{~s}^{-1}\right)$ & $1 \times 10^{7}$ & 228 \\
$\alpha_{\mathrm{b}}$ & 1 & 228 \\
Reliability & & \\
$\Delta \log \left(k_{\mathrm{HOCl}+\mathrm{HBr}}\right)$ & \pm 0.3 & \\
\hline
\end{tabular}

\section{Comments on preferred value}

The preferred values are based on the dataset of Abbatt and Nowak (1997). The expression:

$\frac{1}{\gamma}=\frac{1}{\alpha_{\mathrm{b}}}+\frac{1}{\Gamma_{\mathrm{b}}}$ with $\Gamma_{\mathrm{b}}=\frac{4 H R T \sqrt{D_{\mathrm{l}} k_{\mathrm{HOCl}+\mathrm{HBr}}}[\mathrm{HBr}]}{\bar{c}}$

was constrained using preferred values of $H$ and $D_{1}$ for $\mathrm{HOCl}$ and $H$ for $\mathrm{HBr}$ (IUPAC, 2012, datasheets VI.A4.17 and VI.A4.13) with $k_{\mathrm{HOCl}+\mathrm{HBr}}$ varied to adjust $\gamma$ to match the experimental data. $\alpha_{\mathrm{b}}$ was assumed to be unity. The preferred value of $k_{\mathrm{HOCl}+\mathrm{HBr}}$ is larger than reported by Abbatt and Nowak owing to use of lower values of $H \sqrt{D_{1}}$. As noted by Abbatt and Nowak, the value of $k_{\mathrm{HOCl}+\mathrm{HBr}}$ is orders of magnitude larger than that reported for low-acidity aqueous solutions (Kumar and Margerum, 1987).

\section{References}

Abbatt, J. P. D. and Nowak, J. B.: J. Phys. Chem. A, 101, 2131-2137, 1997.

Kumar, K. and Margerum, D. W.: Inorg. Chem., 26, 2706-2711, 1987. 
VI.A4.24

$\mathrm{ClONO}_{2}(\mathrm{~g})+\mathrm{HCl}(\mathrm{aq}) \rightarrow \mathrm{HONO}_{2}(\mathrm{aq})+\mathrm{Cl}_{2}(\mathrm{~g})$

\section{Experimental data}

\begin{tabular}{|c|c|c|c|c|c|}
\hline Parameter & $\begin{array}{l}{\left[\mathrm{H}_{2} \mathrm{SO}_{4}\right]} \\
(\mathrm{wt} \%)\end{array}$ & $\begin{array}{l}{[\mathrm{HCl}] /\left[\mathrm{HNO}_{3}\right]} \\
\mathrm{M}\end{array}$ & $T / \mathrm{K}$ & Reference & Technique/Comments \\
\hline \multicolumn{6}{|l|}{$\gamma\left(\mathrm{ClONO}_{2}\right)$} \\
\hline $3 \times 10^{-3}$ & 65 & & 210 & Tolbert et al. (1988) & Kn-MS (a) \\
\hline $2 \times 10^{-3}$ & 40 & & 218 & Hanson and Ravishankara (1991) & WWFT-CIMS (b) \\
\hline $2 \times 10^{-4}$ & 60 & & 215 & & \\
\hline$<1 \times 10^{-4}$ & 65 & & 215 & & \\
\hline$<2 \times 10^{-5}$ & 70 & & 220 & & \\
\hline$<2 \times 10^{-5}$ & 75 & & 230 & & \\
\hline 0.038 & 46.6 & $<10^{-4}$ & 202 & Hanson and Ravishankara (1994) & WWFT-CIMS (c) \\
\hline 0.10 & 46.6 & $10^{-3}$ & & & \\
\hline 0.30 & 46.6 & $6 \times 10^{-3}$ & & & \\
\hline $0.16 \pm 0.06$ & 49 & $5.8 \times 10^{-3}$ & 197 & Zhang et al. (1994) & WWFT-CIMS (d) \\
\hline $0.10 \pm 0.05$ & 51 & $2.2 \times 10^{-3}$ & 198.5 & & \\
\hline $0.04 \pm 0.013$ & 55 & $3.3 \times 10^{-4}$ & 201 & & \\
\hline$(9.5 \pm 3.2) \times 10^{-3}$ & 60 & $2.5 \times 10^{5}$ & 205.5 & & \\
\hline$(1.8 \pm 1.6) \times 10^{-3}$ & 65 & $2.5 \times 10^{-6}$ & 211 & & \\
\hline 0.3 & 43 & $8.2 \times 10^{-4}$ & 194 & Elrod et al. (1995) & WWFT-MS (e) \\
\hline 0.083 & 47 & $1.4 \times 10^{-4}$ & 196 & & \\
\hline 0.038 & 51 & $2.4 \times 10^{-5}$ & 198 & & \\
\hline 0.01 & 55.2 & $3 \times 10^{-6}$ & 201 & & \\
\hline 0.11 & 20.2 & $4.88 \times 10^{-4}\left(28.35 \% \mathrm{HNO}_{3}\right)$ & 195 & & \\
\hline 0.058 & 44 & $6.18 \times 10^{-5}\left(6.1 \% \mathrm{HNO}_{3}\right)$ & 197 & & \\
\hline 0.021 & 50.3 & $1.38 \times 10^{-5}\left(2.26 \% \mathrm{HNO}_{3}\right)$ & 199 & & \\
\hline 0.07 & 45 & $10^{-8} \mathrm{mbar}$ & $203-205$ & Hanson (1998) & WWFT-CIMS (f) \\
\hline 0.6 & 45 & $10^{-6} \mathrm{mbar}$ & & & \\
\hline 0.03 & 51 & $10^{-8} \mathrm{mbar}$ & & & \\
\hline 0.019 & 51 & $10^{-6} \mathrm{mbar}$ & & & \\
\hline 0.011 & 55 & $10^{-8} \mathrm{mbar}$ & & & \\
\hline 0.043 & 55 & $10^{-6} \mathrm{mbar}$ & & & \\
\hline $0.18 \pm 0.10$ & 44 & $10^{-6} \mathrm{mbar}, 4.4 \% \mathrm{HNO}_{3}$ & 205 & & \\
\hline $0.25 \pm 0.15$ & 20.3 & $10^{-6} \mathrm{mbar}, 25.6 \% \mathrm{HNO}_{3}$ & & & \\
\hline $0.38 \pm 0.1$ & $49 \pm 1$ & $1.1 \times 10^{-7} \mathrm{mbar}$ & 240 & Hanson (1998) & AFT-CIMS (g) \\
\hline $0.51 \pm 0.14$ & $49 \pm 1$ & $2 \times 10^{-7} \mathrm{mbar}$ & & & \\
\hline
\end{tabular}

\section{Comments}

(a) The $\mathrm{H}_{2} \mathrm{O}$ vapor pressure in the flow reactor was $5.3 \times 10^{-4} \mathrm{mbar}( \pm 30 \%)$. Before $\mathrm{ClONO}_{2}$ uptake at typical pressures of $6.4 \times 10^{-3} \mathrm{mbar}$, the $65 \mathrm{wt} \% \mathrm{H}_{2} \mathrm{SO}_{4} / \mathrm{H}_{2} \mathrm{O}$ solution was exposed to $1.7 \times 10^{-3} \mathrm{mbar} \mathrm{HCl}$ for an hour to result in an estimated mole fraction ratio $\mathrm{HCl}: \mathrm{H}_{2} \mathrm{O}=2 \times 10^{-4}$. More than $85 \%$ of the $\mathrm{HCl}$ is recoverable as $\mathrm{Cl}_{2}$ from the 65 wt \% $\mathrm{H}_{2} \mathrm{SO}_{4}$ solution at $210 \mathrm{~K}$. Resulting $\gamma$ values are very similar to experiments without added $\mathrm{HCl}$.

(b) The cold aqueous solution of $\mathrm{H}_{2} \mathrm{SO}_{4}$ was flowed down the walls of the vertical flow tube with a liquid film residence time of 20-30 s. $p\left(\mathrm{H}_{2} \mathrm{O}\right)$ was generally around $1.3 \times 10^{-3}$ mbar, $[\mathrm{HCl}]$ for the experiments on the $40 \mathrm{wt} \%$ solution was $2 \times 10^{11}$ molecule $\mathrm{cm}^{-3}$, for the 60 to $75 \mathrm{wt} \%$ solution was in the range 1 to $3 \times 10^{11}$ molecule $\mathrm{cm}^{-3}$. The error limits are reported to be $(+100 \%,-50 \%)$ except for the 40 and the $60 \mathrm{wt} \%$ solution. The uptake of $\mathrm{ClONO}_{2}$ in the presence of $\mathrm{HCl}$ is not accelerated compared to experiments without $\mathrm{HCl}$. A number of experiments were performed at high $\mathrm{HCl}$ concentrations with the result that $\gamma$ is significantly enhanced at comparable $\mathrm{ClONO}_{2}$ concentrations: for a $60 \mathrm{wt} \%$ solution $\gamma$ was $2 \times 10^{-4}(215 \mathrm{~K}), 0.006(215 \mathrm{~K})$ and $\sim 0.01(238 \mathrm{~K})$ for gas phase $\mathrm{HCl}$ concentrations of $2 \times 10^{10}, 7 \times 10^{12}$ and $\sim 5 \times 10^{12}$ molecule $\mathrm{cm}^{-3}$, respectively. 
(c) Liquid $\mathrm{H}_{2} \mathrm{SO}_{4}$ (46.6 wt \% to $65 \mathrm{wt} \%$ ) was applied as a cold liquid to the inner wall of the flow tube. The $\mathrm{HCl}$ was either added to the liquid (46.6 and $51 \mathrm{wt} \%)$ or taken up from the gas phase (55.6, 57.5, 58.5, 59.8 and $65 \mathrm{wt} \%)$. No significant temperature dependence of the uptake coefficient in the temperature range 192 to $208 \mathrm{~K}$ was observed. The uptake coefficient increased with increasing $p(\mathrm{HCl})$ and increasing $\mathrm{H}_{2} \mathrm{O}$ activity. Significant uptake was observed at $[\mathrm{HCl}] \rightarrow 0$ which was attributed to the $\mathrm{ClONO}_{2}$ hydrolysis reaction. It was found from fitting experimental data over a wide range that a surface-mediated reaction between $\mathrm{Cl}^{-}$and $\mathrm{ClONO}_{2}$ scaling with $p(\mathrm{HCl})$ was required in addition to the competitive bulk reaction to account for the observed uptake rates.

(d) Total pressure of $\mathrm{He} 0.67 \mathrm{mbar}$ and linear flow velocity $890 \mathrm{~cm} \mathrm{~s}^{-1}$. The partial pressure of $\mathrm{H}_{2} \mathrm{O}(5 \mathrm{ppm}$ at 100 mbar) was held constant throughout the range of 195 to $220 \mathrm{~K}$ in order to control $\left[\mathrm{H}_{2} \mathrm{SO}_{4}\right]$ between 45 and $70 \mathrm{wt} \%$ as a function of temperature. $p\left(\mathrm{ClONO}_{2}\right)$ and $p(\mathrm{HCl})$ were varied between $(1-2.5) \times 10^{-7}$ and $(2.7-27) \times 10^{-7} \mathrm{mbar}$, respectively. The value of $\gamma$ increases by a factor of ten with increasing $[\mathrm{HCl}]$ in the given range. Identical values of $\gamma$ were measured on liquid sulphuric acid containing up to $5 \mathrm{wt} \%$ of $\mathrm{HNO}_{3}$ and $5 \mathrm{ppm} \mathrm{H}_{2} \mathrm{O}$.

(e) Reactive uptake experiment using a vertically-mounted WWFT coupled to a differentially-pumped beam-sampling quadrupole MS. The substrates were bulk ternary or quaternary solutions of $\mathrm{H}_{2} \mathrm{SO}_{4}-\mathrm{H}_{2} \mathrm{O}-\mathrm{HCl}-\mathrm{HNO}_{3}$. The uptake measurements were performed at $203 \mathrm{~K}$, and the composition of the solutions selected to correspond to various atmospheric equilibrium temperatures in the range 194-201 K. $p(\mathrm{HCl})$ over the solutions was measured at temperatures in the range 208-233 K to determine $H^{*}(\mathrm{HCl})$ and $p\left(\mathrm{ClONO}_{2}\right)$ was of the order of $1.3 \times 10^{-6} \mathrm{mbar}$. It was established that $\gamma_{\mathrm{ss}}$ was essentially independent of temperature at a given composition and that it was controlled by the $\mathrm{HCl}$ solubility in the condensed phase.

(f) Uptake experiment in RWFT using CIMS detection for $\mathrm{ClONO}_{2}, \mathrm{Cl}_{2}, \mathrm{HOCl}$ and water vapor. $\mathrm{HCl}$ was doped into the 49.5, 51, 53 and $55 \mathrm{wt} \% \mathrm{H}_{2} \mathrm{SO}_{4} / \mathrm{H}_{2} \mathrm{O}$ solutions from the gas phase. For $45 \mathrm{wt} \%$ sulphuric acid solutions $\mathrm{HCl}$ was added by mixing pure with sulphuric acid containing known amounts of $\mathrm{HCl}$. The measured uptake is the sum of the reactions of $\mathrm{ClONO}_{2}$ with $\mathrm{HCl}$ and the hydrolysis with $\mathrm{H}_{2} \mathrm{O}$. The parametrization of the total uptake contains an interfacial term for $\mathrm{ClONO}_{2}+\mathrm{HCl}$ which is important for $[\mathrm{HCl}]>10^{-3} \mathrm{M}$. For liquid ternary solutions containing $\mathrm{HNO}_{3}$ the uptake was significantly lower compared to pure sulphuric acid solutions: for partial pressures corresponding to $5 \mathrm{ppm} \mathrm{H}_{2} \mathrm{O}$ and $5 \mathrm{ppb}$ $\mathrm{HNO}_{3}$ at $19 \mathrm{~km}$ altitude $\gamma_{\mathrm{ss}}$ was typically lower by a factor of two.

(g) Uptake on submicron aerosol particles of $\mathrm{H}_{2} \mathrm{SO}_{4} / \mathrm{H}_{2} \mathrm{O}((49 \pm 1) \mathrm{wt} \%)$ doped with $\mathrm{HCl}$, measured at $240 \mathrm{~K}$ and 120 mbar total pressure to determine surface accommodation coefficient, $\alpha_{\mathrm{s}}$. The surface-area-weighted mean diameter was $160 \mathrm{~nm}$ and the number density $(2-5) \times 10^{5} \mathrm{~cm}^{-3}$. The particles were doped with $\mathrm{HCl}\left(p(\mathrm{HCl})=1.1\right.$ and $\left.2.0 \times 10^{4} \mathrm{mbar}\right)$, resulting in an $\mathrm{HCl}$ content of $9.6 \times 10^{-3}$ and $1.7 \times 10^{-2} \mathrm{M}$, respectively. The weak dependence of $\gamma$ on $p(\mathrm{HCl})$ suggets that reaction rate is not quite fast enough to force the measured $\gamma$ to the value of $\alpha_{\mathrm{s}}$. A best estimate for $\alpha_{\mathrm{s}}$ based on a crude analysis gave $0.72 \pm 0.1$ but a value of $\alpha_{\mathrm{s}}=1$ is consistent with the measurements.

\section{Preferred values}

\begin{tabular}{lll}
\hline Parameter & Value & $T / \mathrm{K}$ \\
\hline$\alpha_{\mathrm{s}}$ & 1.0 & 298 \\
$b_{0} / \mathrm{M}^{-2} \mathrm{~cm}^{-2}$ & $7.9 \times 10^{-11}$ & \\
$k_{\mathrm{H} 2 \mathrm{O}} / \mathrm{s}^{-1}$ & $1.95 \times 10^{10} \exp (2800 / T)$ & $190-280$ \\
$k_{\mathrm{H}^{+}} / \mathrm{M}^{-1} \mathrm{~s}^{-1}$ & $1.22 \times 10^{12} \exp (6200 / T)$ & $190-280$ \\
$\Gamma_{\mathrm{s}}$ & $66.12 \exp (-1374 / T) \times \mathrm{H}_{\mathrm{ClONO} 2} \times \mathrm{M}_{\mathrm{HCl}}$ & \\
$H_{\mathrm{ClONO} 2} / \mathrm{M} \mathrm{atm}^{-1}$ & $1.6 \times 10^{-6} \exp (4710 / T) \exp \left[(-0.306+24.0 / \mathrm{T}) \mathrm{M}_{\mathrm{H} 2 \mathrm{SO}}\right]$ & $200-280$ \\
$D_{\mathrm{l}} / \mathrm{cm}^{2} \mathrm{~s}^{-1}$ & $5 \times 10^{-8} T / \eta$ & $180-240$ \\
Reliability & & \\
$\Delta \log (\alpha)$ & \pm 0.1 & 298 \\
$\Delta \log (\gamma)$ & \pm 0.3 & $200-280$ \\
\hline
\end{tabular}

$\mathrm{M}_{\mathrm{H} 2 \mathrm{SO} 4}=$ molarity $\mathrm{H}_{2} \mathrm{SO}_{4}\left(\mathrm{~mol} \mathrm{dm}^{-3}\right) ; \mathrm{M}_{\mathrm{HCl}}=$ molarity $\mathrm{HCl}\left(\mathrm{mol} \mathrm{dm}^{-3}\right)=p(\mathrm{HCl}) \times \mathrm{H}_{\mathrm{HCl}}^{*}$.

\section{Comments on preferred values}

There is a large body of experimental data on the reactive uptake of $\mathrm{ClONO}_{2}$ in the presence of $\mathrm{HCl}$ on $\mathrm{H}_{2} \mathrm{SO}_{4} / \mathrm{H}_{2} \mathrm{O}$ surfaces, mainly covering the range of temperature and humidity, and acid composition relevant for the upper troposphere and lower 
stratosphere. The uptake leads to efficient formation of $\mathrm{HNO}_{3}$ and $\mathrm{Cl}_{2}$ products both of which transfer rapidly to the gas phase. At low $p(\mathrm{HCl})$, when hydrolysis of $\mathrm{ClONO}_{2}$ contributes, $\mathrm{HOCl}$ is also observed as a product.

The kinetic results are generally consistent between the different studies which used both bulk and dispersed (aerosol) surfaces, although the uptake coefficients measured on bulk surfaces often required large correction for gas phase diffusion effects, because of fast reactive uptake of $\mathrm{ClONO}_{2}$ (or $\mathrm{HCl}$ ) at the surface. The reactive uptake coefficient uptake increases strongly with $\mathrm{H}_{2} \mathrm{O}$ content of $\mathrm{H}_{2} \mathrm{SO}_{4} / \mathrm{H}_{2} \mathrm{O}$ solutions in the corresponding range $40-70 \mathrm{wt} \%$ at constant $p(\mathrm{HCl})$, which reflects the increasing solubility of $\mathrm{HCl}$ in $\mathrm{H}_{2} \mathrm{SO}_{4} / \mathrm{H}_{2} \mathrm{O}$ as relative humidity increases. The uptake coefficient shows only a very weak dependence on temperature.

The uptake coefficient also shows a complex dependence on $p(\mathrm{HCl})$, or on $[\mathrm{HCl}]_{1}$ in experiments where the solutions were specifically prepared. At intermediate [HCl] Elrod et al. (1997) found $\gamma$ proportional to [HCl] ${ }^{1 / 2}$, whilst Zhang et al. (1994) who used higher $p(\mathrm{HCl})$, gave close to linear dependence on $[\mathrm{HCl}]_{1}$. Hanson and Ravishankara (1994) covered a wider range of $p(\mathrm{HCl})$, and found that for intermediate and high $\mathrm{HCl}$ amounts, $\gamma$ values were proportional to $p(\mathrm{HCl})^{1 / 2}$ and $p(\mathrm{HCl})$ respectively, attaining a $\gamma$ value of 0.3 at $1.3 \times 10^{-4} \mathrm{mbar} \mathrm{HCl}$ at $202 \mathrm{~K}$. At low $p(\mathrm{HCl}), \gamma$ ends to a constant value of $\sim 0.01$, which is due to the additional contribution of hydrolysis of $\mathrm{ClONO}_{2}$ to the overall $\gamma$. The observed effects of temperature can also be rationalised by its effect on $\mathrm{HCl}$ solubility in $\mathrm{H}_{2} \mathrm{SO}_{4} / \mathrm{H}_{2} \mathrm{O}$ solution of varying mole fraction, together with compensating effects on the rate coefficient of the liquid phase reaction. At low temperatures the presence of $\mathrm{HNO}_{3}$ in $\mathrm{H}_{2} \mathrm{H}_{2} \mathrm{SO}_{4} / \mathrm{H}_{2} \mathrm{O}$ solutions leads to significantly lower $\gamma$ relative to solutions without $\mathrm{HNO}_{3}$ (Hanson, 1998). The effect increases with $\left[\mathrm{HNO}_{3}\right] /\left[\mathrm{H}_{2} \mathrm{SO}_{4}\right]$ and at equal wt $\%$ amounts to a $50 \%$ reduction in $\gamma$ at $205 \mathrm{~K}$.

Hanson and Ravishankara (1994) suggested that two pathways control the rate of heterogenous reaction of $\mathrm{ClONO}_{2}$ with $\mathrm{HCl}$ : a direct surface reaction; and a bulk phase reaction involving reaction of solvated $\mathrm{ClONO}_{2}$ with $\mathrm{Cl}^{-}$, leading to the distinct kinetic dependencies on $p(\mathrm{HCl})$. Hanson (1998) has reanalysed their earlier data, and those of Elrod et al. (1997) and Zhang et al. (1994) in the light of improved measurements of $\mathrm{HCl}$ solubilty, and has formulated a parameterisation for overall $\gamma$ taking into account the different reactive processes, using a resistance-model formulation, Eq. (1):

$\frac{1}{\gamma}=\frac{1}{\alpha_{\mathrm{s}}}+\frac{1}{\frac{1}{\frac{1}{\Gamma_{\mathrm{b}}}+\frac{1}{\alpha_{\mathrm{s}}} k_{\mathrm{sol}}}+\Gamma_{\mathrm{s}}}$

Hanson's parameterisation gives overall $\gamma$ for uptake of chlorine nitrate as a function of mole fraction of $\mathrm{H}_{2} \mathrm{SO}_{4}$ and $p(\mathrm{HCl})$ for stratospheric conditions near $200 \mathrm{~K}$, using an empirical representation of the composition-dependent liquid phase resistance due to chemical reaction.

Shi et al. (2001) have adopted the Hanson model and extended the parameterisation to include temperature dependence, using re-evaluated $\mathrm{H}_{2} \mathrm{SO}_{4} / \mathrm{H}_{2} \mathrm{O}$ composition and temperature dependent expressions for $\mathrm{HCl}$ solubility, $H_{\mathrm{HCl}}^{*}$ (see VI.A4.14), chlorine nitrate solubility, $H_{\mathrm{ClONO} 2}$, and resistance term $\Gamma_{\mathrm{b}}$ for the $\mathrm{ClONO}_{2}+\mathrm{H}_{2} \mathrm{O}$ reaction (see VI.A4.25). Shi et al. (2001) assumed that the $\mathrm{ClONO}_{2}+\mathrm{HCl}$ reaction is $\mathrm{H}^{+}$catalysed and its rate is diffusion controlled, as deduced by Hanson (1998). They also assume that the direct surface reaction of $\mathrm{ClONO}_{2}$ with $\mathrm{HCl}$ depends on bulk-liquid $\left[\mathrm{ClONO}_{2}\right]$ and $[\mathrm{HCl}]$ through their respective $T$ - and composition-dependent $H$ values.

The preferred value $\alpha_{\mathrm{s}}$ is based on the measured uptake coefficients on HCl-doped aerosols reported by Hanson (1998), which support a surface accommodation coefficient near unity $\left(\alpha_{\mathrm{s}}=1\right.$, see comment $(\mathrm{g})$ above). It follows that the term $\alpha_{\mathrm{s}} k_{\mathrm{sol}} / k_{\mathrm{des}}$ which is equivalent to the surface to bulk resistance term, $\Gamma_{\mathrm{sb}}$, must also be close to unity, and Eq. (1) reduces to:

$\frac{1}{\gamma}=1+\frac{1}{\left(\Gamma_{\mathrm{b}}+\Gamma_{\mathrm{s}}\right)}$

The resistance term $\Gamma_{\mathrm{b}}$ for the bulk reaction probability is given by: $\Gamma_{\mathrm{b}}=4 R T H\left(D_{1} k^{\mathrm{I}}\right)^{\frac{1}{2}} / c$ where $D_{1}$ and $H$ are respectively the diffusion coefficient and Henry's constant for $\mathrm{ClONO}_{2} \cdot k^{\mathrm{I}}$ is the sum of the first order rate coefficients for reaction of $\mathrm{ClONO}_{2}$ with $\mathrm{Cl}^{-}\left(k_{\mathrm{HCl}}^{\mathrm{I}}\right)$ and $\mathrm{H}_{2} \mathrm{O}\left(k_{\mathrm{H} 2 \mathrm{O}}^{\mathrm{I}}\right)$ in the bulk. Combining the resistance terms for these two processes acting in parallel gives:

$\Gamma_{\mathrm{b}}=\Gamma_{\mathrm{H} 2 \mathrm{O}} \sqrt{1+\frac{k_{\mathrm{HCL}}^{\mathrm{I}}}{k_{\mathrm{H} 2 \mathrm{O}}^{\mathrm{I}}}}$

Here $\Gamma_{\mathrm{H} 2 \mathrm{O}}=4 R T H\left(D_{1} k_{\mathrm{H} 2 \mathrm{O}}^{\mathrm{I}}\right)^{\frac{1}{2}} / c$ and the recommended temperature and composition dependence of the first order rate coefficient, $k_{\mathrm{H} 2 \mathrm{O}}^{\mathrm{I}}$, and solubility of $\mathrm{ClONO}_{2}, \mathrm{H}$, are given in the functional forms described in the data sheet for the $\mathrm{ClONO}_{2}+\mathrm{H}_{2} \mathrm{O}$ reaction (see VI.A4.25). The overall hydrolysis rate constant is given by the expression:

$k_{\mathrm{H} 2 \mathrm{O}}^{\mathrm{I}}\left(\mathrm{s}^{-1}\right)=\left(k_{\mathrm{H} 2 \mathrm{O}}+k_{\mathrm{H}^{+}} a_{\mathrm{H}^{+}}\right) a_{\mathrm{w}}$ 
where $a_{\mathrm{w}}=$ water activity; $a_{\mathrm{H}^{+}}=$acid activity $\left(\mathrm{Mol} \mathrm{dm}^{-3}\right) \cdot a_{\mathrm{w}}$ is calculated from:

$a_{\mathrm{w}}=\exp \left[\left(-69.775 X-18253.7 X^{2}+31072.2 X^{3}-25668.8 X^{4}\right)\left(1 / T-26.9033 / T^{2}\right)\right]$.

The diffusion controlled rate coefficient for the $\mathrm{ClONO}_{2}+\mathrm{HCl}$ reaction is given by the expression:

$k_{\mathrm{HCl}}^{\mathrm{I}}\left(\mathrm{s}^{-1}\right)=b_{0} D_{\mathrm{l}} a_{\mathrm{H}^{+}} H_{\mathrm{HCl}}^{*} p(\mathrm{HCl})$

The recommended value for the constant $b_{\mathrm{o}}\left(=7.9 \times 10^{-11} \mathrm{M}^{-2} \mathrm{~cm}^{-2}\right)$, was determined from the experimental measurement of the reacto-diffusive length at $250 \mathrm{~K}$ at high [HCl] (Hanson, 1998). The value of $H_{\mathrm{HCl}}^{*}$ is given as a function of $\mathrm{H}_{2} \mathrm{SO}_{4} \mathrm{~mole}$ fraction, $\mathrm{X}$, by the expression:

$H_{\mathrm{HCl}}^{*}=\left(0.094-0.61 X+1.2 X^{2}\right) \exp \left(-8.68+\left(8515-10718 X^{0.7}\right) / T\right)$

as given in data sheet for $\mathrm{HCl}$ solubilty VI.A4.14. The acid activity is derived from the data from the thermodynamic model of Carslaw et al. (1997). For the expression for $a_{\mathrm{H}^{+}}$in the table the Carslaw model was extended to include the acidity of pure water, to provide values of $a_{\mathrm{H}^{+}}$as a function of acid wt \% (wt) in units of $\mathrm{M} \mathrm{dm}^{-3}$ extending to dilute solution (wt $\sim 0 \%$ ):

$$
\begin{aligned}
a_{\mathrm{H}^{+}} & =\exp \left[60.51-0.095 w t+0.0077 w t^{2}-1.61 \times 10^{-5} w t^{3}-\left(1.76+2.52 \times 10^{-4} w t^{2}\right) T^{0.5}\right. \\
& \left.+\left(-805.89+2.53 .05 w t^{0.076}\right) / T^{0.5}\right]
\end{aligned}
$$

Diffusion coefficients, $D_{1}$, are calculated using the expression: $D_{1}=C T / \eta$, with $C=5 \times 10^{-8} \mathrm{~cm}^{2} \mathrm{cP} \mathrm{K}^{-1} \mathrm{~s}^{-1}$ (taken from Klassen et al., 1998). Viscosity data for $\mathrm{H}_{2} \mathrm{SO}_{4} / \mathrm{H}_{2} \mathrm{O}$ obtained by Williams and Long (1995) was reparameterized to give a more general formulation for $D_{1}$ covering the temperature range $200-300 \mathrm{~K}$ and $0-80 \mathrm{wt} \% \mathrm{H}_{2} \mathrm{SO}_{4}$ :

$\left.\eta=A T^{-1.43} \exp \left(448 / T-T_{0}\right)\right)$

$A=169.5+5.18 w t-0.0825 w t^{2}+3.27 \times 10^{-3} w t^{3}$

$T_{0}=144.11-0.166 w t+0.015 w t^{2}-2.18 \times 10^{-4} w t^{3}$

The resistance term $\Gamma_{\mathrm{s}}$ for the surface reaction probability was parameterised by Shi et al. (2001) as follows:

$\Gamma_{\mathrm{s}}=66.12 \exp (-1374 / T) H_{\mathrm{ClHONO} 2} H_{\mathrm{HCl}}^{*} p_{\mathrm{HCl}}$

which assumes a dependence of surface reaction rate on liquid phase concentrations of reactants, which is determined by their solubilites. An Arrhenius temperature dependence is assumed and the recommended constant term was evaluated by fitting to the $\mathrm{ClONO}_{2}$ uptake rate data at high $[\mathrm{HCl}]$. This expression gave a better representation of the temperature dependence of the surface reaction component than that used by Hanson (1998).

The model gives a good fit to the data over the range of conditions employed and will give reasonably accurate values of $\gamma\left(\mathrm{ClONO}_{2}\right)$ for UT/LS conditions. Overall the deviation reported by Shi et al. (2001) from experimental data used for the fit was $40 \%$, compared with $46 \%$ for the parameters reported by Hanson (1998). These form the basis of the recommended uncertainty in $\gamma$ over the temperature range $200-280 \mathrm{~K}$. This uncertainty remains also appropriate in view of explicit measurements of the protonation state of $\mathrm{HSO}_{4}^{-}$by Knopf et al. (2003). The temperature dependence of the $\gamma_{\mathrm{r}}$ is in fact rather small due to compensating effects of the temperature dependence of $D_{1}$ and $H_{\mathrm{HCl}}^{*}$. For detailed discussion of the model/measurement comparison the paper by Shi et al. (2001) should be consulted.

\section{References}

Donaldson, D. J., Ravishankara, A. R., and Hanson, D. R.: J. Phys. Chem. A, 101, 4717-4725, 1997.

Carslaw, K. S., Clegg, S. L., and Brimblecombe, P.: J. Phys. Chem., 99, 11557-11574, 1995.

Elrod, M. J., Koch, R. E., Kim, J. E., and Molina, M. J.: Faraday Discuss., 100, 269-278, 1995.

Hanson, D. R. and Ravishankara, A. R.: J. Geophys. Res., 96, 17307-17314, 1991.

Hanson, D. R. and Ravishankara, A. R.: J. Phys. Chem., 98, 5728-5735, 1994.

Hanson, D. R.: J. Phys. Chem. A, 102, 4794-4807, 1998.

Huthwelker, T., Peter, Th., Luo, B. P., Clegg, S. L., Carslaw, K., and Brimblecombe, P.: J. Atm. Chem., 21, 81-95, 1995.

Klassen, J. K., Hu, Z., and Williams, L. R.: J. Geophys. Res., 103, 16197-16202, 1998.

Knopf, D. A., Luo, B. P., Krieger, U. K., and Koop, T.: J. Phys. Chem. A, 107, 4322-4332, 2003.

Shi, Q., Jayne, J. T., Kolb, C. E., Worsnop, D. R., and Davidovits, P.: J. Geophys. Res., 106, 24259-24274, 2001.

Tolbert, M. A., Rossi, M. J., and Golden, D. M.: Geophys. Res. Lett., 15, 847-850, 1988.

Williams, L. R. and Long, F. S.: J. Phys. Chem., 99, 3748-3751, 1995.

Zhang, R., Leu, M.-T., and Keyser, L. F.: J. Phys. Chem., 98, 13563-13574, 1994. 


\section{VI.A4.25}

$\mathrm{ClONO}_{2}(\mathrm{~g})+\mathrm{H}_{2} \mathrm{O}(\mathrm{l}) \rightarrow \mathrm{HONO}_{2}(\mathrm{aq})+\mathrm{HOCl}(\mathrm{g})$

\section{Experimental data}

\begin{tabular}{|c|c|c|c|c|}
\hline Parameter & $\begin{array}{l}{\left[\mathrm{H}_{2} \mathrm{SO}_{4}\right]} \\
\text { wt } \%\end{array}$ & $T / \mathrm{K}$ & Reference & Technique/Comments \\
\hline $\begin{array}{l}\gamma, \gamma_{\mathrm{ss}}, \gamma_{0}\left(\mathrm{ClONO}_{2}\right) \\
(3.2 \pm 0.8) \times 10^{-3}\end{array}$ & 95.6 & & Rossi et al. (1987) & Kn-MS (a) \\
\hline $2.6 \times 10^{-3}$ & 65 & 210 & Tolbert et al. (1988) & Kn-MS (b) \\
\hline $3 \times 10^{-4}$ & 75 & 230 & & \\
\hline $0.064 \pm 0.010$ & 40 & 218 & Hanson and Ravishankara (1991a) & WWFT-CIMS (c) \\
\hline$(3.1 \pm 0.5) \times 10^{-3}$ & 60 & 215 & & \\
\hline$(1.2 \pm 0.2) \times 10^{-3}$ & 65 & 215 & & \\
\hline$(3.9 \pm 0.7) \times 10^{-4}$ & 70 & 220 & & \\
\hline$(1.9 \pm 0.3) \times 10^{-4}$ & 75 & 230 & & \\
\hline$(8.1 \pm 1.3) \times 10^{-2}$ & 40 & $220 \pm 5$ & Williams et al. (1994) & Kn-MS (d) \\
\hline$(4.1 \pm 0.7) \times 10^{-3}$ & 57.5 & & & \\
\hline$(2.1 \pm 0.35) \times 10^{-4}$ & 75 & & & \\
\hline$(3.8 \pm 1.2) \times 10^{-2}$ & 46.6 & 202 & Hanson and Ravishankara (1994) & WWFT-CIMS (e) \\
\hline$(6.1 \pm 2.0) \times 10^{-3}$ & 57.5 & & & \\
\hline$(9.3 \pm 3.0) \times 10^{-4}$ & 65 & & & \\
\hline$(2.0 \pm 0.6) \times 10^{-2}$ & 50 & 197.5 & Zhang et al. (1994) & WWFT-CIMS (f) \\
\hline$(2.5 \pm 0.7) \times 10^{-3}$ & 60 & 205 & & \\
\hline$(7.5 \pm 2.5) \times 10^{-4}$ & 65 & 211 & & \\
\hline$(3.0 \pm 1.0) \times 10^{-4}$ & 70 & 218 & & \\
\hline $2 \times 10^{-3}$ & 65 & 250 & Hanson and Lovejoy (1995) & AFT-CIMS (g) \\
\hline 0.11 & 53 & 200 & Zhang et al. (1995) & WWFT-CIMS (h) \\
\hline 0.034 & $29,16.4 \mathrm{wt} \% \mathrm{HNO}_{3}$ & 195 & & \\
\hline 0.021 & $5,41 \mathrm{wt} \% \mathrm{HNO}_{3}$ & 200 & & \\
\hline 0.045 & $40,10 \mathrm{wt} \% \mathrm{HNO}_{3}$ & 200 & & \\
\hline 0.10 & $5,41 \mathrm{wt} \% \mathrm{HNO}_{3}$ & 220 & & \\
\hline$(3.7 \pm 0.6) \times 10^{-3}$ & 59 & 241 & Robinson et al. (1997) & DT-TDLAS (i) \\
\hline$(5.60 \pm 0.84) \times 10^{-2}$ & 39 & 229 & & \\
\hline$(2.62 \pm 0.39) \times 10^{-2}$ & 39 & 259 & & \\
\hline $0.071 \pm 0.025$ & 36 & 245 & Ball et al. (1998) & AFT-CL (j) \\
\hline $0.038 \pm 0.009$ & 43 & 248 & & \\
\hline $0.0094 \pm 0.003$ & 54 & 253 & & \\
\hline $0.113 \pm 0.023$ & 36.5 & 203 & Hanson (1998) & WWFT CIMS (k) \\
\hline $0.086 \pm 0.017$ & 36.5 & 230 & & \\
\hline $0.053 \pm 0.011$ & 45 & 203 & & \\
\hline $0.038 \pm 0.008$ & 45 & 230 & & \\
\hline $0.011 \pm 0.002$ & 55 & 203 & & \\
\hline$(1.6 \pm 0.3) \times 10^{-4}$ & 75 & 270 & & \\
\hline$(1.4 \pm 0.3) \times 10^{-4}$ & 75 & 250 & & \\
\hline$(1.1 \pm 0.2) \times 10^{-4}$ & 75 & 230 & & \\
\hline$(6.4 \pm 1.3) \times 10^{-5}$ & 75 & 217 & & \\
\hline$(2.5 \pm 1.0) \times 10^{-5}$ & 75 & 200 & & \\
\hline $0.019 \pm 0.004$ & $44,4.6 \mathrm{wt} \% \mathrm{HNO}_{3}$ & 203 & & \\
\hline $0.042 \pm 0.016$ & $20,26 \mathrm{wt} \% \mathrm{HNO}_{3}$ & 205 & & \\
\hline
\end{tabular}




\section{Comments}

(a) Simultaneous flows of $\mathrm{H}_{2} \mathrm{O}\left(1.5 \times 10^{13}\right.$ molecule $\left.\mathrm{cm}^{-3}\right)$ and $\mathrm{ClONO}_{2}\left(9.4 \times 10^{11}-4.5 \times 10^{13}\right.$ molecule $\left.\mathrm{cm}^{-3}\right)$ were exposed to bulk $95.6 \% \mathrm{H}_{2} \mathrm{SO}_{4}$ at ambient temperature; $\gamma$ is independent of $\left[\mathrm{ClONO}_{2}\right]$ and declines with exposure time.

(b) The $\mathrm{H}_{2} \mathrm{O}$ vapour pressure in the flow reactor was $5.3 \times 10^{-4} \mathrm{mbar}( \pm 30 \%)$. Uptake of $\mathrm{ClONO}_{2}$ at typical pressures of $6.4 \times 10^{-3}$ mbar on $65 \% \mathrm{H}_{2} \mathrm{SO}_{4} / \mathrm{H}_{2} \mathrm{O}$.

(c) Flowing aqueous $\mathrm{H}_{2} \mathrm{SO}_{4}$ film. $p\left(\mathrm{H}_{2} \mathrm{O}\right)$ was $\sim 1.3 \times 10^{-3}$ mbar and $\left[\mathrm{ClONO}_{2}\right]$ was approx. $10^{10}-10^{11}$ molecule $\mathrm{cm}^{-3}$. The temperature dependence of $\gamma$ as measured for the $60 \mathrm{wt} \%$ and $70 \mathrm{wt} \% \mathrm{H}_{2} \mathrm{SO}_{4}$ solution: none was found within the reported error limits.

(d) $\left[\mathrm{ClONO}_{2}\right]$ was approx. $10^{12}-10^{13}$ molecule $\mathrm{cm}^{-3}$. The following analytical expression was obtained for the uptake/reaction probability $(\gamma)$ of $\mathrm{ClONO}_{2}: \log \gamma=1.87-0.074 \cdot\left[\mathrm{H}_{2} \mathrm{SO}_{4}\right](\mathrm{wt} \%)( \pm 15 \%)$ valid for the range 40 to $80 \mathrm{wt} \%$ $\mathrm{H}_{2} \mathrm{SO}_{4} / \mathrm{H}_{2} \mathrm{O}$ mixtures at $220 \mathrm{~K}$.

(e) Quiescent liquid $\mathrm{H}_{2} \mathrm{SO}_{4}$ surface with CIMS detection. $\mathrm{H}_{2} \mathrm{SO}_{4}$ (46.6 wt $\%$ to $65 \mathrm{wt} \%$ ) was applied as a cold liquid to the inner wall of the flow tube.

(f) Walls coated with a $70 \mathrm{wt} \% \mathrm{H}_{2} \mathrm{SO}_{4}$ solution of approximately $0.1 \mathrm{~mm}$ thickness. The partial pressure of $\mathrm{H}_{2} \mathrm{O}$ was held constant (5 ppm at 100 mbar pressure) throughout the temperature range $195-220 \mathrm{~K}$ in order to control the acid concentration with temperature leading to $\left[\mathrm{H}_{2} \mathrm{SO}_{4}\right]$ in the range 45 to $70 \%$ by weight.

(g) High pressure ( 0.3 to $0.8 \mathrm{~atm}$ ) flow tube using slow-flow conditions and sub-micron $\mathrm{H}_{2} \mathrm{SO}_{4}$ aerosol generated by homogeneous nucleation from the reaction of $\mathrm{SO}_{3}+\mathrm{H}_{2} \mathrm{O}$. Particle size $60-250 \mathrm{~nm}$ diameter. The uptake coefficient for the reaction of $\mathrm{ClONO}_{2}$ with $60 \mathrm{wt} \%$ sulphuric acid aerosol increases monotonically with particle size at $250 \mathrm{~K}$. The reacto-diffusive length ( $l$, the effective depth into the liquid over which reaction occurs) derived from these experiments is $(0.037 \pm 0.007) \mu \mathrm{m}$.

(h) Two methods of film preparation of defined ternary composition $\mathrm{H}_{2} \mathrm{SO}_{4} / \mathrm{H}_{2} \mathrm{O} / \mathrm{HNO}_{3}$ at low temperatures resulted in identical values of $\gamma$ which does not change in the presence of $\mathrm{HNO}_{3}$, even at a limiting composition of $15 \% \mathrm{HNO}_{3} / 30 \%$ $\mathrm{H}_{2} \mathrm{SO}_{4}$ at $195 \mathrm{~K}$.

(i) Fast train of $200 \mu \mathrm{m} \mathrm{H}_{2} \mathrm{SO}_{4} / \mathrm{H}_{2} \mathrm{O}$ droplets traversing a flow tube with TDLAS detection. Pressures $=13.3$ mbar and droplet-gas interaction times of 2 to $20 \mathrm{~ms}$. The temperature of the droplets was inferred from the water partial pressure measured by TDL absorption. A negative temperature dependence of $\gamma_{\mathrm{ss}}$ was observed for $T \geq 230 \mathrm{~K}$ and $\gamma_{\mathrm{ss}}$ slightly increased with increasing concentration of $\mathrm{H}_{2} \mathrm{SO}_{4}$ measured at 39,54 and $69 \mathrm{wt} \%$. A model involving neutral and acid catalysed mechanism for $\mathrm{ClONO}_{2}$ hydrolysis was used to extract valies of $\alpha_{\mathrm{b}}$ and liquid phase rate constants by fitting data from several laboratories over a range of temperature and composition. The temperature dependence of $\alpha_{\mathrm{b}}$ was given in the form $\alpha_{\mathrm{b}} /\left(1-\alpha_{\mathrm{b}}\right)=\exp (-17.89+4515 / T)$.

(j) High pressure ( 0.3 to $0.8 \mathrm{~atm}$ ) flow tube using slow flow conditions and sub micron $\mathrm{H}_{2} \mathrm{SO}_{4}$ aerosol generated by homogeneous nucleation from the reaction of $\mathrm{SO}_{3}+\mathrm{H}_{2} \mathrm{O}$. Particles of a narrow size range were selected with a DMA for each $\mathrm{H}_{2} \mathrm{SO}_{4}$ concentration used: mean size $95 \mathrm{~nm}, 104 \mathrm{~nm}$ and $63 \mathrm{~nm}$ radius for 36,43 and $54 \mathrm{wt} \%$ respectively. $\mathrm{ClONO}_{2}(30$ to $200 \mathrm{ppb}$ ) detected by titrating with $\mathrm{NO}$ in a heated quartz tube, using TDLAS to monitor $\mathrm{NO}$ and also $\mathrm{H}_{2} \mathrm{O}$ vapor. The average value of $\gamma$ was used to derive a value of $l=26 \mathrm{~nm}$ for the reacto-diffusive length at $\sim 43 \mathrm{wt} \% \mathrm{H}_{2} \mathrm{SO}_{4}$

(k) Uptake of $\mathrm{ClONO}_{2}$ measured in two flow reactors. $a$ : RWFT with sulphuric acid wall film $(0.2 \mathrm{~mm}$ thickness $)$. The pressure was $0.5 \mathrm{mbar} \mathrm{He}$ in the coated wall flow tube and 240 mbar of $\mathrm{N}_{2}$ in the aerosol flow tube. The range of $\left[\mathrm{H}_{2} \mathrm{SO}_{4}\right]$ investigated was 36.5 to $55 \mathrm{wt} \% \mathrm{H}_{2} \mathrm{SO}_{4} / \mathrm{H}_{2} \mathrm{O}$ at $203 \mathrm{~K}, 36.5$ to $45.0 \mathrm{wt} \%$ at $230 \mathrm{~K}$ and $75 \mathrm{wt} \%$ in the temperature range 200 to $270 \mathrm{~K}$. $b$ : sub-micron aerosol (particle size $0.1 \mu \mathrm{m})\left(49 \pm 1\right.$ ) wt $\% \mathrm{H}_{2} \mathrm{SO}_{4} / \mathrm{H}_{2} \mathrm{O}$. CIMS detection for $\mathrm{ClONO}_{2}, \mathrm{HOCl}$ and water vapor. Initial concentration was $5 \times 10^{11}$ molecule $\mathrm{cm}^{-3}$ in both studies. The results for small sulphuric acid particles resulted in a lower limit of $\alpha_{\mathrm{S}}>0.5 . \mathrm{ClONO}_{2}$ reaction probabilities were also measured on $\mathrm{H}_{2} \mathrm{SO}_{4}$ solutions containing significant amounts of $\mathrm{HNO}_{3}$. In contrast to previous reports, $\mathrm{HNO}_{3}$ was found to have a significant reducing effect on $\gamma$ for $\mathrm{ClONO}_{2}$. 


\section{Preferred values}

\begin{tabular}{lll}
\hline Parameter & Value & $T / \mathrm{K}$ \\
\hline$\alpha_{\mathrm{b}}$ & 1 & 298 \\
$k_{\mathrm{H} 2 \mathrm{O}} / \mathrm{s}^{-1}$ & $1.95 \times 10^{10} \exp (2800 / T)$ & $190-280$ \\
$k_{\mathrm{H}^{+}} / \mathrm{M}^{-1} \mathrm{~s}^{-1}$ & $1.22 \times 10^{12} \exp (6200 / T)$ & $190-280$ \\
$H_{\mathrm{ClONO} 2} / \mathrm{M} \mathrm{atm}^{-1}$ & $1.6 \times 10^{-6} \exp (4710 / T) \cdot \exp \left[(-0.306+24.0 / T) \cdot \mathrm{M}_{\mathrm{H} 2 \mathrm{SO}}\right]$ & $200-280$ \\
$D_{\mathrm{l}} / \mathrm{cm}^{2} \mathrm{~s}^{-1}$ & $5 \times 10^{-8} T / \eta$ & $180-240$ \\
Reliability & & \\
$\Delta \log \left(\alpha_{\mathrm{b}}\right)$ & \pm 0.1 & 298 \\
$\Delta \log (\gamma)$ & \pm 0.2 & $200-280$ \\
\hline
\end{tabular}

$\mathrm{M}_{\mathrm{H} 2 \mathrm{SO} 4}=$ molarity $\mathrm{H}_{2} \mathrm{SO}_{4}\left(\mathrm{~mol} \mathrm{dm}^{-3}\right)$

\section{Comments on preferred values}

There is a large body of experimental data on the uptake of $\mathrm{ClONO}_{2}$ on $\mathrm{H}_{2} \mathrm{SO}_{4} / \mathrm{H}_{2} \mathrm{O}$ surfaces covering relevant temperatures, humidity and sulphuric acid aerosol composition for the atmosphere between the surface and the lower stratosphere. The results are generally consistent between the different studies, which used both bulk and dispersed (aerosol) surfaces. The uptake leads to hydrolysis of $\mathrm{ClONO}_{2}$ and formation of $\mathrm{HOCl}$ and $\mathrm{HNO}_{3}$, which both transfer to the gas phase. The presence of $\mathrm{HNO}_{3}$ in the $\mathrm{H}_{2} \mathrm{SO}_{4} / \mathrm{H}_{2} \mathrm{O}$ solutions leads to a reduction in the uptake rate (Hanson, 1998; Zhang et al., 1995). Based on uptake measurements of Hanson (1998) on $\mathrm{HNO}_{3} / \mathrm{H}_{2} \mathrm{SO}_{4} / \mathrm{H}_{2} \mathrm{O}$ solutions corresponding to conditions in the polar lower stratosphere ( $\sim 5 \mathrm{ppb} \mathrm{HNO}_{3}$ in the gas phase), the $\gamma$ values would be approximately a factor of 2 lower than for $\mathrm{H}_{2} \mathrm{SO}_{4} / \mathrm{H}_{2} \mathrm{O}$ solutions.

Uptake rates show strong dependence on $\mathrm{H}_{2} \mathrm{O}$ content of the sulphuric acid solution/aerosol, $\gamma_{\mathrm{ClONO} 2}$ decreasing in the range $20-70 \mathrm{wt} \% \mathrm{H}_{2} \mathrm{SO}_{4} . \mathrm{H}_{2} \mathrm{O}$ content depends on both temperature and relative humidity and consequently there is a complex variation of $\gamma$ for atmospheric conditions: generally low temperature and high RH favour rapid reactive uptake with $\gamma$ values $\sim 0.1$ in $40 \% \mathrm{H}_{2} \mathrm{SO}_{4}$ falling off to $\sim 10^{-4}$ in $75 \mathrm{wt} \% \mathrm{H}_{2} \mathrm{SO}_{4}$. At low temperature the effect of composition dominates leading to weak negative $T$ dependence of $\gamma$.

These characteristics indicate that uptake is determined by chemical reaction in the liquid droplet and can be interpreted in terms of the resistance model. Thus the overall uptake coefficient is given by Eq. (1)

$\frac{1}{\gamma}=\frac{1}{\alpha_{\mathrm{b}}}+\frac{1}{\Gamma_{\mathrm{b}}}$

$\Gamma_{\mathrm{b}}=4 R T H\left(D_{\mathrm{l}} k^{\mathrm{I}}\right)^{1 / 2} / \bar{c}$

where $H$ is the Henry's law constant of $\mathrm{ClONO}_{2}, D_{1}$ is the diffusion coefficient of $\mathrm{ClONO}_{2}$, and $k^{\mathrm{I}}$ the first order rate constant for hydrolysis of $\mathrm{ClONO}_{2}$ in $\mathrm{H}_{2} \mathrm{SO}_{4} / \mathrm{H}_{2} \mathrm{O}$ solutions.

Robinson et al. (1977) presented a phenomenological model addressing solubility, diffusion and chemical reactivity of $\mathrm{ClONO}_{2}$, which accounts for the observed dependence of the uptake coefficients on concentration and temperature. Two hydrolysis pathways are proposed, a direct reaction with $\mathrm{H}_{2} \mathrm{O}$ and an acid-catalysed reaction involving $\mathrm{H}^{+}$ions to promote the dissociation: $\mathrm{ClONO}_{2}+\mathrm{H}^{+} \rightarrow \mathrm{HOCl}+\mathrm{NO}_{2}^{+}$. The hydrolysis rate coefficient representing the two pathways was given in the form: $k^{\mathrm{I}}=k_{\mathrm{H} 2 \mathrm{O}} a_{\mathrm{w}}+k_{\mathrm{H}^{+}} a_{\mathrm{H}^{+}}$; here $a_{\mathrm{w}}$ and $a_{\mathrm{H}^{+}}$are the activities of $\mathrm{H}_{2} \mathrm{O}$ and $\mathrm{H}^{+}$in solution respectively. They extracted temperature and composition dependencies for the individual parameters, $\alpha_{\mathrm{b}}$ and $k^{\mathrm{I}}$ from a fit of their experimental $\gamma$ values using this model, together with a parameterisation of $H$ based on solubility data given by Huthwelker et al. (1995) for $\mathrm{HOCl}$ as a proxy for $\mathrm{ClONO}_{2}$. $D_{1}$ was parameterized using the expression: $D_{1}=\mathrm{cT} / \eta$, with $c$ evaluated from viscosity data for $\mathrm{H}_{2} \mathrm{SO}_{4} / \mathrm{H}_{2} \mathrm{O}$ solutions obtained by Williams and Long (1995).

Hanson (1998) has used a similar model, which gives $\gamma$ values as a function of mole fraction of $\mathrm{H}_{2} \mathrm{SO}_{4}, \mathrm{X}$, which is defined for a given temperature and water activity (RH). Only a single direct hydrolysis reaction was used for $k^{\mathrm{I}}$. Composition dependent values of $\Gamma_{\mathrm{b}}$ were obtained from a fit of Eq. (1) to experimental X-dependent $\gamma$ values for 200-205 K, assuming $\alpha_{\mathrm{b}}=1.0: \Gamma_{\mathrm{b}}=\exp \left(-0.392-13.13 \mathrm{X}-50.914 \mathrm{X}^{2}\right)$ (Eq. 3). This simple expression can be used to calculate $\gamma$ from Eq. (1) with reasonable accuracy for specified values of $\mathrm{H}_{2} \mathrm{SO}_{4}$ concentrations in the range 40-65 wt \% in and for temperatures near $200 \mathrm{~K}$; at $\geq 70 \mathrm{wt} \%$ the observed $\gamma$ values are seriously underpredicted. Thus this formula only applies for only for a limited range of lower stratospheric conditions. Hanson also derived individual parameterisations for variation of $H, D_{1}, \mathrm{H}_{2} \mathrm{SO}_{4}$ acidity $\left(a_{\mathrm{H}^{+}}\right.$, $\left.a_{\mathrm{H} 2 \mathrm{O}}\right)$ as a function of mole fraction of $\mathrm{H}_{2} \mathrm{SO}_{4}$ at temperatures near $200 \mathrm{~K}$. 
Shi et al. (2001) have reported further analysis using these models for representation of uptake coefficients for $\mathrm{ClONO}_{2}$ hydrolysis and reaction with $\mathrm{HCl}$ in $\mathrm{H}_{2} \mathrm{SO}_{4}$ solutions. They adopt a general mechanism involving both a direct and an acidcatalyzed channel for $\mathrm{ClONO}_{2}$ reaction with $\mathrm{H}_{2} \mathrm{O}$ and $\mathrm{HCl}$, with the reactive species controlled by following equilibrium:

$\mathrm{ClONO}_{2}$ (liq) $+\mathrm{H}^{+} \Leftrightarrow \mathrm{HClONO}_{2}^{+}$(liq) $K_{\text {eq }}$

The hydrolysis rate constant is given by:

$k^{\mathrm{I}}=k_{\mathrm{H} 2 \mathrm{O}} a_{\mathrm{w}}+k_{\mathrm{H}^{+}} a_{\mathrm{H}^{+}} a_{\mathrm{w}}$,

where the acid catalysed rate constant, $k_{\mathrm{H}^{+}}$, includes the term $K_{\mathrm{eq}}$, arising from the assumption that protonated species are in equilibrium. The values of $D_{1}, H, \mathrm{H}_{2} \mathrm{SO}_{4}$ acidity and water activity $\left(a_{\mathrm{H}^{+}}, a_{\mathrm{w}}\right)$ were parameterized independently of the experimental uptake measurements.

The thermodynamic model of Carslaw et al. (1995) was used to derive a parameterization of $a_{\mathrm{w}}$ in terms of the mole fraction $(X)$ of $\mathrm{H}_{2} \mathrm{SO}_{4},(X=w t /(w t+(100-w t) 98 / 18))$ :

$a_{\mathrm{w}}=\exp \left[\left(-69.775 X-18253.7 X^{2}+31072.2 X^{3}-25668.8 X^{4}\right)\left(1 / T-26.9033 / T^{2}\right)\right]$.

Note however that for atmospheric modelling $a_{\mathrm{w}}$ is usually calculated from the local $\mathrm{H}_{2} \mathrm{O}$ mixing ratio and temperature. For the acid activity the Carslaw model was extended to include the acidity of pure water, to provide values of $a_{\mathrm{H}^{+}}$as a function of acid $w t$ in units of $\mathrm{M}$ extending to dilute solution $(w t \sim 0 \%)$ :

$$
\begin{aligned}
a_{\mathrm{H}^{+}} & =\exp \left[60.51-0.095 w t+0.0077 w t^{2}-1.61 \times 10^{-5} w t^{3}\right. \\
& \left.-\left(1.76+2.52 \times 10^{-4} w t^{2}\right) T^{0.5}+\left(-805.89+253.05 w t^{0.076}\right) / T^{0.5}\right] .
\end{aligned}
$$

Diffusion coefficients, $D_{1}$ were estimated using the expression: $D_{1}=\mathrm{cT} / \eta$, with $\mathrm{c}=5 \times 10^{-8} \mathrm{~cm}^{2} \mathrm{cPK}^{-1} \mathrm{~s}^{-1}$ (taken from Klassen et al., 1998). Viscosity data for $\mathrm{H}_{2} \mathrm{SO}_{4} / \mathrm{H}_{2} \mathrm{O}$ obtained by Williams and Long (1995) was re-parameterised to give a more general formulation covering the temperature range $200-300 \mathrm{~K}$ and $0-80 \mathrm{wt} \% \mathrm{H}_{2} \mathrm{SO}_{4}$ :

$$
\begin{aligned}
& \left.\eta=A T^{-1.43} \exp \left(448 / T-T_{0}\right)\right) \\
& A=169.5+5.18 w t-0.0825 w t^{2}+3.27 \times 10^{-3} w t^{3} \\
& T_{0}=144.11-0.166 w t+0.015 w t^{2}-2.18 \times 10^{-4} w t^{3}
\end{aligned}
$$

The variations of $H$ and $k_{1}$ with acid strength are constrained by the experimental values of $H\left(k_{1}\right)^{1 / 2}$, which is determined from experimental uptake coefficients using Eq. (2) for defined $D_{1}$. Following Robinson et al. (1997), the solubility of $\mathrm{HOCl}$ was used as proxy for $\mathrm{ClONO}_{2}$, and is given in the functional form:

$$
\begin{aligned}
& H=H_{\mathrm{o}} \exp (B / T) \cdot \exp \left(-S_{\mathrm{t}} \mathrm{M}_{\mathrm{H} 2 \mathrm{SO} 4}\right) \\
& S_{\mathrm{t}}=c_{\mathrm{S}}+d / T
\end{aligned}
$$

$H(\mathrm{HOCl})$ was re-parameterized taking into account the higher temperature and wt $\% \mathrm{H}_{2} \mathrm{SO}_{4}$ data of Donaldson et al. (1997) which extended and improved that of Huthwelker et al. (1995). The Setchenow coefficient, $S_{\mathrm{t}}$, was assumed to depend on the molarity (rather than molality) of the $\mathrm{H}_{2} \mathrm{SO}_{4}$ solution. $H$ was derived from indirect analysis of aerosol kinetics measurements of Hanson and Lovejoy (1995), which provided uptake coefficient, $\gamma$, and reacto-diffusive length, $l$, for hydrolysis of $\mathrm{ClONO}_{2}$ on $60 \% \mathrm{H}_{2} \mathrm{SO}_{4}$ at $250 \mathrm{~K}$. This provides a value for $\mathrm{H}_{\mathrm{ClONO} 2}$ at a single temperature and to obtain the temperature dependence of $H$ (and also of $k^{\mathrm{I}}$ ), use was made of the kinetic data for the $\mathrm{ClONO}_{2}+\mathrm{HCl}$ reaction, for which the temperature dependence includes that of $H_{\mathrm{ClONO} 2}$ and $k_{\mathrm{HCl}}^{\mathrm{I}}$. Assuming the latter is diffusion limited (following Hanson, 1998) its temperature dependence is fixed, allowing extraction of the following parameters for calculation of the solubility of $\mathrm{ClONO}_{2}: H^{0}=1.6 \times 10^{-6}$, $B=4710, c_{\mathrm{s}}=0.306$, and $d=24.0$ in Eqs. (4) and (5).

The rate coefficients for the direct and acid catalysed hydrolysis were expressed in Arrhenius form:

$k_{\mathrm{H} 2 \mathrm{O}}=A_{\mathrm{H} 2 \mathrm{O}} \cdot \exp \left(-E_{\mathrm{H} 2 \mathrm{O}} / T\right)$

$k_{\mathrm{H}^{+}}=A_{\mathrm{H}^{+}} \cdot \exp \left(-E_{\mathrm{H}^{+}} / T\right)$

The values of $k^{\mathrm{I}}$ for experimental conditions were calculated from Eq. (3), using the parameterisations for $a_{\mathrm{H}^{+}}, a_{\mathrm{H} 2 \mathrm{O}}$ given above. The $A$ and $E$ values for the temperature dependence of $k_{\mathrm{H}}$ and $k_{\mathrm{H} 2 \mathrm{O}}$ were determined from a global fit to experimental 
uptake coefficients for both the $\mathrm{ClONO}_{2}$ hydrolysis and $\mathrm{HCl}$ reaction data, assuming the reaction $\mathrm{ClONO}_{2}+\mathrm{HCl}$ is diffusion limited, in the same procedure as the determination of $H_{\mathrm{ClONO} 2}$ over a range of temperature. The values obtained from fitting of the data from (Hanson, 1998; Ball et al., 1998; Robinson et al., 1997; Hanson and Lovejoy, 1995; Zhang et al., 1994; Manion et al., 1994; Hanson and Ravishankara, 1991, 1994) were:

$A_{\mathrm{H} 2 \mathrm{O}}=1.95 \times 10^{10} s^{-1} E_{\mathrm{H} 2 \mathrm{O}}=2800 \mathrm{~K}$

$A_{\mathrm{H}^{+}}=1.22 \times 10^{12} \mathrm{M}^{-1} s^{-1} E_{\mathrm{H}^{+}}=6200 \mathrm{~K}$

All three models give a good description of the experimental $\gamma$ values for the range of conditions used to derive the parameters. However the parameterisations for $H, D_{1}, k_{1}$ and the other data on which they are based, differ considerably. The simpler parameterisation for $\Gamma_{\mathrm{b}}$ (Eq. 3) obtained by Hanson gives a reasonable representation of observed $\gamma$ values as a function $\left[\mathrm{H}_{2} \mathrm{SO}_{4}\right]$, but only up to $65 \mathrm{wt} \%$, and at temperatures around $200 \mathrm{~K}$. The more complex parameterisation of Shi et al. (2001) gives an excellent description of the experimentally observed data over a range of temperature $190-260 \mathrm{~K}$ at $\left[\mathrm{H}_{2} \mathrm{SO}_{4}\right]$ in the range $35-75 \mathrm{wt} \%$. The parameters of Shi et al., given in the table above, are recommended as the preferred values for hydrolysis of $\mathrm{ClONO}_{2}$ covering most atmospheric conditions. The standard deviation of uptake coefficients calculated using the Shi et al. model with respect to all experimental data used in the global fit was $32 \%(1 \sigma)$. This forms the basis of the recommended uncertainty in $\gamma$ over the temperature range $200-280 \mathrm{~K}$. This uncertainty remains appropriate also in view of explicit measurements of the protonation state of $\mathrm{HSO}_{4}^{-}$by Knopf et al. (2003).

\section{References}

Ball, S. M., Fried, A., Henry, B. E., and Mozurkewich, M.: Geophys. Res. Lett., 25, 3339-3342, 1998.

Carslaw, K. S., Clegg., S. L., and Brimblecombe, P.: J. Phys. Chem., 99, 11557-11574, 1995.

Donaldson, D. J., Ravishankara, A. R., and Hanson, D. R.: J. Phys. Chem. A, 101, 4717-4725, 1997.

Golden, D. M., Manion, J. A., Reihs, C. M., and Tolbert, M. A.: in: CHEMRAWN VII: Chemistry of the Atmosphere: The Impact of Global Change, edited by: Calvert, J. G., Oxford University Press, 1992.

Hanson, D. R. and Ravishankara, A. R.: J. Geophys. Res., 96, 17307-17314, 1991 a.

Hanson, D. R. and Ravishankara, A. R.: J. Phys. Chem., 98, 5728-5734, 1994.

Hanson, D. R. and Lovejoy, E. R.: Science, 267, 1326-1328, 1995.

Hanson, D. R.: J. Phys. Chem. A, 102, 4794-4807, 1998.

Huthwelker, T., Peter, Th., Luo, B. P., Clegg, S. L., Carslaw, K., and Brimblecombe, P.: J. Atm. Chem., 21, 81-95, 1995.

Klassen, J. K., Hu, Z., and Williams, L. R.: J. Geophys. Res., 103, 16197-16202, 1998.

Knopf, D. A., Luo, B. P., Krieger, U. K., and Koop, T.: J. Phys. Chem. A, 107, 4322-4332, 2003.

Manion, J. A., Fittschen, C. M., Golden, D. M., Williams, L. R., and Tolbert, M. A.: Isr. J. Chem., 34, 355-363, 1994.

Robinson, G. N., Worsnop, D. R., Kolb, C. E., and Davidovits, P.: J. Geophys. Res., 102, 3583-3601, 1997.

Rossi, M. J., Malhotra, R., and Golden, D. M.: Geophys. Res. Lett., 14, 127-130, 1987.

Shi, Q., Jayne, J. T., Kolb, C. E., Worsnop, D. R., and Davidovits, P.: J. Geophys. Res., 106, 24259-24274, 2001.

Tolbert, M. A., Rossi, M. J., Malhotra, R., and Golden, D. M.: Science, 238, 1258-1260, 1987.

Williams, L. R., Manion, J. A., Golden, D. M., and Tolbert, M. A.: J. Appl. Meteorol., 33, 785-790, 1994.

Williams, L. R. and Long, F. S.: J. Phys. Chem., 99, 3748-3751, 1995.

Zhang, R., Leu, M.-T., and Keyser, L. F.: Geophys. Res. Lett., 22, 1493-1496, 1995.

Zhang, R., Leu, M.-T., and Keyser, L. F.: J. Phys. Chem., 98, 13563-13574, 1994. 


\section{VI.A4.26}

$\mathrm{HOBr}(\mathrm{g})+\mathrm{HCl}(\mathrm{aq}) \rightarrow \mathrm{BrCl}(\mathrm{g})+\mathrm{H}_{2} \mathrm{O}(\mathrm{l})$

\section{Experimental data}

\begin{tabular}{llllll}
\hline Parameter & $\begin{array}{l}\mathrm{H}_{2} \mathrm{SO}_{4} \\
\mathrm{wt} \%\end{array}$ & {$[\mathrm{HCl}] / p(\mathrm{HOBr})$} & $T / \mathrm{K}$ & Reference & Technique/Comments \\
\hline$\gamma(\mathrm{HOBr})$ & & & & & \\
0.023 & 69.8 & $\mathrm{HCl}=0.22 \times 10^{12} \mathrm{~cm}^{-3}$ & 228 & Abbatt (1995) & CWFT-MS (a) \\
0.060 & 69.8 & $\mathrm{HCl}=0.96 \times 10^{12} \mathrm{~cm}^{-3}$ & & & \\
0.12 & 69.8 & $\mathrm{HCl}=2.5 \times 10^{12} \mathrm{~cm}^{-3}$ & & & \\
0.20 & 69.8 & $\mathrm{HCl}=6.0 \times 10^{12} \mathrm{~cm}^{-3}$ & & & \\
0.2 & 60 & $p(\mathrm{HCl})=2.7 \times 10^{-7} \mathrm{mbar}$ & 210 & Hanson and Ravishankara (1995) & CWFT-MS (b) \\
$\gamma(\mathrm{HCl})$ & & & & & \\
$0.11 \pm 0.04$ & 59.7 & $p(\mathrm{HOBr})=8 \times 10^{-7} \mathrm{mbar}$ & 228 & Waschewsky and Abbatt (1999) & CWFT-MS (c) \\
$0.032 \pm 0.008$ & 65.6 & $p(\mathrm{HOBr})=1 \times 10^{-6} \mathrm{mbar}$ & 228 & & \\
$0.060 \pm 0.015$ & 70.1 & $p(\mathrm{HOBr})=3.4 \times 10^{-5} \mathrm{mbar}$ & 228 & & CWFT-CIMS (d) \\
0.19 & 58 & $p(\mathrm{HOBr})=1 \times 10^{-5} \mathrm{mbar}$ & 250 & Hanson (2003) & \\
0.07 & 62 & $p(\mathrm{HOBr})=1 \times 10^{-5} \mathrm{mbar}$ & & & \\
0.011 & 65 & $p(\mathrm{HOBr})=1 \times 10^{-5} \mathrm{mbar}$ & & & \\
0.002 & 69.5 & $p(\mathrm{HOBr})=1 \times 10^{-5} \mathrm{mbar}$ & & & \\
\hline
\end{tabular}

\section{Comments}

(a) $\mathrm{HOBr}\left(<1 \times 10^{12}\right.$ molecule $\left.\mathrm{cm}^{-3}\right)$ was generated by the reaction sequence: $\mathrm{H}+\mathrm{NO}_{2} \rightarrow \mathrm{OH}+\mathrm{NO}$ and $\mathrm{OH}+\mathrm{Br}_{2} \rightarrow \mathrm{HOBr}$, ionised by electron impact and detected as $\mathrm{HOBr}^{+}$. The carrier gas flow was humidified to maintain the $\mathrm{H}_{2} \mathrm{SO}_{4}$ concentration $\left(69.8 \mathrm{wt} \%\right.$ ). Excess $\mathrm{HCl}$ (gas phase concentration $(0.2-7.0) \times 10^{12}$ molecule $\mathrm{cm}^{-3}$ ) added simultaneously with $\mathrm{HOBr}\left(>1 \times 10^{12}\right.$ molecule $\left.\mathrm{cm}^{-3}\right)$. HOBr loss was first order, and no sytematic dependence of $\gamma$ on [HOBr] was observed. Using measured values of $\mathrm{HD}_{1}^{1 / 2}$ for $\mathrm{HOBr}\left(20 \pm 10 \mathrm{M} \mathrm{atm}^{-1} \mathrm{~cm} \mathrm{~s}^{-1 / 2}\right)$ and for $H^{*}$ for $\mathrm{HCl}$ the cited $\gamma$ value constrained the bimolecular rate constant for the $\mathrm{HOBr}+\mathrm{HCl}$ reaction to be $1.4 \times 10^{5} \mathrm{M}^{-1} \mathrm{~s}^{-1}$.

(b) $\mathrm{HOBr}$ was generated from the hydrolysis reaction of $\mathrm{BrONO}_{2}$ on $60 \% \mathrm{H}_{2} \mathrm{SO}_{4}$ and detected using $\mathrm{SF}_{6}^{-}$chemi-ions. $\mathrm{BrCl}$ was observed as a gas phase product indicating a fast effective bimolecular reaction on $\mathrm{H}_{2} \mathrm{SO}_{4}$. A bimolecular rate constant for the $\mathrm{HOBr}+\mathrm{HCl}$ reaction of $(0.3-1) \times 10^{5} \mathrm{M}^{-1} \mathrm{~s}^{-1}$ was derived from the uptake data.

(c) $\operatorname{HOBr}\left(\approx 5 \times 10^{-10} \mathrm{~atm}\right.$, measured by UV absorption at $\left.254 \mathrm{~nm}\right)$ was generated ex-situ by passing a humidified flow of $\mathrm{Br}_{2}$ in $\mathrm{He}$ over $\mathrm{HgO}$, ionised by electron impact and detected as $\mathrm{HOBr}^{+}$. Decay of $\mathrm{HCl}$ and formation of $\mathrm{BrCl}$ was measured in presence of excess $\mathrm{HOBr}$. Uptake coefficients determined from both kinetic curves were within $10 \%$. $\gamma$ increased with $p(\mathrm{HOBr})^{1 / 2}$ at $65-70 \mathrm{wt} \%$. Bimolecular rate constants for the $\mathrm{HOBr}+\mathrm{HCl}$ reaction derived from the uptake data using $H^{*}(\mathrm{HOBr})$ determined in the same study were in the range of (1.6-270) $\times 10^{5} \mathrm{M}^{-1} \mathrm{~s}^{-1}$, increasing strongly with wt $\% \mathrm{H}_{2} \mathrm{SO}_{4}$ and less so with temperature $(213-228 \mathrm{~K})$. The $\left[\mathrm{H}_{2} \mathrm{SO}_{4}\right]$ dependence was attributed to an acid catalysed mechanism and the temperature dependence to diffusion limitation.

(d) Rotating CWFT with stirring of the $\mathrm{H}_{2} \mathrm{SO}_{4}$ film (58-70 wt \%). $\mathrm{HOBr}$ (typically $10^{-10}$ atm) was generated by reacting $\mathrm{BrONO}_{2}$ with water and detected using $\mathrm{SF}_{6}^{-}$chemi-ions. First order loss of $\mathrm{HCl}$ was measured in the presence of excess $\operatorname{HOBr}(0.2-2.0) \times 10^{-10} \mathrm{~atm}$. $\Gamma_{\mathrm{b}}$ was extracted assuming $\alpha_{\mathrm{b}}=1.0$, and was $\propto p(\mathrm{HOBr})^{1 / 2}$. Using $H_{\mathrm{HCl}}$ from Carslaw et al. (1995) and $H_{\mathrm{HOBr}}$ determined in the same study (see reaction VI.A4.16) values of $k^{\mathrm{II}}$ were derived. The values $\left(k^{\mathrm{II}}=(2.5-6.0) \times 10^{7} \mathrm{M}^{-1} \mathrm{~s}^{-1}\right.$ over the range $58-69.5 \mathrm{wt} \% \mathrm{H}_{2} \mathrm{SO}_{4}$ at $\left.250 \mathrm{~K}\right)$ showed a lower dependence on acid strength compared to results of Waschewsky and Abbatt (1999), obtained at lower temperatures. 
Preferred values

\begin{tabular}{lll}
\hline Parameter & Value & $T / \mathrm{K}$ \\
\hline$\alpha_{\mathrm{b}}$ & 1.0 & $190-250$ \\
$k^{\mathrm{II}}\left(\mathrm{M}^{-1} \mathrm{~s}^{-1}\right)$ & $\exp (154-1.63 w t) \exp (-(38500-478 w t) / T)$ & $200-230$ \\
Reliability & & \\
$\Delta \log \left(\alpha_{\mathrm{b}}\right)$ & \pm 0.3 & 298 \\
$\Delta \log \left(k^{\mathrm{II}}\right)$ & \pm 0.2 & $210-230$ \\
\hline
\end{tabular}

\section{Comments on preferred values}

The experimental studies show that the uptake coefficient of $\mathrm{HOBr}$ or $\mathrm{HCl}$ on $\mathrm{H}_{2} \mathrm{SO}_{4} / \mathrm{H}_{2} \mathrm{O}$ containing $\mathrm{HCl}$ or $\mathrm{HOBr}$ increases with the concentration of the co-reactant in solution. The $\gamma_{\mathrm{HOBr}}$ values from the earlier study of Abbatt (1995) are uncertain because the assumed relative solubilities of $\mathrm{HOCl}$ and $\mathrm{HCl}$ were incorrect. The measured $\gamma_{\mathrm{HCl}}$ in the studies of Waschewsky and Abbatt (1999) and Hanson (2003) agree well and the $\gamma$ values show a strong increase with the water content of the $\mathrm{H}_{2} \mathrm{SO}_{4}$ and a rather weak temperature dependence. The kinetics are consistent with the resistance model with a large accommodation coefficient $\left(\alpha_{\mathrm{b}}=1\right)$, and rate of uptake controlled by bulk phase chemical reaction $\mathrm{HOBr}+\mathrm{HCl}$ :

$\frac{1}{\gamma}=\frac{1}{\alpha_{\mathrm{b}}}+\frac{1}{\Gamma_{\mathrm{b}}}$

$\Gamma_{\mathrm{b}}=\frac{4 R T H_{\mathrm{HOBr}}}{\bar{c}} \sqrt{D_{\mathrm{l}} k^{\mathrm{II}} H_{\mathrm{HCl}}^{*} p_{\mathrm{HCl}}}$ for $\gamma_{\mathrm{HOBr}}$

or $\Gamma_{\mathrm{b}}=\frac{4 R T H_{\mathrm{HCl}}^{*}}{\bar{c}} \sqrt{D_{\mathrm{l}} k^{\mathrm{II}} H_{\mathrm{HOBr}}^{*} p_{\mathrm{HOBr}}}$ for $\gamma_{\mathrm{HCl}}$

where $H^{*}$ are the Henry's law constants and $D_{1}$ are the liquid diffusion coefficients for $\mathrm{HOBr}$ and $\mathrm{HCl}$ which are a function of mole fraction of $\mathrm{H}_{2} \mathrm{SO}_{4}, X$.

There are significant differences in the heterogeneous reaction rate constants derived from the experimental uptake coefficients in the two studies. Thus the values of $k^{\mathrm{II}}$ derived by Waschewsky and Abbatt (1999) from their data at 213-238 K was a factor of $\sim 8$ lower than the values expected from extrapolation from the $250 \mathrm{~K}$ value of $k^{\mathrm{II}}$ derived by Hanson (2003), based on an estimated activation energy of $15 \mathrm{~kJ} \mathrm{~mol}^{-1}$. This discrepancy can be largely attributed to the use of different values for $H_{\mathrm{HOBr}}$ in the derivation of $k^{\mathrm{II}}$. The preferred value for $H_{\mathrm{HOBr}}=5.22 \times 10^{-5} \exp (5427 / T)$ is based on Hanson (2003) (see IUPAC evaluation VI.4.16), which showed only a weak dependence on acid strength in the range $60-70 \% \mathrm{H}_{2} \mathrm{SO}_{4}$. Using this choice of $H_{\mathrm{HOBr}}$ Hanson obtained coherent set of $k^{\mathrm{II}}$ as a function of $T$ and wt $\% \mathrm{H}_{2} \mathrm{SO}_{4}$, from the results of all studies. $k^{\mathrm{II}}$ showed a very strong $T$-dependence at $60 \mathrm{wt} \%$ acid and a much weaker one at $70 \%$. Hanson gives an expression for $k^{\mathrm{II}}$ for stratospheric conditions $\left(w t=w t \% \mathrm{H}_{2} \mathrm{SO}_{4}\right)$ :

$k^{\mathrm{II}}\left(\mathrm{M}^{-1} \mathrm{~s}^{-1}\right)=\exp (154-1.63 w t) \exp (-(38500-478 w t) / T)$

This equation reproduces the experimentally derived $k^{\mathrm{II}}$ values at $210-228 \mathrm{~K}$ but the predicted values at 238 and $250 \mathrm{~K}$ are over estimated by a factor of 3 and 6 respectively. Neverthless this is the recommended expression to calculate the values of the uptake coefficients for stratospheric conditions, using Eqs. (1)-(3). The $X$-dependent expressions used for $H_{\mathrm{HCl}}^{*}$ (based on Shi et al., 2001; see this evaluation: VI.A4.14) and for $H_{\mathrm{HOBr}}^{*}$ (based on Hanson, 2003; see this evaluation: VI.A4.16), are given below:

$$
\begin{array}{lll}
H_{\mathrm{HOBr}}^{*} / \mathrm{M} \mathrm{atm}^{-1} & 5.22 \times 10^{-5} \exp (5427 / T) & 210-270 \\
H_{\mathrm{HCl}}^{*} / \mathrm{M} \mathrm{atm}^{-1} & \left(0.094-0.61 X+1.2 X^{2}\right) & 203 \\
& \exp \left(-8.68+\left(8515-10718 X^{0.7}\right) / T\right) & \\
D_{1}(\mathrm{HCl}) / \mathrm{cm}^{2} \mathrm{~s}^{-1} & 7.8 \times 10^{-8} T / \eta & 190-240
\end{array}
$$

( $X=$ mole fraction $\mathrm{H}_{2} \mathrm{SO}_{4}, \eta=$ viscosity $\mathrm{H}_{2} \mathrm{SO}_{4}$ )

The expression for $D_{1}(\mathrm{HCl})$ is taken from Klassen et al. (1998), based on viscosity data given by Shi et al. (2001) (see this evaluation: VI.A4.25). 


\section{References}

Abbatt, J. P. D.: J. Geophys. Res., 100, 14009-14017, 1995.

Hanson, D. R. and Ravishankara, A. R.: Geophys. Res. Lett., 22, 385-388, 1995.

Hanson, D. R.: J. Phys. Chem. A, 102, 4794-4807, 1998.

Hanson, D. R.: J. Geophys. Res., 108, art. no. 4239, doi:10.1029/2002JD002519, 2003.

Klassen, J. K., Hu, Z., and Williams, L. R.: J. Geophys. Res., 103, 16197-16202, 1998.

Shi, Q., Jayne, J. T., Kolb, C. E., Worsnop, D. R., and Davidovits, P.: J. Geophys. Res., 106, 24259-24274, 2001.

Waschewsky, G. C. G. and Abbatt, J. P. D.: J. Phys. Chem. A, 103, 5312-5320, 1999. 
VI.A4.27

$\mathrm{HOBr}(\mathrm{g})+\mathrm{HBr}(\mathrm{aq}) \rightarrow \mathrm{Br}_{2}(\mathrm{~g})+\mathrm{H}_{2} \mathrm{O}(\mathrm{l})$

Experimental data

\begin{tabular}{lllll}
\hline Parameter & wt $\% \mathrm{H}_{2} \mathrm{SO}_{4}$ & $T / \mathrm{K}$ & Reference & Technique/Comments \\
\hline$\gamma(\mathrm{HOBr})$ & & & & \\
$>0.25$ & 69.8 & 228 & Abbatt (1995) & CWFT-MS (a) \\
\hline
\end{tabular}

\section{Comments}

(a) $\mathrm{HOBr}\left(<1 \times 10^{12}\right.$ molecule $\left.\mathrm{cm}^{-3}\right)$ was generated by the reaction sequence: $\mathrm{H}+\mathrm{NO}_{2} \rightarrow \mathrm{OH}+\mathrm{NO}$ and $\mathrm{OH}+\mathrm{Br}_{2} \rightarrow \mathrm{HOBr}$, ionised by electron impact and detected as $\mathrm{HOBr}^{+}$. The carrier gas flow was humidified to maintain the $\mathrm{H}_{2} \mathrm{SO}_{4}$ concentration $\left(69.8 \mathrm{wt} \%\right.$ ). $\mathrm{HBr}$ (concentration $\geq 1 \times 10^{12}$ molecule $\mathrm{cm}^{-3}$ ) was added simultaneously with $\operatorname{HOBr}\left(<1 \times 10^{12}\right.$ molecule $\left.\mathrm{cm}^{-3}\right)$. $\mathrm{HOBr}$ loss was first order.

\section{Preferred values}

\begin{tabular}{lll}
\hline Parameter & Value & $T / \mathrm{K}$ \\
\hline$\alpha_{\mathrm{b}}$ & 0.3 & $190-250$ \\
$k^{\mathrm{II}} / \mathrm{M}^{-1} \mathrm{~s}^{-1}$ & $5 \times 10^{4}$ & 228 \\
$\begin{array}{l}\text { Reliability } \\
\Delta \log \left(\alpha_{\mathrm{b}}\right)\end{array}$ & \pm 0.5 & 298 \\
\hline
\end{tabular}

\section{Comments on preferred values}

The single study of Abbatt (1995) at $228 \mathrm{~K}$ reported a rapid uptake coefficient of $\mathrm{HOBr}$ on a $69.8 \mathrm{wt} \% \mathrm{H}_{2} \mathrm{SO}_{4}$ surface in the presence of $1 \times 10^{12}$ molecule $\mathrm{cm}^{3} \mathrm{HBr}$. Experimental constraints did not allow measurements at lower concentrations. The authors derived a lower limit for the second order rate constant of $k^{\mathrm{II}}>5 \times 10^{4} \mathrm{M}^{-1} \mathrm{~s}^{-1}$ for the liquid phase reaction: $\mathrm{HOBr}+\mathrm{HBr} \rightarrow \mathrm{H}_{2} \mathrm{O}+\mathrm{Br}_{2}$ at $228 \mathrm{~K}$, using the resistance model with an assumed accommodation coefficient of $\alpha_{\mathrm{b}}=1$, and using values of $H D^{1 / 2}$ for $\mathrm{HOBr}$ and $H_{\mathrm{HBr}}^{*}$ from their own study. However if the IUPAC recommended expressions for the solubility terms $\left(H_{\mathrm{HOBr}}=1.14 \times 10^{6} \mathrm{M} \mathrm{atm}^{-1}\right.$ from VI.A4.16 and $H_{\mathrm{HBr}}^{*}=7 \times 10^{3} \mathrm{M} \mathrm{atm}^{-1}$ (from VI.A4.17), and for the diffusion coefficients in $70 \mathrm{wt} \% \mathrm{wt} \mathrm{H}_{2} \mathrm{SO}_{4}$ at $228 \mathrm{~K}$, the Abbatt $\gamma$ value gives $k^{\mathrm{II}}>6.8 \times 10^{2} \mathrm{M}^{-1} \mathrm{~s}^{-1}$. Abbatt presents an argument for value of $k^{\mathrm{II}}$ closer to the diffusion controlled limit $\left(10^{7} \mathrm{M}^{-1} \mathrm{~s}^{-1}\right)$ so the assumptions that $\alpha_{\mathrm{b}}=1$ and that the experimental uptake coefficient was controlled by $\mathrm{HBr}+\mathrm{HOBr}$ liquid phase reaction rates, may be incorrect. In view of this we are unable to recommend a value for $k^{\mathrm{II}}$ consistent with $\alpha_{\mathrm{b}}=1$.

However, an estimate of the reactive uptake coefficient for $\mathrm{HOBr}+\mathrm{HBr}$ for stratospheric conditions can be obtained using Eqs. (1) $+(2)$, assuming $\alpha_{\mathrm{b}}=0.3$ and a value of $k^{\mathrm{II}}=5 \times 10^{4} \mathrm{M}^{-1} \mathrm{~s}^{-1}$, as deduced by Abbatt (1995):

$\frac{1}{\gamma}=\frac{1}{\alpha_{\mathrm{b}}}+\frac{1}{\Gamma_{\mathrm{b}}}$

$\Gamma_{\mathrm{b}}=\frac{4 R T H_{\mathrm{HOBr}}}{\bar{c}} \sqrt{D_{1} k^{\mathrm{II}} H_{\mathrm{HBr}}^{*} p_{\mathrm{HBr}}}$

The values $H_{\mathrm{HOBr}}$ and $H_{\mathrm{HBr}}^{*}$, are taken from the IUPAC evaluation and are given below:

$$
\begin{array}{lll}
H^{*}(\mathrm{HOBr}) / \mathrm{M} \mathrm{atm}^{-1} & 5.22 \times 10^{-5} \exp (5427 / T) & 210-270 \\
H^{*}(\mathrm{HBr}) / \mathrm{M} \mathrm{atm}^{-1} & 10^{\wedge}\left\{1000 \times\left(-1.977 \times 10^{-4} w t^{2}-2.096 \times 10^{-2} w t+4.445\right) / T\right. & 195-250 \\
& \left.+\left(-8.979 \times 10^{-5} w t^{2}+2.141 \times 10^{-2} w t-6.067\right)\right\} & \\
D_{1}(\mathrm{HOBr}) & 6.4 \times 10^{-8} T / \eta & 200-300
\end{array}
$$

In the expression for $H^{*}(\mathrm{HBr})$, wt is the $\mathrm{H}_{2} \mathrm{SO}_{4}$ concentration in wt $\%$. $D_{1}(\mathrm{HOBr})$ is taken from the work of Klassen et al. (1998), with viscosity calculated from the parameterisation given by Shi et al. (2001). 


\section{References}

Abbatt, J. P. D.: J. Geophys. Res., 100, 14009-14017, 1995.

Klassen, J. K., Hu, Z., and Williams, L. R.: J. Geophys. Res., 103, 16197-16202, 1998.

Shi, Q., Jayne, J. T., Kolb, C. E. Worsnop, D. R., and Davidovits, P.: J. Geophys. Res., 106, 24259-24274, 2001. 


\section{VI.A4.28}

$\mathrm{BrONO}_{2}(\mathrm{~g})+\mathrm{H}_{2} \mathrm{O}(\mathrm{l}) \rightarrow \mathrm{HOBr}(\mathrm{g})+\mathrm{HNO}_{3}(\mathrm{aq})$

\section{Experimental data}

\begin{tabular}{lllll}
\hline Parameter & $\mathrm{H}_{2} \mathrm{SO}_{4} / \mathrm{wt} \%$ & $T / \mathrm{K}$ & Reference & Technique/Comments \\
\hline Uptake coefficients: $\gamma$ & & & & \\
$0.5_{-0.25}^{+0.5}$ & 45 & 210 & Hanson and Ravishankara (1995) & CWFT-CIMS (a) \\
$0.4_{-0.2}^{+0.6}$ & 60 & 210 & & \\
$0.3_{-0.1}^{+0.7}$ & 70 & 220 & & \\
$1.0(0.1 \mu \mathrm{m}$ radius) & 48 & 229 & Hanson et al. (1996) & AFT-CIMS (b) \\
$0.81(0.1 \mu \mathrm{m}$ radius) & 47 & 249 & & \\
$0.75(0.1 \mu \mathrm{m}$ radius) & 66 & 272 & & \\
$0.26(0.1 \mu \mathrm{m}$ radius) & 76.5 & 294 & & \\
0.8 & 66 & 250 & Hanson (2003) & \\
0.95 & 72 & 250 & & \\
0.5 & 75 & $250-293$ & & \\
0.2 & 79 & $250-293$ & & \\
0.15 & 82 & $250-293$ & & \\
\hline
\end{tabular}

\section{Comments}

(a) Uptake measurement on a WWFT coupled to CIMS detection. The source ion was $\mathrm{SF}_{6}^{-}$and $\mathrm{BrONO}_{2}$ and $\mathrm{HOBr}$ were monitored as $\mathrm{BrONO}_{2} \mathrm{~F}^{-}$and $\mathrm{SF}_{5} \mathrm{O}^{-}$, respectively. Large corrections (factor 5) to the observed loss rates of $\mathrm{BrONO}_{2}$ were made to take diffusive effects into account. $\mathrm{HOBr}$ was detected as the primary hydrolysis product of the title reaction at a typical partial pressure of $\mathrm{BrONO}_{2}$ of $(1-3) \times 10^{7}$ molecule $\mathrm{cm}^{-3}$.

(b) Aerosol flow reactor operated at total pressures $\left(\mathrm{N}_{2}\right)$ ranging from (239 \pm 40 ) (majority of experiments) to $(825 \pm 13)$ mbar between 249 and $298 \mathrm{~K}$. BrONO $2\left(10^{12}\right.$ molecule $\left.\mathrm{cm}^{-3}\right), \mathrm{HOBr}$ and $\mathrm{HNO}_{3}$ were detected as $\mathrm{BrONO}_{2} \mathrm{~F}^{-}$, $\mathrm{SF}_{5} \mathrm{O}^{-}$and $\mathrm{NO}_{3}^{-}$, respectively, using $\mathrm{SF}_{6}^{-}$as reagent ion. The sulphuric acid aerosol particle size distribution was lognormal with a typical surface area-weighted peak radius of $0.1 \mu \mathrm{m}$. Uptake coefficients $\gamma$ were independent of the particle radius over a range of 0.05 to $0.17 \mu \mathrm{m}$ for $78 \%$ wt $\mathrm{H}_{2} \mathrm{SO}_{4}$ particles at $298 \mathrm{~K}$. In some experiments, $\mathrm{HCl}$ was added to the $\mathrm{H}_{2} \mathrm{SO}_{4}$ in order to trap $\mathrm{HOBr}\left(\right.$ as $\mathrm{BrCl}$ ) in order to prevent potential regeneration of $\mathrm{BrONO}_{2}$ from reaction of $\mathrm{HNO}_{3}$ with $\mathrm{HOBr}$.

(c) Rotating CWFT with stirring of the $\mathrm{H}_{2} \mathrm{SO}_{4}$ film (58-85 wt \%, 240-293 K) at 0.5-2.6 mbar total pressure. The aerosol flow tube was operated at room temperature and 160 Torr total pressure. Initial $\mathrm{BrONO}_{2}$ concentration was $10^{11}-10^{12} \mathrm{~cm}^{-3}$ in the RWFT and $10^{12}-10^{13} \mathrm{~cm}^{-3}$ in the AFT. Uptake coefficients showed a strong fall off towards high $\mathrm{H}_{2} \mathrm{SO}_{4} \mathrm{wt} \%$, a few representative values are listed in the table.

\section{Preferred values}

\begin{tabular}{lll}
\hline Parameter & Value & $T / \mathrm{K}$ \\
\hline$\alpha_{\mathrm{b}}$ & 0.8 & $210-300$ \\
$\Gamma_{\mathrm{b}}$ & $0.11+\exp (29.2-0.40 \mathrm{wt})$ & $210-230$ \\
Reliability & & \\
$\Delta \log \left(\alpha_{\mathrm{b}}\right)$ & \pm 0.10 & $210-300$ \\
$\Delta \log (\gamma)$ & \pm 0.15 & $210-300$ \\
\hline
\end{tabular}

\section{Comments on preferred values}

The three studies yield consistent results, with values of $\gamma$ close to unity in diluted ( $45 \mathrm{wt} \%$ ) $\mathrm{H}_{2} \mathrm{SO}_{4}$, and decreasing to 0.15 at $\sim 80 \mathrm{wt} \%$. Owing to the large rate constant for $\mathrm{BrONO}_{2}$ hydrolysis in the condensed phase (the authors estimate a diffusionlimited rate constant $k^{\mathrm{II}}$ on the order of $10^{9} \mathrm{M}^{-1} \mathrm{~s}^{-1}$ ) no size-dependence of $\gamma$ is expected, because the reacto-diffusive length, 
$\left(D_{1} / k^{\mathrm{II}}\right)^{0.5}$ is short. $\mathrm{HOBr}$ (and $\mathrm{HNO}_{3}$ ) is seen as the major product of $\mathrm{BrONO}_{2}$ uptake to $\mathrm{H}_{2} \mathrm{SO}_{4}$. Some $\mathrm{Br}_{2}$ was also observed, which likely stems from reactions of $\mathrm{HOBr}$ and not from an additional $\mathrm{BrONO}_{2}$ loss process.

Since the $\mathrm{BrONO}_{2}$ solubility is not known, a detailed parameterisation of the uptake coefficient is not possible. We therefore adopt the expression suggested by Hanson (2003) that reproduces the uptake coefficients measured on both bulk and aerosol from all three studies:

$\frac{1}{\gamma}=\frac{1}{\alpha_{\mathrm{b}}}+\frac{1}{\Gamma_{\mathrm{b}}}$

\section{References}

Hanson, D. R. and Ravishankara, A. R.: Geophys. Res. Lett., 22, 385-388, 1995.

Hanson, D. R., Ravishankara, A. R., and Lovejoy, E. R.: J. Geophys. Res., 101, 9063-9069, 1996.

Hanson, D. R.: J. Geophys. Res., 108, art. no. 4239, doi:10.1029/2002JD002519, 2003. 
VI.A4.29

$\mathrm{HNO}_{2}(\mathrm{~g})+\mathrm{HCl}(\mathrm{aq}) \rightarrow \mathrm{CINO}(\mathrm{g})+\mathrm{H}_{2} \mathrm{O}(\mathrm{l})$

Experimental data

\begin{tabular}{|c|c|c|c|c|c|c|}
\hline Parameter & $\begin{array}{l}p_{\mathrm{HCl}} / \\
\text { mbar }\end{array}$ & $\begin{array}{l}p_{\mathrm{HNO} 2} / \\
\text { mbar }\end{array}$ & $\begin{array}{l}{\left[\mathrm{H}_{2} \mathrm{SO}_{4}\right] /} \\
\text { wt } \%\end{array}$ & $T / \mathrm{K}$ & Reference & Technique/Comments \\
\hline \multicolumn{7}{|l|}{ Uptake coefficients: $\gamma$} \\
\hline$\gamma_{\mathrm{HCl}}=(2.0 \pm 0.5) \times 10^{-2}$ & $4.0 \times 10^{-7}$ & $6.7 \times 10^{-7}$ & 60.8 & 208 & Zhang et al. (1996) & CWFT-CIMS (a) \\
\hline$\gamma_{\mathrm{HCl}}=(1.1 \pm 0.4) \times 10^{-2}$ & & & 65.1 & 213 & & \\
\hline$\gamma_{\mathrm{HCl}}=(1.6 \pm 0.1) \times 10^{-2}$ & & & 68.0 & 217 & & \\
\hline$\gamma_{\mathrm{HCl}}=(2.0 \pm 0.2) \times 10^{-2}$ & & & 71.3 & 223 & & \\
\hline$\gamma_{\mathrm{HCl}}=(0.5-1.0) \times 10^{-4}$ & $1.5 \times 10^{-5}$ & $1.3 \times 10^{-5}$ & $62.5-65$ & $225-230$ & Fenter and Rossi (1996) & Kn-MS (b) \\
\hline$\gamma_{\mathrm{HCl}}=(2.0 \pm 0.7) \times 10^{-3}$ & & & 60 & $225-230$ & & \\
\hline$\gamma_{\mathrm{HNO} 2}=1.1 \times 10^{-3}$ & $4.8 \times 10^{-6}$ & & 50 & 250 & Longfellow et al. (1998) & RWFT-CIMS (c) \\
\hline$\gamma_{\mathrm{HNO} 2}=1.5 \times 10^{-2}$ & $1.6 \times 10^{-4}$ & & 50 & 250 & & \\
\hline$\gamma_{\mathrm{HNO} 2}=3.7 \times 10^{-2}$ & $8.5 \times 10^{-7}$ & & 50 & 205 & & \\
\hline$\gamma_{\mathrm{HNO} 2}=1.5 \times 10^{-1}$ & $1.2 \times 10^{-5}$ & & 50 & 205 & & \\
\hline$\gamma_{\mathrm{HNO} 2}=3.8 \times 10^{-2}$ & $4.4 \times 10^{-6}$ & & 60 & 219 & & \\
\hline$\gamma_{\mathrm{HNO} 2}=9.2 \times 10^{-2}$ & $2.8 \times 10^{-5}$ & & 60 & 219 & & \\
\hline$\gamma_{\mathrm{HNO} 2}=9.4 \times 10^{-3}$ & $2.8 \times 10^{-6}$ & & 60 & 230 & & \\
\hline$\gamma_{\mathrm{HNO} 2}=5.9 \times 10^{-2}$ & $5.4 \times 10^{-5}$ & & 60 & 230 & & \\
\hline$\gamma_{\mathrm{HNO} 2}=2.9 \times 10^{-3}$ & $5.6 \times 10^{-6}$ & & 60 & 250 & & \\
\hline$\gamma_{\mathrm{HNO} 2}=2.4 \times 10^{-2}$ & $9.6 \times 10^{-5}$ & & 60 & 250 & & \\
\hline$\gamma_{\mathrm{HNO} 2}=6.8 \times 10^{-2}\left(r_{\mathrm{p}}=64 \mathrm{~nm}\right)$ & $4.8 \times 10^{-4}$ & & 60 & 250 & & \\
\hline$\gamma_{\mathrm{HNO} 2}=5.5 \times 10^{-2}\left(r_{\mathrm{p}}=232 \mathrm{~nm}\right)$ & $4.8 \times 10^{-4}$ & & 60 & 250 & & \\
\hline$\gamma_{\mathrm{HNO} 2}=1.5 \times 10^{-2}\left(r_{\mathrm{p}}=83 \mathrm{~nm}\right)$ & $1.2 \times 10^{-4}$ & & 60 & 250 & & \\
\hline$\gamma_{\mathrm{HNO} 2}=1.5 \times 10^{-2}\left(r_{\mathrm{p}}=306 \mathrm{~nm}\right)$ & $1.2 \times 10^{-4}$ & & 60 & 250 & & \\
\hline$\gamma_{\mathrm{HCl}}=5.1 \times 10^{-3}$ & & $1.1 \times 10^{-7}$ & 70 & 215 & & \\
\hline$\gamma_{\mathrm{HCl}}=1.1 \times 10^{-2}$ & & $1.6 \times 10^{-6}$ & 70 & 215 & & \\
\hline$\gamma_{\mathrm{HCl}}=1.0 \times 10^{-3}$ & & $1.6 \times 10^{-6}$ & 67 & 250 & & \\
\hline$\gamma_{\mathrm{HCl}}=5.2 \times 10^{-3}$ & & $1.1 \times 10^{-5}$ & 67 & 250 & & \\
\hline$\gamma_{\mathrm{HCl}}=3.3 \times 10^{-4}$ & & $3.1 \times 10^{-6}$ & 70 & 269 & & \\
\hline$\gamma_{\mathrm{HCl}}=1.3 \times 10^{-3}$ & & $1.6 \times 10^{-5}$ & 70 & 269 & & \\
\hline
\end{tabular}

\section{Comments}

(a) CWFT with CIMS detection of $\mathrm{HNO}_{2}$ after reaction with $\mathrm{SF}_{6}^{-} \cdot 0.1 \mathrm{~mm}$ thick liquid $\mathrm{H}_{2} \mathrm{SO}_{4}$. The total pressure was $0.5 \mathrm{mbar} \mathrm{He}$; the partial pressure of $\mathrm{HNO}_{2}$ and $\mathrm{HCl}$ was around $6 \times 10^{-7} \mathrm{mbar}$ and $6 \times 10^{-7} \mathrm{mbar}$, respectively. The sulphuric acid composition was controlled by maintaining fixed temperature and $\mathrm{H}_{2} \mathrm{O}$ partial pressure of $6 \times 10^{-4}$ mbar in the gas flows. $\mathrm{ClNO}$ was observed as product with approximately unity yield. Separation of solubility driven $\mathrm{HCl}$ uptake from reaction driven uptake was achieved by allowing enough time for establishing steady state at each injector position.

(b) Knudsen cell reactor with MS detection. $\mathrm{H}_{2} \mathrm{SO}_{4}$ solutions were prepared by dilution of a $95 \mathrm{wt} \%$ solution. $\mathrm{HNO}_{2}$ and $\mathrm{HCl}$ were prepared by adding $\mathrm{H}_{2} \mathrm{SO}_{4}$ to $\mathrm{NaNO}_{2}$ and $\mathrm{NaCl}$, respectively. $\mathrm{MS}$ traces were consistent with full conversion of $\mathrm{HCl}$ into $\mathrm{ClNO}$ in presence of $\mathrm{HNO}_{2}$. Reaction probabilities (as listed in the table) were obtained from the difference of the $\mathrm{HCl}$ loss in presence and absence of $\mathrm{HNO}_{2}$ to account for $\mathrm{HCl}$ uptake due to solubility of $\mathrm{HCl}$ alone.

(c) Most uptake experiments were performed in a $2.2 \mathrm{~cm}$ i.d. CWFT and a $1.84 \mathrm{~cm}$ i.d. RWFT with CIMS detection of $\mathrm{HNO}_{2}$. The reaction of $\mathrm{HNO}_{2}$ with $\mathrm{SF}_{6}^{-}$was revisited to come up with an improved estimate of the rate constant and the branching ratio for the formation of $\mathrm{SF}_{5}^{-}$vs. $\mathrm{HFNO}_{2}^{-}$. The observed loss of $\mathrm{HNO}_{2}$ in the flow tube was corrected for the hydrolysis reaction of the product $\mathrm{ClNO}$ yielding back $\mathrm{HNO}_{2}$ by taking into account the reaction probability of ClNO of $2.5 \times 10^{-3}$ on $60 \mathrm{wt} \%$ and $3.0 \times 10^{-3}$ on $50 \mathrm{wt} \%$ solutions at $250 \mathrm{~K}$ determined in separate experiments. $\mathrm{HNO}_{2}$ uptake to deliquesced $\mathrm{NaCl}$ at $268 \mathrm{~K}$ did not lead to detectable amounts of $\mathrm{HNO}_{2}$. A few experiments were performed with aerosol particles also listed in the table. 


\section{Preferred values}

\begin{tabular}{lll}
\hline Parameter & Value & $T / \mathrm{K}$ \\
\hline$\alpha_{\mathrm{s}}$ & 1 & $200-300$ \\
$\Gamma_{\mathrm{s}, \mathrm{HNO} 2}$ & $9 \times 10^{4} \exp (-3000 / T)[\mathrm{HCl}] H_{\mathrm{NO}+}^{*}$ & $200-300$ \\
$H_{\mathrm{NO}+}^{*}\left(\mathrm{M} \mathrm{atm}^{-1}\right)$ & $C \exp (D w t)$ & $200-300$ \\
$\left.C(\mathrm{M} \mathrm{atm})^{-1}\right)$ & $2.0 \times 10^{8} \exp (-14000 / T)$ & $200-300$ \\
$D\left((\mathrm{wt} \%)^{-1}\right)$ & $297.3 / T-0.474$ & $200-300$ \\
$k_{\mathrm{b}}\left(\mathrm{M}^{-1} \mathrm{~s}^{-1}\right)$ & $25\left[\mathrm{H}^{+}\right] \mathrm{T} / \eta$ & $200-300$ \\
$\Gamma_{\mathrm{s}, \mathrm{HCl}}$ & $4 \times 10^{-3}\left[\mathrm{NO}^{+}\right] H_{\mathrm{HCl}}^{*}$ & $200-300$ \\
$\operatorname{Reliability}$ & & $200-300$ \\
$\Delta \log \left(\alpha_{\mathrm{s}}\right)$ & \pm 0.3 & $200-300$ \\
$\Delta \log \left(H^{*}\right)$ & \pm 0.3 & $200-300$ \\
$\Delta \log \left(k_{\mathrm{b}}\right)$ & \pm 0.3 & \\
\hline
\end{tabular}

\section{Comments on preferred values}

The available studies agree that efficient reaction of $\mathrm{HNO}_{2}$ with $\mathrm{HCl}$ occurs in sulphuric acid solutions to yield ClNO. Most likely, the reaction proceeds through one of the protonated forms of $\mathrm{HNO}_{2}$, e.g., $\mathrm{NO}^{+} \mathrm{HSO}_{4}^{-}$. The data by Longfellow et al. (1998) cover a sufficiently wide parameter range to allow constraining the kinetics. The pressure dependence observed for the uptake of $\mathrm{HNO}_{2}$ in presence of $\mathrm{HCl}$ deviates from the expectation based on bulk reaction alone and thus is indicative of a surface process. While Longfellow et al. reported individual contributions for the surface vs. bulk terms to overall uptake for each individual solution composition and temperature, we adopt here a more general parameterisation. Following a similar procedure as for $\mathrm{HOCl}$ and $\mathrm{HCl}$, the bulk reaction is parameterised with the acid concentration and the viscosity to represent diffusion limited kinetics of an acid catalysed reaction that largely controls temperature and composition dependence.

In absence of limitations by surface accommodation or surface to bulk transfer, for the uptake of $\mathrm{HNO}_{2}$, the uptake coefficient simplifies to:

$$
\frac{1}{\gamma_{\mathrm{HONO}}}=\frac{1}{\alpha_{\mathrm{s}}}+\frac{1}{\Gamma_{\mathrm{s}, \mathrm{HONO}}+\frac{1}{\frac{1}{\Gamma_{\mathrm{sb}, \mathrm{HONO}}}+\frac{1}{\Gamma_{\mathrm{b}, \mathrm{HONO}}}}} \approx \frac{1}{\Gamma_{\mathrm{s}, \mathrm{HONO}}+\Gamma_{\mathrm{b}, \mathrm{HONO}}}
$$

The surface reaction is assumed to be a direct reaction between $\mathrm{NO}^{+}$and $\mathrm{HCl}$. In absence of data constraining their surface concentrations, we simply assume that the latter is proportional to the bulk concentration, which is tied to the gas phase pressures through the Henry's law constant. The equilibrium constant describing the concentration of $\mathrm{NO}^{+}$is given by the second term of the expression for the solubility of $\mathrm{HNO}_{2}$ given in datasheet VI.A4.7, as given in the preferred value table. The concentration of $\mathrm{HCl}$ is calculated using the expression for the solubility recommended in datasheet VI.A4.14:

$H_{\mathrm{HCl}}^{*}=\left(0.094-0.61 X+1.2 X^{2}\right) \exp \left(-8.68+\left(8515-10718 X^{0.7}\right) / T\right)$

The mole fraction, $X$, of sulphuric acid is given by $X=w t /(w t+(100-w t) 98 / 18)$.

The bulk reaction rate constant requires knowing the proton concentration. We suggest using the parameterisation of Shi et al. (2001):

$$
\begin{aligned}
{\left[\mathrm{H}^{+}\right] } & =\exp \left[60.51-0.095 w t+0.0077 w t^{2}-1.61 \times 10^{-5} w t^{3}\right. \\
& \left.-\left(1.76+2.52 \times 10^{-4} w t^{2}\right) T^{0.5}+\left(-805.89+253.05 w t^{0.076}\right) / T^{0.5}\right]
\end{aligned}
$$

For the viscosity, we suggest using the parameterization presented by Shi et al. (2001), which fits well to data by Williams and Long (1995) but extends into tropospherically more relevant dilute solutions at high $T$ :

$$
\begin{aligned}
& \eta=A T^{-1.43} \exp \left(448 \mathrm{~K} /\left(T-T_{0}\right)\right), \\
& \text { with } A=169.5+5.18(w t)-0.0825(w t)^{2}+3.27 \times 10^{-3}(w t)^{3}, \\
& \text { and } T_{0}=144.11+0.166(w t)-0.015(w t)^{2}+2.18 \times 10^{-4}(w t)^{3}
\end{aligned}
$$


This allows calculating the contribution of the bulk reaction according to:

$\Gamma_{\mathrm{b}, \mathrm{HNO} 2}=4 H_{\mathrm{HNO} 2}^{*} R T \sqrt{D_{1, \mathrm{HONO}} \cdot k_{\mathrm{b}}^{\mathrm{II}} p_{\mathrm{HCl}} H_{\mathrm{HCl}}^{*}}\left[\operatorname{coth}\left(\frac{r_{\mathrm{p}}}{l_{\mathrm{HNO} 2}}\right)-\left(\frac{l_{\mathrm{HNO} 2}}{r_{\mathrm{p}}}\right)\right] / \bar{c}_{\mathrm{HNO} 2}$

For the effective solubility of $\mathrm{HNO}_{2}$, we suggest using the expression recommended on datasheet VI.A4.7: $H^{*}=$ $A \exp (B(\mathrm{wt}))+C \exp (D(\mathrm{wt}))$, with $A=4.2 \times 10^{-6} \exp (4873 / T) ; B=13.16 / T-0.0856 ; C=2.0 \times 10^{8} \exp (-14000 / T)$; $D=297.3 / T-0.474$.

The diffusion coefficient for $\mathrm{HNO}_{2}$ is parameterized by $D_{1, \mathrm{HNO} 2}=C_{\mathrm{HNO} 2} T / \eta$; with $C_{\mathrm{HNO} 2}=6.90 \times 10^{-8} \mathrm{~cm}^{2} \mathrm{cP} \mathrm{K}^{-1} \mathrm{~s}^{-1}$, estimated as suggested by Klassen et al. (1998) using a molar volume of $36 \mathrm{~cm}^{3} \mathrm{~mol}-1$ (da Silva et al., 2006). The reactivodiffusive length needed to account for finite particle sizes is given by $l_{\mathrm{HNO} 2}=\left(D_{1, \mathrm{HNO} 2} /\left(k_{\mathrm{b}} p_{\mathrm{HCl}} H_{\mathrm{HCl}}^{*}\right)\right)^{0.5}$

Similarly, for the uptake coefficient of $\mathrm{HCl}$, the expression for the combined contribution of surface and bulk processes, is given by:

$$
\frac{1}{\gamma_{\mathrm{HCl}}}=\frac{1}{\alpha_{\mathrm{s}}}+\frac{1}{\Gamma_{\mathrm{s}, \mathrm{HCl}}+\frac{1}{\frac{1}{\Gamma_{\mathrm{sb}, \mathrm{HCl}}}+\frac{1}{\Gamma_{\mathrm{b}, \mathrm{HCl}}}}}
$$

The surface accommodation coefficient is assumed to be one. For calculating $\Gamma_{\mathrm{s}, \mathrm{HCl}}$, the tendency of $\mathrm{HCl}$ to adsorb to the surface is again expressed as proportional to the Henry's law constant, while the concentration of $\mathrm{NO}^{+}$is given by $p_{\mathrm{HNO} 2} H_{\mathrm{NO}+}^{*}$. $\Gamma_{\mathrm{sb}, \mathrm{HCl}}=k_{\mathrm{sol}} / k_{\mathrm{des}}$ is obtained using $k_{\mathrm{sol}}=7.84 \times 10^{10} / \eta(\mathrm{cP})$ and $k_{\mathrm{des}}=8.0 \times 10^{17} \exp (-5000 / T)$ from datasheet VI.A4.14. The expression for the resistance due to the bulk reaction is given by:

$\Gamma_{\mathrm{b}, \mathrm{HCl}}=4 H_{\mathrm{HCl}}^{*} R T \sqrt{D_{1, \mathrm{HCl}} \cdot k_{\mathrm{b}}^{\mathrm{II}} p_{\mathrm{HNO} 2} H_{\mathrm{HNO} 2}^{*}}\left[\operatorname{coth}\left(\frac{r_{\mathrm{p}}}{l_{\mathrm{HCl}}}\right)-\left(\frac{l_{\mathrm{HCl}}}{r_{\mathrm{p}}}\right)\right] / \bar{c}_{\mathrm{HCl}}$

The diffusion coefficient of $\mathrm{HCl}$ can be expressed as $D_{1, \mathrm{HCl}}=7.8 \times 10^{-8} \mathrm{~T} / \eta$ as explained on datasheet VI.A4.14. The reactivodiffusive length needed to account for finite particle sizes is given by $l_{\mathrm{HCl}}=\left(D_{1, \mathrm{HCl}} /\left(k_{\mathrm{b}} p_{\mathrm{HNO} 2} H_{\mathrm{HNO} 2}^{*}\right)\right)^{0.5}$.

This surface and bulk reaction model describes the available data relatively well. The strongly non-linear dependencies of the solubility of $\mathrm{HNO}_{2}$ and $\mathrm{HCl}$ impose strong constraints on adjusting the model to the data, only three parameters in the two surface reaction terms and one for the bulk rate coefficient expression are adjusted. Assuming the bulk reaction only does not allow to consistently explain both, the $\mathrm{HNO}_{2}$ uptake coefficients and the $\mathrm{HCl}$ uptake coefficients. It would also lead to quite strong disagreement with the pressure dependence for the 50 and the $60 \mathrm{wt} \%$ solutions. The only temperature dependence in the formalism required to fit the data was for the surface reaction of $\mathrm{HNO}_{2}$, likely to represent the temperature dependence of the surface coverage. The case for the surface process for $\mathrm{HCl}$ is relatively poor. Longfellow et al. did not include it given the scatter in the data, even though the slope of the pressure dependence appears to be steeper than expected for bulk only reaction. We include this surface reaction to also improve agreement with the Zhang et al. (1996) data, even though it leads to some overestimate of the Longfellow data at $219 \mathrm{~K}$, but we refrain from including a temperature dependence there in absence of more data to constrain it. The $\mathrm{HCl}$ uptake coefficients reported by Fenter and Rossi (1996) appear to be at least an order of magnitude lower than expected based on the relatively large $\mathrm{HNO}_{2}$ pressures used.

\section{References}

Zhang, R., Leu, M.-T., and Keyser, L. F.: J. Phys. Chem., 100, 339-345, 1996.

Shi, Q., Jayne, J. T., Kolb, C. E., Worsnop, D. R., and Davidovits, P.: J. Geophys. Res., 106, 24259-24274, 2001.

Longfellow, C. A., Imamura, T., Ravishankara, A. R., and Hanson, D. R.: J. Phys. Chem. A, 102, 3323-3332, 1998.

da Silva, G., Dlugogorski, B. Z., and Kennedy, E. M.: AIChE Journal, 52, 1558-1565, 2006.

Klassen, J. K., Hu, Z., and Williams, L. R.: J. Geophys. Res., 103, 16197-16202, 1998.

Fenter, F. F. and Rossi, M. J.: J. Phys. Chem., 100, 13765-13775, 1996.

Williams, L. R. and Long, F. S.: J. Phys. Chem., 99, 3748-3751, 1995. 


\section{VI.A4.30}

$\mathrm{HNO}_{2}(\mathrm{~g})+\mathrm{HBr}(\mathrm{aq}) \rightarrow \mathrm{BrNO}(\mathrm{g})+\mathrm{H}_{2} \mathrm{O}(\mathrm{l})$

\section{Experimental data}

\begin{tabular}{|c|c|c|c|c|c|c|}
\hline Parameter & $p_{\mathrm{HBr}} / \mathrm{mbar}$ & $p_{\mathrm{HNO} 2} / \mathrm{mbar}$ & {$\left[\mathrm{H}_{2} \mathrm{SO}_{4}\right] / \mathrm{wt} \%$} & $T / \mathrm{K}$ & Reference & Technique/Comments \\
\hline \multicolumn{7}{|l|}{ Uptake coefficients: $\gamma$} \\
\hline$\gamma_{\mathrm{HBr}}=4.0 \times 10^{-2}$ & $10^{-5}-10^{-4}$ & $10^{-5}-10^{-4}$ & 40 & 210 & Seisel and Rossi (1997) & Kn-MS (a) \\
\hline$\gamma_{\mathrm{HBr}}=4 \times 10^{-4}$ & $10^{-5}-10^{-4}$ & $10^{-5}-10^{-4}$ & 95 & 270 & & \\
\hline$\gamma_{\mathrm{HNO} 2}=5.5 \times 10^{-3}$ & $10^{-5}-10^{-4}$ & $10^{-5}-10^{-4}$ & 40 & 210 & & \\
\hline$\gamma_{\mathrm{HNO} 2}=2 \times 10^{-3}$ & $10^{-5}-10^{-4}$ & $10^{-5}-10^{-4}$ & $52-69$ & $210-230$ & & \\
\hline$\gamma_{\mathrm{HNO} 2}=2.2 \times 10^{-2}$ & $10^{-5}-10^{-4}$ & $10^{-5}-10^{-4}$ & 95 & 270 & & \\
\hline
\end{tabular}

\section{Comments}

(a) $\mathrm{H}_{2} \mathrm{SO}_{4}$ solutions were prepared by dilution of a 95 wt $\%$ solution. $\mathrm{HNO}_{2}$ was prepared by adding $\mathrm{H}_{2} \mathrm{SO}_{4}$ to $\mathrm{NaNO}_{2}$. Formation of BrNO was observed for all solution compositions. Uptake coefficients as listed in the table were due to the total uptake of $\mathrm{HBr}$ and not corrected for solubility limited uptake of $\mathrm{HBr}$ alone.

\section{Preferred values}

\begin{tabular}{lll}
\hline Parameter & Value & $T / \mathrm{K}$ \\
\hline$\alpha_{\mathrm{b}}$ & 1 & $200-300$ \\
$k_{\mathrm{b}}\left(\mathrm{M}^{-1} \mathrm{~s}^{-1}\right)$ & 0.1 & $200-300$ \\
Reliability & & \\
$\Delta \log \left(\alpha_{\mathrm{b}}\right)$ & \pm 0.7 & $200-300$ \\
$\Delta \log \left(k_{\mathrm{b}}\right)$ & \pm 1 & $200-300$ \\
\hline
\end{tabular}

\section{Comments on preferred values}

Seisel and Rossi (1997) observed conversion of $\mathrm{HNO}_{2}$ to BrNO. The interpretation of the kinetic data is somewhat complicated by the fact that solubility limited uptake of $\mathrm{HBr}$ or $\mathrm{HNO}_{2}$ was not always clearly separated from reaction limited uptake. E.g., at low wt $\%$, the uptake of $\mathrm{HBr}$ was not sensitive to the presence of $\mathrm{HNO}_{2}$; similarly, at high wt $\%$, the uptake of $\mathrm{HNO}_{2}$ was not sensitive to the presence of $\mathrm{HBr}$. At intermediate compositions, the uptake coefficients seem to represent reaction limited conditions. Taking into account the composition dependent solubilities of $\mathrm{HBr}$ and $\mathrm{HNO}_{2}$ and assuming a simple bulk reaction to drive uptake leads to reasonable agreement with data especially for the $\mathrm{HNO}_{2}$ uptake coefficient, and reproduces the decreasing trend of the uptake coefficient of $\mathrm{HBr}$ with increasing wt $\%$ and the slightly increasing uptake coefficient of $\mathrm{HNO}_{2}$ over the same composition range. In absence of a more extensive data set over a larger range of pressures, we refrain from invoking a surface reaction to explain the relatively high uptake coefficients at high wt $\%$, which are clearly underestimated by the model.

The uptake coefficient of $\mathrm{HNO}_{2}$ is given by:

$$
\begin{aligned}
\frac{1}{\gamma_{\mathrm{HNO} 2}} & =\frac{1}{\alpha_{\mathrm{b}}}+\frac{1}{\Gamma_{\mathrm{b}, \mathrm{HNO} 2}} \\
\Gamma_{\mathrm{b}, \mathrm{HNO} 2} & =4 H_{\mathrm{HNO} 2}^{*} R T \sqrt{D_{\mathrm{l}, \mathrm{HNO} 2} \cdot k_{\mathrm{b}}^{\mathrm{II}} p_{\mathrm{HBr}} H_{\mathrm{HBr}}^{*}}\left[\operatorname{coth}\left(\frac{r_{\mathrm{p}}}{l_{\mathrm{HNO} 2}}\right)-\left(\frac{l_{\mathrm{HNO} 2}}{r_{\mathrm{p}}}\right)\right] / \bar{c}_{\mathrm{HNO} 2}
\end{aligned}
$$

For the effective solubility of $\mathrm{HNO}_{2}$, we suggest using the expression recommended on datasheet VI.A4.7: $H^{*}=$ $A \exp (B(w t))+C \exp (D(w t))$, with $A=4.2 \times 10^{-6} \exp (4873 / T) ; B=13.16 / T-0.0856 ; C=2.0 \times 10^{8} \exp (-14000 / T) ;$ $D=297.3 / T-0.474$.

The diffusion coefficient for $\mathrm{HNO}_{2}$ is parameterized by $D_{1, \mathrm{HNO} 2}=C_{\mathrm{HNO} 2} T / \eta$; with $C_{\mathrm{HNO} 2}=6.90 \times 10^{-8} \mathrm{~cm}^{2} \mathrm{cP} \mathrm{K}^{-1} \mathrm{~s}^{-1}$, estimated as suggested by Klassen et al. (1998), but using a molar volume of $36 \mathrm{~cm}^{3} \mathrm{~mol}^{-1}$ (da Silva et al., 2006).

For the viscosity, we suggest using the parameterization presented by Shi et al. (2001), which fits well to data by Williams and Long (1995) but extends into tropospherically more relevant dilute solutions at high $T$ :

$\eta=A T^{-1.43} \exp \left(448 \mathrm{~K} /\left(T-T_{0}\right)\right)$ 
with $A=169.5+5.18 w t-0.0825 w t^{2}+3.27 \times 10^{-3} w t^{3}$,

and $T_{0}=144.11+0.166 w t-0.015 w t^{2}+2.18 \times 10^{-4} w t^{3}$

According to data sheet VI.A4.17, the solubility of $\mathrm{HBr}$ can be parameterised by:

$\log _{10} H_{\mathrm{HBr}} *=1000 \mathrm{~m} / T+b$,

where $m=m_{1}\left[\mathrm{H}_{2} \mathrm{SO}_{4}\right]^{2}+m_{2}\left[\mathrm{H}_{2} \mathrm{SO}_{4}\right]+m_{3}$ and $b=b_{1}\left[\mathrm{H}_{2} \mathrm{SO}_{4}\right]^{2}+b_{2}\left[\mathrm{H}_{2} \mathrm{SO}_{4}\right]+b_{3}$ and the $\mathrm{H}_{2} \mathrm{SO}_{4}$ concentration $\left[\mathrm{H}_{2} \mathrm{SO}_{4}\right]$ is in wt $\%$.

$m_{1}\left(\mathrm{wt} \%^{-2} K\right)=-1.977 \times 10^{-4} ; m_{2}\left(\mathrm{wt} \%^{-1} K\right)=-2.096 \times 10^{-2} ; m_{3}(\mathrm{~K})=4.445 ;$

$b_{1}\left(\mathrm{wt} \%{ }^{-2}\right)=-8.979 \times 10^{-5} ; b_{2}\left(\mathrm{wt} \%^{-1}\right)=2.141 \times 10^{-2}$.

The reactivo-diffusive length needed to account for finite particle sizes is given by $l_{\mathrm{HNO} 2}=\left(D_{1, \mathrm{HNO} 2} /\left(k_{\mathrm{b}} p_{\mathrm{HBr}} H_{\mathrm{HBr}}^{*}\right)\right)^{0.5}$.

Similarly, the uptake coefficient of $\mathrm{HBr}$ is given by:

$\frac{1}{\gamma_{\mathrm{HBr}}}=\frac{1}{\alpha_{\mathrm{b}}}+\frac{1}{\Gamma_{\mathrm{b}, \mathrm{HBr}}}$

$\Gamma_{\mathrm{b}, \mathrm{HBr}}=4 H_{\mathrm{HBr}}^{*} R T \sqrt{D_{\mathrm{l}, \mathrm{HBr}} \cdot k_{\mathrm{b}}^{\mathrm{II}} p_{\mathrm{HNO} 2} H_{\mathrm{HNO} 2}^{*}}\left[\operatorname{coth}\left(\frac{r_{\mathrm{p}}}{l_{\mathrm{HBr}}}\right)-\left(\frac{l_{\mathrm{HBr}}}{r_{\mathrm{p}}}\right)\right] / \bar{c}_{\mathrm{HBr}}$

The diffusion coefficient of $\mathrm{HBr}$ can be expressed as $D_{1, \mathrm{HBr}}=7.9 \times 10^{-8} T / \eta$ as explained on datasheet VI.A4.17. The reactivodiffusive length needed to account for finite particle sizes is given by $l_{\mathrm{HBr}}=\left(D_{1, \mathrm{HBr}} /\left(k_{\mathrm{b}} p_{\mathrm{HNO} 2} H_{\mathrm{HNO} 2}^{*}\right)\right)^{0.5}$.

\section{References}

da Silva, G., Dlugogorski, B. Z., and Kennedy, E. M.: AIChE J., 52, 1558-1565, 2006.

Klassen, J. K., Hu, Z., and Williams, L. R.: J. Geophys. Res., 103, 16197-16202, 1998.

Seisel, S. and Rossi, M. J.: Ber. Bunsen Ges. Phys. Chem. Chem. Phys., 101, 943-955, 1997.

Shi, Q., Jayne, J. T., Kolb, C. E., Worsnop, D. R., and Davidovits, P.: J. Geophys. Res., 106, 24259-24274, 2001.

Williams, L. R. and Long, F. S.: J. Phys. Chem., 99, 3748-3751, 1995. 


\section{VI.A4.31}

$\mathrm{HOCl}(\mathrm{g})+\mathrm{H}_{2} \mathrm{SO}_{4}(\mathrm{aq}) \rightarrow$ products

\section{Experimental data}

\begin{tabular}{lllll}
\hline Parameter & {$\left[\mathrm{H}_{2} \mathrm{SO}_{4}\right] / \mathrm{wt} \%$} & $T / \mathrm{K}$ & Reference & Technique/Comments \\
\hline Solubility: $H\left(\mathrm{M} \mathrm{atm}^{-1}\right)$, Diffusion: $D_{1}\left(\mathrm{~cm}^{2} \mathrm{~s}^{-1}\right)$ & & & & \\
$H D_{1}^{1 / 2}=3.4 \times 10^{-5} \exp (2640 / T)$ & 58.5 & $200-230$ & Hanson and Ravishankara (1993) & CWFT-CIMS (a) \\
$H D_{1}^{1 / 2}=3.9 \times 10^{-5} \exp (2810 / T)$ & 55.6 & $205-250$ & & \\
$H D_{1}^{1 / 2}=1.8 \times 10^{-5} \exp (3070 / T)$ & 50.5 & $200-230$ & & \\
$H D_{1}^{1 / 2}=2.6 \times 10^{-6} \exp (3590 / T)$ & 46 & $200-230$ & & \\
$H D_{1}^{1 / 2}=41$ & 57 & 204 & Zhang et al. (1994) & CWFT-MS (b) \\
$H=1.4 \times 10^{3}$ & 59.5 & 251 & Hanson and Lovejoy (1996) & CWFT-CIMS (c) \\
$D_{1}=(6 \pm 2) \times 10^{-7}$ & & & & \\
$H D_{1}^{1 / 2}=9$ & 58 & 220 & Donaldson et al. (1997) & CWFT-CIMS (d) \\
$H D_{1}^{1 / 2}=7.1$ & 60 & & & \\
$H D_{1}^{1 / 2}=4.6$ & 63 & & & \\
$H D_{1}^{1 / 2}=2.7$ & 67 & & & \\
$H D_{1}^{1 / 2}=0.9$ & 75 & & & \\
$H=2.5 \times 10^{3}$ & 52 & 250 & & \\
$H=1.1 \times 10^{3}$ & 62.5 & & & \\
$H=1.1 \times 10^{3}$ & 65 & & & \\
$H=0.9 \times 10^{3}$ & 67 & & & \\
$H=1.0 \times 10^{3}$ & 70 & & & \\
\hline
\end{tabular}

\section{Comments}

(a) $\mathrm{HOCl}$ was made in-situ from hydrolysis of $\mathrm{ClONO}_{2}$ in $\mathrm{H}_{2} \mathrm{SO}_{4}$ or ex-situ by the reaction of $\mathrm{Ca}(\mathrm{OCl})_{2}$ with $\mathrm{HCl}$. Time dependent $\mathrm{HOCl}$ uptake coefficients were analysed to derive values of $H D_{1}^{1 / 2}$ for 59.6, 55.6, 50.5 and $46 \mathrm{wt} \% \mathrm{H}_{2} \mathrm{SO}_{4}$ solutions. The parameters listed in the table were obtained by fitting to the tabulated datasets given by Hanson and Ravishankara (1993).

(b) Time dependent $\mathrm{HOCl}$ uptake coefficients were analysed to derive values of $H D_{1}^{1 / 2}$. Only a single value for $H D_{1}^{1 / 2}$ was reported. The experiment was conducted at $204 \mathrm{~K}$ with the $\mathrm{H}_{2} \mathrm{O}$ vapour pressure adjusted to $4.9 \times 10^{-4}$ Torr. This was converted to a $\mathrm{H}_{2} \mathrm{SO}_{4}$ concentration using the measurements of Zhang et al. (1993). Other datasets obtained were stated to be in good agreement with Hanson and Ravishankara (1993).

(c) Rotated CWFT. HOCl (usually present at $\sim 3 \times 10^{10}$ molecule $\mathrm{cm}^{-3}$ ) was synthesised by flowing $\mathrm{HF}$ over $\mathrm{Ca}(\mathrm{OCl})_{2}$. The solubility was measured directly, the diffusion coefficient was derived from the dependence of the uptake coefficient on the $\mathrm{HCl}$ concentration in solution (i.e. measurement of $H\left(D_{1} k\right)^{1 / 2}$ where $k$ is the first order constant for reaction of $\mathrm{HOCl}$ with dissolved $\mathrm{HCl}$ ).

(d) Rotated CWFT. The $\mathrm{H}_{2} \mathrm{SO}_{4}$ concentration (49-75 wt \%) was adjusted by variation of the $\mathrm{H}_{2} \mathrm{O}$ partial pressure. The $\mathrm{HOCl}$ solubility at $250 \mathrm{~K}$ was measured directly. Values for $H D_{1}^{1 / 2}$ at $220 \mathrm{~K}$ were derived from time dependent uptake coefficients. 


\section{Preferred values}

\begin{tabular}{lll}
\hline Parameter & Value & $T / \mathrm{K}$ \\
\hline$c\left(\mathrm{~cm}^{2} \mathrm{cP} \mathrm{K}^{-1} \mathrm{~s}^{-1}\right)$ & $6.4 \times 10^{-8}$ & $200-250$ \\
$A$ & $169.5+5.18 w t-0.0825 w t^{2}+3.27 \times 10^{-3} w t^{3}$ & \\
$T_{0}$ & $144.11+0.166 w t-0.015 w t^{2}+2.18 \times 10^{-4} w t^{3}$ & \\
$H^{0}\left(\mathrm{M} \mathrm{atm}^{-1}\right)$ & $1.91 \times 10^{-6}$ & \\
$\mathrm{~B}(\mathrm{~K})$ & 5862.4 & \\
$c_{\mathrm{S}}$ & 0.0776 & \\
$d$ & 59.18 & $200-250$ \\
Reliability & & \\
$\Delta \log (H)$ & \pm 0.3 & \\
\hline
\end{tabular}

\section{Comments on preferred values}

The majority of the experimental data on $\mathrm{HOCl}$ interaction with $\mathrm{H}_{2} \mathrm{SO}_{4}$ solutions has come from one research group (Hanson and Ravishankara, 1993; Hanson and Lovejoy, 1996; Donaldson et al., 1997). Solubilities have been derived directly from stirred solutions or indirectly (via measurement of $H D_{1}^{l / 2}$ ) using static solutions.

The diffusion of $\mathrm{HOCl}$ in $\mathrm{H}_{2} \mathrm{SO}_{4}$ has not been investigated directly. Klassen et al. (1998) have parameterised the diffusion coefficient for $\mathrm{HOCl}$ in $\mathrm{H}_{2} \mathrm{SO}_{4}$ as:

$D_{1}=c T / \eta$

where $c$ is a constant $\left(\mathrm{cm}^{2} \mathrm{cP} \mathrm{K}^{-1} \mathrm{~s}^{-1}\right)$ and $\eta$ is the viscosity of $\mathrm{H}_{2} \mathrm{SO}_{4}$ at a given wt $\%$ and temperature. Shi et al. (2001), have taken viscosity data from Williams and Long (1995) and for pure water to derive an extended formulation to cover $\mathrm{H}_{2} \mathrm{SO}_{4}$ viscosities from 0 to $80 \mathrm{wt} \%$, which can be used with the $C$ constant above to derive $D_{1}$ over the same concentration range using:

$\eta=A T^{-1.43} \exp \left(448 /\left(T-T_{0}\right)\right)$

This parameterisation results in values of $\eta$ which agree to better than $10 \%$ (for $40-70 \mathrm{wt} \% \mathrm{H}_{2} \mathrm{SO}_{4}$ solutions) with those of Klassen et al. (1998). Solubilities derived from measurements of $H D_{1}^{l / 2}$ and values of $D_{1}$ calculated as described above are in good agreement.

Based on the experimental data of Hanson and Ravishankara (1993) and solubility data for pure $\mathrm{H}_{2} \mathrm{O}$, Huthwelker et al. (1995) developed a semi-empirical expression for the solubility of $\mathrm{HOCl}$ in $\mathrm{H}_{2} \mathrm{SO}_{4}$ solutions. Experimental data which appeared later (Donaldson et al., 1996) indicates an $\mathrm{HOCl}$ solubility which is substantially larger than that calculated at high $\mathrm{H}_{2} \mathrm{SO}_{4}$ concentrations $(>65 \mathrm{wt} \%$ ). Donaldson et al. (1996) suggested application of a temperature independent, empirical correction factor $(f)$ to the calculated solubilities of Huthwelker et al.: $f=1+1.052 \exp (0.273 \cdot w t-65.66))$. Use of this factor and the diffusion coefficients of Huthwelker et al. (1995) also aligns the direct measurements of $H D_{1}^{l / 2}$ presented in Donaldson et al. In addition, Shi et al. (2001) have reanalysed the available data for $\mathrm{HOCl}$ solubility in $\mathrm{H}_{2} \mathrm{SO}_{4}$ and $\mathrm{H}_{2} \mathrm{O}$ and derived a further expression, which reproduces the data well. We adopt their formulation, which can be used for a wide range of temperatures (190-250 K) and $\mathrm{H}_{2} \mathrm{SO}_{4}$ concentrations (0-75 wt \%):

$H=H^{0} \exp (B / T) \exp \left(-S M_{\mathrm{H} 2 \mathrm{SO} 4}\right)$

where $S$ is the Setchenow coefficient $\left(S=c_{\mathrm{S}}+d / T\right)$ and $\mathrm{M}_{\mathrm{H} 2 \mathrm{SO} 4}$ is the molarity of the $\mathrm{H}_{2} \mathrm{SO}_{4}$ solution, which can be calculated from temperature and concentration dependent $\mathrm{H}_{2} \mathrm{SO}_{4}$ densities.

\section{References}

Donaldson, D. J., Ravishankara, A. R., and Hanson, D. R.: J. Phys. Chem. A, 101, 4717-4725, 1997.

Hanson, D. R. and Lovejoy, E. R.: J. Phys. Chem., 100, 6397-6405, 1996.

Hanson, D. R. and Ravishankara, A. R.: J. Phys. Chem., 97, 12309-12319, 1993.

Huthwelker, T., Clegg, S. L., Peter, T., Carslaw, K., and Luo, B. P.: J. Atmos. Chem., 21, 81-95, 1995.

Shi, Q., Jayne, J. T., Kolb, C. E., Worsnop, D. R., and Davidovits, P.: J. Geophys. Res.-Atmos., 106, 24259-24274, 2001.

Williams, L. R. and Long, F. S.: J. Phys. Chem., 99, 3748-3751, 1995.

Zhang, R., Wooldridge, P. J., Abbatt, J. P. D., and Molina, M. J.: J. Phys. Chem., 97, 7351-7358, 1993.

Zhang, R. Y., Leu, M. T., and Keyser, L. F.: J. Phys. Chem., 98, 13563-13574, 1994. 
VI.A4.32

$\mathrm{CH}_{3} \mathrm{SO}_{3} \mathrm{H}(\mathrm{g})+\mathrm{H}_{2} \mathrm{SO}_{4}(\mathrm{aq}) \rightarrow$ products

Experimental data

\begin{tabular}{lllll}
\hline Parameter & {$\left[\mathrm{H}_{2} \mathrm{SO}_{4}\right] / \mathrm{wt} \%$} & $T / \mathrm{K}$ & Reference & Technique/Comments \\
\hline Uptake coefficient: $\gamma$ & & & & \\
$0.86 \pm 0.08$ & $47-90<50 \%$ & 296 & Hanson (2005) & AFT-CIMS (c) \\
$0.64 \pm 0.2$ & 50 & 296 & & \\
$0.25 \pm 0.05$ & 65 & 296 & & \\
\hline
\end{tabular}

Comments

(c) Uptake to sulphuric acid aerosol was studied in an AFT coupled to CIMS detection using $\mathrm{HNO}_{3}$ as source of primary ions. Sulphuric acid particles were generated by homogeneous nucleation from supersaturated vapour leading to a lognormal particle size distribution within $50-120 \mathrm{~nm}$, with a few $10^{4}$ particle per $\mathrm{cm}^{3}$, characterised by a differential mobility analyzer. Concentrations of $\mathrm{CH}_{3} \mathrm{SO}_{3} \mathrm{H}$ were $3 \times 10^{10}$ molecule $\mathrm{cm}^{-3}$ in the flow tube. The measured uptake coefficients were corrected for gas phase diffusion using the Fuchs-Sutugin correction factor. The diffusion coefficient was directly measured based on the observed wall loss rates in absence of aerosol particles. Its average value was $0.0786 \mathrm{~atm} \mathrm{~cm}^{2} \mathrm{~s}^{-1}$ over the full range of humidity.

\section{Preferred values}

\begin{tabular}{lll}
\hline Parameter & Value & $T / \mathrm{K}$ \\
\hline$\alpha_{\mathrm{b}}$ & 1 & 296 \\
Reliability & & \\
$\Delta \log \left(\alpha_{\mathrm{b}}\right)$ & \pm 0.3 & 296
\end{tabular}

\section{Comments on preferred values}

The aerosol flow tube study by Hanson (2005) leads to uptake coefficients of $\mathrm{CH}_{3} \mathrm{SO}_{3} \mathrm{H}$ not significantly different from unity for solution compositions below $50 \mathrm{wt} \%$, from which we adopt a value of 1 for $\alpha_{\mathrm{b}}$. Hanson argues that the solubility of $\mathrm{CH}_{3} \mathrm{SO}_{3} \mathrm{H}$ may be lower at higher $\mathrm{H}_{2} \mathrm{SO}_{4}$ concentration, so that uptake ran into solubility equilibrium during his experiments, which would explain the low uptake coefficient for high wt \% solutions. No data of $\mathrm{CH}_{3} \mathrm{SO}_{3} \mathrm{H}$ solubility in $\mathrm{H}_{2} \mathrm{SO}_{4}$ solutions are available to our knowledge to assess this in more detail.

\section{References}

Hanson, D. R.: J. Phys. Chem. A, 109, 6919-6927, 2005. 


\section{VI.A4.33}

$\mathrm{N}_{2} \mathrm{O}_{5}(\mathrm{~g})+\mathrm{HCl}(\mathrm{aq}) \rightarrow \mathrm{HONO}_{2}(\mathrm{~g})+\mathrm{ClNO}_{2}(\mathrm{aq})$

\section{Experimental data}

\begin{tabular}{lllllll}
\hline Parameter & & $\begin{array}{l}{\left[\mathrm{H}_{2} \mathrm{SO}_{4}\right] /} \\
\mathrm{wt} \%\end{array}$ & $\begin{array}{l}{[\mathrm{HCl}]} \\
\mathrm{M}\end{array}$ & $T / \mathrm{K}$ & Reference & Technique/Comments \\
\hline$\gamma\left(\mathrm{N}_{2} \mathrm{O}_{5}\right)$ & $\Phi\left(\mathrm{ClNO}_{2}\right)$ & & & & & \\
$0.11 \pm 0.02$ & $0.02 \pm 0.002$ & 50 & 0.0001 & 220 & Talukdar et al. (2012) & RWFT-CIMS (a) \\
$0.11 \pm 0.01$ & $0.24 \pm 0.03$ & & 0.001 & 210 & & \\
$0.11 \pm 0.01$ & $0.42 \pm 0.03$ & & 0.002 & 210 & & \\
$0.10 \pm 0.01$ & $0.92 \pm 0.09$ & & 0.01 & 205 & & \\
$0.11 \pm 0.01$ & $1.1 \pm 0.11$ & & 0.1 & 215 & & \\
$0.11 \pm 0.01$ & $0.047 \pm 0.010$ & 60 & 0.0001 & 220 & & \\
$0.09 \pm 0.01$ & $0.28 \pm 0.03$ & & 0.001 & 210 & & \\
$0.11 \pm 0.01$ & $0.35 \pm 0.03$ & & 0.0019 & 210 & & \\
$0.124 \pm 0.005$ & $0.74 \pm 0.01$ & & 0.005 & 205 & & \\
$0.087 \pm 0.005$ & $0.92 \pm 0.09$ & & 0.05 & 223 & & \\
$0.14 \pm 0.01$ & $1.00 \pm 0.11$ & & 0.1 & 215 & & \\
\hline
\end{tabular}

\section{Comments}

(a) Uptake coefficients of $\mathrm{N}_{2} \mathrm{O}_{5}$ and yields of $\mathrm{ClNO}_{2}$ and $\mathrm{Cl}_{2}$ (relative to measured $\mathrm{N}_{2} \mathrm{O}_{5}$ loss) in the interaction on neat and $\mathrm{HCl}$-doped aqueous $\mathrm{H}_{2} \mathrm{SO}_{4}(50 \mathrm{wt} \%$ and $60 \mathrm{wt} \%$ ) were measured at 205-225 K. All gaseous species were measured using calibrated CIMS with $\mathrm{I}^{-}$as reagent ion. The acids were applied as a cold liquid to the inner wall of a RWFT. Standard $\mathrm{HCl}$ solution was mixed with the aqueous $\mathrm{H}_{2} \mathrm{SO}_{4}$ to produce the desired $[\mathrm{HCl}]_{\text {liq }}$. Gaseous $\mathrm{HCl} / \mathrm{He}$ mixtures were added to the flow tube to maintain the correct $[\mathrm{HCl}]_{\text {liq }}$. There was no significant dependence of the uptake coefficient on temperature, $[\mathrm{HCl}]_{\text {liq }}$ or $\left[\mathrm{H}_{2} \mathrm{SO}_{4}\right]$ in the range covered. The reaction yields of $\mathrm{ClNO}_{2}$ showed a strong function of $[\mathrm{HCl}]$ in the range $(0.00006-0.1 \mathrm{M} \mathrm{HCl})$; yields of $\mathrm{Cl}_{2}$ were $<1 \%$ in all experiments.

\section{Preferred values}

\begin{tabular}{lll}
\hline Parameter & Value & $T / \mathrm{K}$ \\
\hline$\alpha_{\mathrm{b}}$ & 0.11 & $200-220$ \\
$k_{\mathrm{Cl}} / k_{\mathrm{H} 2 \mathrm{O}}\left(50 \mathrm{wt} \% \mathrm{H}_{2} \mathrm{SO}_{4}\right)$ & $(1.0 \pm 0.3) \times 10^{4}$ & $190-280$ \\
$k_{\mathrm{Cl}} / k_{\mathrm{H} 2 \mathrm{O}}\left(60 \mathrm{wt} \% \mathrm{H}_{2} \mathrm{SO}_{4}\right)$ & $(1.6 \pm 0.4) \times 10^{4}$ & $190-280$ \\
Reliability & \pm 0.1 & \\
$\Delta \log \left(\alpha_{\mathrm{b}}\right)$ & & $200-230$ \\
\hline
\end{tabular}

\section{Comments on preferred values}

The cited study provides the only experimental data on the reactive uptake of $\mathrm{N}_{2} \mathrm{O}_{5}$ in the presence of $\mathrm{HCl}$ on $\mathrm{H}_{2} \mathrm{SO}_{4} / \mathrm{H}_{2} \mathrm{O}$ surfaces. The uptake leads to formation of $\mathrm{HNO}_{3}$ and $\mathrm{ClNO}_{2}$ products. No formation of $\mathrm{Cl}_{2}$, which is produced from reaction of $\mathrm{N}_{2} \mathrm{O}_{5}$ in aqueous salt solutions containing $\mathrm{Cl}^{-}$at higher temperatures and low $\mathrm{pH}$, was observed on $\mathrm{H}_{2} \mathrm{SO}_{4} / \mathrm{H}_{2} \mathrm{O}$ surfaces (IUPAC datasheets VI.A2.06 and VI.A2.09).

These observations can be explained by a mechanism involving an acid-catalysed solvation of $\mathrm{N}_{2} \mathrm{O}_{5}$ to form $\mathrm{H}_{2} \mathrm{NO}_{3}^{+}$followed by competition between it's reaction with $\mathrm{Cl}^{-}$and with $\mathrm{H}_{2} \mathrm{O}$. In the absence of $\mathrm{HCl}$, uptake of $\mathrm{N}_{2} \mathrm{O}_{5}$ on aqueous $\mathrm{H}_{2} \mathrm{SO}_{4}$ leads solely to hydrolysis, producing $\mathrm{HNO}_{3}$. There is compelling evidence that under these conditions this occurs by an acid catalysed mechanism (Robinson et al., 1997):

$$
\begin{aligned}
& \mathrm{N}_{2} \mathrm{O}_{5}+\mathrm{H}_{3} \mathrm{O}^{+} \rightarrow \mathrm{HNO}_{3}+\mathrm{NO}_{2}^{+} \\
& \mathrm{NO}_{2}^{+}+\mathrm{H}_{2} \mathrm{O} \rightarrow \mathrm{H}_{2} \mathrm{NO}_{3}^{+} \\
& \mathrm{H}_{2} \mathrm{NO}_{3}^{+}+\mathrm{H}_{2} \mathrm{O} \rightarrow \mathrm{HNO}_{3}+\mathrm{H}_{3} \mathrm{O}^{+}
\end{aligned}
$$


In the presence of $\mathrm{HCl}$ the following reaction occurs:

$\mathrm{H}_{2} \mathrm{NO}_{3}^{+}+\mathrm{HCl} \rightarrow \mathrm{ClNO}_{2}+\mathrm{H}_{3} \mathrm{O}^{+}$

As $p(\mathrm{HCl})$ increases the observed yield of $\mathrm{ClNO}_{2}$ product increases due to competition between reaction of $\mathrm{H}_{2} \mathrm{NO}_{3}^{+}$with $\mathrm{H}_{2} \mathrm{O}$ and $\mathrm{Cl}^{-}$. Though, the overall reactive uptake coefficient remains unchanged and is equal to the recommended value for uptake on $\mathrm{H}_{2} \mathrm{SO}_{4} / \mathrm{H}_{2} \mathrm{O}$ surfaces without $\mathrm{HCl}$ present (see data sheet VI.A4.11 of this evaluation). The yield of $\mathrm{ClNO}_{2}$ is given by the expression:

$\Phi\left(\mathrm{ClNO}_{2}\right)=\frac{k_{\mathrm{R}}\left[\mathrm{Cl}^{-}\right]}{k_{\mathrm{R}}\left[\mathrm{Cl}^{-}\right]+\left[\mathrm{H}_{2} \mathrm{O}\right]_{1}} \quad$ where $\quad k_{\mathrm{R}}=\frac{k_{\mathrm{Cl}}}{k_{\mathrm{H} 2 \mathrm{O}}}$

The recommended values for $\alpha_{\mathrm{b}}$ and $k_{\mathrm{Cl}} / k_{\mathrm{H} 2 \mathrm{O}}$ are based on the work of Talukdar et al. (2012) together with consideration of the data for the uptake of $\mathrm{N}_{2} \mathrm{O}_{5}$ into aqueous $\mathrm{H}_{2} \mathrm{SO}_{4}$ over a wider range of temperature and compositions. The molarity of $\mathrm{Cl}^{-}$ in aqueous $\mathrm{H}_{2} \mathrm{SO}_{4}$ can be calculated using the recommended expression for $H_{\mathrm{HCl}}^{*}$ from Shi et al. (2001): $M_{\mathrm{HCl}}=$ molarity $\mathrm{HCl}$ $\left(\mathrm{mol} \mathrm{dm}{ }^{-3}\right)=p(\mathrm{HCl}) \cdot H_{\mathrm{HCl}}^{*}$. Note that the recommended value of $k_{\mathrm{Cl}} / k_{\mathrm{H} 2 \mathrm{O}}$ was derived using $\left[\mathrm{H}_{2} \mathrm{O}\right]$ expressed as molarity.

It is generally believed (Thornton et al., 2003; Griffiths et al., 2009) that in neutral or mildly acidic solution, free $\mathrm{NO}_{2}^{+}$is not formed, and $\mathrm{HNO}_{3}$ and other products (e.g. $\mathrm{ClNO}_{2}$ in the presence of $\mathrm{Cl}^{-}$) are formed from competitive bulk liquid reactions of $\mathrm{H}_{2} \mathrm{NO}_{3}^{+}$formed via (slower) heterolytic dissociation of solvated $\mathrm{N}_{2} \mathrm{O}_{5}$ (aq) to $\mathrm{H}_{2} \mathrm{NO}_{3}^{+}$(aq) and $\mathrm{NO}_{3}^{-}$(aq).

\section{References}

Griffiths, P. T., Badger C. L., Cox, R. A., Folkers, M., Henke, H. H., and Mentel, T. F.: J. Phys. Chem. A, 113, 5082-5090, 2008.

Robinson, G. N., Worsnop, D. R., Kolb, C. E., and Davidovits, P.: J. Geophys. Res., 102, 3583-3601, 1997.

Shi, Q., Jayne, J. T., Kolb, C. E., Worsnop, D. R., and Davidovits, P.: J. Geophys. Res., 106, 24259-24274, 2001.

Talukdar, R. K., Burkholder, J. B., Roberts, J. M., Portmann, R. W., and Ravishankara, A. R.: J. Phys. Chem. A, 116, 60036014, 2012.

Thornton, J. A., Braban, C. F., and Abbatt, J. P. D.: Phys. Chem. Chem. Phys., 5, 4593-4603, 2003. 